Konrad Clewing (Hg.)

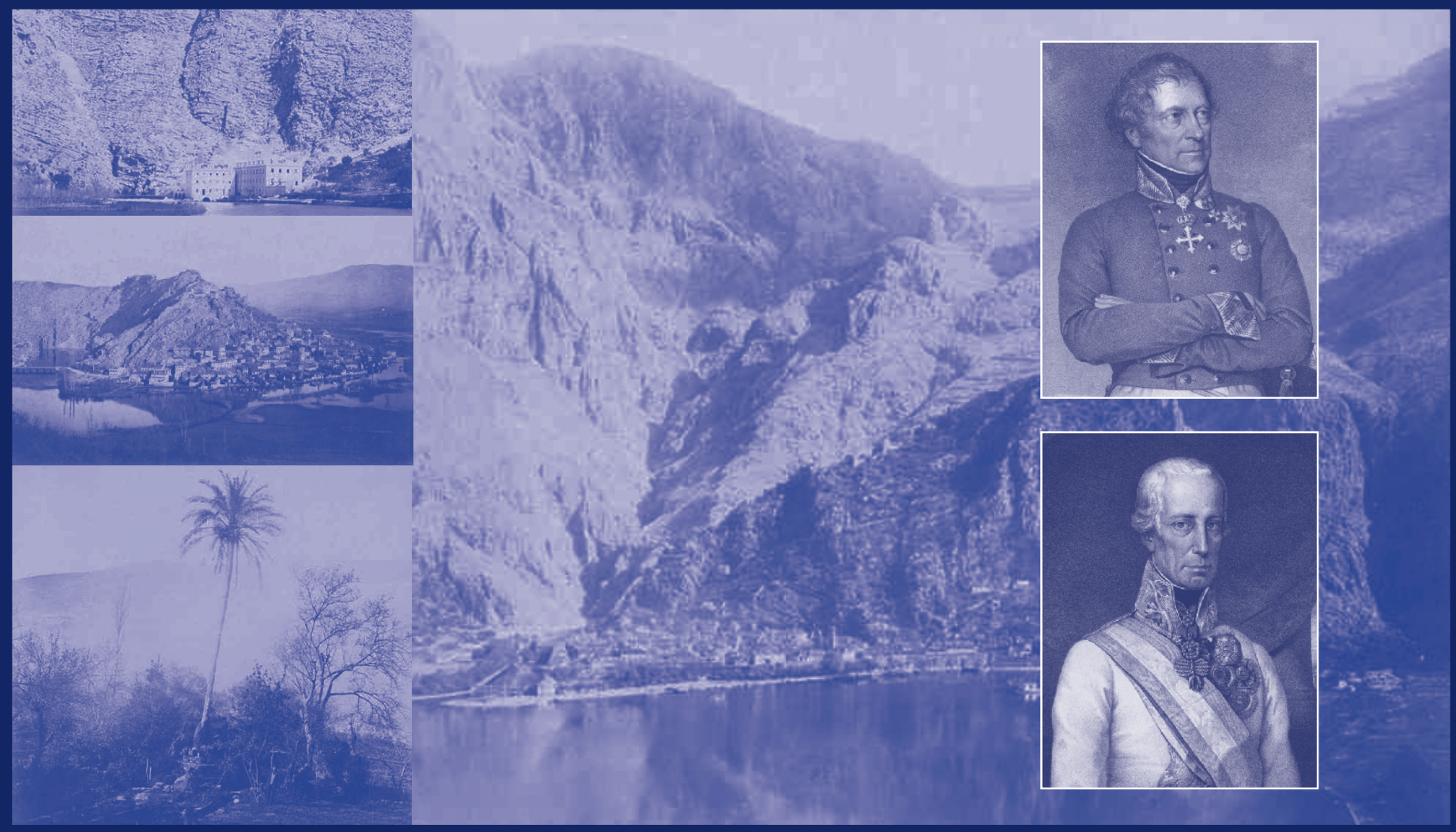

\title{
Roher Diamant Dalmatien
}

Die habsburgische Verwaltung, ihre Probleme und das Land, wie beschrieben von seinem Gouverneur Lilienberg für Kaiser Franz I. (1834) 
DigiOst - Band 1 


\section{DigiOst}

Herausgegeben für

Collegium Carolinum, München

Herder Institut, Marburg

Institut für Ost- und Südosteuropaforschung,

Regensburg

von

Martin Schulze Wessel

Peter Haslinger

Ulf Brunnbauer 


\section{Konrad Clewing (Hg.)}

\section{Roher Diamant Dalmatien}

Die habsburgische Verwaltung, ihre Probleme und das Land, wie beschrieben von seinem Gouverneur Lilienberg für Kaiser Franz I. (1834)

Verlag Otto Sagner

München - Berlin - Leipzig - Washington/D.C.

\section{DigiOst - Band 1}




\section{DigiOst, Band 1}

Herausgegeben vom

Institut für Ost- und Südosteuropaforschung

Landshuter Str. 4

D-93047 Regensburg

- www.ios-regensburg.de

im Rahmen des Projektes OstDok

- www.ostdok.de; www.ostdok.eu

Langzeitarchiviert von der Bayerischen Staatsbibliothek

URN: urn:nbn:de:bvb:12-ostdok-x-103-0

Empfohlene Zitierweise der digitalen Fassung

Konrad Clewing (Hg.), Roher Diamant Dalmatien. Die habsburgische

Verwaltung, ihre Probleme und das Land, wie beschrieben von seinem

Gouverneur Lilienberg für Kaiser Franz I. (1834).

München, Berlin, Leipzig, Washington/D.C. 2015

(URL und Datum der Einsichtnahme)

\section{Umschlag}

Umschlaggestaltung: Christopher Triplett, KI-Media Marburg - London

Verwendete Abbildungen: Franz Thiard De Laforest, Album von Dalmatien. Photographien aus der Anstalt von Franz Laforest in Cattaro (Fotos: Kotor/Cattaro; Dattelpalme bei Castelnuovo; Fabrik am Ambla-Ursprung; Ansicht von Knin), (c Hrvatski Državni Arhiv, Zagreb; oberes Porträt: Vetter von Lilienberg, Wenzel Alois Graf (vor dem Ätna, in seiner Dienstzeit in Sizilien), (c) Bildarchiv Austria; unteres Porträt: Kaiser Franz I. von Österreich (ca. 1820), Wikimedia Commons.

Kubon \& Sagner Digital Library

http://digital.kubon-sagner.com/digiost/title/8062E

Printausgabe

www.kubon-sagner.de/digiost

(C) 2015 Institut für Ost- und Südosteuropaforschung, Regensburg

„Verlag Otto Sagner“ ist ein Imprint der Kubon \& Sagner GmbH

ISBN (Print) 978-3-86688-500-4

ISBN (eBook) 978-3-86688-501-1 


\section{Inhalt}

Die vormärzliche Verwaltung in Österreich und das Kronland Dalmatien.

Ein Gouverneur schreibt an seinen Kaiser $\quad \ldots \ldots \ldots \ldots \ldots \ldots \ldots \ldots \ldots \ldots$

1. Der administrative Sinn des Reisens: Verwaltung durch

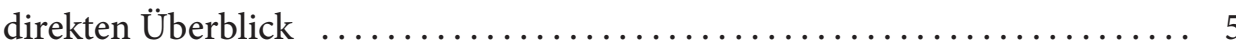

2. 1834/35: Hektik und vergebliche Hoffnung am

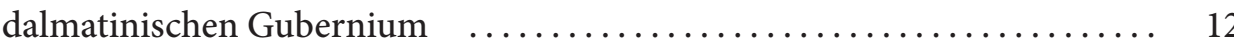

3. Gouverneur und Kaiser: im Labyrinth der

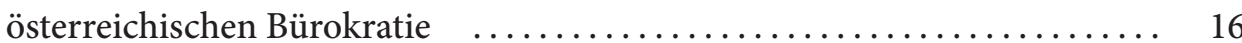

4. Zum Wert der Quelle und zur Praxis ihrer Edition $\ldots . \ldots \ldots \ldots \ldots . . . . .29$

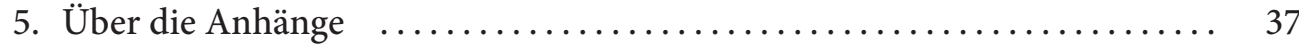

Detailliertes Inhaltsverzeichnis der »Darstellung der Provinz Dalmatien nach der ämtlichen Bereisung, in den Jahren 1832, 1833 und 1834«

»Darstellung der Provinz Dalmatien nach der ämtlichen Bereisung in den Jahren 1832, 1833 und 1834 « - Textedition .................. 49

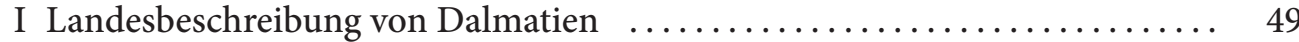

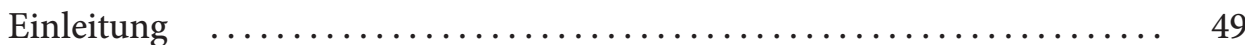

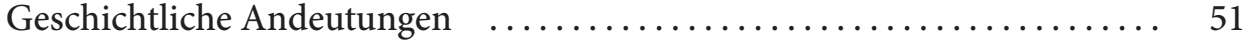

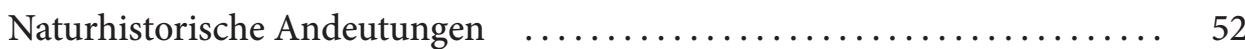

Geographisch-statistische Bemerkungen $\ldots \ldots \ldots \ldots \ldots \ldots \ldots \ldots \ldots . \ldots 6$

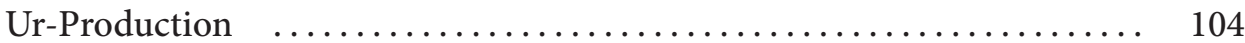

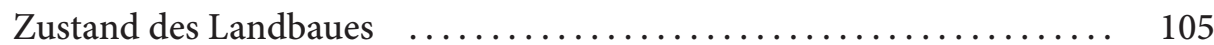

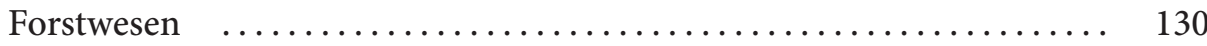

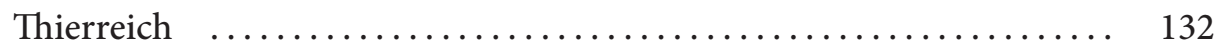

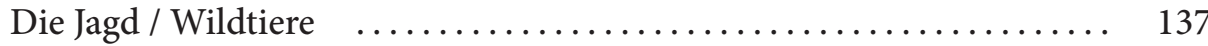

Fischerey und Meerprodukte $\ldots \ldots \ldots \ldots \ldots \ldots \ldots \ldots \ldots . . \ldots \ldots$

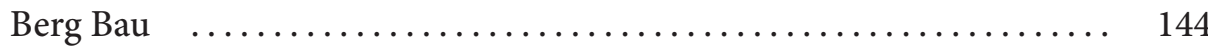

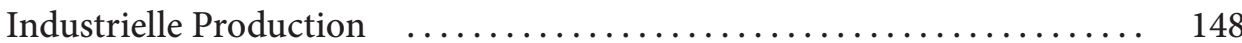

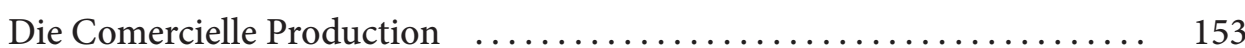

Phisische und Gemüths Beschaffenheit der Bewohner $\ldots \ldots \ldots \ldots \ldots .616$ 
II Dermalige politische Eintheilung des Landes

Eigenheiten und Schwierigkeiten der Provinz Verwaltung

im Allgemeinen

Mittel um die Administration dieses Landes im Allgemeinen

so viel als möglich zu fördern $\ldots \ldots \ldots \ldots \ldots \ldots \ldots \ldots \ldots \ldots \ldots \ldots . \ldots \ldots . \ldots \ldots$

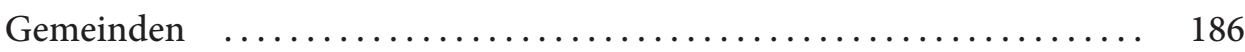

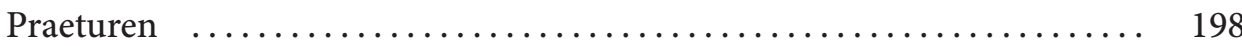

Kreisämter ......................................... 208

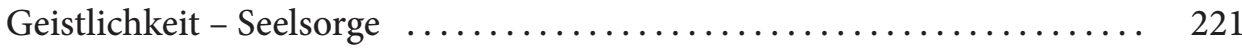

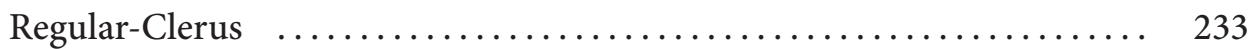

Öffentliche Erziehungs- und Unterrichtsanstalten. $\ldots \ldots \ldots \ldots \ldots \ldots .241$

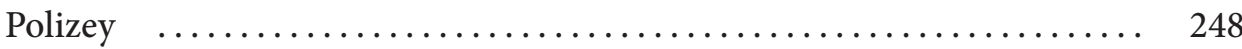

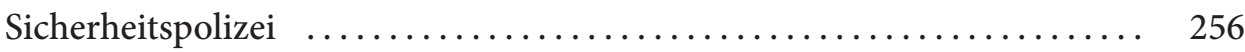

Geheime und höhere Polizey $\quad \ldots \ldots \ldots \ldots \ldots \ldots \ldots \ldots \ldots \ldots . \ldots \ldots$

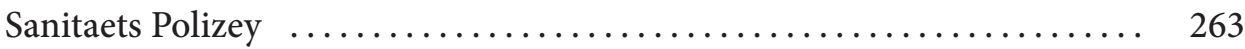

Offentliche Baulichkeiten $\ldots \ldots \ldots \ldots \ldots \ldots \ldots \ldots \ldots \ldots \ldots . \ldots \ldots 7$

Finanz .............................................. 269

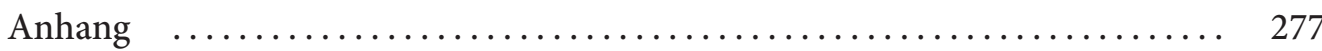

Verzeichnis der in der Lilienbergschen Darstellung

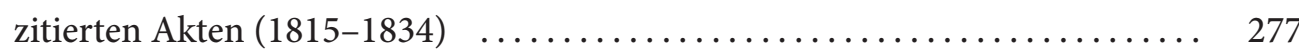

Verzeichnis der $1834 \mathrm{im}$ Staatsrat behandelten Akten zu Dalmatien ...... 285

Verzeichnis der Originalbeilagen (in der Reinschrift und

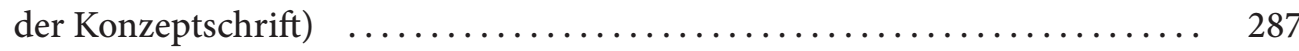

Verzeichnis der Kartenbeilagen der Edition $\ldots . \ldots \ldots \ldots \ldots \ldots \ldots \ldots . . \ldots 289$

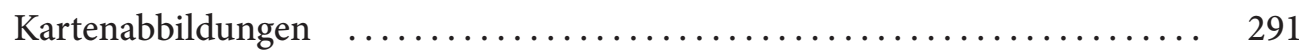

Quellenanhang 1 Vom sehr traurigen Geschick, in Dalmatien

Landeschef zu sein ......................................... 309

Quellenanhang 2 Relation über die Präturen Dalmaziens $\ldots \ldots \ldots \ldots \ldots . . \ldots 15$

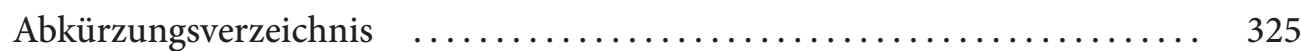

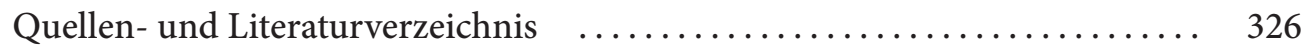

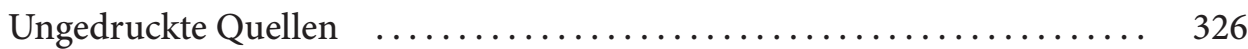

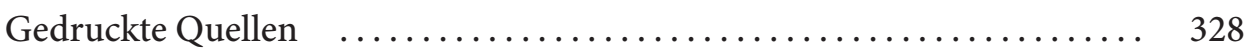

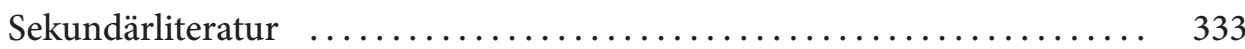

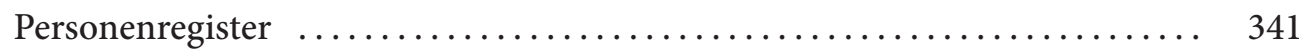

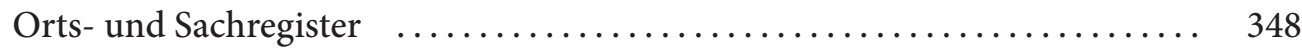




\section{Die vormärzliche Verwaltung in Österreich und das Kronland Dalmatien. Ein Gouverneur schreibt an seinen Kaiser}

\section{Der administrative Sinn des Reisens: Verwaltung durch direkten Überblick}

Es war ein Anliegen des ersten österreichischen Kaisers höchstpersönlich, den unmittelbaren Augenschein von den allgemeinen und den Verwaltungsverhältnissen im Habsburgerreich zu einer administrativen Strategie zu erheben. Seit sich Franz I. 1804 selbst in seine neue Kaiserwürde erhoben hatte, führte der Monarch genauestens Buch über die regelmäßigen Reisen, die ihn mit der Zeit an sämtliche Enden des Reiches führen sollten. Freilich setzte er damit auch eine Praxis seines Oheims Kaiser Joseph II. fort. Er vertiefte sie aber noch weit über das ohnehin schon erhebliche Maß hinaus, mit dem sein dynastischer Vorvorgänger und zeitweiliger Lehrmeister ähnliche Landesbereisungen vorgenommen hatte. Joseph hatte zudem mit dem Anfertigen der an seine Mutter (und ihm »vorgesetzte« erbländische Mitregentin) Maria Theresia gerichteten Notizen über diese Reisen sofort aufgehört, als er nach ihrem Tod 1780 niemandem mehr ähnliche Rechenschaft schuldig war. Franz I. hingegen füllte Abertausende von Seiten mit akribischen Aufzeichnungen über das Gesehene, die ihm zu seiner eigenen späteren Verwendung dienen sollten. Im Jahr 1818 erfasste dieses reisende Herrschaftsinstrument auch das hier besonders interessierende Dalmatien sowie das angrenzende Militär- und Zivilkroatien. ${ }^{1}$

1 Dabei sind bislang die Reisen von Joseph II. deutlich mehr in den Blick der Historiker geraten als diejenigen von Franz I. Zu diesen liegt nicht nur kaum Ediertes vor, sondern auch wenige anderweitige Auswertungen der außerordentlichen Datenmenge seiner Aufzeichnungen, die sich wie diejenigen von Joseph II. im Wiener Haus-, Hof- und Staatsarchiv im Bestand Familienarchiv, Hofreisen befinden. Die bisher einzige umfassende kritische Edition eines franziszeischen Reisetagebuches ist einer eher untypischen Reise gewidmet, weil sie den Monarchen über weite Strecken in das (wenn auch »nahe«) Ausland führte und starke italien- und kirchenpolitische Aspekte hatte (Kuster, Thomas: Das italienische Reisetagebuch Kaiser Franz I. von Österreich aus dem Jahre 1819. Eine kritische Edition. Münster 2010). Die administrativen Aspekte, die das Gesamtsystem der Reisen prägen, traten in diesem Fall daher nicht in den Vordergrund. Daneben ist hier wegen ihres kroatisch-dalmatinischen Kontextes vor allem die gedruckte Übersetzung der das heutige Kroatien umfassenden Teile eines Tagebuches der Reise von 1818 von Belang, die den Kaiser bis nach Dubrovnik geführt hatte (Krmpotić, Ljudevit [Hg.]: Car Franjo I. u Hrvatskoj 1818. 2 Bde. Hannover, Čakovec 2002). - Eine Teilpublikation der Reiseberichte beider Kaiser befindet sich durch den Verfasser in Vorbereitung als ein Projekt am Institut für Ost- und Südosteuropaforschung (Regensburg). Dabei sollen ab Herbst 2014 sukzessive die Tagebuchpassagen 
Aspekte der Herrschaftsrepräsentation spielten bei diesen Unternehmungen natürlich eine wichtige Rolle. Des Kaisers wochen-, oftmals auch monatelange Abwesenheiten von der Residenzstadt Wien waren in besonderer Weise herrscherliche Bewegungen im offenen »Untertanengelände«. Fallweise, besonders im städtischen Umfeld, wurden sie nach allen Vorschriften des Hofzeremoniells und unter Zuhilfenahme sämtlicher seinerzeit verfügbarer medialer Mittel inszeniert, von Presseberichten über akustische Erlebnisse bis hin zu memorialen Hinterlassenschaften. ${ }^{2}$ Die regelmäßigen und großangelegten Audienzen sowie die Besuchs- oder vielmehr Inspektionstermine in unzähligen öffentlichen Institutionen bezweckten auch, möglichst vielen Beamten und anderen Untertanen die Gelegenheit zu einem persönlichen Erleben ihres Monarchen zu geben. Seine physische Präsenz und die mit ihr dargebotene symbolische Erfahrbarkeit auch des Reiches waren für die ideologische Verankerung und Legitimation von Kaiser wie Imperium zweifellos höchst bedeutungsvoll. ${ }^{3}$

Trotzdem stellten die Reisen jenseits der Ebene der Repräsentation in mindestens dem gleichen Maße eine ganz handfeste Administrationsmethode dar. Sie umfassten einen derart großen Teil des kaiserlichen Herrscheralltags (1816 bis 1834 war Franz I. an 4105 Tagen in Wien, aber an nicht weniger als 2835 Tagen unterwegs!), dass ein verwaltender Monarch von der Art des Kaisers Franz niemals so viel Zeit für in erster Linie repräsentative Zwecke hätte übrig haben können. Der Herrscher führte denn auch auf den Reisen seine gewöhnlichen, extrem intensiven Alltags-Aktenarbeiten dank eines kostspieligen Kuriersystems unvermindert fort. ${ }^{4}$ Desgleichen verbat er sich zur Zeitersparnis und Intensivierung seiner Arbeitsmöglichkeiten vielerorts ausdrücklich die

über ein gutes Dutzend der Hauptorte der Monarchie online zur Verfügung gestellt werden (ohne Wien, das als Sitz des Hofes nicht Reiseziel war). Aus Dalmatien und dem angrenzenden Raum betrifft dies Zadar, Zagreb, Ljubljana, Triest und Venedig.

2 Vgl. etwa Oesterreichisch-kaiserliche Wiener Zeitung, Nr. 238 v. 17.10.1818, mit einem Bericht aus Mähren von der Grundsteinlegung eines Obelisken auf dem »Franzensberg« (vormals Petersberg) in Brünn durch den Kaiser selbst unter großem militärischem Aufmarsch und 18 Kanonenschüssen von der gegenüberliegenden Festungsanhöhe Spielberg im Moment der Grundsteinversenkung.

3 Das von Unowsky, Daniel L.: The Pomp and Politics of Patriotism: Imperial Celebrations in Habsburg Austria, 1848-1916. West Lafayette 2005 vorbildlich umgesetzte Forschungsinteresse daran, wie die öffentliche Inszenierung des Monarchen als Symbol von Staatsgewalt, imperialer Einheit und religiöser Glaubensstärke gegen konkurrierende (vor allem nationale) Loyalitätsangebote unternommen wurde (bei Unowsky vor allem anhand Galiziens untersucht), wäre also sinnvollerweise für die frühere Phase unter Franz I. zu adaptieren, da es bei ihm noch kaum gegen nationalideologische Konkurrenzangebote ging.

4 Hartmann, Eleonore: Die Hofreisen Kaiser Franz I. Diss. Wien 1968 (Angaben zu den Anwesenheits- und Abwesenheitstagen: 256). Die Dissertation behandelt die Zeit ab 1816, gliedert die Reisen nach Typen und schildert die Abläufe, freilich ohne Interpretation ihrer Funktion im Verwaltungssystem. Zu den Auslagen und dem hohen Anteil der Portokosten siehe anhand von Reisebeispielen ebd., $234 \mathrm{ff}$.

DigiOst 1 | 6 
Anwendung des bei voller Inszenierung so zeitaufwendigen Hofzeremoniells. ${ }^{5}$ Unerkannt von der bisherigen Forschung, standen also bei den Reisen die praktische Verwaltungsarbeit und die administrative Informationsbeschaffung im Vordergrund. ${ }^{6}$ Für die auf die Stellung seiner eigenen Funktion zentrierte Regierungsführung von Franz I. war es grundlegend, selbst systematische Kenntnisse aus erster, eigener Hand über die Landesteile und die Institutionen mitsamt deren Personal zu erwerben. Insgesamt war es ein durchaus eindrucksvoller Versuch, sich unter den Gegebenheiten des von ihm verfochtenen spätabsolutistischen Verwaltungssystems einen uneinholbaren Kenntnisvorsprung gegenüber den nachgestellten Verwaltungsebenen zu verschaffen - wirklich »Herrschaftswissen « im engsten wie im weiteren Sinn. Angesichts der zu seiner Zeit in vielen Dingen noch sehr groben statistischen und landeskundlichen Erfassung weiter Teile der Monarchie ergab diese aufwendige Methode von Informationsbeschaffung in der Tat Sinn. Das von Kaiser Franz I. verfochtene eigene Dasein als »Endentschei-

5 Allgemein und mit Beispielen: Hartmann: Die Hofreisen, 27, 68 (Preßburg 1825), 78 (Preßburg 1832), 99 (Lemberg 1823).

6 Hartmann etwa thematisiert die Gründe für das kaiserliche Reiseverhalten nicht näher. Ivan Pederin, der sich unter den kroatischen Forschern am meisten mit der Dalmatienreise von Franz I. auseinandergesetzt hat, verortet sie ohne Berücksichtigung des reichsumspannenden Reise-Systems als Einzelfall und suchte ihre Durchführung allzu isoliert mit strategischen Absichten (gegenüber dem Osmanischen Reich) und Legitimationsabsichten für das eigene Kaisersein in Bezugnahme auf die römische Vergangenheit Dalmatiens zu erklären sowie den Reisebericht im Rahmen der historischen Reiseliteraturforschung zu interpretieren (s. v. a. Pederin; Ivan: Njemački putopisi po Dalmaciji. Split 1989, dort 74-108 mit Einordnung und auszugsweiser Übersetzung; speziell 76-78). Einer umfassenden Interpretation wesentlich näher kommt Thomas Kuster, der 35 f. für den »Inlandsteil« seiner Reise einen Inspektionscharakter herausarbeitet und auf einige andere franziszeische Reisen dieser Art verweist. Aber auch bei ihm treten diese Verwaltungsaspekte zurück, zumal er wie gesagt eine wegen der hohen Auslandsanteile eher untypische Unternehmung zum Gegenstand genommen hat und sie vorrangig hinsichtlich "persönlicher Motive« des Monarchen wiederum nach den Maßgaben der historischen Reiseforschung untersucht (vgl. 33). Wohl deshalb präsentiert sie sich auch ihm vorrangig wie ein Einzelfall. Für die Italienreise als solche ist sein Urteil dabei nachvollziehbar: Sie sei nicht als einheitliches Unternehmen geplant gewesen und habe ganz unterschiedliche Zielsetzungen vereint (35): »Die Hofreise von 1819 war schlussendlich eine Kombination aus Inspektions-, Vergnügungs-, Bildungs- und Lustreise, also eine Verbindung aus allen der Reiseforschung bekannten Typen.« Dass der zusätzlich herausgestrichene politische Charakter der Reise in ihrem Romteil nur auf die Wünsche der Kurie zurückgegangen wäre (37), erscheint mir aber bereits angesichts der schon ab 1815 und massiv ab 1817 sowie nochmals verstärkt ab Anfang 1819 verfolgten Pläne Wiens zur Neugestaltung der katholischen Kirchenstrukturen in vielen Teilen des Reiches, besonders auch die administrativ sehr relevanten Diözesangliederungen betreffend, nicht plausibel (vgl. mit Literaturangaben zu Dalmatien und anderen betroffenen Gebieten Clewing, Konrad: Staatlichkeit und nationale Identitätsbildung. Dalmatien in Vormärz und Revolution. München 2001, 106-108).

DigiOst 1 | 7 
der « in unzähligen Einzelfragen ließ sich auf Grund solchen Herrschaftswissens relativ rational und effektiv gestalten. Es war ein a priori sinnvolles Gegenmittel zu den entscheidungstechnischen Wirkungen, die die zunehmende Ausweitung der Staatlichkeit in die gesellschaftliche Sphäre zeitigte. Es war aber dennoch ein entscheidungsökonomisch unzureichendes Mittel. Jene Wirkungen waren systemimmanent nicht mehr zu steuern, auch nicht mit noch so gründlichen Informationsmethoden des obersten Entscheidungsträgers. Denn im gegebenen Rahmen der absolutistischen Entscheidungsprozesse kamen durch sie immer mehr Einzelentscheidungen wie in einem hierarchischen Flaschenhals auf den Monarchen zu und untergruben so die Systemrationalität insgesamt und auf Dauer; der Monarch wurde zu einem zentralen Mitverursacher der Langsamkeit und Ineffizienz des Systems.

Dessen ungeachtet folgte Wenzel Vetter Graf von Lilienberg, seit Herbst 1831 Gouverneur von Dalmatien, dem hohen Vorbild, als er sich von 1832 an in verschiedenen Etappen über zwei Jahre hinweg zu einer gründlichen Erkundung des ihm unterstellten Verwaltungsgebietes aufmachte. Auch er wollte sein Bild von den Verhältnissen nicht bloß auf die Aktenlage und die unzureichende vorhandene Dalmatienliteratur gestützt sehen. ${ }^{7}$ Doch obwohl der Monarch die Methode der Inspektionsreisen an der Spitze des Reiches bereits seit bald drei Jahrzehnten in aller Öffentlichkeit vorexerziert hatte, war Lilienbergs Amtsreise mindestens ihrem Umfang nach für Dalmatien eine Pioniertat. Es scheint mir auch nicht sicher, dass derlei zur gleichen Zeit bei den Gouverneuren in den anderen Ländern der Monarchie in vergleichbarer Weise Teil der gängigen Praxis gewesen ist. In Dalmatien war Lilienberg auf alle Fälle der erste und wohl auch der einzige Chef der Landesverwaltung, der diese Methode derart intensiv betrieben hat. ${ }^{8} \mathrm{Ob}$ freilich seine eigene Mutmaßung stimmte, vielleicht mit Ausnahme einiger subalterner Beamter überhaupt der Erste gewesen zu sein, der ganz Dalmatien so intensiv bereist hat, muss hier letztlich offen bleiben. Einiges spricht dafür, allein schon eingedenk der extrem schlechten Zugänglichkeit großer Teile des Hinterlandes wie auch der Tatsache, dass die drei historischen Bestandteile des Landes (das ex-venezianische Dalmatien, Dubrovnik und das ex-venezianische "Albanien « rund um Cattaro) Anfang der 1830er Jahre noch nicht einmal seit zwei ganzen Jahrzehnten in eine einzige Provinz zusammengeführt waren. Vor ihrer Vereinigung hätten reisende Beamte kaum einen Grund und erst recht nicht die Möglichkeit gehabt, dienstlich alle die Orte zu besuchen, die Lilienberg von 1832 bis 1834 aufgesucht und beschrieben hat. ${ }^{9}$

7 Vgl. Lilienbergs dezidierte Abgrenzung gegen ein nur "papierenes« Landesbild und dessen Unzulänglichkeiten in den $\$ \$ 1-2$ der Darstellung.

8 An manchen Orten selbst im Hinterland war er sogar zweimal anwesend, um sich vom Fortgang spezieller von ihm in die Wege geleiteter Maßnahmen einen Eindruck zu verschaffen; vgl. $\$ 52$ zu Trockenlegungsmaßnahmen an der Krka bei Knin.

9 Vgl. $\$ 1$ der Lilienbergschen Darstellung. Allerdings erwähnt auch Joseph Freiherr von Weingarten, der 1819 bis 1826 als Gubernialrat in der Hierarchie der Landesverwaltung an zweiter Stelle gestanden war, in seiner Selbstbiographie, dass er sich gleich im Mai 1819 auf eine Be- 
Der lange Bericht über die Reise ist auf jeden Fall einzigartig. Als »Darstellung der Provinz Dalmatien nach der ämtlichen Bereisung, in den Jahren 1832, 1833 und 1834" untersuchte darin Lilienberg für den Kaiser das Land und seine Verwaltung, und zwar sehr stark unter dem immer wieder durchdringenden Aspekt der zu geringen Berücksichtigung Dalmatiens und seiner Interessen durch das Agieren der Zentralbehörden. ${ }^{10}$ Besonders dank dieser eindringlichen Kritik an verwaltungspolitischen Grundlinien der Zentralverwaltung sind Lilienbergs Schilderungen deshalb nicht nur für eine Betrachtung der lokalen Verhältnisse in Dalmatien von hohem Wert. Sie stellen auch eine wichtige Quelle dar für eine Analyse des vormärzlichen Verwaltungssystems im habsburgischen »Cisleithanien« als Ganzem. Das gilt umso mehr, als zu diesem System generell wenig Forschung vorliegt. Gerade über die hier berührten grundlegenden Aspekte

reisung des Hinter- und Küstenlandes der Kreise Zara und Spalato, dann Ragusa und Cattaro und auf dem Rückweg noch der Inseln Curzola, Lissa und Lessina gemacht hat: AVA, Nl. Hohenwart, Kt. 14b, »Selbstbiographie Weingartens«, Bogen IX. Er kann bei diesem deutlich kürzeren und einmaligen Unterfangen aber nicht gleich viele Orte besucht haben wie später dann Lilienberg.

10 Die hier zur Edition verwendete Konzeptfassung wurde mir ursprünglich durch Marko Trogrlić, Split, zugänglich gemacht und liegt im Original im Državni arhiv u Zadru (Staatsarchiv Zadar, in der Folge: DAZd), im Bestand Prezidijalni spisi Namjesništva (Präsidiale des Guberniums, in der Folge: PSN), in Karton 154. Die wesentlich später aufgefundene Reinschrift trägt einen modifizierten Titel und ist vorhanden in der Österreichischen Nationalbibliothek: Cod. Ser. N. 12354: Vetter, Wenzel Graf von Lilienberg: Allerunterthänigste Relation über die in den Jahren 1832, 1833 und 1834 gemachte Dienst-Reise in Dalmatien. Zara [laut Katalog fälschlich: o. O.] 1834; sie ist dort inzwischen auch als Digitalisat zugänglich unter http://data.onb.ac.at/rec/AL00069461. - Der individuelle Charakter der Beschreibung, der sich in weiten Passagen niederschlägt, unterscheidet den Bericht auch sehr von früheren summarischen, aus den Akten gewonnenen Gouverneursberichten, wohl zumeist Jahresberichte. Auch von dieser Gattung sind aber für das frühere 19. Jahrhundert in der Forschung bislang nur die auf ihre Art auch sehr informativen Jahresberichte bekannt, die zu Zeiten des Königreichs Italien der für Dalmatien (in den vorherigen venezianisch-österreichischen Provinzgrenzen) zuständige Gouverneur Vincenzo Dandolo an den Kaiser und König Napoleon I. gesandt hat. Dandolo, Vinczeno: La Dalmazia al 31 decembre 1806. Opera economico-politica. [gedr.] Zara 1909; ders.: La Dalmazia ai 31 Decembre 1807. Opera in dieci parti divisa. [Ms.] Zara, 31 Dicembre 1807; ders.: La Dalmazia ai 31. Decembre 1808. Opera economico-politica. Continuazione ai due Rapporti Generali 31. Decembre 1806 e 31. Decemb [re] 1807. [Ms.] Zara, 31. Decembre 1808; ders.: La Dalmazia ai 31. Decembre 1809. Opera economico-politica. Continuazione ai Tre Rapporti 31 Decembre 1806, 1807, e 1808. [Ms.] Zara 31 Decembre 1809. Abgesehen von dem ersten, 1909 in Druckform aufgelegten und inzwischen auch digital zugänglichen Bericht sind alle weiteren nur als in Manuskript in mehreren zeitgenössischen Abschriften überliefert. Ich danke herzlich Josip Vrandečić, Split, für die Überlassung einer Fotokopie nach den im Spliter Archäologischen Museum überlieferten Exemplaren. 
des Zusammenspiels und Gegeneinanders der gesamtstaatlichen und der Provinzebenen wusste man bislang wenig.

Im konkreten Fall hegte der Gouverneur Lilienberg große Hoffnungen auf die Wirkung seines Berichts, als er Mitte Juli 1834, mit ihm im Gepäck, vom Sitz der Landesverwaltung in Zadar nach Wien aufbrach. Das wird bei der Lektüre überdeutlich, denn abgesehen von dem Wunsch nach einer Stärkung der Landesverwaltung gegenüber Wien verfolgt seine Darstellung vor allem ein Kernargument: Dalmatien habe viele Probleme, aber auch hohes Potential. Das Land mochte in den Schwierigkeiten, die es durch seinen Entwicklungsstand und seine Nöte für das Wirken der staatlichen Verwaltung aufwarf, einem "verzogenen Kinde« gleichen. Aber das könne man ändern, und zwar nicht durch Zwang, sondern durch praktisches Vorbild und staatliche Anreize. ${ }^{11}$ Am Ende lag es in Lilienbergs Augen an der Regierung selbst, durch vermehrte Zukunftsinvestitionen den »rohen Diamant« in einen Brillanten umzuschleifen. Anders als die früheren Herrschaften über Dalmatien habe die österreichische Verwaltung und habe auch der Kaiser auf diesem Weg schon einiges unternommen. Aber Lilienberg machte zugleich sehr deutlich, dass für diese bessere Zukunft noch viel mehr Engagement möglich und nötig war, und zwar im ureigenen Interesse des Staates. ${ }^{12}$

Lilienberg hatte über Jahre hinweg enorm viel Mühe aufgewendet, sich die Wissensbasis für diese Analyse und dieses Plädoyer zu verschaffen, ${ }^{13}$ und hatte am Schluss auch

11 Vgl. $\$ 79$ seiner Darstellung: »Den Fleiß des Landmanns kann man nur auf zweierley Art heben, nämlich: 1 wenn man ihn praktisch belehrt und durch den Erfolg dieser Belehrung überzeugt, daß der Endertrag wirklich zugenommen hat; und dieses würde man am leichtesten und zweckmäßigsten auf die itzt beschriebene Art thun, dann 2 durch die Austheilung einiger Prämien, welches besonders in einem rohen und dürftigen Lande, das einen verzogenem Kinde gleicht und mit Strenge nicht leicht dießfalls unmittelbar angehalten werden kann, sehr geeignet ist, die Betriebsamkeit zu heben."

12 Siehe dazu insbesondere am Ende seiner Darstellung, im vorletzten Absatz: Unter einigen Voraussetzungen könne »man mit Zuversicht annehmen, daß dieser rohe Diamant, der durch viele Generationen blos als ein gemeiner Gneis behandelt wurde, durch Euer Majestät unerreichbare Weisheit, da Allerhöchst dieselben die Gegenwart der Zukunft zu opfern und Vieles auf dieses Land väterlich zu verwenden nicht gescheut haben, zum Brillant neugestaltet und die große Schuld dem Staate in dankbarster Anerkennung unzähliger allerhöchster Wohlthaten vollkommen zurückgezahlt wird.«

13 Nicht nur müssen die Reisen schlicht sehr strapaziös gewesen sein, zumal für einen kriegsversehrten Menschen, der 1832 bereits 65 Jahre alt war. Sondern Lilienberg nützte sie auch gleich während der Reise zu zahlreichen Begegnungen und Amtsgeschäften, abgesehen davon, dass er zu einem erheblichen Teil ähnlich wie der Kaiser auf seinen Reisen auch den üblichen Geschäftsverkehr erledigte. Zeugnis dessen sind drei Register- und Protokollbände, die allein die Reiseetappe von 1833 dokumentieren. Sie machen die Hälfte von insgesamt sechs Lilienberg zugeordneten Handregistern aus (DAZd, Vlada/Namjesništvo za Dalmaciju, Lilienbergovi protokoli i indeksi, Bde. I-VI). Bd. I (alte Indexnummerierung 184): »Protocoll über die Verhandlungen der Bereisung der Provinz von Seite Seiner Excellenz des Herrn Landes Gouverneurs Grafen von Lilienberg etc. etc. 1833«. Dieser Band enthält Ge- 
äußerst intensive Textarbeit geleistet. Er erwartete nichts weniger, das wird an zahlreichen Stellen deutlich, als eine grundlegend neue Haltung der Wiener Führungsebenen gegenüber den vielen Entwicklungsproblemen zu bewirken, mit denen Dalmatien wegen seiner schlechten Ausgangsposition am Ende der »Franzosenzeit» wie auch aufgrund seiner peripheren Lage im Gesamtstaat konfrontiert war. Überdies kam es Lilienberg darauf an, durch den direkten Rapport an den Kaiser in diversen konkreten Entscheidungsfragen die von ihm bei der übrigen Wiener Zentralverwaltung diagnostizierten Hemmnisse zu umschiffen. Fällige Entscheidungen suchte er beschleunigt herbeizuführen, beziehungsweise an mancher Stelle schon getroffene Wiener Entscheidungen durch den Kaiser revidieren zu lassen. ${ }^{14}$

Der Gouverneur rekurrierte dabei mit Bedacht auf das monarchische "Landesvatertum «. Mit diesem in seinem Fall oft nur scheinbar unterwürfigen Ansatz ging er auf geradezu dialektisch-kreative Weise um, um den Monarchen zu einem Verbündeten für das Anliegen von mehr staatlichen Investitionen in Dalmatien zu machen. Wo er es für nötig hielt, hatte Lilienberg Chuzpe genug, kaum verblümt eine Verbindungslinie zwischen Landesvatertum und einer Dankespflicht der Landesbewohner herzustellen, die es erst noch durch konkrete kaiserliche Taten zu verdienen oder zu steigern galt. ${ }^{15}$

sprächsnotizen und Eingangsanzeigen zu Anliegen, die auf dieser Reise an Lilienberg herangetragen wurden (durchnummeriert nach Vorgängen von 1-316, mit den Rubriken »Tag der Einlangung «, »Namen des Erstatters und Tag der Erstattung «, »Gegenstand «, »Erledigung «, »Tag der Erledigung «, »Ob eine hohe Entschliessung, oder Bericht erwartet wird «, »N.o unter welcher dieser eingelangt is « «, zu Bencovaz (Benkovac) 23.6.1833, am Ende steht etliches aus Castelnuovo sub 26.7.1833. Bd. II (alte Nr. 185), »Reise-Protocoll für Seine Ecxellenz 1833«, bietet eine etwas adaptierte Fortsetzung zu Bd. I, mit laufenden Nummern 317-581. Die Datierungen der Einlangungen reichen von Ende Juni bis Mitte August 1833; die Erledigung des meisten wird schon für September verzeichnet. Angesichts der Reiseumstände und im Vergleich mit dem im österreichischen Vormärz Üblichen erscheint mir das sehr zügig und effizient. Bd. IV (alte Nummer 187) ist ein »Index über die Verhandlungen auf der Bereisung der Provinz von Seite Seiner Excellenz des Herrn Landes Gouverneurs Grafen von Lilienberg etc. etc. 1833«; hier finden sich (sämtlich in deutscher Sprache) Einträge zu Personen und Themen, mit Verweis auf Aktennummern, die aber alle ziemlich niedrig sind und sich vielleicht auf einen persönlichen Handbestand von Lilienberg bezogen haben.

14 Vgl. $\$ \$ 118$ (im letzten Drittel, wegen Hofkammer), 119, 143 (am Ende, wegen Katasterbericht an den Obersten Hofkanzler der Hofkanzlei), 150 (Einengung der Personalausstattung, langwierige "Systemisierung « und falsche haushaltspolitische Grundsätze der Wiener Stellen), 160, 227 (Wiederzulassung der Karawanen), 230 (Rückgängigmachung). Sein Werben um den Kaiser hinderte Lilienberg aber nicht daran, an einigen Stellen sogar kaiserliche Entschlüsse nur mäßig diplomatisch zu kritisieren; siehe $\$ 92 \mathrm{zu}$ dem für Lilienberg besonders wichtigen Thema der Finanzausstattung für den Landwirtschaftsfonds.

15 Vgl. wiederum zum Punkt des Landwirtschafts- bzw. Agrikulturfonds, am Ende von $\$ 106$; auch $\$ 137$. 
Mit Blick auf die nichtdynastischen Zentralinstanzen legte Lilienberg erst recht keine Scheu an den Tag. Er schreckte selbst vor harscher Kritik nicht zurück. Wenn er etwa wegen der schmerzlichen ökonomischen Verbotsfolgen die Wirkung des von Wien aus verhängten Verbots der lange Zeit üblichen Karawanen mit osmanischen Erzeugnissen bis an die wichtigsten Küstenorte auf eine Ebene mit den verheerenden Konsequenzen stellte, welche die (im vormärzlichen amtlichen Österreich wohlgemerkt mehr als verrufene!) napoleonische Herrschaft für den dalmatinischen Seehandel hervorgerufen hatte, hätte sich seine Kritik kaum härter formulieren lassen. ${ }^{16}$

Das von Lilienberg gewünschte Maß an Änderungen ging weit hinaus über bloße Details. Er zielte auch auf den Kern der Verwaltungsstrukturen. In der Summe erhoffte er mehr allgemeinen administrativen Handlungsspielraum für die Landesebene, um das starr zentralistische habsburgische System zumindest am Punkt von Dalmatien flexibler und dezentraler zu gestalten. Er wollte Regelungen, die an die örtlichen Verhältnisse angepasst waren. Ein wenig anachronistisch gesagt, hoffte der Gouverneur auf mehr Subsidiarität anstelle des real existierenden Zentralismus. ${ }^{17}$ Ganz im Einklang damit stand auch seine fast schroffe Forderung, er selbst und die Landesverwaltung mögen bei den Zentralbehörden in Wien doch endlich einmal sachkundige, sprich ortskundige Ansprechpartner erhalten. ${ }^{18}$

\section{1834/35: Hektik und vergebliche Hoffnung am dalmatinischen Gubernium}

Die Schlussphase für die Anfertigung des umfang- und inhaltsreichen Dokuments hatte im späten Frühjahr 1834 begonnen. Von dann an herrschte bis zum letzten Moment größte Betriebsamkeit, ja Hektik in dem kleinen Kreise der drei Personen, die am Guberniumssitz mit dem wichtigen und vertraulichen Text beschäftigt waren. Auf der Zielgeraden, wenige Tage vor der Abreise des Gouverneurs nach Wien, brachte der beauftragte Schreiber Rougier am 12. Juli 1834 die Reinschrift so eben noch zu Ende. ${ }^{19}$ Die

16 Vgl. $\$ 119$.

17 Vgl. $\$ \$ 156,157,158,180,182$ (mittelfristige Notwendigkeit der Forza territoriale, trotz ihrer eigentlichen Systemwidrigkeit, wegen Besonderheiten der Sicherheitslage), 231.

18 Vgl. $\$ \$ 154,159$ (Schluss).

19 DAZd, a. a. O. Auf der ersten Seite findet sich der Kopiervermerk: Copiato 12/7 1834 Rougier. Rougier selbst wird weder im Almanacco della Dalmazia per l'anno 1833. Zara (Dalla Tipografia Governale Demarchi) 1833, noch in dem für 1834 oder 1835 als Amtsträger aufgeführt. Er war vermutlich entweder ein noch nicht fix angestellter Praktikant oder aber und dies ist wahrscheinlicher, weil damit die persönliche Vertrauensstellung zum Gouverneur besser in Einklang zu bringen ist, die für die Mitarbeit an solch einem zweifellos streng vertraulichen Dokument erforderlich war - ein »Tagschreiber» (»Diurnist $)$. Letztere waren rechtlich gesehen Tagelöhner innerhalb der vormärzlichen Verwaltung, die ohne Festanstel-

DigiOst 1 | 12 
Unterschrift Lilienbergs im Konzept ist sogar erst auf den 16. Juli datiert und in der Reinschrift vordatiert auf den 15. Juli. Angesichts dessen stimmte vermutlich die Datierung im Konzept, aber selbst mit dem 15. Juli wäre man denkbar knapp vor der gewiss lang fixierten Abreise Lilienbergs nach Wien gelegen. ${ }^{20}$

Zwei Monate zuvor, am 12. Mai, hatte Lilienberg die Bereisung endgültig abgeschlossen, zu der er den Anfang gleich in seinem ersten vollen Dienstjahr 1832 gemacht hatte. ${ }^{21}$ Vermutlich erst im Anschluss an dieses Ende ging es an die eigentliche Niederschrift. Viele Indizien sprechen dafür, dass sie vorwiegend durch Diktat entstanden ist, stellenweise aber wohl auch durch Zusammenfügung der Notizen und Stichworte, die ansonsten die Grundlage für das Diktat dargestellt haben dürften. ${ }^{22}$ Spätestens seit dem 24. Mai - so ein Bearbeitervermerk am Rande von $\$ 18$ der Reisebeschreibung - war Rougier parallel dazu damit beschäftigt, die ersten Teile der Konzeptvorlage unter teilweiser Berücksichtigung der zahlreich markierten Änderungen und Streichungen in Reinschrift zu bringen. Zugleich wurde durch den Gouverneur und den ihm offenbar

lung einen Tageslohn für ihre Schreibertätigkeiten erhielten. Durch die übliche häufige Verlängerung ihrer prekären, maximal sechsmonatigen Beschäftigungsverhältnisse waren sie aber de facto zumeist Dauerangestellte. Vgl. Orosz, Anton: Worte eines eifrigen und uneigennützigen Staatsdieners, die bei der Regulierung der neuen Verhältnisse des Constitutionellen Dalmatien beachtet werden mögen. Zara 1848, $23 \mathrm{f}$. bzw. Clewing: Staatlichkeit und nationale Identitätsbildung, 90. Die sehr wahrscheinliche Verbindung oder sogar Identität dieses Rougier mit dem späteren Zaratiner Druckereiunternehmer G. Rougier kann hier nicht genau bestimmt werden. G. Rougier war ab 1838 Eigentümer oder Miteigentümer der amtlichen Druckerei Demarchi-Rougier, als direkte Fortsetzung zu der vorherigen Druckerei »Demarchi«; vgl. zu dieser Druckerei sehr knapp, aber mit Verweis auf weitere Literatur Lakuš, Jelena: Izdavačka i tiskarska djelatnost na dalmatinskom prostoru (Zadar, Split i Dubrovnik) u prvoj polovici 19. stoljeća (1815.-1850.). Split 2005, 11, Anm. 18.

20 Siehe dazu im übernächsten Absatz.

21 In dem Konvolut, das im Anschluss an das Berichtskonzept die Aktenanlagen enthält (I/1 6: Reise Seiner Excellenz des H. Gouverneurs, $1666^{1 / 2}$ ) liegt gleich oben auf das Abrechnungsschreiben 1197/p ec off. an die Buchhaltung, 26.5.1834, in dem Lilienberg für die amtliche Bereisung der Provinz um Kostenerstattung bittet und das Reiseende auf den 12. Mai 1834 datiert.

22 Vgl. die Anmerkungen zu mutmaßlichen Hörfehlern des Schreibers etc. in der Edition. Stichworte finden sich zu der Konzeptfassung der Gliederung sowie Punkt für Punkt in einem eigenen Anmerkungsdokument von 12 Seiten (auf eigenen Quadrangeln 1-3) im unmittelbaren Anschluss an die Konzeptausfertigung. Zu $\$ 18$ etwa, in dem die grundlegende Verschiedenheit der österreichischen Förderung des Landes von der bloßen Benützung desselben durch Venezianer und Franzosen behauptet wird, hieß die Notiz »ad 18 S. M. hat zum Zweck die eigene Wohlfahrt Dalmatiens; selbst mit größten Opfern«. Im Anschluss daran finden sich zu den drei wirtschaftspolitisch besonders dringlichen Fragen von Salz und Tabak (Monopolen) und Karawanen (Wiederzulassung) dann noch einmal stärker ausformulierte Zwischenschritte. 
eng vertrauten Sekretär Antonio Costa Rossetti ${ }^{23}$ am ursprünglichen Konzepttext weitergearbeitet. Als die Reinschrift vollendet war, hatten sie beide in Sachen Systematik und Menge der geplanten Änderungen markante Abstriche machen müssen. Dem offenkundigen Zeitdruck geopfert wurde vor allem die systematische »Entpersönlichung" des ursprünglichen Duktus, die Lilienberg zwischenzeitlich angestrebt hatte. Die vielen »ich«, »mein« und »mir«, die dem Text seine für eine amtliche Schrift (noch dazu für eine an einen Monarchen gerichtete) erstaunlich direkte und selbstbewusste Färbung geben, hatten er und Rossetti bis etwa zur Manuskriptmitte fast durchwegs zur Beseitigung markiert. Danach reißen in der Konzeptschrift diese Markierungen ab, und die entsprechenden Änderungen finden sich nicht einmal am Beginn der in Wien erhaltenen Reinschrift eingearbeitet. Vermutlich fehlte es schlicht an der Zeit für solch eine "distanzwahrende«, aber redaktionell wie schreibtechnisch aufwendige Umgestaltung; in jenen Tagen waren die Beteiligten unter anderem mit grundlegenden Änderungen innerhalb der Gliederung beschäftigt und hatten selbst diese nicht zur eigenen Übersicht ein zweites Mal für die Akten in Zadar abschreiben können, wie eine Randbemerkung Rossettis erkennen lässt. ${ }^{24}$

Statt etwa die Gliederung ein zweites Mal abzuschreiben, hat man die letzten verbleibenden Tage bis zur Abreise des Gouverneurs wohl darauf verwenden müssen, dem Dokument noch hastig ein für das kaiserliche Leserauge geeignetes Äußeres zu verleihen. Jedenfalls liegt die fertige Reinschrift in einer Pappkartonmappe vor, die durch Marmorpapier ansehnlich gemacht und im Inneren durch farbige Trachtenzeichnungen und die Kartenbeilagen zusätzlich verschönert ist; ${ }^{25}$ diese Mappe wird Graf Lilienberg bei seinem Wienaufenthalt dem Kaiser wohl persönlich übergeben haben. Der vorherige Aufbruch von Zara war im frühen Morgengrauen des 17. Juli erfolgt und wurde feierlich in Szene gesetzt. Eine militärische Formation und Salutschüsse der Artillerie verabschiedeten den Gouverneur (bei der Schilderung der Szene versäumte die halbamtliche »Gazzetta di Zara« nicht, auch der saufrichtigsten Wünsche der Bevölkerung für eine gute Reise zu gedenken, die den Aufbruch begleitet hätten) ${ }^{26}$ Dass der Gouverneur

23 Vollständige Namens- und Positionsangabe im Almanacco della Dalmazia per l'anno 1834. Zara (Dalla Tipografia Governale Demarchi) 1834, 82. In dieser Funktion figuriert Rossetti auch in den Almanacchi von 1833 und 1835, während in Lilienbergs Anfangszeit noch wie (s. Almanacco von 1830) unter dessen Vorgänger Gouverneur Franz Freiherr Tomassich (Franjo Tomašić) Andrea di Frossard Präsidialsekretär und zugleich >revvisore dei libri ‘ gewesen war, der in den späteren Jahren nur noch letztere Funktion bekleidete.

24 Anmerkung in seiner Handschrift zur Gliederung im Konzept: »NB [Nota bene] Die Seitenzahl ist hier [in dem Inhaltsverzeichnis] nicht richtig, da selbe bei der Copiatur gleich in den mundirten Seiten gehörig eingetragen war, dann aber nicht überschrieben werden konnte, indem die Zeit mangelte."

25 Diese Ausstattung erhielt natürlich nur die am Ende im Rahmen dieses Projekts überraschend doch noch aufgefundene Reinschrift; siehe dazu weiter unten, Anm. 84.

26 Gazzetta di Zara (in der Folge: GdZ) Nr. 58/1834, 22.7., S. 229, Meldung unter Zara 20.7. 
am 23. Juli gut in Wien eingetroffen sei, meldete die gleiche Gazzetta Anfang August so lange brauchten damals die neuesten Nachrichten aus der Hauptstadt für ihren Weg nach Zadar. ${ }^{27}$ Die Gazzetta war im Übrigen damals die einzige Zeitung der ganzen Provinz, und dass sie seit 1832 erschien, war wiederum eine Initiative Lilienbergs. - Schon bald wird der Gouverneur seine Audienz beim Kaiser gehabt haben. Denn im Weiteren ging es für vormärzliche Verhältnisses zunächst außergewöhnlich rasch, Schlag auf Schlag. Bereits am 12. August, für seine Regierungspraxis geradezu unglaublich schnell, reagierte der Kaiser mit einem Handschreiben an Lilienberg, durch das er ihm einen genaueren schriftlichen »Vortrag « auftrug beziehungsweise gestattete, in dessen Zuge der Gouverneur über eine in seinem Reisebericht angesprochene Frage einen Antrag stellen sollte, die Lilienberg besonders wichtig war, nämlich die der Landwirtschaftskommissäre. ${ }^{28}$ Noch ein weiteres kaiserliches Handschreiben einen guten Monat später zu dem im Lilienbergschen Bericht ( $\$ 209$ ) angesprochenen Punkt der »Opere Pie« sowie die vielfache Behandlung von in der Reiseschilderung tangierten Gegenständen in den Aktivitäten des Staatsrats aus jenem Jahr 1834 legen nahe, dass nach der Lektüre durch den Kaiser der Bericht in Wien zunächst etliche Wirkungen entfachte. ${ }^{29}$

Es ist trotzdem mehr als fraglich, ob der weitere Gang der Dinge wirklich den von Lilienberg erhofften Durchbruch für die staatliche Entwicklungspolitik gegenüber Dalmatien hätte bringen können. Die Habsburgermonarchie befand sich seit den zahlreichen Kriegen ${ }^{30}$ gegen das revolutionäre Frankreich und Napoleon in Geldnöten; der offene Staatsbankrott von 1811 war davon zwar der Höhe-, aber nicht der Endpunkt. Und überhaupt macht gerade auch Lilienbergs Schilderung an vielen Stellen für den heutigen Leser deutlich, dass eine tiefgreifende staatliche Durchdringung und Steuerung

27 GdZ 62/1834, 5.8., S. 241 Meldung unter Zara 4.8. mit Berufung auf Nachrichten aus Wien vom 26.7.

28 Nämlich über die zur Landwirtschaftsförderung benötigten Agrarinspekteure beziehungsweise -kommissäre; vgl. bei Lilienberg $\$ 180$. Das Kabinettschreiben liegt in DAZd, Tajni spisi c.k. dalmatinskog namjesništva 1814.-1918. [Geheimakten des k. k. Landesguberniums], Kt. 16. Dieser Karton enthält in einem besonderen Behältnis mehrere kaiserliche Handschreiben des Jahres 1834, darunter die besagte Aufforderung des Kaisers, die Lilienberg äußerst willkommen gewesen sein muss.

29 Ebd., kaiserliches Handschreiben, Brünn, 29. 9.1834. Zu den im Staatsrat behandelten Themen vgl. hier im Anhang (Seite 289-290) die Liste der dortigen Dalmatien im Jahr 1834 betreffenden Akten. Da die Aktenoriginale im Haus-, Hof- und Staatsarchiv Kriegsverluste sind, ist eine Datierung und genauere Verknüpfung der einzelnen Vorgänge mit Lilienbergs Bericht nicht mehr unmittelbar möglich.

30 Vgl. das instruktive Überblicksschema in Siemann, Wolfram: Metternich. Staatsmann zwischen Restauration und Moderne. 2. Auflage, München 2010, 39, aus dem im Vergleich mit den anderen kriegführenden Mächten hervorgeht, dass Österreich mit 1792-1815 fünf Kriegen am häufigsten gegen Frankreich antrat und über weit längere Zeitstrecken als etwa Preußen (wenn auch in der Summe der Zeiten nicht so lange wie das in dieser Hinsicht führende Großbritannien). 
der dalmatinischen gesellschaftlichen Verhältnisse selbst bei Wiener Investitionswillen vor großen Schwierigkeiten gestanden wäre. Für den Gouverneur muss es aber ein sehr herber Schlag gewesen sein, als schon wenige Monate später sämtliche Hoffnungen in die Wirkung einer persönlichen Rückendeckung durch den Monarchen zerstoben: Nach kurzer heftiger Krankheit und deshalb durchaus unerwartet endete das Leben von Kaiser Franz I. am 2. März 1835 infolge einer Lungenentzündung, nachdem er gerade eben siebenundsechzig Jahre alt geworden war. ${ }^{31}$

So wenig der Bericht am Ende über den Regierungswechsel hinweg (dessen Form angesichts der geistigen Unzulänglichkeit des neuen Kaisers Ferdinand I. die Stellung der von Lilienberg nicht eben geschätzten Zentralbürokratie weiter stärkte) konkret bewirken konnte, so sehr ist es für jeden an der vormärzlichen dalmatinischen und österreichischen Geschichte Interessierten ein Glück, dass sich Gouverneur Lilienberg den vielen Mühen des Reisens und Schreibens unterzogen hatte. Es ist das erste derart umfassende Zeugnis der unmittelbaren Eindrücke eines Einzelnen von den Verhältnissen im ganzen Lande. Schon gar nicht gibt es ein vergleichbares Dokument, in dem ein oberster Verwalter der Provinz seine Entwicklungshoffnungen ebenso eindringlich geschildert hätte wie seine Probleme mit der habsburgischen Zentralverwaltung.

\section{Gouverneur und Kaiser: im Labyrinth der österreichischen Bürokratie}

Auch ein wohlmeinender Zeitgenosse hätte vermutlich nicht behauptet, Wenzeslaus oder einfach Wenzel - Vetter Graf von Lilienberg sei ein für jedermann angenehmer Charakter gewesen. Seinem kaiserlichen Herrn freilich war er auf alle Fälle ein energischer und fähiger Staatsdiener, im Schlachtfeld ebenso wie in der Verwaltung, und letzteres im militärischen und im zivilen Bereich. Am 16. März 1767 im mittelböhmischen Czaslau (Čáslav) geboren, hatte Lilienberg ${ }^{32}$ seine Laufbahn als aktiver Offizier

31 Siehe die Chronologie der letzten Lebenstage bei Püchler, Benedikt von: Geschichte der Regierung Kaiser Franz I. 3 Teile Wien 1841, Teil 3, $152 \mathrm{f}$.

32 Er selbst zeichnete stets mit »Lilienberg«, und auch sein wichtigster Nachrufschreiber, der genannte spätere Banus Josip Jelačić (in der zweiten Hälfte der 1830er Jahre Lilienbergs Adjutant), nannte ihn außerhalb der Überschrift des Nachrufs konsequent nur so. Diesem Usus möchte ich folgen und ihn also nicht unter dem vollständigen Adelsnamen Vetter Graf Lilienberg führen. Seinen Vornamen wiederum wie in Teilen der kroatischen Literatur und von dort ausgehend auf diversen internationalen Wikipediaseiten kroatisiert als Venceslav zu führen, scheint mir fast so irreführend wie die eine oder andere komplett falsche Namensvariante auf den besagten Seiten (vgl. etwa die Variante in der auch sonst sehr fehlerhaften habsburgisch-dalmatinischen Gouverneursliste unter http://sh.wikipedia.org/wiki/ Kraljevina_Dalmacija, zuletzt 28.4.2014). Für eine tschechische Teilidentität Lilienbergs, die allenfalls als Begründung für den slawisierten Vornamen herhalten könnte, gibt es kei-

DigiOst 1 | 16 
als Kadett im Jahr 1790 im letzten österreichischen Türkenkrieg begonnen. In der Folge stellte er bis zu einer folgenschweren Verwundung im Jahr 1812 während der diversen antinapoleonischen Feldzüge mehrfach außerordentliche Verwegenheit und größten Einsatzwillen unter Beweis, darin ist seinem später selbst so prominenten Biographen Josip Jelačić vollkommener Glauben zu schenken. Das Militärische lag Lilienberg also nahe. Zumindest machte es auch in Friedenszeiten einen wichtigen Teil seiner Persönlichkeit und seiner Erscheinung aus, inklusive der mit dieser Form von Männerkultur verbundenen Geradlinigkeit oder Grobheit, derer er sich im Zivilleben zu bedienen wusste, wenn ihm danach war oder wenn er die Interessen seines Monarchen oder seines Staates so am besten zu verteidigen vermeinte.

Mit dieser Seite Lilienbergs hatte offenbar nicht zuletzt der in jenen Jahren in Europa sicher bekannteste aller Dalmatiner, Niccolò Tommaseo, Bekanntschaft gemacht. Tommaseo war aus langjähriger Emigration 1838 auf habsburgisches Gebiet nach Venedig zurückgekehrt und hatte 1839 erstmals wieder sein Geburtsland Dalmatien besucht. Sein gewonnener Eindruck von Lilienberg ließ ihn diesen noch Jahre später mit spürbarer Erbitterung als »mittelmäßigen Soldatentyp und noch mittelmäßigeren Menschen " (soldataccio mediocre, uomo men che mediocre) schildern. ${ }^{33}$

nerlei Hinweise. Sein eigenes Heiratsverhalten (mit einer Gräfin von Daun, einer wie die Lilienbergs ebenfalls ursprünglich aus den Rheinlanden stammenden Familie) und dasjenige ihrer beider Kinder (der Sohn mit einer Tochter aus der Wiener Adelsfamilie von Liebenberg und die Tochter mit einem im Mainz ansässig werdenden fränkisch-bayerischen Grafen Castell-Castell) legen vielmehr nahe, dass Lilienberg die auch von Jelačić gleich zu Beginn hervorgehobene reichsritterliche Herkunft der Familie sehr wichtig war. Nachrufe/ Biographien: Jellachich, Joseph Baron [Jelačić, Josip]: Lebensbeschreibung des k. k. Feldzeugmeisters Vetter Grafen von Lilienberg. In: Österreichische militärische Zeitschrift. Jahrgang 1841, Zweiter Band, Heft 4, 189-203 und Heft 6, 306-321. Dieser ausführlichste Nachruf ist der maßgebliche, weil ihm die beiden nachstehenden kompilatorisch folgen, und zwar auch in der starken Konzentration auf die Kriegsverdienste Lilienbergs, die Jelačić an den Tag legt: Voigt, Bernhard Friedrich: Wenzel Vetter Graf v. Lilienberg. In: ders.: Neuer Nekrolog der Deutschen. 19. Jg. (1841), Erster Theil. Weimar 1843, 180-196; Vetter, Graf von Lilienberg, Wenzel. In: Wurzbach, Constantin von: Biographisches Lexikon des Kaiserthums Oesterreich. Bd. 50. Wien 1884, 239-247. Sehr nützliche und korrigierte Übersichtsinformationen zu den Laufbahnen sämtlicher österreichischer Generale der Kriegsjahre 1792-1815, so auch zu Lilienberg (als Eintrag unter Vetter, V12) bietet die von Leopold Kudrna (Wien) erstellte Datenbank: Biographical Dictionary of all Austrian Generals during the French Revolutionary and Napoleonic Wars, 1792-1815. http://www.napoleon-series.org/research/biographies/ Austria/AustrianGenerals/c_AustrianGeneralsIntro.html (1.8.2014).

33 Zitat des Herausgebers aus der Anfang der 1850er Jahre verfassten Tommaseo-Schrift »Italia, Grecia, Illirico, la Corsica, le Isole Ionie e la Dalmazia, in: Tommaseo, Niccolò: Venezia negli anni 1848 i 1849. Hg. Prunas, Paolo. Firenze 1931, 107, Anm. 284. Vgl. dort auch ähnlich zurückblickend in einem anderen Text Tommaseos über das revolutionäre Venedig (107: $»[\ldots]$ Lilienberg (soldataccio di prepotenza e geffagine più che austriache) $[\ldots] \ll$ ). 
Lilienberg war jedenfalls ein überzeugter und engagierter Vertreter des vormärzlichen Kampfes gegen alles Liberale und gegen alle, die vermeintlich oder tatsächlich auf Umsturz der herrschenden Ordnung zielen mochten. Verdächtige Subjekte, und erst recht hochverdächtige Subjekte vom Schlage eines Tommaseo, wollte Lilienberg so scharf wie nur möglich überwacht sehen. Die rückblickende Angabe einer Quelle aus dem Revolutionsjahre 1848, dass Lilienberg als Gouverneur (und im Unterschied zu seinem Amtsnachfolger) seinen Arbeitstag regelmäßig mit einem Bericht des Zaratiner Polizeidirektors über etwaige verdachtserregende Vorkommnisse unter der Beamtenschaft und in der Bevölkerung beginnen ließ, scheint durchaus glaubwürdig. ${ }^{34}$ Vorderhand nicht gerade sympathisch ist auch der Teil seines Wirkens, der Lilienberg für lange Zeit die meiste historiographische Aufmerksamkeit beschert hat, nämlich sein energisches Betreiben der »Union" von möglichst vielen der Orthodoxen in Dalmatien, also deren Eingliederung in die katholische Kirche und deren Jurisdiktion bei Erhalt einer eigenen Gottesdienstordnung und Priesterschaft. Hierauf verwandte Lilienberg bemerkenswerte Energie, und in dieses Projekt flossen erstaunliche Summen staatlichen Geldes. Sie wären in jenen dalmatinischen Armutsjahren an anderer Stelle gewiss besser angelegt gewesen. Dass dabei Geld auch direkt an die einzelnen Konvertiten floss, war so ein Punkt, der Tommaseo bei der Betrachtung Lilienbergs besonders gegen diesen aufbrachte, da er darin offenbar (und ja nicht ohne Grund) eine Art unmoralisches Angebot erblickte. ${ }^{35}$ Nicht von ungefähr erhielt Lilienberg viel später durch serbische Historiker attestiert, im Zuge seiner Förderung der »Union« ruchlos und auch gesetzesverachtend aufgetreten zu sein. ${ }^{36}$

34 So berichtet der aus Ungarn stammende und 1848 strikt anti-vormärzlich schreibende dalmatinische Zahlamtsbeamte Orosz: Worte eines eifrigen und uneigennützigen Staatsdieners, 29 f.; vgl. zu Lilienbergs Vorliebe für die »höhere und geheime Polizei« auch $₫ 218$ seiner Reisedarstellung, wo freilich auch die engen personellen und Machbarkeitsgrenzen des vorhandenen Überwachungssystems deutlich werden.

35 Tommaseo, Niccolò: Storia civile nella letteratura. Studii. Firenze 1872 (digital zugänglich), darin 409-547 die oben in anderer Ausgabe zitierte Schrift: Italia, Grecia, Illirico, la Corsica, le Isole Ionie e la Dalmazia, die betreffende Stelle 536. Zu Lilienbergs Darstellung der Unionsbemühungen siehe auch die $\$ \$ 200$ u. v. a. 201 in seiner Landesbeschreibung und die dort genannte Literatur und neueste kroatische und serbische Publizistik.

36 Vgl. besonders Milutinović, Kosta: Vojvodina i Dalmacija 1760-1914. Novi Sad 1973, dort 31-41 zu dieser Phase der Unionspolitik insgesamt und speziell 35 zur zitierten Beurteilung Lilienbergs. Wenn Milutinović Lilienberg zudem als Klerikalen und Reaktionär bezeichnet (31), mag das zum Teil stimmen, aber auch den Zeitumständen und der Terminologie im sozialistischen Jugoslawien geschuldet gewesen sein. Zu den Motiven der Unionsbemühungen der Verwaltung und des Kaisers scheint mir aber der Hinweis von Weingartens ergiebiger zu sein, der für die ersten derartigen administrativen Versuche (die in den frühen 1820er Jahren ihren Höhepunkt hatten) auf die Befürchtungen vor russischem und montenegrinischem Einfluss auf die orthodoxen Dalmatiner verweist, die die Verwaltung und den Kaiser selbst in dieser Sache angeleitet hätten: AVA, Nl. Hohenwart, Kt. 14b, Bogen IX (zum Jahr 1821). 
Lilienberg hatte aber nicht nur diese eine Seite des vormärzlichen Ordnungshüters und Machtmenschen. Bezeichnenderweise etwa nannte ihn der gleiche Zeitgenosse Orosz, der 1848 Lilienbergs Leidenschaft für Polizeinotizen überliefert hatte, bald darauf an anderer Stelle einen »Zweiten Dandolo«, weil er sich bei Hofe unablässig um eine Möglichkeit zur Unterstützung der dalmatinischen Landwirtschaft bemüht habe. ${ }^{37}$ Dass diesem Feld das besondere Engagement des Landeschefs galt, ist tatsächlich nicht nur anhand seiner Landesbeschreibung in den Akten allenthalben sichtbar, sondern etwa auch in dem kaiserlich im August 1834 angeforderten und im Januar 1835 gelieferten Vortrag, von dem gleich noch die Rede sein wird. Lilienberg war in den Jahren vor seinem Amtsantritt in Dalmatien zunächst 1821 im Zuge des piemontesischen Aufstandes als österreichischer Militärgouverneur von Alessandria hervorgetreten, 1822 bis 1826 war er Kommandant der österreichischen Interventionstruppen auf Sizilien in einer offenbar für die Bevölkerung guten Art und Weise; 1827 wurde er Festungskommandant von Venedig, kam aber noch im gleichen Jahr als Militärkommandant des Küstenlandes nach Triest, ehe er im November 1829 als kommandierender General nach Kroatien in die Militärgrenze ging. ${ }^{38}$ Diese militärische Bilderbuchkarriere weist ihn zugleich auf einigen Etappen (vor allem in Sizilien) auch als erfolgreichen Verwalter im unmittelbaren Kontakt mit der Bevölkerung aus, auch bei schwierigen Ausgangslagen. Geholfen hat ihm dabei zweifellos, dass er ursprünglich für die Zivilverwaltung ausgebildet worden war und dort auch seine ersten Berufsjahre verbrachte, ehe er für den Militärdienst gewonnen wurde. ${ }^{39}$ Für den 1831 erlangten Posten als Militär- und Zivilgouverneur von Dalmatien war das eine seltene Doppelqualifikation, auf die er sich in der Landesbeschreibung beiläufig, aber doch eindringlich beruft, und die sicher zu der erstaunlichen

37 Orosz de Balásfalva, Anton: Das Unhaltbare unseres Steuer-Systems, verglichen mit einer zeitgemäßen Verbesserung desselben. Praktische Ansichten. Wien 1849, 27. Der Autor (identisch mit Anton Orosz) führt auch sonst in dieser Broschüre sehr viele seiner Argumente anhand von Dalmatien aus.

38 Jelačić: Lebensbeschreibung, 312-317.

39 Ebd., 315 (Sizilien), $190 \mathrm{f}$. (Zivillaufbahn und Beeinflussung zugunsten des Militärdienstes durch Feldzeugmeister Josef Freiherr Alvinczy von Berberek; vgl. http://www.napoleonseries.org/research/biographies/Austria/AustrianGenerals/c_AustrianGeneralsA.html\#A7, 1.8.2014). Lilienberg stand damit insbesondere im Kontrast zu seinem Vorgänger Tomassich; diesen schilderte der leitende Beamte von Weingarten schon für die Zeit ab 1819 als alten, gebrechlichen Mann, redlich und auch nicht ohne militärisches Können, aber im Bereich der politischen und Finanzverwaltung ganz unkundig, und außer im Militärischen auch nicht wissenschaftlich gebildet (AVA, Nl. Hohenwart, Kt. 14b, Bogen T [»Mannigfaltiges«]); dafür war Tomassich laut von Weingarten ein Günstling des kaiserlichen Generaladjutanten Kutschera (ebd., Bogen H). Die Rolle von Tomassich in der Frage der zu seiner Zeit nicht stattfindenden Ausschöpfung der vorhandenen Fördermittel für die Landwirtschaft passt sehr gut zu dieser kritischen Einschätzung. 
Amtssouveränität beigetragen haben wird, mit der er unter der Angabe von inhaltlichen und Kostengründen beim Kaiser für die Trennung der beiden Ämter plädierte. ${ }^{40}$

Ein spürbares Indiz für seine vielleicht auch erst spät wiederentdeckte Vorliebe für die zivile Verwaltung ist bereits der auffallend geringe Anteil, den militärische Fragen in dem Bericht einnehmen. Seine Priorität galt hier offenkundig den zivilen Angelegenheiten. ${ }^{41}$ Auf diesen Feldern war er überaus rege: der beschleunigte Straßenbau über den Velebit, die eingeführte Postverbindung auf dieser Straße, die Gründung der Gazzetta di Zara (alles in seinem ersten vollen Amtsjahr 1832) und des Historischen Museums in Zadar weisen ihn als Infrastrukturpolitiker und Institutionenbildner aus; mehrere im Bericht erwähnte offene Anliegen erledigte er im Nachhinein anscheinend mehr oder minder im Alleingang, so den für die moderne Behördeneffizienz tatsächlich wichtigen Bedarf an Dienstvorschriften und Ablaufplänen. ${ }^{42}$

Sein im August 1834 angeforderter »Vortrag» an den Kaiser vom 15. Januar 1835 über die Frage der von ihm so sehr gewünschten »Agrarkommissäre« demonstriert vollends, wie er sich von anderen in seinem militärischen Milieu und wohl auch von vielen in der Zivilverwaltung durch administrativen Gestaltungswillen unterschied. ${ }^{43}$ Der Akt offenbart aber auch einige Mysterien der österreichischen vormärzlichen Verwaltung, ihre Schwächen und inhärente Reibungsverluste im Zusammenspiel der administrativen Ebenen. Deshalb verdient er eine etwas eingehendere Darstellung.

Lilienberg zeigte in seinem Vortrag zunächst auf, dass das Gubernium bereits im Mai 1818 - also im unmittelbaren Umfeld der kaiserlichen Dalmatienreise und vielleicht auch direkt mit ihr in Zusammenhang - beim Kaiser auf die Einrichtung eines Landwirtschaftsfonds in Höhe von 6000 Gulden jährlich und auf die Anstellung von drei »Ökonomiekommissären« angetragen hatte, um den Bauern der Provinz landwirt-

$40 \$ \$ 83$ (sein eigener ziviler Verwaltungsdienst in Böhmen und Oberungarn), 152 (ungeeignete Qualifikation von Militärs für die Stelle als Zivilgouverneur) 159 (Vorschlag der Ämtertrennung).

41 In $\$ 183$ behandelt er unter der Überschrift »Militär « nur die polizeiähnliche Forza territoriale, in den $\$ \$ 215,216$ und 235 verweist er kurz auf eine Unterversorgung der Provinz mit Truppen, und ganz am Ende verweist er auf frühere Berichte.

42 Vgl. \$ 155 dazu den Entwurf für die Dienstvorschrift für das Gubernium selbst, gemäß dem von Ankica Strmota edierten »Instruktionsentwurf « von 1835: Strmota, Ankica: Naputak o uredskom poslovanju predsjedničkog ureda Kraljevine Dalmacije za vrijeme »Druge austrijske uprave« (1814.-1918.). In: Arhivski vjesnik 51 (2008), 57-92, darin der deutsche Text 61-77, kroatische Übersetzung 77-90.

43 In der Folge benützt nach der ausführlichen Wiedergabe in HHStA, MKA 127/1835 auf fast fünfzehn Seiten, durch einen Hofbeamten vorgelegt am 3. Februar (Hornung) 1835. Der von Staats- und Konferenzminister Kolowrat am 7. März unterstützte Resolutionsentwurf fiel in seiner Erledigung durch Kaiser Ferdinand am 17. März schon in die Zeit nach dem Tod von Franz I. Beschlossen wurde eine weitere Prüfung der Anträge Lilienbergs durch die Hofkanzlei und in ihren finanziellen Implikationen durch die Hofkammer.

DigiOst 1 | 20 
schaftliche Kenntnisse zu vermitteln. Am 5. Oktober 1818 wurde der Fonds vom Kaiser bewilligt, die Anstellung der Kommissäre aber »für den damaligen Augenblick « nicht. 1824 stellte das Gubernium erneut den Antrag auf Anstellung dann freilich nur noch eines einzigen Agrarinspektors mit einem Jahresgehalt von 600 Gulden. Dessen allerdings provisorische Anstellung bewilligte der Kaiser diesmal, ziemlich rasch sogar (24. September 1824). Die Auswahl in Zadar (wenn nicht eigentlich in Wien durch die Vereinigte Hofkanzlei) fiel daraufhin sehr rasch, um nicht zu sagen vorschnell. Man erkor einen rückblickend betrachtet offenkundig ungeeigneten Kandidaten, der sich zufällig gerade schon im Lande befand. Dort sollte er zwei Wiener Wissenschaftler bei der von der Vereinigten Hofkanzlei in Auftrag gegebenen Untersuchung der »Detonationen « auf der Insel Meleda (Mljet) unterstützen, die seit 1822 einiges Aufsehen erregt hatten und die Behörden um die Sicherheit der Inselbewohner fürchten ließen. ${ }^{44}$ Der für den Posten Erwählte war August Krause, Assistent der Physik am Polytechnischen Institut zu Wien. Er wurde nun zuvorkommenderweise sogar rückwirkend zum 1. September eingestellt und mit einem Reiseetat von 400 Gulden jährlich ausgestattet, denn er sollte ja, das Land durchreisend, die dalmatinischen Bauern in praktischen Dingen unterrichten.

Wieso für diesen Zweck ein Physiker, der zudem als Wiener Nachwuchswissenschaftler mit allerhöchster Wahrscheinlichkeit des Kroatischen oder Serbischen als der den Bauern im Hinterland einzig verständlichen Sprache unkundig war, vielversprechend erscheinen konnte, bleibt in der Rückschau rätselhaft. Noch rätselhafter aber ist, warum sich im Weiteren das Folgende entwickeln konnte - es sei denn, man nimmt zur Erklärung zum Beispiel gute Beziehungen Krauses in einer der Wiener Hofstellen oder gar bei Hofe an. Letzteres ist umso mehr möglich, als der eine seiner einstigen Mitreisenden, Partsch, als Inspektor im Hofnaturalienkabinett gewiss guten Kontakt zu dem überaus naturwissenschaftsinteressierten und sammelwütigen Kaiser hatte. In Dalmatien jedenfalls folgte, dass dort Krauses dienstliches Wirken genau zwei aktenmäßige Hinterlassenschaften zeitigte. Eine davon war ein Bericht über die besagten Detonationen auf Mljet (und mit entsprechend geringem landwirtschaftlichen Wert), die zweite ein in Zadar verfasster Bericht über den dort wild vorkommenden Safran, was auch

44 Die Angaben zu dem Auftrag durch die Hofkanzlei (und zu den Ergebnissen über die wohl erdbebenbedingten Laute) finden sich in der umfänglichen Darstellung eines der beiden Wissenschaftler, Paul Partsch, Inspektor am Hofnaturalienkabinett zu Wien, der darin den um einiges erweiterten Bericht an die Hofkanzlei zum Abdruck brachte: Partsch, Paul: Bericht über das Detonations Phänomen auf der Insel Meleda bei Ragusa. Nebst geographisch-statistischen und historischen Notizen über diese Insel und einer geognostischen Skizze von Dalmatien. Wien 1826 (211 Seiten), mit Nennung von Franz Riepl, Professor am Wiener Polytechnischen Institut (Vorrede, III) und auch von August Krause (VI), der also Riepls Assistent gewesen sein dürfte. Zum amtlichen Bericht und der Sorge der Behörden und des Kaisers um die Bewohner von Meleda ebd., VI bzw. IV. 
nicht gerade den Kern der agrarischen Aufgabenstellungen im Lande traf. ${ }^{45}$ Auf Reisebegegnungen mit ihm unverständlichen dalmatinischen Bauern hatte Krause hingegen wohl keine rechte Lust; jedenfalls begab er sich schon am 10. Januar 1825 nach Wien, »wo er auf seine definitive Anstellung warten wollte. Am 15. Jänner 1827 wurde ihm der Gehalt eingestellt, dann aber, laut allerhöchster Entschließung vom 25. April $1827 \mathrm{Z}$. 982/768, vom Tag der Einstellung wieder flüssig gemacht." Nachdem Krause am Ende anscheinend geschlagene sechs Jahre ungefähr ein doppeltes Volkschullehrergehalt bezogen hatte für eine nie erbrachte Leistung, entschloss sich der Kaiser wohl doch zu einer Beendigung dieses Verhältnisses. Denn er verfügte mit 17. April 1830 St.Z. 2608/1200 ex 1828 (sic), "von der Anstellung eines agrarischen Inspektors in Dalmazien mit dem Beisatze abkommen zu lassen, daß die Behörden durch andere ihnen zu Gebothe stehende Mittel auf die Beförderung und Veredlung der Landwirthschaft und der damit verbundenen Industrialzweige einzuwirken haben ${ }^{46}{ }^{46}$

In der Folge stellte die vereinigte Hofkanzlei gar noch fest, dass der 1818 eingerichtete Fonds zur Förderung der Landwirtschaft in den Jahren seines Bestehens nie voll ausgeschöpft worden war. Mit Ende 1829 hatte sich in ihm deshalb ein Restvermögen von 23838 Gulden sowie 67/12 Kreuzern angehäuft, das immerhin konnte die Wiener Behörde genau beziffern. Die Konsequenz daraus war nicht etwa eine Rüge für den während der ganzen Vorgänge verantwortlichen Landesgouverneur Tomašić, weil ihm in der unterentwickelten Provinz anscheinend keine sinnvollen Verwendungszwecke für die Fördermittel eingefallen waren. Vielmehr entsprach es anscheinend der sparsamen Systemlogik, dass jetzt Seine Majestät mit Entschließung vom 10. September 1830 »diese erfreulichen Ergebnisse, mit a. h. Zufriedenheitsbezeugung an den Gouverneur Freyherr von Tomassich « zur Kenntnis nahm und anordnete, die laufende Dotation »für den Kultursfond in Dalmazien für das Jahr 1830 einzustellen, und dafür zu sorgen, daß die unverwendet bleibenden Reste desselben einstweilen zur bestmöglichen Verzinsung gebracht werden, damit wo möglich aus diesen Zinsen das für die Verbesserung der Kultur des dalmatinischen Gebietes Erforderliche bestritten werden könne«.

Immer noch gemäß dem gleichen Akt ließ sich aber der verglichen mit seinem Vorgänger weit energischere Lilienberg bei seiner rückblickenden Betrachtung nicht von der Logik eines administrativen Systems beirren, innerhalb dessen die Nichtausgabe von Fördermitteln in einem Land wie dem ihm unterstellten belobigt wurde. Lilienberg folgerte vielmehr mit aus heutiger Sicht recht schlagender Logik und spürbarem Ärger, aus der von ihm gelieferten Darstellung der Dinge gehe »sehr deutlich hervor, daß die provisorische Anstellung des agrarischen Inspektors, da er nach wenigen Wochen sich wieder nach Wien begeben, und auch keine agrarischen Elaborate, die zur Belehrung der Landwirthschaften dienen können, geliefert hat, für die Provinz nicht von dem mindes-

45 Lilienberg war dieses mögliche Absatzprodukt zwar auch einige Hoffnungen wert, aber nur als ein Punkt unter vielen; vgl. die Erwähnung in $\$ 89$ der Landesbeschreibung.

46 Bis hierher und weiterhin nach HHStA, MKA 127/1835. 
ten Nutzen war, obgleich der Inspektor dem Lande mehrere tausend Gulden Auslagen verursacht hat.« Von dort ging er zu der Schilderung des niedrigen Standes der Landwirtschaft über, aus dem er die Notwendigkeit der Anstellung von mehr als nur einem ökonomischen Kommissär ableitete. Die Nennung der vielen einzelnen Produktionszweige, zu der die Wiener Zusammenfassung der Lilienbergschen Darlegungen an dieser Stelle ansetzte, lässt vermuten, dass Lilienberg nun zur Begründung seine Landesdarstellung vom Vorjahr in den betreffenden Passagen noch einmal referierte. Am Ende schloss er damit, die Wiederaufnahme der jährlichen Fondszahlungen von 6000 Gulden zu beantragen und dazu die Anstellung von drei Kommissären auf sechs bis acht Jahre. Alle schriftlichen Anordnungen, so Lilienberg, könnten für die Landwirtschaft unter den gegebenen Landesverhältnissen nichts nützen, nur ein direktes Vorbild könne wirken. Die Kommissäre sollten selber Dalmatiner sein oder ansonsten aus der Zahl der Beamten gewählt werden, die »vollkommen dalmatinisch sprechen, und in der praktischen $^{47}$ Landwirthschaft bereits hinlängliche Kenntnisse besitzen «. Sodann entwarf Lilienberg einen eingehenden Ausbildungsplan, der die Betreffenden unter Instruktion durch das Gubernium zu einer zwanzigmonatigen Schulungsreise nach Oberitalien, Tirol, Siebenbürgen, Österreich, Böhmen und Salzburg führen sollte. Dort überall würden sie für Dalmatien geeignete gute Anbaumethoden und Gerätetechnik und zudem in Prag und Wien theoretische Grundkenntnisse kennenlernen können. Zur Rechtfertigung der Kosten für die vorgeschlagen Schulungsreise und die veranschlagten Gehälter zögerte Lilienberg auch nicht, noch einmal auf ein Thema zurückzukommen, das ihn in der Landesbeschreibung fast genauso intensiv umgetrieben hatte wie Frage der Kommissäre: die zentralstaatliche Einbehaltung der Einnahmen aus dem Dazio consumo (»Verzehrsteuer«), als einer ursprünglich den Gemeinden zustehenden Abgabe, deren nunmehrige Einziehung zugunsten der Staatskasse im Lande so viel kritisiert wurde und auch laut Lilienberg die Gemeinden in den Ruin trieb. ${ }^{48}$ Lilienberg stellte hier eine Rechnung auf, die den Wiener Behörden nicht behagen konnte, weil er indirekt behauptete, dass die von der Zentrale eingenommene Summe eigentlich noch immer dem Land zustehe und nicht Wien. Seit 1814, so kalkulierte er, hätten sich die Erträge aus dem Dazio consumo für die zentralstaatliche Kasse auf insgesamt 374136 Gulden und 11 Kreuzer belaufen. Verglichen damit schien ihm seine Forderung nach mehr landwirtschaftlicher Förderung offenbar bescheiden, denn er meinte, das von ihm Beantragte könne man mit der bezifferten Summe gegenrechnen. ${ }^{49}$

Als Heutiger erhält man mit diesem ganzen Akt von Anfang 1835 den Zutritt zu einer Art von bürokratischem Labyrinth. Die »Betreiber« einzelner Labyrinth-Stationen konnten zwar noch nach Jahren aufwendig und auf den Kreuzer genau berechnen, an

47 Unterstreichung im Original.

48 Vgl. besonders $\$ 170$ der Landesbeschreibung, sowie für die weiteren Nennungen des Themas in der Lilienbergschen Landesbeschreibung im Sachregister unter »Dazio consumo«.

49 Alles bis hierher weiterhin nach HHStA, MKA 127/1835. 
welcher Stelle sich im komplizierten Fondsystem der damaligen Staatsfinanzen wieviel Geld angehäuft haben dürfte, und wodurch. Der überaus tätigen Akribie für solche Berechnungen widersprach es in der Logik des Systems aber nicht, an anderer Stelle gerade Untätigkeit lobenswert zu finden, wenn sie nur mit Ausgabenminderung einherging. In dem gleichen Labyrinth, in dem man mit jener administrativ-finanzplanerischen Akribie auf Zahlen achtete, wurde auch zugleich nicht verhindert, dass ein erkennbar ungeeigneter Kandidat wie jener August Krause sogar trotz von Beginn an nur provisorischer Einstellung erst einmal über Jahre hinweg für nie erbrachte Leistungen ein ganz erhebliches Gehalt beziehen konnte. Mit der haushalterischen Logik des Systems war es also nicht weit her.

Was sich im Labyrinth des Zusammenspiels der vormärzlichen Verwaltungsinstitutionen sonst alles so ereignet haben mag, könnte nur durch umfassendere Studien an den Tag gebracht werden. An dieser Stelle drängen sich aber zumindest einige Fragen über grundlegende Dinge des damaligen politischen und administrativen Systems auf. Ganz besonders gilt das für die Rolle Franz' I. als Monarchen.

Eingangs war mit Blick auf ihn und seine Reisen von einem innersystemisch rationalen Versuch die Rede, die absolutistische Regierungsweise durch Herrschaftswissen effizient zu gestalten. Die Erzählung rund um den Landwirtschaftsfonds taucht den Monarchen demgegenüber in ein weniger günstiges Licht. Der Kaiser war also imstande, einen wichtigen Fonds zu bewilligen und später exakt dessen Nichtausschöpfung zu belobigen. Er selbst ernannte einen Nichtfachmann wie Krause; als dessen Streichung von der Gehaltsliste von anderer Stelle endlich beschlossen worden war, verhinderte der Monarch erst einmal auch noch das. Von rationalem Wirken ist hier nicht viel zu sehen. Angesichts dessen ist nicht mit nur einem Satz schlüssig zu erklären, warum ein so aktiver Gouverneur wie Lilienberg gerade auf diesen Kaiser seine ganze Hoffnung auf grundlegende Besserungen richten konnte. Was weiß man denn heute in der Forschung überhaupt über diesen Kaiser Franz, zu Lebzeiten propagiert und bekannt unter dem Beinamen »der Gute«?

Herzlich wenig weiß man über ihn und seine Funktion im System. Das ist eigentlich verblüffend, denn er war wirklich eine der Schlüsselgestalten unter den europäischen Herrschern des 19. Jahrhunderts, wie der Zagreber Kulturhistoriker Marko Špikić in einer Untersuchung über die Ikonographie des Kaiserkults um Franz kurz, aber treffend bemerkt hat. ${ }^{50}$ Die umfänglichste noch einigermaßen aktuelle wissenschaftliche Darstellung besteht aus zwei ergänzend angelegten Kurzbiographien aus der Feder von Walter Ziegler. Die eine ist dem Habsburger als Kaiser Franz II., letzter Kaiser des Hei-

50 Špikić, Marko: Titus Novus. Emperor Francis I's iconography of power and its reception in Croatia and Dalmatia. In: IKON 5 (2012), 305-319 (auch https://www.academia.edu/2535932/ Titus_Novus._Emperor_Francis_the_Firsts_Iconography_of_Power_and_its_reception_in_ Croatia_and_Dalmatia, zuletzt 15.5.2014).

DigiOst 1 | 24 
ligen Römischen Reiches Deutscher Nation von 1792-1806, die zweite als erstem österreichischem Kaiser von 1804-1835 gewidmet, mit Schwerpunkt auf den Jahren bis 1815. Zieglers Abhandlung ist nicht aus den Quellen gearbeitet und inzwischen auch schon ein Vierteljahrhundert alt. Doch liefert Ziegler wichtige Hinweise, dass die Herrscherfigur hinsichtlich der Wirtschaftsförderung, in Sachen höheres und zumal technisches Bildungswesen, auch bei der Verkehrspolitik, durch die beiden großen Rechtskodifikationen (das Strafgesetzbuch von 1803 und das Allgemeine Bürgerliche Gesetzbuch von $1811^{51}$ ), schließlich auch durch die Fortführung der josephinischen Kirchenpolitik sowie ganz allgemein in Sachen der Förderung der Wissenschaften und Künste positive Seiten aufzuweisen habe. Sie sind mit Ziegler den weit verbreiteten raschen Assoziationen zumindest zur Seite zu stellen, durch die man die Gestalt dieses Kaisers gemeinhin mit unkreativer und lähmender Aktenwirtschaft, Änderungsfeindlichkeit und Restauration sowie mit dem vormärzlichen Polizeistaat in Verbindung bringt. Diese dominanten Assoziationen verortet Ziegler in ganz klaren (kleindeutsch) national und liberal geprägten wissenschaftlichen Traditionen des späteren 19. Jahrhunderts. ${ }^{52}$ Noch schärfer, aber anscheinend nicht minder ungehört hatten etwas früher als Ziegler schon Gerda und Gottfried Mraz durch einen Vergleich der Wahrnehmungsmuster der Nachwelt gegenüber Maria Theresia, Joseph II., Erzherzog Carl und eben Franz I. (II.) eindrücklich herausgearbeitet, wie die (deutsche und deutsch-österreichische) liberale Geschichtsauffassung des späten 19. Jahrhunderts die historiographische Einordnung der dynastischen Vertreter noch über hundert Jahre später bestimmte. ${ }^{53}$

Seitdem hat sich in Punkto wissenschaftlicher Betrachtung von Kaiser Franz I. sehr wenig getan. Allenfalls ist in der deutschen Historiographie eine dritte Säule der Kritik am Kaiser hinzugetreten. Sie erscheint nicht von der liberalen oder nationalen, sondern am ehesten von der Tradition des »dritten Deutschland " geprägt, insofern sie das »Alte Reich« und dessen Funktionstüchtigkeit in den Mittelpunkt der Überlegungen stellt.

51 In Dalmatien erfolgte dessen Einführung in zwei Schritten: durch Patent vom 28.9.1815 mit Wirkung zum 1.1.1816 im Großteil der Provinz, und mit Hofdekret vom 23.7.1816 mit 1.10.1816 dann auch in den bei Ende der Franzosenherrschaft und noch bis 1815 britisch besetzten Inseln Curzola, Lissa, Colomotta, Mezzo, Giuppana, Meleda und Lagosta. Vgl. Winiwarter, Joseph: Handbuch der Justiz- und politischen Gesetze und Verordnungen, welche sich auf das in den Deutschen Provinzen der Österreichischen Monarchie geltende allgemeine bürgerliche Gesetzbuch beziehen. 2. Auflage Wien 1835, $3 \mathrm{f}$.

52 Ziegler, Walter: Franz II. (1792-1806); ders.: Franz I.von Österreich (1806 [sic] -1835), in: Schindling, Anton / Ziegler, Walter (Hgg.): Die Kaiser der Neuzeit: 1519-1918. Heiliges Römisches Reich, Österreich, Deutschland. München 1990, 289-306 und 309-328; dort insbesondere 324 (die Punkte der Vorwürfe an Franz habe ich an dieser Stelle aus der älteren Literatur, etwa Arnold Luschin von Ebengreuth und später noch Erich Zöllner, dabei noch etwas ergänzt).

53 Mraz, Gerda / Mraz, Gottfried: Österreichische Profile. Maximilian I., Wallenstein, Prinz Eugen, Maria Theresia, Kaunitz, Franz II., Erzherzog Carl, Metternich, Radetzky, Franz Joseph I. Wien 1981 (darin 121-156: Kaiser Franz und Erzherzog Carl), hier v. a. 147-149. 
Kaiser Franz taucht dementsprechend in dieser Richtung in einem fatalen historischen Moment auf. Wie das von ihm vertretene politische "Wien « wird er durch die Vertreter dieser Forschungslinie mit gewisser Erbitterung einer Art von Leichenfledderei bei der Verwertung der Konkursmasse des Reiches sowie einer Reduzierung des kaiserlichen Wirkens auf rein österreichische Interessen beschuldigt. ${ }^{54}$ Das bringt wissenschaftlich nicht viel, denn die etwaige Konzentration des Kaisers auf den Aufbau eines eigenen österreichischen Kaisertums ist per se sicher noch kein hinreichender Grund für ein historiographisches Verdikt. Zukunftsweisender wäre hingegen, das von Franz I. als Herrscher nach 1804 Erreichte oder Nichterreichte an österreichischer Staatsbildung einmal ebenso einer umfassenden Analyse zu unterziehen wie sein Wirken als letzter römisch-deutscher Kaiser. Wer sich als Autor diesem Versuch aussetzen wollte, hätte freilich viel zu tun, schon angesichts der kaum überschaubaren Zahl an Aktenkartons, die das kaiserliche Wirken allein in den Wiener Archiven hinterlassen hat. Bedenkt man die schon seit Jahrzehnten übergroße Fokussierung der Forschungen zum habsburgischen 19. Jahrhundert auf die Zeit nach 1848, wird man auf solch eine große Studie wohl noch eine geraume Weile warten müssen.

Trotzdem lässt sich ungefähr beschreiben, wieso der Kaiser für Lilienberg der Hoffnungsträger sein konnte, einmal abgesehen von Lilienbergs sicher großer persönlicher Loyalität dem Herrscher gegenüber. Zum einen war Dalmatien in seinem Hinterland und in Dürrezeiten sogar in seiner Gesamtheit schreiend arm. Das Landesvatertum des Kaisers, wie inszeniert es im Grundton auch gewesen sein dürfte, hielt da zumindest im Ernstfall einer Hungersnot tatsächlich Hilfe bereit, auf die Lilienberg zugreifen konnte und auf die er auch ohne Zögern tatsächlich zugriff. ${ }^{55}$ Zweitens kannte der Kaiser wie gesehen Dalmatien aus eigener Anschauung. Das spielte im Zuge des praktizierten Landesvatertums gegenüber den obersten Zentralstellen durchaus eine Rolle, und Lilienberg, der sich sonst von Wien in der Dringlichkeit der dalmatinischen Anliegen von den dortigen Landesunkundigen wenig verstanden fühlte, durfte beim Kaiser hier auch außerhalb der offenen Notlagen mit gewissem Recht auf etwas mehr Verständnis hoffen.

Drittens galt Lilienberg - als einem Militär, der mehrfach Leib und Leben im Dienste seiner Majestät aufs Spiel gesetzt hatte; vielleicht auch als Altersgefährten - offenbar überdurchschnittlich viel Vertrauen und Sympathie des allgemein als grundmisstrauisch geschilderten Kaisers. Anders finde ich allein schon die Offenheit des Berichtes von Lilienberg an den Monarchen kaum zu erklären. ${ }^{56}$ Die beiden verbanden aller Wahr-

54 So der 2014 verstorbene Hauptvertreter der jüngeren Geschichtsschreibung zum Alten Reich: Aretin, Karl Otmar von: Das Alte Reich, 1648-1806. Bd. 3: Das Reich und der österreichisch-preußische Dualismus (1745-1806). Stuttgart 1997, besonders 509-511.

55 Vgl. Clewing: Staatlichkeit, 132-135 sowie hier im Anhang, Quellenanhang 1.

56 Am deutlichsten scheint mir das nicht gewöhnliche Nahverhältnis der beiden an jener Stelle von Lilienbergs Text hervorzutreten, wo er am Ende von $\$ 174$ den Kaiser fast schon kumpanenhaft um Wahrung der Vertraulichkeit einer Mitteilung gegenüber einem Dritten bittet!

DigiOst 1 | 26 
scheinlichkeit nach mehrfache direkte Begegnungen - vielleicht schon während der antinapoleonischen Kriege (die damalige Bekanntschaft Lilienbergs mit einigen Erzherzögen ist dank Jelačić gesichert überliefert), sehr wahrscheinlich dann im Umfeld von Lilienbergs Kommandofunktion in Sizilien und danach an der oberen Adria und in Kroatien, und ganz sicher zu Lilienbergs Amtszeit. Lilienberg selbst berief sich gegenüber den Hofstellen nach des Kaisers Tod auf mündliche Äußerungen bei ihrem letzten Treffen im Spätsommer (er schrieb: Herbst) $1834 .{ }^{57}$ Es ist absolut wahrscheinlich, dass er auch bei früheren Gelegenheiten in Einzelaudienzen oder ähnlichen Situationen Zugang zum Monarchen gehabt hatte, wenn ihn sein Weg zum »Hoflager« nach Wien führte, wie es in der damaligen Amtsterminologie noch hieß. Die diesbezüglichen amtlichen Bestimmungen zeigen übrigens, dass derlei Fahrten zum »Hoflager« für höhere Provinzialbeamte gängige Praxis waren. ${ }^{58}$ In den meisten Fällen führten sie die Landesbeamten wohl vorrangig zu Besprechungen mit dienstlichen Ansprechpartnern in die Hofstellen und eher selten direkt zum Kaiser. Lilienberg aber hatte, wie gesehen, bei seinen Wienreisen als Gouverneur außer zu den Ministerien auch solch direkten Kontakt mit dem Herrscher. ${ }^{59}$ Eine Stelle in einem der von ihm angelegten Aktenverzeichnisse über seine Bereisung verstehe ich überdies als konkretes Indiz dafür, dass Kaiser und Gouverneur sich noch während Lilienbergs dalmatinischen Reisen schnell über aufkommende relevante Detailaspekte ausgetauscht haben, quasi auf kurzem Dienstweg und das dann natürlich per Post. ${ }^{60}$

57 Vgl. wiederum Quellenanhang 1.

58 Vgl. etwa: Bestimmungen über die Bewilligung der Urlaube für Staatsbeamte und über die hiebei entfallenden Taxen. Hofkanzleidekret vom 29.4.1831, Zahl 9581, gedruckt in: Sammlung der politischen Gesetze und Verordnungen für das Laibacher Gouvernements-Gebieth im Königreiche Illirien, Jahr 1831 (Dreizehnter Band). Laibach 1832, 161.

59 Vergleichbares weiß man inzwischen für das späte 18. Jahrhundert dank der großen Edition der Tagebücher des ersten Gouverneurs von Triest, Karl Graf Zinzendorf. Grete Klingenstein hält in ihrem einleitenden ersten Band fest, dass Maria Theresia persönlich Zinzendorf vor seiner Abreise aus Wien nahegelegt hatte, sich durch jährliche Anwesenheiten von vier Wochen bei den Ministerien in Wien Respekt zu verschaffen und zu wahren (Klingenstein, Grete: Europäische Aufklärung zwischen Wien und Triest. Die Tagebücher des Gouverneurs Karl Graf Zinzendorf, 1776-1782. Wien, Köln, Weimar 2009, 158f.). Klingenstein verweist auch auf mehrere Audienzen Zinzendorfs bei Maria Theresia und Joseph II. (ebd., 160). Anhand der Einträge im etwas kompliziert zu benützenden Registerband (Bd. 4 der Edition, S. 286 bzw. 360) lässt sich festhalten, dass Zinzendorf bei seinen Wienaufenthalten verschiedentlich sogar mehrere Audienz-Begegnungen mit den beiden Kaisergestalten hatte. (Klingenstein, Grete / Faber, Eva / Trampus, Antonio (Hgg.): Europäische Aufklärung zwischen Wien und Triest. Die Tagebücher des Gouverneurs Karl Graf Zinzendorf, 1776-1782. 4 Bde. Wien, Köln, Weimar 2009; die Bde. 2 und 3 bringen die französisch gehaltenen Tagebucheintragungen Zinzendorfs.)

60 DAZd, Vlada/Namjesništvo za Dalmaciju, Lilibenbergovi protokoli i indeksi, Bd. II, Eintrag Nr. 524: Name des Erstatters (sic, bzw. Aktenurhebers): Sua Maesta, Tag der Erstattung 
Und viertens war der Kaiser schlicht und einfach derjenige im System, der alle anderen übergehen konnte, wenn er denn wollte, selbst einen Metternich. ${ }^{61}$ In Dalmatien stand ein Lilienberg zwar als Zivil- und Militärgouverneur unter Ausnahme der Justiz ${ }^{62}$ allen behördlichen Landesinstanzen vor. Er war aber den diversen Hofstellen gegenüber weisungsgebunden. ${ }^{63}$ Wollte er also Anliegen gegen deren Wünsche durchsetzen, konnte das auf geregeltem Wege nur über den Monarchen gehen.

Das Maß seiner sonstigen Unterordnung unter die Hofstellen sollte Lilienberg nach dem Tod von Kaiser Franz gleich erfahren. Die Hofstellen und insbesondere Staatsminister Kolowrat ließen ihn auch deutlich spüren, in welchem Maß er bei ihnen schlecht angeschrieben war, wohl auch wegen seines vorherigen privilegierten Zugangs zum verstorbenen Kaiser und wegen seines Selbstbewusstseins und Gestaltungswillens. Die Zentralstellen trugen aber zweifellos nicht erst bei dieser Gelegenheit ihr gerüttelt Maß dazu bei, dass Lilienberg sein Geschick, in Dalmatien Landeschef zu sein, wortwörtlich »sehr traurig« fand ${ }^{64}$ Den Wiener Vorgaben gegenüber weitgehend machtlos zu sein, vor

19.8.33, Gegenstand »rimette 5 progetti per la coltivazione della sette e richiede parere«, Erledigung: rapport a S. M. (der Kaiser hatte also fünf Projekte zum Seidenanbau an Lilienberg zurückgesendet und dessen Gutachten dazu angefordert). Vgl. dazu auch $\$ 92$ von Lilienbergs Darstellung, wo er anscheinend auf diese Erörterungen und den zugehörigen kaiserlichen Beschluss Bezug nimmt.

61 Vgl. Siemann: Metternich, 54 zum Überwiegen des von Franz vertretenen habsburgischen Hausinteresses bei der Gestaltung Italiens auf dem Wiener Kongress, und 56 mit einem Metternichzitat über die absolute Stellung des Monarchen.

62 Vgl. dazu und zu deren Unterordnung unter den Vorsitzenden des Appellationsgerichts die $\$ \$ 144,156,173$ u. v. a. 174.

63 Dazu und zur Behördeneinteilung nunmehr Kolić, Dubravka: Carsko-kraljevsko Namjesništvo u Zadru 1814.-1918. Institucija i gradivo. Zadar 2010, 34 -37 (allerdings ohne Eingehen auf die Stellung der Justiz) und 37 ff.; die Zusammenführung der obersten Zivil- und Militärgewalt hatte in Dalmatien noch bis 1902 Bestand. Erst für die anschließende letzte Phase der dortigen habsburgischen Herrschaft liegt in größerem Umfang Forschung zu einigen der dann Statthalter genannten Landeschefs vor. Siehe insbesondere die Edition der übersetzten Lebenserinnerungen von Erasmus von Handel, dem ersten Zivilgouverneur, durch Marko Trogrlić (Handel, Erazmo: Sjećanja. Hg. Marko Trogrlić. Zagreb 2007) und die Wiener Dissertation von Pav, Wolfgang: Niko Nardelli - Österreichs Statthalter in Dalmatien 1906-1911. Ein >politischer Beamter $<$ im Spannungsfeld von Zentralmacht und Landesinteressen. Diss. phil. Wien 2010, online abrufbar unter http://othes.univie.ac.at/11678/, zuletzt 20.5.2014).

64 Vgl. dazu Quellenanhang 1. Während dort die entwicklungspolitischen Implikationen dieser Empfindung mitschwingen, hatte er als Gouverneur auch einfach alltäglich mit dem vorhandenen Elend in der Provinz zu tun, was ihn auch bei den Reisen begleitet und behindert haben muss. Siehe dazu Orosz: Worte eines eifrigen und uneigennützigen Staatsdieners, $39 \mathrm{f}$, wo er ein Plädoyer für Minderung der höheren und Erhöhung der untersten Beamtenbezüge führt: »Der einzige Staatsbeamte in Dalmatien, der ein glänzendes Haus führen muss, ist der Landeschef als Stellvertreter seiner Majestät; an ihn wendet sich Alles, bei ihm quar-

DigiOst 1 | 28 
allem auch nicht verhindern zu können, dass bei Interessenkonkurrenz in wirtschaftspolitisch essentiellen Fragen regelmäßig die Anliegen der Zentrale den Vorrang vor Regionalinteressen erhielten (etwa beim Salz- und Tabakmonopol sowie bei der gesamtstaatlich quarantänepolitisch wichtigen Frage des Verbots der Güterkarawanen an die Meereshäfen ${ }^{65}$ ), dies alles musste für einen engagierten und verbesserungsorientierten Verwalter wie Lilienberg frustrierend sein.

Der Kaiser war also zu Lebzeiten ein logischer Hoffnungsschimmer im Kampf um die Verbesserung der eigenen Handlungsmöglichkeiten und um die Ausweitung der staatlichen Präsenz in der dalmatinischen Gesellschaft. Dass Lilienberg dabei manchmal einen direkt jugendlich anmutenden Glauben an die Gestaltungskraft seiner Landesbürokratie an den Tag legte, wenn man sie von Wien aus denn nur machen ließe, steht auf einem anderen Blatt. Zum Beispiel sollte sich die habsburgische Verwaltung noch in der ganzen Zeit ihrer Herrschaft, bis 1918, im Zusammenspiel der beiden oberen administrativen Entscheidungsebenen und angesichts auch der Interessenkonflikte im Lande als unfähig erweisen, die agrar- und gesellschaftspolitisch als Hindernis immer wichtiger werdenden halbfeudalen Kolonatsverhältnisse neu zu regeln. ${ }^{66}$ Dass Lilienberg diese Verhältnisse, die er selbst auch schon unter die wichtigsten Hemmnisse im Bereich der Landwirtschaft reihte, für "gleich« lösbar hielt ( $\$ 77)$, kommt einem so gesehen recht kühn vor. Aber andererseits: Wer weiß, vielleicht hätte ungestörte Tatkraft ja wirklich etwas bewirken können.

tieren sich alle hohen Reisenden ein, er müsste also wenigstens eine Besoldung von jährlichen $10000 \mathrm{fl}$ haben. Das Civil-Aerar bezahlt gegenwärtig dem Landes-Gouverneur unter der Benennung Tafelgeld jährlich $8000 \mathrm{fl}$. Diese Benennung dürfte ungeeignet sein, denn er muss den grössten Teil derselben auf Almosen an verschämte und unverschämte Arme, die sein Haus tagtäglich belagern, verwenden. Wäre es nicht geeigneter diese $8000 \mathrm{fl}$, die man füglich noch vermehren könnte, als einen Privat-Unterstützungs-Fond des Gouverneurs zu benennen? Man muss die grosse Armuth des Landes kennen, man muss erfahren, auf welche Art der Landes-Gouverneur, wenn er manchmal einen Theil der Provinz bereiset, von Nothleidenden überfallen wird, um einzusehen, dass er einen sehr bedeutenden Privat-Unterstützungsfond benöthiget, oder nur sehr selten eine Provinzial-Bereisung unternehmen kann, weil er sonst seinen Gehalt theilweise auf Allmosengeben verwenden müsste.»

65 Vgl. besonders die $\$ \$ 42$ und 112 (Salz), 90 (Tabak) und 35 sowie 119 (Karawanen).

66 Zum politischen Fortwirken der Frage im ganzen 19. Jahrhundert und zu ihrer Beseitigung im ersten Jugoslawien vgl. Lacmanović-Heydenreuter, Haira: Dalmatien in Wien. Die dalmatinischen Abgeordneten im Wiener Reichsrat 1867-1918. Hamburg 2011, hier 285-288 (die freilich auch erkennen lässt, dass die dalmatinischen politischen Eliten im späten 19. Jahrhundert selbst kein Interesse an einer Reform hatten und dann vielleicht sogar mehr als die Verwaltung für das Offenbleiben der Frage verantwortlich waren); und Jakir, Aleksandar: Dalmatien zwischen den Weltkriegen. Agrarische und urbane Lebenswelt und das Scheitern der jugoslawischen Integration. München 1999 (SOA, 104), 148-188 (Agrarreform der Zwischenkriegszeit). 


\section{Zum Wert der Quelle und zur Praxis ihrer Edition}

Lilienbergs Reisebeschreibung ist vor allem ein amtliches Dokument von seltener Tiefe und Offenheit. Sie folgt aber auch grundlegenden Regeln der Reiseliteratur. Dazu zählt, dass Lilienberg mit einem Topos beginnt: »Es wird nicht leicht ein Land in Europa geben, das vom Auslande und selbst vom Inlande so wenig gekannt ist, als Dalmatien [...]. $\aleph^{67}$ Ähnliches steht das ganze Jahrhundert über in Büchern zu vielen Teilen Südosteuropas zu lesen. ${ }^{68}$ Der Satz fügt sich auch bestens in den ähnlich gelagerten Topos vom "halborientalischen « Land Dalmatien ein, das als ein "Zwischenland « wie eine »eigene« Fremde innerhalb der Habsburgermonarchie erschien, was das mitteleuropäische Bild von dem Landstreifen an der Adria bis zum bitteren Ende der Monarchie prägen sollte. ${ }^{69}$ Dass dieses Bild von der besonderen Unbekanntheit des Landes bereits zu Lilienbergs Tagen ein Topos war und nicht einfach Tatsachenfeststellung, kann man schon anhand der Darstellungen von Larry Wolff und Mirna Zeman erkennen, die die zumindest teilweise "Entdeckung « des Landes, besonders seiner »morlakischen« Hinterlandbewohner, im 18. Jahrhundert für die gebildete italienische (Wolff) und für die deutschsprachige Öffentlichkeit (Zeman) beschrieben haben. Diese Art von Entdeckung ging auch deutlich über die bloße Rezeption der für sich schon berühmten Reisebeschreibung von Alberto Fortis von 1774 (Viaggio in Dalmazia) hinaus, ${ }^{70}$ die Lilienberg auffälligerweise mit keinem Wort erwähnt.

Andererseits kann man wahrlich nicht behaupten, Lilienbergs gleichfalls noch in seinem $₫ 1$ geäußerte Kritik am vorhandenen Kenntnissstand wäre aus der Luft gegriffen gewesen: "Was von dieser Provinz aus den, meist nur die Seegebiete behandelnden, großen Theils auch unvollständigen, Reisebeschreibungen bekannt ward, ist demnach ganz unzureichend, sich ein richtiges Bild Dalmatiens zu entwerfen.« Der Lexikonartikel von L. F. Kämtz etwa in der damals maßgeblichen deutschen Enzyklopädie von

$67 \$ 1$.

68 Vgl. zum Beispiel zeitnah zu Lilienberg Grisebach, A.[ugust]: Reise durch Rumelien und nach Brussa im Jahre 1839. Bd. 1 Göttingen 1841, Vorrede, IV: »Es ist bekannt, daß diese Landstrecken, obwohl sie fast unmittelbar an unsere Heimath grenzen, viel weniger untersucht worden sind, als ein großer Theil von Asien oder America."

69 Vgl. dazu als neueste Darstellung Stachel, Peter: Die «eigene` Fremde. Dalmatien in Reiseführern und Reiseberichten (1815-1918). In: Rapp, Christian / Rapp-Wimberger, Nadia (Hgg.): Österreichische Riviera. Wien entdeckt das Meer. Wien 2013, 108-117, besonders 116.

70 Wolff, Larry: Venice and the Slavs. The Discovery of Dalmatia in the Age of Enlightenment. Stanford 2001; Zeman, Mirna: Reise zu den »Illyriern«. Kroatienstereotype in der deutschsprachigen Reiseliteratur und Statistik (1740-1809). München 2013 (SOA, 147). Laut Wolff befand sich Dalmatien im 18. Jahrhundert "genau am Schnittpunkt der neuen kognitiven Landkarten von Osteuropa und dem mediterranen Süden«: Wolff, Larry: Dalmatinische und italienische Reisen. Das Paradies der mediterranen Rückständigkeit. In: Schenk, Frithjof Benjamin / Winkler, Martina (Hgg.): Der Süden. Neue Perspektiven auf eine europäische Geschichtsregion. Frankfurt, New York 2007, 207-228, 225.

DigiOst 1 | 30 
Ersch-Gruber (Allgemeine Encyclopädie der Wissenschaften und Künste) steigt noch 1832 mit einer Zahlendiskussion zum Flächeninhalt des Landes ein, dessen Ungeklärtheit für sich schon bezeichnend genug ist für den Grad an Unsicherheit des vorhandenen Wissens. ${ }^{71}$ Die Reise- und Landesbeschreibungen deutschsprachiger Autoren aus den früheren Jahren der zweiten österreichischen Herrschaft in Dalmatien, aber auch noch das Werk des Dalmatiners Zavoreo, hatten das Land noch ganz überwiegend auf dem Stand und in den Grenzen der ersten österreichischen Herrschaft beschrieben (die Anfang 1806 geendet hatte), was abgesehen von den veralteten Zahlenangaben auch zur hartnäckigen Auslassung der Gebiete von Dubrovnik und Kotor führte. ${ }^{72}$

Auch wenn Lilienberg noch an manchen weiteren Stellen zeittypische Topoi wiedergibt, etwa im Zuge seiner Naturbetrachtungen, so unterscheidet sich seine Landesschilderung dennoch nicht nur durch die eingehende Schilderung der Verwaltungsaspekte von seinen literarischen Vorgängern, sondern auch in den allgemeinen Passagen durch die Dichte der vermittelten Eindrücke aus der ganzen Provinz. Trotzdem fällt auf, wie sehr er sich in dem allgemein gehaltenen ersten großen Teil an ein offenbar klassisches Schema damaliger Landesliteratur gehalten hat: In der Einleitung gibt es die zu erwartenden geschichtlichen Darlegungen, es folgen "geographisch-statistische Bemerkungen«, Angaben zur Urproduktion, zu Bodenschätzen, Handwerk und Gewerbe und angelehnt an das damals allgemeine Interesse an den Morlaken - ein Kapitel über die "physische und Gemütsbeschaffenheit der Bewohner«.

Tatsächlich gibt es für diesen ersten Teil noch genau einen weiteren Autor jener Zeit, der zu Dalmatien Ähnliches geleistet hat und der sich dabei noch dazu in vergleichbar hohem Maß wie Lilienberg auf eigene Wanderungen und sonstige Eindrücke vor Ort stützte. Das war Franz Petter.

Der 1789 im niederösterreichischen Waidhofen geborene Petter, Absolvent der k.k. Realakademie in Wien, war als Gymnasialprofessor 1823 erst nach Dubrovnik, dann Ende 1826 nach Split gekommen. Im Laufe der langen Jahre seines beruflichen Aufenthalts wurde er zum besten dalmatinischen Landeskundler. Als er nach einem Reiseunfall 1853 in Kotor starb, war sein eigentliches Lebenswerk noch nicht erschienen; es kam als "Dalmatien in seinen verschiedenen Beziehungen erst 1857 in Gotha heraus. ${ }^{73}$ Die beiden Bände sind von bleibender höchster Güte und waren für die vorliegende Edition an vielen Stellen ein schier unentbehrliches Hilfsmittel. Freilich: Schon 1836 war das Werk, bereits mit identischem Titel, in der Österreichischen Nationalenzyklopädie

71 Kämtz, L. F.: Dalmatien. In: Ersch-Gruber, Reihe I, Bd. 22 (1832), 88-94, hier 88 f.

72 Vgl. Pederin: Njemački putopisci, 12-73 zu einzelnen Autoren ab etwa 1800, sowie derselbe, stärker enzyklopädisch: Jadranska Hrvatska u austrijskim i njemačkim putopisima. Zagreb 1991, 53-94, zu der deutschsprachigen Literatur der Jahre 1797-1834. Zusätzlich: [Zavoreo, Francesco:] Memoria statistica sulla Dalmazia. Di Francesco Zavoreo, capitanio ingegnere ex-veneto e direttore provvisorio dei lavori edili e idraulici in pensione. Venezia 1821.

73 Petter, Franz: Dalmatien in seinen verschiedenen Beziehungen. 2 Bde. Gotha 1857. 
angekündigt worden. ${ }^{74}$ In der Einleitung der postumen Ausgabe wird zur Erklärung der langen Verzögerung recht allgemein erwähnt, was Petter in einem Brief an den damals aktuell in Kotor weilenden Vuk Karadžić im Februar 1835 näher ausgeführt hatte: »Ich habe über Dalmatien ein dickleibiges Manuscript zum Drucke vorbereitet, allein ich bin noch immer in Ungewissheit, ob es die Druckbewilligung erhält oder nicht, da es zwar seit anderthalb Jahren bei der Censur in Zara liegt, und zwar das 2-te Mahl, weil das erste den Forderungen des Censors nicht entsprochen hat. $\ll^{75}$

Ich stand noch unter dem Eindruck dieser Fundstelle, als ich bei der ersten Lektüre der offenbar nach den Maßgaben der Zensur erstellten Kurzfassung seines großen Werkes - sie ist 1833 und 1834 in Prag erschienen und kam noch 1834 in italienischer Übersetzung auch in Zara heraus - merkliche Ähnlichkeiten des Aufbaus mit dem landeskundlichen Teil von Lilienberg wahrnahm. ${ }^{76}$ Von Entdeckerfreude beflügelt, vermutete ich ein Plagiat Lilienbergs, der das große Pettersche Manuskript im Status seiner Vorlage bei der Zensur gekannt haben könnte und die tatsächlich erschienene kleine Version natürlich auch, vielleicht sogar auf die gleiche Weise bereits vor ihrem Erscheinen. Mein vorschneller Verdacht hat sich aber im Text bei näherem Hinsehen nirgends bestätigt. Lilienbergs Passagen zu den ähnlichen Punkten sind bei genauerer Betrachtung über weite Strecken viel zu persönlich gehalten, als dass er in größerem Umfang etwas abgekupfert haben könnte. Dass allerdings die Gliederung Petters, den er natürlich zumindest aus der Aktenlage, wahrscheinlich aber doch auch persönlich kannte, ${ }^{77}$ Lilienberg für dessen eigene, landeskundlichen Ansprüchen seiner Zeit auffällig gut genügende Textanordnung als Orientierungsfaden gedient haben könnte, bleibt natürlich weiter möglich. Der Text aber ist zweifellos Lilienbergs völlig eigenständige Leistung. Dass er bei seiner Komposition auf jeden Fall außer der ihm vermutlich recht weitgehend bekannten Literatur insbesondere auch viele Akten verwendet hat, kommt in deren Zusammenstellung hier im Anhang zum Ausdruck. ${ }^{78}$ Die Dichte und Lebendigkeit

74 Eintrag Petter, Franz. In: Oesterreichische National-Encyklopädie. Bd. 4, Wien 1836, S. 197 f., hier 198 (verwendet über http://81.10.184.26:9001/personen_add/Petter_Franz_1.PDF, 15.8.2014).

75 Petter an Karadžić, Spalato 5. Februar 1835, gedruckt in: [Karadžić, Vuk Stefanović:] Vukova prepiska. Bd. 6, Beograd 1912, $436 \mathrm{f}$.

76 Petter, Franz: Geographische Skizze von Dalmatien. In: Sommer, Johann Gottfried (Hg.): Taschenbuch zur Verbreitung geographischer Kenntnisse. Übersicht des Neuesten und Wissenswürdigsten im Gebiete der gesammten Länder- und Völkerkunde. Bd. 11, Prag 1833, 1-136 und Bd. 12, Prag 1834, 154-213.

77 Er erwähnt Petter in der Landesdarstellung aber nur an einer Stelle (\$203) und in ganz anderem, dienstlichem Zusammenhang.

78 »Verzeichnis der in der Lilienbergschen Darstellung zitierten Akten (1815-1834)«. Hervorzuheben ist noch ein dort nicht genannter Akt, auf den Lilienberg gleichwohl Bezug genommen hat. Im gleichen Karton 154 der PSN, in dem auch die edierte Konzeptfassung mitsamt Beilagen vorhanden ist, liegt im 1834 zugeordneten Konvolut 1834 I/1, I/2, I/3 ein vermutlich erst nachträglich eingefügter umfänglicher Akt, auf dessen Umschlag vermutlich ein

DigiOst 1 | 32 
seines Textes bietet nicht nur dem Historiker, sondern auch den heutigen Bewohnern und Reisenden die Gelegenheit zu spannender Lektüre.

In welchem amtlichen Auftrag sich Lilienberg einst zur Reise aufgemacht hatte, soll hier am Ende nicht unerwähnt bleiben. Die Beherztheit, mit der er sich dabei die Gelegenheit zur Äußerung seiner Ziele und Wünsche beim Kaiser verschaffte, ist für den Grad seiner inneren Eigenständigkeit und für seine zielgerichtete Energie sehr typisch.

Das fängt schon damit an, dass die Beauftragung zu der 1832 begonnenen Bereisung eigentlich erst im Nachhinein erfolgte. Es war schon 30. April 1833, als Kaiser Franz I. das folgende an Lilienberg gerichtete Kabinettschreiben verfasste:

»Aus Ihrem an Meinen obersten Kanzler gerichteten Schreiben vom 10. April betreffend die beiden türckischen Erdzungen Klek und Suttorina habe Ich ersehen, daß Sie eine Landbereisung vorzunehmen gesinnt sind.

Ich trage Ihnen daher auf, bei dieser Gelegenheit jene oesterreichschen Gebietstheile, welche der Pforte zum Tausch für diese beiden Erdzungen zu überlassen in Antrag seyn, oder am meisten geeignet seyn dürften, wenn je ein Tausch nicht zu vermeiden seyn sollte, nicht nur persönlich zu besichtigen, sondern sich von den Lokalverhältnissen genaue Kenntniß zu verschaffen, so wie über Ihre Landesbereisung aber überhaupt, und was Sie dabei als für das Wohl des Landes und seiner Bewohner nothwendig und nützlich gefunden, und vorgekehrt haben, oder wünschen, dass verfügt werde, Mir eine Relazion unmittelbar zu erstatten. $\ll^{79}$

Mit anderen Worten sollte sich Lilienberg eigentlich wegen einer zwar wichtigen, aber doch ganz speziellen Frage auf die Reise machen, und nebenbei auch über den einen

Archivar den ursprünglichen Aufbewahrungsort und die korrekte Aktennummer vermerkt hat: »PSN god. 1830, svezak 115, Kat II/B broj 1000 (2 djela): Izvještaj grofu Saurau o mjerama za podizanje blagostanje u Dalmaciji.. Enthalten sind ein Konzeptschreiben und eine erste Reinschrift eines circa 80-seitigen deutschen Berichts von Gouverneur Tomassich an Franz Joseph Graf Saurau (damals Leiter der Vereinigten Hofkanzlei), Zara 10.8.1830, über das »Progetto Manfrin per miglior prosperazio della Dalmazia. No. 1000/p 1830«. Tomassich war mit dieser Stellungnahme von Saurau per Dekret vom 12.5.1830 Nr. 10765/1262 beauftragt worden, nachdem eine entsprechende Denkschrift von Marchese Pietro Manfrin über die Möglichkeiten zur Erhöhung des Wohlstands in Dalmatien an den Kaiser gesandt worden war. Tomassich legte darin vor allem abwiegelnd dar, dass Manfrin nach 30jähriger Abwesenheit aus der Provinz die dortigen aktuellen Verhältnisse nicht oder nicht mehr kenne. Lilienberg hat aber anscheinend sowohl das Projekt von Manfrin als auch die Darlegungen Tomassichs gekannt. Die Art seiner Hinweise in den $\$ \$ 61$ u.v. a. 70 (dort auch nähere weitere Angaben) legt dabei nahe, dass er vermutete oder wusste, dass dem Kaiser dieses Projekt Manfrins gleichfalls noch ein Begriff war.

79 HHStA, Kabinettskanzlei, (Bandnummer 444), Separatbilletten-Protokoll 468/1833, Zahl 468. 
oder anderen ihm dringend erscheinenden Eindruck und Wunsch ganz direkt an den Kaiser wenden. Lilienberg muss das als große Chance begriffen haben, und er hatte bestimmt von Anfang an keineswegs die Absicht, es mehr oder weniger bei der angesprochenen Territorialfrage zu belassen. In der Landesbeschreibung spielt sie zwar noch eine gewisse wiederkehrende Rolle, doch Lilienbergs Antwort vom 25. August $1833 \mathrm{zu}$ diesem Thema scheint recht knapp geraten zu sein. Gemäß dem Wiener Eingangsprotokoll ergänzte Lilienberg sie zudem mit einem entscheidenden Beisatz, mit dem er sich selbst alle Freiheiten für eine ganz andere Art von Darstellung nahm: «ilienberg behält sich übrigens vor, die Relation über die von ihm vollendete Bereisung seines Gouvernementgebiethes nachzutragen. ${ }^{80}$ Die solchermaßen gewahrte Gelegenheit zur Sendung seines Problemberichts und administrativen Wunschzettels hat er 1834 mit seiner großen Darstellung auch weidlich ausgenützt.

Der Edition des Dokuments liegt wie bereits angemerkt die Konzeptfassung zugrunde, die sich im Staatsarchiv in Zadar erhalten hat. ${ }^{81}$ Die gezählt 481 Manuskriptseiten sind nicht durchgängig paginiert, auch nicht wie eher üblich foliert, sondern in fortlaufend nummerierten Viererbögen (Quadrangeln) angelegt. Der Umbruch wird in der Edition jeweils in eckigen Klammern unter Angabe der im Original vorhandenen Quadrangelnummer und neu hinzugefügter Seitenzahl innerhalb des Quadrangels vermerkt. Im Anschluss an das Konzeptmanuskript liegt in dem gleichen Konvolut die ausführliche Gliederung der Kapitel und Paragraphen, deren Text sich in leichter Überarbeitung als »detailliertes Inhaltsverzeichnis« an diese Einleitung anschließt. Die Überschriften und Paragraphentitel finden sich im ausformulierten Text der Konzeptschrift nur ausnahmsweise; wo sie fehlten, wurden sie durch Übernahme der Titel aus der besagten Gliederung ergänzt (in eckigen Klammern, und orthographisch oder begrifflich teils modifiziert, dies dann in Kursivsetzung). Im gleichen Konvolut liegen im Archiv wie erwähnt Seiten mit den vorbereitenden Notizen zu den diversen Paragraphen, sowie die handgezeichneten Kartenbeilagen. Letztere wurden hier in den Anhang aufgenommen. ${ }^{82}$

80 HHStA, Kabinettskanzlei, Kabinettskanzlei (Bandnummer 440), Separatakten, Protokoll 3139: Datum Exhibitionis 11.9.1833, Z 3139. Zur Frage von Klek und Sutorina siehe im Register zu unserer Edition; in dem ersten Schreiben hieß es laut Protokoll dazu: »Lilienberg in Zara vom 25. Aug. 1833 zeigt in Folge Kabinettschreibens vom 30ten April 1833 jene Hindernisse an, welche sich dem Austausche der beyden türkischen Erdzungen entgegenstellen - und trägt dagegen an, einen Theil des in den Bocche di Cattaro ober Risano zerstreuten Gränzdorfes Crivoscie an die Türkey aus dem Grunde abzutreten, weil diese Bewohner wild, räuberisch, gegen unsere Behörden sehr ungehorsam und ohne Ausnahme gr. n. u. sind.« Darauf folgte die zitierte Ankündigung dessen, was noch kommen sollte.

81 Siehe oben, Anm. 9.

82 Siehe auch Anhang: Verzeichnis der Originalbeilagen (in der Reinschrift und der Konzeptschrift). Auch hier wurde bewusst die Konzeptfassung verwendet, um den Vergleich mit denr Reinzeichnungen zu ermöglichen, die auf dem Server der ÖNB einzusehen sind.

DigiOst 1 | 34 
Einige häufige Abkürzungen habe ich zur Beseitigung von Lesehindernissen konsequent aufgelöst, zum Beispiel »fl« (für Gulden [Konventionalmünze]) durch Gulden, »X « durch »Kreuzer«. oder »v. J.« durch »vorigen Jahres«. Andere wurden zum Teil beibehalten und lassen sich anhand des Abkürzungsverzeichnisses im Zweifelsfall leicht auflösen. Im Rahmen der Abschrift wurden kürzere zeitgenössische Einfügungen Lilienbergs oder auch Rossettis zum Teil direkt in die Edition eingearbeitet, alle größeren Einfügungen und Änderungen aber in eckigen Klammern ausgewiesen. Die im Original roten Anmerkungen am Rand oder im Text stammen ebenso wie die mit Bleistift geführten anscheinend stets von einer Hand, und zwar von Lilienberg selbst. ${ }^{83}$ Die ebenfalls nicht seltenen Änderungsvorschläge oder Anmerkungen in schwarzer Tinte habe ich dagegen als von Lilienbergs Sekretär Rossetti stammend identifiziert. Die deutsche Rechtschreibung wurde im Gesamttext außer bei reinen Hör- und Schreibfehlern Rougiers nicht verändert, zumal sie mir - besonders in Fragen der Getrennt- und Zusammenschreibung - orthographiegeschichtlich interessant erscheint.

Bei den eigenen Anmerkungen habe ich versucht, alle im Text genannten Örtlichkeiten und Personen zu eruieren. Bei letzteren schien mir das auch deshalb angebracht, weil ich hoffe, dass das Material dadurch auch für kollektivbiographische Arbeiten über die vormärzliche habsburgische Beamtenschaft in Dalmatien oder darüber hinaus verwendbar sein wird.

Die Arbeit sehr erleichtert haben mir frühere Archivarbeiten und Exzerpte, die ich vor allem im Entstehungsprozess meines ersten Buches über Dalmatien angefertigt hatte. Das so Vorhandene habe ich für die Edition unter anderem durch mehrere Forschungszeiten in Wien und zwei Aufenthalte im Staatsarchiv Zadar ergänzt. In Wien galt die Suche lange Zeit auch der Reinschrift des Textes, die ich in den dortigen Archiven vermutete. Als ich längst alle eigentliche Hoffnung aufgegeben hatte (und als die Konzeptschrift auch schon in einer vollständigen ersten Transkriptionsfassung vorlag), kam mir im Herbst 2013 mehr oder weniger der Zufall zu Hilfe, dank einer Suche (unter dem allgemeinen Stichwort »Lilienberg «) in der Handschriftendatenbank (ÖNB-HANNA-Katalog) der Österreichischen Nationalbibliothek. In deren Handschriftenabteilung befindet sich die Reinschrift, unter dem gegenüber der Konzeptfassung leicht veränderten Titel: »Allerunterthänigste Relation über die in den Jahren 1832, 1833 und 1834 gemachte Dienst-Reise in Dalmatien ${ }^{84}$

83 Vgl. in der Edition Anm. 625 zum Wortlaut »Talgkerzen«.

84 Cod. Ser. N. 12354: Vetter, Wenzel Graf von Lilienberg: Allerunterthänigste Relation über die in den Jahren 1832, 1833 und 1834 gemachte Dienst-Reise in Dalmatien. Zara [laut Katalog fälschlich: o. O.] 1834, auf 128 fol., mit zunächst 172 zeitgenössisch paginierten Seiten, dem anschließenden Inhaltsverzeichnis auf den fol. 88r-98v, sechs Farbtafeln mit Trachtenzeichnungen auf den fol. 101-106 und den anschließenden weiteren Karten- und sonstigen Beilagen der Reinschrift (bis hin zu den von Lilienberg eingesandten Schafwollproben); vgl. wiederum die vergleichende Auflistung der in Zadar und in Wien erhaltenen Beilagen, hier im Anhang, 277. Inzwischen hat die ÖNB die Quelle auch als Digitalisat zugänglich ge- 
Die Freude über den späten Fund war nur kurzfristig dadurch getrübt, dass die schöne leserliche Fassung die vorangegangene Entzifferung des Konzeptes an vielen Stellen erleichtert hätte. ${ }^{85}$ Dank freundlicher Auskünfte von Frau Mag. Michaela Ortner, Leiterin der Abteilung Fideikommissbibliothek/Bestandspflege bei der Österreichischen Nationalbibliothek konnte ich in der Folge auch besser verstehen, wodurch die Handschrift in die Nationalbibliothek gelangt ist statt in eines der Wiener Archive. Franz I., so Frau Ortner, habe ein sehr großes Interesse an den eigenen und auch an anderen Reiseberichten gehabt; entsprechende Manuskripte wurden im seinem Arbeitszimmer in eigenen Kästen aufbewahrt. Nach seinem Ableben wurde die Handbibliothek (mitsamt damals 1462 Manuskripten verschiedener Art) aufgelöst und auf diverse Instanzen verteilt; ein Teil gelangte in die ihrerseits bis dahin ganz besonders von Kaiser Franz gepflegte, dann schon einige Zehntausend Bände zählende »Fideikommissbibliothek" der Herrscherfamilie, und über diese später in den Bestand der Nationalbibliothek. Das nach Franzens Tod hingegen dem »Handarchiv« (Arbeitskabinett) zugeordnete Material mit insgesamt nicht weniger als 1112 Faszikeln wurde 1865 an das Haus-, Hof- und Staatsarchiv übergeben. ${ }^{86}$ Es war also vielleicht Absicht (wegen des Themas »Reisemanuskripte «), vielleicht aber auch ein bloßer Zuordnungsfehler, was zu der Verwahrung des Lilienbergschen Berichtes in der Bibliothek geführt hat.

Bei der editorischen Arbeit habe ich immer wieder von den neuen, manchmal fast endlos scheinenden digitalen Zugangsmöglichkeiten profitiert, die sich bei der Kommentierung einer solchen Quelle seit wenigen Jahren auftun. Das gilt vor allem in zwei Beziehungen. Zum einen betrifft dies die noch vergleichsweise schlicht scheinende Zugänglichkeit ansonsten entlegener Publikationen gerade des 19. Jahrhunderts, teils über Google Books, teils über eigene Portale wie etwa das digitale Zeitungsarchiv der Österreichischen Nationalbibliothek »anno« oder aber in den (meist schon etwas älteren) Einzelbilddateien verschiedener großer internationaler Bibliotheken. Keineswegs alles digital

macht, unter http://data.onb.ac.at/rec/AL00069461 (1.8.2014). Bei vergleichenden Verweisen innerhalb der Edition habe ich diese Handschrift als »Reinschrift« zitiert, unter Angabe der paginierten Seite (so vorhanden) und der Scan-Nummer, um bei externem Zugriff das rasche Auffinden der Stellen zu erleichtern.

85 Vor allem die Ergänzungen Lilienbergs zu verfolgen war schwierig. Sie aber nach Möglichkeit überall berücksichtigt zu haben, steigert nach meiner Meinung den Grad der Interpretierbarkeit und damit den Aussagewert der Quelle spürbar.

86 Mitteilungen Frau Mag. Ortners vom 13. und 27. Dezember 2013 an den Verfasser per E-Mail. Das in der ÖNB befindliche Archiv der Fideikommissbibliothek wurde für die Zeit bis 1835 aufwendig als Datenbank aufgearbeitet und digital zugänglich gemacht, unter http://fkb.onb. ac.at/die-archivdatenbank (20.5.2014). Es ist für Schlagwortsuchen bestens aufbereitet und wegen des diversen amtlichen Schriftgutes aus der direkten Umgebung des Kaisers auch weit über bibliotheksgeschichtliche Zusammenhänge hinaus für die Jahre ab 1809 erstaunlich ergiebig.

DigiOst 1 | 36 
Vorhandene aus jener Zeit ist dabei schon über Google Books erschlossen; es existieren nach meinem Eindruck noch in erheblicher Menge solche Einzelblatt-Digitalisate weiterer Titel (die dann meist nur über die einzelnen Bibliotheks-OPACs zuverlässig zu eruieren sind). Mühsam zu benützen sind dabei die zudem insgesamt noch sehr lückenhaft aufgenommenen Periodika und Amtsschriften. Erwähnenswert scheint auf dem aktuellen Stand von Frühjahr 2014 auch, dass die beiden internationalen Großbibliotheken, die innerhalb des von Google getragenen Projekts wegen der Größe ihrer Bestände für die Geschichte der Habsburgermonarchie bzw. Mitteleuropas am wichtigsten sind - nämlich neben der Österreichischen Nationalbibliothek noch die Bayerische Staatsbibliothek - bei der Auswahl der Altbestandsdigitalisate offenbar deutsche Titel gegenüber italienischen und sonstigen anderssprachigen bevorzugt haben oder noch bevorzugen. Das bringt für dalmatinische und allfällige oberitalienische Bezüge deutlich geringere Zugangsmöglichkeiten mit sich als hinsichtlich der zeitgenössischen deutschsprachigen Publikationen. Italienischsprachige amtliche Veröffentlichungen und Zeitungen des 19. Jahrhunderts liegen nach meiner Erfahrung bislang daher nur in $\mathrm{Zu}$ fallsauswahl digitalisiert vor.

Noch stärker waren die editorischen Rahmenbedingungen in einer zweiten Hinsicht durch die großen Digitalisierungsvorhaben geradezu revolutionär erleichtert, nämlich wenn es um die Recherche von sonst nur mühsam oder vielleicht gar nicht entschlüsselbaren Begriffen aus dem frühen 19. Jahrhundert ging. Manches mir Unbekannte hätte man gewiss auch früher schon im Deutschen Wörterbuch der Gebrüder Grimm oder in mehr oder minder zufällig zustande gekommenen Exzerpten finden können. Heute aber ist unglaublich viel zu finden in oft recht einfachen Suchvorgängen möglich. Für diesen Punkt sollen zwei Beispiele genügen. Das im Text ein einziges Mal in $\$ 163$ vorkommende Wort »ausscheifend « (für »weit ausgreifend «; " "ausufernd «, und damit eben nicht identisch mit dem ähnlichen und heute weit bekannteren »ausschweifend ", als was ich es in der Quelle unter Annahme eines eventuellen Schreibfehlers zunächst gelesen hatte) fand sich in einem der letzten Korrekturdurchgänge nach endlich erfolgter buchstabengetreuer Lesart binnen kürzestem über Google Books, wenn auch (Stand 19.11.2013) nur mit vier Treffern, drei davon in Veröffentlichungen des späten 18. Jahrhunderts, der vierte aber sogar in einer theologischen Arbeit von heute. Mühevoller, aber am Ende ebenfalls erfolgreich, gestalteten sich die Entzifferung und Eruierung des Pluralwortes »Lustern«, zumal die Handschrift in diesem Fall nicht gerade gestochen klar gehalten war (\$155). Nach über längere Zeit nicht aufgelösten Entzifferungs- und Recherche-Sackgassen in Richtung vermeintlicher Formen wie "Lustere" oder gar »Bustere « kam ich über einen halb erratenen Zusammenhang mit »Jahrfünft« erst zu einer Suche nach dessen italienischer Entsprechung (»lustro«), dank dessen zu der korrekten Entzifferung »Lustern « und anschließend zu dessen Suchabfrage (in Kombination mit einem weiteren Suchbegriff »Jahrfünft«) auf Google Books. Dass dann auch noch die zugrunde liegende Singularform, nämlich das im Deutschen soweit ich sehe völlig außer Gebrauch gekommene »Lustrum» mit einem Belegtreffer aus einem deutschen 
Wörterbuch von $1835 \mathrm{zu}$ finden war, hätte ich ohne die neuen digitalen Suchoptionen sicher nicht geschafft. Digitale Literatur-Treffer habe ich ansonsten bei der Edition dann als solche ausgewiesen, wenn sie bei seltenen Begriffen besonders mühsam zu eruieren waren oder wenn mir die Belegtreffer selbst thematisch relevant erschienen. ${ }^{87}$

\section{5. Über die Anhänge}

Am Ende sollen hier, noch vor dem Dank, kurze Erläuterungen zu den ausgewählten Anhängen stehen. Den Anfang macht das »Verzeichnis der Originalbeilagen (in der Reinschrift und der Konzeptschrift) «, zum Abgleich der beiden Originalversionen. Ihm folgt das »Verzeichnis der Kartenbeilagen der Edition«, bei denen es sich um die sämtlichen Kartenzeichnungen aus dem Zadarer Konzeptmanuskript handelt. Das anschließende »Verzeichnis der in der Lilienbergschen Darstellung zitierten Akten (1815-1834)« soll dazu dienen, die 1834 aus der Sicht des dalmatinischen Guberniums wohl wichtigsten oder jedenfalls drängendsten administrativen Aufgabenfelder im Überblick erkennbar zu machen und mögliche Suchanstöße als künftige Archivforschungen zu geben. Das »Verzeichnis der 1834 im Staatsrat behandelten Akten zu Dalmatien« dient dem hier weiter oben aufgeführten Argument, indem dadurch die zeitweilige Wirkung des Lilienbergschen Berichtes deutlicher nachvollziehbar wird. Außerdem kann es einen Überblick darüber geben, welche Themen umgekehrt die Zentralverwaltung zu Dalmatien für am wichtigsten befand, damals noch unter Einbezug von Kaiser Franz I. als kaiserlichem Akteur.

Etwas mehr Erklärung benötigen die beiden ausgewählten ergänzenden Quellen. Der erste Dokumentenanhang, "Vom sehr traurigen Geschick, in Dalmatien Landeschef zu sein, oder: nur im Zentrum kann beurteilt werden, wie viel für einzelne Provinzen der Monarchie geschehen kann. Zadar vs. Wien, 1835« bringt Auszüge aus einem Wiener Akt kurz nach dem Ableben des Monarchen, der besonders deutlich das Dienstverständnis von Lilienberg und seine Schwächung durch den Fortfall des Kaisers erkennen lässt, aber ebenso sehr den Anspruch der Wiener Hofstellen (hier vertreten durch Staatsminister Kolowrat), innerhalb des zentralisierten Systems die Übermacht qua Vorrecht und besserer Übersicht zu besitzen.

Der zweite Dokumentenanhang, "Relation über die Präturen Dalmaziens, ihr Personale, ihren Geschäftsbetrieb, Gebrechen und deren Abhilfe (Erzherzog Franz Karl [?], 1844) «, wurde aus verschiedenen Gründen ausgewählt. Nicht ganz vordringlich ist vielleicht der erste Grund, der mir trotzdem nicht unwichtig scheint: Das Dokument findet sich im Original in einem zentralen Bestand für die Regierungszeit von Franz I.,

87 Vgl. im Fall von Lustrum/Lustern die entsprechende Anm. 729 zu $\$ 155$. In das Literaturverzeichnis am Ende der Arbeit habe ich diesen und einige andere Treffer nicht aufgenommen, wenn sie nicht thematisch zu dessen Fokus auf der dalmatinischen und habsburgischen (Verwaltungs-)Geschichte passend waren.

DigiOst 1 | 38 
stammt aber von 1844. Es ist also auch ein Hinweis darauf, welche Überraschungen die Archive für den Historikeralltag bereithalten, und darauf, dass sich in diesem Bestand der »Kaiser-Franz-Akten « vielleicht auch für andere Themenstellungen eine Suche lohnen könnte, wenn es um das anschließende quasi-Interregnum der Regierungszeit von Kaiser Ferdinand I. und die Rolle der tonangebenden »Staatskonferenz« geht. Ein zweiter und stärker mit dem Thema unserer Edition verbundener Grund besteht darin, dass das Dokument zeigt, wie weit bis dahin der von Franz I. so geförderte und vorgelebte Gedanke von dem unmittelbaren Augenschein als Verwaltungs- und Regierungsprinzip schon verbreitet war. Drittens führt der Akt vergleichend zu den betreffenden Lilienbergschen Passagen zentrale Aspekte der für die dalmatinische Verwaltungsstruktur so wichtigen Präturen fort mitsamt den Schwierigkeiten, die ihrer Effizienz entgegenstanden.

Und viertens nehme ich an, dass der - in der zum Abdruck gebrachten Teilabschrift nicht genannte - Autor des Dokuments Erzherzog Franz Karl gewesen ist. Franz Karl war zweitältester Sohn des verstorbenen Kaisers Franz I., Vater des späteren Kaisers Franz Joseph I., aber eben nicht nur das, sondern von 1835-1848 auch Mitglied der Staatskonferenz. Angesichts der Kinderlosigkeit seines mehr oder minder geistig beeinträchtigten älteren Bruders, des nominell regierenden Kaisers Ferdinand I., stand er auf Rang eins in der Liste von dessen potentiellen Nachfolgern. In der Historiographie wird seine Rolle während dieser Jahre für geringfügig erachtet und er selbst im Wesentlichen dahingehend erinnert, dass er Ende 1848 nach dem Thronverzicht von Ferdinand zugunsten seines achtzehnjährigen Sohnes Franz Joseph von der Thronfolge Abstand nahm. ${ }^{88}$ Ich bin mir der Geringfügigkeit seiner vorherigen Rolle nicht so sicher, wie mir überhaupt die Frage des Ausmaßes der in der Staatskonferenz und durch informelle Einflussformen aus dem Kreis der Habsburgerfamilie nach 1835 fortbestehenden monarchischen Herrschaftselemente noch ungeklärt erscheint ${ }^{89}$ Franz Karl zumindest hat zum Beispiel nach Franzens Tod offenbar die Tradition der Herrscherreisen in Ermangelung eines reise- und herrschaftstauglichen eigentlichen Monarchen fortgesetzt. Hinweise darauf kann man seinem Biographen Emmer entnehme. Dazu kommt dessen Fingerzeig, dass die politisch-administrative Rolle des Erzherzogs schon vor 1848 eher zu gering eingeschätzt worden sei und sich diese Unterschätzung nach jenem Epochenjahr wegen seines dann wirklich völligen Rückzugs aus dem politischen Leben retrospektiv noch verstärkt habe. ${ }^{90}$ Ohne Franz Karl nun gleich zu einer eigentlich dominierenden Gestalt umdeuten zu wollen, erscheint mir Emmers Hinweis keineswegs unplausibel. Jeden-

88 Vgl. dazu Siemann: Metternich, 95 und 99.

89 Dass im Einzelfall das Zusammenspiel der Erzherzöge sehr bedeutsam und zum Beispiel für Metternichs Spielraum einengend sein konnte, zeigt wiederum Siemann sehr deutlich; er führt das entsprechende Funktionieren für dieses Beispiel von 1836 und bei anderen Gelegenheiten von da an aber auf eine erfolgreiche Manipulation der Erzherzöge (insbesondere Erzherzog Johanns) durch Metternichs Gegenspieler Kolowrat zurück (ebd., 96-98).

90 Emmer, Johannes: Erzherzog Franz Karl. Ein Erbauungsbüchlein für Volk und Jugend. Salzburg 1883, $12 \mathrm{f}$. 
falls war dem Erzherzog an der systematischen Bereisung des Reiches wohl aus genau denselben Gründen gelegen wie zuvor seinem Vater Franz, wozu passt, dass Franz Karl verwaltungsrelevante Ortskenntnis auch von den untergeordneten Beamten im Zentrum wie in den Provinzen regelmäßig einforderte. ${ }^{91}$ Im Herbst 1842 bereiste er zumal auch Dalmatien für mehrere Wochen. ${ }^{92}$

Der in dem zugrundeliegenden zeitgenössischen Aktenausschnitt nicht namentlich genannte Autor muss jedenfalls eine hohe Position innegehabt haben, denn er konnte gemäß dem Textauszug von der Verwaltungsspitze in Zadar ebenso Auskunft und Unterlagen verlangen wie von allen anderen Beamten, mit denen er auf seiner Reise Berührung hatte. Über die Bereisung selbst hatte er, darauf weist er ziemlich am Anfang hin, ein ausführliches »Reisejournal« angefertigt, das man sich wohl ähnlich detailliert vorzustellen hat wie die früheren Reiseaufzeichnungen von Franz I. Anhand einer Bemerkung in der edierten Auszugskopie müsste sich der Autor am Ende zuverlässig identifizieren lassen, nennt er doch am Schluss des Auszuges seine Tätigkeit als »Referent für das lombardisch-venetianische Königreich « als eine seiner Funktionen. Leider ist es mir trotzdem und selbst mit der freundlichen Hilfe einer so ausgewiesenen Forscherin zur Geschichte des habsburgischen lombardo-venetianischen Königreichs wie Brigitte Wallnig (Innsbruck) nicht gelungen, nach dieser Angabe den Inhaber jener Position zu ermitteln.

Meine Hypothese, dass mit der »Referentenstelle« hier eine Funktion innerhalb des Staatsrates gemeint ist, und dass es sich bei dem Schreibenden um Franz Karl gehandelt hat, sehe ich aber durch verschiedene Indizien gestützt. Dafür spricht die im Text erfolgende Einforderung der Landeskenntnis, dafür spricht der Duktus (»unsere Gesetze«), dafür sprechen die belegte Reise von 1842 und ähnliche Interessen des Schreibenden wie in früheren Jahren bei den Herrscherreisen von Franz I. (etwa die Arrestzellen und damit zusammenhängend die Lage der Häftlinge). Dafür spricht für mich aber auch meine Vermutung, dass nach dem Tod von Franz I. nur ausgewählte Dokumente, und vorrangig wohl solche mit Bezug zum näheren Umfeld der Familie, noch in den Bestand der »Kaiser-Franz-Akten« aufgenommen wurden. Außerdem und nicht zuletzt hatte Franz Karl in seinem amtlichen Wirken über die Jahre hinweg diverse Berührungspunkte mit dem Lombardo-Venetianischen Königreich gehabt und dieses auch mehrfach bereist. ${ }^{93}$ Der Quellen- und Vergleichswert des Dokuments für unsere Edi-

91 Ebd., $14 \mathrm{f}$.

92 Vgl. ebd., $37 \mathrm{f}$., sowie zur ungefähren Datierung des Aufenthalts in Dalmatien auf Oktober und Anfang November 1842 den ausführlichen Bericht über einen Teil der Reise in der Laibacher Zeitung, Nr. 90/1842, 8.11.1842, S. 603-605 (gefunden unter http://www.dlib.si/ details/URN:NBN:SI:DOC-ALC74P8C/?, zuletzt 25.5.2014).

93 So begleitete er 1825 Franz I. auf dessen Reise in Oberitalien (Püchler: Geschichte der Regierung Kaiser Franz I., Teil 3, 78). Bei der von ihm mit gemachten Krönungsreise von Ferdinand I. nach Mailand und Venedig spielte er 1838 ebenfalls neben Erzherzog Ludwig (als amtierendem Vizekönig) eine auffallend hervorgehobene protokollarische und in der Publi-

DigiOst 1 | 40 
tion, als ein Auszug aus einer etwas späteren, in der Struktur der amtlichen Bereisung Dalmatiens durch eine zweifellos hochgestellte Persönlichkeit der österreichischen Verwaltung, wäre indessen auch dann nicht wesentlich verringert, wenn sich eines Tages eine andere Zuordnung des Autors ergeben würde.

Es bleibt der Dank. Am meisten schulde ich ihn dem Kollegen und Freund Marko Trogrlić von der Universität Split. Er hat mir vor bald vier Jahren eine vollständige Kopie des Lilienbergschen Berichts gezeigt und überlassen. Dass wir daraus demnächst gemeinsam auch ein kroatisches Buch formen werden, freut mich sehr. Marko Trogrlić war zugleich Leiter des vom kroatischen Ministerium für Wissenschaft, Bildung und Sport (Ministarstvo znanosti, obrazovanja i športa) finanzierten Forschungsprojekts »Dalmatien und die Wiener Zentralinstitutionen im 19. Jahrhundert « (Dalmacija i bečke središnje institucije, Projektnummer 244-2690754-0762). Als externer Projektmitarbeiter konnte ich 2012 und 2013 meine Rechercheaufenthalte im Staatsarchiv von Zadar durchführen, und das Projekt hat auch sonst immer wieder einzelne Schritte unterstützt. Gemeinsam mit Marko Rimac (Split) half mir Marko Trogrlić nicht zuletzt intensiv dabei, viele der durch Lilienberg erwähnten Toponyme doch noch zu finden, die für mich auf keiner modernen Karte klassischer oder digitaler Art zu eruieren waren.

Bei der intensiven Suche im Haus-, Hof- und Staatsarchiv (Wien) nach der Reinschrift wurde ich von den dortigen Archivaren Joachim Tepperberg und Gerhard Gonsa überaus freundlich unterstützt. Von der sehr zuvorkommenden Hilfe durch Brigitte Wallnig (Innsbruck) und Michaela Ortner (Wien) war etwas weiter oben bereits die Rede. Der versierte Biograph Leopold Kudrna (Wien) hat mich in einem Augenblick, in dem ich wohl nach dem ins Leere gegangenen Verdacht gegen Lilienberg immer noch zu sehr von moralisierender Aufdeckungswut besessen war, zu verstehen gelehrt, dass ein nach heutigen Kriterien tatsächlich feststellbares Plagiat (begangen vom enzyklopädischen Biographen Wurzbach an Josip Jelačić und dessen Nachruf auf Lilienberg) zwar einer häufigeren kompilatorischen Methode Wurzbachs entsprach, die bei ihm neben seine vielen genuinen Forschungsleistungen tritt, dass dies aber seine enorme Lebensleistung nicht entscheidend schmälert, von der wir am späten Habsburgerreich Interessierten bis heute zehren können. Am Südost-Institut und danach am Institut für Ost- und Südosteuropaforschung haben mich schließlich seit 2010 erst Daniel Knežić und danach mit besonderem Sprachgefühl und Akribie Marija Đokić durch die Erstellung der Transkription der Lilienbergschen Relation tat-

zistik hervorgehobene Rolle; vgl. dazu Oesterreichischer Beobachter Nr. 249/1838, 6.9.1838, außerordentliche Beilage: „Ceremoniell bei der Krönung Sr. Majestät Kaiser Ferdinands I. als König des lombardisch-venetianischen Königreichs, S. 1-8; und Oesterreichischer Beobachter Nr. 256/1838, 13.9.1838; Nr. 259/1838, 16.9.1838. 
kräftig unterstützt. Frau Đokić möchte ich an dieser Stelle ganz besonders danken. Peter Mario Kreuter hat mich im Herbst 2013, kurz vor dem Auffinden der Lilienbergschen Reinschrift, bei einem eigenen Aufenthalt im Haus-, Hof- und Staatsarchiv sehr liebenswürdig durch Einsichtnahme in einige Kartons unterstützt, bei denen ich aus der Ferne noch vage Hoffnung hegte. Ihm verdankt sich dadurch das Auftauchen des von mir auf Erzherzog Franz Karl zurückgeführten und hier im Anhang edierten Aktes aus den »Kaiser-Franz-Akten«. Benjamin Schett (Basel) kam in einer späteren und kürzeren Phase mit wertvollen Vorarbeiten zu den Registern der Edition zu dem Kreis derer hinzu, denen ich hier von Herzen Dank erstatten möchte. 


\section{Detailliertes Inhaltsverzeichnis der $»$ Darstel- lung der Provinz Dalmatien nach der ämtli- chen Bereisung, in den Jahren 1832, 1833 und $1834 \lll$}

\section{Landesbeschreibung von Dalmatien}

$\S 1-3$ Einleitung

Geschichtliche Andeutungen

$\S 4$ Dalmatien im Allgemeinen $-\S 5$ Bocche di Cattaro $-\S 6$ Ragusa $-\S 7$ Verschiedenartigkeit der Bestandteile $-\S 8$ Altertümer $-\S 9$ Naturhistorische Andeutungen

Charakteristik des Verwaltungssystems unter den früheren Regierungen

$\S 10$ Tendenz der Republik Venedig $-\S 11$ Verfassung unter derselben $-\S 12$ Zwecke der Republik - $\$ 13$ Folgen dieses Herrschaftssystems für Dalmatien $-\$ 14$ Erste österreichische Regierungsepoche $-\$ 15$ Italienische Regierung $-\$ 16$ Tendenz des Provveditore Dandolo $-\$ 17$ Französisch-illyrische Regierung $-\$ 18$ Standpunkt der jetzigen Landesverwaltung

Geographisch-statistische Bemerkungen $\$ 19$ Bestandteile und Beschaffenheit des Gebietes $-\$ 20$ Geographische Lage, Grenzen im Allgemeinen $-\$ 21$ Beschreibung der Grenze und ihrer Länge gegen Kroatien $\$ 22$ Idem, bis zur türkischen Erdzunge Klek - $\$ 23$ Idem, von Klek bis zur türkischen Erdzunge Sutorina $-\$ 24$ Von Sutorina bis Punto Dubizza $-\$ 25$ Länge der Gränzen und Peripherie des ganzen Landes $-\$ 26$ Vorteile und Nachteile der geographischen Verhältnisse $-\$ 27$ Menge der Grenzstreite

Inseln

$\$ 28$ Inseln im Allgemeinen $-\$ 29$ Vielzahl der Häfen

Gebirge

$\S 30$ Ausrichtungen der Gebirge und Gebirgszüge im engeren Dalmatien - $₫ 31$ Sniexnizza, Kreise Ragusa und Cattaro $-\$ 32$ Nacktheit der Berge

Flüsse

$\S 33$ Im Allgemeinen $-\S 34$ Zermagna $-\S 35$ Kerka $-\S 36$ Cetina $-\S 37$ Narenta 
Seen

$\$ 38$ See auf der Insel Pago $-\$ 39$ See Boccagnazzo bei Zara $-\$ 40$ See Nadin, Kreis Zara - $\$ 41$ See Vrana, Kreis Zara $-\$ 42$ See Zabbacchie und Biscupie bei Sebenico - $\$ 43$ See Prolosaz bei Imoschi $-\S 44$ See Rostok $-\S 45$ See Jezero $-\S 46$ See Jezerac $-\S 47$ See auf der Insel Curzola

Moräste

$\S 48$ Morast bei Vrana $-\S 49$ Morast von Sordovan unweit des Sees Nadin $-\S 50$ Morast bei Ostrovizza $-\$ 51$ Morast Morpolazza - $\$ 52$ Morast bei Knin $-\$ 53$ Morast bei Sign $-\S 54$ Morast bei Uspor $-\S 55$ Morast an der Narenta $-\S 56$ Morast bei Castel Lastua

Thäler und Ebenen

$\S 57$ Um Zara $-\S 58$ Thäler im übrigen dalmatinischen Festland $-\S 59$ Kanal von Cattaro $-\$ 60$ Thäler auf den Inseln $-\$ 61$ Ebenen

Beschaffenheit des Bodens

$\S 62$ Verschiedenheit des Bodens, Erdarten $-\S 63$ Beurbarter Boden, Größe desselben

Klima

$\S 64$ Charakteristik des Klimas $-\S 65$ Winde

Straßen

$\$ 66$ Hauptverkehrstraßen $-\$ 67$ Militärstraße von Zara zum Fort Clissa $-\$ 68$ Kommunikationsstraßen auf dem Festland und auf den Inseln

Urproduktion

$\$ 69$ Ihr Wert $-\$ 70$ Zustand des Landbaus - $\$ 71$ Behandlungsart der Gründe $\$ 72$ Ackerwerkzeuge - $\$ 73$ Ackerbaumethode $-\$ 74$ Gründe des vernachläßigten Ackerbaus $-\S 75$ Wert der Landwirtschaft für Dalmatien $-\S 76$ Hauptmittel, die Landwirtschaft zu heben $-\$ 77$ Ausführungsarten dieser Mittel $-\$ 78$ Ökonomische Kommissäre $-\$ 79$ Aufmunterung zum Fleiße $-\$ 80$ Verbesserung der Produktion. Häufigere Saatenwechsel und Fruchtfolge $-\S 81$ Belehrung des Landmannes über den Nutzen hier einheimischer Pflanzen $-\$ 82$ Absatzförderung

Getreide Bau

$\S 83$ Gattung desselben $-\S 84$ Hülsen-Früchte $-\S 85$ Erdäpfel

Garten und andere vorzüglichere Feldfrüchte

$\S 86$ Kraut $-\S 87$ Futterbau und Wiesen

\begin{tabular}{l|l} 
DigiOst 1 & 44
\end{tabular} 
Hutweiden

$\S 88$ Ausdehnung der Hutweiden. Beschaffenheit $-\$ 89$ Handlungs- und Verarbeitungspflanzen - $\$ 90$ Tabak - $\$ 91$ Erdschwämme - $\$ 92$ Obst und verwandte Produkte $\$ 93$ Weinstock - $\$ 94$ Kastanien $-\$ 95$ Maulbeerbaum $-\$ 96$ Weitere wilde fruchttragende Bäume $-\$ 97$ Forstwesen

Tierreich

$\$ 98$ Viehzucht $-\$ 99$ Hornvieh $-\S 100$ Schafvieh $-\$ 101$ Geißen $-\$ 102$ Borstenvieh $\$ 103$ Hausgeflügel $-\$ 104$ Jagd $-\$ 105$ Ertragsfähige Insekten $-\$ 106$ Seidenwürmer $\S 107$ Blutegel $-\$ 108$ Fischerei

Verschiedene andere Meeresprodukte

$\S 109$ Seidenmuscheln $-\$ 110$ Korallen $-\S 111$ Meer- oder Wasserschwämme $\$ 112$ Meersalz

[Bodenschätze]

$\S 113$ Bergbau $-\S 114$ Erdpech $-\S 115$ Marmor und sonstige Steinbrüche $-\S 116$ Andere Mineralien $-\$ 117$ Mineralwasser

$\$ 118$ Industrielle Produktion

Kommerzielle Produktion [Handel und Transport]

$\$ 119$ Dermaliger Zustand $-\$ 120$ Transport und Verkehr im Innern des Landes $\$ 121$ Ausfuhrhandelsgüter $-\$ 122$ Einfuhrhandelsgüter $-\$ 123$ Handelskapital $\$ 124$ Handelsstruktur

Physische und Gemütsbeschaffenheit der Bewohner ${ }^{1}$

$\$ 125$ Abstammung der Dalmatiner und Außeinflüsse - Geheimorganisationen $\$ 126$ Physische Eigenschaften $-\$ 127$ Volksspiele $-\$ 128$ Kleidung $-\$ 129$ Wohnungen $-\$ 130$ Moralischer Charakter $-\S 131$ Rache, eine nationale Eigenschaft $-\S 132 \mathrm{Ex}$ zesse bei Kirchweihen, Fest- und Totenmahlen $-\$ 133$ Aberglaube, Hexen, böse Geister, Vampire $-\$ 134$ Starrsinn, ebenfalls ein Charakterzug $-\$ 135$ Verbrechen und andere Übertretungen $-\$ 136$ Allgemeine Betrachtungen: gute Aussicht in die Zukunft $\$ 137$ Wert der Provinz

1 Anmerkung am Rande: »Alle folgenden $\$ \$$ sind falsch numerirt.« Es gab eine falsche Numerierung mit Tinte, dann zwei mit Bleistift, und die (zumindest im Rahmen der Gliederung) korrekt durchlaufende Zählung mit Rotstift. Diese wurde in der Folge übernommen Bei $§ 148$ kam sie wieder mit der Numerierung in Tinte zusammen. 


\section{Dermalige politische Einteilung [= Verwaltungsgliederung] des Landes}

$\$ 138$ Kreis-, Präturs- und Kommunalbezirke $-\$ 139$ Gründe gegen Vereinigung der Kreise Ragusa und Cattaro - $\$ 140$ Einteilung des Landes in den vecchio, nuovo und nuovissimo acquisto - $\$ 141$ Prätursbezirke $-\S 142$ Negative Folgen der Aufhebung der Prätur Arbe $-\$ 143$ Gemeindebezirkseinteilung $-\$ 144$ Doppelzuteilung des Gebiets Rogosnizza, im Kreise Zara und Spalato $-\$ 145$ Gebiet Poglizza in drei Bezirken

Eigenheiten und Schwierigkeiten der Provinzverwaltung im Allgemeinen

$\$ 146$ Hauptstandpunkt der Verwaltung $-\$ 147$ Schwierigkeiten infolge der Topographie - $\$ 148$ Schwierigkeiten bei der Einführung neuer Systeme $-\$ 149$ Von den Eigenheiten des Landes und der Bewohner $-\$ 150$ Unverhältnißmäßig geringer Personalstand $\S 151$ Beschaffenheit der Beamten $-\$ 152$ Von dem Umstande, daß der Landeschef ein Militär ist $-\$ 153$ Von dem eigenen Verhältnisse des Landeschefs zum jeweiligen Hofrat $-\$ 154$ Von dem Umstande, dass bei den Hofstellen sich Niemand befindet, welcher den gegenwärtigen Zustand des Landes kennt

Mittel zur Förderung der Administration dieses Landes im Allgemeinen $\$ 155$ Schleunige Besetzung erledigter Stellen $-\$ 156$ Personal Aushülfen $-\S 157$ Verminderung der Aktenproduktion $-\$ 158$ Ausbildung geschickter und qualifizierter Beamten $-\S 159$ Bestimmung eines Zivilgouverneurs für die Landestelle

Gemeinden

$\$ 160$ Verhandlungen über das Gemeindewesen $-\$ 161$ Gemeindetypen $-\$ 162$ Zustand der Gemeindeämter im Allgemeinen $-\$ 163$ Beschaffenheit des Personals bei denselben und Geschäftsbehandlung $-\$ 164$ Bürgermeisterämter der Hauptorte $-\$ 165$ Beschaffenheit der anderen einzelnen Kommunalämter im Kreise Zara $-\$ 166$ Beschaffenheit der Kommunalämter im Kreise Spalato $-\$ 167$ Beschaffenheit der Kommunalämter in den Kreisen Ragusa und Cattaro $-\$ 168$ Die Capi Villa $-\$ 169$ Vermögensstand der Gemeinden $-\$ 170$ Ehemaliger Genuss der Octrois und jetziger Dazio consumo - $\$ 171$ Höchst nachteilige Folgen für die Gemeinden, das Land und den Staat wegen des gesunkenen Vermögensstandes der Kommunen $-\$ 172$ Politische Präturen $-\$ 173$ Landpräturen $\$ 174$ Maßregeln zur Verbesserung der Präturen

Kreisämter

$\$ 175$ Kreisamt von Cattaro $-\$ 176$ Kreisamt von Ragusa $-\$ 177$ Kreisamt von Spalato $\$ 178$ Kreisamt von Zara $-\$ 179$ Allgemeine Bemerkungen und Mängel $-\$ 180$ Mittel zur Abhilfe $-\S 181$ Katastraldirektion $-\S 182$ Forza territoriale $-\S 183$ Militär 
Geistlichkeit - Seelsorge

$\$ 184$ Zustand im Allgemeinen $-\$ 185$ Schilderung des Klerus $-\$ 186$ Gründe dieser Mängel - $\$ 187$ Die ältere Geistlichkeit der Städte $-\$ 188$ Geistliche des ehemaligen illyrischen Seminars $-\$ 189$ Geistlichkeit aus dem jetzigen Zentralseminar $-\$ 190$ Nachwuchsmangel - $\$ 191$ Zahl der Säkulargeistlichkeit $-\$ 192$ Schlechter Zustand der Kirchen und Pfarrhäuser $-\$ 193$ Mittel zur Hebung der Mängel $-\$ 194$ Bessere Dotirung $-\$ 195$ Befreiung von der Abhängigkeit des Klerus vom Landvolke $-\$ 196$ Feier verbotener Festtage

\section{Ordensklerus}

$\$ 197$ Zustand desselben $-\S 198$ Frauenklöster $-\$ 199$ Mittel dem Regularklerus aufzuhelfen $-\$ 200$ Griechische [orthodoxe] Geistlichkeit $-\$ 201$ Umtriebe der nicht unierten Griechen und Mord am unierten Pfarrer Kriška

Öffentliche Erziehungs- und Unterrichtsanstalten $\$ 202$ Höhere Bildungsanstalten $-\$ 203$ Elementarschulen $-\$ 204$ Mittel zu deren Beförderung $-\$ 205$ Technische Schulen $-\$ 206$ Sonntagsunterricht $-\$ 207$ Sonstige Bildungsanstalten $-\$ 208$ Polizei $-\$ 209$ Armen und Wohlthätigkeitsanstalten $-\$ 210$ Notstand $-\S 211$ Arbeits und Besserungsanstalten $-\$ 212$ Monte di Pietà $\$ 213$ Dienstbotenwesen $-\$ 214$ Wilde Ehen und Bigamien

Sicherheitspolizei

$\$ 215$ Verbrechen $-\S 216$ Besondere Verhältnisse im Kreise Cattaro $-\$ 217$ Schwere Polizeiübertretungen

Geheime und höhere Polizei

$\$ 218$ Überwachungsobjekte $-\$ 219$ Geheime Sekten $-\$ 220$ Maßregeln $-\$ 221$ Anträge zur zweckmäßigen Organisirung der Polizei

Sanitäts Polizei

$\$ 222$ Mängel der Seesanitätsorganisirung $-\$ 223$ Fehlerhafte Verteilung und Bevollmächtigung der Seedeputationen $-\$ 224$ Mittel $-\$ 225$ Kontumazanstalt zu Gravosa $\S 226$ Landessanitätsanstalten $-\S 227$ Karavanen in Sanitätbeziehung $-\S 228$ Spitäler

Öffentliche Bauten

$\$ 229$ Zustand, Menge $-\S 230$ Landesbaudirektion

Finanzverwaltung

$\$ 231$ Finanzangelegenheiten $-\$ 232$ Organisirung der Finanzinspektorate $-\$ 233$ Postwagenfahrt $-\$ 234$ Salinenwesen $-\$ 235$ Schmuggel $-\$ 236$ Tabakbau; Verhandlungen $-\$ 237$ Zehent-Aufhebung $-\$ 238$ Domänen $-\$ 239$ Vermögen aufgehobener Brüderschaften in Ragusa $-\$ 240$ Fiskalprozesse 
Konrad Clewing - 978-3-86688-501-1 


\section{"Darstellung der Provinz Dalmatien nach der ämtlichen Bereisung in den Jahren 1832, 1833 und 1834« - Textedition}

[Qu $1 / 1]$

No. 1600 1/2 zu 1834

Copiato 12/7 1834 Rougier

Euere Majestät!

Allergnädigster Herr!

Mit allergnädigstem Cabinetschreiben: Wien den 30. April 1833 Zahl 468 P. $^{2}$ haben Euere Majestät zu befehlen geruhet, über meine Landesbereisung überhaupt, so wie über das, was ich für das Wohl des Landes, und seiner Bewohner nothwendig und nützlich gefunden, und vorgekehrt habe, oder in aller Unterthänigkeit wünsche, daß vorgekehrt werde, Euerer Majestät unmittelbar in tiefster Ehrfurcht, zu relationiren, und da ich dermahlen die Bereisung beendigt habe, so säume ich nicht diesem allerhöchsten Befehl, in so weit es meine beschränkten Kräfte gestatten, allerunterthänigst nachzukommen.

Darstellung

Der Provinz Dalmatien nach der ämtlichen Bereisung in den Jahren 1832, 1833 und 1834.

\section{Landesbeschreibung von Dalmatien}

\section{Einleitung}

$\$ 1$ Es wird nicht leicht ein Land in Europa geben, das vom Auslande und selbst vom Inlande so wenig gekannt ist, als Dalmatien, von welchem man [Qu 1/2] im Allgemeinen genommen so unrichtige Begriffe hat, und das, größten Theils mit Unrecht, so gering geschätzt wird.

Der Hauptgrund jener Unkenntniß mag wohl bezüglich der Bewohner der übrigen österreichischen Provinzen in der Entfernung, Abgeschiedenheit, und in der Schwierigkeit einer Anherreise liegen. Vorzüglich abschreckend, auch für den wißbegierigen Ausländer, und selbst für den gebildeten Einwohner, ist aber die Beschwerlichkeit des

2 In Abschrift erhalten in HHStA, Kabinettskanzlei, (Bandnummer 444), Separatbilletten-Protokoll 468/1833. Im weiteren Verlauf der Quelle fehlen zumeist die »Paragraphenüberschriften«. Wo dies der Fall war, wurden sie in eckigen Klammern eingefügt. Kursivsetzungen bedeuten dabei vom Sinn nahegelegte Abweichungen vom Wortlaut des »detaillierten Inhaltsverzeichnisses«, welches der originalen Gliederung folgt. 
Fortkommen im Lande selbst, weshalb von Łenen meist nur die Seenstädte besucht werden; die gebildetern Eingebornen aber, selten über den Bezirk ihres Wohnortes ins Innere dringen, und selbst wenn sie Geschäfte zu längern Reisen nöthigen, doch nur so weit sich wagen, als sie die wenigen einigermaßen gangbaren Wege, ohne sich großen Gefahren und unbeschreiblichen Unbequemlichkeiten auszusetzen, benützen können.

Einige niedere Beamte ausgenommen, welche besondere Pflichten hierzu nöthigen, die [gestrichen: hiezu vollkommene] genug körperliche Kräfte und hinlängliche Entschlossenheit besitzen, um ihre [Qu 1 / 3] Bezirke, wenn diese auch sehr wilde Gegenden einschließen, zu besuchen, hat daher bis nun, so weit es mir bekannt ist, Niemand diese Provinz ganz bereiset, um solche zu allen ihren Theilen mit einiger Gründlichkeit kennenzulernen.

Was von dieser Provinz aus den, meist nur die Seegebiete behandelnden, großen Theils auch unvollständigen, Reisebeschreibungen bekannt ward, ist demnach ganz unzureichend, sich ein richtiges Bild Dalmatiens zu entwerfen.

$\$ 2$ Eben so unzulänglich sind die aus Geschäfts-Acten geschöpften Daten, da ihr eigentlicher Zweck der behandelte Geschäfts-Gegenstand oder Administrations-Zweig seyn muß und immer nur so viele abgerissene Andeutungen über einzelne Verhältniße und Bewohner darin aufgenommen werden können, als, und in wie ferne sie eben zu dem behandelten Umstand Beziehung haben.

Wer sich aber von diesem Lande, aus Anschauungen in anderen Provinzen gesammelt, und aus den unvollständigen historischen, statistischen und isolirten ämtlichen [Qu 1/4] Daten ein Gedankenbild entwirft, ohne das Land selbst gesehen, dessen unendliche Besonderheiten gehörig aufgefaßt zu haben, wird stets in der Gefahr seyn, sich sehr zu täuschen.

Hiervon hat mich der auffallende Contrast der Begriffe vollkommen überzeugt, welche ich von der Beschaffenheit Dalmatiens bloß nach der Geschäfts-Erfahrung und jener, die ich nach vollendeter Landesbereisung erhalten habe.

$\S 3$ Ich kenne kein Land, welches solche Mannigfaltigkeit, und solche Verschiedenheit in den meisten Beziehungen vergleichsweise zu anderen hätte, als Dalmatien.

Einige dieser Eigenheiten sind zwar schon bei mehreren ämtlichen Anlässen von Zeit zu Zeit angedeutet und den höhern Behörden geschildert worden; doch erscheint mir ihre gedrängte Zusammenfassung um so wichtiger und nothwendiger, als solche nie genug gewürdigt, nie genug hervorgehoben werden können, da von deren gehöriger Beachtung die Realisirung der allerhöchstväterlichen Absichten Euerer Majestät und die Wohlfahrt des Landes abhängt; im entgegen [Qu 2/ 1] gesetzten Falle aber alles Streben und Wirken für das Beste Dalmatiens ohne bedeutenden Erfolg bleibt. 


\section{Geschichtliche Andeutungen}

$\$ 4$ [Dalmatien im Allgemeinen] Dalmatien war von den ältesten Zeiten bis auf unsere Tage ein Schauplatz sich stets wieder erneuernder Kriege, durch äußere Mächte und fremde Völkerschaften: [gestrichen: veranlaßt und von gegenseitigen Befehdungen unter den eingeborenen Völkerschaften und Oberhäuptern der] Pelasger, Argonauten, Colcher, Griechen, Etolier, Liburnier, Umbern, Hetoniter, Gallier, Illyrier aller Geschlechter und Herkommens $^{3}$ veranlasst, als sich die Römer des ganzen Landes bemächtiget, und solches zum größten Hoch [unsichere Lesart] gebracht haben, dessen großartige Überreste, obwohlen von der alles vernichtenden Zeit, und von barbaren Händen größtentheils zu Grund gerichtet, noch hinlänglich Gelegenheit zu Bewunderung geben. Nach Zerstörung des morgenländischen Reiches haben: Attila, dann die nachgefolgten Avaren, Vandalen, Ostgoten und Langobarden das Land ganz verheert; bis nach und nach die Venetianer obwohlen öfters von den Croaten, Hungern und Türken unterbrochen, sich des eigentlichen damaligen Dalmatien bemächtigt haben.

$\$ 5$ [Bocche di Cattaro] Die Boche di Cattaro ${ }^{4}$, oder österreichisch Albanien, welches in den altesten Zeiten von allen Abenteurern zur See besucht und belästiget wurde, und unzweifelhaft hauptsächlich aus Macedonen, Serbiern und Bosniern bestehet, ist erst im 15. Jahrhunderte unter die Herrschaft der Republik Venedig gekommen, aber die restlichen Stämme, von welchen es bewohnet wird, unterscheiden sich bis auf diesen Augenblick auf das auffallendste.

$\$ 6$ [Ragusa] Das Gebiet von Ragusa ${ }^{5}$, welches seit dem 6. Jahrhundert als ein Freystaat, und später ganz unter dem Einfluß des ottomanischen Reiches sich auf die neuesten Zeiten erhalten hat ${ }^{6}$, ist slavischen Ursprungs. Was aber seine Inseln anbelangt, sind solche mit verschiedenartigen Volkerschaften bewohnt.

Die Mannigfaltigkeit in Sitten, und Kleidung, dieser vielen Urbewohner des damaligen Gesamt-Dalmatiens erhält sich theilweise bis auf diese Zeiten ${ }^{7}$; und ich erlaube mir,

$3 \mathrm{Ab}$ hier waren im Konzept geplant zahlreiche Streichungen und Randeinfügungen bis zum Ende von $\$ 4$ und am Anfang von $₫ 5$ und $\$ 6$.

4 Toponym (im Weiteren: TN) Bocche di Cattaro / Boka kotorska (in der ersten Hälfte des 19. Jahrhunderts daneben in der Nachfolge der früheren Bezeichnung als »venezianisch Albanien« auch noch als »österreichisch Albanien« bezeichnet), als Benennung der fjordartigen Meeresbucht unter Bezug auf den Ortsnamen (im Weiteren: ON) Cattaro / Kotor.

5 ON Ragusa / Dubrovnik.

6 Nämlich bis zum Frühjahr 1806 (Besetzung durch die französischen Truppen) bzw. bis zur förmlichen Einverleibung in das französisch dominierte Königreich Italien unter dem Datum 31.1.1808. Für die französische und die anschließende frühe österreichische Herrschaft in Dubrovnik s. Ćosić: Dubrovnik nakon pada republike (1808.-1848.); dort auch 13-31 zu den letzten Jahren der unabhängigen Republik.

7 Zu verstehen als: bis heute/bis zu diesem Tage. 
in lezterer Hinsicht, von den auffallendsten Trachten [Qu 2 / 2] einige Zeichnungen in tiefster Ehrfurcht Eurer Majestät zu unterlegen ${ }^{8}$.

Mit Ausnahme der Epoche unter römischer Herrschaft, both Dalmatien einen fast beständigen, beispiellosen Wechsel der Regierungen seit der ältesten Zeit.

$\$ 7$ [Verschiedenartigkeit der Bestandtheile] Seit Jahrtausenden bestand hier eine Menge, nach eigenen Gesetzen, Statuten, Gewohnheiten sich selbst verwaltender kleiner Staaten, welchen eine ähnliche Selbstständigkeit, zum Theile auch unter der venezianischen Regierung beibelassen worden war, und die auch besonders was die Colonen Verhältnisse, und die arbiträren Gerichte anbelangt, vieler Orten noch bis auf diesen Augenblick bestehen; die nie ein, durch Gleichheit der Intereßen, Sitten, der Verfaßung und Verwaltung abgeschlossenes Ganzes bildeten, und durch den, seit 1en July 1797 bis 9en December 1813 dreyfachen Wechsel der Regierungen, die in ihrem politischen Wirken so äußerst verschieden, und ihre Einführungen so sehr widersprechend waren, noch mehr verworren wurden.

Im Ganzen war es stets ein Bild ewigen Wechsels, [Qu 2 / 3] ewiger Unstätigkeit, verschiedener Tendenzen, eine sich oft wieder erneuernde beständige Vermischung zwischen den Eingeborenen und eingedrungenen Fremden.

$\$ 8$ [Alterthümer] Dalmatien ist ungeachtet der oftmaligen Verwüstungen eine Fundgrube aller Orten zerstreuter und zum Theil vergrabener Schätze von Ruinen aus seiner blühenden Zeitepoche. -

Nicht nur diese großartigen Monumente der Vorzeit, sondern auch die Cultur, der Wohlstand, Ackerbau, die Industrie, der Handel, die Gewerbe, Künste und Wissenschaften, geriethen nach der Römerherrschaft ganz in Verfall, und da auch die Venezianer im wesentlichen für dieses Land nichts Wohltätiges gemacht haben, so blieb es bis auf die neuesten Zeiten größtentheils in dem Zustande der Verödung und der Dürftigkeit.

\section{Naturhistorische Andeutungen}

$\S 9$ Dalmatien erscheint aber nicht minder merkwürdig durch seine Naturrevolutionen ${ }^{9}$, als durch dessen Völkergeschichte.

Aller Orten zeigen sich die auffallendsten [Qu 2 / 4] Spuren großer Naturereigniße, die mächtig einwirkend hier gewaltet haben müssen, wenn sie gleich in jene Zeiten zurückreichen, von denen kein geschriebenes Denkmal Kunde giebt.

8 Diese Beilagen sind im Konzept nicht erhalten, wohl aber in der Reinschrift, dort die Tafeln I bis VI (fol. 101-106, bzw. die Scans 205, 207, 209, 211, 213 und 215).

9 Ein Begriff, der in jenen Spätzeiten des noch in biblischen Altertumsvorstellungen zur Erdgeschichte geprägten Denkens grundlegende, nicht weiter erklärbare Phänomene, etwa Gesteinsformationen und andere, später plattentektonisch erklärbare Vorgänge etc. fassen sollte.

DigiOst 1 | 52 
Hiervon zeugte aber: das zerrissene Eiland, die durchbrochenen Küstenstrecken, die vielen zerstreuten Inseln, diese Höhen eines durch das eingedrungene Meer mit dem Festlande Dalmatiens und Italiens einst in Zusammenhange gestandenen Gebieths enthalten Flußsand, und öfters Versteinerungen, die ganz fremden Meeren angehören; - Eingestürzte Berge, losgerißene Erd- und Felsenstücke im Meere und auf dem Lande, und Gerölle, welche noch fortwähren; scharf abgeschnittene Wände isolierter Höhen, schwebende, dem Einsturz drohende, überhängende Maßen; ganze Bergreihen verschiedenster, verkehrter, umgestürzter und in mannigfaltigsten Richtungen vermengter Erd- und Steinschichten; unzählige Abgründe, Grotten, unterirdische weitgehende Aushölungen, und Schlünde, welche bei naßen Zeiten das Wasser mehrere Klafter hoch aussprudeln große Seen bilden, und bey einer trocknen wieder verschlingen ${ }^{10}$.

An vielen Orten trifft man [Qu 3 / 1] eine Menge stehender Wässer auf den höchsten Gipfeln der Berge, bedeutende unterirdische Ströme; beträchtliche Seen, die mit einander und mit dem Meere in Zusammenhang stehen, wie der Jesero ${ }^{11}$ und der Rastok ${ }^{12}$.

In allen Theilen des Festlands und auf mehreren Inseln stoßt man auf eine große Menge eingesenkter Krater ausgebrannter Vulkane, auf ganze Strecken geschmolzener Lavamaßen, auf ungeheuere weitverbreitete Schichten reiner Steinkohlen, auf Erdpech, und Gips- und Farbenerde aller Art.

\section{Geist des Verwaltungssistemes unter den früheren Regierungen}

$\$ 10$ Tendenz der Republik Venedig] ${ }^{13}-\$ 11$ [Verfaßung unter derselben] Der Geist des Verwaltungssistemes, seine Tendenz, Zwecke und die Mittel diese zu realisiren, bestimmen das Schicksal jedes Landes, und seiner Bewohner in moralischer, und materieller Hinsicht.

Die Republik Venedig beachtete Dalmatien in so ferne, als sie durch deßen Besitz die Herrschaft über das adriatische Meer und die Beschränkung der Türken, mit denen sie Jahrhunderte hindurch im Kriege war, zu erzielen strebte. Ihr Zweck blieb fortwährend dahin gerichtet, sowohl durch verschiedene Monopole als durch starke Werbungen ${ }^{14}$ so

10 Zum Satzverständnis: die Schlünde spucken erst das Wasser aus und »verschlingen« es dann wieder ...

11 TN Jesero / Jezero; siehe dazu weiter unten, die $\$ \$ 44$ und v. a. 45. Petter: Dalmatien, Bd. 1, 44 schildert ebenfalls diesen jahreszeitlichen, mit dem nachstehenden Gewässer durch unterirdische Karstwasserläufe verbundenen See in der Gegend südöstlich von Vrgorac.

12 TN Rastok / spätere Schreibung im Text auch Rastock (vgl. unten, $₫ 44$ ); Petter, a. a. O.: jahreszeitlicher See bei Vrgorac (östlich des Ortes), gespeist vom kleinen Fluss »Tihaglina« / Tihaljina bzw. Tijaljska rijeka.

13 Der im Inhaltsverzeichnis genannte $\$ 10$ : Tendenz der Republik Venedig« fehlt im Konzept als eigene Markierung; in der Reinschrift, Seite 5, steht er hier an der Stelle der Konzept-Markierung von $\$ 11$, während $\$ 11$ in der Reinschrift (Seite 6) vor dem übernächsten Absatz eingefügt ist (»Als die verschiedenen Theile $[\ldots] \lll)$.

14 Im Sinne von: Werbungen/Anwerbungen/Rekrutierungen von Soldaten. 
viele [Qu 3 / 2] Vortheile, als möglich, aus dieser Provinz zu ziehen, dagegen aber so wenig Aufwand als thunlich für dieselbe zu machen. ${ }^{15}$

Als die verschiedenen Theile des eigentlichen Dalmatien nach und nach unter die venetianische Herrschaft gekommen sind, bildete jede Stadt mit dem dazu gehörigen Gebiethe einen besondern Körper, welcher nach eigenen von den [Qu 4 / 1-2 sic] Gemeinheiten ${ }^{16}$ und Consigli der Adeligen, Bürger und des Volks funktionirten Statuten, die zugleich Civil- und Criminal-Gesetze, Verordnungen über die Auflagen und die Gemeindeauslagen enthielten, verwaltet wurde.

Die Republik hatte hieran, aus den früher geschilderten Gründen, so wenig wie möglich geändert, da sie zu dem Bestehenden nur so viel noch hinzu fügte, als unumgänglich nöthig war, um alle diese zerstückten Theile ihrer Provinz einem leitenden Oberhaupte untergeben zu erhalten und zu ihren Zwecken materiell zu benützen.

$\$ 12$ [Zwecke der Republik] Daher zeigte sie sich um Volkserziehung, Beförderung echter Religiosität, zweckmäßige Organisirung der verschiedenen Verwaltungszweige, Hebung der Agrikultur und Industrie sehr wenig bekümmert, sondern alle ihre Aufmerksamkeit war auf geheime Spionagen seltner und verächtlichster Art gerichtet; und nach diesen verläumderischen Angaben verfügte, und richtete sie. -

Die vielerlei Reibungen und Streitigkeiten zwischen den verschiedenen Gemeinden, Körperschaften ${ }^{17}$ und den Gliedern der Familien suchte jene Regierung nicht zu unterdrüken, um dadurch den Ertrag an Gerichtstagen und Sporteln ${ }^{18}$ zu vermehren und die, mit sich selbst beschäftigten Einwohner desto leichter in Abhängigkeit und Gehorsam zu erhalten.

$\$ 13$ [Folgen dieses Herrschaftssystems für Dalmatien] Dieses egoistische Sistem konnte keine andere Folgen haben, als das verwahrloste Dalmatien, welches zugleich der fast beständige Schauplatz von Kriegen mit den Türken war, moralisch und phisisch dem Verfalle zuzuführen, wozu auch die Nobili Rappresesentanti ${ }^{19}$ durch ihre [gestrichen: eigenen] selbstischen Zwecke [Qu 3 / 3] befördernd mitwirkten, indem sie die kurze Zeit ihres Aufenthaltes hierlands zu ihrem persönlichen Vortheile zu benutzen wußten.

15 Die nachstehenden weiteren Passagen bis Beginn von $\$ 12$ zur venetianischen Herrschaft sind entsprechend zu der an dieser Stelle stehenden Randbemerkung von Bogen (Quadrangel) 4 hier eingefügt.

16 Im Sinne von: Gemeinschaften/Körperschaften.

17 Im Sinne von: Körperschaften/Korporationen der unter Venedig noch vorhanden gewesenen Stände (innerhalb der Stadtgemeinden).

18 Gerichtsgebühren.

19 Gemeint sind offenbar die »conti« bzw. »knezovi« innerhalb des venezianischen Beamtenapparates, vgl. zu ihnen Peričic: Dalmacija uoči pada Mletačke Republike, 26 f.

\begin{tabular}{l|l} 
DigiOst 1 & 54
\end{tabular} 
$\$ 14$ [Erste österreichische Regierungs-Epoche] Die vielen wohltätigen Einrichtungen, welche Eure Majestät allerhöchste Weisheit während der Jahre 1797 bis zum 19 Februar 1806 hier einzuführen geruhten, hatten sehr vortheilhaft auf diese Provinz gewirket und ließen die segenreichesten Fortschritte erwarten. Doch zu kurz währte diese glückliche Epoche.

$\$ 15$ [Italienische Regierung] Die italienische Regierung welche vom Monate May 1806 bis July 1809 dauerte, so wie die illirische, welche dann begann und im Dezember 1813 endete, hatten eine nicht weniger [ergänzt: frevelhafte und] eigennützige Tendenz als die venezianische, indem sie [ergänzt: ohne auf die Sittlichkeit und das wahre Interesse des Volkes zu achten] [gestrichen: eine bedeutende Armee in Dalmatien unterhielt, welche einen beträchtlichen Theil des Provinzeinkommens unter verschiedenen Titeln aufzehrte ferner] unter Beibehaltung der früher bestandenen Auflagen, auch hierlands alle die Giebigkeiten, welche Italien belasteten, einzuführen bestrebt war, und im Ganzen [gestrichen: wesentlich] nur die Absicht hatte, das Land zu militärischen Zwecken zu benützen [Qu 3/4] und auszusaugen.

$\$ 16$ [Tendenz des Proveditore Dandolo] Der berüchtigte Provveditore Dandolo ${ }^{20}$, welchem die Leitung Dalmatiens unter der italienischen Regierung anvertraut war, bemühte sich in seinem politischen Fanatismus, nur, alles Gute was Eure Majestät allergnädigst einzuführen geruheten auf höchst leidenschaftliche Weise zu zerstören, [Gestrichen: und] nach seiner Verworfenheit gehäßig zu schildern, und die politischen Sekten jeder Art im Lande einzuführen.

$\$ 17$ [französ. illirische Regierung] Die nachgefolgte illyrische Regierung verfolgte denselben Hauptzweck unter andern administrativen Formen und mit unbeschreiblichen Intriguen, auch mit noch weniger Gerechtigkeit, da besonders gegen die Letzt [am Ende ihrer Herrschaft; K.C.] alles verkäuflich war. -

Auch war diese Epoche noch von viel geringeren Vortheilen für die Eingebornen, deren Beamte nicht einmahl ihre Besoldungen vollständig bezogen, indem man doch andererseits bemüht war, die Landesauflagen jeder Art zu erhöhen.

$\S 18$ [Standpunkt der jetzigen Landesverwaltung] Euer Majestät allerhöchster Wohlthätigkeitssinn betrachtet dagegen Dalmatien nicht wie die früheren Regierungen, als bloßes

20 Vincenzo Dandolo $(* 1758, \dagger 1819)$ war venezianischer Chemiker, Mediziner und Agronom, 1806-1809 als Generalprovveditore Vorsteher der Verwaltung Dalmatiens innerhalb des napoloenischen Königreichs Italien. Die Charakterisierung als »berüchtigt « steht in klarem Widerspruch zu der späteren, keineswegs mehr so negativen Schilderung seines dalmatinischen Wirkens bzw. einzelner Maßnahmen der von ihm geführten Verwaltung durch Lilienberg (vgl. etwa $\$ 97)$. 
Mittel, sondern der edelste, uneigennützigste Zweck, dessen eigene möglichste [Qu 4 / 1] Wohlfahrt, erscheint in allen allerhöchsten Willensäußerungen, als das schöne Ziel, das Eurer Majestät Vaterherzen ${ }^{21}$ in allem vorschwebt, wodurch es den übrigen glücklichen und cultivirtesten Ländern der österreichischen Monarchie gleich behandelt, und, [gestrichen: wenngleich] mit großen Opfern, auf den höheren Standpunkt der Civilisirung emporgehoben werden soll.

Eine Tendenz, welche, so gerade entgegengesetzt jener der frühern Regierungen sie ist, eben so sicher, wenn man in allen Theilen genau nach E. M. allerweisesten und allergnädigsten Willensmeinung verfahren wird, diese Provinz aus dem Zustande der materiellen Verwahrlosung und geistigen Verwilderung, zu jenem des erwünschtesten physischen und moralischen Wohlseyns, zum unfehlbaren Ersatze aller großmüthgen Vorschüß $\mathrm{e}^{22}$, und zur nie vergänglichen innigsten Segnung Eurer Majestät führen muß.

[Hier roter (Zwischen-)Schlussstrich mit dem Vermerk abgeschrieben 24/5., d. i. 24. Mai 1834]

[Gestrichen: Überschrift Dermalige politische Eintheilung des Landes, und vier Absätze dazu. Sie werden später im Abschnitt »Dermalige politische Eintheilung« unverändert an richtiger Position wiederholt.]

[Qu 5/ 1]

Geographisch-statistische Bemerkungen

$\$ 19$ [Bestandtheile und Beschaffenheit des Gebietes] Die unverhältnißmäßige Länge dieser Provinz zu ihrer Breite, die Rohheit der Völker die sie umgeben, und die meistens sehr unvortheilhaften Begränzungen, haben mich bei meinen Bereisungen von der Beschwerlichkeit in administrativer Hinsicht noch mehr überzeugt. Dalmatien besteht nebst dem Festlande, das jedoch durch zwei Erdzungen ${ }^{23}$, welche bis ans Meer reichen

21 Eine direkte Beschwörung des allenthalben offiziell gepflegten Bildes vom »Landesvater « Kaiser Franz, das in der Landesbeschreibung von Lilienberg wiederholt auch nahezu dialektisch dazu verwendet wird, um den so Angesprochenen für die Unterstützung der Lilienbergschen Verbesserungswünsche bzw. als Verbündeten gegen die Wiener Zentralverwaltung und deren dalmatienpolitische Handlungen bzw. Unterlassungen zu gewinnen.

22 "Vorschüsse« im Sinne des gesamtstaatlichen Systems, das keine langfristig "passiven « (nämlich durch Eigenmittel unterfinanzierten) Kronländer vorsah. Vgl. zu diesem Grundgedanken auch die Schlussbemerkungen Lilienbergs am Ende seines Textes.

23 Gemeint sind Neum (in der damaligen Amtsterminologie Klek, das heute nur noch einen auf der kroatischen Seite befindlichen Grenzort und die vor Neum gelegene Halbinsel bezeichnet) und Sutorina, nördlich und südlich des Kreises Dubrovnik. Vgl. insbesondere die nachstehenden $\$ \$ 22-24,66$ u. a. (s. a. Register).

\begin{tabular}{l|l} 
DigiOst 1 & 56
\end{tabular} 
und nun beide zu dem Paschalik Herzegowina ${ }^{24}$ gehören, durchschnitten mithin wie es aus der ad 7 anliegenden Übersichtskarte erhellet ${ }^{25}$, in 3 ganz abgesonderte Gebieths-Strecken getheilt wird, annoch aus 51 bedeutenden Inseln, zu welchen eine noch viel größere Anzahl kleinerer gehört, die in dem adriatischen Meere zerstreut, und mehrere 8 bis 10 deutsche Meilen ${ }^{26}$ von unserem und einige sogar viel näher an dem königlich neapolitanischen Gestade gelegen sind ${ }^{27}$.

$\$ 20$ [Geograph. Lage, Grenzen im Allgemeinen] Dieses Königreich liegt zwischen den $42^{\circ}, 10^{\prime}, 12^{\prime \prime}$, und $44^{\circ}, 45^{\prime}, 21^{\prime \prime}$, nördlicher [Qu $5 / 2$ ] Breite, dann $12^{\circ}, 25^{\prime}, 29^{\prime \prime}$, und $16^{\circ}, 38^{\prime}, 30^{\prime \prime}$ östlicher Länge von Paris. Das Festland gränzt gegen Norden mit dem k. k. Militär Croatien $^{28}$, gegen Süden mit türkisch Albanien ${ }^{29}$ und zum Theile an Montenegro; gegen Osten an Bosnien und die Herzegowina; und im Westen wird dessen Küste von dem adriatischen Meere benetzt.

$\$ 21$ [Beschreibung der Grenze und Länge derselben gegen Croatien] Die Gränze welche [gestrichen: von dem quarnerischen Meere] in dem Kanale della Morlacca ${ }^{30}$ und ei-

24 Das Paschalik war der Amtsbezirk eines osmanischen Paschas, hier also des 1832 gegründeten Paschaliks Herzegowina, das bis zu dieser zeitweiligen Verselbständigung (die eine Strafmaßnahme gegen die 1831/32 aufständischen Bosniaken und eine Belohnung für die reichsloyale Haltung des nunmehrigen herzegowinischen Paschas Ali Rizvanbegović darstellte) als Sandschak Teil des Eyalets Bosnien gewesen war. Vgl. Aličić: Pokret za autonomiju Bosne od 1831. do 1832. godine; Imamović: Historija Bošnjaka, 336.

25 Karte 1 hier im Anhang, Seite 292, bzw. Reinschrift, fol. 107 / Scan 217.

26 Die deutsche Meile entspricht bei Lilienberg (im Unterschied zu der deutlich kürzeren italienischen Meile) dem Längenmaß von umgerechnet gerundet 7,59 km, das in anderen Quellen auch als geographische oder österreichische Postmeile bezeichnet wurde.

27 Lilienberg scheint hier die Entfernung der vom dalmatinischen Festland abgelegensten Inseln eher zu überschätzen oder zu übertreiben, denn tatsächlich etwas näher am italienischen (bzw. damals noch zum neapolitanischen »Königreich beider Sizilien« zählenden) Festland liegt bloß die kleine Felsengruppe rund um das unbewohnte Eiland Palagruža.

28 Also der kroatischen Militärgrenze, konkret hier im Bereich des Likaner und des Ottochaner Regiments innerhalb der Karlstädter Grenze (Karlstädter Generalat).

29 »Türkisch Albanien« in Abgrenzung von dem damals noch recht üblichen »österreichisch Albanien« (wie erwähnt für das ehemalige »venezianische Albanien«, nämlich den Bezirk Kotor im südlichen Dalmatien). Die Grenze nach »türkisch Albanien« befand sich ca. 15 Kilometer nördlich der bis 1878 noch osmanischen und ab dann montenegrinischen Stadt Bar (ital. Antivari, albanisch Tivar), bzw. südlich des noch österreichischen Ortes Budva.

30 TN Kanal della Morlacca / an späterer Stelle deutsch: Morlachen-Kanal (bei Pag) / italien.: Canale della Morlaccha (auch: della montagna), entspricht ab der Höhe von Pag nach Süden bis Maslenica dem Süddteil des größeren Meeresarms, der kroatisch heute als Velebitski kanal bezeichnet wird. Vgl. Generalkarte von Mitteleuropa, Blatt »Zara» (http://lazarus. elte.hu/hun/digkonyv/topo/200e/33-44.jpg; 23.7.2014). 
gentlich von dem Hafen Santa Madalena ${ }^{31}$ an Militair-Croatien - nämlich an der Lica bis zum dreifachen Confinio ${ }^{32}$ mit Bosnien auf den Berg Koinska Glava ${ }^{33}$ fortläuft, ist die natürlichste, da sie größten Theils durch den Kamm des Gebirges Velebich ${ }^{34}$ bezeichnet ist, und hier fand ich sie gut und zweckmäßig; auch sind mir keine Klagen vorgekommen, weil eben die gemeinschaftliche Reambulation, die alle drei Jahre vorgenommen wird $^{35}$, vollendet war.

Diese beträgt nach ihren Krümmungen 131/2, in der geradesten Linie aber 91/4 deutsche Meilen.

$\$ 22$ [Idem, bis zur türkischen Erdzunge Klek] Von diesem ersten triplo confinio [Qu 5 / 3] über das zweite mit Bosnien und Herzegowina ${ }^{36}$ läuft anfangs die Gränze durch eine sehr

31 ON Santa Madalena / kroat. Sveta Magdalena, ein Ort in der Nähe von Karlobag (nahe der damaligen Grenze der Provinz Dalmatien, schon auf dem Gebiet der kroatischen Militärgrenze gelegen).

32 Hier im engen und eigentlichen Wortsinn eines Dreiländerecks (Kroatien - Dalmatien Bosnien). In einem erweiterten Sinne wird die Umgebung speziell dieses einen dreifachen oder »triplo Confinio« von der Historiographie seit Ende der 1990er Jahre zur Bezeichnung einer frühneuzeitlichen Strukturregion »Triplex confinium« verwendet, die sich auf allen drei anstoßenden historischen Territorien verorten lässt (im Zuge eines von Drago Roksandić, Zagreb, geleiteten Projekts).

33 TN Koinska Glava / Konjska glava (Berg, 1336 m) an der kroatisch-bosnischen Grenze am ehemaligen Dreiländereck, oberhalb des Dorfes Golubić (Gemeinde Knin)

34 TN Velebich / Schreibvariante Vellebich / Velebit.

35 Ein Beleg für eine offenbar regelmäßige gemeinsame Wiederbegehung der Grenze bzw. des Zustands der Grenzabmessungen durch Beamte aus der kroatischen Militärgrenze und aus Dalmatien.

36 Von Nordwesten aus betrachtet am Zusammstoß des Paschaliks Bosnien mit dem, wie gesehen 1832 aus dem vorherigen Eyalet Bosnien herausgelösten, Paschalik Herzegowina an der dalmatinischen Grenze. Nach einigen Karten wäre dies auf der Höhe zwischen Grahovo und Livno zu verorten; dies ist aber für die hier behandelte Zeit falsch (vgl. dazu hier im Anhang die Karten 1 und vor allem 6 und 7 mit der Markierung der damaligen Grenze zwischen den beiden Paschaliks). Auch der stets sehr gründliche Petter hält ausdrücklich noch für die Zeit gegen 1850 fest, Livno werde zwar oft und selbst von dem seinerzeit führenden Balkan-Kartographen Heinrich Kiepert fälschlich für in der Herzegowina gelegen betrachtet, es sei aber in Bosnien. Die Grenze der beiden Gebiete stoße bei Aržano an Dalmatien an: Petter: Dalmatien, Bd. 2, 99 (dort Anm. 1). Zu früheren Zeiten war Livno freilich von der osmanischen Verwaltung auch administratorisch zur Herzegowina geschlagen worden, und wird auch heute von vielen Betrachtern und vielleicht auch von den Bewohnern selbst für herzegowinisch gehalten. Vgl. für derlei teils fluide Regionalbegriffe und -diskurse in Südosteuropa demnächst ein im Abschluss befindliches Buchprojekt an der Österreichischen Akademie der Wissenschaften (»Das Südosteuropa der Regionen«), geleitet von Michael Metzeltin, Oliver Jens Schmitt und Thede Kahl. 
gebirgige Gegend, aber doch bloß über die Abhänge der dinarischen Alpen ${ }^{37}$, und eigentlich über den Ast dieses Gebirges den Berg Prologh ${ }^{38}$ bis zu dem Gränz-Kastel Arxano $^{39}$ und gegen Imoschi ${ }^{40}$.

Es sind schon in dieser Strecke viele Unannehmlichkeiten, weil manche Dörfer, was besonders rücksichtlich der sogenannten Backia ${ }^{41}$ so wie E.M. aus der Anlage N. $8^{42}$ allergnedigst zu ersehen geruhen wollen - der Fall ist, getheilt sind, und deswegen viele Streitigkeiten vorkommen; aber von hier angefangen, fand ich die Begränzung noch schlechter, denn es ist durchaus unmöglich die unaufhörliche Communication der beyderteiligen Gränzbewohner zu verhüten ${ }^{43}$.

37 Dieser damals wohl noch recht neue (und eventuell wirklich, wie von ihm angedeutet, von Balthasar Hacquet 1785 geschaffene Begriff; Hacquet: Physikalisch-politische Reise aus den Dinarischen durch die Julischen, Carnischen, Rhätischen in die Norischen Alpen, Teil 1, dort 4), in Analogie zu den Alpen gebildete und bis heute im Deutschen übliche Begriff für den großen, naturrämlich als Einheit verstandenen Gebirgszug war zu Lilienbergs Zeit in der deutschen Erdkunde offenbar bereits gut eingeführt. Vgl. etwa die Nennung in Malchus: Handbuch der Militär-Geographie oder Erd- und Staatenkunde von Europa, 516 (in der Beschreibung Dalmatiens); sowie Grisebach: Reise durch Rumelien und nach Brussa im Jahre 1839, 113, wo der Autor die dinarischen Alpen als die "wahre Hochgebirgslinie Rumeliens" bezeichnet, gelegen in einer Breite von etwa 20 deutschen Meilen etwa zwischen Split und Banja Luka oder Kotor und Užice, die sich über Kroatien, Bosnien, die Herzegowina, Dalmatien, Montenegro und den nördlichsten Teil von Albanien erstreckten. Vgl. auch einen lateinischen Beleg bei einem dalmatinischen Autor weiter unten, Anm. 109.

38 TN Prologh: gemeint ist angesichts der Verortung zwischen dem zweiten Triplex Confinium und Aržano wohl eine (ältere) ungefähre Entsprechung zum heutigen Ausdruck Dinara-Gebirge. Dafür, dass »Prolog « seinerzeit weitgefasst für das dalmatinische Grenzgebirge in Gebrauch war, sprechen auch die noch heutigen Toponyme des Ortes P. auf der herzegowinischen Seite des Grenzgebirges auf halbem Weg zwischen Sinj und Livno und in Dalmatien des Prolog-Sees (Prološko blato, sowie des östlich davon gelegenen Ortes Donji Proložac) und des noch weiter südöstlichen Prolog bei Vrgorac (ein Bergrücken zwischen den jahreszeitlichen Seen Rastok und Jezero und weiter östlich längs der Grenze zwischen der Herzegowina und Dalmatien, heute mit den Ortschaften Veliki Prolog, in der Mitte des Bergrükkens, und Mali Prolog).

39 ON Arxano / Aržano: Grenzort ca. $20 \mathrm{~km}$ nordwestlich von Imotski, mit gleichnamigem Ort(steil) gleich auf der anderen Seite der Grenze; siehe dazu hier im Anhang, Seite 294 Karte 2, bzw. Originalanlage VIII, Reinschrift fol. 109 /Scan 220.

40 ON Imoschi / Zweitvarianten im Text auch Imoski und Imosky / Imotski.

41 TN (Landschaftsname) Backia / Bekija: Ostteil des Beckens des Imotsko polje, der bei der Grenzziehung von 1718/19 (Friede von Passarowitz) auf osmanischem Gebiet verblieben war.

42 Siehe im Anhang die Karte 2, wie eben.

43 Der vormodern offene Charakter der dortigen österreichisch-osmanischen Grenze ist typisch für den ganzen Bereich des Triplex confinium für die Zeit bis Ende der frühen Neuzeit, aber zum Teil eben auch noch im 19. Jahrhundert. Mit Blick auf Dalmatien war er - im Sinne der stark eingeschränkten Kontrollierbarkeit durch die Behörden und insofern nur gesehen nur 
Die Gränze geht nämlich bei Vergoraz ${ }^{44}$ durch den Morast Rastock; dann eine Strecke der fahrbaren Straße nach, welche die Franzosen auf dem türkischem Gebiethe mit Gewalt der Waffen gebaut, und wir fortan beibehalten haben ${ }^{45}$; weiters an dem [Qu 5 / 4] See Jesera ${ }^{46}$ vorbey und durch eine größtentheils mit starkem Laubholz-Anfluge bewachsene, auf keiner Seite ausgelichtete [Randergänzung] Ebene, von wo man das ganze türkische Gebiet bis zu der Stadt [gestrichen: Klibuschie] Gliubuski ${ }^{47}$ vollkommen übersieht, und diese, wenn es nöthig wäre, sehr leicht überfallen könnte. Nun lenkt sie in ein enges gemeinschaftliches Thal ein, und gehet gegen das an einer starken Anhöhe stehende Dorf Vido ${ }^{48}$; senkt sich dann in das Narenta Thal, lauft abermalen durch eine schöne und fruchtbare Ebene, wo die Gränze blos durch einen seichten Graben bezeichnet ist, und man den bedeutenden etwa eine halbe Meile entlegenen türkischen Ort Gabella ${ }^{49}$ immer vor Augen hat, bis zum Kastel und Lazzaret von Unka ${ }^{50}$ vor Metkovich ${ }^{51}$, - wo die Narenta $^{52}$ in unser Gebiet einfällt; von da gehet sie aber eine starke Anhöhe an die schon erwähnte türkische Erdzunge Klek $^{53}$.

als Problem für die Herstellung und Durchsetzung der staatlichen Ordnung - im Vormärz über Jahrzehnte hinweg Gegenstand zahlreicher Berichte des Guberniums nach Wien. Vgl. dazu auch hier in den $\$ \$ 26,119,124,149,182,215,216,236$.

44 ON Vergoraz / Vrgorac: Ort im süddalmatinischen Hinterland, etwa auf halber Distanz zwischen Makarska und Metković (Neretva).

45 Gemeint ist der Abschnitt der Straße auf dem weiter oben genannten Höhenzug des Prolog, zwischen den heutigen Ortschaften Veliki und Mali Prolog (vgl. die Darstellung des Wegeverlaufes hier in Karte 8, Seite 300, bzw. Originalanlage XIV, Reinschrift fol. 115 [Scan 232]). Die dort noch heute über bosnisch-herzegowinisches Gebiet verlaufende Verbindung wurde demzufolge vom Osmanischen Reich auch in diesen Abschnitten nicht kontrolliert.

46 TN Jeseraz (weiter unten auch Jeseratz) / Jezerac: jahreszeitlicher See bzw. Morast nördlich des heutigen Ortes Mali Prolog im Vrgorsko polje, vgl. weiter unten, $₫ 46$. Petter: Dalmatien, Bd. 1, 44 schildert ihn als nahe dem Rastok gelegen und auf fast gleichem Niveau wie dieser.

47 ON (Herzegowina) Gliubuski / Ljubuški.

48 ON Vido / Vid (Ansiedlung nordnordwestlich des nahen Metković).

49 ON (Herzegovina) Gabella / Gabela, unweit von Metković.

50 ON (Kastel, Lazarett) Unka: die Angabe der nahe oder unmittelbar bei Metković gelegenen Einrichtung ließ sich nicht näher lokalisieren.

51 ON Metkovich / später im Text auch Metcovich / Metković: Grenzort an der Neretva, am Beginn von deren damaligen Mündungsdelta ca. $10 \mathrm{~km}$ oberhalb von ihrer Mündung ins Meer; zugleich letzter größerer Ort am Südende des ehemals venezianischen Bereichs von Dalmatien.

52 Hydronym TN Narenta / Neretva.

53 ON Klek / Klek. Die Landzunge Klek ist identisch mit der heutigen bosnisch-herzegowinischen Landzunge Neum, die bis zum Meer führt. Der kleine heutige Ort Klek selbst liegt nicht auf diesem bis 1878 bzw. 1908 osmanischen Gebiet, sondern knapp nördlich davon auf einem Gebiet, das zur Reisezeit Lilienbergs österreichisch war und heute kroatisches Staatsterritorium ist. 
Hier endet das eigentliche Dalmatien ${ }^{54}[\mathrm{Qu} 6 / 1]$ aus welchem der Zaraer und Spalatoer Kreis bestehet.

Die ganze Strecke beträgt in gerader Linie $24^{1 / 2}-$ und nach ihrem krummen Gange 30 deutsche Meilen.

$\$ 23$ [Idem, von Klek bis zur türkischen Erdzunge Suttorina] Auf der andern Seite von Klek, so eine deutsche Meile breit ist, und wo das Ragusäische Gebiet beginnt, gehet die Gränze vom Meer angefangen über eine starke Anhöhe und dann bis zu dem Punkte, wo sie die Erdzunge Klek verläßt, durch eine steinige - mit Bäumen schütter bewachsene Ebene, lauft dann mit manchen Krümmungen durch das Gebirg fort; beenget unser Gebiet so sehr, da uns an einem Orte nur die Breite von 1/4 deutscher Meile bleibt, und kommt dann zu der zweiten türkischen Erdzunge, Suttorina ${ }^{55}$ genannt, lauft auf der

54 Damit ist gemeint das bis 1797 venezianische Dalmatien, im Unterschied zu dem südlich innerhalb des späteren Kronlandes gelegenen Gebiet der ehemaligen Republik Ragusa und noch weiter südlich des bis 1797 zwar ebenfalls venezianischen, aber nicht förmlich mit Dalmatien vereinigten Gebietes von »venezianisch/österreichisch Albanien« (Boka kotorska).

55 ON Suttorina / Sutorina. Wie Klek war Sutorina im Gefolge der Friedenschlüsse von Karlowitz und Passarowitz (in deren Wortlauten die Frage freilich entgegen häufigen Annahmen nicht explizit berücksichtigt worden war) von der Republik Ragusa an das Osmanische Reiche überantwortet worden, um künftig die eigene Republik nicht mehr direkt an die als bedrohlich wahrgenommene Markusrepublik angrenzen zu lassen. Über die Verwaltung von Klek und von Sutorina wurde im 19. Jahrhundert zwischen den beiden Reichen über Jahrzehnte hinweg verhandelt; vgl. HHStA, Staatenabteilung (StAbt.) Türkei III, Karton 17: Grenzverhältnisse 1699-1859 (enthält im Umfang eines halben Kartons das Konvolut »Grenzakten betr. Klek und Sutorina 1815-1859«, darunter zahlreiche »Erhebungsakten und Relationen des Militärkommissärs Obersten Grafen von Caboga vom Jahre 1815 bis incl. 1840«, inklusive sehr genauer Kartenzeichnungen speziell zu einem Tauschprojekt mit Krivošje und einer Gemeinde im Ragusaner Gebiet, und zu österreichischen Straßenbauprojekten in Klek und Sutorina in den 1850er); sowie Šljivo, Galib: Izlaz Bosne i Hercegovine na Jadran, Tešanj 2001 (aufgebaut auf eine unveröffentlichte Magisterarbeit aus den 1970er Jahren). Zu den 1832/33 von Österreich angesichts der neuen französischen Truppenpräsenz in Ancona bzw. dem Adriaraum aufgenommenen diplomatischen Verhandlungen mit der Hohen Pforte über einen Erwerb der beiden Landzungen s. nunmehr Šedivý: Metternich, the Great Powers and the Eastern Question, 684f. - Im Gefolge eines bilateralen Grenzabkommens zwischen Kroatien und Bosnien-Herzegowina von 1999, das kroatischerseits bis Herbst 2012 nicht ratifiziert worden war, war der nicht zuletzt verkehrstechnisch wegen der Brückenplanung zur Umgehung von Neum wichtige genaue Grenzverlauf im Raum Klek heftig umstritten. Die Veröffentlichungen mehrerer renommierter kroatischer Historiker, die den Nachweis erbracht zu haben meinten, dass die Spitze der Halbinsel Klek (Ponta Kleka), zwei kleine vorgelagerte Inseln und ein im Meer gelegener Felsen eigentlich Kroatien zustünden, brachten zahlreiches historisches Material zur Frage von Klek bzw. Neum als Ganzes zutage. Vgl. insbesondere: Ćosić / Kapetanić / Vekarić (Hgg.): Prijevara ili zabluda, 2012 bzw. ähnlich schon 1999: Ćosić / Ljubić / Kapetanić / Vekarić: Hrvatska granica na Kleku. Für die Publizistik im Umfeld der Zagreber Parlamentsabstimmung zu 
Crête [K. C.: der Grat, der Kamm] einer fast ganz fruchtbaren Anhöhe um bei dem Gebirgspunkt Kobila ${ }^{56}$ am Meere, unweit der Punta d'ostro ${ }^{57} \mathrm{zu}$ enden, und das Gebiet der ehemaligen aristocratischen Republik des dermaligen [Qu 6 / 2] Kreises Ragusa, von Dalmatien und von österreichisch Albanien ganz abzusondern.

Diese Strecke beträgt in gerader Linie $113 / 4$ und nach ihren Krümmungen berechnet 15 deutsche Meilen.

$\$ 24$ [Von Suttorina bis Punto Dubizza] Auf der andern Seite der Suttorina, von dem Grenzpunkte und Kastel Magazza ${ }^{58}$, welcher schon zu österreichisch Albanien, oder zu dem Kreise Cattaro gehört, läuft sie einige Dörfer durchschneidend, durch ein sehr starkes Gebirg, gegen Crivoscie ${ }^{59}$, wo wir ohne dermahlen mehr angefochten zu werden seit 50 Jahren etwa 3/5 Quadratmeilen von den Türken usurpirt haben so wie sich Eure Majestät aus der anliegenden Skizze sub N. 9., in welcher der usurpirte Theil gräulich angelegt ist, allergnädigst zu überzeugen geruhen; dann zieht sie sich gegen das neu gebildete triplex-Confinium mit der Herzegowina und Montenegro ${ }^{60}$.

Von hier aus gehet sie zwischen diesem [Qu 6/3] Gebiete und jenem des unsrigen Dorfes Dobrota $^{61}$ - welches obwohl wir äusserst beengt sind, doch nichts von der alten natürlichen Gränze bis an den heutigen Tage verloren hat -, und man muß leider sagen fast bis an das Thor der Stadt und Festung Cattaro. Hier und bis zum Kloster Stagnevich $^{62}$ [korrigiert aus: Stojanich], welches die Montenegriner auch als ihr Eigenthum an-

dem Grenzabkommen im Herbst 2012 vgl.: http://www.index.hr/vijesti/clanak/vrh-kleka-jehrvatski-teritorij-evo-dokaza/636616.aspx und mit einer gegen das Abkommen gerichteten Wortmeldung auch des Historikers und Politikers Ivo Banac: http://www.politikaplus.com/ novost/63919/tko-od-zastupnika-digne-ruku-za-ratifikaciju-ugovora-neka-mu-se-sasusiruka (6.12.2013).

56 TN (Berg) Kobila / Berg und Kap am Westrand der Bucht von Kotor am Zusammenstoß des Dubrovniker bzw. damals österreichischen Gebiets und Suttorina.

57 TN (Halbinsel) Punta d'ostro / Ponta oštro.

58 ON (Kastel) Magazza / Magaza.

59 TN / ON Crivoscie / andere Schreibung im Text Krivoschie / Krivošje: Landschafts- und Ortsname in Kreis Cattaro, heute Montenegro.

60 Gelegen am Nordende der Krivošje. Vgl. die Karte 3, Seite 295 hier im Anhang, bzw. Originalanlage IX, Reinschrift fol. 110 /Scan 222.

61 ON Dobrota / Dobrota, ein Dorf im Norden von Kotor.

62 ON Stagnevich / Stanjević / Stanjevići: bedeutendes und auch strategisch wichtig gelegenes orthodoxes Kloster im Kreis Cattaro. Bis zu seinem Ankauf durch den österreichischen Staat im Jahre 1839 für 17000 Gulden befand es sich zusammen mit dem damals ebenfalls angekauften Kloster Maine im Besitz des Vladika von Montenegro (laut dem Zeitgenossen Vialla de Sommières, 95, war dies erst seit dem Ende der Venezianerherrschaft 1797 der Fall). Ihm dienten beide Klöster sogar als hauptsächliche Residenzen. Nach 1839 wurde Stanjević zu einem k. k. militärischen Stützpunkt umgewidmet. Zur Anbahnung des Kaufes 1838 und zu den strategischen Aspekten des Klosters s. Milović: Memoar o ispravljanju granice 
sehen wollen, haben sie sich sehr viel von dem zu unserem Albanien gehörigen Gebiete auf verschiedene Art zuzueignen gewußt.

Von dem Kloster Stagnevich [wieder korrigiert aus Stojanich] angefangen wird unsere Lage etwas besser, wenigstens sind wir nicht so beengt, obwohl auch hier, [gestrichen: überall $^{63}$ ] so wie mich die Gemeindeältesten, welche mich auf dieser Bereisung begleitet haben, versicherten, die Montengriner überall stark über die ehemalige Gränze gerückt und im Besitze unserer Gründe ${ }^{64}$ sind.

In Verfolgung dieser Demarcation fand ich in der Gegend von Braichi ${ }^{65}$ an der Gränze ein kleines Thal, welches nach Montenegro führt, und wodurch man vielleicht [gestrichen: am leichtesten] [Qu 6/4] mit wenigster Beschwerlichkeit dahin dringen könnte. Von hier läuft die Gränze an unserem Gebiete von Pastrovichio ${ }^{66}$ bis zu dem vierten triplex confinium ${ }^{67}$ mit Montenegro und dem Baschalik von Scutari ${ }^{68}$. Weil in der letzt genannten Streke die Bewohner von Pastrovichio am meisten über die Usurpation geklagt haben, so ließ ich, obzwar mit vieler Schwierigkeit - diese Gegend mit dem Tische aufnehmen, und unterfange mich diese Aufnahme sub 10. allerunterthänigst zu Füßen zu legen ${ }^{69}$. Die gelbe Linie deutet das Terrain an, welches die Montenegriner über die alte Gränze itzt inne haben. Von dem vierten triplici confinio habe ich die Gränze die in grader Linie an den Besitzungen der unruhigen sogenannten Spitzanotten ${ }^{70}$, die selbst ihrem Bascià viel zu thun geben, bis zu unserem äußersten südlichen Grenz-Punkte am

iz 1838., hier 375-377; sowie Oršolić: Boka kotorska u svjetlu austrijske politike tridesetih godina XIX. stoljeća, 421. Für Belege der Verwendung beider Klöster als montenegrinische Dienstresidenzen siehe die Ortsangaben zu zahlreichen abgedruckten Dokumenten in Milović: Petar I Petrović Njegoš. Pisma i drugi dokumenti.

63 Beispiel für satzbaubezogene Änderung in der laufenden Schreiberhandschrift von Rougier ein Hinweis darauf, dass die erste Fassung streckenweise als Diktat Lilienbergs entstanden ist (vermutlich verwendete dieser dabei die am Ende dem Akt beigefügten Notizen). Ähnliche Belege sind die Hörfehler bei Stagnevich "Stojanich« und weitere hier in den Anmerkungen festgehaltene Beispiele.

64 Grund: in dieser Verwendung süddeutsch bzw. Austriazismus für Grundstück; gemeint sind hier auf österreichischem Territorium gelegene Grundstücke im Eigentum von Montenegrinern.

65 ON Braichi / Brajići: Ansiedlung im Nordosten von Budva, Kreis Cattaro.

66 TN Pastrovichio / später im Text auch in der Schreibung Pastrovicchio / Paštrovići: Gebietsbzw. Landschaftsname im Südosten von Budva, Kreis Cattaro.

67 Gelegen südöstlich von Budva.

68 ON Scutari / albanisch Shkodër, Shkodra / serbisch, kroatisch Skadar: damals wie heute wichtigste Stadt von Nordalbanien (damals Hauptort des osmanischen Paschaliks bzw. Sandschaks Shodra, türk. İșkodra).

69 Karte 4, hier im Anhang Seite 296, bzw. Originalbeilage X, Reinschrift, fol. 111 / Scan 224.

70 Die Bewohner der ersten auf osmanischem Gebiet gelegenen Grenzgegend Spič / Spizza (darin der heutige Ferienort Sutomore), deren Gebiet 1878 im Gefolge des Berliner Vertrages von Österreich-Ungarn annektiert und an Dalmatien angeschlossen wurde. An späterer Stelle findet sich im Text die Schreibung Spizzanoten. 
Meer bei der Punta Dubizza ${ }^{71}$ oder Pecci ${ }^{72}$ fortläuft, ganz in der Ordnung gefunden. Die Länge der Grenze dieser [Qu $7 / 1]$ lezten Strecke, nämlich von der Suttorina bis an den itzt genannten Gränzpunkt, beträgt in gerader Linie 9 - und nach den Krümmungen, 12 deutsche Meilen.

$\$ 25$ [Länge der Gränzen und Peripherie des ganzen Landes] Die Begränzungslinie gegen die uns umgebenden Länder macht also im Ganzen in grader Richtung 541/2 und der wesentlichen Simeochiteeten ${ }^{73}$ nach $70^{1 / 2}$ deutsche Meilen aus.

Die Länge der Küste des festen Landes von dem Grenzpunkte an dem Kanale della Morlacca bei dem Hafen St. Madalena in Militair Croatien, bis an die äußerste Punta Dubizza beläuft, sind in grader Linie auf 61 1/4 und nach den Krümmungen, den großen Umkreis der Halbinsel Sabioncello ${ }^{74}$ mit gerechnet, auf 1613/4 deutsche Meilen.

Wenn man um die Peripherie ${ }^{75}$ der bedeutendsten Inseln ohne die vielen Scogli die $\mathrm{zu}$ solchen gehören zu berechnen, mit 3011/2 [gestrichen 304²/4] deut. Meilen hinzuschlägt, so findet man eine Küstenlinie die von dem adriatischen Meere [Qu 7 / 2] bespühlt wird, von 4631/4 [gestrichen: 466] deutschen Meilen und wenn noch die Land-Gränze mit Croatien den ottomanischen Provinzen, und Montenegro zugerechnet wird, so ergiebt sich der, zum Flächen-Inhalt und zur Bevölkerung dieses Landes in keinem Verhältniß stehende Umkreis von 533 3/4 deutschen Meilen.

$\$ 26$ [Vortheile und Nachtheile der geographischen Verhältnisse] Dieser sehr bedeutende Umkreis beträgt blos 228 [gestrichen: 280] Quadratmeilen an Flächen Inhalt und schließt nur 15 Städte, 13 Flecke $^{76}$ und 486 Dörfer mit 356873 Einwohnern ein.

Ich überzeugte mich bei der genauen Besichtigung dieser außerordentlich[en] und zu ihrem Flächeninhalte ganz unverhältnißmässigen Ausdehnung der Gränze vollkommen, was für eine Unmöglichkeit es sey, dieses Land in Sanitarischer, Zollämtlicher und polizeilicher Hinsicht durch stehende Posten zu sichern.

71 TN Punta Dubizza / Rt Dubica: unterhalb des auf der Karte des Kreises Cattaro bei Petter 1841 als Monte Dubovizza bezeichneten Berges (vgl. Kartenabdruck in Kozličić / Bralić: Stanovništvo, 335).

72 TN Pecci / Peči: Toponym an dem Küstenabschnitt Pećina, ganz in der Nähe des Rt Dubica.

73 Unsichere Entzifferung und Sinn - als Angabe für eine Messmethode - entsprechend nicht geklärt. In der Reinschrift (Seite 15 bzw. fol. 7r; Scan 17) entziffert als weiterhin unklares Sinuoxitäten.

74 TN Sabioncello / Pelješac: langgestreckte Halbinsel auf einst zur Republik Dubrovnik gelegenem Gebiet, in Richtung der (ihrerseits bis 1797 venezianischen) Insel Korčula.

75 Hier im Sinne von Außenumfang.

76 »Flecke« sind hier zu verstehen als Synonym von »Marktflecken«, also mittelgroße Orte, die keine Städte sind, aber in Größe und Bedeutung die reinen (kleineren) Dörfer übertreffen und gegebenenfalls Marktrechte hatten. Zum Begriff in Bezug auf Dalmatien und seiner dortigen Unschärfe: Petter: Dalmatien, Bd. 1, 240.

DigiOst 1 | 64 
Dagegen halte ich fest dafür, daß dieser Nachtheil bei weitem [Qu 7 / 3] durch den Vortheil überwogen werden dürfte, welchen diese Provinz aus ihrer glücklichen topographischen Lage durch das Comerce ziehen kann.

Ich kenne kein Land welches durch die Natur seiner diesfällichen günstigen Verhältniße wenn die Landesstelle E.M. allerweiseste Absichten vollkommen auffassen und beherzigen wird ${ }^{77}$ - in dem Erträgnisse des Landes und der Schiffahrt allein soviel Hülfs-Quellen finden dürfte, als Dalmatien.

$\$ 27$ [Menge der Grenzstreite] Wegen den vielen Gränz-Streitigkeiten die sich von Zeit zu Zeit ereignen, wäre es in polizeilicher Hinsicht zwar zu wünschen, daß eine Gränz-Berichtigung mit dem [osmanischen, K. C.] Nachbarstaate erfolge; aber ich halte dafür, daß man dieses mit den Türken auf so lange verschieben sollte, bis nicht die Frage über die Cession [Qu 7/4] der zwei Erdzungen Klek und Suttorina entschieden sein wird. Auch werden wir nichts gewinnen, denn dann würde vermuthlich der ganze Vorsprung von Crivoscie wie ich schon allerunterthänigst angedeutet habe, verlohren gehen. ${ }^{78}$

Mit Montenegro, hatten wir viel anzusprechen, aber bis nun hat man um diese Ansprüche zu beweisen keine rechtsbeständige Urkunde vorgefunden, auch ist ohnehin dermahlen auf öfentlichem [sic] Wege mit diesem Staate nichts anzufangen. Ich habe versucht, ob man ihnen nicht durch Privat-Kauf einige der für uns wichtigsten Strecken abgewinnen könnte, wo dann nach und nach das Altum Dominium ${ }^{79}$ an uns gekommen wäre; aber alle Versuche haben fehl geschlagen; es bleibt demnach nichts übrig als das, was wir haben, entschlossen zu verteidigen, und einen günstigen Augenblick zur Revidierung des Verlorenen abzuwarten. ${ }^{80}$

$[Q u$ 8/1]

Inseln

$\$ 28$ [Inseln im Allgemeinen] Die vielen Inseln, derer ich bereits, der Zahl und Peripherie nach, in tiefster Erfurcht erwähnt habe, bilden zwei Archipelage.

Der Nordwestliche, welcher in dem ehemaligen liburnischen Meere liegt, von welchem die Insel Arbe und $\mathrm{Pago}^{81}$ nördlich stehen und der sich bis Capo Cesto ${ }^{82}$ erstreckt,

77 So auch in der Reinschrift, Seite 12. Dagegen lautete ursprünglich die gegenüber den Wiener Hofstellen mutigere Formulierung: "wenn die Landesregierung und die Hofstellen Eurer Majestät allerweisesten Absichten vollkommen auffaßen und beherzigen werden «.

78 Nämlich wegen des von österreichischer Seite vorgeschlagenen Gebietstausches, vgl. $\$ 24$.

79 Oberhoheit.

80 Vgl. oben zu $\$ 24$.

81 ON / TN Pago / Pag: auf Arbe südlich folgende norddalmatinische Insel mit dem gleichnamigen Hauptort.

82 TN Capo Cesto / entspricht wohl dem TN / ON Primošten (auf dem Festland gut 10 Kilometer südlich von Šibenik), zur südlichen Begrenzung des Bereiches dieser nördlicheren Inselgruppe. 
dekt den nördlichen Theil der Küste und wird durch die Insel Promuda ${ }^{83}$, Scarda $^{84}$, Isto ${ }^{85}$ und Melada ${ }^{86}$, wie nicht minder durch die mit unzähligen Scoglien umgebene sehr bedeutende Isola grossa ${ }^{87}$ und Isola incoronata ${ }^{88}$ die sich alle in der vordersten Linie befinden - dann durch die in der zweiten Linie befindlichen Inseln Selvo ${ }^{89}$, Ulbo ${ }^{90}$, Uglian ${ }^{91}$ und Passman ${ }^{92}$ gebildet.

Durch diese zwei Inselreihen, deren letzte ungefähr eine deutsche Meile von dem festen Lande entfernt ist, entsteht in dem nordwestlichen Archipelag ein doppelter Canal; doch waltet der Unterschied ob, daß der, so zwischem dem festen Lande und [Qu 8/2] der ihr nächsten Inselreihe besteht, für aller Art Schiffe - jener aber, der durch die zweite Inselreihe gebildet wird, blos für kleine Schiffe und eigentlich nur für die innere Comunication, da in diesem Kanal selbst noch viele kleine Inseln sich befinden - fahrbar ist.

Der zweite, nämlich der südöstliche Archipelag, wird durch die in vieler Hinsicht beträchtlichen Inseln: Lissa ${ }^{93}$, Solta ${ }^{94}$, Brazza ${ }^{95}$, Lesina ${ }^{96}$, Curzola $^{97}$, Lagosta ${ }^{98}$, und Mel[gestrichen: -a-; ergänzt: -e-] da ${ }^{99}$, gebildet, von wo dann die mehr landeinwärts gelegenen

83 TN Promuda / Insel Premuda (mit gleichnamigem Dorf) als nordwestlichste zum Kronland Dalmatien gehörige Insel, gegenüber dem vormals ebenfalls dalmatinischen, aber damals (seit 1815/16) zu Istrien (bzw. dem Königreich Illyrien) gehörenden Mali Lošinj.

84 TN Scarda / Insel Škarda (südöstlich von Premuda).

85 TN Isto / Insel Ist (ostsüdöstlich von Škarda).

86 TN/ON Melada / Molat: Insel und gleichnamiger Ort südöstlich von Ist.

87 TN Isola grossa / Insel Dugi otok.

88 TN Isola incoronata / Insel (Veliki) Kornat.

89 TN/ON Selvo (andere zeitgenössische Schreibung: Selve) / Silba: Insel und gleichnamiger Ort östlich von Premuda (von dieser getrennt durch den Silbanski kanal).

90 TN/ON Ulbo / Olib: Insel und gleichnamiger Ort östlich von Silba.

91 TN/ON Uglian / die Zadar gegenüber gelegene langgezogene Insel Ugljan.

92 TN Passman / Pašman: Insel und gleichnamiger Ort westlich des festländischen Biograd na Moru.

93 TN/ON Lissa / Vis: küstenferne Insel und gleichnamiger Ort gut zwanzig Kilometer westsüdwestlich der Westspitze von Hvar.

94 TN Solta / Insel Šolta: die nordwestlichste unter den größeren dieser zentraldalmatinischen Inseln, südwestlich von Split.

95 TN Brazza / Brač: die größte mitteldalmatinische Insel südsüdöstlich von Split.

96 TN/ON Lesina / Hvar: Insel mit dem gleichnamigen Hauptort.

97 TN/ON Curzola / Korčula: Insel und gleichnamiger Ort im NNW von Dubrovnik, bis 1797 venezianisch-dalmatinisch, zur Zeit des Berichts zum Kreis Dubrovnik gehörend.

98 TN/ON Lagosta / Lastovo: Insel mit gleichnamigem Hauptort gut 10 Kilometer südlich von Korčula (ehemals zur Republik Ragusa).

99 TN Meleda / Insel Mljet (Kreis und ehemalige Republik Dubrovnik). 
Inseln: Giuppana ${ }^{100}$, Isola di mezzo ${ }^{101}$ und Calamotta ${ }^{102}$, den Seefahrer bis in den Hafen von Gravosa ${ }^{103}$ leiten; und auf solche Art sichert dieser Archipelag den südlichen Theil der Küste so, daß durch diese beiden Archipelage die Handelsverbindung zu Meer mit Istrien, dem ungarischen Litorale ${ }^{104}$ und ganz Dalmazien, selbst wenn feindliche Flotten im Golfo ${ }^{105}$ wären, ohne große Schwierigkeit erhalten werden kann.

$\$ 29$ [Viele Häfen] Es wird vielleicht kein Küstenland [Qu 8/3] geben, welches so viele und so sichere Häfen, und außer diesen eine so große Anzahl von solchen guten Ankerplätzen hätte, als Dalmatien in Vereinigung mit seinen Inseln wirklich hat; und weil sich das neapolitanische und päpstliche, uns gegenüber stehende, Gestade in einem ganz entgegen gesezten Falle befindet; so suchen auch alle Schiffe, die aus dem mittelländischen Meere in das adriatische, oder aus diesem in jenes segeln, ihren Zufluchtsort an den dalmatinischen Küsten.

Dieser günstige Umstand bringt auch mittelbar dem Lande, wegen Absatz der Victualien $^{106}$ vielen Nutzen und weil bei dieser Gelegenheit meistens Handelsoperationen geschehen, so gewinnt auch das allerhöchste Aerarium ${ }^{107}$ dadurch.

Seitdem Euere Majestät dem Lande einen gut construirten [Qu 8 / 4] Cavafango ${ }^{108}$ mit der nöthigen Bemannung allergnädigst bewilligt haben, wird auch auf die Reinigung dieser Häfen mit Nachdruck gesehen.

Zum Beweis unterfange ich mich in tiefster Ehrfurcht anzuführen: daß ich bei meiner ersten Bereisung im Jahre 1832 den Hafen von Spalato ${ }^{109}$ so verschlammt gefunden habe, daß ich mit einer Galette nicht einfahren, sondern weit draußen auf der Rhede Anker werfen mußte.

Anno 1833 überzeugte ich mich dagegen von der zweckmäßigen und erfolgreichen Verwendung dieses Reinigungs-Aparats, denn es war bereits ein gutes Stück Arbeit vollendet, und ein Theil des Hafens gereiniget.

100 TN Giuppana / Insel Šipan.

101 TN Isola di mezzo / Insel Lopud (als eine von drei größeren küstennahen Inseln nordwestlich von Dubrovnik gelegen zwischen Šipan und Koločep, daher der italienische Name).

102 TN Calamotta / Insel Koločep, mit gleichnamigem Ort.

103 ON Gravosa / Gruž: Ortschaft und Hafen nahe nördlich von Dubrovnik, heute zum Stadtgebiet gehörig.

104 Zeitgenössisch auch »ungarisches Küstenland«; gemeint ist das der direkten ungarischen Herrschaft unterstellte Gebiet von Fiume / Rijeka und südlich davon bis Bakar.

105 Anderes Wort für die Adria.

106 Veraltet für »Lebensmittel« (vgl. noch den heutigen »Viktualienmarkt« in München).

107 Heute veralteter Austriazismus für Finanzverwaltung/öffentliche Kassen.

108 Ein »Sandschiff« zum Aushub der Hafenbecken bzw. -zufahrten.

109 ON Spalato / Split. 
[Qu 9 / 1]

Gebirge

$\$ 30$ [Richtungen der Gebirge und Gebirgszüge im engeren Dalmatien] Dalmatien wird überall und nach allen Richtungen von Bergen durchschnitten, zwischen welchen vier Haupt- und andere Flüße, mehrere Bäche; Seen und Moräste, aber auch viel schöne Thäler und Ebenen, liegen.

Unter die vorzüglichsten Gebirge, von welchen ich einige bereits bei der Gränzbeschreibung angeführt habe, gehört der Velebich / Alpes bebiae ${ }^{110} /$ welcher die Gränze mit Militair-Croatien bildet; Koinska glava am Triplex-Confinium mit Bosnien und Milit. Croatien, von welchem ich ganz Dalmatien übersehen habe; das Gränzgebirg Pro$\log \mathrm{k}^{111}$, welches sich über Imoschi erstreckt; der Berg Promina ${ }^{112}$ der zwischen Knin ${ }^{113}$ und Dernis ${ }^{114}$ liegt, und einen ungeheueren Reichthum an Steinkohlen, die bis an die Oberläufe reichen, und nach Versicherung der Sachverständigen auch andere nützliche Minerale in sich faßt; die Monti tartari ${ }^{115}$; welche von Sebenico ${ }^{116}$ gegen Spalato laufen und wo der stärkste Wein den ich je getrunken habe und [Qu 9/2] welcher dem Madera [Madeira] sehr ähnlich ist, wächst; der Berg Sfilaja ${ }^{117}$, welcher zwischen Derniš und Sign ${ }^{118}$

110 Antike bzw. antikisierende Bezeichnung für das Velebitgebirge; vgl. (gefunden über Google Books) die Verwendung und Positionsbestimmung bei Visiani, Roberto de: Stirpium dalmaticarum specimen. Patavii [Padua] 1826, Einleitung Seite V in seiner Bestimmung der dalmatinischen Grenzen, und dort Anm. 6: Alpes Bebiae: »Nunc Vellebich, Montagna della Morlacca«. Ebd. Seite VI auch ein Beleg für die alpes dinaricae.

111 TN Prologk / Prolog bei Imotski (vgl. oben, Anm. 38).

112 TN Promina / Promina, Gebirgszug bei Drniš.

113 ON Knin / Knin.

114 ON Derniš (ein seltener Fall des Sonderzeichens »š« in Ortsnamen in diesem Text; dort aber auch Schreibung als Dernis) / Drniš: größeres Dorf im Binnenland im SO von Zadar.

115 TN Monti tartari / Trtar: Kuppe bzw. Hügelkette ca. $5 \mathrm{~km}$ nordöstlich von Šibenik. Petter nennt den kartographisch schon früh belegten Namen als wahrscheinlich auf die 1248 bis Dalmatien vorgestoßenen Mongolen (Tataren) zurückzuführen, die sich über diesen Höhenzug zurückgezogen hätten, und gibt den kroatischen Namen Tartarska gora an: Petter: Dalmatien, Bd. 2, 28. Die Bezeichnung hat sich im Weiteren offenbar auf nur die eine Bergkuppe verengt; bereits auf dem entsprechenden Blatt der Zentralkarte von Mitteleuropa ist nur mehr der eine Monte Tartaro verzeichnet (vgl. http://lazarus.elte.hu/hun/digkonyv/ topo/200e/34-44.jpg; 24.7.2014).

116 ON Sebenico / Šibenik.

117 TN Sfilaja / Gebirgszug Svilaja von ca. 30 km Länge zwischen Sinj und Petrovo polje, bis $1508 \mathrm{~m}$.

118 ON Sign / Sinj. 
liegt; der Mossor ${ }^{119}$ / Mons aureus ${ }^{120}$ der Alten / welcher sich zwischen Trigl ${ }^{121}$, Clissa ${ }^{122}$ und Almissa ${ }^{123}$ ausbreitet; der Berg Dinara ${ }^{124}$, welcher ohnweit Duare ${ }^{125}$ am linken Cettina ${ }^{126}$-Ufer steht; und der Berg Biocovo ${ }^{127}$, welcher von Macarsca ${ }^{128}$ gegen die Narenta sich erstreckt und dessen Abhänge so viel nur immer möglich terrassenartig zugerichtet; mit Wein, Oliven, Feigen und Mandeln; vieler Orten auch mit Getreide bebaut, und eine herrliche Augenweide für die Vorübersegelnden sind.

An dem linken Narenta-Ufer an der türkischen Erdzunge Klek, ist der bedeutende Berg Xaba ${ }^{129}$ unter welchem das dalmatinische Dorf Metcovich steht.

$\$ 31$ [Sniexnizza im Ragusäischen und im Kreis Cattaro] Die Gebirge im Ragusanischen und im Kreise von Cattaro scheiteln meistens über die dalmatinische Gränzlinie. Der bedeutendste Berg im Ragusaischen ist der Sniexnizza ${ }^{130}$. In oesterreichisch Albanien ist der Berg Sella ${ }^{131}$ bei Cattaro, der Berg Goliš ${ }^{132}$ [mit Sonderzeichen im Ori-

119 TN Mossor / Mosor, Gebirgszug nahe der Küste zwischen Split und Omiš, bis 1339 m.

120 In der Antike in römischen Gebieten relativ weit verstreuter Bergname; hier unter Rückgriff auf die »Alten« (der Antike) eine entweder echt antike oder vielleicht auch nur antikisierende Bezeichnung für den Berg Mosor.

121 ON Trigl / Trilj (Ort ca. 10 km südöstlich von Sinj).

122 ON Clissa / Ort bzw. Festung Klis.

123 ON Almissa / Omiš.

124 TN Dinara / Dinara: Bergkette längs dem Meer östlich von Omiš; wegen der Verortung nahe dem Dorf Duare / Zadvarje meint Lilienberg damit vermutlich nicht die heutige Omiška dinara, sondern den östlich daran anschließenden Höhenzug der Rogoznica (788 m).

125 ON Duare / Zadvarje.

126 TN Cettina / Cetina: Fluss, mit der Quelle ca. $30 \mathrm{~km}$ nordnordwestlich von Sinj zwischen den Gebirgszügen des Kozjak und der Dinara, Mündung bei Omiš.

127 TN Biocovo / Biokovo: Gebirgszug oberhalb des Makarsko primorje, bis $1762 \mathrm{~m}$.

128 ON Macarsca / Makarska.

129 TN Xaba / Žaba: Gebirgszug südlich von Metković, teils auf dalmatinischem, teils auf herzegowinischem Gebiet (dort maximal bis $954 \mathrm{~m}$ ).

130 TN Sniexnizza / Snježnica: Berg nördlich der Konvavle, bis 1234 m.

131 TN Sella / Monte Sella war ein Synonym zum zwischen Kotor und dem montenegrinischen Cetinje gelegenen Gebirge Lovchien (Lovćen, bis 1749 m) oberhalb von Kotor: vgl. Petter: Dalmatien, Bd. 2, 249. Die höheren Gipfel inclusive des »Sella «lagen seinerzeit sämtlich klar auf montenegrinischem Gebiet, vgl. die Karte des Kreises Cattaro aus Petter 1841 in Kozličić / Bralić, 335.

132 TN Goliš / an anderer Stelle auch Golis / Berg Goliš (1046 m) im Gebiet von Grbalj; vielleicht aber bei Lilienberg auch weiter als heute gefasst und unter Einschluss benachbarter höherer Gipfel (etwa dem Grabov Pod, 1452 m, und Koložun, 1474 m). 
ginal] [Qu 9/3] bei Xuppa ${ }^{133}$, der Berg Vottergnak ${ }^{134}$ bei Braichi und Treploghi ${ }^{135}$ an der Gränze von Scuttari.

Auch die meisten Inseln sind sehr gebirgig; wegen der Höhe zeichnen sich besonders die Berge auf den Inseln Arbe, Uglian, Lissa, Lesina, Brazza, Curzola und Lagosta aus.

$\$ 32$ [Naktheit der Berge] Was mir bei der Bereisung sehr empfindlich kam ${ }^{136}$, war die $\mathrm{Na}[\mathrm{c}] \mathrm{ktheit}$ der Felsen aus denen diese Berge meistens bestehen, da man die Wälder, welche dem Lande in mancher Hinsicht zum großen Vortheil und diesen Gebirgen zur Zierde dienten, ausgehauen, und so den Regengüssen und den hier herrschenden sehr starken Winden die Wegschleppung der Erde erleichtert hat ${ }^{137}$.

Wie ich jedoch von mehreren bejahrten Einwohnern versichert und auch durch einige glaubwürdige Schriften belehrt worden bin, geschah diese Verwüstung nicht ganz aus Uibermuth oder Unwirthschaft, sondern auch aus dem Grunde weil die Türken durch diese Wälder begünstigt sich leichter bis an das Meergestade ungestraft einschleichen und das [Qu 9/4] Land mit Raub und Flammen verheeren konnten; man glaubte demnach durch diese Lichtung der Wälder die Einbrüche und Räubereien wenigstens um vieles zu erschweren, und vergaß ganz auf die Erhaltung des Forstwesens ${ }^{138}$, weil das Hauswesen dem Kopfe und Herzen viel näher lag.

Um eine Uibersicht der genannten Gebirge auf dem festen Lande Eurer Majestät zu verschaffen, unterfange ich mich eine kleine orographische Karte, die ich eigens, so gut als möglich war, zusammen setzen ließ, in tiefster Ehrfurcht unter der Z. $\mathrm{N}^{\circ}=11^{139}$ vorzulegen.

133 TN (Boka kotorska) Xuppa / Talschaft Župa mit den Teilgebieten Gornja župa östlich von Tivat, und südlich davon Donja župa (oder Grbaljska župa, die Gegend von Grbalj),

134 TN Vottergnak: ein nicht näher eruierbarer Gipfel im Gebirgszug nördlich von Budva (dieser mit der höchsten Höhe von 1147 m auf der damaligen Grenze zu Montenegro, laut Generalkarte von Mitteleuropa, Blatt http://lazarus.elte.hu/hun/digkonyv/topo/200e/37-42.jpg; 25.7.2014).

135 TN Treploghi: Berggipfel zu lokalisieren an der damaligen k. k. Grenze zum osmanischen Paschalik Shkodra, evtl. identisch mit dem auf der Generalkarte von Mitteleuropa (wie eben) als höchster dortiger Gipfel verzeichnete Megjed (992 m).

$136 \mathrm{Zu}$ verstehen als: sehr negativ beeindrucken.

137 Ein Beispiel für eine am mitteleuropäischen Landschaftsbild orientierte Umweltwahrnehmung durch Lilienberg, infolge derer ihm die felsige Karstlandschaft abweisend und öd erschienen sein dürfte.

138 Vgl. zum Stand desselben zur Zeit von Lilienberg weiter unten, $₫ 79$ und auch $₫ 180$.

139 Spätere Randeinfügung. Siehe Karte 5, hier im Anhang Seite 297, bzw. Beilage XI, Reinschrift, fol. 112 / Scan 226.

DigiOst 1 | 70 
[Qu 10 / 1]

Flüsse

$\S 33$ [Im Allgemeinen] Zum Uiberblick dieser, der Seeen und der Moräste habe ich eine hydrographische Karte thunlichst verlässlich entwerfen lassen, und schließe diese hier in tiefster Ehrfurcht unter der Zahl 12 bei $^{140}$.

Die bedeutendsten Flüsse Dalmatiens sind: der Zermagna ${ }^{141}$, Kerka ${ }^{142}$, Cettina und Narenta.

Außer diesen gibt es noch mehrere kleine Flüsse, Bäche und Torrente ${ }^{143}$; ich unterfange mich aber blos derjenigen zu erwähnen, die eine Bedeutenheit in einer oder der anderen Hinsicht erhalten haben; und diese sind folgende:

Der Fluß Verlika ${ }^{144}$, welcher auf den Fluren bei Imocki entspringt und sehr oft jene Gegend überschwemmt; von welchem Gegenstande ich jedoch bei dem See von Sign handeln werde.

Der Torrente Cicola ${ }^{145}$, der in früheren Zeiten viele Uiberschwemmungen und Schaden in dem fruchtbaren Thale Petrovopoglie ${ }^{146}$ bei Dernis verursacht hat, seit 1816 aber durch EurerMajestät allergnädigste Spenden ${ }^{147}$ unschädlich gemacht worden ist.

Der Salona $^{148}$ bei Spalato, welcher [Qu 10 / 2] viele Mahl- und Walkmühlen, und seit einem Jahre auch ein Kupferdrukerwerk ${ }^{149}$ in Bewegung setzt; beim starken Regen aber öfters vor seiner Einmündung ins Meer vielen Schlamm absetzt und einige Moräste verursacht, die jedoch, wie ich dafür halte, ohne großen Aufwand werden gehoben werden können.

140 Siehe Karte 6, hier im Anhang Seite 298, bzw. Beilage XII, Reinschrift, fol. 113 / Scan 228.

141 TN Zermagna / Zrmanja: Fluss, Quelle ca. $10 \mathrm{~km}$ nordwestlich von Knin (knapp jenseits der damaligen Grenze zwischen Dalmatien und der Lika in der kroatischen Militärgrenze; Mündung unterhalb von Obrovac in das Novigradsko more.

142 TN Kerka / Krka; Fluss, Quelle ca. 3,5 km nordöstlich von Knin, Mündung bei Šibenik.

143 Sporadisch wasserführende Bachläufe.

144 TN Verlika / kleiner Karstfluss Vrljika am Südrand des Imotsko polje.

145 TN Flusslauf Cicola / Čikola: Quelle am Südrand des Svilaja-Gebirges ca. $15 \mathrm{~km}$ südöstlich von Drniš, an diesem vorbeifließend und mit Mündung in die Krka; ab etwa Drniš nicht ganzjährig wasserführend.

146 TN Petrovopoglie / Petrovo polje, Talschaft bei Drniš.

147 Eine personalisierende Repräsentation der staatlichen Investitionspraxis als herrschaftliches kaiserliches Agieren in der Provinz, wodurch der Monarch als gleichsam persönlich spendengebender Landesvater figuriert. Zur Semantik des »Spendenbegriffs« für Ausgaben, die eigentlich aus dem Ärar und keineswegs aus der Privatschatulle des Monarchen kamen, vgl. auch in $₫ 35$, Anm. 272 zu $\$ 53$ und am Ende von $\$ 124$ (dort: für die Provinz ‘gespendete kaiserliche Wohltaten $)$.

148 TN Salona: Fluss bzw. Bach Jadro, der durch den Ort Salona (Solin) fließt.

149 In $\$ 118$ bezeichnet Lilienberg dieses Werk dann als Eisendruckwerk und geht näher auf es ein. 
Der Omblay ${ }^{150}$ im Ragusäischen, welcher gleich bey seiner Entstehung viele Mühlen treibt, einen sehr kurzen Lauf hat, bei dem Porto Gravosa ${ }^{151}$ sich ins Meer ergießt und mehr einer Bucht als einem Fluße gleicht.

Der Torrente Opacizza ${ }^{152}$ und Gliuta ${ }^{153}$, so die schöne und fruch $[t]$ bare Gegend bei Canali ${ }^{154}$ oft überschwemmen und vielen Schaden anrichten, worüber ich jedoch bei der Beschreibung der Thäler das Nähere allerunterthänigst anführen werde.

Endlich die Fiumera ${ }^{155}$ bei Cattaro, welche als sie kaum unter den hohen Felsen kräftig hervorgebrochen, sich auch gleich ins Meer stürzt.

Die vielen hier nicht genannten Wässer [Qu 10 / 3] werden erst dann eine Wichtigkeit, der sie vieler Orten fähig sind, erhalten, wenn sich die National-Industrie etwas gehoben, der Landwirth solche zur Irrigation und der Spekulant zu wohlgeordneten Fabriken und anderen Treibwerken zu benutzen gelernt haben wird ${ }^{156}$.

Die Irrigation, welche hier mit außerordentlichem Nutzen, weil uns die Dürre sehr oft straft, angewendet werden könnte, werde ich bemühet seyn, sobald die von E.M. allergnädigst bewilligte Anpflanzung der Maulbeerbäume ${ }^{157}$, Erzeugung der Seide und die Spinnereyen ein wenig in Gang kommen werden, auf eine schickliche Art in Anregung zu bringen.

Die Verbesserung oder Erbauung neuer wichtigerer Treibwerke muß man der Zeit und der Spekulazion der Privaten überlassen.

150 TN Omblay / spätere Form im Text Ombla: Fluss bzw. Flüsslein Ombla nahe Dubrovnik (auch: Rijeka dubrovačka).

151 ON Porto Gravosa, andere Form für Gravosa / Gruž.

152 TN torrente Opacizza / Opačica: temporärer Bachlauf im Gebiet von Konavle.

153 TN torrente Gliuta / Ljuta: Name einer Quelle, eines heftig daraus entfließenden Bachlaufs und einer kleinen Ortschaft im Gebiet von Konavle. Vgl. die umweltgeschichtlich interessante Mikrostudie von Kapetanić: Mlinovi na Rijeci ljutoj u Konavlima, die außer mit moderner Bildkartographie auch mit den vormärzlichen Katastermaterialien arbeitet.

154 TN Canali / Konavle: Landschaft auf Dubrovniker Gebiet zwischen Cavtat (Ragusavecchia) und Sutorina.

155 TN Fiumera: Bachlauf im Stadtgebiet von Kotor. Der Bach ist offenkundig identisch mit dem von Petter: Dalmatien, Bd. 2, 250, genannten Bach Scurda, der gleich vor dem nördlich gelegenen Stadttor Porta Fiumera aus dem Fuße des nackten Berges hervorquelle und dafür sorgte, dass die Stadt sommers keinen Wassermangel litt.

156 Ein Ausdruck von Lilienbergs vorwiegend rational-aufgeklärtem Umwelt- und Naturbild, in welchem der Wert der Natur in der Regel (aber nicht immer, vgl. abweichend etwa bald darauf zu den Krka-Fällen in $₫ 35$ und zur Wahrnehmung der Bucht von Kotor in $₫ 59$ ) wie hier eng verknüpft mit Nützlichkeitsdenken erschien. Schön (etwa Täler, Waldungen) sind demnach die von menschlicher Hand gestalteten und genützten Landschaften (vgl. im Register unter "Naturempfinden «).

157 Vgl. die $\$ \$ 92$ und 95 zu den betreffenden Entwicklungsprojekten der Verwaltung. 


\section{Zermagna}

$\$ 34$ Dieser Fluß entsteht in den Gebirgen Popina ${ }^{158}$ in der Licca, bricht bei Kravin brod ${ }^{159}$, wo eine steinerne Brücke dießen umfaßt, nach Dalmatien ein, fließt zwischen sehr hohen Felsen-Ufern, nimmt den Bach Grappa ${ }^{160}$ auf, tritt nur unter Obbrovazzo-vecchio ${ }^{161}$ [Qu 10 / 4] manchesmal aus, ohne jedoch Moräste zu hinterlassen, macht sonst keine bedeutende [sic] Uiberschwemmungen, gehet bey Obbrovazzo-nuovo vorüber, wo ihn eine gute Jochbrücke, die sich mit der Hauptstraße über den Vellebich verbindet, überspannt und ergießt sich dann in die See bei Novigrad ${ }^{162}$. Es hat mehrere natürliche Wehren, welche Wasserfälle bilden; treibt verschiedene Mahl- und Walkmühlen, die ebenfalls von der gemeinsten ${ }^{163}$ Construction sind; ist bis Obrovazzo mit mittleren Schiffen, mithin auch mit Trabakeln ${ }^{164}$, welche bis 2000 Metzen $^{165}$ Getreide laden, zu befahren und ist der Einzige, der dem Aerario schönen Zoll einträgt und bis auf die unbedeutende Reparatur der erwähnten zwey Brücken, nicht das Mindeste kostet.

Wenn er auch manchesmal bei Obrovazzo, wo die Schiffe anlanden und seine Ufer sehr nieder sind, ein wenig austritt, so ist es von keinem besonderen Belange und auch dieses könnten die Einwohner, welche sehr viel Geld bei dem Handel gewinnen verhüten, wenn man nicht sogar [Qu 11 / 1] mit den unbedeutendsten Verbesserungen auf das Aerarium rechnete.

\section{Kerka}

$\S 35$ Dieser Fluß kömmt am Fuße des dinarischen Hauptgebirgs in unserem Gebiete ober Knin hervor, wird gleich durch die Kerchizza ${ }^{166}$, die mit einem schönen Wasserfall ihre Vereinigung ankündet, verstärket und treibt gleich bedeutende Mühlen.

158 TN Gebirge Popina (am Südrand der Lika); vgl. die Likaner Ortschaften Velika und Mala Popina nahe Gračac.

159 ON / TN (?) Kravin brod: nicht eruierbare Bezeichnung für Ort oder Toponym am damaligen Grenzpunkt zwischen Militärkroatien und Dalmatien am Laufe der Zrmanja.

160 TN Grappa / Bach Krupa (rechter Zufluss der Zrmanja ca. $10 \mathrm{~km}$ östlich von Obrovac).

161 ON Obrovazzo-vecchio / als Teil von Obrovac: die Unterscheidung zwischen Obrovazzo vecchio und dem nachstehenden O. nuovo konnte nicht geklärt werden. Eventuell bezeichnete O. vecchio die im 17. Jh. zerstörte Festung O., direkt bei der Stadt O.

162 ON Novigrad / Novigrad: Ortschaft am südwestlichen Ufer der Buch der Meeresbucht Novigradsko more.

163 Im Sinne von: schlechtesten, primitivsten.

164 Eine traditionelle, für Dalmatien spezifische Form von kleinen Zweimastsegelschiffen.

165 Die Angaben mit dieser alten Maßeinheit sind hier zu verstehen als Angaben in Wiener Metzen; ein solcher Metzen hatte in der 1777 vorgenommenen Norm einen Inhalt von 61487 Litern.

166 TN Bach (Wildbach) Kerchizza / Krčić, der unterhalb des Berges Dinara auf dalmatinischem Gebiet entspringt und bei Knin in die Krka mündet. 
Bei Knin, wo sich die Bäche Radiglievaz ${ }^{167}$ und Butishnizza ${ }^{168}$ mit diesem Fluße vereinigen, verursachet er mehrere Sümpfe.

Von Knin angefangen fließt er zwischen hohen Bergen, welche bald enger, bald weiter von einander stehen; nimmt in seinem Laufe verschiedene Läufe auf, wird aber in diesen durch 9 natürliche Felsendämme gehindert und zu Wasserfällen von 20-80 Fuß ${ }^{169}$ Tiefe gezwungen, wodurch bei starken Regengüssen große Uiberschwemmungen verursacht und Moräste gebildet werden.

Der lezte Wasserfall, der diesen Fluß bei Scardona ${ }^{170}$ macht, ist einer der [Qu 11 / 2] schönsten, die man sehen kann. ${ }^{171}$

Dort vermischt sich dieser schon mit gesalzenem Wasser, gehet durch den See Proclian ${ }^{172}$, wo der Torrente Cicola zu ihm stoßt, mündet in den Hafen von Sebenico ein, um sich dann durch den engen Canal von Sant'Antonio ${ }^{173}$, bei dem in jeder Hinsicht merkwürdigen ${ }^{174}$ Dorf St. Nicolò ${ }^{175}$ in den Golfo zu ergießen.

Uiber diesen Fluß gehet eine Brücke halb von Holz, halb vom Stein gebaut, bei Knin, so die Comunication mit Militair-Croatien auf dem alten Weg sichert, dann eine von Stein bei Topoglie ${ }^{176}$ welche vollkommen für Wägen brauchbar ist; und eine steinerne Brücke bei Roncislapp ${ }^{177}$, welche zur Verbindung der wichtigsten Militair-Strasse durch das In-

167 TN Radiglievaz / später auch Radiglievac geschrieben / Radljevac: Bach nahe Golubić (Ort ca. $5 \mathrm{~km}$ nördlich von Knin), verläuft weithin nahe westlich zum nachstehenden Bach.

168 TN Butishnizza / später auch in der Schreibung Butischnizza / Butišnica: größerer Bach im Tallauf nördlich von Knin.

169 Ein Fuß (enthielt zwölf Zoll à umgerechnet rund 2,63 cm) entspricht gerundet 31,61 cm.

170 ON Scardona / Skradin.

171 Die Krka-Fälle, insbesondere ihr unterster, gelten hier Lilienberg also wie uns Heutigen als besondere Schönheiten der Natur. Dem tat bei Lilienberg trotz allem sonstigen Rationalismus keinen Abbruch, dass wie zuvor durch ihn festgehalten die Engstellen im Flusslauf bei starkem Regen große Überschwemmungsschäden hervorrufen konnten.

172 TN Proclian (andere zeitgenössische deutsche Schreibung auch Proklian) / Prokljansko jezero: Brackwasser führende und mit dem Meer verbundene seeartige Verbreiterung der Krka unterhalb von Skradin.

173 TN und ON Sant'Antonio / Zaton.

$174 \mathrm{Zu}$ verstehen als: »bemerkenswerten«.

175 ON San Nicolò / (Tvrđava) Sv. Nikole. Trotz der Wortwahl »Dorf « meint Lilienberg vermutlich die Festungsinsel in der Mündungsbucht der Krka gegenüber von Šibenik.

176 ON Topoglie / Topolje: Ortschaft nahe Kovačić unweit oberhalb von Knin, mit dem Wasserfall des Topoljski buk, wo nahe der besagten Brücke die Wasser des kleinen Flusses Krčić $22 \mathrm{~m}$ fallen. Lilienberg begreift den Krčić (wörtlich: die kleine Krka) hier offenbar als den Oberlauf der Krka. Den gleichen Begriff hat Petter: Dalmatien, Bd. 1, 38, der ebenfalls von der Brücke über die Krka bei Topolje spricht (als zu seiner späteren Zeit einer von dann schon drei Brücken längs dem Flussverlauf).

177 ON und TN Roncislapp / im Text auch in alternativer Schreibung Roncislapo / Roški Slap: Ansiedlung und hoher Wasserfall an der Krka, im heutigen Krka-Nationalpark. 
nere ${ }^{178}$ von der Festung Zara über Benkovacz ${ }^{179}$, Derniš, Much ${ }^{180}$ und Clissa dienen soll, wenn diese Strasse nicht ganz zu Stand kommen wird. Diese Brücke ist jedoch nach der alttürckischen Art bloß zum Reiten; bei ihrer Solidilisation könnte sie leicht für Wägen erweitert werden. Annebst ist eine Uiberfuhr bei Scardona, bis wohin man auch mit Pieleghi ${ }^{181}$ und Trabakeln wohlbefrachtet segeln kann.

Gleich von der Entstehung angefangen bis zu dem beträchtlichsten Wasserfall von Scardona, bewegt dieser Fluß viele Mahl- und Walkmühlen ${ }^{182}$, [Qu 11 /3] alle von der ordinärsten Art. Ich habe dort Ruinen von Eisenhämmern und Sägemühlen getroffen, welche durch die Einstellung der Caravanen ${ }^{183}$ und daraus erfolgte Verarmung der dortigen Einwohner zu Grunde gegangen sind.

Zweimal habe ich den Lauf dieses Flusses besichtiget, und jedes Mal mit sehr gerührtem Herzen das Glück mit jenen Bewohnern gefühlt, welches ihnen durch die allerhöchste Gnade E. M. bereits zu Theil geworden ist; weil sie vieler Orten von der Uiberschwemmung und von dem Schaden, welchen dieser Fluß der Landwirthschaft und der Gesundheit der Menschen zufügt, befreyt wurden; und wenn E. M. allergnädigste Spenden nicht versiegen und die Arbeiten immer zweckmäßig geschehen werden; wie es im Allgemeinen bis nun der Fall ist, so wird die Gegend von Knin eine der fruchtbarsten werden können.

Es ist mir aber leid zugleich [Qu 11 / 4] allerunterthänigst bemerken zu müssen, daß sich dieser Fluß in einem ganz entgegengesetzten Verhältniße mit dem Vorhergehenden befinde, da die Zermagna nie, die Kerka aber immer dem allerhöchsten Aerario Unkösten verursachen wird, wenn man mit dem Laufe der Zeit nicht größtentheils das alte Uibel wieder herbeiführen will.

Ich habe sowohl bei Beurtheilung dieses Flußes, als bei jener der übrigen Wasserobjekte, von welchen ich in aller Unterthänigkeit in technischer Rücksicht sprechen werde, den sehr geschikten und auch in diesem Fache erfahrenen Adjunkten ${ }^{184}$ der hiesigen

$178 \mathrm{Zu}$ verstehen als: das Landesinnere / das Binnenland.

179 ON Bencovaz (neben der hiesigen Form Bencovacz) / Benkovac.

180 ON Much / Muć.

181 Pielego (auch pièlego), Plural pieleghi: ein für die mittlere und nördliche Adria typischer zweimastiger Segelbootstyp, ähnlich einer kleineren Variante des Trabakels.

182 Mahlmühlen sind die noch heute bekannten Mühlen zum Mahlen von Getreide; Walkmühlen dienten der Verarbeitung und Verdichtung von Tuch, das zu diesem Zweck mechanisch gewalkt wurde.

183 Vergleiche zu dem für Lilienberg zentralen Thema der Karawanen und ihrer von ihm erhofften Wiederzulassung weiter unten die $\$ \$ 70,119,120,124,127$ und im Lilienbergschen Schlussabschnitt.

184 Almanacco 1834, 88: Aggiunto della Direzione delle pubbliche costruzioni Valentino Presani, dottore nella facoltà matematica, achitetto, socio onorario della accademia delle belle arti in Venezia, socio corrispondente dell'Ateneo di Treviso, e membro dell'accademia agraria di Udine. 
K. K. Baudirektion mit mir gehabt und zu Rathe gezogen und wir haben uns leider durch mehrere Merkmale vollkommen überzeugt, daß der Bach Butishnizza und Radiglievac, welche sich mit dem Kerka vereinigen, sehr viel Kalk, Sand und solchen Schlamm mitführen, der sich dann in Verbindung mit dem Wasser dieses Flußes sehr geschwind coagulirt und zum festen Tufstein wird, welcher auch auf der [Qu 12 / 1] Luft nicht verwittert.

Einen noch sprechenderen Beweis für diese Behauptung erhielt ich im vorigen Jahr, als ich diesen Fluß zum zweitenmale aus dem Grunde besichtigte, weil man den Rinnsal bei Babodol ${ }^{185}$ durch Aussprengungen eben vertiefet hatte. Bei dieser Gelegenheit fand man in den Tufsteinfelsen mehr als 15 Fuß tief, in den zersprengten Steinpflöcken römische Münzen, verschiedene Ornamente, Bruchstücke von Inscriptionen, Stücke gefärbten Glases und verschiedene andere kleine Geräthe aus der Zeit des Verfalles der schönen Künste, die ich selbst dort gesehen habe.

Dieser bedenkliche Formations-Prozeß wird sich leider unfehlbar immer reproduciren, und es dürfte nichts erfunden werden, das zur gänzlichen Vorbeugung dieses Uibels angewendet werden könnte, ohne von Zeit zu Zeit die Aussprengung zu wiederholen, wenn man diese Gegend nicht aufs neue ganz verschlämmt und verpestet sehen will.

[Qu 12 / 2]

\section{Cettina}

$\$ 36$ Dieser Fluß, soll nach Meinung aller dortigen Bewohner aus den Gewässern, welche sich im türkischen Gebiete in der Gegend von Livno ${ }^{186}$ sammeln, und durch unterirdische Gänge gegen unsere Gränze fortlaufen, entstehen. Dieses schließt man aus dem starken Geräusche, welches in der beträchtlichen Grotte ${ }^{187}$ ober Verlika ${ }^{188}$ gehört wird.

Er kömmt am Fuße des Bergs Glinat ${ }^{189}$ bei Verlika durch mehrere Quellen, die bedeutend sind, hervor und bildet gleich einen sehr tiefen See ${ }^{190}$.

Der Lauf dieses Flußes ist Anfangs sehr gemächlich und die Ufer bis zu dem Ort Trigl ${ }^{191}$ sehr seicht. Hier wird er aber zwischen Felsen eingeengt, muß sich Anfangs mit Anstrengung durchdrängen, von Streke zu Streke stark herabsenken, um unweit dem Orte Duare durch einen sehenswerth-schaudervollen ${ }^{192}$ und dann durch einen mindern Wasserfall bei Almissa ins Meer einzumünden.

185 ON Babodol / Bobodol: Ansiedlung ca. $12 \mathrm{~km}$ südwestlich von Knin.

186 ON Livno BiH / Livno: im damaligen Paschalik Bosnien gelegene Stadt knapp 20 km östlich der zwischenstaatlichen Grenze, etwa auf der Höhe von Sinj.

187 TN Grotte bei Vrlika / Gospodska špilja.

188 ON Verlika, eine spätere Schreibung auch Verlicca / Vrlika: Ort ca. $20 \mathrm{~km}$ südöstlich von Knin auf der Strecke Knin-Sinj.

189 TN Berg Glinat: ein Berg nahe Vrlika.

190 Gemeint ist der See an der Cetina bei Vrlika: Peručko jezero.

191 ON Trigl / Trilj: Ansiedlung ca. $10 \mathrm{~km}$ südsüdöstlich von Sinj.

192 Im Sinne der Romantik zu verstehen als »ehrfurchtsgebietend «, »beeindruckend «, nicht etwa im heutigen Sinne von »schauderhaft» (grässlich). 
Da sich sein Bett bei Trigl sehr verenget und bei dem Punkt Bersatak ${ }^{193}$ auch noch etwas höher steht, so ist es natürlich, daß dieser Fluß mehr, [Qu 12/3] aufwärts, wo die Ufer so seicht [statt zunächst Hörfehler des Schreibers: feucht] sind und ein unbedeutender Fall bestehet, austreten und in dem schönen Thale von Sign Uiberschwemmungen verursachen müssen, woraus Moräste und verpestete Luft entstanden sind. Auf diesen Gegenstand werde ich jedoch bey Beschreibung der Moräste noch zurückkommen.

Zwei Brücken führen über diesen Fluß, eine von Stein zwischen Cigliane ${ }^{194}$ und Bribarich ${ }^{195}$; und die andere mit gemauerten Säulen und hölzerner Dielung bei Blato ${ }^{196}$.

Annebst sind zwei fliegende Brücken angebracht, eine bei Han ${ }^{197}$, wo der Bazzar mit den Türken gehalten wird und der Weg über Bilibrigk ${ }^{198}$ in die Türkei geht; und die andere bei Trigl, wo die fahrbare Strasse über Sign und Vergoraz gegen die Narenta führt.

Bei Almissa, kurz vor der Einmündung des Flußes ins Meer, auf welchem Wege jezt der [Qu 12 / 4] Haupt-Briefpostkurs ${ }^{199}$ stabil eingeleitet wird, ist eine Uiberfuhr.

Alle diese Comunicationen fand ich in gutem Stande.

193 TN Bersatak: nicht eruierbares Toponym an der Cetina.

194 ON Cigliane: vermutlich der Ort Koljane südöstlich von Vrlika, vgl. (mit Brücke, Stand 2. Hälfte 19. Jahrhundert) Generalkarte von Mitteleuropa, http://lazarus.elte.hu/hun/digkonyv/ topo/200e/34-44.jpg, 23.7.2014.

195 ON Bribarich: nicht eruierbares Toponym oder ON.

196 ON Blato / Blato na Cetini: Ort am Unterlauf der Cetina, nordöstlich des Gebirgszuges Mosor.

197 ON Han / Han: Örtlichkeit (Militärposten) nordöstlich von Sinj am linken Ufer der Cetina, wo laut Petter: Dalmatien, Bd. 2, 89, bis zum 14. Oktober 1835 der Grenzmarkt abgehalten wurde, ehe er eine halbe Stunde Fußmarsch weiter bergauf verlegt wurde nach Bili brig, also näher an die Grenze (in einer weiteren halben Fußwegstunde Entfernung von dieser). Auf dem Stand von 1831 schrieb Petter (Geographische Skizze von Dalmatien, 155), der Bazar fände alle Donnerstage statt. »Ein Militär-Detachment erwartet die türkische Karawane an der Gränze, welche [...] auf der Abdachung des Berges Prologh liegt, und führt sie auf dem Bazar-Platz hin, und Abends an die Gränze zurück. Dieser Bazar ist nächst jenem von Ragusa der bedeutendste der Provinz.«Vgl. auch die zusätzliche Erwähnung seiner Bedeutung bei Lilienberg, in $₫ 58$ sowie dort Anm. 288 zum Bazar von Grab und den weiteren Grenzmärkten.

198 ON Bilibrigk / Bili Brig: grenznahes Örtlein auf der Wegstrecke Sinj - Livno; auf osmanischer Seite führte der Handelspfad über einen Bergpass über das Dinara-Gebirge (Passhöhe auf der bosnisch-herzegowinischen Seite des heutigen Verbindungsweges: $1173 \mathrm{~m}$ ).

199 Vgl. Petter: Geographische Skizze, 84 mit einer Übersicht zu der transversalen Postroute durch Dalmatien von der kroatischen Grenze bis Cattaro auf dem Stand von 1831; der Postweg bei Omiš verlief in der einen Richtung zur nächsten Station Split, in der anderen nach Makarska. Der Transport erfolgte durch Saumpferde, da der Weg für einen Wagen nicht befahrbar war. 


\section{Narenta}

$\$ 37$ Dieser Fluß entspringt auf den Höhen des Berges Sugliaga ${ }^{200}$, welcher die Herzegowina von Bosnien scheidet und einstens wieder die Gränze von Dalmatien machen dürfte. -

Nachdem dieser Fluß durch viele Schluchten gedrungen, viele andere Wässer aufgenommen, seine Richtung ganz geändert und sich bei Mostar durch eine mit äußerst hohen Pfeilern noch in Zeiten der Römer erbaute Brücke ${ }^{201}$ durchgezwängt hat, fällt er bei Metcovich in Dalmatien ein; nimmt rechts den Norino und Vratar, links den Bilivir, Misslina und Cernarica auf, theilt sich bei Fort' -Opus ${ }^{202}$ in 2 Arme und ergießt sich bald, durch viele Mündungen ins Meer, wie es aus dem [Qu 13 / 1] dießfälligem Plan $N^{\circ} 13$ hervorgeht. ${ }^{203}$

Diesen vielfältigen Ausmündungen ungeachtet, bleibt dieser Fluß vom Meere bis Metkovich mit beladenen Trabakeln fahrbar und man findet nur einige Ungelegenheit wenn man starken Holzstämmen begegnet, welche bei oftmaligen bedeutenden Anwachsen des Wassers aus den türkischen Waldungen, aus welchen auch für diesseitige Schiffswerften vieles Holz kommt, fortgeschwemmt werden.

Auf die Moräste, welche dieser Fluß bildet, werde ich später in aller Unterthänigkeit zurückkommen.

Da über diesen Fluß bei Torre di Norino ${ }^{204}$ sowohl die Poststrasse ${ }^{205}$ die am Ufer des Meeres läuft, als auch die fahrbare Straße, welche über Sign und Vergoraz gehet, zusammen trifft und die Comunication weiter durch die türkische Erdzunge Klek ins Ragusäische erhalten werden muß, bis jetzt aber nur kleine Barken zur Uiberfuhr vorhanden sind, so wird man vorzüglich dann, wenn die Unterhandlungen wegen Erlangung [Qu 13 / 2] dieser für das Land sehr wichtigen Erdzunge gelingen sollten, eine fliegende Brücke ${ }^{206}$ bei Torre di Norino errichten müssen.

200 TN Sugliaga; vgl. den Berg Mala Šuljaga westlich von Bugojno, 1229 m. Gemeint sein muss aber wohl doch ein Berg im oder insgesamt das Gebirge von Zelengora, wo die Neretva entspringt.

201 Die in der »orientalistischen « Annahme wurzelnde Vorstellung, dass derartige Bauwerke nicht von »Türken« hätten erbaut werden können und die Brücke von Mostar sei eine Römerbrücke, hielt sich bei west- und mitteleuropäischen Betrachtern, aber teilweise auch im Lande selbst noch lange, bis gegen 1900, wie zahlreiche historische Ansichtskarten in den aufgedruckten Texten belegen. Auch Petter: Geographische Skizze, 9, nennt sie »römische Brücke«.

202 ON Fort'-Opus, im weiteren Text Fort Opus / Opuzen: Ort im Mündungsbereich der Neretva.

203 Siehe Karte 7, hier im Anhang Seite 299, bzw. Beilage XIII, Reinschrift, fol. 114 / Scan 230.

204 TN bzw. Örtlichkeit Torre di Norino / Kula norinska: Turm (Kula) und Bach.

205 Die »Poststraße« war wie erwähnt nur ein Reitweg, während die fahrbare Straße weiter im Hinterland und nahe der osmanischen Grenze zur Zeit der Franzosenherrschaft aus strategischen Gründen angelegt worden und fahrbar war.

206 Eine »fliegende Brücke« ist eine besondere From von seilgeführter Flussfähre (»Gierfähre«), die seit dem 17. Jahrhundert offenbar vor allem im Bereich des Rheins und in Nord- 
Seen

\section{$\$ 38$ See auf der Insel Pago}

Dieser hat einen Flächenraum von 238 Jochen ${ }^{207}$, troknet bey sehr großer Dürre zum Theil, aber nie ganz aus. Hat einen vortrefflichen Boden, wird nach Thunlichkeit mit türkischem Waitzen ${ }^{208}$ und mit Hirse jährlich angebaut; und lohnt diese Mühe meistens vollkommen.

Da der Eigenthümer ${ }^{209}$ eben als ich diesen See besichtigte zweckmässige Kanäle nach allen Richtungen, so weit es nöthig scheint, einzuschneiden begonnen hat, so wird er noch mehr Terrain zum Anbau besitzen und in diesen Canalen den Blutegelfang beßer fördern können, wobei auch die Luft etwas minder schädlich gemacht werden wird.

\section{Der See bei Bocagnazzo $0^{210}$}

$\$ 39$ Blos über eine sanfte Anhöhe, etwa eine kleine deutsche Meile von Zara, liegt dieser See. Er hat [Qu 13 / 3] einen Flächen Inhalt ${ }^{211}$ von 700 Joch, troknet alle Jahre aus und wird großentheils mit Getraid bebaut.

Auf den ersten Blick überzeugt man sich, daß die gänzliche Abzapfung und Austrocknung dessen sehr schwierig und kostspielig werden müßte und deßwegen hat man auch daran nie gedacht, obwohl die Luft durch diesen See, wenn er im Frühjahr auszutreten begint ziemlich nachtheilig ist.

\section{See von Nadin ${ }^{212}$}

$\$ 40$ Dieser liegt zwischen Zara und Benkovaz; sein Flächeninhalt beträgt ohngefähr 800 Joch, und wird durch die kleinen Bäche, welche von der umliegenden Gegend sich in dieser Vertiefung sammeln und vorzüglich durch den Torrente Klicsevac ${ }^{213}$ im Spätherbst

deutschland verbreitet war. Aber etwa auch im ungarischen Gran (Esztergom) war zeitgleich zu Lilienbergs Bericht eine solche Gierfähre in Betrieb, deren verkehrsgeographisch wichtige Existenz und mutmaßliche Bekanntheit ihn zu der hier geäußerten Idee angeregt haben könnten; s. von Malchus: Handbuch der Militär-Geographie, Abt. 2, 510.

207 Das Joch (Tagwerk) war in Österreich wie andere vom Klafter her berechnete Maße seit 1756 rechtlich geregelt. Ein solches österreichisches Joch entsprach 1600 Quadratklaftern $=5754642 \mathrm{~m}^{2}$ (vgl. http://de.wikipedia.org/wiki/Alte_Ma\%C3\%9Fe_und_ Gewichte_\%28\%C3\%96sterreich\%29, 23.7.2014).

208 Mais, Kukuruz.

209 Gemeint ist der in $\$ 100$ zur Schafzucht namentlich genannte »Landwirt« Darchich, vgl. dazu den verknüpfenden Hinweis durch Lilienberg in $\$ 107$.

210 ON Bocagnazzo / Bokanjac: Ansiedlung im Norden von Zadar, heute zu dessen Stadtrand gehörig.

211 Orthographiegeschichtlich interessante Ausbesserung aus unvollendet gebliebener Zusammenschreibung »Flächeninh«.

212 ON Nadin / Nadin: Ansiedlung gut $10 \mathrm{~km}$ westnordwestlich von Benkovac (in Richtung Zadar).

213 TN torrente Klicsevac / jahreszeitlicher Bach Kličevac (vgl. die gleichnamige Festung). 
und Winter gebildet, und verliret sich dann durch unterirdische Abflüße und durch die Evaporation.

Auch hier ist an eine vollkommene Austroknung nicht zu denken, zudem ist der Grund und Boden zu schlecht $[Q u$ 13 / 4] und wird nur zur Weide benutzt.

\section{Der See von Vrana ${ }^{214}$}

$\$ 41$ Die Oberfläche dieses Sees beträgt bey 5215 Joch, und da dieser durch unterirdische Schlünde mit dem nahen Meer Verbindung hat; so ist sein Wasser gesalzen und Ebbe und Fluth äußern auf solches ihre vollkommene Wirkung. Das Uibrige rücksichtlich dieses Sees wird bei dem Moraste des nämlichen Namens allerunterthänigst nachgetragen werden.

Der See bei Zablacchie $e^{215}$ und Biscupie $e^{216}$

[ $\$ 42]$ Diese zwei ${ }^{217}$ Seen betragen 138 Joch u. liegen unweit Sebenico, haben Comunication mit dem Meer und dienten einst zu Salinen.

Der von Zablacchie wäre besonders hiezu geeignet, wenn man es einstens bei Entstehung eines bedeutenden Krieges mit den Seemächten ${ }^{218}$, wo die Comunication mit Sicilien gesperrt würde oder bey größerer Vermehrung der dalmatinischen Population nöthig finden sollte.

Besonders in dem lezten Falle dürfte es einst Staatsanliegen werden, das Salz, dessen sämmtliche Provinzen bedürfen, ganz in den Ländern Eurer Majestät zu erzeugen, wenn solches gleich höher [Qu 14 / 1] als das Sicilianische zu stehen kommt, um das Geld nicht in die Fremde zu schicken und um den Unterthanen den dießfälligen Erwerb und Nahrung nicht zu entziehen. ${ }^{219}$

214 ON Vrana / Vrana: Ansiedlung ca. $10 \mathrm{~km}$ südsüdwestlich von Benkovac. Der danach benannte Vransko jezero liegt in rund $2 \mathrm{~km}$ Entfernung und längs der Küste; auf der anderen Seite liegt auf der schmalen Landzunge zum Meer hin der Ort Pakoštane.

215 ON Zablacchie / Zablaće: Ansiedlung westsüdwestlich von Šibenik, auf der diesem gegenüberliegenden Halbinsel.

216 ON Biscupie / vermutlich Biskupija: die gemäß der Lilienbergschen Beschreibung unmittelbar neben Zablaće zu verortende Ansiedlung Biscupie ist demnach nicht identisch mit dem Biskupija im Hinterland zwischen Drniš und Knin, jedoch auf den mir zugänglichen aktuellen Karten nicht (mehr) aufzufinden.

217 Die beiden Seen sind offenkundig der sogenannte »Veliko jezero" (mit Insel) und westlich davon, noch näher am Meer und an Zablaće der kleinere »Malo jezero«. Welcher davon welchem alten Toponym entspricht, war für mich nicht feststellbar.

218 Gemeint müssen hier wohl sein Frankreich und Großbritannien, mit ihrer beider starken Marinepräsenz im östlichen Mittelmeer (Levante und Griechenland).

219 Lilienberg, der am Ende seiner Darstellung eine gedankliche Nähe seiner wirtschaftspolitischen Konzepte und Wünsche zum Physiokratismus selbst benennt (und diese hinsichtlich etwa der Wichtigkeit der Urproduktion und der Bevölkerung immer wieder durchscheinen 


\section{Der See von Proloxaz $z^{220}$}

$\$ 43$ Dieser See liegt in dem Thal von Imosky [sic] und wird hauptsächlich durch den Wildbach Suaja ${ }^{221}$ und andere Abflüße aus den türkischen Gebirgen gebildet. Er könnte so wie der Morast Uspor ${ }^{222}$, den ich hier auch berühre, damit ich das Nämliche was beide gleich angeht, um so mehr als sie mit einander in Verbindung stehen, nicht wiederholen müsse, zum Theile abgezapft werden. Die à la vue entworfene Skizze $\mathrm{N}^{\circ} 8$ wird auch diesen Umstand klärer darstellen.

Wenn der See Proloxaz durch vielen Zufluß, den er bey starken Regen-Güßen aus den nahen Gebirgen erhält ${ }^{223}$ überfüllt wird, entstehet der Bach Siha ${ }^{224}$, der sich mit dem Virlica ${ }^{225}$ vereiniget; da nun dieser meistens auch gleichzeitig aufschwellt und ein anderer Bach, welcher in entgegengesezter Richtung aus dem Türkischen kommt und den Morast Uspor bildet, seinen Gang hindert, er auch ohnehin nach und [Qu 14 / 2] nach sein Bett ganz verliert und sich in dem dortigen Thale ausbreitet, so muß bey überhäuftem Zufluße von dem nahen Gebirge eine sehr starke Uiberschwemmung geschehen, weil das Wasser nur nach und nach von der Erde absorbirt oder, wenn es zu hoch ist, durch einen Schlund, welcher sich in dem nahen türkischen Gebiete befindet, etwa 5 oder 6 Klafter hoch und Jama ${ }^{226}$ benannt ist, abgeführt wird, wie es der erwähnte Plan so viel möglich versinnlicht.

Hier ist keine andere Abhülfe als Gräben einzuschneiden, um dadurch bei niederer Uiberschwemmung einiges terrain geschwinder frey zu machen. Um aber der großen und sehr schädlichen Uiberschwemmung vorzubeugen, müßte mit der türkischen Behörde eine förmliche Unterhandlung eingeleitet werden, damit der Schlund Jama genannt erweitert und eigentlich die Öffnung so tief als nöthig gemacht werde. Eine schwierige Arbeit; aber die Unterhandlung wird noch schwieriger seyn; ${ }^{227}$ ich mache deßwegen den Versuch, ob es nicht leichter ginge, wenn sich der Prätor ${ }^{228}$ blos mit den jenseitigen [Qu 14 / 3] Grundbesitzern, oder Agas darüber einverstände, denn mit dem

lässt), ist wie hier an vielen Stellen in handelspolitischer Hinsicht als Anhänger von Importsubstitution und Teilautarkie zu erkennen.

220 ON und TN Proloxaz / Donji Proložac: Ansiedlung nordwestlich von Imotski; der See ist der Prološko blato.

221 TN Wildbach Suaja (nahe Imotski) / Suvaja.

222 TN Morast Uspor: Morast südöstlich von Imotski, teils auf dalmatinischem, teils auf osmanischem Gebiet.

223 Statt der zunächst gewählten süddeutschen Variante: erhaltet.

224 TN Bach Siha: verband den See von Proložac mit dem Überschwemmungsgebiet Uspor, siehe dazu und zum Uspor selbst hier im Anhang die Karte 2, Seite 294, bzw. Originalanlage VIII, Reinschrift fol. 109 /Scan 220.

225 TN Bach Virlica (in der besagten Karte 2: Verlicca) / Vrljika.

226 TN Schlund Jama: wohl der auch auf heutigen Karten erkennbare Schlund nahe dem herzegowinischen Ort Drinovci, in dem die Vrljika verschwindet.

227 Ein Ausdruck für den schwierigen Amtskontakt mit osmanischen Behördenvertretern.

228 Almanacco provinciale 1834, 97: Prätor von Imotski (Imoschi) Antonio Coron. 
Visir ${ }^{229}$ komme ich zu keinem Ende, und in diplomatischem Wege gehen die Unterhandlungen noch viel schwerer.

\section{Rastok}

$\S 44$ Dieser wohlbekannte See, welcher 500 Joch Flächeninhalt hat, liegt bei Vergoraz zwischen hohen Bergen und seine Umgebungen sind nur gegen Morgen ${ }^{230}$, wo er mit dem türkischen Rastok gränzt, eben und leider! gegen unsere Gränze etwas abhängig; so daß der Fluß Svitie ${ }^{231}$ der meistens in den Fluß Trebisat ${ }^{232}$ geflossen, durch die Gewinnsucht und Bosheit der Türken, welche einige Mühlen dort angelegt haben, leicht in diesen Kessel geleitet werden konnte.

Dieses Uibel ist groß, aber nicht die einzige Ursache an der Uiberschwemmung und dieses könnte vielleicht durch glückliche Unterhandlungen mit den Türken abgewendet werden; aber so wie ich mich bei Besichtigung dieser Gegend überzeugt zu haben glaube, halte ich dafür, daß man dennoch außer Stand sein wird, diese Gegend gänzlich von der Uiberschwemmung zu retten.

Außer diesen [sic] unangenehmen Umstand, daß der Fluß Svitie in den Käßel [Kessel] geleitet wird, befinden sich darin, $\left[Q u\right.$ 14 / 4] wie es aus dem Plan $\mathrm{N}^{\circ} 14$ ersichtlicht ist $^{233}$, mehrere Schlünde; die, welche mit A bezeichnet sind, sprudeln entweder immer oder wenigstens bey sehr nasser Witterung, Wasser aus der Erde; die mit B bezeichneten absorbiren und führen es unterirdisch, in den See Jesero, von welchem später die Rede seyn wird.

Nach dem Verhältniße, als der Zufluß mittelst der erwähnten Schlünde, durch die Anschwellung des Flußes Svetie und bei starken Regengüßen, oder beim gähen ${ }^{234}$ Schmel-

229 Gemeint sein muss wegen der Zugehörigkeit der osmanischen Seite zu der seit 1832 als Paschalik eigenständigen Herzegowina der dortige Vezir Ali Pascha Rizvanbegović. Da er selbst 1833 nahe der Grenze auf herzegowinischer Seite in großem Umfang Reisanbau mit einführte und die Gegend am Trebižat zum Teil trockenlegen ließ zur Intensivierung der Landwirtschaft (Kartoffelanbau), mag seine Weigerung zu einer Vereinbarung mit Lilienberg auch von konkreten direkten Interessenkonkurrenzen geprägt gewesen sein. Vgl. auch Anm. 239 zum Kapetan von Ljubuški, Sulejman-beg.

230 Im Sinne von »Osten«; der jahreszeitliche See lag beiderseits der Grenze in der Niederung zwischen Vrgorac (in Dalmatien) und den beiden herzegowinischen Orten Grab bzw. noch weiter östlich Ljubuški.

231 TN Flussname Svitie / etwas später im Text: Svetie (in Karte 8, hier im Anhang Seite 300 bzw. Originalanlage XIV, Reinschrift fol. 115 / Scan 232, als Fiume Svitje verzeichnet; für die Lokalisierung siehe dort: auf der herzegowinischen Seite direkt an der Grenze beginnender Bachlauf, der von dort aus in ostwestlicher Linie auf dalmatinischem Gebiet in Richtung Vrgorac bis zum Rastok floss. Auf heutigen Karten konnte ich ihn nicht ausmachen.

232 TN Flussname Trebisat / Trebižat (in der Herzegowina).

233 Siehe Karte 7 hier im Anhang, Seite 299, bzw. Beilage XIV, Reinschrift, fol. 115 / Scan 232.

$234 \mathrm{Zu}$ verstehen als »jähen« (raschen), vgl. bair. »gach«. 
zen des Schnees stärker ist, als der Abfluß, ist auch die Uiberschwemmung anhaltender und stärker.

Da sich aber die absorbirenden Schlünde öfters durch Gras, Getraid und selbst durch den Schlamm, der von den nahen Gebirgen dahin gebracht wird, mehr oder weniger; die aussprudelnden Schlünde aber nie verstopfen, so geschieht auch, daß das Wasser manchesmal viel länger stehen bleibt. So lange man demnach das Wasser, welches aus der Türkei in den Keßel kommt, nicht in den Fluß Trebisat, wo es früher geflossen seyn soll, wird [Qu 16/ 1 sic $^{235}$ ] leiten können, bleibt nichts anderes übrig, als die Schlünde, welche das Wasser absorbiren, wo es möglich ist, zu erweitern und rein zu erhalten; dann den Eigenthümern, welche nur aber zur Handanlegung nicht geneigt scheinen, zu überlaßen durch Anlegung tiefer Gräben so viel terrain und so zeitlich als möglich, vom Wasser frey zu erhalten.

Allerdings wird durch die vorgeschlagene Erweiterung der Schlünde das Wasser viel geschwinder in den nahen See Jesero ${ }^{236}$ geführt, aber, da es dieser ohnehin aufnehmen muß und kein anderes Mittel übrig bleibt; so muß man doch einem Theile eine Erleichterung zu schaffen bemühet seyn.

Der See Rastok ist jetzt fast ganz ausgetrocknet. [Am Rande: vidi foglio separato; der Text des eingefügten Einzelblattes Qu 14 1⁄2 folgt hier dementsprechend.]

[Qu 14 1/2] Hierbei glaube ich noch a[ller] u[ntertänigst] anführen zu sollen, daß im J[ahre] 1830, in der Voraussetzung, daß einige auf dem türkischen Gebiethe aufgeführte Rinnen und andere willkührliche Unternehmungen die erwähnten Überschwemmungen veranlaßten, im Einvernehmen mit dem Visir von Bosnien ${ }^{237}$ eine aus kk. österreichischen und türk. Beamten und Ingenieurs zusammengesezte Commission die Localerhebungen im türkischen Gebieth dießfalls unternahmen, daß auch der türk. Beamte die NiederreiBung mehrerer Ruinen anbefahl, die Ausführung dessen aber [von dem früheren ${ }^{238}$ ] der Capitain v. Gliubuschi ${ }^{239}$ und die dortige Bevölkerung vereitelte[n]. Hierauf wurde im

235 Auf Bogen (Quadrangel) 14 folgt ein eingefügtes, als $14 \frac{1}{2}$ gezähltes Blatt mit nur einer Seite, die inhaltlich und entsprechend einem Einfügungszeichen auf dem nachfolgenden Bogen 16, S. 1 vor dem Beginn des $₫ 45$ eingefügt worden ist. Quadrangel 15 fehlt in der Zählung.

236 Wie bei sonstigen (späteren) Entwässerungsmaßnahmen allgemein empirisch feststellbar, sah auch schon Lilienberg problematische Folgen von Trockenlegungsmaßnahmen in Gestalt beschleunigten Wasserabflusses voraus, auch wenn er diese für unumgänglich und in Kauf zu nehmen erklärte.

2371830 (also dalmatinischerseits noch unter Lilienbergs Vorgänger Tomašić) war der beteiligte bosnische Vezir Morali Ali Namik Pascha, der von 1828 bis Juni 1831 amtierte; vgl. (allerdings ohne präzise Datumsangaben) Aličić: Pokret za autonomiju Bosne, 69.

238 Die Worte »von dem früheren « sind im Konzept ausgestrichen, stattdessen »der « eingefügt.

239 Kapetan von Ljubuški war seit spätestens 1827 (und offenbar eigentlich bis zur Aufhebung der Kapetanate 1835) Sulejman-beg. Siehe Kreševljaković: Kapetanije u Bosni i Hercegovini, 255 f. Gerade dieser Kapetan hat sich laut Kreševljaković um landwirtschaftliche Verbesserungen bemüht und insbesondere den Reisanbau in das ihm unterstellte Gebiet eingeführt. Sein Widerstand gegen die dalmatinisch-bosnische Abmachung und Eingriffe in sein Ge- 
diplomatischen Wege ein dießfälliger großherrlicher Ferman ${ }^{240}$ erwirkt womit dem Visir von Bosnien die entsprechende Vollendung dieser Verhandlung aufgetragen wurde.

Im vorigen Jahr verwendete ich mich demnach abermals an jenen Visir um Abordnung einer Commission; er entschuldigte sich dießfalls, daß die in Bosnien statt gehabten früheren Unruhen ${ }^{241}$ solches bis dahin verhindert hatten, daß er jedoch bei nächster Gelegenheit das Geeignete veranlassen und mir den nöthigen Avviso zusenden werde.

Dies unterblieb aber wegen Ohnmacht der ottom[anischen] Regierung und des unsteten Zustandes in Bosnien, weshalb mir der Oberste Kanzler ${ }^{242}$ im vorigen Jahr bedeutete, die Ausführung dieser Verhandlung bis auf einen angemesseneren Zeitpunkt zu verschieben.

[Fortsetzung von $\mathrm{Qu} 16 / 1]$

\section{Der See Jesero}

$\$ 45$ Diese Gegend die etwa 3500 Joch an Flächenraume hat, ist von der Schöpfung zur öfteren starken Uiberschwemmung bestimmt, denn sie ist ganz mit Bergen umgeben von welchen sie das ganze Wasser bei starkem [Qu 16 / 2] Regen herabbekomt, und hat annebst fünf Schlünde, welche das Wasser[,] so unterirdisch aus dem nahen See Rastok geleitet wird[,] von welchem eben itzt die Erwähnung war, ausspucken und nur einen einzigen Schlund durch welchen dieses abgeführt wird.

biet muss daher andere Gründe haben als bloßen Änderungsunwillen. Die ursprüngliche Formulierung den »früheren« Kapetan betreffend geht vermutlich darauf zurück, dass Sulejman-beg sich 1831 auf die Seite von Ali Rizvanbegović gestellt hatte und 1832 daraufhin vorübergehend vor dem Machtanspruch von Husein Gradaščević auf dalmatinisches Gebiet hatte flüchten müssen. Erst nach dieser Unterbrechung und der anschließend in Sarajevo durch Kara-Mahmud Pascha erhaltenen Bestätigung in seinem Amt war er wieder förmlich Kapetan des Gebiets (vgl. a. a. O.). Die Ausbesserung Lilienbergs zeigt von daher gut an, wie die Grundlage des Berichts durch seine Aufzeichnungen (hier zu diesem Detail wohl zunächst Stand 1832 oder 1833) gelegt wurde, aber auch, wie er offenbar bis zuletzt Nachrichten berücksichtigte und Verbesserungen einbaute.

240 Erlass des Sultans.

241 Vgl. die zitierte monographische Darstellung von Aličić. Warum Lilienberg allerdings 1833 über einen Vorgang in der Herzegowina noch mit dem Vezir von Bosnien verhandelt haben sollte, bleibt unklar. Vielleicht hat das offizielle Österreich zunächst die Herauslösung der Herzegowina aus dem Vilajet Bosnien nicht zur Kenntnis genommen, oder hier ist doch der herzegownische Vezir Rizvanbegović gemeint. Bosnischer Vezir von Juli 1833 bis ca. Ende Juni 1835 war Davud Pascha (auch Bagdat Velisi Erbak Daud Pașa), zuvor vom Frühjahr 1832 bis Juni 1833 Mahmud Hamid Pascha, der mit den von ihm geführten Truppen den großen bosnischen Aufstand von 1832 niederschlug; Biščević: Bosanski namjesnici osmanskog doba, 376-380.

242 Oberster Kanzler der Hofkanzlei war von 1830 bis zu seinem Tod 1842 Anton Friedrich Graf Mittrowsky. 
Man hat einigemal, als der See wie es itzt der Fall ist ganz troken war, den Schlund bei Cernivir ${ }^{243}$ um vieles öffnen [es fehlt für den Sinn hier etwas, zum Beispiel: wollen] und verschiedene andere Versuche, wo man absorbirende und verschlämmte Schlünde vermuthete, zu ihrer Ausräumung gemacht, aber dieses war nie von einem Erfolge und meistens wurde die Arbeit durch hinzugekommene starke Regengüße ganz unterbrochen. Weil aber dermalen, nach der Anzeige des Kreisamtes dieser See ganz trocken ist, und angebaut wird, so hat die Landesstelle dieser Behörde den Auftrag ertheilt, den Ingenieur ${ }^{244}$ dahin zu senden, um die dießfälligen Verhältniße so genau als möglich [Qu 16/3] zu erheben und dann über das Ergebniß Bericht zu erstatten.

\section{Der See von Jeseratz}

$\$ 46$ Dieser See, der nach meiner Beurtheilung dermalen blos ein Morast genannt werden sollte, ist von der nämlichen Beschaffenheit wie die zwei itzt genannten, nur daß seine absorbirenden Öffnungen mehr im Verhältniß mit den wasserausspuckenden seyn müssen, weil er öfters ganz austrocknet und seine Oberfläche von 270 Joch bebaut werden kann. Hier ist durchaus, weil auch die unterirdischen Ab- und Zuflüße fast unkenntlich sind, nichts anderes zu machen, als tiefe Gräben auszuheben und den übrigen Theil desto leichter frey zu erhalten, dieses muß aber den Eigenthümern überlassen werden.

$\$ 47$ [See auf der Insel Curzola] Auf dem Weg von Porto Luca ${ }^{245}$ nach Blatta ${ }^{246}$ befindet sich auf der ersten Ebene eine mäßige Vertiefung die aber ziemlich ausgedehnt ist.

[Qu 16 / 4] Diese wird alle Jahre durch unterirdische Schlünde, die das Wasser aussprudeln und auch durch Zusammenfluß des Wassers von den nahen Bergen bald mehr, bald weniger überschwemmt, und vollkommen zum See umgestaltet, wo viele kleine Fische gefangen werden; trocknet aber auch alle Jahre früher oder später ganz aus, wo dann meistens eine sehr gute Getraid-Ernte erfolgt.

Ich war das vorige Jahr eben dort, als dieser See von Menschen wimmelte die frohlockend ihre Früchte einbrachten und einige auch gleich droschen.

243 TN Schlund von Cernivir / Ponor (jezero) Crni vir, ein tiefes Karstwasserloch am Südrand der südöstlich von Vrgorac gen Osten liegenden Niederung (ca. $7 \mathrm{~km}$ nordnordöstlich von Ploče).

244 Almanacco 1834, 95: Kreisingenieur in Split war Giovanni Lucchini, dottore nella facoltà matematica. Zu den Funktionen eines Kreisingenieurs vgl. Ćosić: Waidmannsdorfov izveštaj 1823., 209, Anm. 11.

245 ON Porto Luca / Vela Luka, Ort an der Westspitze von Korčula.

246 ON Blatta / Blato, im westlichen Inselinneren von Korčula. 
[Qu 17 / 1]

Moraeste

Morast bei Vrana

$\S 48$ Dieser Morast, welcher an den See gleichen Namens anstoßt, gehört zu dem Lehnsgute des Borelli ${ }^{247}$ und Galbiani ${ }^{248}$, entsteht aus den Gewässern, welche von den Anhöhen um Zemonico ${ }^{249}$ herabkommen und hat eine Oberfläche von 3832 Joch.

Man war der Meinung, daß dieser Morast ausgetrocknet werden könnte, wenn man den See gleichen Namens, an welchen er anstoßt, abzapfen würde.

Es wurde von den Besitzern dieses Lehngutes mit großem Aufwand ein Kanal ausgehoben, der See blieb aber in gleichem Niveau, weil, wie ich bereits allerunterthänigst anführte, solcher unterirdisch mit dem Meer in Verbindung steht, welches man durch das gesalzene Wasser und durch die Ebbe und Fluth, woran er Theil nimmt, hätte einsehen, und sich die unnöthigen Kosten ersparen sollen.

Diesem Moraste dürfte demnach auf keine andere Art, als dadurch zum Theil geholfen ${ }^{250}$ werden, daß man tiefe Canäle einschneiden und an schicklichen ${ }^{251}$ Orten so viel als möglich Bäume anpflanzen möchte, welches jedoch den Eigenthümern überlassen werden muß.

\section{Morast von Sordovan ${ }^{252}$}

$\$ 49$ Dieser liegt unter dem Dorf Peruschitz ${ }^{253}\left[\mathrm{Qu} 17\right.$ / 2] und Callerine ${ }^{254}$ unweit des Sees Nadin und entsteht aus dem Zusammenfluße verschiedener Regenbäche, welche aus dieser Vertiefung keinen unmittelbaren Ausfluß haben, sondern sich bloß unterirdisch und durch die Evaporation verlieren müssen.

Auch hier ist schwer Hilfe zu schaffen, weil man die unterirdischen Abflüße nicht so leicht auffinden und rein erhalten kann.

247 Die Ortschaft Vrana war ein Lehensgut der Familie Borelli. Der von Lilienberg Gemeinte war vielleicht schon damals Francesco Borelli (1810-1884); jedenfalls findet sich bei Dominique Reill bereits für 1837 ein Beispiel, in dem er als Familienoberhaupt figurierte: Reill: Nationalists Who Feared the Nation, 33.

248 Näheres zu diesem Galbiani war nicht herauszufinden; evtl. Graf Antonio Galbiani di Vrana.

249 ON Zemonico / Schreibung später auch Zemoniko / Zemunik nahe Zadar.

250 Im Sinne von »abgeholfen«, soll heißen: »beseitigt werden«.

251 Im Sinne von: "geeigneten«.

252 TN (Morast) Sordovan, bei Perušić.

253 ON Peruschitz / Perušić: Ansiedlung nahe (und heute ein Ortsteil von) Benkovac.

254 ON Callerine: nicht exakt eruierbar; vielleicht eine venezianische Form auf lateinischer Grundlage (Corinium), dies wäre dann die Ortschaft mit dem kroatischen Namen Karin (für den Hinweis danke ich Marko Rimac).

DigiOst 1 | 86 


\section{Morast bei Ostrovizza ${ }^{255}$}

$\$ 50$ Aus den nahen Bergen kommt der Bach Otres ${ }^{256}$ hervor, und da er sein Bett wegen der vielen Materien, die er von dem Gebirge mitbringt, ganz verschlämmt, so vergießt er sich über sein rechtes Ufer und hat eine Fläche von beiläufig 245 Joch in Sumpf verwandelt.

Der topographische Plan $\mathrm{N}^{\circ} 15$ macht dieses ersichtlich ${ }^{257}$.

Diesem Uibel dürfte am leichtesten abgeholfen werden, wenn man die Straße, welche sich bei Lissane ${ }^{258}$ theilt, gegen Xaxvich ${ }^{259}$ gehet und ohnehin sehr schlecht ist, ganz verlassen ${ }^{260}$, dagegen zu Erreichung dieser nämlichen [Qu 17/3] Comunication auf der Straße, die über das Dorf Ostrovizza gegen Knin lauft, eine Verbindung und eigentlich dort, wo es nothwendig zu werden anfängt, auf dem rechten Ufer des Torrente Otres eine Dammstraße errichten und so den Ergießungen ein Ende machen möchte.

\section{Der Morast von Morpolazza $a^{261}$}

$\$ 51$ Dieser wird durch die Gewässer, welche von den Anhöhen und Feldern von Benkovaz herabkommen, gebildet.

So lang der Kanal von Goducie ${ }^{262}$, welcher in den See von Proclian führt, und der Torrente Mutizza ${ }^{263}$ von Zeit zu Zeit hinlänglich gereiniget wurde, bestand dieser Morast, welcher die Luft stark verpestet und 1052 Joch der Cultur entzieht, nicht.

Nach meiner Uiberzeugung wird es auf die nämliche Art wieder gut gemacht werden können; da aber der hydraulischen Arbeiten zu viel in diesem Lande sind und bedeutenden Aufwand immer erfordern, auch das Bau-Direkzionspersonale zu beschränkt ist, um [Qu 17 / 4] genaue und vieler Orten nöthige Aufsicht auf einmal führen zu können, so werden die verschiedenen Regulierungen und Austroknungen der Gewässer erst nach und nach durch Eure Majestät allerhöchste Gnaden ins Werk gesetzt werden können.

255 ON Ostrovizza / Ostrovica: Ansiedlung ca. $15 \mathrm{~km}$ südsüdöstlich von Benkovac.

256 TN (Bach, torrente) Otres / Otres (auch gleichnamige Ansiedlung), nahe Ostrovica bzw. nahe dem Ort Bribir.

257 Siehe hier im Anhang Karte 9, Seite 301; bzw. Originalanlage XVa, Reinschrift fol. 116 / Scan 234.

258 ON Lissane / Lišane Ostrovičke: Ansiedlung knapp nordwestlich von Ostrovica.

259 ON Xaxvich / Žažvić: Ansiedlung ca. 2 km südlich von Bribir.

$260 \mathrm{Zu}$ verstehen als: auflassen, aufgeben.

261 TN (auch ON) Morpolazza / Ansiedlung Morpolaca, nur wenig südlich von dem gerade behandelten Bereich von Ostrovica.

262 TN (Kanal) Goducie / Goduće, auch Guduće: canyonartiger kleiner Flusslauf, dessen Einzugsgebiet knapp südlich von Benkovac beginnt und in Südostrichtung ca $25 \mathrm{~km}$ bis zum Prokljan-See (Unterlauf der Krka) verläuft.

263 TN (torrente) Mutizza / heute evtl. Mutica oder Matica, floss (oder fließt) laut Kartenanhang XVa bei Niedrigwasser direkt durch den Bereich des Morastes von Morpolaca; auf heutigen Karten nicht mehr eruiert. 


\section{$\$ 52$ Moräste von Knin}

Diese entstehen, wie ich schon allerunterthänigst bei Beschreibung der Flüße bemerkt habe, aus Ursache der vielfälltigen in dem Fluße Kerka befindlichen natürlichen Wehren und vorzüglich jener von Babodol und Zanchi-Buch ${ }^{264}$ und aus einigen Lokal-Verhältnißen, die später vorkommen.

Ich habe bei meiner zweimaligen Bereisung mit sehr gerührtem Herzen das Glück mitgefühlt, welches jenen Bewohnern durch die allerhöchsten Gnaden Eurer Majestät bereits zweckmässig ausgeführten Arbeiten an der Kerka und Austroknung von mehr als 120 [gestrichen: 90] Jochen zu Theil geworden ist, und eben in dem nämlichen Augenblick wie ich schon früher [Qu 18 / 1] Allerunterthänigst bemerkt habe, wurden an der Vertiefung des Rinnsales bei Babodol ganz den Umständen und der Kunst angemessen gearbeitet; mit welcher Arbeit auch heuer und auf's Jahr ${ }^{265}$ fortgefahren werden wird. ${ }^{266}$

Es wird durch diesen Einschnitt vieles von der Uiberschwemmung gerettet werden; aber gänzlich die Moräste bei Knin auszutrocknen, dürfte nicht so leicht werden, weil einige sehr tiefe Seen ober Knin bestehen, mit den Morästen in Verbindung sind und die Butischnizza welche sich abwärts von Knin in den Fluß Kerka hineinstürzt, wenn sie stark angeschwellt ist, auch den Lauf des Flußes hemmt und die Gegend überschwemmt werden muß.

Der Bauadjunkt Pressani ${ }^{267}$, der, wie ich schon allerunterthänigst erwähnte, auch in dieser Gegend mit mir war, ist der Meinung, daß man unter dem Örtchen Sibut ${ }^{268}$ in die Butischnizza einen Einschnitt machen und den Kanal in den Morast leiten könnte, wodurch dieser nach und nach aufgeschwemmt und vieleicht sogar die Seen mit dem [Qu 18 / 2] verschiedenen Schlamm, welchen dieser Bach führt, ausgefüllt werden dürften. Diese Arbeit erscheint mir sehr schwierig und kostspielig; und da die Kerka ohnehin immerfort wegen ihrer Reinigung dem Staate viele Unkösten verursachen und durch die Arbeiten welche itzt im Antrag sind, nach meiner Meinung sehr wesentliche

264 ON (oder TN) Zanchi-Buch (gemäß Randanmerkung am Original wohl zu korrigieren in: Tanchi-Buch, oder Canchi-Buch), nahe Knin, nicht näher bestimmbar, es sei denn, man geht von einem Hörfehler der Beteiligten aus und versteht die Angabe als Form für den an der Krka gelegenen Skradinski buk (Wasserfall bei Skradin).

265 Auf's Jahr, zu verstehen wie: bis in einem Jahr.

266 Zweifellos bewusst hat Lilienberg mit dieser und weiteren, vorgeschlagenen Trockenlegungsmaßnahmen ein Thema vertieft, bei dem er mit besonderem Interesse und besonderer Investitonsbereitschaft des Kaisers rechnen konnte; vgl. etwa zeitgenössisch Meynert: Kaiser Franz I. von Österreich und sein Zeitalter, 319 (auch mit Bezug auf Dalmatien); Groß-Hoffinger: Leben, Wirken und Tod des Kaisers, $169 \mathrm{f}$.

267 Laut Almanacco 1834, 88: Presani (s. o., Anm. 184).

268 ON Sibut: konnte nicht verortet werden. Auf der Karte zur Gegend von Knin (Beilagentafel XVb, in der Reinschrift fol. 117 / Scan 236 ist verzeichnet (offenbar statt wie hier Sibut): Sinobat. Diese kleine Ansiedlung ist nördlich der Festung Knin auf etwa halbem Weg in Richtung Kninsko polje zu verorten und heute offenbar (und vielleicht unter Verlust des Toponyms) als Teil von Knin mit diesem verwachsen.

DigiOst $1 \mid 88$ 
Abhilfe geschehen wird, so muß man vorerst abwarten, was die Vollendung des Rinnsals bey Babodol und Zanchi Buch ${ }^{269}$ für eine Wirkung im allgemeinen hervorbringen wird.

\section{$\$ 53$ Morast bei Sign}

Wie ich schon bei Bereisung des Flußes Cettina allerunterthänigst erwähnt habe, wird dieser 3212 Joch große Morast hauptsächlich durch die Verengungen des felsigen Bettes und den hohen Stand dieses [Flussbettes] bei dem Punkte Bersatak gebildet.

Es sind bereits auf dieser Stelle einige zweckmäßige, aber noch nicht hinlängliche Arbeiten, welche doch theilweise gute Folgen hervorbrachten, ausgeführt worden und schon für diese segnet das dortige dankbare Volk Eure Majestät unaufhörlich. ${ }^{270}$

Für das künftige Jahr sind auf diese [Qu 18 / 3] Arbeit 10000 Gulden präliminirt ${ }^{271}$ worden, und ich hoffe, daß die dortigen Bewohner Eurer Majestät in dem künftigen Jahre wegen allgemeiner Austrocknung jener Gegend unendlichen Dank in tiefster Ehrfurcht zollen werden. ${ }^{272}$

Wenn diese Arbeit beendet sein wird, wird man erst in einem oder 2 Jahren mit Gewißheit beurtheilen können, ob und was allenfalls noch fürzukehren erforderlich wäre. Diese Gegend ist schön, ist fruchtbar, und von etwas [gestrichen: mehr als ${ }^{273}$ ] emsigeren Menschen bewohnt, verdient demnach um so mehr, daß man das Uibel, so viel es die Kunst gestattet, hebe.

\section{Der Morast Uspor}

$\$ 54$ Dieses Morastes erwähne ich nur um in aller Unterthänigkeit zu bemerken, daß von solchen im Wesentlichen bei dem See Prolosaz gehandelt wurde.

\section{Der Morast an der Narenta}

[§ 55] Dieser Morast ist nach meiner und dem [sic] mehrerwähnten Bau- [Qu 18 / 4] Adjunkten [Presani] Uiberzeugung nicht durch die Vernachläßigung des Flußes gleichen

269 An dieser Stelle ist die Ortsnamenschreibung nicht korrigiert.

270 Eine Präsentation der Dankbarkeit des Volkes gegenüber dem "guten Kaiser Franz«, die diesen wiederum zu weiteren Taten motivieren sollte.

271 Präliminiert: »Kosten vorbestimmt, eingeplant «.

272 An dieser Stelle wird ganz klar, dass es um gewöhnliche Ausgaben des Ärars ging, und dass dies wohl auch auf solche Ausgaben zutrifft, welche Lilienberg weiter oben (vgl. Anm. 147) als »Spenden« des Monarchen bezeichnet hatte (ein Beispiel für personalistische Herrschaftsauffassung bzw. deren Inszenierung sowohl - in anderen Medien belegbar - gegenüber dem Volk als auch gegenüber dem Monarchen selbst).

273 Nach diesem »mehr als« war Platz für Einfügung frei gelassen worden und am Rand mit Bleistift ein Fehlzeichen gesetzt worden. Mit anderer Tinte wurde dann »mehr als« ausgestrichen und »emsigeren Menschen« in die Leerstelle eingesetzt. Ein weiterer Beispielbeleg für einen Diktatcharakter der Aufzeichnung. 
Namens und durch Versumpfung eines trockenen Grundes, sondern durch Verschlämmung der Meeresbucht, die dort einst war, entstanden.

Der Fluß Narenta hat sich auf seiner weiten Bahn und durch die lange Zeit hie und da viel tiefer eingearbeitet, oder aber sein Bett erweitert und von dem Augenblick an immer mehrere Damm- und andere Erde mitgeschwemmt und bei Metcovich, wo der Fall ${ }^{274}$ gering zu werden anfängt, den Schlamm abgesetzt; so daß nach und nach die Bucht immer mehr und mehr angefüllt wird.

Diese Behauptung scheint dadurch, wenn nicht eine volle Gewißheit, doch sehr viel Wahrscheinlichkeit zu erhalten:

a weil auf vielen Orten, wo nach Zusicherung aller Bewohner vor 40 - 30 - 20, oder 10 Jahren noch Aale mit Nezen und Cähnen gefangen [Qu 19/1] wurden, dermal Getraid, Wein, Feigen und andere verschiedene fruchttragende Bäume sehr üppig fortkommen ${ }^{275}$;

b weil überall, wo man Kanäle oder bei anderer Gelegenheit die Erde etwas tiefer aushebt, Meer-Muscheln und andere Meerprodukte hervorkommen.

Diese Gegend wäre vermuthlich bereits um vieles trokener geworden, wenn man durch falsche Eindämmung des Hauptstammes ${ }^{276}$ in früherer Zeit, diese Verrichtung der Natur nicht gestört ${ }^{277}$, und den Erfolg nicht verspätet hätte.

Die Natur hat die Anschwemmung begonnen und diese wird sie nach und nach zu Ende führen und es bleibt vernünftiger Weise nichts übrig, als bei den kleinen Bächen durch einige zweckmäßige ohnehin nicht sehr kostspielige Arbeiten, wie es auch in diesem Jahre geschieht, die Uiberschwemmung der schon trockenen Gründe zu verhindern und hie und da, wo es nützlich erachtet werden wird, Einschnitte in [Qu 19/2] die Hauptdämme zu machen und die Anschwemmung zu befördern, dort aber wo das terrain schon angeschwemmt, aber noch sumpfig ist, Gräben zu ziehen und mit Bäumen, welche Näße lieben, zu bepflanzen, die dann bei gänzlicher Austrocknung dem Getraide und Obstbäumen Platz machen und vermuthlich nach und nach auch die Kanäle unnütz machen werden. Kosten darf diese Arbeit nicht viel, denn der Fluß wird die Anschlämmung bis auf den See Kutti ${ }^{278}$ und die übrigen tiefer gelegenen Seen die aus dem Plan $\mathrm{N}^{\circ} 13$ zu ersehen sind ${ }^{279}$, selbst vollenden, wo dann, so wie bey Sign und Knin sehr beträchtliche Menge Getraid gewonnen werden wird, da blos an der Narenta vielleicht bei 2176 Joch mehr für die Agricultur anwendbar werden.

$274 \mathrm{Zu}$ verstehen im Sinne von: Höhenunterschied, bzw. Gefälle (eines Flusses).

275 »Fortkommen« zu verstehen als: wachsen, gedeihen.

276 Der Hauptverlauf/Hauptarm des Flusses.

277 Lilienbergs Beurteilung von verfehlten bzw. auch riskanten Eingriffen in die Natur. Siehe auch nächster Satz.

278 TN (See) Kutti (an der Neretva) / Kuti: See im südöstlichen Teil des Mündungslaufes der Neretva.

279 Karte 7 hier im Anhang, Seite 299, bzw. Beilage XIII, Reinschrift, fol. 114 / Scan 230.

DigiOst 1 | 90 
Der Morast bei Castel Lastua ${ }^{280}$

$\$ 56$ Dieser Morast wird durch die starke Brandung, da die Gegend tiefer ist als [Qu 19/3] das Meer-Ufer und durch einige Wildbäche gebildet, welche von dem Gebirge herabstürzen.

Diese nämlichen Wildbäche überschwemmen aber oftmals, die ober dem eigentlichen Moraste liegenden fruchtbaren Gegenden, weil ihr Bett nicht rein gehalten wird und ihr Waßer bei starken Regengüßen, oder wenn im Gebirge der Schnee schmelzt, überufert.

Um diesem Uibel zu steuern und nach und nach auch den Morast anzufüllen, muß das Bett dieser Bäche so viel als möglich rein gehalten werden, damit sie nicht auf die Felder austreten, sondern den Schlamm, den sie meistens mitführen, zur Anschwemmung in den Morast fortführen; und darauf wird in der Folge gedacht werden. Was den Morast selbst betrifft, dieser besteht seit erdenklichen Zeiten, und die Bewohner jener Gegenden haben mich versichert, daß die Luft, so lang der Tabakbau erlaubt, und dort im Schwunge war, gar nicht ungesund gewesen [Qu 19/4] wäre. Vielleicht wird ihnen diese Wohlthat, so wie dem übrigen Dalmatien durch Eurer Majestät unermäßliche Gnade wieder zu Theil werden. ${ }^{281}$

[Qu 20/1]

Thaeler

$\$ 57$ [Um Zara] Dalmatien hat einige sehr schöne und fruchtbare Thäler.

Obwohl die Gegend um Zara sehr steinig und im Ganzen genommen nicht sehr fruchtbar ist, so sind doch einige nahe liegende Thäler hiervon ausgenommen, welche mit Getraide und Weinreben bebaut, mit Oliven und anderen fruchtbaren Bäumen beschattet, eine angenehme Weide dem Auge gewähren ${ }^{282}$.

Vorzüglich zeichnet sich das kleine Landgütchen des Doktor Orazio Pinelli ${ }^{283}$, welches etwa eine viertl [sic] deutsche Meile von der Stadt entlegen ist, darin aus, und lie-

280 ON / TN (Kastel) Castel Lastua / Petrovac na moru: Dorf im Kreis Cattaro (heute Montenegro).

281 Also eine Wendung an den Kaiser wegen der von Lilienberg gewünschten Wiederfreigabe des gesamtstaatlich im Staatsmonopol befindlichen und in Dalmatien nicht erlaubten Tabakanbaus, wofür der Gouverneur hier sogar mit einem doch ausgekügelten Argument wie dem von der Entsumpfung und Entfeuchtung der Luft argumentiert.

282 Wieder ein Beleg für den Begriff von bewirtschafteter Natur als schöner Natur (»Augenweide«).

283 Dr. Orazio Pinelli (Landeigentümer nahe Zara), ${ }^{*} 1755, \dagger 1843$, Medizinersohn und selbst Mediziner sowie Agrarunternehmer, wo er sich außer als Tierzüchter und Reisanbauer vor allem als Begründer mehrerer Baumschulen für Obstbäume ab 1819 und für Maulbeerbäume (ab 1827) versuchte, mit verschiedentlicher Bezuschussung und Krediten des Landesguberniums. Nach seinem Tod gingen die Baumschulen, für deren Errichtung die Familie Pinelli noch beim Gubernium verschuldet war, darnieder. Siehe (mit weiteren Quellen- und Literaturangaben) Scotti, Giacomo: I Pinelli di Zara da medici a imprenditori. In: La Voce del Popolo [Fiume] 2.8.2008, S. 16, unter http://www.editfiume.com/archivio/lavoce/2008/ foto/reportage080802.pdf (16.12.2013). 
fert den Beweis, daß auch der sehr steinige Boden wenn man die Mühe nicht scheut, die schönste und üppigste Vegetation hervorbringen kann.

$\$ 58$ [Thäler im übrigen dalmatinischen Festland] Das schöne und fruchtbare Thal von Czerno $^{284}$, dann jenes von Podgraje ${ }^{285}$ sind bemerkungswerth.

Das bei Ostrovizza, von zwei anmuthigen Anhöhen begleitet wird noch viel fruchtbarer werden, wenn die Moräste durch Eure Majestät Huld und Gnade getrocknet seyn werden.

Ein außerordentlich schönes und fruchtbares Thal ist bei Derniš unter dem Berg Promina, Petrovopoglie genannt, dieses lauft gegen Much und dann Clissa mit manigfältiger Verengung und [Qu 20/2] Erweiterung, und hat das Angenehme, daß man auch auf dieser ganzen Strecke verschiedene Wäldchen erblickt, und hinlängliches Wasser findet.

Auch bei Gromila ${ }^{286}$ gegen Ogorie ${ }^{287}$ unter dem Berg Sfilaja fand ich ein sehr anmuthiges, mit Getraid wohl bebautes, Thal und in diesem einen sehr sehenswerthen Nußbaum, dessen Diameter von der Peripherie der Aeste 40 Schritte mißt.

Gleich wie man bei dem Bazzar bei Grab ${ }^{288}$ von der Anhöhe herab kommt, findet man ein fruchtbares Thal, welches sich gegen Knin erstreckt.

Das schöne Thal bei Topoglie unweit Knin verdient auch einer Erwähnung.

In dem anmuthigen Thale von Verlika aber glaubte ich mich in die reitzenden Gefielde Steyermarks versetzt; - hier wechselt der Ackerbau jeder Gattung mit dem Weinswuchs ab und die Cettina, die kaum aus den Felsen hervor gekommen, schlängelt sich zwischen dieser fruchtbaren Flur neben kleinen Dörfern zwischen Wäldchen, und ein-

284 TN (Tal) bzw. ON Czerno / Ortschaft Crno nördlich von Zara.

285 TN (Tal) bzw. Landschaft Podgraje / Podgorje; eine Tallandschaft beiderseits der damaligen Grenze zwischen der kroatischen Militärgrenze und Dalmatien auf der Meerseite des Velebitgebirges, etwa zwischen Senj und der Zrmanja.

286 TN oder ON Gromila: es war nicht eruierbar, ob es sich um eine Ansiedlung gehandelt hat oder um ein Toponym.

287 ON Ogorie / Donje und Gornje Ogorje: Ansiedlung(en) nordnordwest von Split.

288 ON Grab / Grab: Grenzübergang nach dem osmanischen »türkisch Kroatien« nordöstlich von Knin, östlich des Triplex confinium der Militärgrenze, Dalmatiens und Bosniens unterhalb der Konjska glava (zur Lokalisierung siehe hier im Anhang Karte 6, Seite 298, bzw. Originalanlage XII, Reinschrift fol. 113 / Scan 228). Die seinerzeit vorhandenen und die aufgelassenen Grenzbazare für den Handel mit osmanischen Kaufleuten sind auf Karte 1 (hier im Anhang, Seite 292), bzw. Originalanlage VII, Reinschrift, fol. 107 / Scan 217, verzeichnet. Von Nord nach Süd: Grab, Uniste (bei Gradac, aufgelassen), Arxano (direkt an der Grenze, nahe dem Dorf Aržano), Muovaz (bei Vrgorac, aufgelassen), Unka (nahe Metković auf dem Verbindungsweg nach Mostar) und weiter im Süden nur noch einen bei Blockhaus an der Grenze zu osmanisch-Albanien. Zu ergänzen ist der von Han / Bilibrig, vgl. weiter oben, Anm. $197 \mathrm{zu} \$ 36$. Petter: Dalmatien, Bd. 1, 90, listet auf dem Stand gegen 1850 Grab unter damals fünf bestehende Grenzmärkte: Grab, Uniste, Kadinabuqua, Arxano, Bergatto.

DigiOst 1 | 92 
zelne verschiedene Baumgruppen, die man in diesem Thale zerstreut findet, geben dem Ganzen ein sehr liebliches [Qu 20 / 3] Ansehen. ${ }^{289}$

Das sehr ausgedehnte Thal bei Sign, welches rechts und links am Fuße der Gebirge viele Wohnungen und in solchen arbeitsame Landbauern hat, ist ober dem Morast mit Getraid und mit vielem Grünzeug bebaut, auch hier findet man viele Bäume und besonders viele Pappeln, welche diese Gegend recht angenehm machen und zur Reinigung der Luft sehr vieles beitragen. Wenn die Arbeiten, derer ich bei den Morästen allerunterthänigst erwahnt habe, durch Eure Majestät allerhöchste Gnade vollendet sein werden, so dürfte wohl dieser Gegend die schönste und fruchtbarste in Dalmatien werden, weil die Bewohner viel emsiger sind und den Vortheil haben, daß der Handel, welcher über Bilibrigk und Han mit der Türkei gemacht wird, ihnen sehr zu Guten [sic] kommt.

Das schöne Thal von Imoschi, obwohl es manchmal inondirt wird, dann das Thal von Salona bei Spalato, vorzüglich aber jenes bei Poglizza ${ }^{290}$ unweit Macarsca, dessen ich schon in politischer Hinsicht [Qu 20 / 4] erwähnt habe ${ }^{291}$, ist sehr schön und eines von denen, welche sehr fleißig bearbeitet werden.

Im Ragusäischen ist das Thal von Stagno ${ }^{292}$ sehr fruchtbar, wie man aber in die Gegend von Canosa ${ }^{293}$, Valdinoce ${ }^{294}$ und Malfi ${ }^{295}$ kömmt, scheint man in eine andere Provinz gekommen zu seyn; alles ist besser bearbeitet, man findet, daß diese Güter ${ }^{296}$ Grundbesitzern angehören, welche einstens Vermögen und Sinn für Nützliches und Gutes hatten.

Hier fand ich einige Plattanen von ungeheurer Größe; da diese Gegend am Gestade des Meeres liegt und gegenüber viele schöne Inseln hat, so kann man sie wirklich einen

289 Eine Naturbetrachtung und Schönheitsempfinden nach dem Maßstab der Alpenländer; vielleicht auch schlicht ein Ausdruck von Lilienbergschem Heimweh nach den grüneren Gefilden des Nordens.

290 ON (Landschaft / politisches Territorium) Poglizza / Poljica. Vgl. § 145.

291 Ein Hinweis darauf, dass die Gliederung im Verlauf der Texterstellung deutlich verändert worden ist. Ein kurzer Anfang der Behandlung des Kreises Spalato befindet ja wie gesehen tatsächlich weit zu Beginn des Konzepttextes, war dort aber ausgestrichen worden. Die tatsächliche Behandlung der "politischen« Verhältnisse, darunter dann auch diejenigen des Kreises Spalato mitsamt Poglizza, folgt in der am Ende vorliegenden Anordnung aber erst weiter unten (dabei zu Poglizza unter $\$ 145$ ).

292 ON Stagno / Ston Ortschaft am festländischen Anfang der Halbinsel Pelješac.

293 ON / TN Canosa (auch Cannosa) / Trsteno: Küstenort gut $15 \mathrm{~km}$ Luftlinie nordwestlich von Dubrovnik.

294 TN (Talschaft) Valdinoce, an späterer Stelle auch Schreibung Val di Noce / Orašac (südostlich benachbart zu Trsteno).

295 ON Malfi / Zaton: Ansiedlung südöstlich angrenzend an Orašac, ca. auf halber Luftlinie zwischen Trsteno und Dubrovnik.

296 In dieser Passage gibt es in der Vorlage diverse Umformulierungen in zweierlei Handschrift (wohl Rossetti und Lilienberg). In der Reinschrift steht, orthographiegeschichtlich interessant, wie hier übernommen »Güter« statt wie im Konzept »Güther«. 
der angenehmsten Aufenthalte nennen, wo sich auch viele und schöne Landhäuser der Ragusäer befinden. ${ }^{297}$

Noch schöner und manigfältiger in jeder Hinsicht fand ich das Thal von Brenno ${ }^{298}$, welches von Ragusa nur über eine Anhöhe gelegen ist.

[Folgender Absatz am Rand ergänzt:] Schade, daß hier und um Ragusa die Landhäuser vielfältig noch so, wie sie durch die Rußen und Montegriner verwüstet worden sind, öde und verlassen bleiben und an diese traurige Epoche erinnern. ${ }^{299}$

So wie man über Ragusavecchia ${ }^{300}$ den Berg hinauf kommt, öffnet sich ein sehr ausgedehntes und fruchtbares [Qu 21 / 1] Thal, welches Piano de' canali ${ }^{301}$ genannt wird; hier wird sehr viel Sommer-Getreide gebaut und reich gefechst ${ }^{302}$ wenn das Unglück der

297 Ein Fall von romantisch angehauchter Naturbetrachtung Lilienbergs mit einem Schönheitsbegriff, der hier an einheimischen, maritimen Maßstäben bemessen wird. In jenem Dalmatien der vortouristischen Zeit wurden mitunter doch, auch von den Beamten, tourismusähnliche Naturattraktionen bewusst wahrgenommen und als solche präsentiert. Die offenkundig gleichen Platanen von Cannosa (eine damals in Mitteleuropa wohl noch weitgehend fehlende Baumart) wurden 1839 auch den Lesern der »Wiener Zeitschrift« vorgestellt (auch wenn hier nur von »zwei Riesenplatanen« die Rede war), nicht ohne den Hinweis, dass auch Kaiser Franz I. sie 1818 bei seiner Reise in Dalmatien besichtigt habe; Marinelli-König: Die Südslaven, 407. In der Reinschrift steht bereits ebenfalls »Platanen« statt »Plattanen«.

298 TN (Tal) Brenno (auch in der Schreibung Breno): auf dem Gebiet des gleichnamigen Ortes (Župa dubrovačka).

299 Auch in der Reinschrift, Seite 34. Nachdem im Frühjahr 1806 französische Truppen die noch selbständige Republik Ragusa durchquert hatten, um die russischen Verbände aus ihren Stellungen in der Boka kotorska zu vertreiben, stießen diese im Juni 1806 in Gemeinschaft mit montenegrinischen Verbänden und orthodoxen Freischärlern aus der Herzegowina durch den Süden der Republik vor bis zur Stadt Dubrovnik, die sie sodann belagerten. Zwar wurde die Stadt im August 1806 durch französische Verbände unter dem Kommando von Marschall Auguste Marmont entsetzt, aber die Kämpfe in der Umgebung dauerten noch bis September an. Verluste an Handelsschiffen durch russische Aktionen gab es bis 1807, als die russischen Verbände im Gefolge des Friedens von Tilsit die Boka räumten. Die zivilen Kriegsschäden auf dem Gebiet der Republik Dubrovnik waren außerordentlich hoch, allein für die Monate Juni-September 1806 wurden sie in einer Untersuchung des Jahres 1810 auf knapp 9 Mio. Dubrovniker Dukaten beziffert. Siehe Ćosić: Dubrovnik nakon pada republike, 34-37. Die langfristigen Folgewirkungen sind mehrfach belegt. Auch Kaiser Franz I. hatte 1818 mehrfach noch von den damaligen Plünderungen stammende schwere Schäden und Einbußen des Seehandels bis erheblich nördlich der Stadt Dubrovnik festgehalten, so zu Slano (noch sichtbare vernichtete Schiffe und geplündertes Umland) und zur beschädigten Ausstattung zahlreicher Adelssitze in Gruž; Krmpotić (Hg.): Car Franjo I. u Hrvatskoj, Bd. 1, 278 und 281, ebenso die fortdauernde Unbrauchbarkeit des Hafens von Gruž durch von den Franzosen versenkte große Schiffe (ebd., 281).

300 ON Ragusavecchia / spätere Schreibung auch Ragusa vecchia / Cavtat: Kleinstadt südlich von Dubrovnik.

301 TN Piano de' canali / Konavosko polje.

302 Vom bairischen Verb »fechsen« (»ernten«). 
Uiberschwemmung, die jedes Jahr im Winter Statt hat - nicht zu lang im Frühjahr währt, oder im Sommer die Hoffnungen der fleißigen Bauern, wie es im v[origen] J[ahr] geschehen, zerstört.

In dieses Thal stürzen sich, so wie aus dem anliegenden Plan $N^{\circ} 16$ Eure Majestät allergnädigst zu ersehen gereichen werden ${ }^{303}$, unzählige Wildbäche von den Gebirgen, welche dieses Thal so umgeben, daß das Wasser keinen anderen Abfluß als unterirdisch durch einige Schlünde, welche auf dem Plan ersichtlich sind, hat.

Diesem Uibel gänzlich abzuhelfen dürfte wohl unmöglich werden.

Man hat zwar schon in früheren Zeiten verschiedene Projekte zur Abhilfe gemacht, aber alle sind zu kostspielig und in ihrem Erfolge zu ungewiß befunden worden.

Auch dermalen hat die Landesstelle einen Ingenieur zur vollkommenen Aufnahme dieser Gegend dahin abgeschickt, so viel ich aber mit dem Bau-Adjunkten Pressani nach der Besichtigung [Qu 21 / 2] dieser, für die Agricultur sehr bedeutenden, Gegend schließen kann, dürfte kein anderes Mittel zur möglichsten Linderung des Schadens übrig bleiben, als die Schlünde, welche das Wasser bei starken Regengüssen unterirdisch abführen sollen, so viel möglich zu erweitern; einige Kanäle zu ziehen und dadurch, daß man die kahlen Berge, über welche sich das Regenwasser zu geschwinde herabspült ${ }^{304}$, nach und nach bepflanzt und durch kleine Dämme die Bäche künstlich zu Krümmungen zwingt, damit der Zufluß nicht so gähe wird und mehr in Verhältnis mit dem Abfluße kommt.

[Nächster Absatz wohl direkt durch Lilienberg am Rande ergänzt]

Das schöne Thal an der Ombla gleich an dem Hafen von Gravosa habe ich deswegen auf die Seyt [Seite] gelassen, weil es mir das hübscheste und wegen dem Fluß Ombla, welcher es benetzet, dann wegen der vielen Mühlen und Landhäusern das intressanteste schien.

Aus diesem sehr beträchtlichen Thale de' Canali bin ich in das, wegen seiner üppigen Vegetation noch anmuthigere ${ }^{305}$, an der Suttorina gelegene, gekommen. Leider! daß dieses noch in den Händen der Türken, viel schlechter bearbeitet und mit armseligen, von den unzähligen Satrappen ${ }^{306}$, welchen diese kleine Gegend gehört, sehr gedrückten Christen bewohnt $[\mathrm{Qu} 21 / 3]$ ist.

303 Siehe Karte 11 hier im Anhang, Seite 303, bzw. Beilage XVI, Reinschrift, fol. 118 / Scan 238.

304 Hier hat die Korrektur ein »ü« eingefügt anstelle eines sinnlosen »herabspeilt«, was für diese Passage ein Beleg sein dürfte für Diktatcharakter.

305 Hier wieder ein an dalmatinischen Verhältnissen gewonnener Schönheitsbegriff; »nicht schön« ist für Lilienberg also der trockene Karst, »schön« aber die geschilderten Bereiche grüner Vegetation.

306 Ein offenkundig abschätzig gemeinter, auf die antiken Perser anspielender Begriff für die grundbesitzenden muslimischen Agas oder Begs der Gegend. 
An dieses Thal schließt sich jenes von Castel-Nuovo ${ }^{307}$ in österreichisch Albanien, ziemlich gut bebaut, mit verschiedenen Landhäusern versehen und in jeder Hinsicht angenehm; um so mehr da es an der Einmündung der Boche [sic] di Cattaro liegt.

$\$ 59$ [Canal von Cattaro] Meine Feder ist zu schwach, um Eurer Majestät das Gefühl in aller Unterthänigkeit zu schildern, welches mich bei Bereisung der Boche di Cattaro ergriffen hat.

Wenn man aus der Gegend des Como-Sees, der Brenta und des schönen Salzkammerguths in Oberösterreich ein Bild zusammenzusetzen vermochte, so würde vielleicht diese Gegend versinnlicht werden können.

Das Großartige und Anmuthige dieser Gegend, fand ich nie beisammen ${ }^{308}$; man sieht die höchsten Felsen ohne alle Vegetation, Gebirge auf das manigfältigste bebaut, die schönsten und reitzendsten Hügel und Thäler mit glücklichsten [Qu 21 / 4] und natürlichen Zufällen im vollkommenen Einklang und wieder in einem sehenswerthen Contraste und beides in unendlicher Abstufung, weil man fast bei jedem Schritte ein anderes Bild bekommt und die schönste Vegetation und die vielen sehr wohlgebauten und vortrefflich erhaltenen einzelnen ${ }^{309}$, und in Ortschaften befindlichen Gebäude das Auge äußerst angenehm beschäftigen.

Meine Rührung ${ }^{310}$ hatte aber dadurch den höchsten Grad erreicht, weil mich auf dieser Seefahrt um Eure Majestät alerunterthänigst zu huldigen, eine solche Anzahl von Schiffen und Kähnen begleitete, daß, obwohl nun vollkommene Meerstille war, die Wellen, welche durch tausende von Rudern und die schnelle Bewegung der unzähligen Schiffe, wodurch sich die Boccheser in ihrer besondern Geschicklichkeit auszeichnen wollten, entstanden sind, wirklich einem kleinem Sturm glichen, und die unaufhörli-

307 ON Castel-Nuovo, später im Text meist Castelnuovo / Herceg novi: Küstenort in der Boka kotorska.

308 Ein klarer Ausdruck des romantisch geprägten Landschaftsempfindens und Schönheitsbegriffs (nämlich im Sinne spektakulärer Ausblicke und Abwechslungsreichtums der Landschaft) bei Lilienberg: Es gibt zwar auch hier südalpine und österreichische Vergleichspunkte, die aber an dieser Stelle durch ein Einzigartigkeitsempfinden der Boka aufgehoben werden. Die besondere Farbigkeit und Ausführlichkeit der Schilderung der Landschaft in der Boka rührt vielleicht auch daher, dass Lilienberg vermutlich wusste, bis wohin der Kaiser auf seiner Reise von 1818 selbst gelangt war - nämlich nur bis Ragusa, so dass Lilienberg über die Boka mehr »Aufklärungsbedarf« vermuten konnte.

$309 \mathrm{Zu}$ verstehen als »einzelstehenden« (also Gebäude außerhalb geschlossener Ortschaften).

310 Ein Huldigungserlebnis von Seiten der Bevölkerung gegenüber dem Kaiser und zugleich Wendung Lilienbergs an eben jenen; die Stelle ist nicht zuletzt ein Hinweis auf den intensiven Inszenierungscharakter auch der amtlichen Lilienbergschen Bereisung zu stellvertretender Herrschaftsrepräsentation (in Analogie zu den eigentlichen Herrscherreisen). Sie steht aber auch für eine zumindest in diesem Fall wohl wirklich intensive Aufnahme dieser Inszenierung durch die örtliche Bevölkerung.

DigiOst 1 | 96 
chen aufrichtigen Segnungen die man für die theuerste ${ }^{311}$ Erhaltung [Qu 22 / 1] Eurer Majestät aus dem Innersten des Herzens, dem Allmächtigsten darbrachte und welche mit ununterbrochenen Freudenschüßen begleitet waren, hundertfaches Echo in den umliegenden Gebirgen und Schluchten hervorbrachten, mußten einen treuen Unterthan bis zu Thränen rühren. ${ }^{312}$

$\$ 60$ [Thäler auf den Inseln] Auch auf einigen Inseln findet man sehr hübsche und anmuthige Thäler: Dieser Fall ist besonders auf der Insel Pago, wo das Meer durch eine kleine Öffnung aus dem sogenannten Morlachen-Kanal einen sehr großen Hafen bildet, um welchen die schönsten Aecker liegen, jedoch weil sich die Bewohner meistens mit Salz beschäftigen, nicht so gut bearbeitet werden.

Auf der Insel Arbe sind mehrere und besser cultivirte Thäler; so auch auf der Isola Lunga, Lissa, Lesina, Brazza, Meleda und besonders die Insel Lagosta hat [Qu 22 / 2] unzählige kleine aber schöne und anmuthige Thäler.

\section{Ebenen}

$\$ 61$ So wie ich nur der bedeutendsten Thäler erwähnt habe, so werde ich auch nur einige Ebenen in Kürze allerunterthänigst berühren.

Die Ebene bei Nona ${ }^{313}$, wo das Etablisement [sic] des bekannten Manfrin ${ }^{314}$ ziem- $^{2}$ lich vernachläßiget steht, wäre angenehm, wenn die Luft der Gesundheit nicht nachtheilig wäre.

Gleich wie man über die erste Anhöhe von Zara gegen Knin kommt, findet man die schöne Ebene bei Zemoniko, dann jene der Bukovizza ${ }^{315}$, welche aber noch schlechter als die Erstere bearbeitet und von einer Menschenraße bewohnt ist, die zu den excessivesten gehört ${ }^{316}$.

Die Fläche zwischen der Kerka und eigentlich zwischen der Brücke von Roncislap und Derniš, ist bei 3 Meilen lang und auch ziemlich [Qu 22 / 3] breit, da sie aber fast ganz karstartig ${ }^{317}$ ist, so findet man nur hie und da ein mager bebautes Feld.

311 Hier »teuer« im Sinn eines tiefen inneren Anliegens.

312 Sowohl ein Ausdruck von Lilienbergs Eigendefinition als treuer Untertan wie auch eine ergriffene Gelegenheit zur Schilderung seiner eigenen Empfindungen gegenüber dem Monarchen.

313 ON Nona / Nin: Dorf (Kleinststadt) knapp $15 \mathrm{~km}$ nördlich von Zadar, auf dem Weg zur Insel Vir bzw. gegenüber dem Südwestende der Insel Pag.

314 Marchese Pietro Manfrin, damals Familienvorstand der Manfrin (vgl. Einleitung, Anm. 78).

315 TN (Landschaftsname) Bukovizza / später im Text Bucovizza / Bukovica.

316 Ein Ausdruck des Dalmatiner- bzw. Morlakenbildes von Lilienberg: die Landbevölkerung schon des küstennahen Hinterlands als »exzessiver» (das heißt in dem Zusammenhang insbesondere: wenig arbeitsamer) Menschenschlag wie hier zur Bukovica.

317 Hier ein weiteres Indiz für eine Diktatmitschrift durch den Schreiber (Rougier), der den Sinn des Lilienbergschen Vortrags momentan nicht erkannt hatte und dann von Lilienberg selbst 
Dagegen verdient die Ebene von Scardona, besonders aber die schöne Uferstrecke zwischen Trau und Spalato, ai Castelli ${ }^{318}$ genannt, einer Erwähnung: Die leztere gehört vielen wohlhabenden, gebildeten und meistens adeligen Familien, welche sich mit der Landwirtschaft selbst beschäftigen, diese auch vielleicht am Besten in Dalmatien verstehen, [gestrichen: und so] diese Gegend ziemlich gut benützen und auch in jeder Hinsicht in Ordnung erhalten. ${ }^{319}$

Auch in oesterreichisch Albanien giebt es bei Theodo ${ }^{320}$, Xuppa und selbst bei Budua $^{321}$ einige schöne und ebene $[\mathrm{Qu} 22$ / 4] Fluren, doch ist nur die Erstere zweckmässig und mannigfaltig bebaut.

Nicht minder fand ich auf mehreren Inseln einige bedeutende Ebenen, die von Sel$\mathrm{ve}^{322}$ ist gut bebaut, die von Pontadura ${ }^{323}$ meistens blos mit Gestrüpp bewachsen, jene auf der Insel Solta und besonders mehrere Flächen auf der Insel Curzola sind schön und fleißig bearbeitet.

[Qu 23 / 1]

\section{Beschaffenheit des Bodens}

$\$ 62$ [Verschiedenheit des Bodens, Erdarten] In Dalmatien, wie in jedem Lande, welches sich unter mehrere Breitengrade ausdehnt, und viele Natur-Revolutionen überstanden haben mag, ist die Beschaffenheit des Landes sehr verschieden, doch ist hier öder Boden, oder wenigstens solcher, welcher zur Agricultur, ohne eine außerordentliche Anstrengung nicht leicht anwendbar gemacht werden kann, vielmehr als von dem zur Beurbarung geeigneten vorhanden.

Ich habe hier Erde von jeder Gattung und Art - die gute schwarze Dammerde ${ }^{324}$ aber sehr sparsam gefunden.

Kalkartige, sandige, sandige und mehr oder weniger mit Steinen vermischte; Kreide, Mergel, Moorgrund, Ochererde ${ }^{325}$ rein, dann mit wenigen oder vielen Steinen vermengt und besonders Thon von aller möglicher Farbe, Beschaffenheit und Abstufung.

(Handschrift Lilienbergs, mit Rotstift) korrigiert wurde: »karstartig« statt wie vom Schreiber gehört »großartig«.

318 TN (Küstenabschnitt zwischen Trogir und Split) ai Castelli / Kaštela (mit zusammen sieben Ortseinheiten).

319 Die Schönheit einer nutzbaren Landschaft wird hier besonders deutlich eben nach der Bewertung ihrer "guten« (rationalen, intensiven) landwirtschaftlichen Nutzung beurteilt.

320 ON Theodo , spätere Schreibung auch Teodo / Tivat: Kleinstadt am Eingang zur Bucht von Kotor.

321 ON Budua / Budva (am Südende des damaligen Kreises Kotor.

322 ON / TN (Inselname) Selve (weiter oben im Text in der Form Selvo) / Silba.

323 ON / TN (Inselname) Pontadura / Vir: Insel knapp nordwestlich von Nin.

324 Der heute veraltete Ausdruck bezeichnet eine nährstoffreiche Humuserde.

325 Zurm Leseverständnis: die heutige Orthographie lautet »Ockererde«, für den nachstehenden Thon »Ton«. Ockererde ist eine stark rötlich-ocker gefärbte, saure bis stark saure und 
Die Thonerde ist zwar zum Feldbau nicht sehr geeignet, besonders wenn solche der Landmann nicht zu lockern und zu erwärmen versteht; um aber [Qu 23 / 2] auch von diesem Umstande einen kleinen Nutzen zu ziehen, habe ich, da die Provinz noch kein wohlbeschaffenes Hafner-Geschirr ${ }^{326}$ erzeugt hat, einen Meister von Fiume verschrieben ${ }^{327}$, der bereits vortreffliche Gefäße aller Art verfertiget, wo dadurch viel Geld im Lande bleibt, was sonst auswärts gegangen ist ${ }^{328}$.

Diese Erde wird auch für die Erzeugung der Ziegel die in den Kreisen von Zara und Spalato ganz mangelten und mit großem Nachtheil aus dem Päpstlichen ${ }^{329}$ geholt werden mußten, bestens dienen.

$\$ 63$ [Beurbarter Boden, Größe desselben] Man hat bis nun dafür gehalten, daß Dalmatien blos 1/7 von seinem Flächenraume urbar gemacht hätte, aber der Kreis von Zara, welcher dermalen schon ganz vermeßen ist ${ }^{330}$, beweist, daß die Agricultur wirklich bereits vielmehr als 1/6, aber nicht ganz 1/5; nämlich 23/123 nutzbar gemacht hat.

Nachdem, was ich zu beurtheilen Gelegenheit hatte, halte ich dafür, daß der übrige Theil von Dalmatien wenn auch der Kreis von [Qu 23 / 3] Spalato besser stünde, im Ganzen nach gleichem Verhältniße zu beurtheilen wäre, und daß auf keinen Fall, selbst mit der größten Anstrengung, außer daß die Seen und Moräste nach und nach ganz werden abgezapft werden, mehr, als höchstens $1 / 3$ des Flächeninhalts wird urbar gemacht werden können.

Wenn nun der Flächeninhalt den ich $\$ 26$ angeführt habe und der sich erst bei Vollendung der Katastalausmessung bestimmt ergeben wird, nicht irrig angenommen ist, so kann Dalmatien doch 76 Quadratmeilen oder 460000 Joch urbaren Bodens mithin hinlänglich Erde - wenn es diese vegetabel zu machen und zweckmäßig zu benützen

ziemlich unfruchtbare Erde.

326 Also irdenes Geschirr, Tongeschirr.

$327 \mathrm{Zu}$ verstehen als zur Niederlassung (hier: in Dalmatien) anzuwerben versucht.

328 Wieder wirtschaftspolitischer Autarkie- bzw. Importsubsistenzansatz, der sich für Dalmatier in Lilienbergs Zielsetzung inmöglichst regionaler (oder doch zumindest »habsburgischer«) Auftragsvergabepraxis ausdrücken sollte. Vgl. auch den gleich darauf folgenden Absatz.

329 Also aus dem Kirchenstaat.

330 Der sogenannte stabile oder franziszeische Kataster wurde für die westliche Reichshälfte der Monarchie mit 23. Dezember 1817 zur Erstellung angeordnet; in Dalmatien begannen die Arbeiten im Jahr 1823. Die Arbeiten an diesem ersten modernen Kataster, der vor allem der gezielteren Besteuerung (Grundsteuer, Zehent) dienen sollte, wurden 1838 abgeschlossen. Entstanden sind dabei 6725 Katasterpläne (unter Festhaltung von 2381495 Eigentumsparzellen). Die Kosten für dieses Großvorhaben beliefen sich auf 690000 Gulden: Bajić-Žarko: Arhiv mapa za Istru i Dalmaciju, 12f. Zur Organisation bestand innerhalb der Landesverwaltung von 1828 bis 1842 die Katastraldirektion (I.R. direzione di misurazione catastrale), 1836 wurde ein eigenes Archivio provinciale delle mappe zur Verwaltung der Karten eingerichtet, in dem freilich über die Jahre hinweg jeweils nur ein Archivar beschäftigt war. Der Bestand befindet sich seit den 1920er Jahren im Staatsarchiv Split (ebd., 16). 
lernen wird, auffinden, um seine Population, wenn sie auch noch um die Hälfte zugenommen haben wird, vollkommen zu ernähren ${ }^{331}$.

\section{Clima}

$\$ 64$ [Characteristik des Climas] Das Clima fand ich sogar [Qu 23/4] in den gebirgigen Theilen im Ganzen genommen sehr mild; schon die geographische Lage von Dalmatien, da sie in die gemäßigte Zone fällt, deutet es an und der Umstand macht es noch einleuchtender, daß fast die ganze Provinz aus Inseln oder Küstenland besteht, und daß die entferntesten Gebirge des Festlandes in der geradesten Linie, wie die Dunst- und Luftwirkung genommen werden muß, kaum 9 deutsche Meilen, und dieses nur in einem kleinen Theile des Landes, vom Meer entlegen sind, und nur in dem Verhältniße gemächlich zunehmen $^{332}$, wie sich diese vom Meergestade entfernen; dann daß der übrige Theil des Binnenlandes in seinen äußersten gegen das türkische Gebiet gehenden Punkten, nicht mehr als 3-2-1 und $1 / 2$ deutsche Meilen vom Golfo entlegen sind.

An der Küste weiß man wenig von Frösten und selbst gegen das Gebirge dauern diese nur sehr kurz, außer einigen sehr hoch gelegenen Felsen-Rißen der benannten bedeutenden Berge und besonders des Vellebich, welcher 5404 Fuß 7 Zoll hoch ist und wo sich der Schnee fast den [Qu 24 / 1] ganzen Sommer zu verbirgt.

Ich habe selbst bei Knin, Vergoraz und Imoschi, also unter dem Gebirge Prologk der $5000 \mathrm{Fußhoch}$ ist, die Weinreben üppig gefunden und guten, wenn gleich nicht sehr starken Wein getrunken und bey Imoschi auch den Oelbaum vortrefflich vegetiren gesehen.

Unter dem Artikel »Landwirtschaft« werde ich manche Pflanzen anführen, die man sonst in einer mehr südlich gelegenen Provinz suchen würde und die in Dalmatien vollkommen gut fortkommen ${ }^{333}$.

$\$ 65$ [Winde] Da es aber kein Wohl ohne Weh geben kann, so hat dieses Land auch eine große Plage an der Bora / N.N.O. ${ }^{334}$ welche im Winter und im Frühjahr oft sehr stark bläst ${ }^{335}$, sehr kalt ist und im Frühjahr vielen Schaden bei dem jungen Vieh, welches hier immer unter freyem Himmel ist, und an den Pflanzen verursacht, besonders aber dann außerst nachtheilig ist, wenn sie wegen ihrer Heftigkeit viele salzige [Qu 24 / 2] Theile aus

$331 \mathrm{Zu}$ den gravierenden Selbstversorgungsschwächen der dalmatinischen Landwirtschaft (auch mit Blick auf den weiteren Verlauf des Jahrhunderts) vgl. Peričić: Oskudica i glad.

332 Gemeint sind die Gebirge.

$333 \mathrm{Zu}$ verstehen als "gedeihen «, "wachsen «.

334 N.N.O. für die Windrichtung Nord-Nordost.

335 Auch hier ein eindeutiges Beispiel für eher mechanische fehlerhafte Abschrift (oder nicht vollkommen des Deutschen mächtige Diktatmitschrift) des Schreibers, die von Lilienberg dann korrigiert worden ist: Lilienbergs »bläst « statt des Schreibers widersinniges »blößt « (dies wäre eventuell durch gesprochene mundartnahe Variante »blost/blast« zu erklären). Ebenso in dem gleichen Satz noch: »Heftigkeit« statt »Festigkeit«. Das zweite Beispiel würde dabei wohl eher zu einem Abschrift- als zu einem Hörfehler passen. 
dem Meere mitführt, alle Saaten, junge Bäume ganz und sogar viele Aeste alter Bäume, welche sie förmlich mit dem Salze incrustirt ${ }^{336}$, verseucht.

Der zweite, besonders für die Menschen unangenehme, Wind ist der Sirocco / S.O. ${ }^{337}$, weil er oft Krankheiten verursacht; dieser ist aber bei weitem nicht so bedeutend, wie in manchen Theilen Italiens und bei weitem nicht so schädlich, wie in Sicilien, wo dieser oft die ganze Vegetation in 4 bis 5 Tagen verdorrt.

Was den Landmann eben nicht selten sehr plagt und seine Anstrengung bei dem Getraidbau oftmal ganz unütze macht, ist die Dürre, der dieses Land oft ausgesetzt ist.

Auch die Linderung dieses, wie die Hebung anderer unzähliger Uibel, hat die Vorsehung Gottes Eurer Majestät allergnadigstem Vaterherzen vorbehalten, denn man kann mit Zuversicht hoffen, daß wenn durch die allerhöchsten Verfügungen [Qu 24/3] die noch übrig gebliebenen Wälder besser geschont, neue angepflanzt und beide zweckmäßig werden gepflanzt werden, gewiß der Regen in diesem Lande auch nicht so selten seyn wird, wie bis jetzt ${ }^{338}$.

\section{Strassen}

$\$ 66$ [Hauptverkehrstrassen] Bis nicht Eure Majestät über dieses Land zu herrschen begonnen haben, hat man nichts von guten Reitwegen, vielweniger aber von einer fahrbaren Straße etwas gewußt.

Schon während der ersten glorreichen Occupation, wurde durch Euer Majestät allerhöchster [sic] Gnade zur Verbindung mit Militair Kroatien die Straße aus der Licca gegen Knin und auch von dort bis zu der Festung Zara; und eine andere von Knin über Derniš nach Sebenico angelegt.

Unter der französischen Regierung war man gezwungen, weil die Engländer die Communication zu Meer sehr unsicher machen, im Innern Straßen anzulegen; [Qu 24 / 4] dadurch entstand die fahrbare Strasse, welche von Knin über Sign, Narenta und durch die türkische Erdzunge Klek durch das Ragusaische, [gestrichen: früher] wo sie jedoch noch nicht überall beendet ist; dann durch die zweite türkische Erdzunge Suttorina bis nach Castelnuovo führt ${ }^{339}$.

$336 \mathrm{Zu}$ verstehen als: »verkrustet«, »mit einer Kruste überzogen«.

337 S.O. für die Windrichtung Südost.

338 Eine interessante umweltpolitische und klimapolitische Zielsetzung, nämlich mithilfe einer nachhaltigen Forstwirtschaft und Aufforstungen eine Niederschlagserhöhung zu erzielen. Dass sich Lilienberg hier anscheinend auf der Höhe eines im ganzen 19. Jahrhundert sehr aktuellen (wenn auch naturwissenschaftlich offenbar am Ende nicht haltbaren) Diskurses befand, legt der Aufsatz von Engelhard Weigl nahe: Wald und Klima: Ein Mythos aus dem 19. Jahrhundert.

339 Laut Petter: Geographische Skizze, 16f. hatten die venezianischen Behörden 1794 mit dem Bau einer ersten Straße begonnen, einer Fahrstraße von Zara nach Knin, welche die Österreicher 1797/98 fortgesetzt und vollendet hätten; die beiden anderen Straßenbauten der ersten österreichischen Herrschaft schildert Petter ebenfalls (ebd., 17), zusätzlich noch eine 
Seit der für dieses Land so glücklichen Reocupation wurde der Straßenbau, welcher für die Agricultur und besonders für den Handel so nothwendig ist ${ }^{340}$, sogleich aufs Neue allerhöchst beherziget; verschiedene Wege und Straßen alljährlich angelegt und die großartige Straße von Zara über Obbrovazzo und über den Berg Vellebit die jedem Römerwerke zur Seite stehen kann, 1832 ganz beendigt.

Ich unterfange mich zur bequemeren Uibersicht eine eigens entworfene Straßenkarte allerunterthänigst [ergänzt: unter der Zl. 7] beizuschließen. ${ }^{341}$

Die roth angelegten sind die bereits in Ärarial-Regie übernommenen Straßen bis auf das Stück von Knin nach Grab, welches blos [vom Gubernium, K.C.] angetragen, aber noch nicht [in Wien, K. C.] [Qu 25 / 1] bewilligt worden ist.

Bei Uibersicht dieser Karte ergibt sich, daß nebst der schon erwähnten Straße, welche die Franzosen angelegt haben und welche durch die ganze Provinz nahe an die türkische Gränze und hie und da sogar durch das türkische Gebiet, dessen ich schon bei der Gränzbeschreibung erwähnt habe, führt, auch noch eine andere Comunication an der Küste von Zara über Zatton ${ }^{342}$ bis in das Narenta Thal besteht.

Von Zara über Zatton, Sebenico, Trau bis Spalato ist solche fahrbar aber bis Almissa und Macarsca blos zum reiten, und von diesem Ort bis auf die Narenta, auch zu diesem Ende ${ }^{343}$ äußerst schlecht. Da sie aber jetzt definitivo zur Haupt-Brief-Post-Comunication bestimmt worden ist, so wird auch die letzte Straße in brauchbaren Stand gesetzt werden müssen ${ }^{344}$.

weitere von Ostrovizza nach Scardona (ebd.): ^Als die Franzosen vom Lande Besitz genommen hatten, waren sie wegen der Menge feindlicher Kriegs- und Kaperschiffe, die das Meer beunruhigten, nothgedrungen, Landstraßen zu bauen, um mit Sicherheit reisen zu können. So entstand unter der Oberleitung des damaligen Marschalls Marmont, in den Jahren 1807 und 1808, die große Hauptstraße (Strada maestra interna), welche die beiden Kreise Zara und Spalato ihrer ganzen Längen nach durchschneidet, und von Knin bis Torre di Nron (im Sommer bis Metcovich) befahrbar ist.« Diese Route war auf den meisten Strecken eben genug geführt, dass nur bei Knin und Župa Steigungen vorhanden waren, die ohne zusätzlichen Vorspann nur für leichtes Fuhrwerk möglich waren (ebd., 18).

340 Ein Beleg für die von Lilienberg (und der österreichischen Verwaltung insgesamt) verfochtene Infrastrukturpolitik mit Straßenbau hinsichtlich dessen verkehrlicher und Handel fördernder Wirkung.

341 Siehe hier im Anhang Karte 1, Seite 292, bzw. Originalanlage VII, Reinschrift fol. 107 / Scan 217.

342 ON Zatton / Zaton in der Nähe von Šibenik.

$343 \mathrm{Zu}$ verstehen als: »in dieser Verwendung « (zum Reiten / als Reitweg).

344 Den stellenweise schlechten Zustand der »Straße«, die also über längere Strecken nicht befahren, sondern nur beritten werden konnte, verwendet Lilienberg hier als Argument, um Wiener (kaiserliche) Unterstützung für Ausbauinvestitionen gleichsam zu erzwingen, angesichts der erfolgten Bestimmung dieses Weges zur »Poststraße«. Bedenkenswert ist, dass auch die Küstenstraße zwischen Scardona / Skradin und Split nicht wirklich durchgängig 
Von Zara aus wird jedoch die fahrbare Poststrasse nicht über Zatton, sondern über Zemonico, [Qu 25 / 2] Ostrovizza, Scardona und Sebenico nach Spalato gehen, bis wohin auch nächstens der durch Euer Majestät allerhöchste Gnade bereits von Wien bis Zara activirte Diligence-Wagen eingeleitet werden wird ${ }^{345}$.

Auch im Cattaroer Kreise sind mehrere Strassen angelegt worden, so daß man von Budua bis Risano ${ }^{346}$ fast fahren könnte, und diese Straße wird [ergänzt: nun] nach und nach bis Castelnuovo fortsetzen, so daß wir bald eine gute Comunication durch ganz Dalmatien Eurer Majestät allerhöchster Gnade zu verdanken haben werden. ${ }^{347}$

$\$ 67$ [Militärische Straßenverbindung von Zara zum Fort Clissa] Die für Dalmatien, besonders bei Entstehung eines Krieges gleichviel ob von der Seite der See, oder gegen die Türken in strategischer Hinsicht höchst nöthige Strassenverbindung ${ }^{348}$, ist die, welche von Zara über Ostrovizza, Derniš, Much zu dem Fort Clissa, und von da auf mehrere Punkte führt.

Der dritte Theil beilaufig ${ }^{349}$ ist bereits [Qu 25/3] beendet; aber das Beschwerlichste nämlich die Straße von Ostrovizza über die Kerka, dann von Ruxich ${ }^{350}$ über Much ist weder förmlich projectirt viel weniger bewilliget; auch wird solche viel Kosten, da der Zug von der Brücke von Roncislapo sehr beschwerlich und felsig ist.

Diese Verbindung wäre nicht nur wegen ihrer Kürze, sondern hauptsächlich auch deßwegen sehr anwendbar, weil man auf der ganzen Strecke, so wie ich mich selbst überzeugt habe, hinlängliches Wasser und Holz findet.

$\$ 68$ [Comunications Straßen auf dem Festlande und auf den Inseln] Nebst verschiedenen anderen fahrbaren [gleich von Rougier gestrichen: Straßen ${ }^{351}$ ] kurzen Comunications-Straßen und einigen Verbesserungen der Reitwege auf dem festen Lande sind auch auf den Inseln einige Straßen angelegt worden, nämlich auf der Insel Lissa, Curzola, Braz-

geführt war, da bei Skradin keine Brücke über die Krka bestand; dort setzte man vielmehr »auf einer Barke mit Wagen und Pferd« über den Fluss (Petter: Geographische Skizze, 19).

345 Vgl. zur Diligence bzw. dem neu bis Zara eingeführten Postwagen siehe weiter unten, $₫ 233$.

346 ON (Boka kotorska) Risano / Risan.

347 Wieder ein direkt auf die Funktion des Monarchen bezogener Herrschaftsdiskurs: Entwicklungsmaßnahmen / Investitionen als kaiserlicher Gnadenerweis.

348 Strategische Überlegungen beim Straßenbau, hier zugunsten einer dritten Straßenverbindung, ca. auf halbem Weg zwischen den beiden vorhandenen an der Küste bzw. nahe der osmanischen Grenze, die zugleich das zentrale dalmatinische Binnenland erschlossen hätte.

$349 \mathrm{Zu}$ verstehen als: ungefähr ein Drittel.

350 ON Ruxich / Ružić: Ansiedlung ca. 8 km südsüdöstlich von Drnišs, auf der damals noch nicht ausgebauten potentiellen direkten Wegstrecke zwischen Drniš und Klis (im Weiteren dann Split).

351 Eine wiederkehrende Struktur von Verbesserungen, die wiederum für eine zum Teil auch gleich unmittelbar korrigierte Diktatfassung spricht. 
za und Arbe, dann jene auf der Insel Pago welche Eure Majestät [Qu 25 / 4] zum erstenmal zu befahren geruht haben. ${ }^{352}$

Alle Straßen bis auf die roth bezeichneten ${ }^{353}$ sind von der Hofstelle als Bezirks- oder Comunal-Strassen erklärt worden und müssen von dem Lande erhalten werden, ${ }^{354}$ wenn man nicht etwa der äußersten Noth wegen, hie und da eine kleine Unterstützung aus dem Dazio Consumo ${ }^{355}$ angewiesen wird.

[Qu 26/1]

\section{Ur-Production}

$\S 69$ [Ihr Werth] Diese ist die sicherste Grundlage jeder Art Erwerbes, und muß deßwegen vom Staate am meisten befördert werden ${ }^{356}$; wenn sie gleich dem Kunstfleiße im Allgemeinen nicht durchaus unentbehrlich ist ${ }^{357}$.

Unter den verschiedenen Zweigen der Ur-Produktion verdient aber die Landwirtschaft die meiste Aufmerksamkeit, weil sie der industriellen Produktion ${ }^{358}$ die Nahrung

352 Eine direkte Wendung an den Kaiser mit Bezug auf dessen eigene Dalmatienreise, auf der er jenen Straßenabschnitt auf Pag am 4. Mai 1818 eingeweiht hatte. In seinem Reisetagebuch hatte der Kaiser festgehalten, dass die Straße auf Pag gut und eigens für ihn errichtet worden war. Dass er sie zugleich auch einweihte, war offenbar keine nähere Erwähnung wert oder verstand sich für ihn von selbst anhand des Sachverhalts, dass sie für ihn gebaut worden war. Krmpotić (Hg.): Car Franjo I. u Hrvatskoj 1818., 126.

353 Bezieht sich auf die Karte 1, hier im Anhang Seite 292, bzw. Originalanlage. VII, Reinschrift fol. 107 / Scan 217. Auf dieser Straßen- und Wegekarte sind die rot markierten Straßen wie weiter oben von Lilienberg dargelegt die Ärarialstraßen (also die Staatsstraßen).

354 Straßenfinanzierung war also überwiegend Landes- bzw. Gemeindeaufgabe.

355 Der Dazio consumo, deutsch zeitgenössisch auch als Verzehrungssteuer bezeichnet, war als kommunale Abgabe ursprünglich die Haupteinnahmequelle der Gemeinden gewesen; er wurde aber von der österreichischen Verwaltung zur Staatseinnahme umgewidmet, aus deren Aufkommen die Kommunen dann nur noch quartalsweise Entschädigungssummen für die entfallenen Einnahmen erhielten. Petter: Dalmatien, Band 1, $240 \mathrm{f}$. und 243. Vgl. auch $\mathrm{zu}$ den dazu bestehenden vielen dalmatinischen Klagen das Zitat aus einem Stimmungsbericht Lilienbergs für August 1835 in Clewing: Staatlichkeit, 154, Anm. 362, sowie mit scharfer Kritik von Lilienberg selbst hier weiter unten, in $\$ \$ 170$ und 171. Vgl. auch in der Einleitung, 23.

356 Also eine wirtschaftspolitische Schwerpunktsetzung in der Landwirtschaft (mitsamt Forstwirtschaft und Fischerei) und zugleich Zuweisung solchen Engagements als Aufgabe des Staates durch Lilienberg.

357 Der Halbsatz bedeutet soviel wie: [der Staat muss hier fördern], obwohl die Urproduktion (= Produktion in erster Linie der Landwirtschaft) ohnehin einem jeden ein Anliegen sein müsste.

358 Industrielle Produktion hieß im damaligen Sprachgebrauch auch jede handwerkliche Art von Weiterverarbeitung, also nicht beschränkt auf die Industrie im späteren engeren Sinne. Zur Schilderung ihrer Entwicklung in Dalmatien vgl. unten, $\$ 118$. 
und die meisten Stoffe zur Bearbeitung und Benützung für den Handel liefert, mithin die ergiebigsten Quellen jeder Art Thätigkeit eröffnet.

\section{Zustand des Landbaues}

$\$ 70$ In dem Betrieb des Landbaues habe ich so wie in den Sitten und Gebräuchen manche Abstufungen gefunden.

Im Zaraer Kreis wird ein Theil [Qu 26 / 2] bei Knin, Ostrovizza, Scardona und Derniš ziemlich fleißig bearbeitet; auch um Zara giebt es einige Streken, wo man keine Mühe spart und vorzüglich zeichnet sich das Gütchen des Doctor Orazio Pinelli darin aus.

Das Wirtschafts-Etablisement des bekannten Projectanten ${ }^{359}$ Manfrin, wurde schon gegen die Letzt der Lebzeit des Stifters ${ }^{360}$ vernachläßiget und jetzt kömmt es ganz in Verfall, weil die Wirtschaft von einem jungen unwissenden Menschen ohne Aufsicht des Besitzers schlecht behandelt wird.

Im Allgemeinen sind die Insulaner bis auf die - welche sich fast ausschließlich mit dem Fischfange [Qu 26 / 3] oder der Salzerzeugung befassen - die fleißigsten; und zu diesen gehören besonders jene der Insel Arbe und die von den Scoglien ${ }^{361}$ bei Zara, welche sogar Gründe auf dem festen Lande miethen und diese fleißig bearbeiten.

So habe ich auch auf der Insel Solta, Zlarin ${ }^{362}$, Lissa, Curzola viele Anstrengungen gesehen.

In Vergleich mit den zwei Kreisen von Spalato und Ragusa ist jener von Zara im Ganzen genommen weit zurück.

In dem Kreise von Spalato ist eine bessere Betriebsamkeit in [sic] Landbaue zu finden und ich wüßte [Qu 26 / 4] keine andere Ursache anzugeben als daß hier kaum der 20te Theil der Bewohner nicht unirte Griechen, die in jeder Hinsicht schlechter und fauler als

359 Die Bezeichnung bezieht sich auf das »Projekt« Pietro Manfrins vom 1830 gegenüber dem Kaiser.

360 Gemeint ist der Vater des »Projektanten «, Girolamo Manfrin (* Zara 1742, †Venedig 1802). $\mathrm{Zu}$ ihm und seiner bemerkenswerten Unternehmerkarriere in Venetien und in Nona / Nin vgl. den archivalisch recherchierten biographischen Eintrag von Frank, Martina: Girolamo Manfrin. In: Dizionario Biografico degli Italiani - vol. 68 (2007), verwendet unter http://www. treccani.it/enciclopedia/girolamo-manfrin_\%28Dizionario_Biografico\%29/ (7.12.2013).

361 TN (Inselgruppe vor Zara) der Scoglien (von italienisch scoglio, pl. scogli: Klippen, Felsen, Inselchen): bezeichnete die Inseln vor Zadar, und zwar entgegen der Etymologie und sonstigen Verwendung (für kleine, unbewohnte Inselchen) auch die größeren, bewohnten. Vgl. auch Petter: Dalmatien, Bd. 1, 16).

$362 \mathrm{ON} / \mathrm{TN}$ (Inselname) Zlarin / Zlarin. 
die Katholiken sind ${ }^{363}$, hauset; dagegen im Zaraer Kreis die Zahl dieser vernachläßigten Menschen neun Zwanzigstel beträgt. ${ }^{364}$

Dann hat auch Spalato als die Caravanen bestanden, viel stärkeren Handel gehabt, gwinnt [sic] auch dermalen bei dem türkischen Verkehre mehr als der Kreis Zara und so wie die Natur-Production diesen fördert, so wird sie auch von jenem [Handel und Verkehr] [Qu 27 / 1] gegenseitig sehr wohltätig unterstützt.

Am besten wird der Feldbau in der Gegend von Spalato und Salona in der Uferstreke von Trau bis Spalato wo sich die sogenannten Castelli befinden, in dem Thale von Verlika, Imoschi und Sign, in der Gegend von Trigl gegen Duare gegen die Abhänge des Bergs Biocovo vorzüglich aber in der schon in politischer Hinsicht erwähnten Pogliz$\mathrm{za}^{365}$, betrieben.

Die Narenta-Gegend, welche mit jener des Nills [Nils] verglichen werden könnte, würde noch viel mehr abwerfen, wenn die Grundbesitzer in der Agricultur erfahren und betriebsamere Menschen wären.

Im Ragusaer Kreise wird der Landbau im Ganzen noch besser als im Kreise Spalato behandelt. Die Ursache liegt darin, weil das Colonen- [Qu 27 / 2] Wesen dort viel beßer regulirt ${ }^{366}$ und der Grundbesitz bei vermögenderen und durch Reisen in fremde Länder in

363 Ein Ausdruck von Lilienbergs negativem Orthodoxenbild, und zugleich wohl auch seiner Erwartungen an ein gleichgerichtetes Bild von Seiten des Kaisers, der wie in der Einleitung gesehen Lilienbergs Rückhalt in Sachen der Unionspolitik war.

364 Lilienberg taxierte den Anteil der Orthodoxen an der Bevölkerung im Kreis Zadar also auf 45 \% gegen nur fünf Prozent im Kreis Split. Für die Kreisebene fehlen solche Angaben in den zeitgenössischen offiziellen Tafeln zur Statistik; vgl. aber gut vereinbar mit Lilienbergs Schätzungen ähnliche Zahlenangaben durch Prpa-Jovanović: Srpsko-dalmatinski magazin, $19 \mathrm{f}$.

365 Vgl. wie weiter oben, Anm. $290 \mathrm{zu} \S 58$.

$366 \mathrm{Zu}$ den Unterschieden zwischen dem in Dubrovnik (und der Boka kotorska) praktizierten »Kmetstvo« und dem in im engeren Dalmatien vorherrschenden Kolonat (jeweils als privatrechtliche Beziehung der sogenannten »Halbpacht« zwischen dem Grundeigentümer und dem bestellenden Bauern) siehe Obad: Dalmatinsko selo, 19f.; ders.: Agrarni odnosi na području bivše Dubrovačke republike 1814-1815; sowie vergleichend und vertieft bereits 1894 durch den Juristen und Rechtshistoriker Vladimir Pappafava: Studie über den Theilbau in der Landwirtschaft, besonders in Dalmatien, sowie über die Erträge in dem Gebiete der ehemaligen Republik Ragusa. Šime Peričić als der über lange Zeit profilierteste Sozialhistoriker für das dalmatinische 19. Jahrhundert hat in einem Aufsatz das Bild von der vergleichsweise besseren Entwicklung der Landwirtschaft im Kreis Dubrovnik hinterfragt und mit Blick auf die auch dort bestandene Unterversorgung mit Ackerbauprodukten relativiert. Zugleich aber zeigte auch er einen vergleichsweise hohen Stand des Wein- und Olivenbaus sowie des Obstanbaus. Die Dörfer im Raum Dubrovnik erscheinen auch bei ihm als mehr als der Rest der Provinz auf urbane Lebensformen (und damit wohl auch Land-Stadt-Marktbeziehungen) hin ausgerichtet, und er konstatiert seltenere Hungersnot als im übrigen Dalmatien (Peričić: Provobitna proizvodnja dubrovačkog okružja, dort 253 f., 255 f., 257, sowie 252 und 267). Insofern ist die Diagnose Lilienbergs (und einiger anderer Zeitgenossen, die Peričić anführt) der besser entwickelten Verhältnisse für den Bereich Ragusa wohl doch zu 
dieser Hinsicht aufgeklärten Menschen ist, und weil sie als Tributaire des ottomanischen Reiches durch die Kriege und Uiberfälle nie gelitten haben welchen das eigentliche Dalmatien bis auf die neuesten Zeiten immerfort ausgesetzt war und sich deswegen mehr den Waffen die es bis jetzt noch leidenschaftlich liebt, als dem Pfluge gewidmet hat ${ }^{367}$.

Auch war der Handel im Ragusaischen immer beträchtlich und dessen Bewohner haben die Caravanen bis auf den heutigen Tag behalten. Nichts destoweniger findet sich auch hier ein Unterschied in der Betriebsamkeit.

Die Ufer-Gegenden Canosa, Val di Noce, Malfi und Vitaglina ${ }^{368}$, das Thal der Ombla, ein bedeutender Theil des Gebiets von [Qu 27/3] Ragusavecchia, das Thal von Breno ${ }^{369}$ und Canali dann ein Theil der Halbinsel Sabioncello werden viel beßer bearbeitet, als es bei den mehr im Gebirge gelegenen Gründen geschieht und doch suchen diese Bewohner annoch so viel Gründe als möglich in der Türkei zu pachten ${ }^{370}$.

Der Kreis von Cattaro ist im Ganzen genommen noch schlechter daran, als der von Zara und ich glaube aus den nämlichen Ursachen, denn in diesem ist das Mißverhältniß zwischen den Katholiken und den nicht unirten Griechen so groß, daß die Leztern dreimal mehr an der Zahl als die Erstern sind. ${ }^{371}$ Dieses Volk ist noch roher und was hier sehr nachtheilig auf die Haushaltung überhaupt einwirkt sind die vielen Inquisiti [Qu 27/4] deren die Gerechtigkeit nicht habhaft werden kann, obwohl sie mit ihren Familien meis-

bestätigen. Ein simpler Zusammenhang mit der ehemaligen Republik und deren Strukturen besteht indessen nicht, denn laut den Angaben bei Peričić (254) zum Weinbau war dieser in den 1830er und 1840er Jahren erst im eigentlichen Aufschwung und dies am stärksten auf der Insel Korčula, die zwar zum Kreis Dubrovnik zählte, aber vor 1797 Teil von venetianisch-Dalmatien gewesen war.

367 Dies ist eine durchaus plausible Diagnose von Folgen der longue durée durch eine kriegsgeprägte Grenzlage und mangelnde Sicherheitsverhältnisse und -empfindungen infolge der osmanischen Bedrohung im ehemals venezianischen Gebiet, bzw. der Folgen der erfolgreichen Friedenswahrung für die einstigen Bewohner der Republik Dubrovnik. Die Einschätzung durch Lilienberg ist überdies insofern konsequent, als er an anderer Stelle auch eine Darstellung der negativen Folgen der allgemeinen Bewaffnung der männlichen dalmatinischen Landbevölkerung nicht nur für die Sicherheitslage, sondern auch für die Wirtschaft leistet; vgl. $\$ \$ 74$ und 126.

368 ON / TN (Kreis Ragusa) Vitaglina / Vitaljina: Dorf in dem Gebiet der Konavle.

369 TN (Tal, Kreis Ragusa) Breno / Župa dubrovačka (hier Breno statt weiter oben Brenno).

370 Ein Beleg für Pachtverhältnisse von österreichischen Untertanen auf osmanischem Gebiet entlang der Grenze, die für weitere Forschungen spannende Fragen etwa hinsichtlich der dafür offenbar ausreichenden Rechtssicherheit für Ausländer an der Peripherie des Osmanischen Reiches nahelegt.

371 Hier die erneute Darlegung von Lilienbergs negativem Orthodoxenbild. Jenseits dessen mag ein möglicher realer Hintergrund dafür, die schlecht entwickelte Landwirtschaft mit der Konfessionszugehörigkeit in Verbindung zu bringen, im offenkundig durchschnittlich wirklich nochmals deutlich schlechteren Bildungsstand der Orthodoxen (angefangen mit ihren Geistlichen) gelegen haben, wozu natürlich ihr geringer Anteil an der dalmatinischen urbanen Bevölkerung wesentlich beitrug, in der die kleine Bildungsschicht des Landes konzentriert war. 
tens leben und schwelgen; ihre Zahl beläuft sich auf mehr als 300 Köpfe und es wird von dieser Plage an seinem Orte umständlicher gehandelt werden. ${ }^{372}$

Doch giebt es auch hier manche Ausnahmen, zu welchen viele reiche Capitaine ${ }^{373}$ und auch einige bedeutende Güterbesitzer gehören, welche besonders die Gründe die an dem Canal von Cattaro liegen - sehr fleißig bearbeiten. Ich fand selbst eine Ausnahme bei den nicht unirten Griechen und zwar in der Gegend von Pastroviechio [sic] wo der Grund und Boden mit vieler Betriebsamkeit benutzt wird.

[Qu 28 / 1]

$\S 71$ [Behandlungsart der Gründe] Bei genauer Prüfung und Beurtheilung des hiesigen Landbau-Betriebs, habe ich aber auf meiner ganzen Reise und selbst bei den Mitgliedern der sogenannten Agriculturgesellschaft ${ }^{374}$ eine wahrhaft rationelle Behandlung der Gründe, wie man solche in den deutschen und vielfältig auch in den italienischen Provinzen sieht, hier nicht gefunden.

Ich sah leider, daß man sich um die genaue Erforschung der Beschaffenheit des zu benützenden Bodens gar nicht kümmere.

Von einer Beurtheilung der Beschaffenheit der Felsen oder einer anderen Mineral-Art, welche dem zu bebauenden Boden zur Unterlage dient und sehr wesentlichen Einfluß auf die Benutzungs- und Behandlungsart und auf die Erträgnißfähigkeit hat, verstehet man gar nichts. ${ }^{375}$

372 Ein deutlicher Hinweis auf die mangelnde Durchsetzungskraft des staatlichen Gewaltmonopols (und der Rechtsdurchsetzung) im Kreis Kotor.

373 Ein Beispiel für die durch den Fernhandel in der Boka vorhandene Vernetzung mit der Levante und das Ausmaß individuellen Wohlstandes einzelner Kapitäne bietet die GdZ 70/1834, 2.9., S. 280: Meldung zur Erinnerung an den verstorbenen Giovanni Boscovich aus Castelnuovo, Kreis Cattaro. Der in Smyrna ansässig gewordene und verstorbene Handelskapitän hatte mit Testament vom 2. Mai 1825 seine Hinterlassenschaft den Armen seiner Heimat zukommen lassen, im Wert von sechstausend türkischen Piastern. Derlei Abwanderung reicher Kaufleute aus dem Bereich Kotor war keine Ausnahme: In seiner umfassenden Darstellung österreichisch- und osmanisch-Albaniens (ÖNB, HS Ser.n. 2078) erwähnt Fedor Karacsay diese Tendenz als sehr stark (fol. 47v/48r). Trotzdem und trotz wachsender Konkurrenzprobleme mit griechischen und anderen Schiffen beschäftigte nach seiner Schätzung die Handelsschifffahrt in der Boka rund ein Drittel der Erwerbstätigen (Männer): fol. 50r.

374 Welche Gesellschaft hier gemeint ist - vermutlich mit Sitz in Zadar - bleibt offen; die "Società agronomica centrale di Zara« jedenfalls wurde erst 1850 unter Leitung des schon erwähnten Francesco Borelli gegründet.

375 Hier und in den folgenden Absätzen findet sich eine auch anderweitig untermauerbare, plausible Darstellung des Mangels an rationaler Landwirtschaftskenntnis in der Bevölkerung (betreffend praktische Bodenkunde, Düngemittelverwendung und Fruchtfolge). Vgl. auch weiter unten, $₫ 85$ (Kartoffelanbau), $\$ 86$ zum (Weiß-)Kraut, $₫ 87$ zum Viehfutteranbau bzw. zur nicht angewandten Stallhaltung (und Dunggewinnung) für das Vieh, $\$ 93$ zum Weinbau und $₫ 98$ zur Viehzucht im Allgemeinen. Dagegen zeigt die ausgeprägte innerdal- 
Ich habe sogar fast allgemein gesehen, daß man einen Unterschied zwischen der rohen oder todten Erde und zwischen der vegetablen ${ }^{376}$ und zur Fruchtbarkeit vollkommen tauglichen kaum in einigen Gegenden zu machen wisse.

Man kennt auch nicht den Unterschied [Qu 28 / 2] der Behandlungsart, welche zwischen dem schweren und festen oder lokeren Boden, eben so wenig auch zwischen dem gesäuerten oder Thon- und kalkartigen Boden statt zu finden hat.

Man weiß nicht zweckmäßig die für jeden besonderen Boden geeignete Dünge-Gattung fürzuwählen, erhitzt den Acker noch mehr, welcher abgekühlt werden sollte; macht den andern noch schwerer, oder säuerer, der gelokert oder versüßt werden sollte und umsoweniger kennt man die organischen Substanzen, deren Uiberbleibsel in diesem oder jenen Grunde vorgefunden werden, um darnach die Düngung und die Benützung angemessen einzuleiten.

Die Wenigsten kümmern sich, nach der Eigenschaft und Lage des Bodens die Gattung der Anpflanzung anpaßend zu bestimmen, sondern fast jeder baut jenes Getreide an, welches ihm am liebsten ist, ohne zu beurtheilen, ob die Beschaffenheit dieses Grundes hierzu tauge und so geschieht es, daß dort, wo Hafer, Gerste und [Qu 28 / 3] Korn sehr gut gerathen würde, der angebaute, gemeine oder türkische Waitzen [Mais] und Hirse äußerst schlecht gerathen, und durch die Wiederholung dieses Anbaues der Landmann verarmen muß.

Noch weniger weiß man hier von einem zweckmäßigen Turnus, wodurch bei gehöriger Abwechslung der verschiedenen Winter- und Sommergetraide-Gattungen, der Hülsen- und Knoll-Früchte, des Klees p.p. [usw.] die Fruchtbarkeit und die Ertrags-Kraft der Erde erhalten und meistens sogar genährt und befördert, im entgegengesezten Falle aber ganz erschöpft wird, und die Anstrengungen des unwissenden Bauers nicht lohnen kann. ${ }^{377}$

$\$ 72$ [Ackerwerkzeuge] Der Pflug ist meistens sehr schlecht ${ }^{378}$; man weiß ihn fast nirgends angemessen zu führen und da man auch die Bestandtheile der Erde nicht beurtheilen kann, so wird oft die gute Grumme ${ }^{379}$ vergraben und eine viel schlechtere Erde

matinische Ausdifferenzierung des Bildes zum Hornvieh (also der Rinderhaltung), die Lilienberg in $\$ 99$ vornimmt, dass er keineswegs einfach Pauschalurteile zu diesen Fragen abgegeben hat, sondern sich in seinem Urteil zu einem großen Teil von seinen konkreten, vor Ort gewonnenen Eindrücken leiten ließ - wodurch seine Darstellung der großen Schwächen der landwirtschaftlichen Praxis stark an Quellenwert und Aussagekraft gewinnt.

$376 \mathrm{Zu}$ verstehen als »fruchtbaren«.

377 Laut freundlicher mündlicher Mitteilung von Marko Rimac (Split) von September 2013 gab es aber örtlich durchaus auch Drei- oder sogar Vierfelderwirtschaft.

378 Zeichnungen eines typischen Pfluges und diverser weiterer Gerätschaften enthält der Kommissionsbericht von Franz Graf Hohenwart aus dem Jahr 1829: HHStA, St. K. Prov., Dalmatien 7 (alt 7/8), alt 8, fol. $229 \mathrm{ff}$.

379 Heutige Schreibung: Krume (Ackerboden). 
hervorgebracht, und indem meistens nur [Qu 28 / 4] ein einziges Mal geackert ${ }^{380}$ wird, diese ebenfalls nicht gehörig vegetabel gemacht.

Auch findet man, daß aus Mangel des Fundus instructus ${ }^{381}$ überhaupt oft die Pflüge und das Zugwirch ${ }^{382}$ dem Landwirthe gänzlich fehlen, die Feldarbeit - verspätet und dann übereilt werden, welches zwar in anderen Orten, wo es viele dürftige und kleine Besitzer, wie hier giebt, eben der Fall ist [sic, Satzbau].

Von einer zweckmaßigen Egge sah ich hier nirgend etwas, es kann seyn, daß sie wo bestehen mag, denn ich bin doch nicht in allen Gegenden gewesen, habe aber durch die drei Jahre, in welchen ich meine Bereisung vornahm, diese nirgends gefunden.

Man will [anstatt mit Eggen, K. C.] das ausgesähte Getraid mit Sträuchern, so wie man es auch in andern vernachläßigten Ländern zu machen pflegt, einscharren ${ }^{383}$; da aber die Furchen zum bedeutenden Nachtheile des Ertrags zu groß gemacht werden, und das [durch den Pflug, K. C.] umgestürzte Erdreich, weil es nur ein einziges Mal [Qu 29 / 1] geackert wird, fest beisammen bleibt, auch meistens hohl liegt, so werden die Körner vielfältig in die Furchen und in die Löcher hinabgewischt um zu verfaulen, oder von dem Ungeziefer verzehrt zu werden.

Die übrigen Landbau-Handwerkzeuge so wie die Wirtschafts-Wägen sind fast allgemein von einer antidiluvianischer [sic] Gattung ${ }^{384}$; die ersten ruiniren den Menschen, weil sie ihn zu sehr ermüden ${ }^{385}$, die Leztern das Zugvieh, weil sie unverhältnißmäßig schwer und ungeschickt gebaut sind.

$\$ 73$ [Akerbau-Methode] Von Reinigung des Ackers durch Entfernung der nachtheiligen Graswurzeln, von Zerschlagung der Schollen und von der Ausrottung des Unkrauts fand ich nirgend einen Beweis.

Um die Sammlung des Düngers kümmert sich der Gebirgsbauer, welcher dessen am meisten benöthigt sehr wenig; von diesem Vorwurf sind jedoch die Inselbewohner

$380 \mathrm{Zu}$ verstehen im Sinne von »umgepflügt«.

381 Hier zu verstehen als Hofausstattung (im engeren Wortsinn die Ausstattung, die über Generationen hinweg durch Erbe in einem Haushalt oder auf einem Hof angewachsen war; an derartigem Ausrüstungsfundus mangelte es den dalmatinischen Bauern offenbar völlig, die allein schon mit ihren damals armselig kleinen gemischten Wohn- und Nutzbauten sowie im Hinterland aus großer Knappheit an Holz und Metall zur Anhäufung solchen Haus- und Hofrates nicht imstande waren). Vgl. Petter: Dalmatien, Bd. 1, 136 zum extremen Mangel an verarbeitbarem Holz, das in der Provinz fast zur Gänze importiert werden musste und angesichts der Transportprobleme und resultierenden Preise der Bevölkerung des Hinterlandes fast nicht zur Verfügung stand.

382 Zugwerk, also das Spanngeschirr zum Einspannen der Zugtiere.

383 Vermutlich händisch mit einer Art Besen.

384 Also »vorsintflutlichen « Art.

385 So waren etwa einfache Hacken anstelle von Pflügen sehr verbreitet, mit den entsprechenden Mühen für die Bearbeitenden (vermutlich hier in hohem Maße Frauen). 
[Qu 29 / 2] die auf ihre gebirgigen Gründe sogar vom festen Lande den Dünger zuführen, so wie die Ragusäer und einige wenige Küstenbewohner ausgenommen.

Von einer Irrigation, die doch hier, da dieses Land sehr viel von der Dürre zu leiden hat, am zweckmäßigsten angebracht und auch vieler Orten möglich wäre, kennt man außer der Gegend um Trau und Spalato, wo einige wenige Besitzer solche einigermaßen anwenden, im Allgemeinen nichts.

Daß man durch diese Behandlungsart auch von dem besten Boden und in dem gemäßigsten Clima bei weitem einen guten Ertrag nicht erhalten könne und die Ernte, besonders bei Feldern, die einer sorgfältigen Pflege bedürfen, meistens kaum die Beurbarungs Kosten vollkommen bezahlt, dürfte nicht zu bezweifeln seyn.

[Qu 29/3]

$\$ 74$ [Grunde des vernachläßigten Akerbaues] Diese unbegreifliche Vernachläßigung rührt hauptsächlich davon her, weil Venedig, als ein erobernder und zugleich Handeltreibender Staat, sich um die Agricultur überhaupt, um Dalmatien aber am wenigsten in dieser Hinsicht kümmerte, und wie ich es schon in der Einleitung allerunterthänigst erwähnt habe, die moralische und Erwerbs-Ausbildung dieses Landes gleichsam geflißentlich - um es bloß als Werkzeug benützen zu können, vernachläßigte. ${ }^{386}$

Viel trägt allerdings zur Hintansetzung des Landbaues und der Hauswirtschaft überhaupt auch die allgemeine Bewaffnung der Bewohner des nuovo und nuovissimo aquisto [acquisto] ${ }^{387}$ des Kreises von Zara und Spalato und im ganzen Kreise Cattaro bei ${ }^{388}$, weil sich dadurch die [Qu 29 / 4] Leidenschaft für die Jagd bei dem Landmann erhält, und diese viele Zeit und viele Hände dem anderen Erwerbe entzieht.

386 Diese Venedigkritik lässt sich umgekehrt als Beleg dafür lesen, dass Lilienberg in der Landwirtschafts- und Ausbildungspolitik in erheblichem Maß die Verantwortung beim Staate liegen sah - natürlich auch im Sinne seiner Forderung nach mehr Unterstützung für Dalmatien aus der Wiener Zentralverwaltung!

$387 \mathrm{Zu}$ Lilienbergs näherer Darlegung der Begriffe des vecchio, nuovo und nuovissimo acquisto vgl. weiter unten $₫ 140$. Siehe auch Kartenbeilage 13, Seite 305 (bzw. auch Karte 3 in Clewing: Staatlichkeit, 418). Die Unterscheidung bezog sich auf die verschieden alten venezianischen Besitzstände im Bereich des späteren Kronlands (acquisto vecchio: venez. ab 1406 bzw. bis spätestens 1669; nuovo: venez. Erwerbungen auf Kosten des Osmanischen Reiches auf dem Frieden von Karlowitz 1699; nuovissimo: solche Erwerbungen auf dem Frieden von Passarowitz 1718). Zwischen dem acquisto vecchio und den beiden später erworbenen Gebietsteilen bestanden derartige rechtliche und strukturelle Unterschiede, dass der Zagreber Historiker Nikša Stančić den überzeugenden analytischen Begriff von den »zwei Dalmatien" geprägt hat, die auch noch zur österreichischen Zeit Bestand hatten. Stančić: Hrvatska nacionalna ideologija, 23 und 26.

388 Beurteilung (und Verurteilung) der inneren Folgen der allgemeinen Bewaffnung im Binnenland und in Kotor, die aber von Lilienberg gleich im Anschluss daran angesichts der auswärtigen Bedrohungssituation für noch nicht beseitigbar betrachtet wurde. 
Da man aber diese [allgemeine Bewaffnung] wegen der unruhigen Nachbarschaft der Türken und Montenegriner noch nicht abschaffen kann, so muß man bloß bemühet seyn, ihre widrige Einwirkung auf die Landwirthschaft so viel als möglich zu mindern.

Zum Theil glaube ich es dadurch mittelbar bezweckt zu haben, daß ich wie es in allen civilisirten Ländern zur Schonung der Jagd geschieht, das Jagen in der ganzen Provinz vom 15 März bis inclusive 15 July $^{389}$ mit der Gubernial Verfügung vom 21 May 1832 Z 4192 untersagt habe.

$\S 75$ [Werth der Landwirthschaft für Dalmatien] Weil nun unter allen Zweigen [Qu 30 / 1] der Ur-Produktion die Landwirthschaft, nach meiner allerunterthänigsten Meinung obenan stehen sollte, vorerst, weil durch diese unschuldigste Spekulation die Anstrengung des Menschen mit dem Segen der Natur und des Himmels in Verbindung kommt und wo diese blüht, die Sitten sicher gebessert sind, weil, da auch Fleiß und Anstrengung in Schwung ist, welche die Laster verschmähen; dann, weil nur da, wo die Urprodukte in gehöriger Menge hervorgebracht werden, die Manufakturen unabhängig von fremder Aushülfe, die wegen verschiedener äußern Verhältniße auch oft ausbleibt, leichter entstehen und besser hervorgebracht werden können und diese dann zur Belebung des Handels zweckmäßig beitragen, mithin die gehörige Benützung der Urstoffe, auch die Urquelle des Wohlstandes ist, so ist es auch meine vorzüglichste Pflicht, diesen [Qu 30 / 2] Erwerbszweig besonders Eurer Majestät Huld und Gnade in tiefster Ehrfurcht um somehr anzuempfehlen, weil Dalmatien auch aus dem Grunde durch diesen am leichtesten und am sichersten, nachdem es zur Errichtung der Fabriken und zur stärkeren Betreibung des Handels im Allgemeinen zu wenig Capitalien hat, seine oeconomische Lage wird verbessern und auf solche Art auch zur Erfüllung der Zwecke des Staates am Ausgiebigsten wird beitragen können. ${ }^{390}$

$\$ 76$ [Hauptmittel sie zu heben] Dieses dürfte, nach einer genauen Prüfung aller phisischen und moralischen Verhältniße und nach meinem allerunterthänigsten Dafürhalten, auf folgende Weise am Zweckmäßigsten geschehen:

a daß man den Feldbau von aller Hemmung und Druck entfeßele,

b daß man den Landwirth anweise, wie er seinen Boden durch die zweckmäßigste Bearbeitungs- [Qu 30 / 3] und Benutzungsart nach den in diesem Zweige gemachten und durch die Erfahrung bestätigten vielfältigen Entdeckungen so viel Ertrag als möglich abgewinne, und

389 Einführung einer Schonzeit bei der Jagd durch Lilienberg im Jahre 1832. 1834 zum Beispiel wurde sie auch in der Gazzetta di Zara im Frühjahr wieder kundgemacht.

390 Eine interessante Argumentation Lilienbergs zugunsten eines Vorranges für Landwirtschaftsförderung in Dalmatien gegenüber anderen wirtschaftspolitischen Aktivitäten. Der ganze $\$ 75$ ist dabei ein einziger Satz! 
c_ daß man seinen Fleiß, ohne welchen kein Wohlstand, vielweniger ein Reichtum bestehen kann, auf jede angemessene Art hebe, dann

d daß man auf die Verbesserung der Produkte möglichst einwirke, welches besonders rücksichtlich des Oehles und Weines höchst nothwendig ist;

e daß man sie aneifere ${ }^{391}$ die vielfältigen Pflanzen welche die Natur hervorbringt und die ganz unbenützt bleiben, zum Hausbedarf und zum Handel zu benützen, endlich f daß man den Absatz der Produkte mittelst thunlicher Entfernung aller denselben im Wege stehenden Hinderniße, erleichtere. ${ }^{392}$

$\S 77$ [Ausführungsart dieser Mittel] Um zu diesem gewünschten Ziele [Qu 30 / 4] gelangen zu können, ist nach meiner Uiberzeugung nothwendig

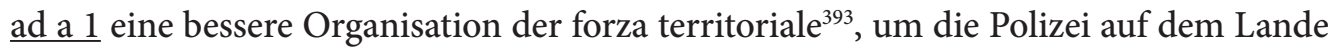
besser aufrecht erhalten und die unendlichen Feldschäden welche meistens aus Rache geschaffen und oft mehrjährige Anstrengung durch Aushauung der Weingärten und Oelbäume in einer Nacht vereiteln, von dem Feldbaue abzuwenden;

[ad] $2^{394}$ Die Aufhebung der öffentlichen Roboth ${ }^{395}$, wenn einmal der Zeitpunkt hiezu gekommen sein wird; worüber unter dem 24 December 1833 Z22227/7910 von der Landesstelle der vereinten Hofkanzlei ein umständliches Elaborat vorgelegt worden ist.

$391 \mathrm{Zu}$ verstehen als: »daß man sie [die Bauern] dazu anrege«.

392 Hier mit Bleistift Bearbeitungsvermerk am Rand: Dal Signor Segret. revisto [Gestrichen: copiato]. Gemeint ist: bis hierher ist bis zu einem bestimmten, nicht näher genannten Datum diese Durchsicht geschehen, aber noch nicht die Reinschrift.

393 Vgl. zu ihrer Struktur und Bedeutung Clewing: Staatlichkeit, 80 f. und 165, sowie nunmehr vor allem die betreffenden Arbeiten von Oršolić (dazu und zu weiteren Ausführungen Lilienbergs siehe unten, zu $\$ 182$ ).

394 Dieser Abschnitt (ad) 2 wurde am Rand ergänzt, dadurch wurde der fortlaufend anschlieBende Punkt zwei zu nunmehr drei, ebenso drei zu vier. Der Aktenbeleg geht auf eine entsprechende Randanmerkung bereits in der Gliederung zurück.

395 Robot: in der historischen österreichischen Verwaltungssprache übliche Bezeichnung für Frohndienste (mit der italienischen Entsprechung bei Petter: Fazioni pubbliche). Vgl. zur dalmatinischen Praxis Petter: Dalmatien, Bd. 1, 263 f. den Abschnitt »Frohndienst und Robottwesen«. Die von ihm aufgeführten Frohndienste waren dörfliche Wachdienste (mit Patrouillen oder »Ronda«), »um Diebstähle auf Feldern und in Weingärten zu verhüten«, täglich wechselnde Ordonnanzdienste beim Podestà oder Sindaco, ferner »Dienstleistungen bei Abgrabungen von Sümpfen, Eindämmungen der Flüsse, Reparaturen der Landstrassen, welche die Gemeinden betreffen, denn bei ärarischen Strassenbauten erhalten die Arbeitenden eine kleine Löhnung «, in gesundheitspolitischen Gefahrenmomenten auch Kordonsdienst sowie in Normalzeiten Vorspanndienste für das Militär (alles 262). »Die Aufforderung zur Frohne macht der Gemeindevorsteher, er sei nun Podesta, Sindaco oder Capovilla. Diese sind verpflichtet, eine strenge Reihenfolge (Turno) [unter den Robotpflichtigen, K.C.] zu beobachten. Zur Frohne sind alle männlichen Individuen von 16 bis 60 Jahren verpflichtet. Befreit sind diejenigen, welche körperlicher Gebrechen halber zur Arbeit untauglich sind, 
[ad] 3 Die baldigste Sistemisierung des Colonenwesens und Bestimmung der Rechtspflege bei den dießfälligen Streitigkeiten, weil die dermaligen Unordnungen und Mißbräuche, die bei den unendlichen und unbestimmten Verträgen dem Betrieb der Landwirthschaft sehr schädlich sind und nicht nur die neuen Untersuchungen, sondern sogar die gewöhnlichen Betreibungen des Ackerbaues äußerst [Qu 31 / 1] hemmen; [ad] 4 die möglichste Beschleunigung des Catasters, damit die Zehent-Einhebung, oder eine provisorische Einführung der Steuer, da Eines und das Andere unvortheilhaft ist, entbehrlich werde.

Diese drei [sic, Zählung zu erklären mit der Ergänzung um Punkt 2] Mittel würden wesentlich zur Hebung der Landwirtschaft beitragen; die da [mit Nr.] 1 und 3 könnten gleich angewendet, und das [gestrichen: Dritte; ergänzt 4t], wenn es Eurer Majestät gefällig wäre, auch in 8 oder längstens 10 Jahren ganz Dalmatien zu Theil werden.

$\$ 78$ [Ökonomische Kommissäre] ad b Da hier keine herrschaftlichen Meierhöfe, nur sehr wenig Landwirthschaften ${ }^{396}$ und solche nur am Gestade des Meeres; im Gebirge jedoch, wo es am meisten Noth hat, nicht vorhanden sind, welche aufgeklärteren und gemächlicheren Eigenthümern gehörten; die ersten politischen Organe ${ }^{397}$ aber von der Feldwirthschaft [Qu 31 / 2] im Allgemeinen gar keine Ideen haben; neugebildete Geistliche vorerst sehr wenige vorhanden sind, und ihre beschränkten theoretischen Begriffe, die sie in den Schulen von der Landwirthschaft erhielten, ohne Benützung einer Musterwirthschaft oder sonstige praktische Erfahrung eben so wenig ${ }^{398}$, wie die sogenannten Landwirthschafts Chatechismen dem unkündigen Landmann nützlich sind ${ }^{399}$, so kenne ich kein anderes Mittel, wenn man in dieser Hinsicht in viel kürzerer Zeit zum Ziele gelangen will, als besondere oekonomische Kommißaire zu diesem Zwecke anzustellen.

Diese würden in den Monaten Dezember, Jänner, Februar und März eine förmliche Lehrkanzel halten; die übrige Jahreszeit aber unaufhörlich ihre Kreise bereisen, um dem Landmanne in allem Nöthigen und die Landwirthschaft Betreffenden praktisch an die Hand zu gehen; Ihre Pflicht [Qu 31 / 3] wäre also:

I den Bauern mit einem zweckmäßigen Pflug und mit einer Egge bekannt zu machen;

ferner die Adeligen, die Diener der Religion und die Beamten. Wer sich davon frei machen will, kann einen Substituten stellen.« (262f.)

396 Gemeint sind größere (Guts-)Betriebe, die als Musterbetriebe wirken könnten.

397 Gemeint sind die Präturen; siehe auch den Abschnitt mit den Verbesserungsvorschlägen zu denselben ( $\$ 174$ ) und im Anhang das Dokument von Ehz. Franz Karl, Seite 315-324.

398 Also ist für diese Anfangsjahre eine nur geringe praktische (hier landwirtschaftliche) Bildung auch der neuausgebildeten jüngeren Geistlichen zu konstatieren.

399 In Dalmatien waren also, als ein spürbarer Unterschied zum damals überwiegend schon alphabetisierten Kernraum der Monarchie, die Bauern durch berufsbezogenes Schrifttum so gut wie nicht zu erreichen, allein schon, weil sie in der übergroßen Mehrheit nicht lesen konnten. 
II ihn lehren, wie er diesen überhaupt, so wie die übrigen Werkzeuge, nach Verschiedenheit des Bodens anwenden solle;

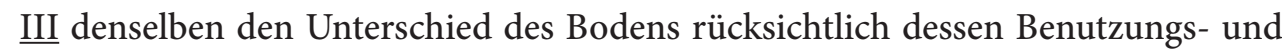
Düngerungsart, begreiflich machen;

IV ihm die Mittel an die Hand geben, wie er das Feld vom Unkraut und verschiedenem schädlichen Ungeziefer zu bewahren habe, endlich

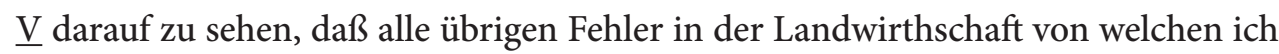
in aller Unterthänigkeit Erwähnung gemacht habe, nach und nach beseitigt und zweckmäßiger Turnus, nach Beschaffenheit des Bodens, der Getraid-Arten, die man baut, und des Clima, eingeführt werde.

Das Weitere rücksichtlich dieser oekonomischen Commissaire werde [Qu $31 / 4]$ ich unter dem Artikel Kreisämter allerunterthänigst nachtragen. ${ }^{400}$

$\$ 79$ [Aufmunterung zum Fleiße] ad c Den Fleiß des Landmanns kann man nur auf zweierley Art heben, nämlich:

$\underline{1}$ wenn man ihn praktisch belehrt und durch den Erfolg dieser Belehrung überzeugt, daß der Endertrag wirklich zugenommen hat; und dieses würde man am leichtesten und zweckmäßigsten auf die itzt beschriebene Art thun, dann

$\underline{2}$ durch die Austheilung einiger Prämien, welches besonders in einem rohen und dürftigen Lande, das einen verzogenem Kinde gleicht und mit Strenge nicht leicht dießfalls unmittelbar angehalten werden kann, sehr geeignet ist, die Betriebsamkeit zu heben.

$\$ 80$ [Verbeßerung der Production] ad d Die Verbesserung der Produkte würde dieser Commissär dadurch zu erzielen haben:

$\underline{1} \mathrm{Daß}$ er mit Sorgfalt auf die [Qu 32 / 1] Auswahl des Samens zur Aussaat,

$\underline{2}$ auf die Auswahl des Bodens, der für diese oder jene Gattung des Getraides und Pflanzen dient;

$\underline{3}$ und auf die öftere Verwechslung des Samens selbst, so wie

$\underline{4}$ auf gehörige Zeitigung der Früchte ${ }^{401}$ sehe.

Was die Vervollkommnung bei Erzeugung des Öhls und Weins anbelangt, darüber werde ich bey diesen besondern Artikeln das Weitere in aller Unterthänigkeit aufzuführen nicht unterlaßen.

$\$ 81$ [Belehrung des Landmannes über den Nutzen hier einheimischer Pflanzen] ad e Um die Benützung der vielfältigen Pflanzen, welche die Natur in diesem günstigen Clima hervor bringt, derer ich unter dem Artikel Handels- und Manufacturs-Gewächse erwähnen werde und die sowohl zum Hausgebrauch als auch zur Arzney, zum Betrieb

$400 \$ \$ 175 \mathrm{ff}$.

401 Gemeint ist wohl der jeweilige Zeitpunkt der Aussaat. 
der Gewerbe und des Handels anwendbar, aber meistens vernachläßiget sind, empor zu bringen, [Qu 32 / 2] müßen diese oekonomische Komissäre:

$\underline{1}$ den Landmann mit diesen bekannt und

$\underline{2}$ ihm den Nutzen den er daraus ziehen kann, dann

$\underline{3}$ deren Sammlung und Anwendung begreiflich machen;

$\underline{4}$ dürften auch hier, worauf ich noch vielfältig zurückkommen werde, kleine Prämien im Anfange angewendet werden.

$\$ 82$ [Erleichterung des Absatzes] ad f Was die Erleichterung des Absatzes der Produkte anbelangt, haben Euere Majestät so eben dem Lande durch die Allerhöchste Gnade, daß der Zoll bei Einfuhr des Weines über die Hauptlinie von 2 auf einen Gulden herabgesetzt worden ${ }^{402}$, eine große Wohlthat zu erweisen geruht, welche vom besten Erfolge seyn [gestrichen: würde] wird.

Wenn diese Allerhöchste Gnade beim Wein, und früher schon beim Oehle diesem Lande zu Theil geworden ist, so erscheint mir den Umständen und der Beförderung [Qu 32 / 3] der Landwirthschaft viel anpassender, eine Begünstigung für jene Producte bei Eurer Majestät in tiefster Ehrfurcht anzusuchen, die hier so vortrefflich erzeugt, sonst aber meistens nur aus fremden Ländern gebracht werden können und deßwegen das dafür ausgelegte Geld für die innere Circulation der Monarchie auf immer verlohren gehet, so wie die Pasiviteet des Handels vermehrt wird. ${ }^{403}$

Ich habe demnach der Landesstelle den Auftrag ertheilt, darüber die Kreisämter zu vernehmen, um dann die Verhandlung mit der Finanz-Intendanz einzuleiten, und einen wohl erschöpften ${ }^{404}$ Vorschlag dießfalls der Hofstelle vorzulegen.

402 Die Rede ist von der Verzollung der »Ausfuhr« dalmatinischen Weines über die zollpolitische »Hauptlinie« in den zu einem gemeinsamen Zollgebiet vereinten Hauptteil der österreichischen Reichshälfte. Dalmatien war zollpolitisch kein Teil derselben, sondern gemeinsam mit den Quarnerischen Inseln ein eigenes Zollgebiet. Zum konkreten Vorgang s. Hofkanzleidekret vom 20.5.1834 an sämtliche Länderstellen:»Herabsetzung des Einfuhrzolles für die Dalmatinischen Weine von $2 \mathrm{fl}$. auf $1 \mathrm{fl}$. Convetions-Münze In: Sr. K.k. Majestät Franz des Ersten politische Gesetze und Verordnungen für sämtliche Provinzen des Österreichischen Kaiserstaates mit Ausnahme von Siebenbürgen und Ungarn. Bd. 62: 1834. Wien 1836, $123-$ 125, mit den peniblen Ausführungsbestimungen, die dabei für die amtliche Kennzeichnung und Versiegelung des dalmatinischen Weines und der Transportgefäße galten (um den dalmatinischen Wein von ausländischem Wein zolltechnisch zu unterscheiden.

403 Wieder Beispiel für nationalökonomisches handelspolitisches (importfeindliches) Denken Lilienbergs (und seiner Zeit).

$404 \mathrm{Zu}$ verstehen als: »umfassenden«. 
Getraide-Bau

$\$ 83$ [Gattung desselben] In Dalmatien wird jede Gattung des in Europa bekannten Getreides gebaut, bis auf den Reis, mit dem man einmal einen Versuch gemacht und dann diese Cultur verlaßen hat.

Obwohl hier sowohl an den [Qu 32 / 4] verschiedenen Flüßen, als auch an den Seen, hinlänglich Gelegenheit hiezu wäre, so glaube ich doch dermalen keinen Versuch zu machen, weil wir ohnehin so viele Früchte und Gewächse besitzen, die vorerst beßer behandelt werden müßen; vielleicht werde ich bloß mit dem Bergreis ${ }^{405}$, wenn Geldmittel aus allerhöchsten Gnaden Eurer Majestät zu Gebothe kommen sollten, eine kleine Probe erstellen.

Die meisten Felder fand ich mit Winter- und Sommergerste, dann mit türkischem Waizen gebaut; von jeder dieser Sorten werden bei gutem Jahre bei 300000 Metzen und auch darüber gefechst.

Dann sah ich auch viel von der Moor- und gewöhnlichen Hirse ${ }^{406}$, an Heidenkorn ${ }^{407}$ aber wenig.

Von diesen drey Gattungen fechset man bis 178000 Metzen in einem Jahre.

Waizen wird mehr gebaut, als an Halbfrucht ${ }^{408}$ und an Korn ${ }^{409}$, obwohl man von den Leztern [Qu 33 / 1] größeren Ertrag bekommen würde.

Diese drei Gattungen geben auch beiläufig einen jährlichen Ertrag von 150000 Metzen.

An Hafer und Spelt ${ }^{410}$ fechst man in guten Jahren bei 130000 Metzen.

So wie ich nach meiner wenigen Kenntniß, die ich mir selbst sowohl bei der praktischen Landwirtschaft, als bei der Josephinischen Steuer-Regulierung; sowohl in Böhmen, als in Oberungarn gesammelt habe, zu beurtheilen vermag, glaube ich annehmen zu dürfen, daß man, wo nicht doppelt, wenigstens um die Hälfte mehr ernten könnte, wenn man den Feldbau mit mehr Sachkenntniß und Anstrengung behandeln würde, ohne besonderen Kostenaufwand zu machen, zudem [zu lesen als: zu dem, K.C.] die Dalmatiner noch zu arm sind ${ }^{411}$.

405 Der ohne Flutung auf höher gelegenen Feldern anbaubare »Bergreis« wurde im 19. Jahrhundert vom häufigeren "Sumpfreis« unterscheiden und botanisch Oryza mutica benannt. Begriff und botanische Unterscheidung scheinen heute beide nicht mehr üblich zu sein.

406 Moorhirse: im 19. Jahrhundert verbreitete Schreibung für die heutige Mohrenhirse (Sorghum bicolor), die offenbar weltweit wichtigste Hirsesorte.

407 Ein Synonym für Buchweizen.

408 Die Suche auf Google Books liefert für das 19. bis ins frühe 20. Jahrhundert diverse, vor allem (aber nicht nur) österreichische Treffer für diese Bezeichnung für eine Getreide-Gemengesaat; ein aktuelles Dokument der Wiener Universität für Bodenkultur bezeichnet »Halbfrucht« als Synonym für »Mengkorn«: eine gemeinsame Aussaat von Roggen und Weizen.

409 Damit ist in diesem Fall wohl »Roggen « gemeint, wie auch in großen Teilen Süddeutschlands üblich; vgl. auch die übrigen Erwähnungen durch Lilienberg.

410 Eine von diversen älteren Bezeichnungen für die Getreidesorte Dinkel.

411 Nämlich für besonderen Kostenaufwand zur Ertragssteigerung. 


\section{Hülsen-Früchte}

$\$ 84$ An Linsen und Erbsen habe ich außer dem $^{412}$ Zaraer Kreise nur wenig, aber um so mehr Bohnen gebaut gefunden und man fechset ihrer beiläufig im Ganzen in einem Jahr 25000 Metzen.

[Qu 33/2]

\section{Erdäpfel}

$\$ 85$ Zum Glück für dieses Land, daß sich die Erdäpfel eben durch Eurer Majestät allerhöchste Obsorge und besonders im Zaraer Kreise, wo der Landmann durch die lezte Noth ${ }^{413}$ mehr gewitzigt, diese Frucht auch beßer zu schätzen gelernt hat, nach und nach auszubreiten beginnen [Plural, sic]; doch geht es in den anderen Kreisen noch sehr langsam und ich fand deren im Spalatoer Kreis im Verhältniß gegen jenen [von Zara] sehr wenig.

In Ragusa fand ich noch viel weniger von dieser Frucht und der Kreishauptmann Baron Schaller ${ }^{414}$ hat mich versichert, daß ungeachtet aller seiner Mühe er aus dem Grunde nicht viel erzielen konnte, weil man dort eine Gattung von Kraut, welches ich an mehreren Orten sah und früher nicht kannte, baue und vorzüglich deßwegen liebe, weil dieses 4 bis 5 Jahre dauert, Winter und Sommer treibt und der Landmann sich dieser Blätter, wann er immer will zum Genuß bedienen [Qu 33 / 3] könne.

Die Bauern nennen dieses Kraut auch ihr zweites Brod ${ }^{415}$.

Im Zaraer Kreis hat man anno 1833 bei 200000 Zentner Erdäpfel gefechset; im Spalatoer Kreis, welcher im Flächeninhalt jenem nur um 2 Quadratmeilen nachsteht und ihn um 20000 Seelen übertrifft, wurden nur 8000 Zentner; in Ragusa nur 800 Zentner und in Cattaro kaum 200 Zentner gefechset.

Daß man in dem letzten Kreise so wenig Erdäpfel baut, kommt hauptsächlich daher, weil solche in Montenegro sehr viel und von vorzüglicher Gattung wachsen, und die Boccheser solche mit Oel und Feigen sehr leicht eintauschen.

Auch bei dieser Frucht habe ich mich überzeugen müßen, daß man an der Auswahl des anpaßenden Terrains, in der Anpflanzung und Umgrabung, dann in der angemeßenen Beschneidung der Stängeln sehr weit zurück und deßwegen vielfältig der Ertrag sehr mäßig sey.

$412 »$ Außer dem« hier zu verstehen als »außerhalb des«.

413 Zwar war gerade 1834 im festländischen Dalmatien seit dem Frühjahr ein Dürre- und Mangeljahr (Peričić: Oskudica i glad, 109), doch spricht Lilienberg nicht davon, sondern offenbar von der durch eine lange Dürre (1828/29) hervorgerufenen Hungersnot von 1829/30; ab 1830 nahm der dalmatinische Kartoffelanbau deutlich zu (Peričić: Gospodarska povijest, 110), Lilienberg zufolge aber nicht gleichmäßig in der ganzen Region.

414 Ferdinand Baron von Schaller, k. k. Hofrat und Kreishauptmann von Dubrovnik (Almanacco 1834, 100).

415 Welches für die Region Dubrovnik spezifische Kraut bzw. Gemüse damit gemeint sein könnte, war nicht zu eruieren. 
[Qu 33 / 4]

Garten- und andere vorzüglichere Feldgewächse

$\$ 86$ [Kraut] Es wird bereits ziemlich viel Kraut zum Einsäuern gebaut, aber ich habe gesehen, daß man in der Auswahl des Terrains, des Sammens und der Pflanzen nicht genug behutsam seye und daß aus diesem Grunde auch viel weniger und auch eine schlechtere Art erzeugt wird.

Beßer sieht es mit den Knoll-Gewächsen aus und ich habe viele gewöhnliche Krautund einige schwedische Rüben ${ }^{416}$ gesehen, die von außerordentlicher Größe waren.

Auch die Waßerrüben ${ }^{417}$ gerathen sehr gut; von den feinern Gewächsen als: Stöckelund gelbe Rüben; dann Blumen- und anderer feiner Kohl, die Petersilie, Sellerie, der Spinat, Spargel und der gleichen wird äußerst wenig gepflanzt;

Das meiste davon kommt aus dem Päpstlichen und aus Appulien.

Dagegen macht Dalmatien sehr [Qu 34 / 1] gute Fortschritte in der Anpflanzung des Zwiebels und Knoblauchs, für welche, ehe Eure Majestät diese Länder in Besitz genommen haben, sehr beträchtliche Summen, weil sie nebst dem Brod die gewöhnliche Kost der Morlaken sind, ins Ausland geschickt wurden. Ich sah besonders von Zwiebeln so schöne und große Knollen, daß ich einige an die inländisch-deutschen Agriculturs-Gesellschaften versendet habe.

$\mathrm{Zu}$ Derniš fand ich ein Feld von etwa einem Metzen ganz mit Zwiebeln bebaut und der Eigenthümer hat mich versichert, daß ihm dieser im verflossenen Jahre, wo er auch mit dem nämlichen Gewächs bebaut war, mehr als hundert Gulden, da er diesen aber früher mit Getraid baute, nie mehr als 10 Gulden reinen Nutzen eingetragen habe. ${ }^{418}$

Den $\mathrm{Kren}^{419}$ findet man noch äußerst [Qu 34 / 2] wenig, weil die Morlaken überhaupt wenig Fleisch und dieses meistens gebraten genießen, so bedürfen sie um so weniger dieser edleren Pflanze, als ihnen Zwiebel und Knoblauch zu allen Gerüchten [Gerichten] am besten schmeckt.

Im Jahre 1833 war die Fechsung im Ganzen bei allen diesen Garten- und vorzüglicheren Feldgewächsen mehr als 356000 Zentner.

416 Eine andere Bezeichnung für die Steckrübe.

417 Die Wasserrübe (auch Herbst- oder Krautrübe) war eine vor Ausbreitung der Kartoffel auch in Mitteleuropa sehr weit verbreitete, heute aber sehr seltene Speiserübe: http://de.wikipedia. org/wiki/Herbstr\%C3\%BCbe (25.10.2013).

418 Die Erlösangabe für den Zwiebelanbau ist nicht nur im Vergleich zum Getreideerlös sehr hoch, sondern auch verglichen etwa mit den damaligen staatlichen Jahresdotationen von 200 Gulden für einen katholischen Landpfarrer (vgl. Clewing: Staatlichkeit, 113) oder Jahresgehältern für Beamte in den niedrigeren Gehaltsstufen von 300-400 Gulden (Orosz: Worte eines Staatsdieners, 44).

419 Also ein typisches Würzkraut für viele typische gesottene Fleischgerichte der mitteleuropäischen Küche, deren zunehmende Verbreitung (»noch») auch in Dalmatien von Lilienberg dann doch ganz imperial als selbstverständlich vorausgesetzt wurde. 


\section{Futter-Bau und Wiesen}

$\$ 87$ Vom Futterbau weiß man hier, leider, im Allgemeinen gar nichts, und nur hie und da fand ich eine unbedeutende Ausnahme, weil hier von einer Stallfütterung gar keine Rede und dieses auch das große Uibel ist, wodurch die Viehzucht, besonders zur Winterszeit, wo man wenig Weide findet ${ }^{420}$ und der Ackerbau auch sehr viel leidet, weil der ganze Dünger [Qu 34 / 3] der für die hiesigen meistens magern Gründe sehr ersprießlich wäre, verlohren geht.

Die Wiesen werden übrigens auch aus diesem Grunde nicht zweckmäßig behandelt, weil man sie im Frühjahr und auch nach der ersten Heumaht zu lange mit dem Vieh und ohne Unterschied, ob eben in diesem Augenblick der Boden zu naß und durch die tiefen Tritte des Viehs zu viel oder wenig Schaden verursacht wird, abweidet.

Auch in dieser Hinsicht und besonders wegen Düngung oder Aussäuerung und Besamung mit Blumensämen der Wiesen, ist eine Anleitung und der Rath eines erfahrenen Mannes unumgänglich nöthig; denn bis jetzt ist die Futtererzeugung äußerst unbedeutend, so daß solche in den besten Jahren nicht einmal 600000 Zentner abgeworfen hat.

[Qu 34 / 4]

Hutweiden $^{421}$

$\$ 88$ [Ihre Ausdehnung. Beschaffenheit] Diese sind sogar für die beschränkte Zahl des Viehstandes, weil sie mit vielen Gattungen [von] Thieren durch das ganze Jahr und Tag und Nacht benützt werden, nicht hinlänglich und das meiste Vieh wird alle Jahre, manchesmal auch aus Mangel des Trinkwassers, was in vielen Theilen Dalmatiens eben heuer der Fall ist, den Sommer hindurch nach Militair-Croatien und nach Bosnien auf die Weide getrieben, welches zu vielen Unordnungen führt, aber durchaus bis die Landwirthschaft nicht auf den Grad Eurer [gestrichen: Excellenz; ergänzt mit Handschrift Rossetti: Majestät $\left.{ }^{422}\right]$ übrigen glücklichen Provinzen gebracht ${ }^{423}$ und dem Wassermangel nach und nach nicht besser abgeholfen seyn wird, nicht abgeschafft werden kann. ${ }^{424}$

[Qu 35 / 1] Es werden zwar, wenn die Catastral Ausmeßung beendigt ist, sehr beträchtliche Summen an Jochen von Hutweiden vorkommen, aber ich kann zur Aufklärung dieses Umstandes im Voraus in tiefster Ehrfurcht anführen, daß in dieser Rubrick, nach meiner Uiberzeugung, wenigstens die Hälfte ganz nakte Felsen begriffen seyn werden.

420 Das heißt wohl: im Winter gehen die Nutztiere gezwungenermaßen noch weitere Wege und verstreuen ihren Dung daher nach Zufall weit umher.

421 Hutweide: Weidehaltung mit Hirten bzw. Hütebuben.

422 Dieser wohl von seinen üblichen Schreibgeschäften herrührende Flüchtigkeitsfehler des Rougier ist für diese konkrete Stelle ein Hinweis auf eine Ab-oder Zusammenschrift anhand von erweiterten Notizen, denn ein etwaiger Diktatfehler kann dieser Adressatenverwechslung nicht zugrunde liegen.

423 Wirtschaftspolitisches Angleichungsziel an die anderen Provinzen.

424 Von den klimabedingten Fakten und Investionsmangel in Brunnenanlagen etc. erzwungene Offenhaltung der Grenze auch in das osmanische Bosnien, in Fragen der Weidewirtschaft. 
Handlungs- und Manufacturs-Gewächse

[\$ 89] Der Flachs[-] und Hanfbau nimmt langsam zu, so daß man im vorigen Jahre vom ersteren 325 und vom Hanf 70 Zentner erhalten hat ${ }^{425}$.

Man findet hier überall den spanischen Ginster wild, der hie und da so wie der Hanf behandelt und zu grober Leinwand verwendet wird.

Aus den Blättern der Agave americanae, Aloe, welche an viele [sic] Inseln wächst und hanfartige Fäden enthält, werden [Qu 35 / 2] Stricke gemacht.

Rosmarin wächst auf der Insel Lesina und Brazza besonders. Er wird aber auch sonst gefunden, und sogar als Zäumung bei den Gärten gebraucht.

Auf Lesina fand ich aus diesen Sträuchen das vortreffliche Wasser: acqua di Regina, welches auch Handelsartikel ist.

Salbey wächst überall in einer außerordentlichen Menge, wird aber, außer zur Weide für Schafe und Geise [Geißen, K. C.], noch gar nicht benützt.

Saflor ${ }^{426}$ wird nur wenig, etwas mehr an Safran gebaut, besonders auf der Insel Lissa und Lesina. Der Letztere kömmt auch wild vor, ist sehr aromatisch und wird einmal, wenn mehr Betriebsamkeit erwacht, auch einen Handelsartikel bilden.

Orchis-morio und der übrige Orchis [Qu 35 / 3] wächst hier sehr häufig und giebt einen vortreflichen Salep ${ }^{427}$; man hat damit sogar in Wien Proben gemacht, die sehr gut ausgefallen sind; ich gedenke diese zu wiederholen, weil man dabei gut fahren könnte. ${ }^{428}$

Officedro $^{429}$, von welchem der Sandrak Gummi gesammelt wird; wächst, aber noch unbenützt, in Dalmatien.

Salz- oder Sodakraut wächst an der Meerküste und könnte auch auf anderen öden Plätzen angepflanzt und gut benützt werden. Den [sic] Storaxbaum der nur in Sirien und Judäa fortkommt, wird auch an mehreren Orten gefunden.

Kreuzdorn Beern; sie sollen dem Grains [Graines, K.C.] d'Avignon ${ }^{430}$ gleichkommen, werden hier gebraucht, sind aber noch nicht im Handel.

Süßholz wächst von besonderer Güte bey Zara und auf den Inseln vielfälltig.

425 Die Zahlenangaben sind mit rotem Stift korrigiert in 506 bzw. 89 Zentner.

426 Färberdistel.

427 Aus Orchideenwurzeln gewonnenes Verdickungsmittel (seinerzeit auch als Hausmittel bei Durchfall verwendet); vgl. http://de.wikipedia.org/wiki/Salep (25.10.2013).

428 Unterstreichung mit Rotstift.

429 Der Sandarakbaum, ein kleinwüchsiges Zypressengewächs (Tetraclinis articulate), aus dessen Harz mehreren Treffern in der zeitgenössischen landwirtschaftlichen Produkteliteratur zufolge im frühen 19. Jahrhundert andernorts der benannte »Gummi« gewonnen wurde (ein eher geringwertiges Klebemittel).

430 Rhamnus catharticus minor, der Purgier-Kreuzdorn, dessen Früchte getrocknet als Abführmittel verwendet wurden: http://de.wikipedia.org/wiki/Purgier-Kreuzdorn (26.10.2013). 
Die Vallonea [Wallonen-Eiche, K.C.], welche statt Knoppern ${ }^{431}$ verwendet werden könnte [Qu 35 / 4] ist hier hinlänglich ${ }^{432}$ aber noch unbenützt.

Der Wunderbaum Ricinus concumis deßen Anbau vorigen Jahres (1833) versucht ${ }^{433}$ wurde, gedeihet gut.

Die Myrthe, welche auf der Insel Calogera ${ }^{434}$ bei Zara, auf Lesina dann bald als Strauch, bald als Baum vegetirt ${ }^{435}$, hat sehr gewürzhafte Beeren, welche in den Apotheken vielfältig gebraucht werden. Maurelle, Croton tinctorum. Diese hier häufig wachsende, in Frankreich so sehr benützte Pflanze bleibt hier meines Wissens ${ }^{436}$ ganz unbenützt.

Mastix-Bäume werden auch verschiedener Orten angetroffen, aber man weiß sie nicht zu benutzen.

$\mathrm{Krapp}^{437}$; hier kommt sowohl der gemeine, Rubia tinctorum als auch der levantische, Rubia peregrina gut fort, aber wird nicht verwendet.

[Qu 36 / 1] Zedrach, Paternosterbaum ${ }^{438}$, aus dem Baum-Oehl in kleiner Quantität gepreßt wird, kommt gut fort.

Binsenkraut wächst auch viel überall an den Morästen, wird aber gar nicht benützt.

Galläpfel sind hier häufig und sind auch ganz unbenutzt.

Meerzwiebel. Scilla marittima kommt auf der Insel Lissa vor und wird als Arzney gebraucht.

Kappern wachsen an alten Mauern; auf der Insel Lesina fand ich die schönsten und man versichert mich daß man in mehreren Jahren bei 2000 Gulden lösen dürfte. Man bringt sie bereits stets im Handel ${ }^{439}$.

431 Von der Gallwespe an Eichenblättern und -früchten hervorgerufene Wucherung, die in den Zeiten rund um Lilienbergs Bericht ursprünglich vor allem in Ungarn und angrenzenden Ländern beim Ledergerben verwendet wurde und zu umfangreichen Rohhäuteexporten in jene Länder führte. Vgl. Franz Anton Edler von Stubenrauch: Kurzer Bericht von Knoppern und Eichenlohe in Baiern. Ohne Ort 1775, $₫ \$ 2$ und 3.

432 Soll heißen: hinlänglich verbreitet, also einigermaßen verbreitet.

433 Rot ausgebessert statt zunächst »verursacht« (dies klingt wieder nach Diktat-/Hörfehler).

434 ON / TN Calogera/ spätere Schreibung im Text auch Caluggera / Ošljak: kleine Insel mit gleichnamigem Ort im Zadarski kanal, nahe der Stadt und vorgelagert zur Insel Ugljan (mit dem Ort Preko).

$435 \mathrm{Zu}$ verstehen im Sinne von "wächst; gedeiht«.

436 "Meines Wissens« wurde rot, also durch Lilienberg, in der Redaktion ersetzt durch »noch».

437 Förberkrapp, eine vor Erfindung synthetischer Förbemittel für die Verwendung in Mitteleuropa und dem Mittelmeerraum sehr wichtige Färbepflanze mit Hauptverbreitungsgebiet östliches Mittelmeer und Levante: http://de.wikipedia.org/wiki/F\%C3\%A4rberkrapp (26.10.2013).

438 Botanisch: Melia azedarach.

439 Der letzte Satz ist mit Rot ergänzt. 
Mandel-Harz. Nach den Berichten des Kreisamtes zu Spalato vom Jahre 1822 hat man aus der Gegend von Trau und Bossiglina ${ }^{440}$ allein einige tausend Pfund ausgeführt: itzt hat es nachgelaßen.

Manna; mit diesem könnte man [Qu 36 / 2] die ganze Monarchie versehen.

Pistazien sind schon im Handel; könnte aber noch viel erweitert werden.

Das Clima wäre auch ganz für die Baumwolle geeignet, ich will mich bemühen, ob ich aus Sizilien, oder Puglien Samen erhalten kann. ${ }^{441}$

Wenn also diese besonderen Gewächse angemeßen benützt würden, was könnte man für einen Gewinn daraus ziehen und so wie mich der berühmte Botaniker [ausgelassene Stelle, ergänzt in Rossettis Handschrift:] Viviani ${ }^{442}$ versichert, so wird er noch wenigstens 50 ganz unbekannte, bloß in Dalmatien eigene ${ }^{443}$, Gewächse bekannt geben.

\section{Tabak}

$\$ 90$ So wie allgemein versichert wird, wurde in Dalmazien und besonders in der Poglizza, bei Vergoraz und in Pastrovicchio eine vorzügliche Gattung Tabaks gefechset, welche dem Macedonischen an Güte gleich gewesen sein soll.

Da sich die Anpflanzung mit dem Monopol nicht leicht verträgt, so unterblieb solche ganz.

Dieses Monopol trägt dermalen dem allerhöchsten Orario beyläufig $18000 \mathrm{Fr}$ jährlich und es sind $[\mathrm{Qu} 36 / 3]$ der Hofstelle Vorschläge vorgelegt worden, in welchen von mir und von der Landesstelle auf die Aufhebung dieses Monopols angetragen wird. ${ }^{444}$

In einer Provinz, welche eine ganz unverhältnißmäßig große Peripherie zu ihrem Flächeninhalte und zu ihrer Bevölkerung hat und wegen der Coupirung ${ }^{445}$ des Terrains

440 ON Bossiglina / Marina (alt auch eine kroatische Variante: Bosiljina): Ansiedlung und Hafen bei Trogir.

441 Die beiden letzten Sätze sind am Rand schwarz ergänzt und dann noch einmal, in offenbar der gleichen Schrift, rot erweitert, wohl beide Male durch Lilienberg selbst.

442 Gemeint sein muss Domenico Viviani (1772-1840), ein bekannter italienischer Botaniker der Zeit, auch wenn die Suchergebnisse zu ihm vorderhand keine Bezüge zu einer Beschreibung der Botanik Dalmatiens erkennen lassen.

$443 \mathrm{Zu}$ verstehen als: »nur in Dalmatien vorkommende» (endemische) Pflanzen.

444 Dieser Ertrag resultierte aus dem im staatlichen Monopolvertrieb erfolgten Absatz von (nicht in Dalmatien) produziertem Tabak bzw. von Tabakwaren innerhalb der Provinz. Peričić: Gospodarska povijest Dalmacije, 111, nennt 1818 als Jahr des zentralbehördlichen Verbots für den Tabakanbau in Dalmatien, der bis dahin besonders in den Gegenden der Poljica, von Imotski, Makarska und der Boka kotorska floriert hatte.

445 »Coupierung (heutige Schreibung und gewandelter Sinn: Kupierung) bezog sich gemessen an den Treffern einer Google-Suche unter »Coupirung « und »Coupirung Terrain« zeitgenössisch in der Regel auf einen bestimmten Zuschnitt von Wasserbaumaßnahmen vor allem an der Meeresküste (Buhnensetzung); einige wenige Treffer zeigen aber, dass es in wesentlich seltener Verwendung auch für den (zum Teil auch durch Terraingestaltung menschengemachten) »Zuschnitt« einer Landschaft stand. Vgl. insbesondere Wedekind, G.W. Frhr. von 
unmöglich zu überwachen ist wie es bei der Beschreibung der Gränze klar erwiesen wurde ${ }^{446}$, und welche von der Landseite überall mit Ländern umgeben ist, wo der Tabak im Uiberfluße wächst und ganz frey verbraucht und verkauft wird; von der Meerseite durch die Fischers Barken, welche Tag und Nacht im Meer sind, mit allen fremden Schiffen in Berührung steht; läßt sich ein Monopol ohne den größten Nachtheil für die Moralität ${ }^{447}$ nicht aufrecht erhalten; und da der [Qu 36 / 4] Tabak einst einen ergiebigen Erwerbszweig im Lande gebildet hat, das Aerarium auch für dieses Monopol leicht entschädigt, zugleich aber auch das Geld, welches für den Macedonischen Tabak in die Türkei jährlich geschickt wird im Lande behalten werden könnte; so wäre es sowohl in moralischer als oekonomischer Rücksicht räthlich und selbst der Staatsklugheit gemäß, das Monopol frey zu geben. ${ }^{448}$

\section{Erdschwämme}

$\S 91$ Erdschwämme ${ }^{449}$ sind hier äußerst selten, von keiner besonderen Gattung und ich fand selbst in den Wäldern keine.

[Am Rand vermerkt und gestrichen: Bis hier haben der Herr Sek. revidiert]

[Qu 37 / 1]

Obst, andere Bäume und Stauden

$\$ 92$ Die gewöhnliche Obstbaum-Zucht ist hier überhaupt nicht beträchtlich, weil solche auf den Inseln und im Küstenlande durch den Oehl-, Feigen- und Mandelbaum verdrängt wird; doch findet man von Aepfeln einige vorzüglich gute Gattungen im Ragusäischen, wo auch vortreffliche sehr aromatische Quitten vorkommen; Kirschen überall, hauptsächlich in Cattaro, und besonders viele Marasche ${ }^{450}$, aus welchen der vortreffliche Maraschino Rosoglio ${ }^{451}$ gebrannt wird, und deren Beste aus der öfters erwähnten, sogenannten Grafschaft Poglizza herkommen, in ziemlicher Menge.

(Hg.): Neue Jahrbücher der Forstkunde. Heft 18, Darmstadt 1840, 194; sowie weiter unten im Lilienbergschen Text den Begriff »coupirte Grenze« in $₫ 124$.

446 Siehe $\$ 26$.

447 Mit diesem Moralitätsbegriff der damaligen Verwaltung ist nicht nur moralisches Handeln an sich gemeint, sondern das gruppen- bzw. sozialpsychologisch konstitutierte Rechtsempfinden in der Bevölkerung, das in diesem Fall gemäß der plausiblen Diagnose Lilienbergs durch unrealistische staatliche Verhaltensvorgaben untergraben wurde. Das Argument der Irrationalität des Tabakmonopols wird in den folgenden Absätzen wie zu sehen noch auf ökonomische und staatspolitische Argumente hin erweitert.

448 Vgl. auch unten, $\$ 236$. Zugleich ein erneuter Beleg für die Lilienbergsche handels- und wirtschaftspolitische Maxime der Importsubstitution.

449 Im Wesentlichen synonym zu »Schwamm; Pilz« (vgl. das Gegenstück: Holzschwamm).

450 Verbessert aus »Maraschke«; eine kleinfruchtige Art Weichsel.

451 Der Maraschino-Likör wurde damals in Zadar, Šibenik und Split gewonnen. Der aus Zadar besaß als wohl einziges dalmatinisches Produkt über die Provinz hinaus als Marke hohen Bekanntheitsgrad. Rund um dieses Produkt fand - angefangen mit der ausgeprägten Markt- 
Limonien und Pomeranzen sind noch äußerst wenig; dagen [sic! wohl «dagegen`] haben wir auf einigen Inseln sogar die indianischen Feigen ${ }^{452}$ und Datteln; leztere werden aber höchst selten vollkommen reif.

[Qu 37 / 2] Auf die Verbreitung der Pomeranzen und Limonien, die hier auf allen Inseln im Freyen sehr gut gerathen, wird man auch nach und nach, wenn der Maulbeerbaum $^{453}$, auf welchen ich alle Aufmerksamkeit leiten will, beßer aufgekommen ist, einwirken und sehr bedeutenden Gewinn dadurch erhalten können.

Granat- Äpfel kommen überall sehr gut fort und sind um Spalato häufig.

Den Johannisbrotbaum /:Carobe:/ fand ich sehr viel auf den Inseln Lesina, Lissa, Brazza und Meleda. Er kömmt schon im Handel vor und könnte vielleicht den Bedarf für alle oesterreichischen Provinzen decken.

$\left[{ }^{454}\right.$ Gestrichen: Weinstock

Der Weinbau ist in diesem Lande sehr ausgedehnt, und man erweitert solchen immer mehr, weil dieser an allen Orten selbst in den schlechtesten] [Qu 37/3] [Gestrichen: Weinstock]

Die Oehlbaum-Zucht ist sehr ausgedehnt und verschaffet dem Lande den meisten akiven Gewinn, aber auch diesen edlen Baum fand ich, bis auf den Kreis Ragusa, wo er besonders gut gepflanzt wird, äußerst vernachläßigt.

Man sollte glauben, daß, weil der Handel und Wandel die Bewohner des übrigen Dalmatiens vielfältig nach Ragusa bringt, diese sich an der besondern Obsorge des Oelbaumes spiegeln und die Zucht in ihrer Heimath verbeßern würden.

Aber das Vorurtheil, was überhaupt in diesem Lande in vieler Hinsicht auf alle mögliche Art langsam bekämpft werden mu $\aleph^{455}$, macht, daß sie sich darüber ganz gleichgül-

beziehung zwischen den genannten Städten und den Marasken-Lieferanten im jeweiligen weiteren Umland, und von da bis zu Gründungen erster Großbrennereien wie derjenigen in Zadar - einer der ersten und isolierten Ansätze zu industrieller Erzeugung statt. Vgl. Petter: Dalmatien, Bd. 1, 71 f.; sowie Peričić: Gospodarske prilike Dalmacije, $111 \mathrm{f}$.

452 Opuntia ficus indica: Feigenkaktus.

453 Maulbeer- bzw. Seidenzucht als ein landwirtschaftspolitisches (und regionalpolitisches) Hauptziel Lilienbergs: siehe oben, $\$ 33$, weiter unten in diesem Paragraphen (Qu 37 / 4) und $\$ 95$. Die angesichts der hohen Bedeutung dieser Produktion in Italien von der Verwaltung und anderen Betrachtern für die Ausdehnung auf Dalmatien (analog zu damaligen Anläufen an vielen anderen Stellen selbst noch im nördlichen Mitteleuropa) gehegten Hoffnungen verliefen im Weiteren in Dalmatien im Sande. Vgl. noch den Stand ca. 20 Jahre später wie geschildert von Petter: Dalmatien, Bd. 1, $138 \mathrm{f}$.

454 Vgl. statt der hier abgebrochenen Behandlung des Weinbaus den wahrscheinlich wegen seiner hohen Bedeutung kurzfristig gesondert eingeplanten und verfassten $₫ 95$.

455 Ein Beispiel für das bei Lilienberg und überhaupt im zeitgenössischen Morlakendiskurs häufige erzählerische Motiv von der Vorurteilsbehaftenheit der dalmatinischen Bevölkerung, die nicht von anderen zu lernen bereit sei. 
tig hinaussetzen ${ }^{456}$ und wenn von Seite der Landestelle durch Eurer Majestät Allerhöchsten Gnade aus dem Agricultursfonde ${ }^{457}$ nicht alljährlich einige sogenannte Potatori ${ }^{458}$, welche [Qu 37 / 4] mit der Pflege des Oelbaums sehr gut bekannt sind bezahlt und in verschiednen Gegenden Dalmatiens bereits geschickt worden wären, so würde sicher mit der beßeren Pflege gar kein Anfang gemacht worden seyn.

Im gegenwärtigen Jahr mußte diese äußerst nützliche Verfügung, durch welche wenigstens die Hälfte des Ertrages gewonnen werden wird, leider unterbleiben, da in dem Agrikulturfonde kein Geld disponibel war, weil Eure Majestät für diesen im Allgemeinen, so wie ich aller unterthänigst gebeten habe, nicht die von jeher preeliminirten 6000 Gulden, sondern bloß rücksichtlich der Anpflanzung der Maulbeerbäume und der Seidenerzeugung Allergnädigst zu disponiren gemacht haben ${ }^{459}$.

In der Preßung und Behandlung des Oehls sind hier noch außerordentliche [Qu 38 / 1] Gebrechen, [am Rand ergänzt: in Ragusa wird aber das Oehl schon hie und da sehr fein gemacht] so daß dadurch der Preis selbst des ragusaischen Erzeugnißes, welches das Beste ist, sogar dem puglieser nachstehet und auch heuer um $26 \mathrm{~m}$ [26000 Gulden] geringer zu Triest verkauft wurde.

Nachdem das Land, so wie es bis nun aus den Akten aufgemittelt werden konnte, meistens 30 bis 50 tausend Eimer jährlich erzeugt und in manchen Jahren vielleicht eine noch beträchtlichere Quantitaet erzeugt, so ist es auch sehr den Umständen angemeßen, auf die Verbeßerung in der Confection des Oehles im Allgemeinen zu denken, was zwar hie und da zum [Qu 38 / 2] Theil, aber nirgend in dem hohen Grade, wie es schon in anderen Ländern bestehet, geschehen ist und das Dalmatiner Oehl deswegen nicht einmal mit dem puglieser zu Triest die Concurence halten kann.

$456 \mathrm{Zu}$ verstehen als »hinwegsetzen«.

$457 \mathrm{Zu}$ dessen Bedeutung und Geschichte vgl. oben in der Einleitung (S. 20-24) sowie weiter unten in $\$ 93$.

458 Von italienisch potatore, »Baumbeschneider «; diese in der Vergangenheit mögliche Fördermethode selbst ist eine auf den Olivenanbau bezogene Analogie zu dem weiter gefassten Vorhaben der Landwirtschaftskommissäre, und wird von Lilienberg gegenüber dem Kaiser offenkundig als Nachweis für die Erfolgsaussichten derlei praktischer Anschauungsmethoden verwendet.

459 Preeliminiren: präliminieren, vorläufig festlegen. Ab dem Absatz, der mit »Man sollte« beginnt, ist bis hierher über drei Absätze hinweg alles am Seitenrand mit einem roten Strich markiert worden; vermutlich fand Lilienberg, diese Passage sollte noch überdacht oder überarbeitet werden, da sie direkte Kritik am Kaiser impliziert! In der Endfassung sind diese Abschnitte aber unverändert erhalten, vgl. Reinschrift, S. 58. 
Wein-Stock

[ $\$ 93]$ Der Weinbau ist in diesem Lande sehr ausgedehnt, und man erweitert solchen immer mehr, weil dieser an allen Orten, [da er ${ }^{460}$ ] selbst in dem schlechtesten [Qu 38 / 3] Boden fortkommt, hauptsächlich aber, wie ich vielfältig von den Landwirthen versichert worden bin [rote Unterstreichung], deßwegen, weil dieser am wenigsten von allen Gewächsen von der Dürre, die hier so oft die allgemeine Plage ist, leidet.

Es sind hier vorzügliche Gattungen zu finden:

Maraschino ${ }^{461}$ zu Sebenico: Vugava, Refosco und Trebian; Vino di Bol auf der Insel Brazza, Muscato nero e bianco, Muscato di rosa und Prosecco von Almissa, Marzimino di Trau, Almissa, Cattaro und Teodo; Malvasia di Ragusa, dolce e garba [süß und bitter]; Pecno von der Halbinsel Sabioncello und der vortreffliche und sehr starke Wein dessen ich schon allerunterthänigst erwähnte, von den Bergen Tartari bei Sebenico.

Außer diesen besonderen Wein-Gattungen giebt es vortreffliche ordinaire Weine und wenn man einst diese beßer zu behandeln wißen wird, werden die Weine von Spanien und Frankreich sehr leicht entbehrt werden können ${ }^{462}$.

[Nächster Absatz mit Rotstift am Rand ergänzt] Auch wilder Wein ist hier zu finden, und ist mit Umsicht gemacht von vorzüglicher Güte.

[Qu 38 /4] Aber dermalen gehet es noch schlecht, oder wenigstens bei weitem nicht so gut, wie es gehen könnte. ${ }^{463}$

Schon bey Anlegung der Weingärten verfehlt man sehr oft, weil man nicht immer den angemeßenen Boden, viel weniger die entsprechende Lage wählt, obwohl dieses bey dem hiesigen so günstigen Clima am wenigsten schaden würde.

Die Pflege ist aber sehr schlecht; man verstehet nicht den Wein-Stock, gehörig, und zur rechten Zeit zu beschneiden, die Erde, wie es nothwendig ist, um den Wein-Stock [herum] zu lockern und den anpassenden Dünger zu wählen; auch setzt man meistens die Reben zu dicht aus, und wenn diese dann nicht gut beschnitten, und wie es räthlich wäre, nicht entblättert werden, so gedeiht und reift der Wein nicht vollkommen.

460 Zwei überflüssige Worte in der Konzeptschrift - sie finden sich, gleichsam sklavisch abgeschrieben und insofern ein Sinnbild für den geringen intellektuellen Spielraum, den die Schreiben in dem damaligen hierarchischen System der Verwaltung zugewiesen hatten, auch in der Reinschrift an gleicher Stelle wieder (S. 59)!

461 Hier im Sinne der Weinsorte, die Petter: Dalmatien, Bd. 1, 68f. zum Distrikt Zara und vor allem zum Distrikt Sebenico hervorhebt. Vgl. insgesamt dort 68-71 zu ausgewählten Weinsorten und ihrer lokalen Verbreitung. Petter gibt (S. 68) die geschätzte Zahl der dalmatinischen Weinsorten auf 50 wieder, deren systematische Beschreibung noch niemand vorgenommen habe.

462 Gemeint ist hier offenkundig das Potential für den dalmatinischen Wein auf dem gesamtösterreichischen Markt.

463 Vom Beginn dieses Absatzes an sind sechs Absätze (bis zum Absatzende »nach den alten nachtheiligen Gebräuchen geschieht«) am Rande rot angestrichen. 
Viele Trauben hängen zu tief und auf die Erde, werden verschümmelt [verschimmelt] [Qu 39/1] und verfaulen größtentheils; werden ohne ausgeklaubt und gereinigt zu seyn in die Maße ${ }^{464}$ eingemischt und verderben den Wein, oder machen ihn wenigstens viel weniger haltbar.

Die Weinlese ${ }^{465}$ war hier sehr unordentlich; ich habe aber unter 2 August $1832 \mathrm{Zl}$. 13701 durch die Landestelle veranlaßt, daß diese wie es in anderen civilisirten Ländern ist, durch einen Gemeindeausschuß bestimmt werde.

Dieses hat etwas, aber nicht ganz geholfen, weil überhaupt das Preßen und die Gährung, so wie die Reinigung und übrige Behandlung immerfort nach den alten nachtheiligen Gebräuchen geschieht.

Dieser Zweig könnte von einer außerordentlichen Ressource für das Land werden, wenn er rationell betrieben würde, denn es werden deßen ohngeachtet, daß der ordinäre Wein im Allgemeinen durch diese [Qu 39 / 2] schlechte Behandlung nicht dauerhaft ist ${ }^{466}$, bey 150000 bis 160000 Eimer ausgeführt, aber leider selten theurer, als um 1 Gulden 20 . - 1 Gulden 30 höchstens 2 Gulden angebracht ${ }^{467}$.

Wenn Eure Majestät einen Agriculturfond und die oekonomischen Comissaere ${ }^{468} \mathrm{Al}-$ lergnädigst zu bewilligen geruhen werden, wird auch in diesem Zweige sowohl in dem Bau, als in der Confection ${ }^{469}$ eine wesentliche Verbesserung eintreten können.

[Folgender Absatz am Rande ergänzt:] Man hat einige Proben gemacht, ob hier Rosinen, und Weinbeeren erzeugt werden; diese werden vortrefflich, und auch diese Ergänzung gedenke ich nach und nach einzuführen. ${ }^{470}$

[\$ 94] [Kastanien] Die Kastanien, welche wie in Piemont und Savoien und auch in einigen gebirgigen Gegenden österreichisch Italiens den Dürftigen vielfältig zur Nahrung dienen, sind in Dalmatien, so wie die Nußbäume, und Haselnußstauden nur selten, die Leztern [gemeint sind wegen der nachträglichen Einfügung der Haselstauden hier die Nußbäume] nur an der türkischen Gränze, zu finden.

Auch im Kreise Ragusa sind ihrer sehr wenig.

464 Gemeint ist die Gärmasse (Maische).

465 Die Rede ist von den (nach dem Lilienbergschen Eingreifen dann amtlich zu verfügenden) Terminen der Weinlese (die vor allem regelte, ab wann sie jeweils beginnen durfte).

466 »Nicht dauerhaft sein« zu verstehen als: »sich nicht gut halten«, »rasch verderben«.

467 »Angebracht« hier zu begreifen im Sinne von »an den Mann gebracht«, »abgesetzt«, »verkauft".

468 Der Guberniumsantrag auf Einrichtung des entsprechenden Fonds wurde nach dem Tod des Kaisers im Juli 1835 als systemwidrig und zur Erziehung der ‘moralisch dazu nicht disponierten> dalmatinischen Bauern ungeeignet scharf abgelehnt. Siehe dazu mit Zitaten aus den ablehnenden Äußerungen der Hofstellen Clewing: Staatlichkeit, 127, sowie hier im Anschluss, Anhang.

469 Verarbeitung.

470 Der letzte Halbsatz ist dann wieder rot ausgestrichen (wegen der Ich-Form). 
Bloß in östereichisch Albanien habe ich einige gefunden die des Jahres 3 bis 400 Zentner Castanien [Qu 39 / 3] abwerfen sollen [ab »habe« offenbar als zu persönlich - rot ausgestrichen, stattdessen: »werden [...] Castanien gewonnen «].

Auch auf die Vermehrung dieser Pflanze, welche dem Lande bei großer Dürre wichtige Aushülfe leisten kann, wird man nach und nach, einwirken müßen. ${ }^{471}$

In dem vorigen Jahre haben doch alle diese gesammten Obstbäume 71500 Zentner an Früchten abgeworfen.

Wenn auf die Einfuhr an der Zoll-Hauptlinie ${ }^{472}$ eine ähnliche Mäßigung des Einfuhrs-Zolles für diese so vielen und so vorzüglichen Gewerbs-, Arzney- und Handelsfrüchte, welche unter den 2. vorhergehenden Artikeln [Paragraphen] begriffen sind, Allergnädigst bewilliget werden wird, wie dieses mit dem Oehle und Wein bereits geschehen; so wird dadurch zur Beförderung der Landwirthschaft sehr viel beigetragen und auch der Vortheil erzielt werden, daß das Geld, welches nun ins Ausland geschickt wird, im Lande bleibt. ${ }^{473}$

[Qu 39 / 4]

\section{Maulbeerbaum}

$\$ 95$ Dieser so nützliche Baum, welchem viele Länder und besonders die Lombardei ihr Auskommen und Reichthum verdanken, wird auch hier mit Hülfe Gottes den nämlichen Erfolg hervorbringen.

Durch die Allerhöchsten Verfügungen, über deren pünktlichsten Vollzug baldmöglichst der Bericht [seitens des Guberniums; K. C.] der vereinten Hofkanzlei wird erstattet werden ${ }^{474}$, wird gewiß die Anpflanzung dieses Baumes große Fortschritte machen; theils durch die jährliche Gratisverteilung dieser Bäume und auch dadurch, weil sogar auf die Erzeugung der Seide Geld und Medaillen-Prämien Euere Majestät ${ }^{475}$ Allergnädigst zu setzen geruhet haben, wodurch auch die Anpflanzung der Bäume bei den Wohlhabenden

471 Dieser Absatz und die beiden Folgenden sind am Rande rot angestrichen.

472 Vergleiche zur Bedeutung oben, Anm. 402.

473 Die teils erreichte, teils von Lilienberg zusätzlich angestrebte Zollermäßigung für dalmatinische Produkte innerhalb des Reiches wurde als wieder mit einem für den Gesamtstaat möglichen Vorteil, nämlich dem im damaligen wirtschafts- und handelspolitischen Denken besonders populären Ziel der Importsubstitution gerechtfertigt.

474 Der Absatz ist in der Konzeptfassung bis hierher rot angestrichen, in der Reinschrift aber erneut unverändert enthalten.

475 Hier ist in der Konzeptfassung rot und offenbar von Lilienberg selbst eingefügt: Seine Majestät Kaiser Franz - eventuell wurde also vorübergehend von Lilienberg überlegt, das Dokument insgesamt doch nicht direkt an den Kaiser selbst zu adressieren. Das hätte dann bedeutet, nicht nur mit Blick auf Lilienbergs »ich« die Darstellung zu entpersonalisieren und die Hofstellen als die Primäradressaten zu verstehen. Dies ist aber in dieser Form die einzige solche Stelle (vgl. allenfalls mit ähnlicher Stoßrichtung noch zu Beginn von $\$ 97$ ), und dieses Umsteuern wurde, da Lilienberg wie in der Einleitung dargelegt, offenbar die Möglichkeit zu rascher und direkter Übergabe an den Monarchen hatte, im weiteren nicht umgesetzt. 
befördert werden wird. Doch wird diese wie [Qu 40 / 1] jede Landwirthschafts-Verbeßerung, nur dann vollkommene Fortschritte machen, wenn der Landmann durch die bereits angegebenen Mittel und durch moralische Einwirkung der Geistlichkeit, von Feldschaden mehr gesichert sein wird. ${ }^{476}$

An der Narenta [ergänzt: findet man; gestrichen: habe ich] Maulbeerbäume von einer außerordentlichen Größe und Fülle [gestrichen: gesehen], die dem größen Nußbaum in deutschen Ländern gleichen.

\section{Verschiedene andere wilde und Fruchttragende Bäume $e^{477}$}

$\$ 96$ Dalmatien hat auch viele wilde Oehlbäume besonders aber sind diese in den Wäldern der Insel Curzola, auf der Insel Arbe und Pago, auf der langen Spitze die gegen die Insel Arbe zugeht und Puntaloni ${ }^{48}$ heißt, vielfältig. Sie geben viel weniger Oehl, und dieses ist auch noch herb, benöthigen aber gar keine Pflege. Ich habe ihrer mehrere auch auf einigen [anderen, K. C.] [Qu 40 / 2] Inseln gefunden.

Der Erdbeerbaum, den ich vielfältig in den Wäldern auf der Insel Curzola, fast auf allen übrigen Inseln und besonders auch auf der Insel Arbe und Pago gesehen habe, wird außer [in Zeiten, K. C.] einer Hungersnoth nicht viel beachtet, weil die Frucht einen süßlichen-sauern, nicht sehr guten Geschmack hat.

Einstens hat ein Franzoß diese Beeren zur Verfertigung von Landwein verwendet, welcher einen sehr gesuchten Absatz in Triest hatte; der Franzose starb und die Einheimischen wußten den Geist nicht so gut zu rafiniren, der Handel wurde lauer ${ }^{479}$ und unterblieb dann ganz, wie die Erzeugung.

[Am Rand ergänzter Absatz zum wilden Wein:] Dalmatien hat auch wilden Wein, dieser findet sich auf der Insel Pago und Arbe, hier wird er besonders angenehm, läßt sich aber nicht halten.

Wilde Birnen und Aepfeln fand ich sehr wenige.

\section{Forstwesen ${ }^{480}$}

$\$ 97$ Von der wissenschaftlichen Forst- [Qu 40 / 3] Wirthschaft hatte man in diesem Lande eben so wenig einen Begriff, als man dieses von dem Baue der fahrbaren Straßen gehabt hat, bis diesem Lande nicht ${ }^{481}$ das Glück zum Theil wurde, unter dem wohlthätigsten al-

$476 \mathrm{Ab}$ Beginn der Seite bis hierher rote Randanstreichung.

477 Auch in diesem ganzen Paragraphen zum Beispiel sind alle »ichs« durch rot angedeute Streichungen oder Umformulierungen ersetzt, aber in der Reinschrift doch beibehalten.

478 TN (Halbinsel auf der Insel Pag) Puntaloni, spätere Schreibung auch Puntalon / Rt Lun: die Nordwestspitze der Insel Pag (mit dem Ort Lun), wo es bis heute einen besonderen Bestand an jahrhundertealten Olivenbäumen gibt.

$479 \mathrm{Zu}$ verstehen als »geringer«, »schwächer«.

480 Vgl. auch die Umweltwahrnehmungen und historischen Mutmaßungen Lilienbergs zu den Gründen der dalmatinischen Waldarmut in $\$ 32$.

481 »Bis [...] nicht« zu verstehen wie; »ehe« (dem Lande das Glück zu Teil wurde). 
lerhöchsten Zepter Eurer Majestät zu kommen. [Rote Neuformulierung und Entpersonalisierung: "unter Österreichs Regierung zu kommen.«]

Die Wälder wurden theils aus dem Grunde, welchen ich in $₫ 32$ angegeben habe, ausgehauen und seitdem nicht wieder angepflanzt; oder man hat solche wegen unwirthschaftlicher Gebahrung mit dem Holze in der Hauswirthschafth und wegen Eigennutz, weil man das Holz ohne alle Uiberlegung ausgehauen, nach Venedig und ins Päpstliche veräußert hat, vielfältig verwüstet.

Inzwischen habe ich es viel übler geglaubt, als ich es bei meiner Bereisung wirklich gefunden habe ${ }^{482}$; denn ich fand auf dem Berg Vellebich einen sehr schönen Buchenwald; in Curzola viele schöne und beträchtliche Kiefer-Wälder, und große Waldungen auf der Insel Meleda [Qu 40 / 4] und auch auf der Insel Lagosta, so auch einen Steineichen-Wald auf der Insel Pago und ziemlich ausgedehnte ähnliche, aber aus Mangel der Aufsicht meistens verkrüppelte, Waldungen auf der Insel Arbe.

In der Gegend von Trau mehr landeinwärts und in dem nuovissimo acquisto bei Knin, Verlicca und Sign, dann zwischen Vergoraz und der Narenta, wo die Lichtung der Wälder seit der lezten Abtretung dieses Theiles von Seite der Türkei ${ }^{483}$ gar nicht, oder sehr wenig statt fand, sieht man noch ziemlich gut erhaltene Wälder.

Bei vielen Dörfern im Innern fand ich mit trockner Mauer eingezäumte Anflüge ${ }^{484}$, unter dem Namen Boschi Sacri, welche unter dem Proveditore Dandolo eingeführt worden sind. ${ }^{485}$

Der vorzüglichste Baum welcher durch die Tischler verarbeitet wird, ist der Judas-Baum [Qu 41 / 1] [gestrichen: Cirus] Siliquastrum, welcher wegen seiner Schönheit und Güte anfängt geschützt zu werden.

Im Ragusaischen und Oestereichisch Albanien findet man ziemliche Waldungen, besonders hat der Theil von Crivoscie ober Risano, den wir [schwarze Ausstreichung von »wir«; stattdessen: die dortigen k.k. Unterthanen] beinahe seit 50 Jahren von den Türken usurpiren [rote Ausstreichung dieses ganzen Halbsatzes], sehr schöne Waldungen.

482 Ein Beispiel für eine (positive) Korrektur der Lilienbergschen Urteile zu einem Sachverhalt durch den Augenschein, in Abweichung von der vorherigen aus den Akten geschöpften Meinung.

483 Im Frieden von Passarowitz von 1718.

484 »Anflüge« hier zu verstehen als »durch natürlichen Anflug von Samen gewachsenen Buschwald «.

485 Petter: Dalmatien, Bd. 1, 133: als forsterzieherische Maßnahme ließ Dandolo »[...] junge Wäldchen anlegen, welche er, um den Morlaken Achtung gegen dieselben einzuflössen, heilige Haine (boschi sacri) nannte. Er wählte dazu Plätze in der Nähe der Kirchen, welche hier zu Land fast alle fern von den Dörfern vereinsamt dastehen. Das Landvolk pflegt sich an Sonn- und Feiertagen vor denselben zu versammeln, und er wollte damit nichts Anderes erzwecken, als demselben ein lebendiges Bild dessen vor Augen zu stellen, was geschehen kann wenn man ernstlich will. « Vgl. auch unten, Anm. 488. 
$\mathrm{Nach}^{486}$ dem Ausweise den ich mir von der Catastral-Vermessungs-Direction geben ließ, betragen die Waldungen in dem Kreise Zara fast den 4 Theil des Flächeninhalts, nämlich 23 Quadratmeilen und wenn gleich manches Gestrüpp, welches Wald- oder wenigstens Anflugsartig dasteht, unter die Waldungen wie es natürlich ist, gerechnet wurde, so ist doch alle Hofnung [sic] vorhanden, daß auch diesem Zweig [Qu 41 / 2] durch Euer Majestät Huld und Gnade wird ausgeholfen werden und daß man nicht [mehr, K. C.] nöthig haben wird, aus dem ungarischen Litorale, viel weniger aber aus der Herzegowina, aus der Narenta und aus türkisch Albanien das Holz zu dem beträchtlichern Haus- und Schiffbau zu holen; besonders wenn Eure Majestat meinen allerunterthänigsten Vorschlag, welcher unter dem Artikel Kreisämter vorkommen wird, Allergnädigst zu würdigen für gut finden werden. ${ }^{487}$

Ich darf es nicht wagen, mit diesem Gegenstande Eure Majestät weiter zu belästigen, weil ich wegen der Ausdehnung und vielfältigen nöthigen Berücksichtigung, welche bei den Wäldern Statt findet, bei weitem hinter der technischen Schilderung zurückbleiben müßte, welche der durch Euer Majestät Allerhöchste [Qu 41 / 3] Gnade hierher interinaliter gesendete Forst-Inspektor ${ }^{488}$, der bereits seine Arbeiten angefangen hat, erstatten, und diese durch die vereinigte Hofkanzley Eurer Majestät zukommen wird.

Wenn man die Einfuhr und Ausfuhr der verschiedenen Holz-Gattungen bilancirt, so bleibt dem Lande ein jährlicher Gewinn von mehr als 30000 Gulden.

\section{Thierreich}

Die Viehzucht

$\$ 98$ Auch die Viehzucht ist im Allgemeinen wie alles, was zu der Landwirtschaft gehört, sehr vernachläßigt.

Die Pferde und Trag-Thiere sind von sehr kleinem Schlage ohne alle Race, elend behandelt, elend gefüttert, sehr schlecht [mit Hufeisen] beschlagen und werden nirgend zum Zug, sondern bloß als Tragthiere und zum Reiten für das [Qu 41 / 4] Landvolk verwendet. Wer Vorspann zum Fahren benöthigt, der muß sich der Ochsen bedienen.

486 Von diesem Absatzbeginn an bis vor die nächste Überschrift zum Tierreich im Konzept rote Randanstreichung.

487 Vgl. $\$ \$ 175 \mathrm{ff}$.

488 Iterinaliter: vorübergehend. Petter: Dalmatien, Bd. 1, 133: „In den Jahren 1831 bis 1839 bereiste der Forstinspektor Joseph Kargl, dessen Freundschaft ich manche nützliche Notiz für mein Buch verdanke, im Auftrage der Regierung Gemeinde für Gemeinde, und legte erster [der Landesregierung] seine Beobachtungen und Vorschläge zur Verbesserung vor. Dandolo hatte früher schon dasselbe gethan, er liess Forstbeamte aus Italien kommen und das Land nach allen Richtungen durchziehen und sich Bericht erstatten. [... Es folgt eine Schilderung der Bemühung Dandolos um die »heiligen Haine«, vgl. soeben, Anm. 485] Nach der Entfernnung Dandolo's aus der Provinz kümmerte sich Niemand mehr um die heiligen Haine, und nun ist der österreichischen Regierung vorbehalten, die schwere Aufgabe zu lösen; aber das Wie und Wann ist eine andere schwierige Frage." 
Rücksichtlich der Pferdezucht wüßte ich, so wie dieser Zweig dermalen bestellt ist, nichts Zweckmäßiges zur Veredlung, vorzuschlagen, denn, solange die andern Theile der Landwirthschaft nicht etwas gehoben sind und die Landwirthe nicht nach und nach bessere Sitten aus türkisch Albanien, Herzegowina, Bosnien und noch zweckmäßiger vielleicht aus Civil-Croatien ${ }^{489}$ sich angeschafft und [ergänzt: erst] durch die Fortschritte in der [neu: Landwirthschaft, gestrichen: Civilisation], an welcher mit möglichster Anstrengung gearbeitet wird, [Ergänzung in zu schwacher Schrift] nicht gelernt haben werden] [neu: wozu die Regierung das möglichste beträgt], die Pferde schonender [gestrichen: zu behandeln] [neu: behandelt werden] ${ }^{490}$ glaube ich, daß nichts Wesentliches zur Veredlung dieser Thiere unternommen werden könnte; ${ }^{491}$ denn, [Qu 42/1] wann man auch Hengste anschaffen wollte, so würden von den elenden Mutter-Stutten nur sehr schlechte Füllen hervorkommen und diese, eben so wie die jetzigen durch zu frühe Benutzung und vielerley Art Mißhandlung zu Grunde gerichtet werden. ${ }^{492}$

In allem zählt Dalmatien bei 14096 Pferde; wovon Cattaro nur 239, und Ragusa 457 dagegen Zara 8237 und Spalato 5763 Stück hat.

An Tragthieren und Eseln, welche ebenso schlecht gefüttert und behandelt werden, wie die Pferde, und deßwegen auch für dieses verwahrloste und dermalen futterarme Volk am besten taugen, ${ }^{493}$ sind 19098 in allen 4 Kreisen.

Der Kreis Zara zählt an Maulthieren und Eseln 7600 - Spalato 6846 - Ragusa 3741 und Cattaro 911 Stück.

Auch zur Verbeßerung dieser Zucht läßt sich dermalen nichts Wesentliches unternehmen. ${ }^{494}$

489 Eine interessante regionalvergleichende Haltung Lilienbergs, wobei also in der Frage der Pferdezucht und -behandlung nach Meinung Lilienbergs Dalmatien schlechter dastand als alle Nachbarn, inbegriffen diejenigen auf osmanischem Gebiet.

490 In der Summe der roten Neuformulierungen wurde daraus im Konzept der Satz: »und erst durch die Fortschritte in der Landwirthschaft, wozu die Regierung das möglichste beiträgt, werden die Pferde schonender behandelt werden. «Statt zuvor: »und durch die Fortschritte in der Civilisation, an welcher mit möglichster Anstrengung gearbeitet wird, nicht gelernt haben werden, die Pferde schonender zu behandeln [...]«. Die zur Ersetzung vorgesehene Formulierung war wohl in den Augen des Redigierenden - vermutlich Lilienberg - für einen Moment zu sehr dahingehend interpretierbar dahingehend, wer denn an der Verbesserung der Zivilisation arbeite, und dass diese womöglich auch aus dem Osmanischen Reich Vorbilder beziehen könnte. In der Reinschrift (S. 64) ist aber wieder die ursprüngliche Fassung beibehalten.

491 Rote Unterstreichung.

492 Vom Seitenbeginn bis hierher rote Randanstreichung.

493 Der Satzteil zwischen den beiden Kommas wurde rot ausgestrichen, ist aber in der Reinschrift enthalten.

494 Die beiden letzten kurzen Absätze sind im Konzept (vielleicht als für den kaiserlichen Empfänger doch zu detailliert) rot ausgestrichen, aber in der Reinschrift enthalten. 


\section{Horn-Vieh}

$\$ 99$ Dieses fand ich im Allgemeinen [Qu 42 / 2] nicht so weit zurück, als ich es zuvor, da ich nur den Kreis von Zara kannte, geglaubt habe.

In diesem Kreise ist das Hornvieh wirklich größtentheils sehr vernachläßigt und man könnte mit Recht sagen, vielfältig unter dem wilden Natur-Zustande.

Es ist von schlechter Race, die Behandlung deßen auch sehr nachläßig; und weil die Weide meistens sehr mager und kein Stallfutter im Gebrauch ist, so kann das Vieh nicht hinlänglich genährt werden. ${ }^{495}$

Was die Zugochsen anbelangt, so weis man ihre Kräfte nicht zu beurtheilen, spannt sie, wie in allen dürftigen Ländern, zu jung ein, und überladet sie ohne solchen [ihnen, K. C.] die hinlängliche Nahrung zu geben.

Auch mit Trunk, da das Wasser auch in vielen Ortschaften nur durch Cisternen erhalten wird, und sehr oft, besonders zur Sommerzeit mangelt, erquicket man diese nicht gehörig; und auf diese Art [Qu 42 / 3] werden in einen Pflug oder Wagen 10 bis 12 Ochsen eingespannt, die [unter besseren Umständen, K.C.] mit 2 höchsten[s] 4 paar ${ }^{496}$ Ochsen fortgebracht werden könnten.

In dem Spalatoer Kreis ist die Hornvieh-Zucht viel besser und ich habe, besonders um Verlicca und Sign sehr schönes Hornvieh gesehen ${ }^{497}$.

Ebenso verhält es sich in Ragusa, wo jedoch wenig derlei Vieh gehalten wird.

In Cattaro wird ebenfalls wenig Hornvieh, aber doch im Verhältniße mehr, als in Ragusa gehalten. Auch in Cattaro ist das Rindvieh, so wie in dem Kreise Zara, meistens vernachläßiget. In Allem zählt Zara 40 325, Spalato 40 442, Ragusa 3366 und Cattaro 4110, mithin ganz Dalmazien 88443 Stück Horn Vieh aller Gattung.

Zur Veredlung des Hornviehs würde es wohl nicht so schwer seyn, nach und nach langsam beizutragen, weil man selbst im Lande hie und da bessere [Qu $42 / 4]$ Race findet, und weil man sie besonders in Bosnien und in der Herzegowina um einen ziemlich billigen Preis bekommen kann.

Nach meinem Wißen verlegt sich Niemand besonders auf die Rind-Viehzucht, außer der durch Eure Majestät allerhöchsten Gnade bereits mit einer großen goldenen Medaille belohnte Doktor Orazio Pinelli. Dieser hat aus Steyermark einen Stier kommen laßen, der sehr schön ist und durch welchen der Anfang zur Verbeßerung gemacht werden kann.

Wenn Eure Majestät einen Industriefond ${ }^{498}$ für die Folge allergnädigst zu bestimmen geruhen werden, so würde ich auch auf diesen Zweig meine Aufmerksamkeit wenden.

495 Vom Beginn des $\$ 99$ ist der Text im Konzept bis hierher rot ausgestrichen, doch in der Endfassung enthalten.

496 Also 4-8 Ochsen.

497 Durch Korrekturen mit Rotstift im Konzept entpersonalisiert umformuliert in: »[...] viel besser, besonders um Verlicca und Sign findet man sehr schönes Hornvieh.«

498 Direkte Ansprache des Kaisers in Sachen eines offenbar von Lilienberg bereits beantragten Industrieförderfonds. 
Ich würde zugleich nicht vergeßen auf die Verbeßerung des Käses und der Butter zu denken. [Mit Rotstift ergänzt: ${ }^{499}$ ] Guter Käß und besonders die Butter ist äußerst selten.

Die Leztere ist besonders so selten und so äußerst schlecht und unflatt ${ }^{500}$, daß sie außer dem Morlaken, der sie ${ }^{501}$ [Qu 43 / 1] macht, Niemand ohne Abscheu genießen kann. Der Käse aber, besonders von den Schafen und Geisen, könnte in diesem Lande, wo so viele aromatische Kräuter und Stauden sind, von einer ausnehmenden Güte seyn und jedes andere Land bey weitem zurücklaßen.

\section{Schaf-Vieh}

$\$ 100$ Viel reicher ist Dalmatien an Schafvieh, aber dieses ist eben von der ordinairsten Gattung, so daß der Zentner Wolle, welcher dermalen ein so bedeutender Handels Artikel ist, kaum um 16 Gulden verkauft wird.

Man hat mich, ehe ich die Bereisung anfing, versichert, daß ich Merinos-Schafe finden würde, ich habe aber leider ${ }^{502}$ nur einige wenige MerinoBastarde [ergänzt zur Neuformulierung: findet man] bei Trau und auf der Insel Lissa, ächte Merinos aber nur auf der Insel Pago ${ }^{503}$ getroffen, wo auch die verbeßerte hießige Race schon im bedeutender Zahl gefunden wird.

Der Landwirth von Pago namens Darchich ${ }^{504}$, versicherte mich, daß er von ächten [Qu 43 / 2] spanischen Widdern und von den hiesigen gemeinsten langhaarigen Mutter-Schafen die Wolle, welche ich mir die allerunterthänigste Freyheit nehme in 6 Päckchen ${ }^{505}$ beizuschließen, gleich nach der ersten Generation erhalten und solche ohne allen Anstand um 60 Gulden den Zentner verkauft wird. Er versicherte mich auch, als ich bey ihm wohnte, daß auch diese Art Wolle hier so gut gedeihe daß er von einem Widder ächter Race im vorigen Jahre 7 1/2 Wiener Pfund ${ }^{506}$ an Wolle erhalten habe.

Da diese Art Veredlung so leicht von Statten gehet und einen so auffallenden Unterschied gleich in der ersten Generation hervorbringt, daß das Product viermal edler wird, mithin statt 16 Gulden 60 für ein Zentner Wolle der Producent erhalten kann, so

499 In der Reinschrift (Seite 65) aber nicht enthalten.

500 Das von Lilienberg adverbial verwendete »unflatt« findet sich im heutigen Deutschen offenbar nur noch als (ganz seltenes) maskulines Substantiv »Unflat «: »widerlicher, ekelhafter Schmutz, Dreck«, Die »unflatte« Butter war also eine ekelhaft schmutzige/verdorbene.

501 Am Seitenende steht hier im Konzept eine nicht entzifferte rot geschriebene Ergänzung.

502 Bis hierher Absatz rot ausgestrichen; in der Endfassung ist er aber mitsamt den Elementen des Ich-Erzählers verblieben, vgl. dort Seite 66.

$503 \mathrm{Ab}$ hier Rest des Absatzes rot ausgestrichen, ist aber in der Endfassung erneut erhalten.

504 Offenkundig Leopoldo Darchich oder Dorcich (so die Schreibung im Artikel von Scotti: I Pinelli di Zara, siehe oben, Anm. 283).

505 Randanmerkung: [Beilage] 17; kein Rest davon liegt im Archiv in Zadar, sie ist aber als Beilage XII in der Wiener Reinschrift, fol. 199 (Scan 240) in sechs kleinen, der Herkunft des jeweiligen Tieres entsprechend beschriebenen Briefchen tatsächlich bis heute erhalten.

506 Ein Wiener Pfund entsprach 561,3 Gramm, ein Zentner hatte 100 Pfund (56,13 kg). 
würde ich bei einigen größeren Landwirthen die um Benkovaz und Ostrovizza [Qu 43 / 3] unweit von Zara in dem nuovo acquisto zu finden sind und bey welchen ich auf meiner Bereisung war, den Anfang mit der Veredlung der Race machen, wenn ich so glücklich werden sollte, eine mäßige allergnädigste Anweisung für den so oft erwähnten Agriculturs- und Industrie-Fond zu erflehen. ${ }^{507}$

Alle 4 Kreise zählen zusammen 639809 Schafe; und es dürfte sich der Mühe lohnen, diese nach und nach zu veredeln! $!^{508}$

\section{Geise $^{509}$}

$\$ 101$ Diese Thiergattung hat seitdem man sie in dem nuovo und nuovissimo acquisto mit $3 \frac{1}{2}$ Kreuzer und in vecchio acquisto mit $1 \frac{1}{4}$ Kreuzer an Erbatico ${ }^{510}$ besteuert hat, ziemlich, aber doch nicht so abgenommen, als man hätte erwarten sollen, was auch nach meiner Meinung nicht früher geschehen wird können, bis sich nicht die Zunft des Hornund Schafviehs beßer gehoben und dem Dürftigen seine Nahrung [Qu 43 / 4] mehr gesichert hat, weil die Geise beim Mangel an Brod wenigstens die Kinder in ganz Dalmatien vor dem Erhungern [Verhungern] vollkommen retten können, denn ihre Zahl beläuft sich auf 398512, sie ist mithin um 42000 größer als die gesammte Zahl der Menschen.

In einigen Ortschaften, was besonders der Fall auf der Insel Pago ist, fand ich bei einem Schaf-Bestand von mehr als 22000 Stück keine einzige Geis, dieses macht die Veredlung der Schafzucht, auch sind die Paghesaner durch die Erzeugung des Salzes vor jeder Noth mehr gesichert. ${ }^{511}$

507 Ein Beispiel für Lilienbergs Taktik zur Vertretung seiner Wirtschaftsförderpolitik in Bezug auf den Kaiser und dessen Zusammenspiel mit den (durch Lilienberg möglichst zu umgehenden) Wiener Stellen. - Zu diesem Anliegen Lilienbergs, das nach des Kaisers Tod an der weitgehenden Ablehnung durch die Hofstellen im Wesentlichen gescheitert ist, vgl. Clewing: Staatlichkeit, $127 \mathrm{f}$. Derweil existierte schon seit der Amtszeit von Gouverneur Tomašić ein (allerdings sparsam dotierter) Agrikulturfond. Vgl. dazu weiter unten im Text zu $\$ 106$ (hier der Aspekt der finanziell eingeschränkten Förderung der Seidenkultur), bzw. weiter oben, in der Einleitung (20-24).

508 Bis hierher ist im Konzept die ganze Seite und die vorangegangene Seite am Rand rot angestrichten; zugleich hier am Ende ab dem Halbsatz rot durchgestrichen, weil sie wohl vorübergehend als zu drängend empfunden wurde. In der Reinschrift ist die Passage aber wiederum erhalten (dort Seite 66 bzw. fol. 34v). Die mit Rotstift an die Stelle der hier gegebenen Gesamtzahl der Schafe darüber gesetzte Zahl 726134 findet sich in der Reinschrift nicht, es blieb bei der hier im Text genannten Ziffer.

509 Geißen / Ziegen.

510 Erbatico: »Weidezoll« für Ziegen, der laut Petter: Dalmatien, Bd. 1, 130 zur Zeit des Königreichs Italien von Vincenzo Dandolo eingeführt worden war, um deren Zahl zu begrenzen.

511 Letzter Absatz im Konzept mit roter Randanstreichung. 
Borsten-Vieh

$\$ 102$ Dieses ist im Verhältniß zu anderen Ländern sehr unbedeutend an der Zahl und wird sich auch erst mit der Landwirthschaft ${ }^{512}$ vermehren.

In Arbe ist das Schweinfleisch und der Schinken die man dort [Qu 44/1] verfertigt, wegen der Eichelweide, die man in der dortigen Steineichen-Waldung findet, am vorzüglichsten.

In Allem hat Dalmatien 31871 Stück Schweine.

\section{Hausgeflügel}

$\S 103$ Dieses ist in hinlänglicher Quantität und nebst dem ${ }^{513}$ daß es der Landmann vielfältig selbst genießt, macht er in den Städten einen guten Gewinn damit.

Ein besondere Gattung oder vorzügliche Art, giebt es hier nicht.

\section{Die Jagd}

$\$ 104$ Diese ist dadurch, daß das ganze Volk bewaffnet ist, und indem, ohne die mindeste Einschränkung das ganze Jahr hindurch bis zu meiner Ankunft; wie ich schon $\$ 94$ allerunterthänigst erwähnte, das Jagen erlaubt war, fast gänzlich zu Grunde gegangen. ${ }^{514}$

Von Hirschen, Rehen, Dammhirschen und Schwarzwild ist dermalen ${ }^{515}$ keine Spur mehr, nur in oesterreichisch Albanien findet man einige [Qu 44 / 2] Gemsen.

Hasen, Stein- und Rebhühner, dann Schnepfen aller Art findet man, der Raserey der Einwohner für die Jagd ungeachtet, hinlänglich, so wie es eine außerordentliche Menge von Wasserzug-Vögel[n] im Herbst, und im Winter hier giebt.

Die Federn der vielfältigen weißen und schwarzen Reiher und Schwäne werden hauptsächlich an der Narenta gesammelt und machen auch einen kleinen Handels-Artikel aus; [gestrichen: ich habe deren einige sehr schöne gesehen].

Ob man nicht einstens, wenn der Augenblick zur Desarmirung des Landes nahe sein [wird; K. C.], mit einer mäßigen Jagdsteuer den ersten Schritt wird machen können, dieses wird von Eurer Majestät allerhöchster Weisheit abhängen. ${ }^{516}$

Von schädlichen Thieren, als Bären und Wölfen, so auch Füchsen [Qu 44 / 3] p.p. [etc.; K.C.] werden die ersten zwei Gattungen gegen die gesetzliche Belohnung fleißig vertilgt ${ }^{517}$, und auch dieserwegen segnet der Landwirth Eure Majestät dankbar, weil er dermal an seinen zahmen Thieren viel weniger Schaden leidet, als es früher der Fall war.

512 Gemeint ist eine auf Gelderwerb abzielende, in den Methoden moderne Landwirtschaft.

513 "Nebst dem« heißt soviel wie »abgesehen davon«.

514 Rote Ergänzung offenbar Lilienbergs, schwer leserlich: »Nicht in Dal[matien], doch lebt an der Grenze noch das Wild. « Findet sich in der Reinschrift nicht.

515 Rot unterstrichen und darüber gesetzt »aber« (wegen dem Einschub, dass es an der Grenze Wild gebe).

516 Dieser Absatz ist rot ausgestrichen, in der Reinschrift aber vorhanden.

517 Nach »fleißig vertilgt« ist der Rest des Absatzes rot ausgestrichen, in der Reinschrift aber vorhanden. 
Auf der Insel Curzola sind in einer Höhle wilde Hunde /:chacale:/518 ich habe mir aber bei meiner Anwesenheit und auch bis jetzt alle Mühe umsonst gegeben, und konnte keines ansichtig werden.

\section{Ertragsfähige Insekten}

$\$ 105$ Die Bienenzucht, die hier so ausgiebig seyn könnte, fand ich überall sehr vernachläßiget und wenn die Bienen auch nicht durchgehends, um sie ihres mühsam erworbenen Reichthums zu berauben, getödtet werden, so ist es [Qu 44 / 4] mir doch nicht gelungen auf meiner ganzen Bereisung eine nur einigermaßen nach neuer Art [rot neu: Weise] zweckmäßig geordnete Bienenpflege anzutreffen ${ }^{519}$.

Auch hier wird einiges zur Verbeßerung geschehen können und dieser Zweig verdient es um so mehr, da ein vortrefflicher Honig überhaupt und der vorzüglichste, den ich je gekostet habe, auf der Insel Solta erzeugt wird..$^{520}$

Dalmatien wird auch einmal mit Cochenille ${ }^{521}$ einen Handel treiben können, denn ich fand besonders ${ }^{52}$ auf den Inseln, auf den Feigen-Bäumen so häufig ein ganz ähnliches Insekt, wie es in Indien gesammelt wird ${ }^{523}$. Auch hatte es beym Zerdrücken die schöne rothe Farbe, wie jene im ausländischen Handel vorkömmt und so theuer bezahlt wird.

518 Schakale.

519 Erneut lässt sich der Zuverlässigkeit der Aussagen Lilienbergs durch einen Vergleich mit dem ebenfalls gründlichen Petter bestätigen. Dieser schreibt noch zwei Jahrzehnte später (Dalmatien, Bd. 1, 73): »Die Bienenzucht verdiente von dem Landwirthe Dalmatiens weit mehr beachtet zu werden, als sie es ist, denn kein Land der Monarchie eignet sich mehr dafür. [...] In Dalmatien steht dieser Industriezweig noch immer auf der untersten Stufe."

520 Wieder ein Beispiel für die vorübergehend beabsichtigte Entpersonalisierung: Nach Maßgabe der roten Änderungen hätte der Abschnitt am Ende heißen sollen (beginnend ab bzw. statt »Auch«): »Der Honig ist überall gut, der vorzüglichste aber auf der Insel Solta, der weit ausgeführt wird."

521 Cochenille oder Cochenilleschildlaus: eine ursprünglich in Süd- und Mittelamerika beheimatete Insektenart; aus den weiblichen Tieren wird Karminsäure als Grundlage des Farbstoffs Karmin gewonnen.

522 Danach folgt im Konzept ein unleserlich ausgestrichenes Wort; in der Reinschrift heißt es aber, vermutlich dem ursprünglichen Wortlaut entsprechend: »besonders heuer auf den Inseln« (Seite 69 bzw. fol. 36r).

523 Dieser Satz hätte nach Maßgabe der roten Änderungen heißen sollen: Dalmatien wird auch einmal mit Cochenille Handel treiben können, man findet auf den Inseln auf den Feigenbäumen so häufig ein ganz ähnliches Insekt, wie es in Indien gesammelt wird.« In der Reinschrift blieben diese Änderungen wieder unberücksichtigt. 
[Qu 45 / 1]

Ertragsfehige Würmer

Seiden Würme [sic]

$\$ 106$ Diese werden sich dermalen gewiß vermehren und Dalmatien wird ganz gewiß durch die Beihülfe dieses Zweiges seinen Wohlstand finden, denn das Clima scheint von sehr günstigem Einfluß auf das Fortkommen dieser Thierchen zu seyn. Am sorgfältigsten pflegt man solche auf der Insel Arbe. Ich habe mehrere Bauern Hütten besucht und fand überall, daß sich die Weiber sehr angelegentlich damit beschäftigen.

Es scheint, daß sich diese besondere Sorgfalt noch von uralten Zeiten erhalten hätte. Die Seidenkultur scheint auf der Insel Arbe früher einheimisch gewesen zu seyn, als solche die bewährtesten Schriftsteller in Europa eingeführt wißen wollen, so wie es aus dem in dem Comunal Archiv gefundenen [Qu 45 / 2] und hier in Copia sub Nr XVIII beigeschlossenen Documente vom Jahr 1018 durch welches sich das Bisthum verbindlich gemacht hat, jährlich 10 Pfund Seide dem Doge von Venedig zu liefern, klar hervorgehet. ${ }^{524}$

$\mathrm{Die}^{525}$ Praemien die Eure Majestät auf die Erzeugung der Seide allergnädigst bewilliget haben, haben schon heuer, obwohl man diese allergnädigste Verfügung nicht zeitlich genug publiziren konnte, sehr guten Effekt hervorgebracht. So viel ich vernommen habe, so sind viel mehr Cocons als in anderen Jahren erzeugt worden und Alles ist in der Bewegung, um sich die vorgeschriebenen Zeugniße zur bevorstehenden Prämien-Zeichnung zu verschaffen.

Bei meiner Bereisung der Provinz fand ich, daß in dem Spalatoer Kreis so auch in Ragusa und Cattaro, die Seide sehr rauh und fast wie [Qu 45 / 3] Wolle zu berühren war und ich habe durch die Gefälligkeit des Grafen Hartigg ${ }^{526}$ [sic] den feinsten Würmersaa-

524 Beilage Nr. XVIII, wie verzeichnet in der Übersicht, Seite 277, bzw. im Original der Dokumentenabschrift in der Reinschrift, fol. 121 / Scan 244. Für die Abschrift und ihre Richtigkeit zeichnete dort Urbano Appendini (Direktor des k.k. Lyzeums in Zara) unter dem 25. Mai 1834. Dieses Dokument aus dem Kommunalarchiv Arbe wurde vermutlich in der Folge zur historischen Untermauerung der Werbemaßnahmen für die Seidenkultur im Lande auch publizistisch verwendet. Jedenfalls erwähnt es auch Petter: Dalmatien, Bd. 1, 138, wo er den für die 1830er und frühen 1840er Jahre zu konstatierenden vorübergehenden Aufschwung der Seidenwirtschaft schildert, was er mit der (vom weiteren Verlauf bestätigten) Skepsis verbindet, ob dieser Wirtschaftszweig ohne stärkere regierungsamtliche Subventionierung und größer angelegte Maulbeerzucht einen dauerhaften Aufschwung nehmen könne.

525 Von hier bis zum Ende dieses Paragraphen 106 rote Randanstreichung. Die Stelle zeigt gut, dass die Randanstreichungen per se wohl nicht Kürzungen markieren sollten, sondern redaktionellen Überarbeitungsbedarf.

526 Franz Graf von Hartig ( ${ }^{*} 1789$ ), einer der tätigsten unter den obersten Verwaltungsbeamten des österreichischen Vormärz. Ab 1830 war er Gouverneur der Lombardei und als solcher Amtskollege Lilienbergs. Von ihm stammt eine der wichtigsten kritischen Schriften aus dem Kreis der Verwaltungselite über die vormärzlichen Verhältnisse (Genesis der Revolution in Oesterreich 1848. Leipzig 3. Auflage 1851). 1860 war er in der Umbruchphase hin zu konstitutionellen Verhältnissen eine prägende Gestalt des verstärkten Reichsrates. Vgl. die 
men in hinlänglicher Qualität aus der Lombardei verschrieben und erhalten, welches den besten Erfolg hatte.

Heuer konnte ich den zwei Kreisen nicht so viel geben, als sie gewünscht haben, weil der Agricultursfond zu arm war.

Ich hoffe zu Gott daß dieser Zweig außerordentlich gut fortkommen, in 20-30 Jahren das Land großentheils zum Wohlstand bringen und auch aus diesem Grunde die innigste aufrichtige Segnung dieses dankbaren Volkes Eurer Majestät auf ewige Zeiten bleiben wird ${ }^{527}$.

Blutegel $^{528}$

$\$ 107$ Die Blutegel welche schon in Kroatien und Ungarn zu mangeln anfangen und auch in Spanien erschöpft worden sind [Qu 45 / 4] fangen an, [in Dalmatien; K. C.] seit zwei Jahren ein Ertrags- und Handels-Artikel zu werden.

Ich $^{529}$ habe, besonders an der Narenta und auf der Insel Pago, viele Menschen getroffen, die sich durch die Einfangung dieser [Tiere] Nahrung verschaffen.

Besonders hat mich der Eigenthümer ${ }^{530}$ des Sees von welchem ich unter jenem Artikel [in $₫ 37$; K. C.] und auch bey der Schafzucht bereits gesprochen habe, versichert, daß er heuer bei 4000 Gulden zu gewinnen hoffe; was aber bei der eingetretenen starken Dürre schwerlich der Fall seyn dürfte.

\section{Fischerey}

$\$ 108$ Diese ist schon bei den süßen Seen und bei den Flüßen bedeutend, beschäftiget und ernährt viele Menschen.

Der Aalenfang der Narenta könnte aber viel ausgiebiger werden, wenn man ihn ordentlich zu betreiben [Qu 46/1] wüßte; weil dieser aber durch die Anschlämmung, die unfehlbar nach und nach Statt haben wird, alle Jahre beengt werden muß und man diese mehr, als den Aalenfang zu beherzigen Ursache hat, so ist auf eine stabile und zweckmäBige Vorrichtung, wie solche in Comacchio ${ }^{531}$ besteht, auch aus dem Grunde nicht fürzu-

Angaben bei Wurzbach, Bd. 7 (1861), 399-402 (mit falscher Datierung des Amtsantritts in Mailand auf 1836).

527 Hier wird im Rahmen des von Lilienberg angerufenen "Landesvatertums« ziemlich bohrend die Dankbarkeit des Volkes an zu schaffende materielle Gründe für diese Dankbarkeit geknüpft!

528 Von wesentlich späterer Hand mit Bleistift hinzugefügt die kroatische Bezeichnung: Pijavice.

529 Von hier bis zum Ende des Paragraphen im Konzept wieder rote Anstreichung, offensichtlich wegen der Ich-Erzählerform.

530 Leopoldo Darchich.

531 ON Comacchio: Kleinstadt im Bereich des südlichen Podeltas, damals zum Kirchenstaat gehörig, aber mit österreichischer Festungsbesatzung und vermutlich deshalb - sowie wegen diverser historischer Bezüge und Streitfragen (18. Jahrhundert) um eine etwaige Zugehö- 
denken, weil sie an der Narenta mit viel mehr Vorsicht und viel größerem Aufwand eben aus Ursache der öfteren starken Uiberschwemmung gebaut werden müßte.

Der Meerfischfang ist in Dalmatien sehr beträchtlich und gehört schon zu einem der nahmhaften und ausgiebigen Erwerbszweige des Landes.

Wenn gleich dieser rücksichtlich des Thonfisches auf der niedrigsten Stuffe steht und auch der Scombri- und Sardellen-Fang nicht am gewandtesten, wie alle ${ }^{532}$ behaupten wollen, [Qu 46/2] betrieben wird, so ist der Leztere doch so ergiebig, daß mich die Fischer von Lissa versichert haben, daß blos eine einzige Gesellschaft auf der Insel Lissa und in einer einzigen Nacht, um 2000 Gulden Sardellen gefischt hätte.

Heuer, 1834, sollen die Fischer von Comicsa ${ }^{533}$ aber auf der Insel Lissa in einer Nacht bei zwei Millionen Stück Sardellen gefangen haben!

Im Ganzen kann man annehmen, daß ein Jahr zum andern 40 bis 50000 Barilli5 $^{34}$ an Sardellen gefischt und drey Theile davon im Handel auswärts versendet werden.

In diesem Jahre sind die Sardellen überhaupt so wohlfeil, daß man hier zu Zara, wo alles viel theuerer ist ${ }^{535}, 5$ Stück um 1 Kreuzer verkauft. ${ }^{536}$

rigkeit zum Alten Reich - im Österreich der 1830er Jahre für die Elite ein bekannter Begriff (und ein auch daher naheliegender Bezugspunkt für transadriatische Vergleiche).

$532 \mathrm{Zu}$ verstehen als »alle Dalmatiner«, die darüber offenbar anderer Meinung waren als Lilienberg...

533 ON Comicsa / Komiža: Ort auf der Insel Vis (Lissa).

534 Petter: Dalmatien, Bd. 1, 281 hält das Auseinanderklaffen von amtlichen Normalmaßen (Wiener Maße) und den auf den Märkten und privat dominierenden dalmatinischen Lokalmaßen fest und gibt 281-293 eine umfassende Darstellung der in Dalmatien relevanten zahlreichen Einheiten. Die in Dalmatien als Flüssigkeitshohlmaß weithin übliche (und zweifellos auch von Lilienberg gemeinte) Barilla war die venezianische (daneben gab es noch drei lokale Barille in Split, in der Poljica und in Makarska); sie entsprach leicht gerundet 1136 Wiener Eimern (a.a.O., 284). Ein Wiener Eimer entsprach 565891, eine venezianische Barilla dementsprechend 64285l. Vgl. zu den alten und damals von Ort zu Ort noch im Alltag unterschiedlich gebrauchten Maßeinheiten am Beispiel Splits den Aufsatz von Zaninović-Rumora: Stare mjere Splita. Die mit Verweis auf eine Kundmachung im Landesgesetzblatt von 1856 verbundene Auffassung der Autorin, erst damit seien die österreichischen Maße amtlich geworden, dürfte mit Blick auf die Angabe Petters von den »amtlichen Normalmaßen" wohl zu modifizieren sein. Im amtlichen Gebrauch galten wohl schon zuvor die österreichischen, nur wurden im privatwirtschaftlichen Gebrauch wohl auch die althergebrachten amtlich geduldet.

535 Dies hing zusammen mit dem relativen Wohlstandsniveau der Stadt infolge ihrer Funktion als Verwaltungszentrum mit der entsprechenden Nachfragestruktur seitens der Beamtenschaft. Vgl. auch schon die Bemerkung von Kaiser Franz I. auf seiner Dalmatienreise 1818 zu Zadar, »das Leben ist teuer «: Krmpotić (Hg.): Car Franjo I. u Hrvatskoj, Bd. 1, 147.

536 Dieser Absatz ist im Konzept rot ausgestrichen, in der Reinschrift aber weiter enthalten. 
Bei Sebenico fängt man vielfältig die Dentali di Corona ${ }^{537}$ welcher der edelste Fisch ist und den man im adriatischen Golfo sonst nirgend, wohl aber bey Constantinopel, häufig findet.

[Qu 46 / 3] Austern werden in dem Novigrader See, und auch bei Brevilacqua ${ }^{538}$ so groß wie einst die Arsenal-Austern in Venedig waren, gefischt; mir scheinen sie aber viel besser, weil diese aus einem ganz reinen Wasser kommen.

Auch werden manchesmal viele Schildkröten gefischt, woraus man auch Fett gewinnt; es kommt sowohl dieses als die Schale im Handel vor.

Muscheln und andere sogenannte Meeresprodukte, werden im Ueberfluss gefangen und genossen. ${ }^{539}$

\section{Verschiedene andere Meerprodukte ${ }^{540}$}

$\$ 109$ [Seidenmuscheln] Es werden an mehreren Orten die Steckmuscheln /: Pinne :/ gefangen, welche eine Art Seide enthalten, die ohnehin Eurer Majestät wohl bekannt ist ${ }^{541}$ und auch einigen Gewinn den armen Menschen verschafft.

An diesen seidenartigen Fasern [gestrichen: sollen auch kleine] [mit Rotstift ergänzt: hängen oft] kleine, doch sehr unregelmäßige, Perlen [rot ausgestrichen: oft hängen], die man deßwegen ${ }^{542}$ blos zur Medizin in der Apotheke verbraucht.

537 Petter: Dalmatien, Bd. 1, 78 erläutert den Dentale mit spraus dentex, Zahnbrasser (sic); gemeint ist auch mit der Lilienbergschen Bezeichnung vermutlich eben die Zahnbrasse (heutiger lat. Name: dentex dentex), die heute italienisch »dentice« heißt.

538 ON (Punta) Brevilacqua / Privlaka: Ortschaft nordwestlich von Nin.

539 Der letzte Satz bzw. Absatz ist rot ergänzt: er kommt in der Reinschrift nicht vor. Dafür ist im Absatz davor im Vergleich mit der Reinschrift erkennbar, dass manche Ergänzungen doch (noch) eingearbeitet wurden; nicht berücksichtigt wurden offenbar später bzw. zuletzt noch vorgesehene. Der Absatz lautete nämlich im Konzept zunächst: »Auch werden manchesmal viele Schildkröten gefischt, woraus man auch Fett gewinnt, und sowohl dieses als die Schallen kommen im Handel vor.« Mit stärkerer Feder sind verändert (und in der Reinschrift berücksichtigt): »es kommt« statt »und «, Korrektur von »Schallen« und Ausstreichung von »kommen«. Die mit schwächerer Feder vorgenommene (und hier im Einklang mit dem Schwerpunkt der Edition auf der Konzeptfassung auch übernommene), anscheinend spätere Veränderung der "gefischten« in "gefangene» Schildkröten findet sich hingegen in der Reinschrift nicht (dort Seite 71 / fol. 37r).

540 Überschrift im Konzept mit Rotstift ersetzt durch: »Muscheln, und andere sogenannte Meeresfrüchte«. In der Reinschrift nicht umgesetzt.

541 Der Einschub zum Kaiser wurde rot ausgestrichen, steht aber in der Reinschrift.

542 Wegen ihrer Unregelmäßigkeit. 
[Qu 46 / 4]

Corallen

$\$ 110$ Besonders in der Gegend der Insel Zlarin und Zuri ${ }^{543}$ werden ziemlich viele gefischt, die Pachtung ist pro Aerario, der Contract dauert noch bis zum Jahr 1843, und trägt jährlich 568 Gulden. ${ }^{544}$

Wenn die Aufklärung und die Industrie zunehmen wird, wird man wohl auch darauf denken, ordentliche Taucher zu erhalten und den Reichthum, welcher in der Tiefe des Meeres liegt, überhaupt zu erforschen und auch beim Corallenfange zweckmäBiger zu verfahren.

\section{Meer-oder Wasserschwämme}

$\$ 111$ Diese werden vielfältig gewonnen und ernähren so wie die Korallenfischerey viele Küstenbewohner. Man findet ihrer oft an der Küste, wenn sie vom stark bewegten Meer dahin ausgespült werden. Bei Brevilacqua zwischen dieser Punta und der Insel Pago werden viele, die meisten $[Q u$ 47/1] aber nach der Insel Zuri gefischt, man versichert aber, daß man sie fast überall an der Küste findet.

\section{Meer-Salz}

$\$ 112^{545}$ Der wichtigste Ertrag aus den Gewässern Dalmatiens für die Bewohner und für das allerhöchste Aerarium besonders, ist die Erzeugung des Meersalzes. [rot am Rand ergänzt:] auf Pago, Arbe, und bey Stlagno wird sehr viel Salz um einen sehr geringen Preiß erzeugt.

[Am Rand mit Tinte ergänzt und gestrichen: Finanz.-Int. frag. ?] Das Aerarium kauft [ergänzt: von unseren Erzeugungen in Pago und Arbe] den Centner [ergänzt: weißes; gestrichen: graues] Salz um [ergänzt: 20 1/5 bis $231 / 3$ Kreuzer]. ${ }^{546}$

$\mathrm{Die}^{547}$ anderen Transport- und Administrationskosten betragen etwas mehr, so daß der Centner dem Aerarium auf [gestrichen: 46] 49 Kreuzer zu stehen kommt.

543 ON / TN Zuri / Žirje: Insel und gleichnamiger Ort im Südwesten von Šibenik.

544 Am Rande vermerkt: »Nachfragen!« Die Jahreszahl und die Ertragssumme wurden daraufhin später eingefügt, und sind auch in der Gliederung am Rande vermerkt.

545 Der ganze (inhaltlich wegen der Bedeutung des Produkts und der Folgen des Staatsmonopols dem Schreiber offenbar besonders wichtige) Paragraph ist im Konzept voller Änderungen in Tinte und roten Ergänzung und vor allem auch mit längeren roten Streichungen; diese letzteren konnten mangels Nachvollziehbarkeit nur zum Teil berücksichtigt werden. Vgl. in der Reinschrift Seite $72 \mathrm{f}$. / fol. 37.

546 Gestrichen ist die Fortsetzung: »und verkauft das meiste an die Türken um 2 Gulden 7 Kreuzer, an die Einwohner das weiße um 4 Gulden 30, das schwarze um 3 Gulden 30. Dies fehlt auch in der Reinschrift.

547 Ab hier sind der Rest des Absatzes und der folgende Absatz am Rand mit Handschrift von Rossetti ergänzt und dann rot durchgestrichen, aber in der Reinschrift enthalten. 
Das graue Salz von Stlagno kommt dem Ärar an 46 Kreuzer, das weiße aber auf auf [sic] [gestrichen 49] 50 Kreuzer, jenes aus Sizilien auf 53 3/4 Kreuzer, dann das weiße istrianer Salz [ergänzt: auf] 1 Gulden 18 2/3 Kreuzer zu stehen. Das Letzte wird an die kk. Unterthanen um 4 Gulden 30, das graue von Pago und Stlagno denselben um 3 Gulden 30, dagegen das weiße von Stlagno und jenes aus Sicilien an die Türken um 2 Gulden 7 Kreuzer verkauft.

Die Landesstelle ist um die Verminderung des Salzpreises [ergänzt: für die k.k. Unterthanen] eingekommen [ergänzt: damit sie dießfalls den Türken gleichgehalten würden ${ }^{548}$ ]. Durch diese allerhöchste Gnade würde dem dürftigen Volke und der Viehzucht große Wohlthat ergehen, und ich nehme mir die ehrfurchtsvolle Freiheit, allerunterthänigst zu bitten diesen Umstand allergnädigst zu beherzigen.

Auch dieses [Produkt] ist hie und da [Qu 47 / 2] vernachlässiget ${ }^{549}$ und besonders die Anlage von Stlagno mangelhaft; ich habe diese in Gesellschaft des Bauadjunktens Pressani besichtigt um zu sehen, wie man den Reparations-Aufwand möglichst mäßigen und dennoch einen guten Erfolg erreichen kann. Dermalen wird von einem Ingenieur alles gehörig aufgenommen, um darnach der allgemeinen Hofkammer den verlangten Vorschlag wohlgegründet vorlegen zu können.

Wenn man die türkische Erdzunge, Suttorina genannt, eintauschen könnte, wäre es auch aus dem Grund sehr vortheilhaft, weil es den Türken leicht einfallen könnte, dort Salinen anzulegen, wo sie unter den Venezianern meistens bestanden haben und so wie ich gesehen [Qu 47/3] habe, in ziemlicher Ausdehnung angelegt werden könnten.

\section{Berg Bau}

$\S 113$ Dermalen ist in Dalmatien keiner ${ }^{500}$; denn die Eisengrube, welche der Cavaliere Geragini ${ }^{51}$ von Trau zwischen Verlicca und Sign bearbeitet hat, wurde vermuthlich aus Mangel an Holz verlassen.

Man findet aber vieler Orten Thoneisenstein; besonders sind aber große stockförmige Lagermaßen bey Imoschi.

Auch habe ich auf den Berg Vellebich Eisen Erz gefunden. ${ }^{552}$

Annebst ist hier das Eisenbahnen Erz vielfältig. Dieses findet sich am Boden der Kuppel der Thäler an verschiedenen Orten.

548 Es ist nicht gut zu sehen, wo im Konzept die rote Streichung endet. Vermutlich hier, doch ist alles in der Reinschrift enthalten.

549 Ab hier bis zum Ende des Paragraphen rote Ausstreichung, doch erhalten in der Reinschrift.

$550 \mathrm{Ab}$ hier der Absatz rot ausgestrichen.

551 Vorname Geraginis und Jahresangaben zu der einstigen Erzgrube konnten nicht eruiert werden.

552 Dieser Satz/Absatz ist rot ausgestrichen. 
Wenn einst die Wälder, oder die Steinkohlen-Brüche in Schwung kommen, wird Dalmatien das Eisen nicht mehr aus Bosnien nehmen. ${ }^{553}$

An Steinkohlen hat diese Provinz vieler Orten und besonders auf [Qu $47 / 4]$ dem Berg Promina einen unerschöpflichen Vorrath ${ }^{554}$.

Die Ausbeutung giebt schon Steinkohlen um 50000 Gulden jährlich in auswärtiger Handlung; sie scheinen aber doch noch der englischen nachzustehen.

Eine Gesellschaft von Wien untersucht, wie es Euer Majestät bekannt ist, schon seit vielen Jahren dieses Gebirg, hat auch einige Schächte zur Probe bereits eröffnet und die Investitur bei der Landesstelle angesucht; auch hat sie bereits den Plan zur Eisenbahn bis zum Meer entworfen. ${ }^{555}$

Wenn dieser Bau zu Stand kommen wird ${ }^{556}$, was von der Regierung durch billige Bedingniße auf jede Art begünstigt werden sollte, so wird es für jene Gegend von nicht unbedeutendem Nutzen und für das ganze Land so wie auch für's Aerarium von einigem Vortheil seyn; weil mit Beihülfe dieser [Eisenbahn] vielleicht auch die Eisen- und andere Bergwerke und gewiß manche Manufacturen [Qu 48/1] werden betrieben werden können.

\section{Erd-Pech}

$\$ 114$ Bei Vergoraz ist eine bedeutende Quantität von diesem brennlichen Minerale, aber diejenigen welche diese Investitur erhalten haben, durch die frühern Verhältnisse verarmt, können noch die hinlänglichen Capitalien nicht finden, um die Grube zu eröffnen und das Geschäft gehörig zu betreiben. ${ }^{557}$

Auch auf der Insel Bua ${ }^{558}$ findet man Erdpech.

553 Dieser Satz/Absatz ist rot ausgestrichen. Zur sehr urtümlichen Machart des aus Bosnien importierten Eisens vgl. Petter: Dalmatien, Bd. 1, $140 \mathrm{f}$.

554 TN Promina, Berg bei Drniš (1149 m); die dort vorhandene und seit einigen Jahren vor 1834 abgebaute Kohle war aber Braunkohle, nicht Steinkohle im heutigen Sinne.

555 Dieser Absatz ist am Rand rot ergänzt, und auch in der Reinschrift enthalten.

556 Tatsächlich fand die Kohlenbergwerkseröffnung (ohne Transporteisenbahn zum Meer) durch die Wiener »Steinkohlen-Gewerkschaft für Istrien und Dalmatien« (eine Aktiengesellschaft) in Drniš noch im gleichen Jahr 1834 statt: Gazzetta di Zara, 90/1834, 11.11., S. 357 Bericht sub Dernis 30 ottobre. Petter: Dalmatien, Bd. 1, 26, erwähnt den Beginn der dortigen Exploration 1829 und die Beteiligung des Freiherrn von Rothschild (gemeint sein muss Salomon Mayer Rothschild, der Gründer der Rothschild-Bank in Österreich) an dem Kapital der Gesellschaft; vgl. auch ebd., 22 zum Namen der Aktiengesellschaft.

557 Die Frage wurde bald darauf rechtlich gelöst: Die Altrechtsinhaber Georg und Meht. Giurich wurden durch Vertrag mit dem Gubernium vom 5.10.1835 in ihren Rechten bestätigt, mit Dekret vom 18.11.1835 erhielten sie darauf die betreffende »Investitur«. Der Abbau ging aber wegen Transportproblemen auch in den Folgejahren und auch nach baldiger Übernahme durch die kapitalkräftigere »Steinkohlen-Gewerkschaft« nur schleppend voran (Petter, ebd., 22f.).

558 TN (Inselname) Bua / Čiovo, unmittelbar Trogir vorgelagert. 


\section{Marmor und sonstige Steinbrüche}

$\$ 115$ Es giebt an vielen Orten in Dalmatien verschiedenartigen und verschiedenfärbigen Marmor, welcher aber noch nicht im Handel vorkömmt.

Auf der Insel Arbe ist ein ganz [Qu 48 / 2] weißer Marmor zu finden, welcher der berühmte Canova ${ }^{559}$ benützen wollte; dann aber einen beßeren gefunden haben soll und es unterblieben alle ferneren Versuche.

Auf der Insel Curzola fand ich einen sehr bedeutenden Steinbruch und auch viele Steinmetze in der Arbeit beschäftiget. Dort werden sehr beträchtliche Geschäfte, besonders mit Thür- und Fenster-Stocken, Säulen, großen Gefäßen und verschiedenen andern Ornamenten, dann werden auch Quader-Stein zum Haus- und Kirchenbau wie nicht minder viele Mühlsteine gemacht.

Von diesen Fabrikaten gehen sehr viele auch ins Ausland; besonders führt man diese nach Italien, und auch [Qu 48 / 3] als Ballast [für die Schiffsfahrt] in die Levante.

\section{Andere Mineralien ${ }^{560}$}

$\$ 116$ Als ich den Berg Promina und die eröffneten Schachten mit dem Bergbau-Verständigen der schon erwähnten Gesellschaft besichtigte, so wurde ich von diesem versichert, daß es in der dortigen Gegend verschiedene Mineralien gebe, als: Bley, welches silberhältig seyn soll bei Verlicca, dann christalisirten Gyps [Gips], Porzellan-Erde auf dem Vellebich und Kreide, die auch bei Scardona vorhanden ist, nebst verschiedenen andern Erdfarben. Dieses wird sich, wenn der Steinkohlenbau eröffnet werden sollte, erst dann am besten erörtern und benützen lassen.

Bei Kliake ${ }^{561}$ und Gradaz ${ }^{562}$ im Kreise Zara findet sich ein Bleierz, da es aber nichts an edlen Metallen enthällt, so wurde es nie bearbeitet.

In der Gegend von Knin hat man mir vielfältig von einem Silbererze gesprochen und behauptet, daß 1780 die Grube eröfnet und ein gewißer Carzaniga ${ }^{563}$ damit investirt dann aber kurz darauf diese Befugniß zurück genommen worden wäre. Ich werde das Gubernium von Venedig um die dießfällige Auskunft angehen. So wie ich mich auch rücksichtlich der geognostischen Untersuchung von Dalmatien überhaupt, die durch einen k. k. Commisär während der ersten Occupation vorgenommen wurde und alle be-

559 Antonio Canova (1757-1822), venezianischer Bildhauer, ein Hauptvertreter des italienischen Klassizismus.

560 Zahlreiche rote Streichungen bis hin zu dem Absatzende »[...] dießfalls ansuchtn«, zu Beginn von Qu 48 / 4. Sie konnten hier nicht nachvollzogen werden und wurden in die Reinschrift auch offenkundig nicht übernommen und u. a. die im Konzept ergänzten, rot durchgestrichenen zwei Absätze darin enthalten sind.

561 ON Kliake / Kljake: Ortschaft ca. $15 \mathrm{~km}$ südöstlich von Drniš, entlang der im Text schon öfter beschriebenen Verbindungsrichtung zwischen Drniš und Klis.

562 ON Gradaz / Gradac: Ansiedlung etwa auf halber Strecke zwischen Drniš und Kljake.

563 Näheres zu Carzaniga war nicht zu eruieren. 
züglichen Akten bei der all[gemeinen] Hofkammer vorliegen sollen, an diese Hofstelle verwenden werde. ${ }^{564}$

Auf der Insel Lissa [ist] ein schöner Quarz-Sand, welchen man in früherer Zeit zu Glasfärberey [Qu 48 / 4] nach Venedig einführte und eben vor einigen Tagen hat sich ein Jude bey mir gemeldet, der eine Investitur dießfalls ansuchte $e^{565}$.

Zuletzt muß ich der hier vielfältig vorkommenden Knochen-Bréccia ${ }^{566}$ erwähnen, welche in den Spalten oder Höhlen im Jura-Kalk [auftritt], welcher hier häufig vorkömmt, da der Kalkstein beiderlei Formation den wesentlichsten Bestandtheil dieser Gebirge ausmacht.

Diese so berühmte Knochen-Bréccia, welche sich bey Rogošnizza ${ }^{567}$, Salona, und auf der Insel Caluggera findet, enthält meistens Knochen, welche die geschicktesten Geognosten wiederkäuenden Thieren aneignen; es finden sich aber auch in einigen Stücken Seethierchen versteinert.

Auf der Insel Lesina fand ich Schiefer-Stein, welcher seltne Fischabdrücke enthält.

[Qu 49/1]

[Qu 49 / 2, 3, 4 fehlen in der Zählung, aber inhaltlich besteht keine Lücke]

564 Dieser und der vorangestellte Absatz wurden im Konzept am Rand, wohl durch Rossetti, ergänzt. Gemeint ist die erste österreichische Herrschaft (1797-1806). Der angesprochene Kommissär war der Montanistiker Joseph Ritter von Pantz (nach 1815 Rat im Department für Bergbau beim Venezianer Gubernium), der 1801, 1802 und 1803 Istrien, das engere Dalmatien und "Österreichisch-Albanien « auf Kosten der Hofstellten bereiste und montanistisch explorierte, ehe er 1803 einen umfassenden Endbericht an die Hofkammer sandte. Diese Angaben (denen Lilienberg hier inhaltlich so eindeutig folgt, dass seine Verwendung der Brodmannschen »Memorie« als hinreichend belegt gelten kann) finden sich bei [Brodmann]: Memorie politico-economiche, $266 \mathrm{f}$.

565 Nach »einführte« ist der Rest mit der auf die unmittelbaren Tage der Niederschrift bezogenen Passage dann wieder rot ausgestrichen worden. Die Art der Formulierung legt hier wieder einmal Diktatcharakter nahe.

566 Brekzie oder Breccie (von italienisch breccia: Geröll), ein aus eckigen Gesteinstrümmern in feinkörniger Grundmasse bestehender Gesteinstyp. Eine Stichwortsuche auf der Google-Books-Kopie von Fortis' Viaggio in Dalmazia, Bd. 2, bringt nicht weniger als 19 Treffer für breccia und neun weitere für breccie, wobei Fortis seine erdgeschichtliche Interpretation wiederholt gegen andere Auffassungen (Wallerio) erörtert. Die europaweite Berühmtheit der dalmatinischen "Knochen-Breccia« ist vor genau diesem Hintergrund der nur mühsam möglichen Einordnung solcher Funde in ein biblisch gebundenes Weltbild zu sehen, das für die Erdgeschichte zwischen vor- und nachsintflutlich unterschied. Fossile Versteinerungen wurden im Zuge dessen als Knochen der größten im eigenen Umfeld vorhandenen Tiere (Wiederkäuer) eingeordnet. Vgl. unter diesem Aspekt auch noch die Angaben bei Petter: Dalmatien, Bd. 1, 28-30 über »die für den Geologen so merkwürdige Knochen-Breccie von Dalmatien« (28f.).

567 ON Rogošnizza, an späteren Stellen Rogosnizza / Rogoznica, nahe Šibenik. 


\section{Mineral-Wässer}

$\$ 117$ Dalmatien hat in dem Kreise Zara, unweit von Obbrovazzo, bey Crussevo ${ }^{568}$ ein Wasser, welches viele Magnesia führt und vielfältig von den Einwohnern als gewöhnliches Trink-Wasser gebraucht wird.

Dann in dem Kreise Spalato ist ein Schwefelbad ohnweit Spalato selbst, und ein Gesundheits-Brunnen bey Verlicca, der manchesmal von Bade-Gästen besucht, mit Vortheil für die Gesundheit gebraucht wird, aber da das Wasser schwach ist, fast allgemein auch zum gewöhnlichen Trunk dient.

Auch im Ragusaer Kreis bey Ragusavecchia ist ein mit Schwefel geschwängertes Wasser, aber bis nun hat man es nicht besonders verwendet.

Vor wenigen Tagen ist in der Stadt Zara ein sehr mächtiges Schwefel-Wasser entdeckt worden, welches ich chemisch untersuchen lassen werde; denn besonders dieses könnte sehr wohlthatig für diese Gegend werden. ${ }^{569}$

Bey Verlica ist ein etwas säuerliches [folgendes Wort unleserlich] eigenes Wasser.

[Qu 50 / 1]

\section{Industrielle Production}

$\$ 118$ Die industrielle Produktion fängt an sich etwas zu heben.

Ich habe hie und da mit wahren ${ }^{570}$ [sic] Vergnügen eine Gewerbsbetriebsamkeit gefunden, welche jener der anderen Provinzen nicht viel nachstehet. ${ }^{571}$

568 ON Crussevo / Kruševo: Ansiedlung ca. drei Kilometer südwestlich von Obrovac, in Richtung Karinsko more.

569 Der letzte Absatz ist rot durchgestrichen. Ähnlich wie etwas weiter oben geht also ein Geschehen direkt aus den Tagen der Niederschrift des Berichts in diesen ein, und zwar in einer Formulierung, die nach Diktat klingt. In der Reinschrift ist er erhalten, anders als der im Konzept rot ergänzte und hier aufgenommene nachstehende Satz.

570 Bei gelegentlichen Kasusfehlern wie diesem in der Konzeptschrift scheint wohl durch, dass Rougier kein deutscher Muttersprachler gewesen sein dürfte. In der Reinschrift steht aber stattdessen korrekt »wahrem «.

571 Dieser Absatz ist im Konzept rot ausgestrichen und am Rand mit schwachem Bleistift und wohl gleicher Handschrift (nämlich vermutlich Lilienbergs) wie das sonstige Rote durch eine nur teilweise entzifferbare, nur im Konzept befindliche Phrase ersetzt: »[Unleserliches Wort] bestehen in der Hauptstadt Zara ganz und ansonsten [ein Wort unleserlich] sehr wesentlich." 
Vorzüglich ist die Ziegelschlägerei zu Ragusa bemerkungswerth, die sehr gute Bauund Dachziegel erzeugt ${ }^{572}$. Man findet ${ }^{573}$ selbst in den deutschen Ländern keine vollkommenere.

Dieses erscheint um so wünschenwerther, als Dalmatien fast alle Ziegel aus dem Päpstlichen holen mußte.

Es sind dermal zu Cartole ${ }^{574}$ im Kreise Cattaro und bei Gruda ${ }^{575}$ im Ragusaer Kreise Ziegelschlägereyen, doch von viel minderem Belange und sehr gemein betrieben.

Auch bey Dernis wird itzt ein großer Ziegeloffen errichtet wo mit Steinkohle die Erzeugung gehen wird. ${ }^{576}$

Die Seidenspinnerey des Doktor Pinelli, die an Feinheit der Gespunst von keiner in Italien übertroffen $[Q u$ 50 / 2] werden dürfte.

$\mathrm{In}^{577}$ Blinn ${ }^{578}$ bestehen bereits in mehreren Orten Seidenspinnereyen, zu deren Existenz auch Vorschuß vom Ärarum gegeben wird.

Auf der Insel Eso ${ }^{579}$ wird Hafnerarbeit zu guter, aber ganz ordinärer Qualität gemacht, so wie eine solche hier an [zwei Wörter unleserlich]. Eine Anstalt von feinerer Hafnerarbeit, die in Zara besteht, kommt nicht besonders fort. ${ }^{580}$

Das ${ }^{581}$ Eisen-Druckwerk bei Spalato, von welchem bei Beschreibung der Flüße Erwähnung geschah und welches erst im vorigen Jahre errichtet wurde, liefert gute Fabrikate, hat auch nach dem Auslande Bestellungen; doch kann solches wegen Mangel an Capitalien noch nicht recht vorwärts, arbeitet dermalen blos Eisen-Waaren, könnte aber bei

572 Die Ziegelbrennerei zweier dörflicher Unternehmer im Bereich der Konavle - Marko Radonić und Miho Čupić - war 1830 eröffnet worden. Sie stand in der Nachfolge einer 1806 von den montenegrinischen Kämpfern vollkommen zerstörten früheren, was als eindrückliches Beispiel dafür gelten kann, wie lange unter den damaligen Umständen Kriegsschäden negativ fortwirkten, wovon auch Lilienberg in seiner Reiseschilderung verschiedentlich spricht. Vgl. Peričić: Gospodarske prilike Dalmacije, 94.

573 So mit Rotstift umformuliert anstelle von zuvor (und erhalten in der Reinschrift): »Ich habe selbst in den deutschen Ländern keine vollkommenere gesehen."

574 ON Cartole / Krtole: Ansiedlung im Nordwesten von Budva (Kreis Cattaro).

575 ON Gruda / Gruda: Dorf im Konavle, im Südosten von Cavtat (Kreis Ragusa).

576 Dieser Absatz ist eine rot verfasste Ergänzung.

577 Die folgenden beiden Absätze sind am Rande mit schwach leserlichem Bleistift eingefügt (Handschrift Lilienbergs), und in der Reinschrift nicht berücksichtigt worden.

578 ON Blinn; entspricht bei Kozličić / Bralić Billine = Bjelina, eine Ansiedlung nordwestlich von Kistanje.

579 TN (Inselname) Eso / Iž.

580 »Fortkommen« hier zu verstehen im Sinne von »vorankommen«, "gut gehen«.Gemeint ist offenkundig eben die Hafneranstalt, die zwei Absätze später so lobend erwähnt wird (allerdings war dieser Absatz mit der lobenden Hervorhebung laut Markierung eigentlich zur Streichung vorgesehen).

581 Die nachstehenden drei Absätze sind im Konzept rot ausgestrichen. 
einer zweckmäßigen Unterstützung dem Lande einmahl sehr nützlich werden, weil es zur Erzeugung von Kupferwaaren eben eingerichtet ist. ${ }^{582}$

Eine vorzügliche Hafner-Anstalt ist hier in Zara, welcher ich schon $\$ 62$ erwähnt habe und die schönes und sehr gutes Erdgeschirr, das bis nun ganz aus dem Auslande geholt werden mußte, in hinlänglicher Menge für das ganze Land und auch bedeutend zum auswärtigen Handel liefern wird.

Der Unternehmer wird auch einen Ziegelofen errichten, dessen wir noch bedürfen, weil in dem verfloßenen Jahre annoch mehr [Qu 50 / 3] als 11000 Gulden für diesen Artikel ins Ausland bezahlt wurden. ${ }^{583}$

Eine Bierbräuerrey in Zara, welche sehr gutes Bier erzeugt. ${ }^{584} \mathrm{Zu}$ Sign ist eine sehr künstliche ${ }^{585}$ und sehr zweckmäßige, durch thierische Kraft zu bewegende Mahlmüh$\mathrm{l}^{586}$ erfunden worden, worüber der Erfinder ein fünfjähriges Privilegium ${ }^{587}$ im Jahre 1832 erhalten hat.

In Ragusa bestehet eine vorzügliche Oehl-Preß-Maschine, die ein Privilegium schon im Jahre 1829 auf 5 Jahre erhielt.

$\mathrm{Zu}$ Sebenico hat man eine sehr künstliche und sehr zweckmäßige Maschine zum Stopfen ${ }^{588}$ der Bouteillen erfunden, die viel vorzüglicher und zweckmäßiger ist, als alle aus- und inländischen, die ich bis nun gesehen habe ${ }^{589}$, weil auf diese Art nie eine Bouteille zersprengt, nie zu voll und nie zu wenig, sondern immer [Qu 50 / 4] gleichmäßig gefüllt werden kann und da von Innen gegen Außen die Stopfung geschieht; auch der leere Raum, der zwischen dem Stöpsel ${ }^{590}$ und dem Wein bleibt, immer gleich und ganz Luft leer ist und deswegen die Erhaltung des Weines gewinnen muß.

Der Nämliche, welcher diese Maschine erfunden hat, ist jetzt mit einer Oelpreße beschäftiget, die an Vorzüglichkeit alle bisherigen übertreffen soll; da er aber das nöthige Capital, welches zur Errichtung dieser erforderlich war, hier nicht auffinden konnte, so hat er sich nach Triest begeben um sein Werk zu beenden, wo er auch associés ${ }^{591}$ gefunden hat.

582 Vgl. oben, in $\$ 33$, sowie zu der kurzzeitig florierenden Eisenwerksgründung der Eigner Giromalo Cobalchini (aus Split) und Michele Dall'Armi (aus Zadar) Peričić: Gospodarske prilike Dalmacije, $103 \mathrm{f}$.

583 Wieder ein Beleg für die Vorstellung von der erstrebenswerten Importsubstitution bzw. von den schädlichen Kaufkraftverlusten bei Importen.

584 Brauerei von Josip Sabalić, gegründet gegen 1830; Peričić: Gospodarske prilike Dalmacije, 112.

585 Veraltet für: »kunstvolle«.

586 Mahlmühle, zu verstehen als Getreidemühle.

587 Wohl direkt zu verstehen als Patent; der Patentschutz galt dann, wie nachstehend zu sehen, nur für fünf Jahre, er gab dem Erfinder also bloß wenig Zeit für sein Nutzungsmonopol.

588 Im Sinne von »mit einem Korken versehen «, "verkorken«.

589 Der Halbsatz mit dem »ich« ist im Konzept mit Rotstift durch eine unleserliche Einfügung ersetzt, in der Reinschrift aber enthalten.

590 Korken.

591 Teilhaber. 
Ich habe zu Ragusa und Cattaro einige Seiden-Manufakturen gesehen, die - wenn gleich nicht vorzüglich, doch nicht für den Anfang ${ }^{592}$ verwerflich [Qu $\left.51 / 1\right]$ sind.

Auf Lagosta wird sehr viel Seide gesponnen, aber sehr grob und diese wird bloß zu Fischernetzen verbraucht; ich hoffe aber, daß dieser Zweig bald beßer benützt werden wird $^{593}$.

In Risano werden Saiten aus Schafgedärmen erzeugt, welche den Römischen nicht viel nachstehen sollen.

So bestehen in Ragusa und Cattaro einige Ledergärbereyen.

Hinlängliche und gute Wachszieher sind in allen Städten.

Dann sind in mehreren Orten und besonders in Zara berühmte Rosoglio- und Geistbrennereyen, derer man schon bey den Vegetabilien erwähnte ${ }^{594}$.

Ich habe die Freude gehabt, auf meiner Bereisung Beweise zu finden, da $\beta^{595}$ die Polizei- [Qu 51 / 2] und Comerzial-Gewerbe sind überhaupt in Aufnahme und unter diesen viele schon der Vollkommenheit nahe.

Deßwegen habe ich die politischen Behörden aufgefordert, auf diesen Erwerbszweig besonderes Augenmerk zu richten, auch von nun an mit mehr Genauheit die dießfälligen Verzeichniße zu verfaßen, und habe nun das Glück, Euer Majestät allerunterthänigst vorzutragen, daß Dalmatien in dieser Hinsicht schon die Früchte der Allergnädigst-väterlichen ${ }^{596}$ Sorgfalt zu fühlen beginnet, da diese früher hierin ganz vernachläßigte ${ }^{597}$ Provinz bereits 540 Manufacturen, 11857 Polizei- und Comercial-Gewerbe ${ }^{598}$ und 660 besondere Beschäftigungen zählt.

592 Diese drei letzten Worte sind rot eingefügt und in der Reinschrift nicht berücksichtigt. Der Satzteil insgesamt heißt damit gemäß dem überarbeiteten Konzept sinngemäß: »für den Anfang sind sie nicht schlecht« (»verwerflich« hier also in einem heute nicht mehr üblichen wörtlichen Sinne von "zu verwerfen«).

593 Rote Ausstreichung im Konzept ab dem Strichpunkt, in der Reinschrift aber enthalten.

594 So die rot veränderte Fassung statt ursprünglich: »derer ich schon bey den Vegetabilien allerunterthänigst erwähnt habe« (so auch in der Reinschrift). Neu hinzugefügt wurde mit Bleistiftschrift (wie die rote Handschrift) als kurzer Absatz ein schlecht leserlicher Satz zu einer Produktion auf Lissa. Er konnte nicht annähernd entziffert werden und ist auch in der Reinschrift nicht enthalten.

595 Der Satz bis hierher sollte laut roten Anstreichungen inhaltlich gestrichen werden, steht aber auch in der Reinschrift.

596 Ein direkter, wohl wegen der umständlichen und vielleicht zu personal gehaltenen Formulierung im Konzept zur Streichung vorgesehener Bezug auf das »Landesvatertum« des Monarchen diesem selbst gegenüber; in der Reinschrift erhalten.

597 Dieser ganze Absatz hatte bis hierher laut roter Ausstreichung wegzufallen. Der Anschluss sollte laut Einschub neu lauten:»Die Provinz zählt [...] besondere Beschäftigungen.«In der Reinschrift sind die Änderungen nicht umgesetzt.

598 Polizei- und Kommerzialgewerbe war im österreichischen Amtsdeutsch jener Zeit im wesentlichen synonym zu heutigen »Gaststätten und Handwerksbetrieben«; erstere unterstanden der »Polizei« (im Sinne von Kommunalaufsicht) und die letzteren der Kommerzialaufsicht 
Dalmazien hat ${ }^{599}$ auch sechs [Qu 51 / 3] vortreffliche Schiffswerften und obwohl diese einen Theil des nöthigen Bauholzes auf der Narenta aus der Türkei beziehen müßen, so ist dieser Erwerbszweig doch von großer Bedeutung ${ }^{600}$ und wird sich sicher wieder heben, wenn Eure Majestät sich Allergnädigst bewogen finden dürften, die von mir unter dem 18 Dezember 1833 Z 2297/P der k. k. allgemeinen Hofkammer vorgeschlagenen Begünstigungen Huldreichst zu bewilligen; weil Dalmatien sonst wegen starken Zolls, der auf die verschiedenen zur Schiffausrüstung nöthigen Artikel gelegt ist, mit Triest und Venedig, wo freye Häfen bestehen, die Concurenz nicht halten könnte und dieser Erwerbszweig, welcher bereits sehr gelitten hat, ganz aufhören und doppelten Schaden [Qu 51 / 4] dem Lande zuführen würde. ${ }^{601}$

Was im Lande besonders fehlt, sind die Seifensieder und da Dalmatien viel rohes Fett und auch gemeines Oehl ausführet, so nehme ich mir vor, wenn es möglich seyn wird, auch auf diesen Zweig zu denken, denn es gehen alljährlich bey 18000 Gulden für die Seife ins Ausland. ${ }^{602}$

Zur Verfertigung von groben Leinwanden und von grobem Halbtuch, Rašcia genannt, sind unter den Einwohnern viele Weberstühle ${ }^{603}$.

Auch sind hinlängliche Färbereyen im Lande vorhanden. -

Ich ${ }^{604}$ habe gegründete Hoffnung, daß sich dieser Erwerbsfleiß immer mehr erheben wird und es ist mir gelungen, um nach und nach einheimische Handwerker in nöthiger Anzahl zu ziehen, [Qu 52/1] arme Kinder zu verschiedenen Meistern gegen einen mäßigen Beitrag aus der Wohlthätigkeits-Anstalt in die Lehre zu geben, welche sehr gute Fortschritte machen. ${ }^{605}$

(Gewerbeaufsicht). Beides waren kommunale Befugnisse bzw. in Dalmatien außerhalb der Städte wohl Befugnisse der Präturen. Vgl. als Beispiel eine Auflistung der einzelnen Kleinbetriebe in der böhmischen Stadt Kladrau (Kladruvy) westlich von Pilsen in: Johann Gottfried Sommer: Das Königreich Böhmen, statistisch-topographisch dargestellt. Bd. 6: Pilsner Kreis. Prag 1838, 147 (benutzt über Google Books).

599 Statt ursprünglich (und so auch in der Reinschrift): „Dalmazien zählt«.

600 Statt ursprünglich (und wieder auch in der Reinschrift): »war [...] einstens von sehr großer Bedeutung...«. Nach der »Bedeutung« sollte von hier an gemäß Konzept der Rest des Absatzes laut roter Ausstreichung wegfallen, ist jedoch in der Reinschrift erhalten.

601 Eine direkte Wendung an den Kaiser mit einem interessanten Argumentationsmuster gegen die zollpolitische Benachteiligung der Dalmatiner Wirtschaft innerhalb des habsburgischen Adriaraums bzw. insgesamt der Monarchie; im Konzept war dieses Argument zur Streichung vorgesehen, es steht aber so in der Reinschrift.

602 Dieser Absatz sollte laut roter Ausstreichung wegfallen.

$603 \mathrm{Zu}$ verstehen als: haben viele der Einwohner Webstühle.

604 Dieser und der nächste Absatz sind rot gestrichen, jedoch in der Reinschrift erhalten.

605 Es gab also eine Ausbildungsförderung Lilienbergs für einzelne arme Kinder, im Handwerk, zunächst um den Mangel an Handwerkern zu verringern. Vgl. auch unten, in $₫ 209$. Da damit aber auch die Möglichkeit zu sozialem Aufstieg verbunden war, stand Lilienberg hierin wohl nicht voll im Einklang mit dem vormärzlichen Herrschaftssystem. Dieses hatte zu- 
Diese Verfügung wird nach und nach, so wie die Begünstigung die man den Fremden, welche sich in dieser Absicht hier niederlaßen, zukommen läßt, den außerordentlichen Vortheil hervorbringen, daß die vielfältigen Producte, welche roh hinausgeführt werden, im Lande zur Erweiterung der Nahrung und des wahren Erwerb-Gewinnes werden bearbeitet und dann als Manufakturen ausgeführt werden können.

\section{Die Comercielle Production}

$\$ 119$ [Dermaliger Zustand derselben] Die Comercielle Production ${ }^{606}$ ist im Vergleiche mit der Epoche Eurer Majestät erster [Qu 52 / 2] glorreichen Domination ${ }^{607}$ nicht von dem Umfange, als sie sein könnte, weil der Seehandel unter der nachgefolgten französischen und italienischen-illirischen Regierung sehr herabgekommen ist; und durch die nachherige Einstellung ${ }^{608}$ der Caravanen der Handel überhaupt fast ganz zu Grunde gegangen war, was auch den innern Handel großen Theils vernichten mußte. ${ }^{609}$

mindest im Bereich der Gymnasialbildung solche Mobilität gerade nicht zum Ziel. Vgl. dazu Clewing: Staatlichkeit, 126f. und Sandgruber: Ökonomie und Politik, 152f. zu Gesamtösterreich.

606 Hier ein Synonym für »Handel«.

607 Rote, im Konzept geplante »unpersönliche« Neuformulierung: »mit der Epoche der ersten Domination Österreichs«. In der Reinschrift ist der Wortlaut aber unverändert (Seite 78 bzw. fol. 40v). Der Sachverhalt an sich ist schlüssig, weil der Seehandel und die Schiffsfahrt, nach einem Aufschwung unter der ersten österreichischen Herrschaft, dann zu der Zeit der napoleonischen Herrschaft extrem unter der britischen Kontinentalsperre, den Kriegshandlungen und dem Freibeutertum gelitten hatten. Vgl. Peričić: Gospodarske prilike Dalmacije, $120 \mathrm{f}$.

608 Eine bemerkenswerte zwar indirekte, aber heftige Kritik an den Wiener Maßnahmen zum Karawanenhandel, zumal deren negative Wirkungen sogar noch schlimmer als die sonst auch von Lilienberg so sehr kritisierten beiden Regierungen der Franzosenzeit beurteilt werden! Vgl. in der Einleitung, 11 f. und 28f. Zum Seehandel der Franzosenzeit hält Peričić: Pomorska trgovina (25) der allgemeinen (älteren) Auffassung vom damaligen Niedergang des Handels entgegen, dies stimme einzig für Dubrovnik, während in Dalmatien ein reger Handel stattgefunden habe, vor allem mit dem Hafen Rijeka. Peričićs Gegenstimme scheint mir hier vorderhand nicht überzeugend, weil gerade die Orientierung an Rijeka (statt an Triest, den italienischen und levantinischen Häfen) durchaus im Einklang mit der Hypothese stehen kann, dass der Handel nur noch in der nächsten Nähe erfolgen konnte und alle weiteren Handelsbeziehungen unter den Verhältnissen der britischen Kontinentalsperre zusammengebrochen sind. Auch der in $\$ 119$ von Lilienberg angesprochene Fernhandel der Boka kotorska zum Beispiel muss damals jedenfalls eingebrochen sein.

609 Von hier an war der ganze lange Absatz (bis »dieser Mißgriff nicht geschehen wäre«) und noch der nachfolgende kürzere Absatz rot durchgestrichen, mitsamt der sehr unverblümten Kritik am Vorgehen der Hofstellen und dem ausdrücklichsten Appell an den Kaiser, die Hofstellen hier zu übergehen. Stattdessen war eine rot geschriebene wesentlich kürzere Neuformulierung am Rand der vorliegenden Seite vorgesehen. Sie konnte im Einzelnen nicht entziffert werden, es geht aber jedenfalls unter anderem um die noch bestehen gebliebenen Karawanenwege. Der Wortlaut in der Reinschrift (Seiten 78f.) ist aber unverändert. 
Als ich durch die allerhöchste Gnade Eurer Majestät als Civil- und Militair Governeur in dieser Provinz ankam ${ }^{610}$, war die erste allgemeine Klage wegen der Aufhebung der Caravanen; ich ließ mir alle Vorakten vorlegen und ging in dieser Hinsicht bis in die frühesten Zeiten der Ex République Venedig zurück.

Als ich auch mit den Verhältnißen [Qu 52 / 3] der Begränzung von welchen ich in dem $\$ 19$ umständlich gehandelt habe, vollkommen bekannt geworden bin und eingesehen habe, daß keine vernünftigerweise annehmbare Truppenzahl die Contrabande vollkommen hindern könnte; daß der Punkt Han, wohin man die Caravanen leiten wollte, aber doch in 16 Jahren nicht zum Zwecke gelangen konnte, durchaus keinen vollkommenen, ja vielmehr einen sehr schwachen Ersatz für das, was früher bestanden hat, leisten würde; daß endlich einige als wesentlich angegebene Gründe, durch welche die Hofstelle irre geführt worden seyn dürfte und die Caravanen eingestellt worden sind, aus der Luft gegriffen wurden und nicht wahr sind, so habe ich diesen Umstand bei dem Hofkammer-Präsidium in Anregung gebracht, welches eine umständliche Verhandlung von mir und von dem Gubernium abverlangt hat, deren Ergebniße seit May 1833 dieser [Qu 52 / 4] Hofstelle vorgelegt worden sind.

Ich bitte Euere Majestät fußfälligst ${ }^{611}$ diesen sehr wichtigen Gegenstand, von welchem auch nach meiner Uiberzeigung die Belebung des Handels von Venedig, des übrigen österreichischen Litorale und insbesondere des Erwerbs-Betriebs Dalmatiens abhängt, allerhöchst Ihre allergnädigste Aufmerksamkeit zu schenken. Anders würden sich die Verhältniße Dalmatiens unter Eure Majestät wohlthätigsten Zepter bis nun gestaltet haben, wenn dieser Mißgriff nicht geschehen wäre.

Obwohl das Land noch weit hinter der comerciellen Bewegung, welche 1805 bestanden haben soll, ist, so bin ich doch so glücklich Euer Majestät allerunterthänigst vorzubringen, daß sich - durch verschiedene allergnädigste Begünstigungen seit einigen Jahren der Handel ein wenig [Qu $53 / 1$ ] gehoben habe.

Seit 3 Jahren wird das Leben etwas reger. ${ }^{612}$

Dalmatien zählt bereits wieder 9 Großhandlungen, 424 verschiedene Waarenhandlungen und Waarenniederlagen, und hat in diesem Augenblick schon wieder 191 ganz eigene, dann 61 an welchen es Theil hat, mithin in allem 252 Schiffe di lungo corso, 439 di grande - und 656 di picolo cabbotaggio. - Die kleinen Schiffe, die blos von einem Orte zum andern, aber in den innern Kanälen zur Fracht dienen, dürften über 3500 an

610 Im Herbst 1831.

611 Lilienberg fällt also hier sinnbildlich vor die Füße des Kaisers, eine Ausdrucksweise, die über das übliche »alleruntertänigst « weit hinausgeht, und die Bedeutung unterstreicht, die er diesem Thema beimaß.

612 Rote Einfügung dieses Absatzes von einem Satz. Seit drei Jahren bedeutet in diesem Zusammenhang insbesondere: seit Beginn von Lilienbergs Amtieren! Zusammengenommen mit der vorhergegangenen Skizze der Fatalität der Wiener Handelspolitik für Dalmatien ein bemerkenswertes Zeichen von Selbstsicherheit des Gouverneurs. In der Reinschrift (Seite 79 bzw. fol. 41 r) fehlt dieser eine Satz.

DigiOst 1 | 154 
der Zahl seyn ${ }^{613}$. Die seit der ersten glücklichen Domination allerdings an der Zahl sehr verminderten Kauffahrthey-Schiffe sind heuer auch etwas mehr als vor einigen Jahren beschäftiget, und ${ }^{614}$ besonders die von Orebich ${ }^{615}$ auf der Insel Sabioncello, auf der Insel Brazza, zu Ragusa und vorzüglich in der Bocche di Cattaro sind meistens in Thätigkeit.

Das einzige Haus Ivanovich ${ }^{616}$ von Dobrota, welches auch zu Triest und Venedig ettablirt ist, befrachtet mit einigen Capitalien wieder [Qu 53 / 2] 12 große Brighs, bey der ersten glorreichen österreichischen Domination hatte er bey 30 Brighs fortwährend in der See.

$\$ 120$ [Bewegungsmittel im Innern des Landes] Die wenigen Bewegungs-Mittel im Innern des Landes sind dem Handel allerdings nicht vortheilhaft ${ }^{617}$ und auch deßwegen würde es noch lange unmöglich bleiben, daß sich ohne Caravanen, die bis an das Meer-Gestade kommen, der Handel heben könnte.

Die Flüße sind nicht schiffbar und werden es bis auf die Narenta, welche nur 3 Meilen lang in unser Gebiet fließt, nie werden können ${ }^{618}$, welches der außerordentliche Fall ${ }^{619}$, den sie haben und ihre anderen Beschaffenheiten, die in den $₫ 34$ und 35 deutlich beschrieben sind, klar beweisen, denn, wenn man das erste Hinderniß überwinden wollte, müßte der Aufwand auf die nöthigen Schleußen jeden möglichen [Qu 53 / 3] Handelsvortheil dieses Landes übersteigen.

[Randanmerkung in Bleistift und unterstrichen: Zu erheben Buchhalter] Dalmatien zählt bereits 2002 Wägen, von welchen ich unter dem $₫ 99$ Erwähnung gemacht habe;

613 Als Kategorien: Hochseefahrt, große Küstenfahrt, kleine Küstenfahrt und Barken/Fischerboote. Ein Hochseeschiff (bastimento a lungo corso, oder bastimento quadro; Typen: Polacà; Brigg; Brigantinen und Goeletten) benötigte eine Lizenz der Hofkanzlei oder der Hofkammer (ab 1848 des Innenministeriums), war fester und stärker als ein Küstenschiff gebaut und unterstand einem Kapitän (capitano). Zu den Küstenschiffen zählten die Pieleghi, Trabakeln, Braciere (Brazzere), Stelle und andere, die Führer wurden padroni di barca genannt. Dazu Petter: Dalmatien, Bd. 1, 268.

614 Dieser Satz (also ab »Die seit der ersten ...«) ist im Konzept bis hierher rot ausgestrichen.

615 ON Orebich, das bei Kozličić / Bralić nur als Orebiči nachgewiesene Dorf auf der Halbinsel Pelješac.

616 Die Handelsunternehmung oder Reederei Ivanovich (Dobrota) gehörte dem Adelsgeschlecht (Grafen laut Wurzbach) der Ivanović; vgl. dazu den Eintrag Ivanovich, die Grafen, in Wurzbach: Bd. 10 (1863), 332-334. Peričić: Gospodarske prilike Dalmacije, 85 erwähnt aus der Familie einen F. Ivanović aus Dobrota für das Jahr 1797 als Gründer einer Tuchfabrik in Kotor. Das »einzige Haus Ivanovich« bedeutet in diesem Fall soviel wie: »Allein schon das Unternehmen Ivanovich«.

617 Ab hier bis zum Ende des Absatzes im Konzept mit Rotstift Ausstreichung (aber in Reinschrift erhalten).

618 Von hier bis zum Ende des nachfolgenden Absatzes (»vorhanden sind») im Konzept Streichung mit Rotstift; in der Reinschrift erhalten. Inhaltlich zu korrigieren hinsichtlich der Zermagne ( $\$ 34)$.

619 Gemeint ist das starke Gefälle dieser wasserfallreichen Flüsse. 
diese befördern aber den Handel gar nicht, weil solche zu schwerfällig und für diese die hinlänglichen Wege noch nicht vorhanden sind.

Die Bewegmittel sind also im Innern bloß die Trag-Pferde und andere Thiere dieser Art; weil diese jedoch sehr vernachläßiget und schwach und bey weitem zu wenig sind, so kömmt der Frachtlohn zu hoch zu stehen und diese würden auf keinen Fall zur Beförderung des Handels im Großen hinlangen.

$\mathrm{Es}^{620}$ scheint, daß man auch diesen Umstand ganz unbeherziget gelaßen hat, als man die Einstellung der Caravanen vorschlug und den auswärtigen Handel an der Gränze ketten wollte. Man glaubte dadurch dem Lande Erwerb zu [Qu 53 / 4] verschaffen, hat aber nicht bedacht, daß der Thiere viel zu wenig sind und wenn solche auch in 40-50 Jahren verdoppelt würden, alle der Landwirthschaft, wenn man solche gut betreibt und fruchten ${ }^{621}$ soll, unentbehrlich seyn würden.

Noch weniger wird man bedacht haben, daß es dem Handelsbetriebe nicht gleichgültig seye, mehrmal die Waaren überladen zu müßen, daß es aber einen sehr kleinen Unterschied mache, wenn der Fuhrmann, welcher die Güter am Ursprungsorte geladen und von weiten gebracht hat, auch noch um 5-6 Meilen weiter gehe.

Die Transversal- und viele übrige Communications Straßen fehlen auch noch vielfältig oder sind sehr mangelhaft ${ }^{622}$ und da die meisten, so wie ich $₫ 68$ allerunterthänigst bemerkt habe, für Bezirks- und Comunal-Straßen erklärt wurden, so werden diese nur nach und nach und sehr langsam, damit man der Landwirthschaft nicht zu sehr schade, gemacht werden können. ${ }^{623}$

[Qu 54 / 1]

[\$ 121] [Objecte des Activ Handels] Dermalen bestehet Dalmatiens activer Handel im Wesentlichsten in nachbenannten Artikeln und zu dieser Vorstellung habe ich die Ausfuhr vom Jahre 1833 zur Basis genommen.

An geistigen, im Lande fabrizirten, Getränken wurde um 88000 Gulden ausgeführt. An geräuchertem und eingesalzenen [sic] Fleisch bey 38000 Gulden.

Die Ausfuhr des Rind- und anderen Hornviehes belief sich auf 30000 Gulden.

Die verschiedenen, bei Gewerben und in der Arzney erforderlichen Baum- und Staudenfrüchte betrugen 5132 Gulden 30 Kreuzer.

620 Ergänzung am Rand - statt den im Konzept wieder rot ausgestrichenen zwei nächsten Absätzen. In der Ergänzung geht es um die »Diligence«, die schon weiter oben genannte neue Postverbindung zwischen Zara und Wien, und deren gute Folgen für allerlei Transporte. Vgl. $\$ \$ 66,233$.

$621 \mathrm{Zu}$ verstehen als: »die Ernte einfahren«, »ernten«.

622 »oder sind sehr mangelhaft « als rote Ergänzung (nicht in der Reinschrift). Der Rest des Absatzes ist im Konzept rot ausgestrichen.

623 Der Zusammenhang mit der Landwirtschaft besteht darin, dass diese niederen Straßenklassen von den Bewohnern selbst, also vorrangig den Bauern, in Fronarbeit (Robot) zu pflegen oder zu erweitern waren; vgl. oben, Anm. 395. 
An mehrerlei Färber- und Arzney-Holz betrug die Ausfuhr über 4000 Gulden.

Die verschiedenen besonderen Blüthen und Baumblätter haben auch 11539 Gulden 30 dem Lande eingetragen. ${ }^{624}$

Von diesen drey Artikeln wird einstens, wenn sich die Betriebsamkeit [Qu 54 / 2] heben wird, wohl das Zehnfache ausgeführt werden können.

Limonien, Pomeranzen, Granatäpfel, vorzüglich aber an Johannesbrod hat das Land 22217 Gulden 21 Kreuzer eingenommen; auch rücksichtlich dieser Produkte, besonders was die zwei ersten Artikel anbelangt, wird ohne Vergleich mehr geleistet werden können.

Beträchtlich war aber die Ausfuhr an verarbeiteten Stein-Waaren von Curzola; dann an Kalk und Kreide und diese belief sich zusammen auf 40780 Gulden.

Für Schafwolle, welche hier einen sehr geringen Werth hat, auch vielfältig im Lande verbraucht wird, gingen doch 20000 Gulden ein.

An Korallen wurde in Werthe von 4176 Gulden ausgeführt.

Die Bienen haben, ungeachtet der schlechten Behandlung, an Wachs und Honig über 35000 Gulden dem Lande gebracht.

[Qu 54 / 3] Sehr bedeutende Ausfuhr war aber in folgenden Artikeln:

Die verschiedenen Häute und Felle haben nach der Bilance mit der Einfuhr bei 100000 Gulden an Vortheil betragen.

An Fett allerley Art, dann an Talgkerzen betrug die Ausfuhr 100000 Gulden. ${ }^{625}$

Die Ausfuhr des Weines und des Weinessigs machte 232000 Gulden aus.

Der Gewinn welchen das Land bei der Ausfuhr der Fische gemacht hat, beträgt bilancirt mit der Einfuhr [rot ergänzt: der Stockfische] 437738 Gulden 12 Kreuzer.

Außerordentlich war aber die Ausfuhr in dem verflossenen Jahre 1833 an Oehl, welche auf die sehr bedeutende Summe von 1626617 Gulden gestiegen ist.

$\$ 122$ [Passivhandels-Objecte] Der Handel mit Holz und Holzwaaren trägt auf 40850 Gulden jährlich ein ${ }^{626}$ war ziemlich lebhaft, beschäftigte viele Menschen und ein Capital von 105053 Gulden $6 \mathrm{Kr}$ und brachte dem Nährstande vielen Vortheil obgleich das Land, wenn [Qu 54 / 4] die Bilance gezogen wird, 6131 Gulden $26 \mathrm{Kr}$ mehr ausgezahlt, als eingenommen hat.

624 Es folgte im Konzept ein im Ganzen unleserlicher, rot geschriebener zusätzlicher Absatz am Seitenrand.

625 In diesem Absatz ist rot im Konzept ausgestrichen »an Talgkkerzen«, wodurch der Satz keinen Sinn mehr ergab. Am Rand steht daraufhin mit Bleistift die Frage: »? S.E. fragen«. Das heißt, die roten Ausstreichungen stammen von »S.E.«, mithin von Lilienberg selbst!

$626 \mathrm{Ab}$ »trägt« rote Ergänzung. Danach folgt rot eine lange Streichung des Rests von diesem und der zwei folgenden Absätze bis inklusive Absatzende, über den Anfang von $\$ 123$ hinweg, bis »entstanden ist.« Sie ist in der Reinschrift nicht umgesetzt. Dort fehlt aber umgekehrt die hier im Konzept beinhaltete Angabe zu dem jährlichen Ertrag des Holzhandels. 
Obwohl das Land übrigens blos an Frucht ${ }^{627}$ und verschiedenen Mehl-Erzeugnißen zur Nahrung, wenn man die Einfuhr der wenigen diesartigen Ausfuhr entgegen hält, bei einer halben Million Gulden an das Ausland ${ }^{628}$ bezahlte, auch beim Vieh aller Art mit 40000 Gulden paßiv war; dann für Colonial- und verschiedene Manufakturen- und Fabrique-Waaren, zur Kleidung und andere Haus- und Gewerbs-Bedürfnißen mehr als eine halbe Million Gulden auslegen mußte: so zeigt sich doch in den Ausweisen der Finanzintendanz im Ganzen eine günstige Handels-Bilance von 1719470 Gulden!

$\$ 123$ [Betrachtungen über das Handels Capital] Ich habe mich nicht unterfangen dürfen, bei dieser allerunterthänigsten Darstellung [Qu 55 / 1] ins unnöthige Detail einzugehen, und füge nur noch in tiefster Ehrfurcht bey, daß der für dieses Land im Jahre 1833 ausgefallene Activ Ertrag, aus der Bewegung eines Capitals von 4495844 Gulden $47 \mathrm{Kr}$ entstanden ist. ${ }^{629}$ [schwach leserliche Ergänzung am Rand]

Wenn [gestrichen: ich nun; ergänzt: man] auch jenes Capital mit 1202657 Gulden 3 Kr hinzuschlage, welches in dem Transitohandel verwendet [gestrichen: worden ist; ergänzt: wurde], so zeigt sich 1832 ein Gesammtbetriebs-Kapital von 5698501 Gulden 50 $\mathrm{Kr}$ [euzern] welches die verschiedenartigen productiven Kräfte in Bewegung gesetzt hat.

Im Jahre 1831, in welchem ich eine ähnliche Bilance gezogen habe ${ }^{630}$, betrug das unmittelbare Handels-Capital blos 3087085 Gulden 6 Kr mithin um 1408759 Gulden 41 Kr weniger und das Land blieb nur mit 861421 Gulden $24 \mathrm{Kr}$ activ. ${ }^{631}$

Der Betrag, welcher im Transito-Handel verwendet wurde, war aber dem heurigen fast gleich [Qu 55 / 2] und belief sich auf 1188265 Gulden $30 \mathrm{Kr}$ [euzer] mithin bestand das Gesammtbetriebs-Capital im Jahr 1831 in 4275350 Gulden $36 \mathrm{Kr}$. Es zeigt sich demnach ein größerer Umschwung beim Handel in dem verfloßenen Jahre im Ganzen um 1423151 Gulden $14 \mathrm{Kr}$.

627 Hier im Sinne von Korn (Getreide).

628 »Ausland« schließt in dieser Verwendung offensichtlich alle von Dalmatien aus betrachtet auswärtigen Gebiete mit ein, inklusive derer innerhalb der Monarchie.

629 Die beabsichtigte Platzierung der Bleistiftergänzung lässt sich nicht hinreichend bestimmen. Vermutlich waren sie zu Beginn der vorangehenden langen Streichung auf der vorletzten einzuordnen Seite. Der Text dieser ersten Ergänzung auf Seite Qu 55 / 1 ist aber jedenfalls: »Viele Seeleute gehen auf fremde Schiffe, darunter die Cattarer besonders auch viele als Taglohner nach Constantinopel; und beyde bringen nach wenig oder mehreren Jahren betrechtliche Summen ihren Familien, denen sie sehr zu guthe sind, und besonders hier liebt das Volk die Kinder sehr.« Diese Passage findet sich in der Reinschrift nicht.

630 Dieser Halbsatz zwischen den Beistrichen wurde im Konzept rot ausgestrichen (wegen »ich«).

631 Hier folgt eine kaum entzifferbare Ergänzung am Rand statt dem rot ausgestrichenen nachstehenden Absatz; soweit entziffert: »In dieser Zeit hat man auch mit der Art [nicht entziffert ...] und meisten ausgeführt«. 
$\$ 124$ [Vertheilung des Handels] Das Glück für das Allgemeine dieses Landes, welches eine unproportionirte große Länge gegen seine Breite hat, besteht nach meiner allerunterthänigsten Meinung darin, daß der Handel keinen absoluten Central-Punkt hat und an der ganzen Küste von dem nördlichsten bis zu dem südlichsten Punkt vertheilt ist.

Der Markt Obbrovazzo macht viele Geschäfte in Wein mit der Militair-Gränze und türkisch Croatien ${ }^{632}$.

Zwischen Sign und Spalato wo 7 Großhandlungen bestehen, theilt sich der türkische und [Qu 55/3] der italienische Handel. ${ }^{633}$

Ragusa hat die Caravanen behalten und hat den türkischen und seit Errichtung des Lazzarets auch zum Theil den Levantinischen Handel.

Cattaro betreibt den Handel mit Montenero, mit der Levante ${ }^{634}$, mit Italien und Triest ${ }^{635}$.

$\mathrm{Zu}$ Zara ist die meiste Lebhaftigkeit, aber nicht so viel Speculation im Großen.

$\mathrm{Die}^{636}$ bedeutende Zahl an Civil- und Militair-Beamten und die italienische Garnison, welche namhafte Summen aus Italien bekömmt, dann der Zufluß der Menschen welche täglich aus dem Innern in Geschäften zukommen, betreibt [in Zara, K.C.] den Detail-Handel sehr, und macht daß sich die Kaufleute, und die gesammte Bürgerschaft mit jedem Jahr im Wohlstande beßert.

Von den Inseln treiben die Meisten aktiv Handel: Pago, Lesina, Lissa, Curzola und Brazza. ${ }^{637}$

Der meiste Handel wird zur See $[Q u 55 / 4]$ mit Ancona ${ }^{638}$, Venedig und Fiume getrieben, aber alle die Seeplätze übertrift der Hafen von Triest, welcher auf Dalmatien den meisten Einfluß hat.

632 Gemeint ist die Gegend um die nordwestbosnische Stadt Bihać, die vor ihrer Eroberung durch die Osmanen im Jahre 1592 eine der wichtigsten Festungen des spätmittelalterlichen Kroatien gewesen war.

$633 \mathrm{Ab} »$ Der Betrag, welcher im Transito-Handel« $(\mathrm{Qu} 55$ / 1) bis hierher war rot ausgestrichen, dann aber waren die beiden letzten Absätze ab: »Der Markt Obrovazzo« mit roter Klammer und Bemerkung dazu versehen: »bleibt«.

634 Die eigentlich offenkundig mindestens ebenso richtige »Levante« ist im Konzept rot durchgestrichen und durch Spalato (!) ersetzt; in der Reinschrift blieb es aber bei Levante.

635 »und Triest« ist rot ergänzt und fehlt in der Reinschrift.

636 Dieser Absatz ist rot ausgestrichen, stattdessen steht am Seitenrand eine nicht hinreichend entzifferbare Ergänzung.

637 Es folgen im Konzept, statt dem zu einem guten Teil rot ausgestrichenen nachstehenden Absatz, diverse gutteils unleserliche Ergänzungen mit Rot- und mit Bleistift am Rand und am Seitenende. Danach ist mit Ausnahme von Teilen des nächsten Satzes zu Triest der ganze Rest dieses Paragraphen, also bis zur Überschrift »Phisische und Gemüths Beschaffenheit der Bewohner «, rot durchgestrichen.

638 Vgl. dazu Anselmi: Barche e merci istriano-dlamate nella fiera-franca di Senigallia e nel porto di Ancona. 
Auch wenn Eure Majestät die Caravanen, welche vorzüglich zur Hebung des Handels dieser Provinz beitragen werden allergnädigst, nach meinen [sic] und der Landesstelle [gestrichen: ihren ${ }^{639}$ ] Vorschlage zu bewilligen geruhen, wird der Handel durch das ganze Land vertheilt bleiben und wird auch den innern Betrieb in allen Theilen beleben, ohne in einer einzigen Stadt ein Monopol zu begründen; was für die Gesammtzahl der Einwohner sehr vortheilhaft, und sehr erfreulich für den Staat ist.

Bevor ich diesen Gegenstand verlaße sehe ich es für meine Pflicht an, das für mich empfindliche Geständniß in aller Unterthänigkeit zu machen, daß ich nicht vollkommen überzeugt bin daß die Handels- [Qu 56 / 1] Bilancen für Dalmatien in der Wirklichkeit ganz so günstig seyen, wie es die Ausfuhrs- und Einfuhrs- Documente ausweisen.

Die außerordentliche Ausdehnung der Peripherie von der Seeseite und die äußerste Schwierigkeit, die sehr coupirte Gränze des Binnen-Landes gut zu bewahren, macht, daß durch die Contrabande ${ }^{640}$, ohngeachtet aller erdenklichen Anstrengung sämtlicher Behörden Manches, besonders an Tabak, Salz und Colonial-Waaren, unbefugter Weise eingeführt wird.

Was in meiner und der Landesstelle Macht stehet, ist zur Hindanhaltung dieses Unfugs geschehen, und wird bei jeder neuen Entdeckung stets das Zweckmäßigste veranlaßt werden. Einen sehr ergiebigen Erfolg verspreche ich mir aber in dieser Hinsicht von der Organisirung der Forza territoriale, [Qu 56 / 2] dann von der Regulirung der Doganalämter und der Gränzwache, worüber von der Landes-Stelle auch bezüglich der Wachen im Praesidial Wege von mir den 24ten Jänner No 1668/p die Anträge der Hofkammer vorgelegt worden sind.

Wird aber dieser Provinz noch ein Bataillon [Militär] mehr, welches auch aus anderer Rücksicht höchst nothig erscheint und bereits angesucht wurde, allergnädigst zugewiesen, so wird man großen Theils diesen Uibeln vorbeugen können.

Der auffallende Geldbetrag bei der Ausfuhr des Oehls, welches in Gegenhalt ${ }^{641}$ der Production des nämlichen Jahres das doppelte ausmacht, erregt eben auch an mir die Besorgniß, daß die statistische Faßion überhaupt nicht sehr richtig seyn dürfte, weil die Pächter der Zehntlose auf alle mögliche Art das wahre [Qu 56/3] Erträgniß verheimlichen $^{642}$; oder aber, daß man mit diesem Artikel verbrecherische Unterschleiche treibt,

639 Der auch in der Reinschrift beibehaltene Kasusfehler »meinen« statt »meinem « und die ursprüngliche, in der Reinschrift korrigierte Fassung »der Landesstelle ihren Vorschlag « spricht zum Einen wieder für einen Hörfehler des Nichtmuttersprachlers Rougier und andererseits auch in der umgangssprachlichen Dialektnähe der Formulierung wiederum klar dafür, dass zumindest Teile der ursprünglichen Niederschrift durch Rougier unter Diktat durch Lilienberg entstanden sind.

640 Schmuggel.

$641 \mathrm{Zu}$ verstehen als »verglichen mit«.

642 Das System, durch welches der Staat bei der wichtigsten existenten direkten Besteuerung, dem Zehent, die Einhebung durch ein Pachtsystem vollziehen ließ (bei dem er den Pachtertrag erhielt und nicht die in der Summe darüber liegende konkrete Steuerleistung der Steuer- 
und fremdes Oehl für Dalmatiner anmeldet, um die Begünstigung des Einfuhrs-Zolles an der Hauptlinie, welche für das Dalmatier Oehl Eure Majestät allergnadigst zu bestimmen geruht haben, zu erschleichen.

Wenn nach meinem allerunterthänigstem Vortrage vom 12 Decemb. 833 die Einhebung des Zehentes auf einige Jahre im ganzen Lande in die Aerarial-Regie kommt, wird sich der erste Anstand wegen Ungewißheit der Erträgniße leicht beheben lassen.

Um aber dem zweiten Uibel vorzubeugen, hat die Landesstelle nach dem Auftrage der allgemeinen Hofkammer vom 26 März 1833 Z 5434/556 einen umständlichen Vortrag unter dem 14 August 1833 Zahl 11826/4355 erstattet und alle Mittel vorgeschlagen, durch welche man dem Unfug [Qu 56/4] steuern kann, damit keine und besonders jene fremden Artikel nicht für Dalmatiner Waaren in die übrigen k. k. Häfen ausgegeben werden können, die sich einer besonderen Zoll-Erleichterung erfreuen.

Obwohl der Handel, besonders mit Wein, seit dem sich die Engländer in Ionien festgesetz $\mathrm{t}^{643}$ und den Weinbau dort eingeführt haben, ziemlich zurückgegangen ist, so hat sich doch im Ganzen sowohl die industrielle, als die comercielle Production in dieser Provinz etwas gehoben, und da fast wochentlich neue Fahrzeuge für den Seehandel zuwachsen und Eure Majestät unaufhörlich viele Wohlthaten dem Lande zur Belebung der Industrie jeder Art allergnädigst spenden, so glaube ich mit Zuversicht in tiefster Ehrfurcht anführen zu dürfen, daß die Erwerbsverhältniße dieses Landes glücklicherweise wenigstens am Wendpunkte angelangt sind.

[Qu $57 / 1]$

Phisische und Gemüths Beschaffenheit der Bewohner

$\$ 125$ [Abstammung der Dalmatiner und Außeinflüsse - Geheimorganisationen]

Es ist schwer von Dalmatien ein richtiges Bild in dieser Hinsicht zu entwerfen, da ein großes Gemisch von Menschen hier einheimisch ist. Die meisten stammen aus Croatien, Bosnien, Serwien und Macedonien.

Auch die äußeren Verhältniße wirken theilweise mehr oder weniger günstig auf sie ein.

Von den Städtern werde ich nur bei [sic] einem Charakterzuge sprechen, denn diese sind jenen der Venezianischen terra ferma gleich, da sie mit diesen durch viele Jahrhunderte in Verbindung lebten und viele auch von dort herstammen, sie theilen mit jenen das Gute und Uible und da sie auch durch die vielfältigen politischen Sekten unter den Franzosen noch einigermaßen gelockert worden, so sind sie ihnen ziemlich gleich. Das Land zählt noch 61 Individuen, die entweder Freymaurer, Guelfi, [gestrichen: fratelli bianchi; ergänzt: greci nel silenzio] oder Carbonari waren.

zahler), wurde erst 1838 gemäß einem Lilienbergschen Antrag von 1833 auf staatliche Eigenregie umgestellt. Siehe dazu Clewing: Staatlichkeit, $77 \mathrm{f}$.

643 De facto mit der Besetzung der bis 1797 venezianischen Inselgruppe im Jahre 1809, de jure (und mit potentiellen Rückwirkungen auf den Weinhandel) ab der Errichtung der britisch kontrollierten Republik der Ionischen Inseln auf dem Wiener Kongress 1815. 
$\$ 126$ [Phisische Constitution des Dalmatiners] Was die phisische Constitution des Dalmatiners anbelangt, fand ich das Volk durchgehend stark und gut proportionirt.

Die Insulaner sind zwar meistens [Qu 57 / 2] von Körperbau etwas schwächer, als die Bewohner des Binnen- und besonders als jene des Gebirgs-Landes, aber auch diese sind von hinlänglicher Größe und wohl gebaut.

Äußere auffallende Gebrechen habe ich auf meiner Reise äußerst wenig gefunden.

An der Gesichtsbildung findet man selten etwas unregelmäßiges; meistens ist diese vortheilhaft und bei den Männern sehr ausdrucksvoll; auch kann man mit Recht sagen, daß alle Theile des Körpers mit dem Ganzen in Harmonie stehen und daß in Dalmatien wirklich ein sehr schöner Schlag von Menschen ist.

Sie sind von Kindheit an sehr abgehärtet und haben viele körperliche Stärke, können jede Anstrengung aushalten; wenden sie aber nur selten für den Feldbau in hohem Grade an; dagegen ist ihnen keine Jagd zu beschwerlich. ${ }^{644}$

$\$ 127$ [Volksspiele] Auch üben sie ihre Kräfte bei ihren Volks-Spielen unaufhörlich, welche im Pferderennen, Zufußelaufen, in die Höhe- und in die Breite springen und Zentner schwere Steine [Qu 57/3] in die Höhe und in die Weite werfen bestehen; selbst der Kollo-Tanz, der unter freyem Himmel in der stärksten Sommerhitze Stunden lang pathetisch fortwähret, dient zu ihrer Abhärtung.

$\$ 128$ [Kleidung] Uiber die Kleidung des Landvolks geben die Zeichnungen unter den Beilagen I-VI eine Aufklärung ${ }^{645}$.

Der Mann schätzt die Kleidung wenig, aber umsomehr seine Waffen.

Vor der Kälte schützt er sich so wenig, wie wenig er sich um die heißeste Sonne kümmert.

Das rothe Käppchen ist die Bedekung des Kopfes bei Männern und Mädchen. Die ersteren, welche an der türkischen Gränze wohnen, winden auch ein Tuch um und tragen eine Art von Turban.

Die Weiber haben ihren Kopf mit einem weißen Tuch bedeckt.

$\$ 129$ [Wohnungen] Die Wohnungen in den Städten überhaupt und jene in den Dörfern an der Küste und auf den [Qu $57 / 4]$ Inseln sind gemauert, die Häuser meistens beisammen und auch in den Dörfern ziemlich gut.

In den Städten Zara, Spalato besonders in Ragusa, und selbst in Cattaro, Macarsca, Arbe und Pago fand ich einige bedeutende Gebäude, welches auch der Fall in den Ort-

644 Ein Beleg für einen grundlegenden positiven Erzählmodus im Dalmatiner- bzw. Morlakenbild Lilienbergs, der neben den zugleich wiederholt auch bei ihm vorhandenen negativen Morlakendiskurs tritt.

645 Diese Beilagen gingen mit der Reinschrift nach Wien (in der Reinschrift fol. 101-106, bzw. die Scans 205, 207, 209, 211, 213 und 215). In Zadar liegt keine Kopie. 
schaften der Bocche di Cattaro ist, wo die Schiff-Capitaine sehr bequem und meistens schön bewohnt sind.

In dem nuovo und nuovissimo acquisto aber, wo die Wohnungen äußerst zerstreut sind, fand ich die meisten Landleute, die den Trogloditen ${ }^{646}$ gleich, mehr unter, als ober der Erde in sehr elenden und niedrigen Rauchhütten, die mit Stroh, Schilf und bei den etwas vermöglicheren ${ }^{647}$ mit Schiefer-Kalkstein, der fast überall zu finden ist, bedekt sind, wohnen.

Wenn auch der Mann eine Pritsche oder einen Strohsack zum Nachtlager hat, so liegt seine Gattin die der Morlak blos als seine Magd oder Sclavin ansieht, doch nur entweder auf der bloßen [Qu 58/1] Erde, oder höchstens auf einem nakten Brette, neben, oder unweit von ihm.

$\$ 130$ [Moralischer Character] Was den moralischen Charakter anbelangt fand ich allgemein viel Begriffs-Vermögen und meistens natürlichen Witz, dann viel Sinn für das Mystische.

Die Dalmatiner haben viel Entschlossenheit und Tapferkeit. Sehr viele Reitzbarkeit, Rachgier und starken National- und Starsinn; aber auch einen seltnen Schatz an Edelmuth und innigstem Trieb für die Anhänglichkeit und Treue an ihren Monarchen. ${ }^{648}$

Obwohl die Insulaner nicht so kriegerisch und hiezu auch nicht gezwungen sind, wie es bei den Bewohnern des festen Landes und besonders des Gebirges der Fall ist, die mit den Türken angränzen, so halte ich sie doch ebenfalls für brav ${ }^{649}$, denn sie sind als unerschrockene Seeleute bekannt.

Diesen guten Ruf besitzen auch einige Küstenbewohner; vorzüglich behaupten ihn die Boccheser und [Qu 58 / 2] Ragusäer seit Jahrhunderten.

Die Nahrung, welche bei den Morlaken selten in gekochtem Hirse und Kukurutz-Brei, und noch seltener in gesottenem oder gebratenem Fleisch, was nur an großen Festtagen,

646 Die Troglodyten waren in der altgriechischen Mythologie sagenhaft ausgestaltete urtümliche Höhlenbewohner. Jenseits des unmittelbaren Bezuges auf das antikebezogene Bildungsgut seiner Zeit mag Lilienberg aber auch eine zeitnähere Interpretation mit vor Augen gehabt haben. Mit ihr hatte der berühmte schwedische Tierbiologe Carl von Linné diese antiken Troglodyten zusammen mit den damals bekannten Menschenaffen und den gleichfalls antiken Satyrn in eine eigene Primatenordnung namens homo nocturnus gereiht! Vgl. http:// de.wikipedia.org/wiki/Troglodyten (8.12.2013).

647 Wohlhabenderen.

648 Diese Monarchentreue wird in den amtlichen Stimmungsberichten der Zeit regelmäßig floskelhaft beschworen. Tatsächlich lässt sich diese personenbezogene Loyalität unter der breiten bäuerlichen Bevölkerung zumindest im engeren Dalmatien (anders als in der zeitweilig in Aufruhr befindlichen Boka kotorska) im Revolutionsjahr 1848 nachweisen, weil sie sich in tatkräftiger Anti-Haltung der Landbewohner gegen Revolutionierungsversuche durch einzelne national aktive Städter geäußert hat. Vgl. dazu Clewing: Staatlichkeit, $239 \mathrm{f}$.

649 Tapfer, mutig. 
Hochzeiten und Todtenmählern geschieht, sondern meistens in ungesäuertem schlechten Brod, in rohen Zwiebeln, Knoblauch, gesalzenem Fleisch und Fischen besteht und der Genuß des überaus sehr starken und dicken ${ }^{650}$ Weines, muß ihre Galle vermehren und, da die Heftigkeit in ihrem gesunden und sehr kräftigen Körper inwohnet; durch moralische und religiöse Bildung, besonders bei den Gebirgs-Bewohnern bis nun sehr wenig, oder gar nicht gemildert worden ist, auch das Beispiel ihrer [osmanischen] Nachbaren, mit welchen sie immerwährend im Handel oder im Krieg begriffen sind, wohlthätig nicht einwirken kann, so ist es nicht auffallend, wenn sie zu Excessen geneigt sind und wenn die [Qu 58 / 3] mehr Vernachläßigten unter diesen öfters und besonders die Rache, welche ein National-Laster ist ${ }^{651}$, sogar mit einer Art von Lust ausüben.

$\$ 131$ [Rache ein Nazionalzug] Rachgierig finde ich auch die Städtler und selbst die wißenschaftlich gebildeteren Menschen, denn die Rache, so wie ich später allerunterthänigst bemerken werde, ist in diesem Lande gleichsam geheiliget.

Der einzige Unterschied ist, daß sich die Städter durch Verleumdung, die Morlaken aber durch Mord und Brand oder Feld-Schaden rächen; aber ungerochen [sic] bleibt beim Dalmatiner keine Verkürzung ${ }^{652}$ oder Beleidigung, selbst wenn diese nur eingebildet wäre.

Was den gemeinen Mann besonders zum Mord und Mordbrennereyen aus Rache bringt, ist nebst dem Temperament die niedrige Stufe seiner Civilisation, ein gewißer kriegerischer Hochmuth und vorzüglich der unbändige Aberglaube.

Der Morlak hält dafür, daß keine [Qu 58 / 4] grobe Beleidigung ungerochen bleiben darf und da er immer bewaffnet und bei festlichen Zusammenkünften meistens berauscht ist, so sticht oder schießt er, wo in einem andern Lande der Bauer mit der Faust oder mit einem Prügel zugeschlagen hätte.

Der Aberglaube aber, daß ein getödteter Freund oder Anverwandter keine Ruhe jenseits genießen würde, wenn man ihn nicht rächte, macht, daß man an dem Mörder, [durch] Feuer, oder an deßen Angehörigen, ebenfalls durch Mord oder Brand Rache nimmt.

Die Mutter zeigt das blutige Gewand des gemordeten Vaters oder Bruders dem Kinde und eifert dieses zur Rache an, bis sie erfolgt.

650 Wohl im Sinne von »schwerem Wein«.

651 Die nachstehende Schilderung der noch vorhandenen Geltung des Gewohnheitsrechts bis hin zu Blutrache beschreibt, wie Lilienberg selbst andeutet, wohl vornehmlich die damaligen Verhältnisse in der Boka kotorska. Allerdings waren insgesamt die Zahlen für physische Verbrechen in Dalmatien im gesamtstaatlichen Vergleich sehr hoch. Auch Petter schildert nicht nur einen offenbar weitverbreiteten, eigentlich kaum mehr gewohnheitsrechtlich eingehegten Begriff davon, empfundenen Schaden selbsttätig durch Schädigung des Eigentums (zum Beispiel Tieren) der Gegenseite zu beantworten, sondern auch einige Reste von gewohnheitsrechtlichen Vorstellungen zum »Schadensausgleich « und Wiederherstellungen verletzter Ehre. Vgl. dazu Petter: Dalmatien, Bd. 1, 167-170.

652 Wohl im Sinne von »Hintansetzung« zu verstehen. 
Nie vergießt es eine Familie, die ein Glied durch Todtschlag verloren, der anderen; diese muß jedes mal ein Sühnopfer bringen. Entweder wird ihr Gleiches mit [Qu 59/1] Gleichem vergolten, oder wenn es zu einem Vergleich kömmt, muß diese jener 10 Dukaten für den Kopf, ein Stück rotes Tuch von 1-1¹/4 Ellen, 2-4 Käße und einen Schmaus geben. - Diese Blutrache heißen sie Kervarina [Krvarina, eigentlich das Blutgeld; K. C.], die erwähnten Blutgerichte Vraxstvo ${ }^{653}$ und diese werden vorzüglich in der Bocche di Cattaro noch gehalten. ${ }^{65}$

Das schreckliche Axiom, welches von allen Dalmatinern anerkannt ist, muntert sie noch mehr zur Rache auf, diese [sic] heißt: Kose ne osveti, onse ne posveti ${ }^{655}$ : Der sich nicht rächt, der wird nicht selig.« Und der italienische Dalmatiner wiederholt es auch mit den Worten: chi non vendica, non santifica. ${ }^{656}$

Dieses Vermächtniß der barbarischen Zeiten hat sich leider noch nicht verloren.

Auch die Religion, die hier viel im Aberglauben besteht und die Geistlichkeit, welche bis zur Ankunft Eurer Majestät glorreichen Waffen den Rache-Beschluß segnete, bestärkte diese unglücklichen Bewohner in ihrer canibalischen Meinung.

[Qu 59 / 2]

$\$ 132$ [Excessen bey Kirchweihen, Schmausereien und Todtenmahle] Zu den Excessen tragen wesentlich die vielen Kirchweihen bei, an welchen die zur Ausschweifung Geneigten, ob sie von ihren Glaubens-Brüdern oder von jenen der andern Religion gehalten werden, Antheil nehmen.

Auch die Hochzeits- und Begräbnißgastereyen, bei welchen derb gezecht wird, vermehren bei diesem, den Trunk sehr liebenden Volke, die Verbrechen um Vieles.

653 Vražstvo.

654 Eine interessante zeitgenössische Darstellung haben die gewohnheitsrechtlichen Gegebenheiten in Montenegro, in der Poljica (dies mit Blick auf frühere Verhältnisse, wie geschildert durch Alberto Fortis) und in der Boka kotorska (Paštrovići; Župa) durch einen deutschbaltischen (und slawophilen) Rechtshistoriker erfahren: [Reutz, Alexander von:] Die freien Landgemeinden von Zernagora (Montenegro), Poglizza und andere. Ein Beitrag zur Kenntniß des südlichen Slawenstammes. In: Berghaus, Heinrich (Hg.): Annalen der Erd-, Völker- und Staatenkunde. Bd. 6: Vom 1. April bis 30. September 1838. Berlin 1838, 224-272. (Der Beitrag war bereits 1833, und dort mit dem Autorennamen gekennzeichnet, in mehreren Folgen erschienen in: Dorpater Jahrbücher für Literatur, Statistik und Kunst, besonders Russlands.) Lilienberg hielt Reutz für einen russischen Agenten, der die Gesinnungen der "Griechen « im Kreis Kotor gegenüber Russland ausforschen sollte: HHStA, MKA, 1684/1832, Vortrag des obersten Kanzlers Mittrowsky vom 10.7.1832 über weitere Nachrichten über die Reise des russischen Professors Reutz in Dalmatien.

655 Ko se ne osveti, on se ne posveti.

656 Ein Zeichen für die punktuell doch enge kulturelle Interaktion zwischen Land- und Stadtbevölkerung, trotz im allgemeinen sehr erheblichen sozioökonomischen und soziokulturellen Abstandes. 
Die Regierung macht alles, was zur Abstellung dieses Uibels beitragen kann; aber die zerstreute Lage der Dörfer und der Wohnungen, dann das vielfältig üble Beispiel der Geistlichkeit selbst und rücksichtlich der Todtenmahle der Aberglaube, daß man den Verschiedenen ${ }^{657}$ mit einem Gastmahle ehren und ihm bei dieser Gelegenheit Aufträge an die schon früher verstorbenen Freunde und Anverwandten mitgeben müße, verzögert vielfältig die Abstellung dieser barbarischen Gebräuche.

Durch solches Schwelgen werden viele häusliche Unordnungen, auf welche Diebstähle und Räubereyen [Qu 59/3] und auch Morde erfolgen, herbeigeführt.

$\$ 133$ [Aberglaube, Hexen, böse Geister, Vampire] Dieses rohe Volk, wie ich schon allerunterthänigst erwähnte, hat sehr viel Sinn für das Mystische und Religiöse, aber eine starke Superstition feßelt noch seine Seele in jeder Hinsicht und verleitet es zu Unbilden.

Die früheren Regierungen haben sich um das Uiberirdische nichts bekümmert, haben die rohesten Geistlichen walten laßen; da aber diese aus dem Aberglauben viel Gewinn zogen, nährten sie diesen und die meisten hängen selbst daran. ${ }^{658}$

Bis auf den heutigen Tag glaubt man fest an Hexen; noch vor eilf Jahren hat man ein unglückliches Weib in dem Dorfe Zavajane ${ }^{659}$, Bezirk Macarsca, Kreis Spalato, aus diesem Grunde verbrannt. ${ }^{660}$

657 Den Verstorbenen.

658 Vgl. näher zum geringen Bildungsstand der katholischen Geistlichkeit die $\$ \$ 185-187$ sowie die dortigen Anmerkungen, zu den Ordensgeistlichen $₫ 197$ und zu den orthodoxen Geistlichen $\$ 200$.

659 ON Zavajane / Zavojane, Ansiedlung nordwestlich von Vrgorac.

660 Laut Lilienberg gab es also eine letzte Hexenverbrennung in Dalmatien im Jahr 1823. Auch wenn unwahrscheinlich ist, dass dem ein förmlicher Hexenprozess nach west- und mitteleuropäischem Muster vorangegangen war, bietet sich für die zeitliche Abfolge ein Vergleich auf die vermutlich letzten Tötungen von Hexen in Deutschland (Landshut, Bayern) und in der Schweiz (Glarus) an, die 1756 bzw. 1782 erfolgten. Zur Geschichte der Hexenverfolgungen im kroatischen Raum scheint trotz solch später Vorkommnisse wenig Forschung zu existieren. Vince-Pallua, Jelka: Da prostite, to mi je žena! Prilog poznavanju položaja žene u drugoj polovici 18. i prvoj polovici 19. stoljeća u Dalmaciji i njezinu zaleđu. In: Studia ethnologica 2 (1990), 77-96, bringt $81 \mathrm{f}$. Angaben auch zum Hexendiskurs bei dalmatinischen gebildeten Autoren der Zeit (die der Verfasserin zufolge im Hexendasein auch einen Ausbruch aus den Zwängen sahen, denen die Frauen in der damaligen Gesellschaft unterworfen waren. Šešo, Luka: Which woman is a witch? The stereotypic notions about witches in Croatian traditional beliefs. In: Studia ethnologica croatica 24 (2012), 195-207 gibt dagegen verblüffende Belege zum Fortbestand des volkstümlichen Hexenglaubens im dalmatinischen Hinterland bis heute. Das aufgezeichnete Gespräch mit Amir Muzur: Vještice i vampiri Liburnije i Istre. In: Hrvatska revija 2003, 120-124, das für das nördlich an Dalmatien angrenzende Küstengebiet offenbar Angaben bis zum 18. und 19. Jahrhundert enthält, war mir nicht zugänglich. Das gleiche gilt für eine kroatische Darstellung der europäischen Hexenverfolgung: Petriška, Sanja [pseud. Viktoria Faust]: Vještice: knjiga sjena. Zagreb 2000. 
Sie halten auch deßwegen sehr geheim die Zeit, wenn ihre Gattinen nahe am Gebären sind, damit es die bösen Geister nicht erfahren und ihr oder dem Kinde nicht schaden.

Sie glauben fest daß viele Menschen nach dem Tode herumgehen, [Qu 59 / 4] und daß die, so Feinde eines andern waren, diesem überall Schaden verursachen. Deßwegen geschieht es bis auf den heutigen Tag, ohngeachtet aller Maßregeln, die dagegen genommen werden, daß sie die Gräber aufmachen und die Beine dieser vermeinten Vampire ganz zerbrechen, ihnen die Köpfe abschneiden und die Augen ausreißen, damit sie nicht aufstehen und herumgehen können, wie es erst im Monate März vorigen Jahres in Provicchio ${ }^{661}$ und im Orte Lucca ${ }^{662}$ des Kreises Zara wieder geschah, worüber Verhandlungen gepflogen und wiederholte Erinnerungen an die Ordinariate erlaßen worden sind, um mittelst der Geistlichkeit diesen abscheulichen barbarischen Aberglauben zu bekämpfen. ${ }^{63}$

$\$ 134$ [Starrsinn, ein Characterzug] Der Starrsinn, der auch einen bedeutenden Zug des Characters beim rohen Dalmatiner ausmacht, hat bis nun auch viele moralische und phisische Uibel $[Q u 60$ / 1] verursacht.

Dieser Starrsinn macht, daß er nicht leicht von den Gebräuchen seiner Vorfahren abzubringen ist und deßwegen seine schlechten Sitten, so wie seinen unzweckmäßigen Feld- und Wirthschaftsbetrieb hartneckig verteidiget und nicht nur allen Neuerungen für sich Feind ist, sondern diese auch bei den übrigen aus stolzem National-Sinn ${ }^{664}$ nicht dulden will und vielen Feldschaden blos aus dem Grunde auf die schrecklichste Art verursacht, damit keine Neuerung statt finde.

Diesen, der wahren Aufklärung höchst schadlichen, Starrsinn haben die Dalmatiner schon in den frühesten Zeiten bewiesen und schon die Römer mußten darüber zu klagen gehabt haben, denn ein Bas relief, welches in den Ruinen vor Salona gefunden wurde, stellt deutlich vor, wie Dalmatien den römischen Genus von sich stoßt. [Randbemerkung: XIX $\left.{ }^{665}\right]$

[Qu 60/2] Ich unterfange mich der vortrefflichen Anspielung wegen hiervon eine Zeichnung in tiefster Ehrfurcht vorzutragen.

$\$ 135$ [Verbrechen und andere Uibertretungen] Die meisten Verbrechen, Todtschläge und starken Verwundungen geschehen in dem Kreise von Zara, wo besonders in dem

661 ON Provicchio / Prvić Luka: Ansiedlung westlich von Šibenik.

662 ON Lucca / Luka: Ansiedlung südwestlich von Zadar.

663 Vergleichend zur Geschichte des Vampirglaubens in der weiteren Region siehe Kreuter: Der Vampirglaube in Südosteuropa.

664 Lilienbergs Dalmatiner- bzw. Morlakenbild mit der Hervorhebung von Konservativismus und Neuerungsfeindlichkeit stand ganz Rahmen der seit dem 18. Jahrhundert üblichen Diskurse über die Provinz.

665 Gemeint ist eigentlich Beilage XIXa; sie ist in Zadar nicht vorhanden, aber in der Reinschrift unter fol. 123 (Scan 248). 
verfloßenen Jahre [1833]: 303 in den übrigen Kreisen aber blos 49 Brandlegungen statt fanden. Am meisten werden diese in dem Bezirke Knin, wo die Mehrzahl der nicht unirten Griechen wohnt, begangen.

Was den Mord anbelangt, wird dieser auf dem festen Lande im Verhältniß der Population fast gleichmäßig begangen; so auch der Diebstahl und die Veruntreuung.

Der öffentliche Raub ist im Kreise Zara und verhältnißmäßig in Albanien ${ }^{666}$ am stärksten. Im Kreise Spalato aber, welcher früher durch Räuberbanden aus Bosnien stark beunruhigt war hört man jetzt nur selten mehr von derlei Unthaten. Im Ragusaer Kreis ergaben sich im vorigen Jahre nur 2 Raubfälle.

[Qu 60 / 3] Dagegen war Ragusa in Sanitäts-Uibertretungen fast eben so stark, wie das übrige Dalmatien.

Die Insulaner sind aber viel milder in den Sitten: die Brandanlegungen geschehen unter ihnen gar nicht und auch sehr wenige Morde.

Als ich auf der Insel Arbe war, versicherten mich die alten Landleute, das seit einem halben Jahrhundert kein Mord und auch kein Todtschlag dort geschehen war.

Diese kurze ethnographische Skizze, weil ich mir nicht erlauben darf, Eure Majestät mit einem weiteren Detail zu belästigen, dürfte über den Grad der Cultur und den übrigen Zustand des moralischen Aufschwunges dieses vernachläßigten Volkes ${ }^{667}$ ein hinlängliches Licht verbreiten.

$\$ 136$ [Allgemeine Betrachtungen - gute Aussichten für die Zukunft] Wenn man die phisischen und moralischen Kräfte dieses Volkes genau analisirt und sich überzeugt, daß die Leztern weder durch die moralische noch durch die religiöse Bildung die wahre Richtung erhalten [Qu 60 / 4] haben, ja in jedem Anbetracht diese sogar gefließentlich vernachläßiget wurde: so muß man es nicht diesem armen Volke, sondern der früheren Regierung zuschreiben und sehr natürlich finden, daß viele ausgleiten und auf Verbrechen aller Art gerathen. Ja ich wundere mich sogar daß bei diesen Verhältnißen nicht noch mehr Excesse geschehen und schreibe es dem vortreflichen Instinkte dieser Menschen $\mathrm{zu}^{668}$.

Ich empfand auf allen meinen Bereisungen die innigste Freude und die schmeichelhafteste Aussicht in die Zukunft ${ }^{669}$, daß es besser werden wird, denn ich erhielt Beweise:

666 Gemeint ist die Boka kotorska.

667 Eine bemerkenswerte Bezeichnung der Situation der Dalmatiner hier also auch im Jahr 20 nach Beginn der zweiten österreichischen Herrschaft!

668 Die Verantwortung der Regierung(en) für die moralische und auch insbesondere die religiöse Bildung des Volkes tritt hier deutlich als Lilienbergsche Argumentationsmuster gegenüber dem Kaiser hervor. Zugleich zeigt sich Lilienbergs im Grundsatz positives Dalmatinerbild (siehe auch nächste Seite Qu 61 / 1), und erneut sein negatives Bild von der venezianischen Herrschaft.

$669 \mathrm{Ab}$ dieser Stelle gibt es keine roten Markierungen beabsichtigter «Entpersonalisierung « mehr, wegen des nahe bevorstehenden Termins der Abreise nach Wien; vgl. in der Einleitung, Seite 14 . 
durch die willfährliche ${ }^{670}$ Verbreitung der Impfung der Kuhpocken, dann durch [gestrichen: die Betriebsamkeit, beßere Comunications-Wege sich zu bauen; und ergänzt bis: Hand anlegten] den lebhaften Wunsch, welchen mir viele äußerten, beßere Comunications-Strassen zu erhalten, wozu mehrere Comunen auch selbst Hand anlegten; ferner durch die Vermehrung und Vervollkommnung der Gewerbe und hie und da auch durch die Verbeßerung der Landwirthschaft; vorzüglich aber durch [Qu 61 / 1] mehrseitiges Bitten, den Trivial Unterricht so viel als möglich zu verbreiten: ${ }^{671}$ daß der angebetete Genius Oesterreichs nicht verstoßen, sondern immer dankbarer und ehrfurchtsvoller aufgenommen werden wird, sobald der Aberglaube durch die allerweiseste und allergnädigste Fürsorge in ächten Glauben umgewandelt und die moralische Bildung durch den Schulunterricht mehr verbreitet seyn wird ${ }^{672}$.

Was mich aber besonders hoffen läßt, daß die väterlichen Bemühungen Eurer Majestät in jeder Hinsicht durch guten Erfolg vor Gott und vor der Welt unfehlbar werden gekrönt werden, ist der Edelmuth und das Mitleiden die ich überall gefunden habe - gegen alle Unglückliche, mit welchen der Dalmatiner seinen lezten Bißen theilt; die aufrichtige Anhänglichkeit bei allen, selbst den widrigsten Verhältnißen ${ }^{673}$ an ihre Freunde und besonders an die sogenannten Wahlgeschwister; [Qu 61 / 2] dann die innigste Liebe und unverbrüchliche Treue gegen Eure Majestät, von welcher ich auf allen meinen Bereisungen außerordentliche Beweise überall gesehen habe, in welcher sich dieses Volk, wie ich fest glaube, von keinem der treuesten Unterthanen Eurer Majestät nie übertreffen laßen wird. ${ }^{674}$

$\$ 137$ [Werth der Provinz] Nach dieser treuen Schilderung unterfange ich mich, in tiefster Ehrfurcht den Schluß zu faßen, daß diese kleine Provinz nicht bloß wegen ihrer Lage, weil sie mit der Türkei gränzt und an das adriatische Meer anstößt, [sowie] rücksichtlich des Handels einen, und sonst, wie man vielfältig glaubt, keinen Werth, - sondern, daß sie wegen der Mannes- und Naturkraft, welche man hier vortheilhaft ge[gestrichen: sparet; ergänzt:]paart ${ }^{675}$ findet, sowohl in materieller als in moralischer Hinsicht sehr viel Werth habe und daß sie wenn einmal die Organisirung [der Verwaltung] ${ }^{676}$ nach $[\mathrm{Qu}$

$670 \mathrm{Zu}$ verstehen als »widerstandslose«, »willige«.

671 Alles zwischen den beiden Doppelpunkten (von vor »durch die willfährliche Verbreitung " der Impfung, bis hierher) ist ein Einschub; der davor begonnene Satz mit den Beweisen geht also inhaltlich hier mit den Äußerungen zum Genius Österreichs weiter.

672 Ein deutlicher Beleg für die Schulbildungsziele (mit dem Volksschulwesen als Grundanliegen) Lilienbergs, unter Berufung auf »mehrseitiges Bitten« (aus der Bevölkerung). Vgl. § 203 und dort Anm. 983 zum schleppenden Ausbau des Volksschulwesens.

$673 \mathrm{Zu}$ verstehen als: die aufrichtige Anhänglichkeit selbst unter den widrigsten Umständen.

674 Vgl. unten, $₫ 218$.

675 »Gepaart«also statt vom Schreiber mechanisch ab- oder mitgeschriebenem, unsinnigen "gespaart «.

676 Vgl. zu den schwerwiegenden, die Landesentwicklung hemmenden Folgen der vormärzlichen Wiener Behandlung der dalmatinischen Verwaltungsordnung als nur provisorisch, ge- 
61 / 3: Einlageblatt, einseitig beschrieben] Eurer Majestät allerhöchster Weisheit vollendet, der herrliche Urstoff durch Wirkung der vorhandenen beiderley ${ }^{677}$ Kräfte, zweckmäßig benützt werden wird - nicht nur den gewünschten Grad der bürgerlichen Bildung und Wohlstand erreichen, sondern dem Staat, wie ich schon früher erwähnt habe, alle Vorschüß ${ }^{678}$ reichlich zurück erstatten und wegen ihrer zweiten und wesentlicheren Schöpfung ${ }^{679}$ Eurer Majestät unvergänglichen Ruhm auf die späteste Nachkommenschaft dankbar überbringen wird.

[Qu 61 / 4 existiert nicht, ohne dass dies den Inhalt unterbrechen würde; es folgt Qu 62 / 1]

\section{Dermalige politische Eintheilung des Landes}

$\S 138$ [Kreis-Präturs und Comunal Bezirke] Die dermalige politische Eintheilung Dalmatiens ist nicht gleichmäßig bezüglich des Gebietsumfanges und der Bevölkerung.

Nach Aufhebung des Kreises von Macarsca im Jahre 1818, bestehen gegenwärtig 4 Kreise $^{680}$ :

Der Kreis Zara mit 98 1/2 Quadratmeilen und 126502 Einwohnern, 7 Präturs-Bezirken und 15 Hauptgemeinden.

Der Kreis Spalato mit 94 Quadratmeilen, 149320 Einwohnern, in 10 Präturs-Bezirken und 34 Hauptgemeinden.

Der Kreis Ragusa mit 86 Quadratmeilen[,] 47556 Einwohnern, in 5 Prätursbezirken und 22 Hauptgemeinden.

Der Kreis Cattaro mit 9 1⁄2/2 Quadratmeilen[,] 33495 Einwohnern, 3 Prätursbezirken und 14 Hauptgemeinden.

koppelt mit einem strikten Zentralismus für alle endültig »systemisierten« Einrichtungen: Clewing: Staatlichkeit, 124-126.

677 Vermutlich im Sinne von »materiell und moralisch«.

$678 \mathrm{Zu}$ diesem eigentümlichen Begriff, der nur im Rahmen einer Verwaltungsideologie zu verstehen ist, innerhalb derer die über die örtlichen Einnahmen hinausgehenden staatlichen Ausgaben als Anomalie galten, die allenfalls vorübergehend in Kauf zu nehmen war, vgl. oben, $\$ 18$ (sowie Clewing: Staatlichkeit, 149 f. mit Blick auf die kritische Sicht dieser Grundsätze durch Joseph von Weingarten als beamteten Zeitzeugen).

679 Die zweite Schöpfung Dalmatiens ist gemeint im Sinne der grundlegenden Neugestaltung der Provinz.

680 In der Reinschrift findet sich hier ein Verweis auf Beilage XIXb (Kreiskarte von Dalmatien; fol. 124 bzw. Scan 250). Im Konzept Bleistiftanmerkung am Rand: »NB Zahlen mit Bleistifte«. Hier in der Vorlage sind sie dann am Ende dagegen in Tinte, die erste Einfügung mit Bleistift ist nur noch ansatzweise zu erkennen. Die Randanmerkung ist also als Anweisung an den Schreiber zu verstehen, und erfolgte in der Handschrift des Sekretärs. Offenkundig sollten die Zahlen zuletzt in die soweit offen gelassene Diktatmitschrift noch nachgetragen und ggf. weiter geändert oder aktualisiert werden können. 
Das auffallende Mißverhältniß beruht auf den Eigenthümlichkeiten und auf der Topographie dieses Landes selbst; wonach die Kreise Zara und Spalato größer ausfallen und auf die dermalige Art begränzt werden müssen ${ }^{681}$, um sie wenigstens auf dem Festlande zweckgemäß arrondiren zu können; Ragusa und Cattaro aber theils durch ihre Lage, dann durch die zwei türkischen Erdzungen, durch ihre ehemalige politische Verfassung und Verwaltung und durch die [Qu 62 /2] Eigenthümlichkeit ihrer Bewohner als natürlich, phisisch und politisch abgesonderte, ein gewißes Ganzes bildende, Provinztheile zu betrachten sind, welche, wenn auch durch die Gewinnung der Suttorina eine Gebiethsverbindung erzielt wurde ${ }^{682}$, nach meiner ehrfurchtsvollsten Meinung, die durch meine genaue Besichtigung jener Gegend und Prüfung aller Verhältniße sich noch mehr bestärkte, nie werden ohne Nachtheil für den allerhöchsten Dienst und für die Administrirten miteinander verschmolzen werden können.

$\$ 139$ [Kreise Ragusa und Cattaro sind nicht zu vereinen. Gründe dagegen] Es erscheint mir daher die Ansicht [ergänzt und wieder gestrichen: welche ein hiesiger; gestrichen: des Hofraths Fölsch ${ }^{683}$, den Kreis von Cattaro, mit Ragusa zu vereinen, welche von einem Oberbeamten an die Hofstelle gemacht worden seyn soll und worüber die v[ereinigte] Hofkanzlei in Folge meines Stimmungsberichts 2139/14. Juli 1832 Z. 287 eine Aeußerung von mir abverlangt, die ich unter d. 13. Aug. Z 324 erstattet habe und unter dem 16. September Z 368/96 näher bezeichnet habe, ganz und gar nicht zweckmäßig ${ }^{684}$; und zwar wegen des bedeutenden Handels des Kreises Cattaro, dann wegen der schwierigen Verhältniße zum [sic] Montenegro und den benachbarten ottomanischen Provinzen, we-

681 »müssen« ist mit Bleistift ausgestrichen.

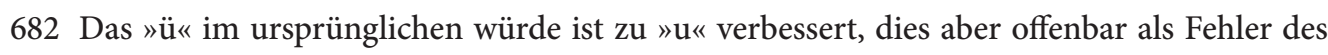
Schreibers (Rougier). Tatsächlich wurde die Sutorina ja erst 1878 durch die Okkupation bzw. de jure 1908 durch die Annexion Bosniens und der Herzegowina Teil des habsburgischen Herrschaftsbereiches (aber nicht des Kronlands Dalmatien). Zu den vormärzlichen Gebietsaustauschvorhaben vgl. weiter oben, in $\$ 112$.

683 Joseph Edler von Fölsch, 1826 aus der Position des Kreishauptmanns von Trient zum Hofrat beim Dalmatiner Gubernium befördert (Zeitschrift für österreichische Rechtsgelehrsamkeit und politische Gesetzkunde, Jahrgang 1826, Bd. 3: Notizenblatt vom Januar - Dezember, 493). In dieser Funktion war er Nachfolger von Joseph von Weingarten, blieb aber nur bis 1828 in Dalmatien. Bei Hofe errang er offenbar beträchtliches Vertrauen. Sein Bericht über seine Inspektionsreise in der Provinz 1827 ist in Auszügen übersetzt bei Kupek: Gospodarske i kulturne prilike u Dalmaciji. Siehe dort $231 \mathrm{zu}$ seiner bereits damals geäußerten Meinung, die beiden südlichen Kreise sollten vereinigt werden, sobald die sie teilende Sutorina erworben sei. Fölsch hier nicht namentlich anzusprechen (so auch in der Reinschrift), mag eine bewusste Entscheidung Lilienbergs gewesen sein, weil eine klare Assoziierung des Vorschlags mit diesem beim Monarchen in Ansehen stehenden Namen den Kaiser eventuell für die von Lilienberg abgelehnte Überlegung hätte einnehmen können.

684 Das Vorstehende ist um die hier vorgenommenen Randergänzungen in Tinte in zwei verschiedenen Handschriften gegenüber dem ursprünglichen Wortlaut komplettiert. 
gen des sehr bedenklichen Umstandes, daß es an der Embouchure [Einmündung, K. C.] des adriatischen Golfs liegt, und die verdächtigen, oder gefährlichen Schiffe dieser Küste am meisten zu thun geben, auch ihr Erscheinen oft viele Klugheit und Festigkeit im Benehmen fordert; wegen der äußerst complicirten Gränze, und zweier dreifacher Gränzpunkte ${ }^{685}$, wo unaufhörliche Streitigkeiten und Unordnungen herrschen, und der Kreisvorsteher [von Cattaro] mit dem Visir der Herzegowina [Ali Rizvanbegović, K.C], mit dem Vladica von Montenegro [Petar II. Petrović Njegoš, K. C.] und dem Visire von Scuta$\mathrm{ri}^{686}$ in immediater Correspondenz stehet, wegen [Qu 62 / 3, 4 existieren nicht] [Qu 63 / 1] der [im Kreise Cattaro] sehr beträchtlichen Mercantil-Marine, welche aus 200 soliden Briggs besteht, mit sehr erfahrenen und entschlossenen Matrosen bemannt, mit mehr als 1000 Canonen bewaffnet ist und meistens Männern angehört, unter welchen sehr viele reich sind, und ihre Schiffe selbst befrachten: Aus allen diesen Gründen bedarf der Kreis Cattaro unumgänglich einer Authorität höheren Ranges und höherer Amtsmacht, welche oft augenblicklich zum Schutze der Gränzen und des nahmhaften Handels, dann bezüglich der Land- und Seesanität und zur Erhaltung der Sicherheit, Ruhe und Ordnung unter den kriegerischen, rohen Landgemeinden selbstständig einzugreifen und Vorkehrungen zu treffen hat; wenn man auch den nicht unbedeutenden Umstand, daß Raguseer und Boccheser im Allgemeinem einander äusserst abgeneigt sind, und die Lezten durch die Vereinigung sehr mißmuthig gemacht würden, ganz unbeachtet lassen wollte. ${ }^{67}$ -

Uibrigens müsste bei Aufhebung [Qu 63 / 2] des Kreisamtes von Cattaro doch immer ein exponirter Kreis Comissär ${ }^{688}$ mit dem nöthigen Concepts- und Kanzleipersonale daselbst belassen werden, welches im Grunde doch wieder eine Art Kreisamt wäre, aber dadurch, daß alle Akten durch das Kreisamt von Ragusa laufen müßten, nur eine dienstschädliche Verzögerung und Vermehrung der Schreiberei und nicht unbedeutenden Schaden den Bewohnern und dem Aerario hervorbringen würde. ${ }^{69}$

Ich kann daher, nach [einer] reifen Beurtheilung aller Verhältniße, keinen Grund dafür auffinden, warum die Benennung dieses Gebieths als Kreis von Cattaro nicht ferner bestehen und nicht wenigstens eine Kreisadministration, mit einem 1. Kreiskomissär, wie sie schon jetzt bestehet, dort belassen werden sollte. ${ }^{690}$

685 Gemeint sind die bei der detaillierten Grenzschilderung dargestellten Dreifachpunkte Nummer 3 und 4 mit der Herzegowina und Montenegro einerseits, mit Montenegro und »türkisch Albanien « andererseits; vgl. oben, $\$ 24$.

686 Vezir von Shkodra war damals aktuell (seit Dezember 1833 und noch bis Herbst 1835) Hafiz / Hafëz Pascha; Historia e popullit shqiptar, Bd. 2, 86 und 90.

687 Die ganze Passage von Beginn $₫ 139$ an bis hierher ist tatsächlich nur ein einziger Satz!

688 Die Kreiskommissäre waren den Kreisämtern zugeordnet, auf der direkten Ebene unter den Kreisvorstehern.

689 Eine Belegstelle für Lilienbergs Interesse, den Instanzenweg innerhalb der Verwaltung möglichst einfach zu halten, das auch an anderer Stelle wiederholt deutlich wird.

690 Die Administration des Kreisamts bestand dort damals in dieser Form, weil der Posten des eigentlich einzusetzenden Kreisvorstehers (Kreishauptmanns) seit mehreren Jahren vakant 
$\$ 140$ [Eintheilung des Landes in den vecchio, nuovo und nuovissimo acquisto] Bevor ${ }^{691}$ ich zur Eintheilung der Präturen übergehe, glaube ich noch einer anderen, gleichsam geschichtlichen Abtheilung des eigentlichen Dalmatiens, nämlich des Kreises Zara und Spalato erwähnen zu sollen, weil in manchem der Verwaltungsart nach diese Abtheilung verschieden ist. Sie bestehet darin, daß man in obigen 2 Kreisen auch das vecchio, nuovo und nuovissimo acquisto von einander absondert, welches eigentlich den Besitzstand nach den Frieden von Candia, Carlovitz und Passarovitz andeutet, und ich nehme mir a[ller] u[nterthänigst] die Freiheit, eine Uibersicht hiezu sub N: Beil[age] XX E[urer] M[ajestät] in tiefster Ehrfurcht vorzulegen. ${ }^{692}$

[\$ 141] ${ }^{693}$ [Pärtursbezirks Eintheilung] Die Zahl der Prätursbezirke erscheint mir ebenfalls der topographischen und der Beschaffenheit der Ortsverhältniße dieser Provinz im Ganzen genommen zweckmäßig, wenn gleich [Qu 63 / 3] manche Bezirke, wie Budua 5181, Lissa 5463, Sabioncello 5622 Einwohner; andere aber wie Zara 36408, Sign 28895, Spalato 24655, Knin 24976 Einwohner zählen; - da eine bedeutende Änderung in dieser Eintheilung nur noch größere Unzukömmlichkeiten erzeugen müßte, weil zum Beispiele der Bezirk Zara nach Obbrovazzo und Sebenico, die ohnehin selbst groß und ausgedehnt sind, nichts, und nach Derniš und Scardona nur wenig abtreten könnte; Spalato von lauter großen Bezirken umgeben, Lissa eine in vielfacher Beziehung wichtige, vom Festlande entfernte Insel ${ }^{694}$; die Aufhebung der Prätur Orebich ${ }^{695}$ auf Sabioncello unthunlich ist, weil dort eine Menge sehr vermögliche, einen ausgebreiteten Handel treibende, Familien sich befinden; Curzola wegen seiner Lage, oftmaligen Hinderung der Seecomunica-

war; dazu vgl. weiter unten, $₫ 175$.

691 Der folgende Absatz bis »in tiefster Ehrfurcht vorzulegen« ist am Rande mit Tinte in der Schrift Rossettis eingefügt und in der Reinschrift Seite $94 \mathrm{f}$. enthalten.

692 Friede von Kandia (Kreta) 1669; siehe hier im Anhang, Seite 305, Karte 13, bzw. Originalbeilage XX, Reinschrift, fol. 125 / Scan 252.

693 Es fehlt im Text die Markierung von $\$ 141$; sie ist aber in der Reinschrift entsprechend enthalten.

694 Gemeint sind offenbar - neben der auch in den 1830ern noch starken Bevölkerung der relativ kleinen Insel - vor allem ihre exponierte Lage weit vor der Küste und die daraus folgende strategische Bedeutung. Die österreichische Armee unternahm vor allem ab 1831 (also ab dem Dienstantritt Lilienbergs auch als Militärgouverneur) diverse Festungsbauten auf Lissa (Petter: Dalmatien, Bd. 2, 160). Zuvor hatte die Insel vor allem von 1809 bis 1815 herausragende strategische Bedeutung für die gegen Napoleon gerichtete Präsenz Großbritanniens im Mittelmeerraum und erlebte unter britischer Besatzung einen kurzzeitigen wirtschaftlichen und demographischen Boom. Dazu nunmehr detailreich Hardy: Velika Britanija i Vis (der ganze Buchtext ist entgegen dem rein kroatischen Buchtitel zweisprachig englisch und kroatisch abgedruckt). Dort sind unter den Anlagen auch mehrere Kartenzeichnungen von $1835 \mathrm{zu}$ Vis und seinen Festungsanlagen aus dem Bestand des österreichischen Kriegsarchivs beigefügt.

695 ON Orebich / Orebić: Dorf am Anfang der Halbinsel Pelješac im Kreis Dubrovnik. 
tion, wegen seiner bedeutenden Waldungen und wegen der, eine geschärfte polizeiliche Aufsicht bedürfenden Bewohner, einer Prätur nicht entbehren kann, Budua aber sie behalten $[Q u 63 / 4]$ müßte, weil es von allen Seefahrern, die in das adriatische Meer segeln vor allen Punkten Dalmatiens am öftersten berührt wird ${ }^{696}$, durch die Gränze von Montenegro beengt ist und Albanien, an dessen Gränze die unruhigen Spizzanoten sich befinden, anstoßt, auch ein bedeutender Bazzar da ist und die Pastrovichianer selbst sehr kriegerisch und unruhige Menschen sind.

$\$ 142$ [Uibelstand wegen Aufhebung der Praetur Arbe] Ich sehe mich verpflichtet eines Uibelstandes allerunterthänigst zu erwähnen, welcher durch die Zusammenziehung der Praeturen entstanden ist.

[Nachfolgender gestrichener Absatz ist am Rand mit der Bemerkung versehen: »erscheint anderwärts « ${ }^{697}$ :] Was die Bezirke der Hauptgemeinden anbelangt, so stehen diese in keinem Verhältniße; die von Zara zählt 15496, Knin 24971, Dernis 14024 Imoschi 18 196, dagegen Solta nur 1500, Castel-Cambio 1582, Jelsa 1931, San. Giorgio 1067, Castel Vetturio 822 Seelen. Dieser Fall ist auch bei den meisten Comunen des Kreises Ragusa. In dieser Beziehung wird aber bei Einführung des stabilen Comunen-Sistems die gehörige Abänderung veranlaßt werden können, worüber ich, [Ende der Streichung]

[Qu 64 / 1] Nach der Aufhebung der Prätur von Arbe wurde diese Insel zu der Prätur von Pago in Folge Hofkanzlei Dekrets vom 31 July 1826 Z 16342/4184 zugetheilt. Ihre Einwohner müssen nun in jeder sie oder die Bezirksverwaltung betreffenden Angelegenheit 15-24 italienische Meilen weite Fuß- und Seereisen machen, und da die Seeüberfuhr bei Puntalon wegen der häufigen und oft lang anhaltenden Bora unausführbar ist, außer der Beschwerlichkeit und den beträchtlichen Reiseaufwand sehr viele Zeit verlieren, wodurch für den allerhöchsten Dienst und für die Administrirten viele nachtheilige Hemmungen und Schwierigkeiten entstehen.

Weil viele Klagen deswegen vorgekommen sind und man sich überzeugt hat, daß besonders zur Zeit des Winters die Comunication wirklich durch die sehr starke und gefährliche Bora oft mehrere Wochen lang unterbrochen wird: so hat man um einigermaßen abzuhelfen dem Comunitaets Sekretär die Verhandlungen über einfache Polizeivergehen, jene über schwere Polizei-Uibertretungen bis zur Sentenz, und die Criminal-Vorerhebungen übertragen. ${ }^{698}$

Um aber diesfalls eine zweckmäßige Abhülfe zu verschaffen, erstattete $[Q u$ 64 / 2] das Gubernium mit Bericht an die Hofkanzlei vom 5 Feb. laufenden Jahres Z. 1242/433 den Vorschlag, einen exponirten Concelliere mit 450 und einen Schreiber mit 300 Gulden, welche dem Personalstatus der Prätur von Pago zugeschlagen wären, daselbst anzustellen.

696 »Vor allen Punkten « hier zu verstehen als: Budua wurde von allen Häfen des Landes am häufigsten von Schiffen angelaufen.

697 Tatsächlich folgt diese Passage - teils wörtlich, teil abgewandelt - dann erweitert in $\$ 143$.

698 Als Kompetenzen, die eigentlich dem Prätor oblagen. 
Die Hohe Hofstelle hat aber den Antrag zu Folge Dekrets vom 17 May 1834 Z 12595 aus dem Grunde zurückgewiesen, weil in dem Falle als ${ }^{699}$ den neuen Vorstellungen der Landesbehörden ein Gewicht beigelegt werden wollte, alles was im Jahr 1824 diesfalls dargestellt worden war, und in dessen Folge die Aufhebung der Praetur von Arbe stattfand, als falsch erkannt werden müsste. [Randergänzung:] und weil man die Comune Arbe mit tauglichen Gemeindebeamten versehen soll, welche die Geschäfte zu besorgen hätten.

Ich habe mich aber von der Wahrheit der im angezogenen ${ }^{700}$ Berichte geschilderten Umstände und von der Wirklichkeit der bestehenden Schwierigkeiten persönlich überzeugt und bitte in aller Unterthänigkeit, die Vorschläge der Landestelle allergnädigst zu reklamiren ${ }^{701}$. Es wäre in der That für den allerhöchsten Dienst und für die Unterthanen sehr drükend, wenn die Verfügung, welche sich im Verfolge ${ }^{702}$ der Ausübung als nachtheilig erwiesen hat, dennoch blos deswegen aufrecht erhalten werden wollte, weil selbe die Behörden aus einer ganz irrigen Auffassung der Verhältnisse selbst verursacht haben $^{703}$; Übrigens wird diese Exposition ${ }^{704}$ um so nöthiger werden, wenn die Vertheilung der vielen Waldungen und Hutweiden, worüber [Qu 64/3] der Vorschlag bei der Hofstelle bereits liegt, geschehen wird.

$\$ 143^{705}$ [Gemeinde-Bezirks-Eintheilung] Was die Bezirke der Hauptgemeinden anbelangt, so stehen diese in keinem Verhältnisse; die von Zara zählt 15496, Knin 24971, Derniš 15024, Imoschi 18793, dagegen Solta nur 1596, Castel Cambio ${ }^{706} 1582$, Jelsa ${ }^{707} 1931$,

$699 \mathrm{Zu}$ verstehen als: »in dem Falle, dass«, bzw. »weil dann, wenn den neuen Vorstellungen ...«. $700 \mathrm{Zu}$ verstehen als: genannten.

701 Ein klarer Konfliktfall zwischen der Landesstelle bzw. Lilienberg selbst und Hofstellen (hier der Hofkanzlei, die an einer einmal getroffenen Entscheidung, selbst wenn sie lange zurücklag, nicht rütteln lassen wollte), in dem sich der Gouverneur also mit heftiger Kritik an der Unbeweglichkeit der Hofkanzlei direkt an den Kaiser wendet, um die an sich überlegene Position der Hofstelle zu umgehen.

$702 » I m$ Verfolge« $z$ u verstehen wie »im Zuge«.

703 Der Wunsch zeigt ein generelles Verlangen nach mehr Flexibilität im System, wodurch eine Überprüfung von einmal getroffenen Entscheidungen auf ihre Wirkung hin möglich gemacht werden sollte. Zugleich ist das Geschilderte ein deutliches Beispiel für den im Regelfall sehr engen Spielraum, den die Landesverwaltung gegenüber Entscheidungen hatte, die in Wien einmal getroffen worden waren.

704 Ich verstehe den an dieser Stelle schwer fassbaren Begriff als Ausdruck für eine »Grundausrichtung " zugunsten der Hinterfragbarkeit von einst getroffenen Verwaltungsentscheiden (weil über die Zuteilung von Waldrechten und Hutweiden wohl schon früher Beschlüsse gefasst worden waren, die es mit dem Antrag des Guberniums nun neu zu hinterfragen und zu regeln galt).

705 Auch zu diesem Paragraphen heißt es am Rand als Anweisung: NB Zahlen mit Blei.

706 ON Castel Cambio / Kaštel Kambelovac: Ansiedlung nordwestlich von Split (eines der Castelli/Kaštela).

707 ON Jelsa / Jelsa (Dorf und Gemeinde auf der Insel Hvar). 
San Giorgio ${ }^{708} 1067$, Castel Vitturi ${ }^{709} 822$ Seelen. Dieser Fall ist auch bei den meisten Comunen des Kreises Ragusa. In dieser Beziehung wird aber bei Einführung des stabilen Comunen-Sistems die gehörige Abänderung veranlaßt werden können; worüber ich mit Benützung der auf meiner Provinzbereisung gesammelten Daten und gemachten Beobachtungen, unter dem 1. October v[origen] J[ahre]s Z. 871/p meine detaillierten Anträge an den Obersten Kanzler erstattet habe.

$\$ 144$ [Unangemesenheit der Zutheilung des Gebiets Rogosnizza, im Kreise Zara und Spalato] Außerdem fand ich, daß der Ort Rogosnizza mit einem schönen und sicheren Hafen zum Theil dem Prätursbezirke Trau, zum Theil jenem von Sebenico gehört, und sich zugleich in zwei Kreisen befindet wodurch mancherlei Schwierigkeiten bei Behandlung der ämtlichen Geschäfte statt finden, und in demselben Orte 2 Capi villa, zwei Capi ron$\mathrm{de}^{710}, 2$ Ciauše ${ }^{711}$ aufgestellt sind. ${ }^{712}$ Die Bewohner haben diesfalls mehrere Beschwerden geführt, und hierüber habe ich die Aufforderung an das Gubernium erlassen, um, nach vorläufig gründlicher Erhebung aller Verhältnisse, diesfalls eine möglichst entsprechende Verfügung im Einverständnisse mit der Appellation ${ }^{713}$ zu treffen.

$\$ 145$ [Gebiet Poglizza in drey Bezirken] Das Gebieth Poglizza im Kreise Spalato, welches seit den ältesten Zeiten [Qu 64 / 4] stets ein durch Verfassung, Gewohnheit und Sitten eng verbundenes Ganzes bildete, ist den drei Prätursbezirken von Almissa, Spalato und Sign zugetheilt. Dessen Bewohner haben hierüber wiederholte und nachdrückliche Vorstellungen überreicht, sie wurden aber zurückgewiesen, weil eben die Missbräuche welche die Poglizzaner sich ehemals erlaubten, schon unter der vorigen Regierung die sonst ungeeignet scheinende, aber in dieser wichtigen Beziehung sehr zweckmäßige Zerthei-

708 ON San Giorgio [di Lesina] / Sućuraj: Dorf und Gemeinde auf der Insel Hvar.

709 ON Castel Vitturi / Kaštel Lukšić: Ansiedlung nordwestlich von Split im Bereich Kaštela.

710 Capi ronde: Angesichts der Bedeutung als »Vorsteher einer Streife« allem Anschein nach ein Synonym zu den Panduren (Diensttuenden bei der Forza territoriale), für die Petter: Dalmatien, Bd. 1, 261 die italienische Bezeichnung Capi Craini gibt. Kroatisch existiert dafür auch der Begriff »rondari« (für den Hinweis danke ich Marko Trogrlić).

711 Ein Ciauš war laut Petter in der Terminologie der Landbevölkerung der Diener des Dorfvorstehers (capo villa, oder auch kapitan[o]), vgl. Petter: Dalmatien, Bd. 1, 240; der Begriff stammt aus dem Osmanischen (çauș) und hat im heutigen Türkischen offenbar ungefähr die semantische Bedeutung von »untergeordneter Amtsträger«, etwa im Sinne von militärisch »Unteroffizier«. Für Dalmatien gibt Orosz de Balásfalva: Das Unhaltbare unseres Steuer-Systems, 28, anders als Petter eine Verdeutschung als »Kleinrichter « an.

712 Nach dem "statt finden« Ergänzung in Rosettis Schrift am Rande. Die Verortung des gleichen Ortes in zwei verschiedenen Kreisen (Zadar und Split) und die darin begründeten administrativen Doppelungen sind ein kurioser Fall von administrativer Ineffizienz!

713 Gemeint ist das Appellationsgericht als oberstes Landesgericht, das hier von der zivilen Landesverwaltung offenbar im Prinzip, weil von solchen Veränderungen auch die territorialen Strukturen der Justizverwaltung betroffen waren, gleichberechtigt konsultiert werden musste. 
lung des Gebietes von Poglizza in verschiedene Distrikte veranlasste, da sie eine Art von ungarisch-bosnischer Rapresentation aufrecht erhielten, welche dem dermaligen politischen Zustande nicht anpassend, und in mancher Hinsicht störend war. ${ }^{714}$

\section{Eigenheiten und Schwierigkeiten der Provinz Verwaltung im Allgemeinen}

$\$ 146$ [Hauptstandpunkt der Verwaltung] Mit Zuversicht darf ich die aller Unterthänigste Ansicht aussprechen, daß schwerlich anderswo die Landesverwaltung mit so vielen, außergewöhnlichen und bedeutenden Schwierigkeiten zu kämpfen hat, als solches gegenwärtig in Dalmatien der Fall ist.

In allen übrigen Provinzen des österreichischen Staates ist der [Qu 65 / 1] Zustand der öffentlichen Verwaltung entweder allmälig aus der Vergangenheit hervorgetreten, hat in allen Theilen feste dauerhafte Wurzel geschlagen und ist von einem seit alter Zeit schon waltenden, den Hauptgrundsätzen dieser glücklichen Monarchie angemessenen Geiste der Entwicklung beseelt; oder er gleicht einem der frischen Schösslinge eines alten einheimischen Stammes.

In Dalmatien ist dieß nicht der Fall, wo der gegenwärtige Zustand, wo das dermalige Verwaltungssistem in seiner Wesenheit und seinem Geiste sehr verschieden von allen vorhergegangenen Verhältnissen und Sistemen, und weit über dem Civilisations-Grade Dalmatiens und seiner Bewohner steht, indem die allergnädigsten und hochst weisen Absichten Eurer Majestaet dahin zielen, diese Provinz, mit möglicher Beschleunigung zu der Cultur und dem Wohlstande, welche die übrigen Eurer Majestät väterlicher Herrschaft ${ }^{715}$ unterstehenden Länder beglückt, emporzuheben.

$\$ 147$ [Schwierigkeiten aus der topographisch. Lage] Aus dieser ehrfurchtsvollsten Andeutung, ergiebt sich außer der nicht [Qu 65 / 2] geringen Schwierigkeit, welche die topographische Lage allerlei Geschäften darbiethet, so wie ich geschildert habe, die erste nicht so leicht zu lösende Aufgabe für die öffentliche Verwaltung in Dalmatien. Indem nämlich selbe in den andren Provinzen der Monarchie größtentheils mit der Erhaltung des Bestehenden, mit der Anwendung der in allen Zweigen schon bestimmten Normen auf die vorkommenden und in nämlicher Art wiederkehrenden Fälle größtenteils sich befasst und nur hie und da stufenweis zu bessern, nachzuhelfen, das Bestehende nach langer Erfahrung zu entfalten, höchst selten aber Neues von Wesenheit ${ }^{716} \mathrm{zu}$ berathen, vorzuschlagen, auszuführen hat; muß sie hierlands die alte verworrne, gemischte unregelmässige

714 Die unter der Oberherrschaft Venedigs noch weitgehend autonome kleine Adelsrepublik der Poljica war in ihrer Sonderstellung zur Zeit des Königreichs Italien 1807 aufgehoben worden. Rubić: Poljica, hier insbesondere 7 und $26 \mathrm{f}$.

715 Eine direkte Wendung an den Kaiser zur Ausmalung der von dem durch Lilienberg konstatierten Entwicklungsrückstand verursachten Sonderstellung Dalmatiens in Verwaltungshinsicht, mit klar zweckgerichteter Anspielung auf das kaiserliche Landesvatertum, das hier als Lilienbergs Rechtfertigung für seine eigenen Entwicklungsziele verwendet wird.

716 »Neues von Wesenheit«: grundlegend Neues. 
Stellung der Dinge und Formen aufheben; einen ganz neuen harmonischen Gang und Ordnung in allen Zweigen einführen und darauf sehen, daß selbe nach allen Richtungen in wirkungs[gestrichen: -voller; ergänzt: reicher] Fülle sich erstrecke und befestige.

Da solches Werk nicht mit einem [Qu 65 / 3] Male ausgeführt werden konnte, so ergab und ergiebt sich noch die Nothwendigkeit die Geschäfte jener Materien, deren neue Sistemisirung noch im Zuge steht, nach den Normen, Gesetzen und Gewohnheiten der verschiedenen früheren Regierungsepochen, dagegen die Angelegenheiten der schon sistemisirten Verwaltungszweige nach den neuen Gesetzen und Vorschriften zu behandeln ${ }^{717}$, wobei sich mancherlei schwierige Fälle, und viele Complicirungen ergeben. Bei diesen Verhältnissen und jenen häufigen Umgestaltungen in den einzelnen Verwaltungszweigen, vermehrt sich nothwendiger Weise auch die Menge der sogenannten currenten und Partheiangelegenheiten. ${ }^{718}$

$\$ 148$ [Schwierigkeiten aus der Einführung neuer Sisteme] Noch größere Schwierigkeiten biethen die Eigenheiten dieses Landes selbst, für welche es in den andern Provinzen kein Beispiel zu ihrer gehorigen [sic] Auffassung und deswegen keinen [gestrichen: wahren] Maßstab [Qu 65 / 4] zu ihrer Erwägung und Behandlung giebt; wofür es auch bey erfolgter gänzlichen Organisirung dieser Provinz schwer sein wird, bestimmte Gesetze und Vorschrifthen vorzuziehen, weil es unmöglich ist die vielfälltigen sich immer erneuernden Ereignisse in den anarchischen benachbarten Provinzen ${ }^{719}$ vollkommen vorauszusehen, und die Schlichtung solcher außerordentlichen Fälle von einer richtigen Beurtheilung, von einem raschen aber klugen und bestimmten Einschreiten von Seite der Ämter und Behörden abhängt.

$\$ 149$ [Aus den Eigenheiten des Landes und der Bewohner] Die besondern Fälle dieser Art, welche nicht selten eintreten, ergeben sich vorzüglich aus der offenen Lage der Provinz gegen das Meer deren Länge sammt der Peripherie der Inseln über 450 deutsche

717 Vgl. zum teilweise langen Nebeneinander bzw. Fortwirken früherer Rechtsetzungen Clewing: Staatlichkeit, $73 \mathrm{f}$. Allerdings waren in Wirklichkeit auch in anderen erst spät erworbenen Gebieten wie etwa Salzburg ähnliche Faktoren wirksam, vgl. ebd., 75, Anm. 100. Der von Lilienberg hier etwas zu vereinfacht auf jenes Fortbestehen alter Regelungen zurückgeführte Bedarf nach Verwaltungssystemisierung (der sich aber auch auf Felder erstreckte, die einst überhaupt nicht staatlich organisiert gewesen waren) war wegen des von Wien festgelegten Vorrangs von Systemkonformität vor etwaigen pragmatischen, an die Landesverhältnisse angepassten Verwaltungslösungen wohl das größte verwaltungsstrukturelle Problem, das in Dalmatien im Vormärz und darüber hinaus zu erkennen ist. Vgl. dazu Clewing a. a. O., insbesondere 124-127.

718 Parteiangelegenheiten: Verwaltungsvorgänge, bei denen sich direkter Kontakt mit Betroffenen ergab (vgl. im heutigen südlichen Amtsdeutsch »Parteiverkehr / Parteienverkehr« für die Öffnungszeiten der Ämter).

719 Im Osmanischen Reich bzw. in Montenegro. 
Meilen beträgt; aus den gar nicht überwachbaren Gränzen des Festlandes, aus den Verhältnissen der hiesigen Gränzbewohner zu jenen der benachbarten ottomanischen Provinzen und den unter rußischem Einflusse ${ }^{720}$ stehenden Montenegrinern, die $[Q u$ 66/1] keine Gesetze und keine Verfassung haben; aus den beständigen Unruhen in diesen Nachbarschaften; aus den Verhandlungen mit ihren rohen Authoritäten; aus dem eigentlichen Naturstande [Naturzustande, K. C.] eines großen Theils der hiesigen Landbewohner, wie die übrigen Provinzen nichts Ähnliches biethen; aus den ihnen eigenthümlichen, unversöhnlichen [Phänomenen von, K. C.] Rache, und Vorurtheilen; aus deren allgemeiner Bewaffnung und kriegerischem Geiste; aus der, durch die Schuld der früheren fremden Regierungen ${ }^{721}$ veranlassten und genährten Demoralisation der meisten Städter; ihrem Intriguen-Verläumdungsgeiste und ihrer Irreligiosität.

$\$ 150$ [Aus dem unverhältnißmäßig geringen Personal] Diese sind die Ursachen, welche oft die Beamten und den Vorsteher, wenngleich diese Provinz der Zahl nach kaum dem größten Kreise von Böhmen, oder von Mähren gleich kömmt, wegen dem bei den meisten administrativen Ämtern und Behörden bestehenden Missverhältnisse des in der Zahl beschränkten Personals zu der Menge und Wichtigkeit der Geschäfte, in eine peinliche Lage $[Q u$ 66 / 2] versetzen.

Der [personalstellenbezogene, K.C.] Status bei denselben wurde größtentheils auf der Basis der unter der vorigen Regierung und nach ihrem bei weitem nicht so complizirten aber auch nicht so wohlthätigem Verwaltungssistem, theils nach den Ergebnissen der Amtsgeschäfte in den ersten Jahren nach der durch die siegreichen Waffen Eurer Majestät erfolgten Wiederbesitznahme dieser Provinz, theils endlich nach der, den Stellen ${ }^{722}$

720 Das Wiener Misstrauen gegen den in Montenegro geltenden russischen Einfluss und dessen Rückwirkungen auf die eigene orthodoxe Bevölkerung, besonders in der Boka kotorska, war eines der bestimmenden Momente für die österreichische Politik Montenegro gegenüber. Lilienberg selbst berichtete verschiedentlich über russische Einflussnahmen, die über Montenegro in der Boka erfolgten (z, B. AVA, PHSt, H. 55/1833 vom 10.10.1833 (Stimmungsbericht für September 1833); vgl. auch mit weiteren Belegen Clewing: Staatlichkeit, 52, Anm. 14. Zum in der Tat großen russischen Einfluss in Montenegro und der lokalen Konkurrenzstellung der beiden Reiche s.a. hierzu immer noch wertvoll Đorđević: Crna Gora i Austrija 1814-1894; und Andrijašević / Rastoder: Istorija Crne Gore, 163 f. und 171 f., insbesondere auch zu der von großem österreichischen Misstrauen begleiteten Russlandreise des Metropoliten Petar II. Petrović Njegoš im Jahr 1833 (und erneut 1837).

721 Erneute Belege für das bewusst gepflegte, und bei Lilienberg auch der Anspornung Wiens bzw. des Kaisers zu dalmatienpolitischem Engagement dienende negative Bild von den venezianischen und französischen Herrschaftsperioden.

722 Gemeint sind die Hofstellen; also wieder eine ganz offen angesprochene Konfliktstellung gegenüber den Wiener Behörden, hier rund um den in ihrer Sicht zentralen, von Lilienberg aber abgelehnten Grundsatz von der nicht zulässigen »Passivität« der Provinzhaushalte. Vgl. oben, Anm. 678 zu $₫ 137$. 
immer vorschwebenden Rücksicht der Passivität Dalmatiens in finanzieller Hinsicht und der möglichsten Ersparung, bestimmt.

Wenn es gleich richtig ist, daß ein vorübergehender Zustand, nicht zur Basis einer bleibenden Organisirung genommen werden darf, so lässt es sich doch auch nicht läugnen, daß die schon lange währende Entwicklung der neuen Sistemisirung, bis selbe nicht vollkommen ausgebildet und befestiget sein wird, was doch nur allmälig geschehen kann, die Landesstelle, ihre Hülfs- und Kreisämter, so auch die Präturen, ungeachtet der unausgesezten größten [Qu 66 / 3] Anstrengung aller Beamten, stets in Besorgniß erhalten wird, entweder in Rückstände zu gerathen, oder in den Arbeiten oberflächlich zu werden.

$\S 151$ [Aus der Beschaffenheit der Beamten] Auch die Beschaffenheit der hierländigen Beamten biethet mancherlei erhebliche Schwierigkeiten. Die Mehrzahl derselben hat entweder keine gründliche Ausbildung oder selbe nicht nach dem österreich[ischen] Studienplan erhalten; ein großer Theil hat unter den vorigen Regierungen, folglich nach einem dem jetzigen fremden Geiste, gedienet; ein anderer Theil hat zwar auf den k.k. Universitäten studirt, aber nur hierlands und meist unter Anleitung der älteren Landesbeamten gearbeitet. Wenige nur haben zugleich die gehörige Ausbildung, Sprach-, Landes- und in anderen Provinzen erworbenen administrativen Kenntniße. Die Mehrzahl hatte also bei allem Fleiße, und bestem Willen nicht die Gelegenheit den Geist des oesterreichischen Verwaltungssistemes gehörig, aufzufassen, ihn lebendig in und außer sich zu entwickeln und das ämtliche Wirken $[Q u 66 / 4]$ darnach in allen Theilen zu gestalten.

So rein und pflichtgemäß endlich der Eifer der Hofstellen bei Behandlung der Angelegenheiten Dalmatiens sich darstellt, so empfindlich scheint es zu sein, daß bei denselben kein einziger höherer Beamte sich befindet. ${ }^{723}$

$\$ 152$ [Aus dem Umstande, daß der Landes Chef ein Militair ist] Eine nicht kleine Schwierigkeit für das Gedeihen der hiesigen Geschäfte scheint mir aber in dem Umstande zu liegen, daß die Leitung der Landesstelle einem Militair anvertraut ist.

Ein politischer Landeschef muß [gestrichen: Seelenkraft, Erfahrung und Klugheit besitzen, vorzüglich aber] alle Vorschriften und positiven Gesetze die das Land angehen, und bis auf den Tag, an welchem er amtirt [hier im Sinne von sein Amt antritt; K. C.], ergangen sind, vollkommen ihrem Geiste und Formen nach, kennen.

In der Anwendung dieser [Gesetze, K.C.] muß er präziser und gewandter, als jeder seiner Untergeordneten seyn, um jeden Gegenstand schnell und gründlich aufzufaßen, jeder Verlegenheit, jeder Irrung vorzubeugen, auf $[Q u$ 67/1] solche Art seinem Berufe zum Besten des allerhöchsten Dienstes zu entsprechen, und ein moralisches Uiberge-

723 Der hier begonnene und durch Streichung (in schwarzer Tinte) abgebrochene Gedankengang findet sich komplettiert in $\$ 154$. 
wicht $\mathrm{zu}$ erhalten, ohne welche magische $\mathrm{Kraft}^{724}$, besonders bei den hiesigen schwierigen und sehr complicirten Verhältnissen überhaupt, vorzüglich aber so lange die Organisirung des Landes nicht vollkommen beendet sein wird, ein günstiges Resultat nicht so leicht zu erwarten sein dürfte.

Mir scheint es unmöglich, daß ein Militair, wenn er auch einige Kenntniße von dem politischen Fache gehabt hätte, diese aber durch 30-40 Jahre nicht in Anwendung bringen konnte, in einem hohen Alter die, für diesen Posten unentbehrlichen positiven Gesetze und Vorschriften vollkommen nachzuholen, im Stande sein sollte ${ }^{725}$.

Es muß demnach am meisten dort mangeln, von wo der meiste Impuls in alle Geschäfte zu ergehen hätte.

$\$ 153$ [Aus dem eigenen Verhältniße des Landeschefs zum jeweiligen Hofrathe] Eben so unmöglich scheint es mir [Qu 67 / 2] daß ein Chef, welchem in der Person des Hofrathes nicht so [sehr] ein Gehülfe als eine Controlle beigegeben wird, sich das Ansehen und Zutrauen erwerben könnte, welches doch einem Landeschef nie mangeln darf. ${ }^{726}$

Uibrigens, wenn auch der Leztere, so wie der ihm zur Seite stehende Hofrath die besten Menschen sind, und keine Art Intrigue oder Spannung zwischen diesen zwei ganz heterogen gebildeten Staatsdienern sich entwickelt, so lähmt schon das Verhältniß selbst die Wirksamkeit und das Ansehen des Chefs.

$\$ 154$ [Gestrichen: Aus dem Umstande, daß bei den Hofstellen sich Niemand befindet, welcher den gegenwärtigen Zustand des Landes kennt] So rein und pflichtgemäß endlich der Eifer der Hofstellen bei Behandlung der Angelegenheiten Dalmatiens sich darstellt, so empfindlich scheint es zu seyn, daß bei denselben kein einziger höherer Beamte sich befindet, welcher den gegenwärtigen Zustand dieser Provinz und seine administrativen Verhältniße vollkommen kennt, da, so viel ich weiß, nur bei der allgemeinen Hofkammer [Qu 67 / 3] einer der Hofräthe, aber dies auch nur in der früheren oesterreichischen Regie-

724 Gemeint ist das »moralische Übergewicht«, über das der Leiter der zivilen Landesverwaltung verfügen müsse.

725 Eine ganz erstaunliche Selbstkritik an der eigenen Qualifikation und an der dann noch bis 1903 beibehaltenen Doppelfunktion von Militär- und Zivilgouverneur durch einen hohen Militär! Allerdings war Lilienberg selbst in so hohem Maß auch in der Zivilverwaltung erfahren, dass er sich solche Kritik in besonderer Weise leisten konnte. Vgl. in der Einleitung, Seite 19.

726 Eine heftige Kritik an seiner administrativ vorgegebenen Stellung; Lilienberg fühlte sich in seiner Leitungsfunktion also durch den beigefügten Hofrat offenkundig untergraben! Abgesehen von diesem systemisch angelegten personalisierten Reibungsmoment ist die Analyse aber auch bezüglich der unterschiedlichen Ausbildungshintergründe und sozialisierungsbegründeten »Kulturen« des jeweiligen Militärs und des ihm als Hofrat beigefügten Zivilbeamten nicht von der Hand zu weisen. 
rungsepoche seit welcher sich die Verwaltungsverhältnisse unendlich geändert haben ${ }^{727}$, von der Hofkanzlei aber gar Niemand in diesem Lande war. Woraus nothwendig folgt, daß die Hofstellen nicht immer die Eigenthümlichkeiten dieser Provinz so aufzufaßen und zu würdigen vermögen, wie es zu wünschen wäre, daß man die hiesigen Angelegenheiten öfter nach einer fremdartigen Basis beurtheilt und daß hieraus neue Schwierigkeiten entstehen, welche um so gewichtiger sind, als sie von den höchsten vorgesetzten Stellen herrühren ${ }^{728}$; [ergänzt: Hier sollte man mehr als irgendwo das; gestrichen: wo doch das] alte Staatsaxiom, daß nicht die abstract vollkommensten, sondern die, für die besondern Verhältniße jedes Landes [ergänzt: an-]passendesten Gesetze und Mittel die Besten für den Landesfürsten und für dessen Unterthanen sind, [gestrichen: nirgend mehr als hier, ; ergänzt: zu] beherzigen [gestrichen: beherziget werden sollte] bemüht seyn.

\section{Mittel um die Administration dieses Landes im Allgemeinen so viel als möglich zu fördern}

$\$ 155$ [Schleunige Besetzung erledigter Stellen]

[Gestrichen: Hier ist viel mehr nothwendig als in andern schon organisirten Ländern; ergänzt:] Die hiesigen verworrenen Verhältnisse und der Umstand, daß das Meiste im Werden begriffen ist, machen vorzüglich nöthig die erledigten [Qu 67 / 4] Amtsplätze ${ }^{729}$ jedesmal so bald als thunlich effectiv zu besetzen, die Organisirung der noch rükständigen Zweige so viel als möglich der Wichtigkeit angemessen zu beschleunigen, damit nach einem ununterbrochenen Besitze dieses Landes von mehr als 4 Lustern ${ }^{730}$ dem Schwanken ein Ende gemacht und dann die Amts-Instruktion für die Kreisämter, Präturen, Co-

727 Der Hof- und Staatsschematismus für das österreichische Kaiserthum 1834, Teil 1, nennt 250 f. insgesamt 25 Männer in der Funktion als k. k. wirkliche Hofräte der Hofkammer. Gemeint war aber vermutlich der ebd., 250 genannte Vizepräsident (seit 1832) der Hofkammer, Joseph Freiherr Mayer von Gravenegg. 1780 geboren in Karlstadt (Karlovac), war Mayer von Gravenegg 1806 Gubernialsekretär in Dalmatien und ab dann für Jahrzehnte ein führender Finanzbeamter an der Hofkammer und anderen Wiener Zentralstellen bis über 1848 hinaus. Siehe Österreichisches biographisches Lexikon, Bd. 6, Wien 1973, 3 f., hier benützt nach http://www.biographien.ac.at/oebl/oebl_M/Maier-Gravenegg_Josef_1780_1870.xml (zuletzt 20.4.2014).

728 Eine besonders starke Kritik an den Zentralstellen in Wien; man beachte auch das nachstehende Plädoyer für an die örtlichen Verhältnisse adaptierte Lösungen und eine Art von Subsidiarität.

729 Die Arbeitsstellen/Dienstposten in der Verwaltung.

730 Vgl. lateinisch »lustrum « und italienisch »lustro«, »Jahrfünft « (vier Jahrfünfte gerechnet vom faktischen Wiedererwerb Dalmatiens 1813/14); Oertel, [Eucharius Ferdinand Christian]: Grammatisches Wörterbuch der deutschen Sprache. Wobei zugleich Abstammung, Lautund Sinnverwandtschaft, Sprachreinigung und Worterneuerung beachtet wird. Bd. 2, Teil 1: L bis Schwa. München 2. Auflage 1835, 49 verzeichnet »Lustrum« im Sinne von 1) Reinigungsopfer; 2) ein Jahrfünft. 
munen und für die forza territoriale verfaßt werden könne, wegen deren Mangel ${ }^{731}$ in der Amtsführung viele Unordnungen bestehen, obwohl ich, [gestrichen: so viel als] möglich [ergänzt: -st], durch specielle Belehrung inzwischen abzuhelfen und zugleich bemüht war, die Materialien und Entwürfe zu dieser Instruktion vorzubereiten.

Es bedarf keiner Begründung, daß das Gedeihen der Geschäfte bei den Ämtern und besonders bey einzelnen Beamten so sehr von dem Bestande und von dem zweckmäßigen Inhalte der bezüglichen Instruktionen abhängt, daß durch die genaue Beobachtung dieser allein der Geist der Regierung in das Streben und Handeln der Verwaltungsorgane übertragen werden und die Bürgschaft gewähren kann, $[Q u$ 68 / 1] daß das bestimmte Verwaltungssistem harmonisch und entsprechend in allen seinen einzelnen Beziehungen sich entwikle. ${ }^{732}$

Wenn aber Instruktionen im Allgemeinen ein unentbehrliches Bedürfniß sind, so müssen sie es in dieser Provinz noch mehr seyn, in welche eine von den früheren fast allen Theilen nach ${ }^{733}$ ganz verschiedene Organisirung und Verwaltung verpflanzt worden ist.

$\$ 156$ [Personal Aushülfen] So ist es auch den hiesigen besonderen Verhältnißen angemessen, für den Fall, wenn hie und da bei den Präturen aus was immer für gegründeter, und anders nicht zu hebender Ursache Aushülfe nothwendig befunden wird, Euere Majestaet dem Gubernium die Vollmacht allergnädigst einzuräumen geruhten ${ }^{734}$, nach Vorschlag der Kreisämter oder nach ihrer Vernehmung, bei den politischen Präturen selbst und bei den gemischten ${ }^{735}$ in Einverständniß mit der Appellation, das unumgänglich Nothige gleich zu veranlassen, und darüber den Bericht zu erstatten. Das Gubernium hat unterm 25 Mai l[aufenden] J[ahres] 7311 [Randanmerkung, auf der Höhe der Zeile mit dem »Einverständnis, auch: 3514/2259 23/4.] diesen Antrag der vereinten Hofkanzley vorgelegt.

$\$ 157$ [Verminderung der Schreiberei] Um aber andererseits unnöthige Schreibereien und andere Geschäfte so viel [Qu 68 / 2] als möglich zu vereinfachen, hat die Landesstel-

731 Gemeint ist der Mangel an solchen Instruktionen (Dienstvorschriften und Ablaufplänen).

732 Wie wichtig Lilienberg dieses Anliegen nahm, zeigt sich anhand der einzigen innerdalmatinischen Verwaltungsebene, von der er hier an dieser Stelle schweigt, nämlich des Guberniums selbst. Auch für diese hatte sein Vorgänger Tomašić offenbar keine Dienstablaufpläne vorgelegt, während dies Lilienberg 1835 erledigte; siehe die Edition durch Strmota: Naputak o uredskom poslovanju predsjedničkog ureda Kraljevine Dalmacije.

$733 \mathrm{Zu}$ verstehen als: eine von den früheren Verwaltungen in fast allen Teilen / in fast jeder Hinsicht ganz verschiedene neue Organisierung und Verwaltung.

734 Also eine direkte Wendung an den Kaiser, mit der Bitte um Erteilung einer Sondervollmacht zur Verfügung von zunächst nicht mit Wien abgeklärten Maßnahmen des Guberniums auf der Ebene der Präturen.

735 Also den "politischen « (administrativen) und juridischen; vgl. zu den Begriffen wiederum hier im Anhang das Dokument von Erzherzog Franz Karl von 1843. 
le in dieser Absicht unter dem 25 September v[origen] J[ahre]s Z 13771/3010 wegen Erweiterung des Wirkungskreises der Behörden und Ämtern, dann unter dem 25 September nämlichen Jahres No 6156/1351 wegen Verminderung der periodischen Berichte die Anträge erstattet, worüber die höhere Erledigung noch gewärtiget wird.

Um [gestrichen: aber; ergänzt: ferner] in dieser Hinsicht kein Mittel unversucht zu lassen und nach und nach den Geschäftsgang ohne im Sisteme etwas zu ändern, möglichst zu verkürzen und alles Unnöthige einer verkehrten oder zögernden Uibung abzustellen, habe ich die Referenten, die Landesstelle und die Kreisämter angewiesen, während ihrer Amtshandlung bei allen einzelnen Gattungen [von; K.C.] Geschäften dasjenige, was vereinfacht werden könnte, vorzubereiten, und gegen Ende jeden Jahres dem Gubernium zur Revision und zur weiters geeigneten Veranlassung zu unterziehen.

$\$ 158$ [Erziehung geschickter und qualifizierter Beamten] Von besonderem Nutzen wäre auch eine Auswahl geschikter Beamten, die nicht nur mit allen vorgeschriebenen [Qu 68 / 3] Kenntnissen und Wissenschaften versehen sind, sondern auch einige praktische Ausbildung im Littorale erhalten haben. ${ }^{736}$ Doch unterfange ich mich bei dieser Gelegenheit Eure Majestät allerunterthänigst zu bitten, bei den einheimischen Individuen, besonders wenn sie einen Posten jahrelang provisorisch mit voller Zufriedenheit aller Behörden und Stellen versehen, den Mangel der Studien allergnädigst nachzusehen, wenn sie keine moralische Makel haben, um sie nicht ganz zu entmuthigen. ${ }^{737}$

[ $\$ 159^{738}$; Bestimmung eines Civil Präsidenten für die Landestelle] Vielleicht wäre auch schon der Augenblick gekommen, wo Eure Majestät mit voller Beruhigung was die äußern Verhältnisse der ottomanischen Gränzprovinzen und Montenegro anbelangt, die Leitung dieser Landesstelle einem Civil-Präsidenten allergnädigst anzuvertrauen geruhen

736 Weil das Küstenland (Littorale) relativ ähnliche Strukturen aufwies, aber schon wesentlich länger zur Monarchie gehörte und daher die Verwaltung dort mehr den gesamtösterreichischen Vorgaben entsprochen hat.

737 Also eine direkte Wendung an den Kaiser mit Bitte um eine für Dalmatien zu erlassende Sonderregelung, die Beamtenausbildungs-Anforderungen betreffend, zugunsten der Dalmatiner unter den Beamten. Mit den "Studien « sind die speziell für die Beamtenausbildung angelegten juridisch-philosophischen Studien an einer österreichischen Universität gemeint, die seit dem Josephinismus zur Anforderung an Beamte (auch an bereits im Dienst befindliche) der höheren Laufbahn vorgeschrieben waren und im Vormärz unter hochgradiger Verschulung des Studiengangs beibehalten blieben. Vgl. Heindl: Gehorsame Rebellen, 2. Auflage, 126137 zum Vormärz. Für Dalmatien bzw. Zadar zu den nach 1848 vorübergehend bestehenden Möglichkeiten vor Ort die entsprechenden Passagen bei Obad: Visoko školstvo u Zadru.

738 Die $\$$-Markierung fehlt im Konzept. 
dürften. ${ }^{739}$ Bedeutende Uiberfälle haben wir durchaus nicht zu besorgen ${ }^{740}$ und die einzelnen Excesse und Räuberreien welche an der Gränze geschehen, werden ohnehin durch die Gränz-Präturen und Serdaren ${ }^{741}$ wenn es sich um Thätlichkeiten [Qu 68 / 4] handelt, augenblicklich ausgeglichen. Sollte aber wo die Intervenirung des Militeurs [sic] nothwendig werden, so geschieht alles den bestehenden Vorschriften gemäß welche nach den vielen früheren Ereignißen, und langer Erfahrung sanctionirt worden sind. Daß das Land ganz bewaffnet ist, kann eben so wenig ein wesentliches Hinderniß machen, denn Alles gehorcht den Kreisbeamten, dem Prätor, und sogar dem Syndicus, um so mehr wird es auch dem Civil Gouverneur gehorchen.

Für die Administration des Landes hielte ich aber diese Verfügung von sehr großem Erfolg.

Der Hofrath würde dann entbehrlich und statt eines commandirenden Generals, dürfte blos ein Feld-Marschall-Lieutenant als Militair Commendant, hier angestellt werden.

Diesen [sic, wegen ursprünglich anderem Satzaufbau] Antrag [gestrichen: hat auch schon in Verhandlung höheren Orts der Hofrath Fölsch ${ }^{742}$ gemacht; statt dessen:] soll auch schon in Verhandlung höheren Orts gewesen ${ }^{743}$, und angetragen worden sein, daß man den Präsidenten [also den Gouverneuren, K. C.] 10000 Gulden gebe, und vielleicht noch manche andere Einsparrung [sic] in den Hülfsämtern machen könnte.

Wenn man nun den Militair Commendant mit 8000 f. jährlich ansetzt [Qu 69 / 1] [Qu 69 / 2, 3, 4 fehlen formal, aber nicht inhaltlich] so würden eben die 18000 Gulden welche der Civil- und Militair-Gouverneur sammt dem Hofrath kostet, und [sic] nicht mehr verwendet, und nach meinem gewissenhaften aller unterthänigsten Dafürhalten dem

739 Also ein nochmaliger Vorschlag zur Besetzung der bis dahin durch einen General bekleideten Leitungsposition durch einen Zivilbeamten; siehe auch $\$ 152$ mit Lilienbergs Grundsatzkritik am System der aus dem Militär stammenden dalmatinischen Gouverneure.

740 Angesichts der eingetretenen Schwäche des Osmanischen Reiches bestand in der Tat von der Landseite keine eigentliche Kriegsgefahr mehr. Bedenkt man die starken Unruhen in Bosnien gerade von 1832/33 und ihre zeitweiligen Rückwirkungen durch Fluchtbewegungen über die Grenze, erscheint diese Auffassung freilich weniger selbstverständlich und zeugt davon, wie sehr Lilienbergs eigenes Hauptinteresse der Zivilverwaltung galt und er als Verwalter gewiss nicht der engstirnige Soldatengeist gewesen ist, als den ihn Tommaseo beschrieben hat (vgl. oben, Einleitung, Seite 17).

741 Offiziere innerhalb der Forza territoriale.

742 In der Zusammenfassung von Fölschs Bericht von 1827 bei Kupek: Gospodarske i kulturne prilike u Dalmaciji krajem trećeg decenija XIX stoljeća, findet sich dazu kein Hinweis. Vermutlich hat Fölsch hierzu (wie auch schon weiter oben zu seinem Vorschlag der Zusammenlegung der beiden südlichen Kreise) gegen 1832 erneut eine Stellungnahme abgegeben.

743 Hier sind, wohl der Wichtigkeit des Vorschlags geschuldet, in der genauen Formulierung im Konzept Korrekturen sowohl von Rossetti als auch abschließend von Lilienberg vorgenommen worden. 
Lande und Eurer Majestät allerhöchstem Dienste, in politischer und militairischer Hinsicht viel besser gerathen ${ }^{744}$ seyn.

Bei dem hiesigen Militair-Commando dürfte aber die Ausnahme statt finden, daß es [K. C.: trotz der vorgeschlagenen Ersetzung der Stellung des kommandierenden Generals durch einen Feldmarschalleutnant keinem dazwischen geschaltetem Generalkommando, sondern] direkte vom k. k. Hofkriegsrathe abhängig bliebe. Endlich erscheint mir auch sehr räthlich, daß ein Hofrath der vereinten Hofkanzlei und einer der allgemeinen Hofkammer mit einem Hofsekretäre oder einem andren Concepts-Beamten diese besondere Provinz ganz und prüfend bereise, um von ihren verschiedenartigen Verhältnißen Kenntniß zu nehmen, oder, daß einige Hofräthe die mehrere Jahre gedient haben ${ }^{745}$ und hiezu sonst Fähigkeiten besitzen, zur Hofstelle gezogen werden. ${ }^{746}$

[Qu 70 / 1]

Gemeinden

[ $\$ 160$ ] [Verhandlungen über das Gemeinde Wesen ${ }^{747}$ ] Nachdem ich in Folge Auftrages des Obersten Kanzlers und eigentlich über die Fragen:

a welche Sindacats Gemeinden ${ }^{748}$ mit den größeren im Prätursitze zu vereinigen.

$\underline{b}$ ob und in wie weit die Besoldungen der Comunal Beamten könnten reduziert werden, einen umständlichen Bericht über das ganze Comunalwesen, mit Benutzung aller, auf meiner Bereisung der Provinz im Jahre 1832 und 1833 gesammelten Daten, so wie ich bereits allerunterthänigst erwähnte, unter dem ersten Oktober v[origen] J[ahre]s Z 871/p erstattet, auch mit demselben eine Ersparung von 8030 Gulden nachgewiesen habe, und dieser Bericht mit Vortrage der vereinten Hofkanzlei allerhöchsten Orts wird vorgelegt werden, so darf ich mich nicht unterfangen, Euerer Majestät mit den dießfäl-

$744 \mathrm{Zu}$ verstehen als: „viel besser angemessen« (die vorgeschlagene Lösung nämlich, im Vergleich zur bestehenden Regelung).

745 Gemeint ist: die in Dalmatien gedient haben.

746 Also ein Vorschlag für eine amtliche Bereisung Dalmatiens durch Hofbeamte oder umgekehrt Gewährleistung von Dalmatienkenntnissen in Wien durch Heranziehung dalmatienerfahrener Beamter nach Wien - in jedem Fall eine konsequente Fortentwicklung von Lilienbergs Argument, dass es in den Wiener Entscheidungsfindungen an den nötigen grundlegenden Kenntnissen über die Provinz fehle (vgl. \$\$ 154 und 171).

747 Randanmerkung Rossettis in der Gliederung: »ad 160 Anträge 1. Oct 1833Z 871/p Ersparung 8030 f. - [bezieht sich eigentlich auf $\$ 162$ :] Überladung der Gemeinde.Ämter mit fremdartiger Arbeit. [Zuoberst hinzugefügt, und eigentlich in Bezug auf $\$ 161$ :] S. M. haben sich im J. 1830 a.h.C. [mit allerhöchstem Kabinettschreiben] v. 16. Nov. die Entscheid[ung] über das Personale bei dem 4 Hauptpodesterien vorbehalten."

748 Mittelgroße Gemeinden, an deren Spitze ein sindaco als Bürgermeister amtierte. Vgl. hier im nachfolgenden Paragraphen 161 den Unterpunkt c. Zu den Funktionen der Gemeinden insgesamt als Grundeinheiten der staatlichen Verwaltung innerhalb der 1822 für ganz Dalmatien (außer dem Kreis Kotor) erlassenen administrativen Ordnung siehe Ivković: Organizacija uprave, 37. 
ligen Wiederholungen zu belästigen, sondern erlaube mir in tiefster Ehrfurcht nur Folgendes anzuführen:

$\$ 161$ [Gattungen der Gemeinden] In Dalmatien bestehen nachstehende Gattungen von Gemeinden:

a In den 4 Kreishauptorten befinden sich in Folge allerhöchster Entschließung vom 16. November 1830 Podestarien, welche den Municipalitaeten der königlichen Städte [Qu 70 / 2] des lombardisch venetianischen Königreichs, mit Ausnahme Mailands und Venedigs, gleich sind und unmittelbar unter dem Kreisämtern stehen.

Wegen Sistemisirung ihres Personales und Ernennung der Podestas für dieselben haben Euere Majestät die weitere allerhöchste Entscheidung sich vorzubehalten geruht; und es wäre für den allerhöchsten Dienst Eurer Majestät sehr vortheilhaft, wenn die allerhöchste dießfällige Resolution beschleunigt werden könnte. ${ }^{79}$

b In den Präturs-Hauptorten bestehen Amministrazioni und consigli comunali, welche für die Kreise Zara, Spalato und Ragusa in [gestrichen: Folge; ergänzt: Gemäßheit] allerhöchster Entschließung vom 4 Maj, Jahr 1821 aufgestellt wurden[.]

$\underline{c}$ Andere größere Orte außer dem Präturssitze ${ }^{750}$ haben Sindaccate. Diese drei Gattungen sind die Obergemeinden des Landes.

d Die Untergemeinden stehen unter einem Capo Comunale oder Capovilla / auf Illirisch capitan / und einem Adjuncten, als dessen [gestrichen: Erster] Stellvertreter. -

Außer den vorerwähnten Bestimmungen für den Hauptort von Cattaro ${ }^{751}$ wurde in diesem Kreise nach dessen Wiedereroberung durch die siegreichen Waffen Eurer Majestät noch keine neue Gemeinde-Verfaßung eingeführt [ergänzt: obgleich auch für denselben die bezüglichen Vorschläge \{gestrichen: von dem Gubernium gleichzeitig mit jener für die übr $\left.{ }^{752}\right\}$ erstellt worden waren,] sondern es ist der alte Stand auf den sich die Gemeinden bei dem Abzuge der Franzosen im Jahre 1813 selbst gesetzt hatten, [Qu 70 / 3] daselbst belaßen worden, welcher mit jenem unter der ersten österreichischen Regierung die ihnen ihre Vorrechte beließ $\beta^{753}$, eine Ähnlichkeit hat.

749 Diese ungewöhnliche Offenheit Lilienbergs in seiner deutlichen Klage über das langsame Entscheidungsprozedere sogar gegenüber dem Kaiser, der in diesem Fall zumindest mitbeteiligt und jedenfalls endverantwortlich war, ist zugleich ein Beleg für das hohe Selbstvertrauen des Gouverneurs bzw. für sein hohes Vertrauen in die Belastbarkeit seines eigenen Zugangs und Verhältnisses zum Kaiser!

$750 \mathrm{Zu}$ verstehen als: außerhalb der Präturssitze.

751 Gemeint sind vermutlich die Ausführungen weiter oben zu $₫ 139$ zugunsten der Aufrechterhaltung des Kreises (und Kreisamtes) Cattaro, die allerdings die eigentliche Gemeindestruktur des Ortes Cattaro nur indirekt behandeln.

752 Bei »übr« wie »übrigen« bricht die Einfügung Lilienbergs ab, offenkundig in Rücksichtnahme auf seine Position gegenüber Wien bzw. dem Kaiser.

753 Ein Bezug auf die erste österreichische Herrschaft, der zugleich die Tiefe der Änderungen gegenüber den venezianischen Verhältnissen erkennen lässt, die während der Franzosenzeit 
$\$ 162$ [Zustand der Gemeindämter im Allgemeinen ${ }^{754}$ ] Während meiner Provinzbereisung habe ich bemerkt, daß bei allen Comunal-Ämtern weit mehr, als die durch das Organisirungs-Dekret ihnen zugewiesenen Geschäfte von den Gemeinden besorgt werden, die theils durch nachträgliche Verordnungen, theils durch die nach und nach eingeschlichene Uibung der Präturen, die Gemeinden in allen Angelegenheiten zu befragen und fast alle Intimationen durch sie bewirken zu lassen, jenen zugewachsen sind. ${ }^{75}$

Da dieser Uibelstand schon seit vielen Jahren besteht und tief in viele Verwaltungszweige eingedrungen ist, so wird nur bei einer allfälligen Revision des ganzen Comunal-Sistems in dieser Beziehung eine wohlerwogene Abhülfe sich treffen laßen.

Einige Gemeinde Ämter habe ich zum Theile in einer gewissen, äußeren materiellen Ordnung, aber sowohl in derselben, als in der Art der Geschäftsbehandlung keine Gleichförmigkeit gefunden; welches vorzüglich dem bisherigen Mangel einer Amtsinstruktion, was ich bereits allerunterthänigst erwähnt habe, zuzuschreiben $[Q u 70 / 4]$ ist.

$\$ 163$ [Beschaffenheit des Personals bei denselben und Geschäftsbehandlung ${ }^{756}$ ] Fast überall überzeugte ich mich, daß die assessori und die consiglieri comunali nur Namensträger sind, welche Ersten den ihnen zustehenden Obliegenheiten sich weder unterziehen können, noch es unter keiner Bedingung thun wollen, da weder Ermahnungen, Drohungen, noch Dienstentsetzungen etwas fruchteten, indem sie meistens selbst, unter Versicherung, daß sie die erforderlichen Fähigkeiten nicht besitzen und keine Zeit haben, [gestrichen: um] ohne Besoldung zu genießen sich der Besorgung ihrer Privatangelegenheiten zu entziehen, um ihre Enthebung ansuchen; und diese können wegen Mangel an geeigneteren Individuen auch nur sehr schwer ersetzt werden.

Alle Geschäfte fand ich fast ausscheifend ${ }^{757}$ von den besoldeten Comunal-Secretaeren besorgt, da nur hin und wieder der Podestà mithilft. Dieser Uibelstand ist allerdings nicht unbedeutend, aber nach meiner aller unterthänigsten Meinung erübrigt nichts Anderes zu thun, als erwähnte Ämter um so sorgfältiger von den Präturen und Kreisäm-

und anschließend im übrigen Dalmatien seitens der neuen österreichischen Verwaltung vorgenommen worden waren. Umgekehrt aber ist die zu Cattaro getroffene Ausnahme (ana$\log \mathrm{zu}$ Sonderregelungen im Steuerwesen dieses Kreises und des Kreises Ragusa) auch ein direkter weiterer Beleg für die Schwierigkeiten des Staates selbst bei der formalrechtlichen Durchdringung der Gesamtprovinz. Auf diesen Kreis ausgedehnt wurde die ansonsten seit 1822 gültige Gemeindeordnung im Jahre 1837 (Ivković: Organizacija uprave, 35).

754 Eine Anmerkung, wohl Rossettis, zu diesem Gliederungspunkt unterstreicht die Probleme: »ad 162) nicht gut. - «.

755 Zugleich ein Beleg für die in der Verwaltungspraxis gegebene Eigendynamik der unteren Verwaltungsebenen gegenüber den ursprünglichen allgemeinen Regelungen, hier also über die Abgrenzung der Zuständigkeiten (zwischen Präturen und Gemeinden).

756 Auch hier wieder eine drastisch formulierte Randanmerkung innerhalb der Gliederung: »Unfähig, der Secretär macht alles«.

757 Ausufernd, [zu] weit ausgreifend. 
tern überwachen zu lassen und darauf bedacht zu seyn, solche nach und nach, wie sich angemeßenere Individuen vorfinden werden, zu vervollständigen[.]

[Qu $71 / 1]$

$\$ 164$ [Podesterien der Hauptorte] In Zara, wo die Municipalität am besten bestellt ist, hat man nach dem Austritte des früheren, provisorischen Podestà, Allesani ${ }^{758}$, dieses Amt dem einzigen, bis dahin bekannten, hierzu geeigneten Assessor Cernizza ${ }^{759}$ ebenfalls provisorisch anvertraut; allein dieser hat eben wegen seiner Privatgeschäfte [gestrichen: um] seine Enthebung angesucht und die Landesstelle wird in größter Verlegenheit seyn, einen Nachfolger zu finden, wenn der frühere, welcher inzwischen die Spitals-Direktion provisorisch führt, diesen Posten nicht wieder annehmen wollte.

Die Podestarie in Spalato stand, als ich im verflossenen Jahre hinkam, unter der Leitung des 1.en Assessors Dudan ${ }^{760}$, welcher ein guter aber schwacher [gestrichen: Mann; ergänzt: Mensch] ist. Da ich die Registratur, und die nothwendige ämtliche Evidenzhaltung nicht in der Ordnung, auch keine Indicis fand, so ertheilte ich ihm die entsprechenden Ausstellungen ${ }^{761}$ und Belehrungen und veranlaßte in der Folge die Ernennung eines anderen geeigneten Podesta, Namens Krussevich ${ }^{762}$.

758 Anton (Antonio) Allesani /Alesani, zeitweiliger provisorischer Podestà und anschließend provisorischer Spitalsdirektor von Zara; der Hof- und Staatsschematismus des österreichischen Kaiserhtums 1837 führt ihn 401 dann als »Controlor« des Zaratiner Spitals (in der Schreibung Alesani).

759 Antonio (Anton, Antun) Cernizza, laut Lilienberg also zeitweiliger provisorischer Podestà von Zara. Der Almanacco 1834, 105 führt ihn als »1o assessore in f.f. [funzione] di podestà«, an Stelle des vakanten Podestà-Postens. Sein Wunsch nach Amtsenthebung als Erster Assessor wurde offenbar abgelehnt; der Hof- und Staatsschematismus des österreichischen Kaiserhtums 1837 führt ihn 401 weiterhin als ersten Kommunalassessor von Zara, als provis. Direktor der dortigen Administrations-Gesellschaft der Wohltätigkeitsanstalt und als Präses der Ackerbaukommission.

760 Leonardo (di) Dudan, zeitweiliger provisorischer Podestà (und erster Assessor) von Spalato, später auch regulärer Podestà; 1848 Kommandierender der Spliter Nationalgarde, 1860-64 autonomistischer Landtagsabgeordneter.

$761 \mathrm{Zu}$ verstehen im Sinne von »Rügen «, »Kritik«.

762 [? Vorname nicht eruiert] Krussevich; der Almanacco 1834 nennt ihn nicht. Vermutlich Schwiegervater des späteren langjährigen Bürgermeisters und Spliter Führers der Autonomistenpartei Antonio Bajamonti (über dessen Ehefrau Luigia Krussevich vgl. http://hr.wikipedia. org/wiki/Antonio_Bajamonti [zuletzt 19.11.2013]); im Übrigen ist die Passage ein Beleg für direkte (und ohne vorherige Billigung in Wien) erfolgende Verwaltungseingriffe Lilienbergs im Gefolge seiner Bereisung der Provinz, und geringe Kommunalautonomie.Vgl. aber auch Anm. 769. 
In Ragusa fand ich die Comunal-Verwaltung in genügender Ordnung und erkannte in dem provisorischen Podestà Ghetaldi Gondola ${ }^{763}$, einen, seinem Fache vollkommen gewachsenen Mann.

[Qu $71 / 2]$

Die Podesterie zu Cattaro war in ziemlicher materiellen [sic] Ordnung; der Podesta Iacogna ${ }^{764}$ ist ein von der Bevölkerung geachtetes Individuum von bestem Willen, scheint aber von keiner höheren Einsicht und besonderen Thatkraft; dürfte jedoch immerhin unter den dortigen einer der zu diesem Posten Geeignetesten seyn.

$\$ 165$ [Beschaffenheit der andern einzelnen Comunal Amtern [sic] im Kreise Zara] Das Amt der Comunal Administration von Derniš ist, vorzüglich aus Verdienst des dortigen Comunal-Sekretärs ${ }^{765}$, in sehr gutem Stande, auch hat der Podesta Plencovich ${ }^{766}$ genügende Einsicht.

$\mathrm{Zu}$ Scardona fand ich die Comunal-Registratur in Unordnung und das Amtszimmer neben dem Privatgeschäftszimmer des Advocaten Mera ${ }^{767}$, welcher zugleich Podesta war, und wo er seine Clienten zu empfangen pflegte. Diesem Uibelstande abzuhelfen, ward nach Verlauf seiner Dienstperiode die Wahl eines anderen Podesta veranlaßt.

Im Podesta Fenzi ${ }^{768}$ zu Sebenico erkannte ich einen gebildeten, bei den Einwohnern Einfluß habenden, auch ziemlich thätigen Mann; da er aber Freimaurer war, und in ämt-

763 Sigismondo di Ghetaldi Gondola, provisorischer Podestà (1. Assessor in f.f. di podestà) von Ragusa (Almanacco 1834, 106). Zum Zeitpunkt seiner Erhebung zum Baron (1845) war er (weiterhin) Bürgermeister von Dubrovnik; vgl. die detaillierten Angaben zu ihm und weiteren, vielfach im österreichischen Beamtenstand tätigen Angehörigen der beiden Familienzweige Ghetaldi und Ghetaldi-Gondola http://it.wikipedia.org/wiki/Ghetaldi (zuletzt 19.11.2013).

764 Almanacco 1834, 106 und 1835, 104: Francesco di Jacogna.

765 Almanacco 1834, 107: Casimiro Forlani.

766 Almanacco 1834: Antonio Plencovich (also nicht identisch mit dem von Lilienberg besonders gelobten Prätor von Makarska, Paolo Plencovich/Pavao Plenković).

767 [?Vorname nicht eruiert] Mera bis 1833 Podestà von Scardona (der Almanacco 1834, 108, führt die Stellung des Podestà bereits als vakant auf).

768 Pietro Antonio Fenzi 1831-1833 und dann, trotz seiner gezielten Ersetzung durch Lilienberg, wieder von 1837-1841 und 1848 Bürgermeister von Šibenik. Vgl. Čoralić: Od zapovjednika hrvatske konjice do gorljivih autonomaša - šibenska obitelj Fenzi, 217. Die Autorin versteht ihren Beitrag über die in Norddalmatien reich begüterte Familie Fenzi als Pionierstudie zur Geschichte der diversen einflussreichen, im 19. Jahrhundert vielfach autonomistisch und später italienischnational agierenden Familien, die wegen ihrer wichtigen lokal- und regionalhistorischen Rolle der Vergessenheit entrissen werden sollten (218). Die Arbeit ist in Terminologie und Ansatz aber selbst noch deutlich gefärbt von eben jener traditionellen betont "anti-autonomistischen « Haltung der kroatischen Historiographie, die diese Vernachlässigung solcher Themen hervorgerufen hat. Italienischerseits ist dieses dalmatinische urbane 
lichen Verhandlungen einen unliebsamen Geist hartneckiger Opposition gegen Verfügungen der vorgesezten Behörden bewiesen hatte, so veranlaßte ich die Wahl eines andern [Qu 71 / 3] Podesta nach seinem bereits verflossenen Dienstestriennarium. ${ }^{769}$

In Pago fand ich die Local-Polizei, besonders die Strassenreinlichkeit, schlecht bestellt, und verfügte sogleich die nöthige Abhülfe.

Der Podesta Dominis ${ }^{770}$ von Arbe, ein, seinem Character nach, sehr würdiger und allgemein geachteter Mann war durch seine zerrüttete Gesundheit fast zum Schatten geworden und hatte eben aus dieser Ursache seine Stelle aufgegeben, als ich dort war, und der Assessor Galzigna ${ }^{771}$ an seine Stelle getreten, welcher, ungeachtet seiner geringen Einsichten, weil Einige, die vielleicht besser taugten, die Stelle durchaus nicht annehmen wollten, belassen werden muß. -

Da [ergänzt: ich] die alten Acten dieses Amtes, besonders aber die bis ins 12. Jahrhundert reichenden Pergamente in großer Unordnung und Verwahrlosung, dann viele Rückstände in schweren Polizei Uibertretungen daselbst traf, so erließ ich eine ausdrückliche Weisung diesfalls an die Comune und veranlaßte die Absendung eines Präturs Beamten dahin, um ihre endliche Aufarbeitung [die der aktuellen Verwaltungsakten, K. C.] zu bewirken.

$\$ 166$ [Beschaffenheit der Kommunalämter im Kreis Spalato] Der Podesta zu Trau, de Grazio $^{772}$, hält sein Amt in Ordnung, aber seine Moralität ist unter aller Critik. Ich habe ihn

und Oberschichtsmilieu hingegen bereits einige Male untersucht worden. Siehe insbesondere ausgewogen und inhaltsreich (für die 2. Hälfte des 19. Jahrhunderts) Monzali: Italiani di Dalmazia. Epochenübergreifend und im Einzelfall nützlich, jedoch seinerseits übermäBig national(historisch) ausgerichtet ist das jüngste Nachschlagewerk von Garbin / de' Vidovich: Dalmazia Nazione. Dizionario degli Uomini Illustri della componente culturale illirico-romana, latina, veneta, italiana (auch unter http://www.dalmaziaeu.it/dalmazianazione. pdf, 22.4.2014). De' Vidovich schreibt z. B. im Vorwort, 9, von wiederholten Denationalisierungsschüben, die aus der ursprünglichen Mehrheit eine kleine Minderheit gemacht hätten, was die dalmatinische Geschichte von der Antike bis heute für diese Fragestellung irreführenderweise in ein »nationales« Kontinuum bringt.

769 Wieder eine direkte administrative Folge der Bereisung, hier in Sachen Bürgermeisteramt von Šibenik; und im für den Vormärz typischen Umgang mit oppositionellen Haltungen (Freimaurerbekämpfung). Auffallend ist aber das Streben nach Unauffälligkeit dieses Eingreifens (die reguläre Amtszeit ließ Lilienberg verstreichen), und genauso die der vorstehenden Anmerkung zu entnehmende Wiedererlangung des Amtes eben durch den unliebsamen Fenzi im Jahr 1837, noch zu Dienstzeiten auch Lilienbergs. Der Almanacco 1834, 107, führte dagegen Girolamo Dominis als (neuen) Bürgermeister von Šibenik.

770 [? Vorname nicht eruiert] Dominis, bis 1832 oder 1833 Bürgermeister des Inselortes Arbe.

771 Girolamo Galzigna, vormals Assessor, dann Bürgermeister von Arbe (als letzterer geführt im Almanacco 1834, 108).

772 Coroliano de Grazio / di Grazio, wird noch im Almanacco 1834, 109 als Bürgermeister von Trau geführt. 
sehr ernstlich ermahnt [Qu $71 / 4]$ und weil er sich nicht bedeutend [gestrichen: gebessert hat; ergänzt: besserte], so hat das Gubernium bereits verfügt, daß zur Wahl eines andern Vorstehers für diese Gemeinde geschritten werde.

Die Comunal Ämter von Sign und Macarsca traf ich in ziemlicher Ordnung.

Die Comune von Almissa hatte einige alte ungarische Dokumente, deren Originalien der Graf Klobuschitzky und eigentlich der Dr Fister, im Jahr 1817 mitgenommen haben soll. ${ }^{773}$

Die Syndacate des Kreises Spalato fand ich wie die meisten anderen der Provinz, wegen Mangel an tauglichen Leuten zum Gemeinde-Vorsteheramte, nicht zum Besten bestellt, und alle Geschäfte ausschließend durch den Sindacats-Actuär besorgt, welcher durch keinen Eid gebunden und ein, alle Augenblicke ammovibler ${ }^{774}$, Privatbeamter des Sindaco ist.

In Much war der größte Theil der Registratur in voller Unordnung in mehreren Winkeln des Dachbodens den Einflüßen der Witterung und dem Verderben ausgesetzt, worüber ich einen eingreifenden Verweis dem Sindacus ${ }^{775}$ ertheilte und die sogleiche $\mathrm{Ab}$ stellung dieses Uibelstandes verfügte.

[Qu 72 / 1] Der ${ }^{776}$ Sindacus von Clissa bei Spalato hielt sein Land ziemlich in Ordnung, doch erlaubte er sich, den Weg vom Dorfe aus zu seinem Hause willkürlich durch Factio-

773 Vermutlich Joseph von Klobuschitzky. Schmitt: Österreichs Blick auf das französische Dalmatien, nennt den Geheimen Rat und Zivilhofkommissär Joseph von Klobusiczky als den verantwortlichen Leiter der Räumung des »ungarischen Litorale« im Zuge von dessen Übergabe an die Franzosen 1809. Der Vorgang selbst mit der mutmaßlichen Entnahme von »ungarischen Akten«, also vermutlich die Rechtsbeziehung von Omiš bzw. Dalmatiens mit dem mittelalterlichen Ungarn betreffend, ist vor dem Hintergrund einer österreichischen Geschichtspolitik zu betrachten, die derartigen Akten einen eventuell störenden Einfluss auf die cisleithanischen Herrschaftsrechte in Dalmatien beimaß und die Dokumente daher möglichst unauffällig nach Wien verbringen ließ. Für einen solchen Fall aus dem Frühjahr 1832 unter Involvierung Lilienbergs und des ungarischen Historikers János Majláth s. Clewing: Staatlichkeit, 146f. Wurzbach: Biographisches Lexikon, Bd. 16, 63, erwähnt s.v. Kovachich, Joseph Nikolaus vermutlich eben jenen Joseph von Klobuschitzky als Obergespan des Komitats Borsod. Mit dem Dr. Fister ist mutmaßlich der württembergische Theologe und Historiker Johann Christian Pfister gemeint, der nach dem Wiener Kongress offenbar über Jahre hinweg in Wien in amtlichem Auftrag Archivbestände durchforstete (vgl. dazu in der Allgemeinen Deutschen Biographie, Bd. 25 [1887], hier nach http://de.wikisource.org/wiki/ ADB:Pfister,_Johann_Christian, zuletzt 22.4.2014). Pfister war damals vermutlich schon wegen seiner 1830 bis 1835 erschienenen fünfbändigen »Geschichte der Deutschen« Lilienberg und seinem kaiserlichen Adressaten Begriff genug, um im Text nur als »der Dr. Fister« angesprochen werden zu müssen.

774 Wohl zu verstehen als »aus seinem Amt entfernbar«; vgl. französisch amovible: absetzbar.

775 Almanacco 1834, 108: Sebastiano di Cambj [Cambi], sindaco von Much.

776 Randergänzung des ganzen folgenden Absatzes mit schwarzer Tinte, in Reinschrift (Seite 110) übernommen. 
nisten $^{777}$ unentgeltlich herstellen zu lassen, weshalb ich denselben, nach eigenem Augenschein und Vernehmung der Bauern, einen strengen Verweis ertheilte und eine ämtliche Verhandlung hierüber veranlaßte, um ihn zur Ersatzleistung zu verhalten. ${ }^{778}$

Die Sindaci der Castelli von Trau können gar nicht lesen und schreiben und man vermag sie auch nicht durch Tauglichere zu ersetzen ${ }^{779}$. Da man in loco auch keine geeigneten Actuare aufzufinden im Stande ist, so befinden sich mehrere dieser Lezten im Präturs Hauptorte vereinigt und senden die zu erstattenden Berichte von dort aus den Sindaci, welche ihr Kreutzzeichen beisetzen und die Amtsschriften sodann an die Behörden einsenden. Ein Ähnliches hat auch bezüglich [ergänzt und wieder gestrichen: aller; gestrichen: mehrerer kleinen Comunen; endgültig ergänzt: den Landcomunen] des Kreisbezirkes Cattaro statt da 7 derselben ihren Actuar im Kreishauptorte haben, weil ${ }^{780}$ alle Menschen von einiger Bildung, deren es in jenen Orten nicht mangelt, sich der Navigatur, dem Handel und einträglicheren Beschäftigungen widmen.

$\$ 167$ [Beschaffenheit der Kommunalämter in den Kreisen Ragusa und Cattaro ${ }^{781}$ ] Der wenig befriedigende Zustand, in welchem ich die Comunal-Ämter von Curzola und besonders von Ragusa vecchia fand, veranlaßte mich zu der Anordnung, daß die Präturen dieselben öfter untersuchen sollen.

Im Kreise Cattaro halten die Comunen außerordentlich auf ihre alten Privilegien und sie würden selbe, welche besonders in gewissen Benennungen und äußeren Auszeichnungen bestehen, sehr ungern verlieren, so wie ich es in dem oberwähnten Berichte an die $\left[\mathrm{Qu} 72\right.$ / 2] Hofkanzlei angedeutet habe ${ }^{782}$.

Das Comunal Amt in Budua fand ich zu meiner Zufriedenheit. Der bei derselben angestellte Secretaer Berdar ${ }^{783}$ ist ein Mann von Geist, Einsicht und Bildung; die ganze

777 Hier wohl zu verstehen als ihm untergebene Angehörige seiner Gemeinde.

778 Also erfolgten auch gegen Vorteilsnahme bzw. Amtsmissbrauch durch Amtsträger Maßnahmen noch direkt auf der Reise. Zu verhalten = zu veranlassen $/ \mathrm{ihn}$ dazu anzuhalten. Sincaco von Klis war laut Almanacco 1834, 108: Luca Tarboglan.

779 Diese anscheinend analphabetischen Sindaci der diversen Kaštel bei Split waren laut dem Almanacco 1834 (108f.): Tomaso Gercich (Castel Cambio), Simeone di Michieli Vitturi (Castel Vitturi; der aber nicht gemeint gewesen sein kann, da gewiss kein Analphabet; vielleicht aber sein ebd. genannter, vermutlich eigentlich amtsführender Vize-Sindaco Antonio Matiazza) und Giovanni Vuletin (Castel Nuovo).

780 Der Rest des Absatzes ist am Rand mit Tinte eingefügt und in sich einmal mit Tinte und einmal mit Bleistift korrigiert.

781 Randanmerkungspunkte innerhalb der Gliederung: »ad 167) In Cattaro wird das neue Comunal- Sistem viele Schwierigkeiten haben Privilegien. In Budua: Berdar.»

782 Vgl. Lilienbergs Darlegungen in $\$ 161$; der Verweis gilt dem Dokument Z 871/p Gouverneursbericht an die Vereinigte Hofkanzlei vom 1.10.1833 (siehe oben).

783 Nicolò Berdar, Kommunalsekretär zu Budua. Er hatte sich wohl Ende 1832 in einem persönlichen Gesuch an Kaiser Franz gewandt, in dem er diesen laut Wiedergabe durch den Vorsitzenden der Polizeihofstelle Josef Graf Sedlnitzky »um die allergnädigste Nachsicht [betreffend] 
Bevölkerung des Hauptortes und das gesammte Landvolk der Pastrovichier Gemeinde, so wie die wilden Stämme von Pobori ${ }^{784}$, Maini ${ }^{785}$ und Braichi, deren Comunal Geschäfte er versieht, sind ihm so äußerst zugethan, daß sein persönlicher Einfluß, den er aber mit Eifer zum Besten des Allerhöchsten Dienstes anwendet, Beachtung verdient. Ich muß daher bedauern, daß selber ${ }^{786}$ einst der Freimaurerei ${ }^{787}$ angehörte, obgleich er nur Apprenti war und auch eine außerordentliche Reue zeigte, daß er eben in der Epoche, als diese Secte gleichsam zum Anstande der Beamten gehörte, nicht die Folgen hinlänglich überlegt habe.

Da er [gestrichen: nach den von mir gemachten Erfahrungen sich; Randergänzung mit Tinte in Rossettis Schrift bis inklusive »seither «]: wie ich vernahm sich von General Milutinovich ${ }^{788}$ bei dem Wiedereintritte der kk. Armee mit Vortheil verwenden ließ, sich bei der Pest im J[ahre] 1815 im Lazzarethe zu Ragusa auszeichnete und seither in jeder Beziehung tadellos benimmt, auch der Regierung [Qu 72 / 3] durch Auskundschaftung der Montenegriner Verhältnisse wesentliche Dienste leistet, so glaube ich allerunterthänigst darauf antragen zu können, daß dieser, ohnehin durch sonst Niemanden ersetzbare Comunitaets-Beamte noch ferner belassen werde.

den ihm anklebenden Makel der Theilnahme an der unter der vormaligen französisch-italienischen Regirung dortlands bestandenen Secte der Freimaurer gebeten. [Absatz] Diese ohne der allerhöchsten Bezeichnung an mich gelangte Gesuch erlaube ich mir in der Nebenlage Eurer Euxcellenz mit der Bitte zu übersenden, solches hiernach abweislich zu erledigen, übrigens aber denselben um so eindringlicher hinsichtlich seiner Haltung und seines Benehmens im Auge halten lassen zu wollen, als die über denselben in früheren Jahren erlangten politischen Notizen ihn als einen sehr verschlagenen, gewandten, auf die gemeine Volksklasse einwirkenden, somit nicht unbedenklichen Mann schildern.« DAZd, Tajni spisi namjestništva, sv. 13, Sedlnitzky an Lilienberg, Wien 9.1.1833, liegt in 29/G.P. 1833.

784 ON / TN Pobori: ein Dorf nahe von Budva.

785 ON / TN (Landschaftsname) Maini / Maini: Ansiedlung(en) nord-nordöstlich von Budva (Kreis Cattaro). Die Kleinregion besteht aus den Orten Maini (Maini di mezzo) und Podmaine (Maini inferiore).

$786 \mathrm{Zu}$ verstehen als »der selbige«, »derselbe« (Berdar).

787 Ein Beleg sowohl für die Politik der Freimaurerbekämpfung, als auch für innerhalb derselben bei besonderen Verdiensten staatlich offerierte »mildernde Umstände«; darunter in diesem Fall nicht zuletzt eine Art "nachrichtendienstliche« Bedeutung gegenüber den Montenegrinern.

788 General Theodor Freiherr Milutinovich von Millovsky und Weichselburg (nobilitiert 1796, Freiherrr seit 1815), aus Syrmien stammender kommandierender General bei der Wiedereroberung Dalmatiens (Süddalmatiens) 1813/14; s. http://www.napoleon-series.org/research/ biographies/Austria/AustrianGenerals/c_AustrianGeneralsM.html\#M50, zuletzt 9.12.2013. 
Die Gemeindevorsteher von Perzagno ${ }^{789}$ und Perasto ${ }^{790}$ sind gebildete und vermögliche Männer.

In Risano traf ich den braven Gemeinde Sekretär [ergänzt: Columbarich ${ }^{791}$ ] welcher der einzige Catholik daselbst ist, [gestrichen: aus Rache] von dortigen nicht unirten Griechen schwer verwundet; wozu zwei eingezogen ${ }^{792} \mathrm{u}$. dem Crim[inal] Gerichte übergeben worden sind. Ich richtete meinen ersten Besuch an denselben, belobte seinen Diensteifer, stärkte und ermuthigte ihn durch freundliche Rede; an die öffentlich versammelte Gemeinde richtete ich aber eine ernste, eingreifende und so weit es nöthig war, drohende Ermahnung, welche tiefen Eindruck machte und ein sodann ruhiges Benehmen jener Gemeindebewohner zur Folge hatte.

$\$ 168$ [Die Capi Villa] Die größte Zahl der Capivillas Dalmatiens können nicht lesen und schreiben ${ }^{793}$; [Qu 72 / 4] wenn ihnen die geschriebenen Verordnungen der Ämter zukommen, wenden sie sich daher an die Seelsorger und lassen sich [durch; K.C.] dieselben, so gut als die auch sehr beschränkten Geisteskräfte der Landgeistlichkeit es gestatten, deren Inhalt erklären. Ich fand daher bei vielen Geistlichen einen Haufen von Verordnungen und gedrukten Circularien liegen, welche eigentlich zur Registratur der Comunal-Vorsteher gehören.

Daß hieraus eine in allen Theilen vollkommene Verwaltung der Comunen und durchaus entsprechende Ausführung der höheren Weisungen noch nicht hervor gehen können, ist nicht zu läugnen; allein dieses hat Dalmatien mit allen Provinzen gemein, wo das Volk auf einer niedren Culturstufe stehet und ein neues Verwaltungssistem erst nach und nach allseitig und gehörig aufgefaßt, begriffen und ins Leben eindringend gemacht werden kann.

Wenn ich aber allerunterthänigst bemerkte, daß ich die Amter [sic] mehrerer [Qu 73 / 1] [gestrichen: Gemeinden; ergänzt: Com(munal) Administr(atione)n] in genügender Ord-

789 ON Perzagno / Prčanj; Ansiedlung nnw. von Kotor; Gemeindevorsteher (capo comunale) war laut Almanacco 1834, 115: Bernardo Lazzari.

790 ON Perasto / Perast: Ansiedlung nw. von Kotor; Gemeindevorsteher (podestà) war laut Almanacco 1834, 114: Vincenzo Crillovich.

791 [? Vorname nicht eruiert] Columbarich, Gemeindesekretär von Risano; der Almanacco 1834, 115 verzeichnet für Risano (Posten des Podestà war vakant) mehrere Aggiunti, aber nicht den Gemeindesekretär.

792 Hier zu übersetzen als »festgenommen, arrestiert«.

793 Ein Ausdruck des fast vollständigen Analphabetismus auf dem Lande, nämlich selbst bei Dorfvorstehern (weit über die in $\$ 166$ hierzu erwähnten Sindachi der Castelli bei Split hinaus), und zumindest funktional teils auch bei den Landgeistlichen. Zugleich ist die Stelle ein eindrücklicher Beleg für die von der Verwaltung auf dem Lande gezielt hergestellte Vermengung der Institutionen zur Gemeindeverwaltung und der katholischen Pfarrgemeinden. Vgl. Clewing: Staatlichkeit, 110-112. 
nung fand, so verstehe ich hierdurch nur die Behandlung der Acten, die Erledigung, Evidenzhaltung derselben und die Einrichtung des Amtes selbst.

Die eigentlichen Interessen der Gemeinden, wozu ich die zweckmäßige Befriedigung ihrer nothwendigen Bedürfnisse, das Vorhandensein aller hierzu erforderlichen Hülfsmittel und Anstalten rechne, habe ich in fast allen Hauptzweigen sehr mangelhaft bestellt gefunden.

$\$ 169$ [Vermögensstand der Gemeinden] Der Hauptgrund hiervon liegt in dem Umstande, daß die wenigsten Gemeinden ein eigenes Vermögen haben, indem nur die Comune Arbe [ergänzt: im Kreise Zara mit 1099 Gulden 27 Kreuzern, S. Giorgio di Lesina mit 336 Gulden 7 Kreuzern, Verbosca ${ }^{794}$ zu Lesina mit 108 Gulden, Jelsa zu Lesina [ergänzt: im Kreise Spalato] mit 197 Gulden, Perasto mit 522 Gulden 5 Kreuzern und der Conta$\mathrm{do}^{795} \mathrm{im}$ Kreise Cattaro mit 174 Gulden Einkommenssteuer die eigenen Administrations Auslagen zu bestreiten vermögen.

$\$ 170$ [Ehemaliger Genuß der Octrois und jetziger Dazio consumo] Die vorige Regierung ${ }^{796}$ hatte aus diesem Grunde den Stadt- und Landgemeinden den Genuß der Octrois überlassen, welche sie nebst den Artikeln, die solchen Abgaben unterworfen [Qu $73 / 2]$ wurden, nach dem jährlichen Bedarfe selbst bestimmten, so daß sie bald mehrere bald wenigere Gegenstände mit Centimen-Zu- oder - Abschlag belegten und auf diese Art ihre jedesmaligen Erfordernisse decken konnten.

Mit Central-Organisirungs-Hofdekret von 7 Juni 1815 Z 11692/1427 wurden diese Octrois aufgehoben, der Consumo-Zoll eingeführt und für den Staatsschatz behoben, und nur in so weit als subsidiar-Quelle für die Stadtgemeinden erklärt, als deren eigenes Einkommen nicht hinreicht und die Octrois ihnen meist [am meisten; K. C.] eintrugen.

Hierbei ward die Hauptbasis: der reelle unumgängliche Bedarf der Gemeinden ganz außer Acht gelassen, welcher zur Zeit der Octrois jährlich wechselnd war, [und] immer noch wechselnd aber von ganz anderer Art ist, weil der beträchtliche Unterschied ein-

794 ON Verbosca / Vrboska: Ansiedlung ostnordöstlich von Hvar (auf der Insel Hvar).

795 TN Contado im Kreis Kotor: eine sichere Lokalisierung war nicht möglich, vermutlich aber ist die Gemeinde Župa gemeint, für die Petter: Dalmatien, Bd. 2, 259 außer der Bezeichnung Garbaglie (d.i. Grbalj) auch »Le quattro Contee (die vier Knescinen)« angibt. Mit der Verortung in dieser armen Gemeinde ließe sich auch das angegebene sehr geringe Aufkommen an Einkommenssteuer gut in Einklang bringen.

796 Gemeint ist die französische zur Zeit der Illyrischen Provinzen, deren Maßregeln für die Gemeindefinanzen hier also bemerkenswert offen und in mindestens punktuellem Widerspruch zu der in manchem eher rhetorischen Verdammung zu Beginn der Landesschilderung hoch gelobt und von Lilienberg denjenigen der Wiener Regelungen weit vorgezogen werden! Vgl. (neben kritischen Stellen) positiv wertend zu einer Maßnahme aus der Zeit der Illyrischen Provinzen auch oben, in $₫ 145$ zu Poljica. 
tritt daß dermalen ${ }^{797}$ ein vollkommenes aber unendlich [Qu 73 / 3] complicirteres Verwaltungssistem besteht, welches in allen Zweigen und in dem Zustande der Comunen einen weit höheren, ungleich vollendeteren, Zustand hervorzurufen und zu begründen die Bestimmung hat; daß ungeachtet dessen nicht mehr ein, nach dem Erforderniße wechselndes, Quantum der Befriedigungsmittel gestattet ist, sondern, nach einem Durchschnitte des reellen Ertrags der ehemaligen Octrois im Maximum stabil sein, und die Landcomunen ganz leer ausgehen sollen, demnach zu Grunde gehen [gestrichen: sollen; ergänzt: müssen] $]^{798}$.

Um das mit Allerhöchster Entschließung von 4 Maj 1821 genehmigte Comunalsistem in Ausführung bringen zu können und auch die darin bezeichneten Gemeinden, die nicht in Städten wohnen ${ }^{799}$, mit Ämtern zu versehen, war die Landesstelle jedoch genöthiget, auch diesen wenigstens so viel aus dem Dazio consumo anzuweisen als die Erhaltung jener Ämter [Qu 73 / 4] erforderte. -

Bei jenen Maximen wurden zwar am Dazio Consumo seit 1815374135 Gulden erspart, welche in die Cameral-Casse geflossen sind. Allein ${ }^{800}$ die Comunen drohen eben deshalb mit schnellen Schritten ihrem Verfalle entgegen zu gehen.

$\$ 171$ [Höchst nachtheilige Folgen für die Gemeinden, das Land und den Staat wegen des gesunkenen Vermögensstandes der Comunen ${ }^{801}$ ] Es fehlen fast überall die zur Erhaltung der Gesundheit unentbehrlichen Vorkehrungen und die nöthigen Gemeinde-Arzte [sic], die Localaufsicht und Localpolizei sind im höchsten Grade verwahrlost; es mangeln [gestrichen: überall] die nöthigen Gemeinde Polizeiagenten, in fast allen Orten die nöthigen Vorkehrungen gegen Feuersgefahr. ${ }^{802}$ [Ergänzt: Mehrere] Beschädigte Häfen und ausgerissene Ufer können nicht hergestellt werden. An sehr vielen Orten ist peinlicher Wassermangel, woraus Krankheiten unter Menschen und Vieh entstehen; es gebricht an den nöthigen Brunnen oder Wasserleitungen, sogar wo sie leicht sein könnten, wie in Zara,

$797 \mathrm{Zu}$ verstehen wie »heutzutage«, »gegenwärtig«.

798 Der ganze voranstehende Paragraph bietet also harsche Kritik am österreichischen System der Gemeindefinanzen und an der Nichtbeachtung von verwaltungstheoretischen Grundsätzen bzw. an grundsätzlichen Mängeln der zentralisierenden und dabei allein auf die (zentrale) Staatskasse fokussierten Wiener Praxis in Dalmatien. Daraus folgten zum Ausgleich, wie Lilienberg im Weiteren eingesteht, in seiner Praxis Notmaßnahmen (unter Selbstermächtigung) der Landesebene.

799 Gemeint ist wohl: Gemeindeämter, die nicht in Städten ihren Sitz haben.

800 »Allein« im Sinne von: »jedoch«.

801 Wie wichtig dieser Punkt im Umfeld Lilienbergs galt, belegt die groß geschriebene Randanmerkung Rossettis zum betreffenden Gliederungspunkt: »ad 171 Höchst wichtig!«, mit fünffacher Unterstreichung! Davon deutlich abgesetzt folgt eine weitere Anmerkung mit Angabe der in diesem Paragraphen als Argument angeführten hohen Ausgaben für die aufwendigen Wasserlieferungen in Zara.

802 Vgl. auch die detaillierteren Schilderungen Lilienbergs in $\$ 208$. 
wo zu der, hohen Orts empfohlenen, Ersparung der [Qu 74 / 1] dießfälligen Auslagen von 24608 Gulden 54 Kreuzern, in trokenen Jahreszeiten für Wasserzufuhren seit 182036410 Gulden $271 \frac{1}{4}$ Kreuzer, im laufenden Jahre allein schon 10400 Gulden ausgegeben worden sind. ${ }^{803}$ Die Armenanstalten in den Hauptorten sind dürftig; auf dem Lande meistentheils bestehen sie gar nicht oder dem Nahmen nach. [gestrichen: Eine Menge] [h] Höchst nöthige[r] Gemeindestraßen bleiben unausgeführt. Die Errichtung der Elementarschulen ist wegen Armuth der Gemeinden auf dem Lande im Stocken, was doch hier bei dieser gänzlichen Verwahr[gestrichen: -lässigung; ergänzt: -losung] der Bewohner und bei dem Umstande, daß man von der eben so rohen Geistlichkeit erst nach dem Absterben [gestrichen: der jetzigen Seelsorger; ergänzt: dieser (Geistlichkeit, K.C.)], auch [gestrichen: in dieser Hinsicht] einen besseren Erfolg wird hoffen können von höchster Wichtigkeit für den Staat und das Land ist ${ }^{804}$. Die meisten Landkirchen und Pfarrhäuser sind im elendesten Zustande. Die Nichtbezahlung der Gemeindebothen erzeugt einen lästigen Factionsdienst u.a.m. [und anderes mehr.]

Von welchen höchst nachtheiligen Folgen [Qu 74/2] alles dieses seyn müsse, bedarf ich nicht auseinander zu setzen; so wie, daß durch die Verschiebung der meisten von den angeführten Vorkehrungen oder Anstalten in der Folge der [ergänzt: Erforderniß; gestrichen: Bedarf] unverhältnißmässig stärker werden muß.

Ungeachtet [gestrichen: vieler] wiederholter dießfälligen [gestrichen: Vorstellungen; ergänzt: Darstellungen des Guberniums] haben die Hofstellen jedoch stets darauf gedrungen, die oberwähnten im Jahre 1815 aufgestellten Grundsätze genau zu beobachten und den Landcomunen ja nichts mehr aus dem Dazio Consumo anzuweisen; die Landestelle hat aber, um das Gemeindewesen nicht einer gänzlichen Zerrüttung auszusetzen, sich verpflichtet gehalten, [gestrichen: selbe; ergänzt: seine ehrerbietigen Vorstellungen] unter dem 2. April 1. Js. Z. 5067 zu wiederholen.

Da die Eröffnung eines genügenden Einkommens für die Gemeinden nach der Entziehung des Octrois eine der dringendsten und wichtigsten Angelegenheiten dieser Provinz ist, und so lange die Agrikultur, der Handel und andere Industriezweige sich nicht zu einem höheren [Qu 74 / 3] [Qu 74 / 4 fehlt in der Zählung, aber nicht inhaltlich] Grade erheben, immer bleiben wird, so hoffe ich Entschuldigung zu finden, wenn ich selbe

803 Die Zahlen waren gemäß Randanmerkung zunächst bei der Buchhaltung erhoben und von dort mit Bleistift nachgetragen worden. Lilienbergs auch sonst wiederkehrende Kritik an auch finanzpolitischer Irrationalität des von Wien vorgegebenen Verwaltungsgebahrens erreicht hier in $₫ 171$ einen Höhepunkt.

804 Wiederum heftige Grundsatzkritik an der österreichischen Verwaltungspolitik, hier speziell zu den von Lilienberg (zurecht) als für eine bessere Zukunft des Landes überaus bedeutend angesehenen Volksschulen (vgl. \$ 136), die in den meisten armen Gemeinden unter den gegebenen Umständen nicht möglich waren. 
hiermit dem Vaterherzen Eurer Majestät in tiefster Unterthänigkeit wärmstens zur allergnädigsten Bedachtnahme zu empfehlen wage. ${ }^{805}$

[Qu 75 / 1]

Praeturen

$\$ 172$ [Politische Präturen ${ }^{806}$ ] Rücksichtlich der politischen Präturen, welche in den vier Hauptorten der Provinz in Folge allerhöchster Erschließung vom 16 November 1830 ihre selbständige Existenz erhielten, habe ich nachstehende Bemerkungen zu machen Gelegenheit gehabt.

Sie waren seit ihrer Activirung oft in Rückständen [bei der Bearbeitung ihrer Obliegenheiten; K. C.]; woran größtentheils die Unverhältnißmäßigkeit ihres provisorischen Personals, welches aus einem Prätor, einem Actuär und einem Schreiber bestehet, vergleichsweise zu ihren Geschäften Schuld ist.

Besonders bemerkbar erscheint in dieser Hinsicht jene von Zara, welcher man bisher fast immer eine Personalaushülfe zuwenden mußte, damit der allerhöchste Dienst und die öffentliche Sicherheit nicht durch die außerordentliche Menge von Rückständen gefährdet werden.

Die Größe des Bezirks mit einer Seelenzahl von 35054 Einwohnern, dann die Hauptstadt der Provinz, erzeugen für selbe [die Prätur Zara, K.C.] eine besondere Geschäftsmenge, und schon die Beobachtung, daß dieselbe jährlich im Durchschnitte [ergänzt und wieder gestrichen: bei $\left.{ }^{807}\right] 600$ schwere und andere Uibertretungen in Verhandlung hat und im v[origen] Jahre diese bis auf 800 stiegen $^{808}$, überdieß 5 bis 7000 Actenstücke jährlich von ihr zu erledigen sind, liefern den Beweis, daß zwei Concepts Beamte allein, wovon der Eine, nämlich [Qu 75 / 2] der Prätor fast den ganzen Tag mit Abhörung ${ }^{809}$ der Partheyen beschäftiget ist, diese Geschäftslast unmöglich aufarbeiten, und daß ein

805 Ein erneuter Appell Lilienbergs, das kaiserliche Landesvatertum in der Praxis spürbar zu machen, und an einen Positionsbezug des Monarchen im Konflikt des Guberniums mit den Hofstellen. Diese Passage war hier auf eigenem Ergänzungsblatt eingefügt.

806 Hierzu zwei Randanmerkungen Rossettis zum Gliederungspunkt: Anmerkung im Original: »ad 172 Für Zara eine Personalvermehrung höchst nothwendig: 600 Prozeduren und 7000 Acten jährlich. [Absatz]: Vorschlag für diesen Prätoren Posten [Zara] 24. April 1833 Z. 4692 von E[uerer] E[xcellenz] an S. M. am 16. Jänn[er] 1[aufenden] J[ahres] « Die Doppelung von Anmerkungen unterstreicht zum einen die Bedeutung, die der Argumentation zur Dringlichkeit des Personalaufwuchses beigemessen wurde. Zum anderen waren im Zuge der vorliegenden Edition gerade diese Stellen eine genügende Basis dafür, die Handschriften auch bei den Gliederungsanmerkungen zuzuordnen: diese Anmerkungen stammten weit mehrheitlich von Rossetti.

$807 \mathrm{Zu}$ verstehen im Sinne von »ungefähr«.

808 Siehe dazu auch weiter unten, $\$ 217$.

809 Das vom Schreiber notierte »Abhörung « wurde in anderer Schrift (vermutlich von Lilienberg selbst) in »Anhörung « korrigiert, was wieder für den Diktatcharakter der Textentstehung spricht. 
Schreiber, wenn auch durch einen Praktikanten ${ }^{810}$ unterstützt, zu allen Kanzleiarbeiten nicht genügen könne.

Sehr viele Schwierigkeiten giebt es in dieser Hinsicht wenn nicht in so hohem Grade, doch auch bei den übrigen drei polit[ischen] Präturen. Gelegenheitlich meiner Bereisung fand ich bei jener zu Cattaro noch 247 schwere Polizei-Uibertretungen, in Ragusa 69, in Zara waren über 120 Proceduren unerledigt; nur die Prätur von Spalato hatte die früher beträchtliche Zahl der eigenen Rückstände in der lezten Zeit durch besondere Anstrengung des Prätors Griesz ${ }^{811}$, den ich für die Prätur von Zara bestens in aller Unterthänigkeit empfohlen habe ${ }^{812}$, unterstützt durch Hülfsbeamte, aufgearbeitet.

Allein, über Antrag des Guberniums, das Personale dieser Präturen zu vermehren, verordnete die vereinte Hofkanzlei noch ehe [ergänzt: bei denselben] die Rückstände aufgearbeitet werden konnten, nämlich mit 1. Oktober v[origen] J[ahre]s alle ihre Hülfsbeamten zu entfernen ${ }^{813}$, um, nach [Qu 75 / 3] Beobachtung der Thätigkeit des ursprünglich festgesezten Personals, sodann die Anträge zur Sistemisierung desselben [ergänzt: zu] würdigen [gestrichen: zu können].

Nach wiederholten Vorstellungen ertheilte sie mir aber unter dem 16. November v[origen] J[ahre]s die Vollmacht, alle nothwendigen Mittel anzuwenden, um sämmtliche

810 Praktikanten waren sehr gering entlohnte Angehörige der Bürokratie ohne Beamtenstatus, in der Regel jüngere Beamtenanwärter; vgl. zu ihrer Zahl Clewing: Staatlichkeit, 90 f. sowie Heindl: Gehorsame Rebellen, 2. Auflage, 181 zum Begriff.

811 Almanacco 1834, 96 unter: Edoardo Griez di Ronse, pretore nel Circolo di Spalato. Almanacco 1830, 102 nennt ihn noch als Allunno di concetto im Kreisamt Ragusa. In den 1840er Jahren war Eduard Griesz (auch Griez) Kreishauptmann von Kotor, im Neoabsolutismus stieg er zum Vizepräsidenten der Statthalterei Temesvar auf (http://www.theeuropeanlibrary.org/ tel4/newspapers/issue/3000051862775, Agramer Zeitung Nr. 94 v. 25.4.1854; 1.8.2014) und wurde in noch späteren Jahren offenbar Mitarbeiter im k. u. k. Außenamt.

812 Der Vorgang war ein weiterer Konfliktfall zwischen Lilienberg und den Wiener Stellen, hier der Hofkanzlei. Dies ist einigen Schreiben zu entnehmen, die in DAZD, Tajni spisi namjesništva, sv. 13 (1833) zugeordnet zu einem Handschreiben von Franz I. an Lilienberg vom 24.12.1833 liegen. Darunter findet sich ein Vortrag der Hofkanzlei an den Kaiser Nr. 647 vom 17.5.1833 mit Kritik am Auswahlgebahren des Guberniums in Sachen Prätorsbesetzung Zara. Die Stelle war schon eine Weile unbesetzt; der Kaiser hatte laut Vortrag mit Handschreiben vom 15.11.1832 bestimmt, dass die Stelle nicht der dalmatische Gubernialkonzipist Kutschig (Carlo Kutschig; 1834 Vizesekretär des Guberniums, laut Almanacco 1834, 82) erhalten und sie neu ausgeschrieben werden sollte. Dies trug die Hofkanzlei dem Gubernium auf, das nun aber in der Folge nach Meinung der Hofkanzlei einen formal ungeeigneten Tertialvorschlag [ohne Griesz, der sich offenbar nicht offen beworben hatte] erstellt hatte. Mit 24.12.1833 fragte nun aber der Kaiser Lilienberg um dessen Meinung über den in Vorschlag gebrachten Griesz. Mit Schreiben vom 16.1.1834 an den Kaiser unterstützte Lilienberg mit Nachdruck Griesz für diese Prätur, (»die in jeder Hinsicht bedeutendste, auch ist sie die größte in Dalmatien«). Mit kaiserlicher Resolution vom 16.10.1834 wurde Griesz bestimmt.

813 Ein weiterer Konflikt Lilienbergs bzw. seiner Landesverwaltung mit Hofstellen, hier der Hofkanzlei. 
polit. Präturen bis Ende März l. Js. von allen Rückständen zu reinigen und sodann, nach einer 6 monatlichen Beobachtungszeit, die ferneren Anträge zu erstatten.

Innerhalb dieser Frist waren die Präturen auch wirklich von allen Rückständen frei, allein, die neuerlich anbefohlene Entfernung aller Aushülfsbeamten konnte nichts anderes als die Wiedererzeugung von Rückständen zur Folge haben, welche in Zara bereits die Zahl von 137 Proceduren und in Spalato 73 Stücke, worunter 32 Proceduren, erreichten. Der provisorische Prätor Sanfermo ${ }^{814}$ von Zara ist ein guter, Eurer Majestät anhängiger, altgedienter Mann, aber ohne genügende Energie. Jener von Ragusa, Bette$\mathrm{ra}^{815}$, entspricht genügend seinem Posten, Griesz zu Spalato hat Thätigkeit und Energie; Wickerhauser ${ }^{816} \mathrm{zu}$ Cattaro ist von keinen [Qu $\left.75 / 4\right]$ besonderen Eigenschaften, hat aber im laufenden Jahre mehr Thätigkeit als früher bewiesen.

814 Almanacco 1834, 92: Francesco di Sanfermo, pretore provvisorio Zara. In diesem Amt war er auch schon 1830 (Almanacco 1830, 94), damals zugleich auch podestà von Zara (107), dirigente der Commissione amministrativa di pubblica beneficienza (122) und Mitglied der von dem späteren Karriere-Landesbeamten Biagio di Ghetaldi geleiteten Deputazione sanitaria des Kreise Zara (136). Diese drei weiteren Ämter hatte er 1834 nicht mehr.

815 Almanacco 1834, 101: Bartolommeo Prospero Bettera, pretore Ragusa, membro onorario dell' i.r. società agronomica di Lubiana (war dort auch schon 1830: Almanacco 1830, 102). Das Amt hatte er seit 1820 inne und sich im Sinne der herrschenden Verhältnisse u. a. 1824 durch seinen Beitrag zur Strafverfolgung gegen seinen eigenen Vetter Vito Maria (Marija) Bettera-Vodopić verdient gemacht, der wegen metternichkritischer Schriften unter Anklage stand. Siehe Maixner: Vito Bettera-Vodopić, hier 424. Ein Luigi Bettera war 1834 (Almanacco 1834, 100) Allunno di concetto im Kreisamt Ragusa.

816 Almanacco 1834, 104: Giuseppe Wickerhauser, Prätor Cattaro. Er war dort auch schon 1830 (Almanacco 1830, 106). Wickerhauser hatte einen eigentümlich bewegten Lebensweg hinter sich und war den Vorgesetzten vielleicht deshalb suspekt. Dazu DAZd, Tajni spisi n., sv. 13, Nr. 85 geh., Polizeidirektor Stocka an Lilienberg, Zara 8.6.1833: »Der nunmehrige Prätor von Cattaro Joseph Wickerhauser ist von Wien gebürtig. Sein Vater war ehemals Postverwalter in Triest. Er selbst widmete sich anfangs durch einige Zeit der Handlung. Im Jahre 1807 kam er, wie ich höre, nach Dalmazien, und wurde unter den Franzosen in untergeordneten Posten angestellt. Nach der Wiedererwerbung Dalmaziens durch die österreichischen Truppen erhielt er die Stelle eines Kanzellisten bei dem Kreisamte zu Ragusa. In der Folge wurde er zum Protokollisten und Registrten bei dem Kreisamte zu Spalato ernannt, später zum Kreissekretär in Cattaro befördert, und einige Zeit darauf erfolgte, wie man wissen will, durch die ihn zu Theil gewordene Protection des damaligen Präsidial-Sekretärs Frapporti, seine Ernennung als Pretore politico in Cattaro.

Die Versicherungen, die ich über seine politische Aufführung erhalte, sind durchaus befriedigend und lauten zu seinen Gunsten. In moralischer und religiöser Beziehung bietet sich gleichfalls kein Grund zur Rüge dar, nachdem er sich ehelich mit einer Person von niedriger Abkunft verbunden hat, mit der er früher durch mehrere Jahre zusammengelebt hatte. Er gilt für einen Mann von Bildung, und als öffentlicher Beamter und Amtsvorsteher betrachtet ist ihm die öffentliche Meinung nicht ungünstig; doch macht man die Bemerkung, daß man in seinen Amtshandlungen die gehörige Beschleunigung vermisse, wovon man den Grund 
Zur definitiven Besetzung des Präturs-Postens für Zara hat die Landesstelle ihren lezten Vorschlag am 24 April 1833 Z 4692 erstattet; auch ich erlaube mir, mit Berufung auf meinen allerunterthänigsten Vortrag vom 16. Jänner 1[aufenden] J[ahre]s welchen ich, in Folge Allerhöchsten Cabinet-Schreibens Wien den 24. Dezember 1833 Z. 1335/p erstattet habe, in tiefster Ehrfurcht die allergehorsamste Bemerkung, daß die baldige Ernennung des stabilen Prätors für diese, in vieler Hinsicht wichtige, Prätur dringend ist. ${ }^{817}$

$\$ 173$ [Landpräturen] Bei den Landpräturen, die in Folge Allerhöchsten [sic] Entschließung in Wirksamkeit gesetzt wurden, habe ich, im Allgemeinen genommen, die politischen Geschäfte in ziemlich currentem Stande gefunden; dagegen erstaunte ich, wie verlachläßigt [sic $]^{818}$ bei den Meisten die Verlaßabhandlungen ${ }^{819}$ und das Pupillarwesen ${ }^{820}$ waren, da ich der ersten zu Knin 683, zu Dernis 376, zu Sebenico 886, zu Trau 345, zu Macarsca 140, zu Pago 196 und bei vielen andern, wenn gleich nicht eine so große Zahl, doch mehr als es seyn [Qu $76 / 1]$ sollte, im Rückstande vorfand.

Bei einigen reichten sie bis zum Jahre 1820, bei manchen selbst bis 1815, 1813, und einige bis zum Jahre 1811 zurück, so, daß rücksichtlich mehrerer blos die Meldung des Todesfalls oder nur die Sperrelation und sonst nichts vorhanden war. Außer in Curzola und Budua und wenigen anderen Präturen traf ich gar keine Pupillar-Tabelle und kein Waisenbuch, und an mehreren Orten war bei einigen Verläßen gar nicht zu ersehen, ob Vormünder bestellt und Rechnungen gelegt worden seyen.

Uiberdieß fand ich in Knin auch 72 Criminal-Proceduren und 41 schwere PolizeiUibertretungen, in Derniš 77, in Trau 38 Criminal Proceduren im Rückstande. Sowohl in dieser Beziehung als wegen sonstiger Mängel in Führung der Protokolle, in Haltung der Registraturen und der Evidenztabellen ertheilte ich theils gleich im Orte die nöthigen Erinnerungen und Ermahnungen theils veranlasste ich durch das Gubernium, ein-

zum Theile in seiner häufigen Kränklichkeit, und zum Theile auch darin sehen will, daß er mit seinem Aufenthalte in Cattaro unzufrieden und deßhalb mißvergnügt ist.

Diese im confidentiellen Wege erhaltenen Auskünfte habe ich die Ehre Euerer Excellenz in Befolgung des hohen Auftraes vom 31. v. M. Z 1070/p zu unterlegen.« Vermerk: Diese Auskünfte werden in vorkommenden Fällen zum Gebrauch dienen. Ad acta. 13.6.1833 Rosetti.

817 Eine eigentümliche Art von »Mahnung « an den Kaiser, die wieder vom hohen Selbstbewusstsein Lilienbergs auch in seiner Beziehung zum Monarchen zeugt.

818 Unkorrigierter Schreiberfehler für »vernachlässigt«.

819 Hinterlassenschaftsverwaltung.

820 Pupillarwesen war gemäß diverser Treffer auf Google Books bis in das späte 19. Jahrhundert in Österreich ein üblicher Verwaltungsbegriff (und im 18. und frühen 19. Jahrhundert noch insgesamt süddeutsch), bei dem die »Pupillen« (offenbar die Hinterlassenschaften, wohl vornehmlich seitens der verstorbenen Eltern, zugunsten der Waisenkinder) zu ihrer Bestandserhaltung amtlich beaufsichtigt wurden. Diese Oberaufsicht oblag in der österreichischen Reichshälfte in der ersten Ebene den Gemeinden. Vgl. insbesondere die Passagen in Barth-Bartenheim: Das Ganze der österreichischen politischen Administration Bd. 1, 692, 695 und 697. 
verständlich mit dem Appellations-Gerichte, die nöthigen [Qu 76/ 2] zeitliche[n] Personalaushülfen wodurch auch viele dieser Rückstände aufgearbeitet worden sind.

Ich erkannte, daß die ämtlichen Unordnungen meistens dort sich ergeben, wo die Prätorsstellen unbesetzt waren; denn die Menge der politischen Akten, Civil-, Criminal-, Finanzproceduren und currenten Jußgeschäfte ${ }^{821}$ bei den hierländigen Präturen gestattet es durchaus nicht, daß ihr, ohnehin in der Zahl beschränktes, Personale irgendwo besonders aber in den Kreisen Zara und Spalato, wo sich die größten Bezirke befinden, längere Zeit unvollständig bleibe. Ich überzeugte mich, daß kein Posten für die Verwaltung, wenn er provisorisch besetzt bleibt, so nachtheilig sei, als eine gemischte Praetur ${ }^{822}$, weil sie von Niemanden im Orte fortwährend controllirt wird und sich ganz allein überlassen ist.

Die beträchtlichsten Rückstände [gestrichelt unterstrichen] waren aus obigem Grunde zu Knin, wo seit einigen Jahren der Praetor mangelt; zu Sebenico, wo die Ernennung des Prätors Domjacussich ${ }^{823}$ nach der Vacanz dieses Postens seit 1828 erst im v[origen] J[ahre] statt hatte; [Qu 76/3] zu Derniš ${ }^{824}$ fand ich die Amtsführung in bedeutender Unordnung da dieser Prätorsposten ebenfalls seit anno 1828 bis 1832 durch den, nicht lobenswerthen, Adjunkten Pellegrini ${ }^{825}$ provisorisch verwaltet war. Die Prätur von Pago war wegen der mehrjährigen Krankheit des Prätors Delio ${ }^{826}$, welcher pensioniert wurde sehr verwahrlost.

An mehreren Orten lag die Ursache der von mir bemerkten ämtlichen Gebrechen in der wenigeren Eignung ihrer Vorsteher, wie zum Theil in Trau, Kreis Spalato, wo der Prätor Drago ${ }^{827}$ sich mehr mit der Schriftstellerei, als mit seinem Berufsfache beschäf-

821 Jusgeschäfte (von österreichisch Jus, »Jura, Juristerei«): juristische Angelegenheiten.

822 »Gemischte« Prätur, da Verwaltungs- und Justizorgan.

823 Almanacco 1833, 92 nennt Pietro Domiacussich, dott. in legge, als Prätor von Sebenico. 1834 ist diese Prätur hingegen vakant (92) und Domiacussich ist consigliere am Tribunale collegiale di prima istanza in Ragusa (162), ebenso 1835 (163); Prätor in Sebenico war 1835: Carlo di Natali (90).

824 Almanacco 1834, 92: Prätur vakant.

825 Die Almanache von 1830, 1831 und 1832 führen die Prätur von Dernis als vakant, aber keiner der dort genannten Mitarbeiter war ein Pellegrini.

826 Almanacco 1831, 94: Pretore von Pago sig. Bernardo Antonio Delio, auch 1832 noch als Prätor geführt. 1833 (94) war das dann Carlo di Natali, der bald darauf Prätor in Sebenico wurde (s.o.).

827 Almanacco 1833, 96 (und Almanacco 1834, 96): Prätor in Traù Vincenzo di Drago. Zu ihm ${ }^{*} 1779$ ) und mit einigen seiner Schriften (die zeitgenössisch erschienenen bezogen sich nicht auf Dalmatien; die Valentinellische Bibliografia della Dalmazia e del Montenero verzeichnet denn auch keine Veröffentlichungen Dragos), darunter eine Panegyrik auf Joseph II. und einen Bericht über den Zustand Dalmatiens: Šimunković (Hg.): Vincenzo (Vicko) Drago. Von ihm stammte ansonsten insbesondere eine sechsbändige Geschichte des alten Griechenlands, erschienen zwischen 1820 und seinem Todesjahr 1836 in Mailand. Eine Todesnachricht in der Beilage der Wiener Zeitschrift 143 (29.11.1836) pries diese als »sehr gute Geschichte Griechenlands« (Marinelli-König: Die Südslaven, 303). 
tiget und nach 12 Jahren Aufenthalts daselbst seinen Bezirk noch nicht kennt; in Scardona, wo der zeitliche Administrator Feruzzi ${ }^{828}$, welcher nun den Dienst resignierte, zu wenig die Sprache der Administrirten verstand ${ }^{829}$; zu Almissa, wo der Prätor Pini ${ }^{830}$ sich befand, welcher decrepid ist. In dessen Amte waren die Civil-Justiz-Protocolle von den Jahren 1828 bis 1833 ohne Conclusa.

$\mathrm{Zu}$ Fort Opus fand ich die Geschäfte ziemlich in currentem Stande. ${ }^{831}$

Die Präturen zu Lesina unter dem Prätor Barbieri ${ }^{832}$, zu Lissa unter dem durch 13 Jahre mit wenigen Unterbrechungen 2 Präturen provisorisch versehenden Administrator Ipsich ${ }^{833}$, welcher seine Fähigkeit zum Prätor, [Qu 76 / 4] ungeachtet er keine Studien hat, nach übereinstimmender Ansicht aller vorgesezten Landesbehörden, vollkommen bewährte und die allerhöchste Ernennung verdient; jene zu Sabioncello unter dem Prätor Potochniak $^{834}$; zu Castelnuovo unter dem Prätor Naghi ${ }^{835}$, welcher obgleich keine höheren Einsichten doch hinreichende Fähigkeiten und lobenswerthe Thätigkeit zeigt; und zu Obrovazzo unter dem Administrator Doimi ${ }^{836}$, befanden sich vergleichsweise zu anderen in besserer Ordnung; dasselbe beobachtete ich zu Curzola, wo der Prätor Ulm ${ }^{837}$ in wenig Zeit 400 Rückstände die sein Vorgänger ihm zurückgelassen hat aufarbeitete

828 Keiner der Almanache 1830-1833 führt zu Scardona einen Mitarbeiter der Prätur namens Feruzzi. 1831, 93, wird ein dagegen ein Gio[vanni] Battista Feruzzi, dottore in legge, als Cancelliere provvisorio an der Prätur in Obrovazzo genannt. Schon 1831 gibt es keinen Eintrag mehr zu ihm.

829 Eine Belegstelle für Sprachenprobleme und Sprachenanforderungen in der Verwaltung im dalmatinischen Hinterland (in Form fehlender Zweisprachigkeit eines italienischen Beamten, die allerdings als Mangel und daher vielleicht auch als Ausnahme erscheint).

830 Almanacco 1833, 99: Pretore von Almissa Timoteo Pini, auch Almanacco 1834, 99. Ebenso $1835,97$.

831 Dies ist deshalb erstaunlich, als der Almanacco 1834, 99 dort sowohl den Prätoren- als auch den Kanzelistenposten als vakant bezeichnet; beide »vengono sostenuto da funzionarj in commssione«.

832 Domenico Barbieri, Prätor von Lesina (Almanacco 1834, 99).

833 Giovanni Maria Ipsich, laut Almanacco 1834, 98 cancelliere der Prätur von Castel S. Pietro di Brazza, »in commissione a Lissa« Der Prätorenposten in Lissa (ebd., 100) wird als vakant geführt.

834 Almanacco 1834, 102: Emerico Potochniak, Prätor von Sabioncello (Dienstsitz Orebich).

835 Almanacco 1833, 104: Giuseppe Nagy, dott. in legge, Prätor von Castelnuovo (der Almanacco 1834, 104, führt die Stelle als vakant), Almanacco 1834, 94: Prätor von Obbrovazzo.

836 Almanacco 1833, 94: Pretore Obbrovazzo Francesco Florido Nakich (in Lilienbergs Text: Nachich), dottore in legge; Cancelliere: Stefano Doimi, provvisorio. 1834 (94) war dort Giuseppe Nagy Prätor, Kanzlist war Andrea Laurich. Ein Stefano Doimi wird 1834 im Almanacco nicht mehr geführt, dafür aber im Almanacco 1835 (96) als aggiunto in der Prätur Macarsca.

837 Almanacco 1833, 102 (auch Almanacco 1834, 102): Prätor von Curzola Francesco Ulm, dottore in legge. 
und sein Amt in Ordnung hält. Der Prätor Pellegrini ${ }^{838}$ zu Sign zeigt Einsicht und Energie, dessen Moralität entsprach aber früher nicht ganz; nach einer ihm jedoch von mir ertheilten kräftigen Ermahnung, gab er keinen Anlaß zu weiteren Bemerkungen.

Für einen der vorzüglichsten Prätoren in Dalmatien halte ich aber Prätor Plencovich $^{839}$ zu Macarsca, welcher Fähigkeit, Kenntniße, Thatkraft, Eifer und anstandsvolles moralisches Betragen vereint. Die mehreren Rückstände [Qu 77 / 1] in Ventilationen ${ }^{840}$ die ich daselbst antraf, sind über eine ihm von mir ertheilte Erinnerung jetzt vollkommen aufgearbeitet und sein Amt ganz im currenten.

Die von mir und dem Gubernium erlassenen Verfügungen und nachdrücklichen Weisungen bewirkten, daß von 102878 im Jahre 1833 bei sämmtlichen Präturen in Verhandlung gestandenen [K. C.: Verwaltungs-] Akten am Schluße des Jahres nur 1029 unerledigt geblieben waren, wovon die Mehrzahl zu dem im lezten Monate Eingelaufenen zu rechnen sind. Von 62801 Justizacten bleiben dagegen 2634 unaufgearbeitet.

$\$ 174$ [Maßregeln zur Verbeßerung der Präturen ${ }^{841}$ ] Um den Zustand der Präturen im Allgemeinen zu verbessern, scheint es mir vor Allem nothwendig, so viel wie möglich mit allen nöthigen Kenntnißen versehene Beamte für diese zu gewinnen. Viele derselben verfahren nämlich in politischen Angelegenheiten oberflächlich, ohne hinreichende Gesetzkenntniß und begnügen sich, fast in allen administrativen Verhandlungen, die Berichte der Comunal Administrationen mit einem bloßen Visto und in einigen Fällen mit einem gewöhnlich unbedeutenden Gutachten [Qu 77 / 2] einzubegleiten. In dieser Beziehung glaube ich, daß zur Erlangung eines Prätors, erstens für die Zukunft die politische Administratur Prüfung zur unerläßlichen Bedingung gemacht werden sollte, indem man bis jetzt sich mit den Justitz-Wahlfähigkeits Dekreten zum Richteramte und mit der Prü-

838 Almanacco 1833, 97 (auch 1834, 97): Prätor von Sign Giovanni Battista di Pellegrini Danieli, dottore in legge.

839 Almanacco 1833, 98: Prätor in Macarsca Paolo Plencovich, dottore in legge. Derselbe (Pavao Plenković), vertrat 1848/49 den Stimmbezirk Šibenik im österreichischen Reichstag und gehörte dabei nationalpolitisch zu den slawodalmatinischen Abgeordneten; vgl. Clewing: Staatlichkeit, 320 und dort insbesondere Anm. 366. Prätor war er erstmals 1823 in Omiš (auf Vorschlag der Obersten Justizstelle vom 4.5.1821), wobei dieser Ernennung eine kaiserliche Entschließung vom 13.9.1822 vorangegangen war zu seiner weiteren Prüfung, vor allem »[...] ob es war sey, daß er in der Zwietrachts angelegenheit zwischen den Griechen und Katholiken in Dernis vielen unbesonnenen und leichtsinnigen Antheil nahm, und worin diese bestanden.« (HHStA, KFA 29 (alt 30), Abschnitt 5, fol. 121). Dazu nahm die Justizstelle mit Vortrag vom 29.4.1823 entlastend Stellung, worauf am 7.8.1823 die kaiserliche Entschließung zu seiner Bestellung folgte (a.a. O., fol. 136-137).

840 Hier offenkundig im heute nicht mehr üblichen Sinn von »Überlegungen, Erörterungen« zu verstehen, wobei nicht zu klären war, auf was im Verwaltungsablauf sich dies genau bezieht. Vielleicht »Gutachten«.

841 Randanmerkung Rossettis in der Gliederung: »ad 174 künftig wären politische Prüfungen zu fordern. Kein Prätor davon zu dispensiren.« 
fung aus dem Strafgesetze sich [Doppelung, sic] begnügte und sich in ganz Dalmazien [nur; K. C.] ein einziger Präturs Beamter befindet, welcher die politische Wahlfähigkeit und dieses noch im Küstenlande, wo er früher angestellt war, sich erwarb.

Dieses hat zur Folge, daß viele Präturs Beamten einen großen Theil der politischen Gesetze gar nicht und die wenigen um die sie sich allenfalls bekümmerten nur oberflächlich kennen, und es scheint mir, daß man in diesem Augenblicke, wo alle Jahre so viele gebildete Menschen die juridischen Studien absolviren, diese höhere Qualification fordern könne.

Da ferners die wenigsten Prätoren ihren Bezirk ganz kennen, so scheint es mir nützlich, daß ihnen zur Pflicht gemacht werde, denselben so bald sie ihre Prätur übernommen haben längstens binnen sechs Monaten und später alle 2 Jahre vollkommen zu bereisen $^{842}$. Hierbei aber [Qu 77/3] alle Verhältniße des Gebietes, den Zustand und die Bedürfniße der Administrirten gründlich zu erforschen, was bei einzelnen Comissionen ${ }^{843}$, wo die Aufmerksamkeit nur auf einen Gegenstand und auf einen Ort gerichtet wird, nicht möglich ist. Bezüglich dieser Reisen dürfte denselben eine angemessene Vergütung bewilligt werden.

Aus dieser Unkenntniß vorzüglich entsteht der Hauptübelstand bei den Präturen, daß sie mehr und fast ausschließend nur schreibende, statt executive, auf die Bevölkerung unmittelbar wirkende, erste politische Instanzen sind; welches aber auch davon herrührt, daß sie in der Praxis die Ausführung der meisten politischen Anordnungen und die Erhebungen bei administrativen Verhandlungen den Comunal Administrationen des Bezirks Hauptorts und den Sindacaten auftragen.

Dießfalls wird bei der Revision des Gemeindesistems durch Zurückführung der Comunal- und Praeturs-Amter auf ihre ursprüngliche Bestimmung, welches auch auf die Vereinfachung und Beschleunigung der Verhandlungen wirken muß; dann durch die nur mit der [Qu 77 / 4] Zeit mögliche sonstige Verminderung der Schreibgeschäfte, zweckmäBig eingewirkt werden können, wonach die Praetoren auch mehr Zeit gewinnen werden, bei allen wichtigen Fällen selbst nachzusehen, zu vernehmen und ihr Wirken mehr in eigenem Einschreiten in Rath, Belehrung und That zu entfalten; was hierlands besonders nöthig ist. ${ }^{844}$

So nützlich ich es überdieß erachte, daß bei den Präturen die politische von der Justizverwaltung getrennt würde; so wage ich es doch nicht, bei den ohnehin bedeutenden

842 Ein beredtes Zeugnis für die Landes-Unkenntnis vieler Beamten, und für Lilienbergs Wertschätzung eines Bereisungssystems bzw. konkreter Ortskenntnisse auf allen Ebenen der Verwaltung. Vgl. auch die entsprechende Darlegung von Erzherzog Franz Karl (?) hier im Anhang, Seite 315.

843 Im Sinne von Dienstreisen aus einem spezifischen Anlass; später verwendet Lilienberg dafür auch den Begriff »Amtsreise«.

844 Ein Indiz für die landesspezifische Erfordernis besonderer personaler Präsenz sowie direkter Kommunikation und Interaktion der Beamten mit der Bevölkerung zur effektiveren Herrschaftsdurchsetzung. 
Administrations-Auslagen dieser Provinz, solches Eurer Majestät allerunterthänigst in Antrag zu bringen, da durch Bestimmung ${ }^{845}$ eigener politischer Commissaere oder Actuare für die Präturen die Kosten für das Aerar vielleicht auf 25000 Gulden vermehrt würden ${ }^{846}$. Was aber bei dem gegenwärtigen Zustande der Praeturen sich als vorzüglich nothwendig darstellt ist, daß selbe oft von den Kreis Commisaeren und jährlich von den Kreis-Hauptleuten visitiert ${ }^{847}$, ihre Gebahrung, Geschäftsbehandlung und Thätigkeit gründlich erforscht, auf die Abstellung [Qu 78 / 1] aller entdeckten wesentlichen Gebrechen ernstlich gedrungen, und die Befolgung der dießfalligen Weisungen unabläßlich überwacht werde, worüber ich bei Darstellung der Kreisämter das Weitere in tiefster Ehrfurcht zu bemerken mir allerunterthänigst erlauben werde.

Nicht minder und zwar noch dringender erforderlich, scheint mir auch, die Justizverwaltung der Präturen öfters durch einen Tribunals Rath gründlich untersuchen und die nöthige Abhülfe gegen die bemerkten bedeutenden Mängel treffen zu lassen, da die Verlassenschaften und die Pupillarangelegenheiten in vielen Orten nicht so vernachlässigt geblieben wären, die Rückstände in Criminal Proceduren und die Unordnungen in Führung der Civil-Protocolle an manchen Orten, wenigstens nicht so weit gelangt seyn könnten, wenn man die lezte Maßregel nicht seit 12 Jahren, wo sie zum len und lezten Male und dieß nur bei acht Praeturen statt fand, unterlassen hätte ${ }^{848}$. Ich habe mich diesfalls mit dem Appellations Präsidenten besprochen und ihn hierin willfährig gefunden, indem er die $[Q u$ 78/2] Nothwendigkeit dessen vollkommen einsieht. Da solches aber noch nicht geschehen ist, so vermuthe ich, daß der Grund im Mangel hinreichenden Personals bei den Tribunalen liege, nachdem diese selbst mit Geschäften überhäuft sind, weil mit Zuwachs der Population sich jährlich die Verbrechen und andere Ange-

845 Im Sinne von Zuordnung/Zuweisung.

846 Dies ist wohl zu verstehen als Form, eine Beantragung in indirekt-informeller Weise durchzuführen (also per Vorlage direkt beim Kaiser statt förmlichem Antrag, der über die Zentralstellen zu richten gewesen wäre). Allerdings waren diese geschätzten Zusatzkosten gegenüber dem bestehenden System bei den Präturen erheblich, denn die Personalkosten für die Justizverwaltung bei den Präturen lagen 1835 bei 56355 Gulden (und bei den politischen Präturen bei 8813 Gulden): Tafeln zur Statistik 1835, Tafel 57 (Dalmatien), Tabelle zu »Stand und Aufwand sämmtlicher zur Civil-Verwaltung gehörigen, aus Staatskassen beköstigten Individuen, dann der Pensionisten und Provisionisten mit Ende des Verwaltungsjahres 1835«.

847 Ein erneuter Bezug auf eine nötige persönliche Präsenz von Verwaltenden in der Fläche bzw. vor Ort, und auf die Notwendigkeit systematischer amtlicher Bereisungen, hier zum Zweck der Wahrnehmung der praktischen Aufsicht durch die zuständige höhere Verwaltungsebene. Vgl. auch den nächsten Absatz analog dazu für den Justiz-Bestandteil des Wirkungskreises der Präturen.

848 Die vorherigen Kontrollformen waren demnach von großer Unregelmäßigkeit geprägt (hier die Evaluation durch vorgesetzte Richter). Diese Kritik Lilienbergs an den Aufsichtsverhältnissen im Justizwesen ist aber auch vor dem Hintergrund zu verstehen, dass er selbst für diesen Bereich nicht als Oberaufsicht zuständig war, sondern der Appellationsgerichtspräsident: Giovanni Nepocumeno cav. di Vlach (Johann Nepomuk Ritter v. Vlach) Almanco 1834, 158). 
legenheiten verhältnißmäßig vermehren und weil bei Erledigung [gestrichen: -sfällen; ergänzt: -en ${ }^{849}$ ] die dießfälligen Posten öfter längere Zeit unbesetzt bleiben, die Collegial Gerichte selbst dadurch in Verlegenheit gerathen und keinen Mittelsrath auf längere Zeit entbehren können.

Ich fühle mich aber nach Pflicht und Gewissen verbunden, Eure Majestät auf das Inständigste allerunterthänigst zu bitten, die erwähnten Prätursvisitationen durch einen Tribunalrath auf irgend eine, dem allerhöchsten Dienste entsprechende Art allergnädigst anzuordnen und sich über deren Resultat jährlich einen allerunterthänigsten Vortrag erstatten zu laßen, hierbei aber die Allerhöchste Gnade zu haben dem Appellations Praesidenten [Qu 78 / 3] [Qu 78 / 4 fehlt formal, aber nicht inhaltlich] nicht zu eröffnen daß meine allerunterthänigste Vorstellung die Veranlassung dieses Allerhöchsten Befehles sey, weil daraus in diesem kleinen Orte eine unangenehme, dem Allerhöchsten Dienste nur nachtheilige, Collision entstehen würde, ich aber es nicht hätte wagen dürfen, einen so wichtigen Gegenstand, wie es die erwähnten Mängel in einigen Zweigen der Justizverwaltung sind, Eurer Majestät zu verschweigen und dadurch das Interesse der Pupillen wie es Eure Majestät aus der Anzahl der Verlaßverhandlungen, welche ich unerledigt gefunden habe, Allergnädigst ersehen haben, zu vernachlässigen. ${ }^{850}$

[Qu 79 / 1]

\section{Kreisämter}

$\$ 175$ [Kreisamt von Cattaro] Das Kreisamt Cattaro, welches jährlich ungefähr 7000 Geschäftsstücke zu bearbeiten hat, wird seit der im Jahre 1830 erfolgten Uibersetzung des

849 »Erledigung« bezieht sich hier auf ein »Freiwerden« von Stellen durch das Ausscheiden des vorherigen Amtsinhabers.

850 Eine erstaunliches direktes Herantreten an den Kaiser, verbunden mit der fast schon komplizenhaften und gegenüber einem Monarchen zweifellos gewagten Bitte um diskrete Behandlung (!), da die höhere Justizverwaltung in Dalmatien dem Gouverneur gegenüber offenbar gänzlich unabhängig war. Anders als im Großteil Cisleithaniens, wo sie bei der adeligen Grundherrschaft lag, war dabei die Gerichtsbarkeit in Dalmatien auch auf der untersten Ebene (also der Präturen) komplett »verstaatlicht«; vgl. im Unterschied dazu die Angaben von Heindl: Gehorsame Rebellen, 2. Auflage, 74f. Zu den Kompetenzverhältnissen in Dalmatien hingegen Maštrović: Razvoj sudstva; er hält 66 fest, die im wesentlichen 1820 geregelten dalmatinischen Gerichtsverhältnisse hätten weitgehend der zur Franzosenzeit eingeführten Trennung von Justiz und Verwaltung entsprochen, auch in Sachen der Aufsichtsfunktionen. Weil aber die Aufsicht über die Präturen doppelt geführt war (in Justizsachen unterstanden sie dem Appellationsgericht, in politisch-administrativen Dingen dem Gubernium), spricht Maštrović ebd. von einer nicht vollständigen Trennung der beiden Gewalten in Aufsicht und Amtsform, weil damit zwei Rechtsbereiche vermischt worden seien, die damals nach seiner Meinung schon nicht mehr hätten gemeinsam administriert werden dürfen, selbst wenn dies in der Praxis auf die bloß formalistische gemeinsame Form der Institution beschränkt war. 
Kreishauptmannes Paitoni ${ }^{851}$ nach Triest von einem ersten Kreis Kommissär und zwar früher mehrere Jahre durch Martellini ${ }^{852}$, welcher gegenwärtig dem Kreisamte von Zara wohin er besser taugt, zugetheilt ist und seit April 1833 durch den Kreis Commissär Ivacich ${ }^{853}$ zweckmäßig verwaltet, indem ich das Amt in einem entsprechendem Zustande antraf.

Rücksichtlich der Nothwendigkeit des Fortbestandes dieser Kreisbehörde glaube ich mich auf die, gelegentlich der Darstellung der hiesigen Landeseintheilung angegebenen, Motive allerunterthänigst berufen zu sollen.

$\$ 176$ [Kreisamt von Ragusa] Das Kreisamt von Ragusa, welches dermalen ungefähr 15000 Geschäftsstücke jährlich zu bearbeiten hat, wird seit mehr als 6 Jahren von dem sehr eifrigen, kenntnißreichen, umsichtigen und gewandten Kreishauptmann [Qu 79/2] Baron Schaller ${ }^{854}$, geleitet, der sich durch Festigkeit, Consequenz und gehörige Auffassung der österreichischen Sisteme besonders auszeichnet.

Dagegen fand ich das übrige Personale dieses Kreisamtes der verhältnißmäßig großen Geschäftsmenge und den anderen Forderungen des Dienstes weniger gewachsen.

Der einzige für dieses Kreisamt sistemische Kreis-Commissaer, Tromba ${ }^{855}$ ist ein bereits 38 Dienstjahre zählender, rechtlicher Mann, durch fehlgeschlagene Hofnung [sic!] zu höherer Beförderung niedergeschlagen und [gestrichen: weder] zu einer Gubernal-Rath

851 Almanacco 1830, 105: Capitano circolario von Cattaro Giuseppe di Paitoni, i.r. consigliere di governo. DAZd, Tajni spisi, sv. 13, Nr. 87/geh. 1833 enthält eine Laufbahntabelle von Paitoni, der um Versetzung nach Ragusa angesucht hatte. Dies wurde vom Gubernium mit 14.6.1833 nicht unterstützt. Mit Beilage Nr. 116 R., Zara 8.6.1833 hatte Polizeidirektor Stocka an Lilienberg mitgeteilt, Paitoni habe ehedem wirklich zur Freimaurergesellschaft gehört. Offenbar ein Sohn dieses Giuseppe Paitoni (die Paitoni waren eine Adelsfamilie aus Traù, deren Nobilität 1823 durch Franz I. anerkannt wurde) war Federico de Paitoni, Reichstagsabgeordneter für Split-Land im Reichstag von 1848/49; vgl. mit einigen Angaben Clewing: Staatlichkeit, 341-343, sowie zur Anerkennung des Adelstitels und zur Angabe des Vaters „Giuseppe Paitoni« Ghezzo: Nobiltà dalmata e università di Padova, 209.

852 Michele Martellini (auch Martelini) wird noch vom Almanacco 1833, 103 genannt als Commissario circolare di I. classe, Cattaro; 1834, 91 dann als erster von zwei Commissarj circolari von Zara. Seine Versetzung weg von Cattaro hatte eine geheime Liebesbeziehung des verheirateten Martellini mit einer dortigen orthodoxen Witwe zur Ursache gehabt. Deshalb also »taugte er besser « für Zara. DAZd, Tajni spisi namjesništva, sv. 13, Aktenzeichen 17/g.p. 1833 vom 19.1.1833, darin Schreiben des Zaratiner Polizeidirektors Adam Stocka an Lilienberg, Zara 14.1.1833, Nr. 342/g. anno 1832 (sic). Martellini hatte sich in der Folge dagegen zur Wehr gesetzt und die Beziehung in Abrede gestellt: a.a. O., Schreiben desselben an das Landespräsidium, Cattaro 8.2.1833 (liegt in Nr. 38/g).

853 Gabriele Ivacich, Almanacco 1834, 103: Commissario circolare di I. classe in Cattaro, und 206: Vorsitzender der Commissione agraria von Cattaro. Noch der Almanacco 1835, 101 führt die Kreishauptmannstelle Cattaro als vakant.

854 Almanacco 1833, 100: Capitano circolare von Ragusa Ferdinando barone di Schaller, i.r. consigliere di governo (außerdem 187: direttore des Gymnasiums von Ragusa!).

855 Almanacco 1833, 100: Commissario circolare di I. classe Ragusa: Giovanni Tromba. 
oder Kreishauptmannsstelle nicht vollkommen geeignet, indem er die nöthigen Administrations-Kenntniße nicht besitzt. Er kann daher dem Kreishauptmann nicht mehr viel wesentliche Dienste leisten.

Noch weniger lässt sich dermalen, von dem, einst sehr eifrigen und sehr thätigen, Kreissekretär Zangerolimi ${ }^{856}$ erwarten, welcher in früheren Epochen allein fast [Qu 79 / 3] alle Concepts Arbeiten durch einige Zeit erledigte, aber jetzt, nach fast 40jähriger Dienstleistung, im vorgerükten Alter wenig Thatkraft besitzt, da er in der Gesundheit sehr geschwächt ist.

Der Kreishauptmann hat daher größtentheils auf die Hülfe eines Concepts-Praktikanten bei Erledigung der vielen Geschäfte zu rechnen.

Das erwähnte unangenehme Verhältniß ließe sich, nach meiner allerunterthänigsten Ansicht, nicht anders heben, als durch die allmälige, bei schicklichem Anlasse zu verfügende Pensionierung des Kreiskommissärs Tromba und des Kreissekretärs Zangerolimi.

Die Kreisämter von Spalato und Zara haben jährlich zwischen $\underset{\mathrm{m}}{17} \operatorname{und}^{20}[17$ und 20000 ] Akten zu erledigen.

$\$ 177$ [Kreisamt von Spalato] Jenes von Spalato, seit dem Jahre 1824 vom Kreishauptmann Nani ${ }^{857}$ geleitet, welcher vom Diurnisten ${ }^{858}$ sich auf seinen gegenwärtigen Posten emporgearbeitet hat, viele Ordnungsliebe, sehr regen Eifer, Einsicht und praktische Kenntniße, selbst in größeren wichtigen Elaboraten, bewährt, befindet sich in erwünschtem Stande.

[Qu 79 / 4] Auch ist es mir angenehm Eurer Majestät alleruntertänigst anzeigen zu können, daß der früher bestandene Verdacht, als habe Nani zur Freimaurer-Secte gehört, durch die von mir veranlaßten neueren Nachforschungen des Polizei Direktors Stoka ${ }^{859}$ ganz gehoben worden ist.

Nur wäre es zu wünschen, daß er anstatt des bei der Bevölkerung gar nicht im Ansehen stehenden, wenig verläßlichen Kreis Kommissärs Marichich ${ }^{860}$, recht bald einen

856 Almanacco 1833, 100: Segretario am Kreisamt Ragusa: Antonio Zangerolimi.

857 Almanacco 1833, 95: Girolamo Nani, i.r. consigliere di governo.

858 Eine Art von Tagelöhnern oder eigentlich »Zeitarbeitern« im damaligen österreichischen öffentlichen Dienst, zeitgenössisch auch Tagschreiber genannt; s. Clewing: Staatlichkeit, 90 bzw. Heindl: Gehorsame Rebellen, 2. Auflage, 155 und $258 \mathrm{f}$.

859 Almanacco 1833, 90: Direttore der Direzione di polizia in Zara Adamo Stocka, i. r. consigliere di governo, decorato della grande medaglia d'oro d'onor civile (in deutschen Akten - er berichtete u. a. in monatlichen Stimmungsberichten nach Wien, die vor allem, aber nicht nur an die Polizeihofstelle gingen - firmiert er mit Adam Stocka). Stocka hatte vor seinem Dienst in Dalmatien Diensterfahrungen im habsburgischen Oberitalien gemacht; am 9.9.1821 erhielt er vom Kaiser taxfrei den Titel eines k. k. Rats, damals war er 1. Adjunkt bei der Generalpolizeidirektion in Venedig (Österreichischer Beobachter, 10.9.1821, Nr. 253, S. 1162).

860 Almanacco 1833, 95: 1. Kommissär am Kreisamt Spalato Francesco Maricich. Seine Versetzung in einen Manipulationsdienst wurde von Lilienberg und mehr oder minder energisch auch von den Zentralstellen betrieben, aber bis dahin erfolglos - ein Beispiel dafür, dass sich auch politisch erwünschte bzw. kaiserlich angeordnete Beamtenversetzungen teils über Jah- 
tüchtigen 1en Kreis Commisär erlangen könne und ich muß es nur bedauern, daß sich [gestrichen: hierlands] noch keine Gelegenheit ergab, ihn [Marichich] an einen Manipulations Dienstposten zu übersetzten wie es Eure Majestät mit allerhöchstem Erlasse vom 13 July 1829 anzuordnen geruht haben. Ich glaube sogar, daß er in Dalmatien auch zu diesem nicht ganz mit Beruhigung zugetheilt werden könnte, weil hierlands wegen Intriguen, an die man unter den früheren Regierungen gewohnt ward und die noch eine Zeit lang bestehen werden, großer Nachtheil für den Allerhöchsten Dienst und für die Partheien entstehen kann, wenn [Qu 80 / 1] man rüksichtlich der Amtsakten und ihrer Geheimhaltung nicht mit der gesetzlichen Gewissenhaftigkeit gebahret. ${ }^{861}$

Der zweite Kreis-Commisär Stermich ${ }^{862}$ hat zwar keine auszeichnenden Eigenschaften entspricht aber seiner Bestimmung hinlänglich.

$\$ 178$ [Kreisamt von Zara] Das Kreisamt von Zara steht in der Pünktlichkeit und Schnelligkeit der Geschäftsbehandlung jenem von Spalato etwas nach, weil der Kreishauptmann Naverschnigg ${ }^{863}$, welcher zwar seine Fähigkeit, Rechtlichkeit und Kenntniße im Küstenlande auf das Lobenswertheste bewährt hatte, sich [aber, K.C.] nicht so bald in die Eigenheiten dieses Landes, seiner Bewohner und der administrativen Verhältniße einzustudiren vermochte ${ }^{864}$. In der neuesten Zeit hat sich dieser Mangel jedoch zu he-

re hinweg nicht verwirklichen ließen! DAZd, Tajni spisi n., sv. 13 enthält unter 72/g.p. 1833 vom Vorsteher der ver. Hofkanzlei Graf Anton Friedrich Mittrowski (Mittrowsky) von Nemischl, Wien 5.4.1833, in dem er u. a. mitteilte, "sehe ich mich, was den [in einem kürzlichen Schreiben Lilienbergs ausgedrückten Wunsch wegen Unterbringung des ersten Kreiskommissärs Maricich bei einem Manipulationsamte betrifft, veranlaßt Eurer Excellenz zu eröffnen, daß in dieser Beziehung bereits von Seite der k. k. vereinigten Hofkanzley die erforderliche Weisung an sämtliche Länderstellen erlassen wurde."

861 Die in die Amtszeit von Lilienbergs Amtsvorgänger Tomassich zurückreichenden Vorwürfe gegen Maricich bestanden offenbar in mangelnder Wahrung des Amtsgeheimnisses und vielleicht in daraus folgender Vorteilnahme. Die Passage ist ein Beleg für vorkommende Unregelmäßigkeiten und vielleicht auch Korruption in der Beamtenschaft und weist auch darauf hin, dass die Durchsetzung des administrativen Geheimhaltungs- bzw. Vertraulichkeitsprinzip in der allgemein stark personalisierten Kultur des Landes schwer durchzusetzen war, außerdem, dass die Versetzung unliebsam gewordener Beamter für die Vorgesetzten nicht leicht möglich war.

862 Almanacco 1833, 95: 2. Kommissär am Kreisamt Spalato Antonio Stermich, dottere in legge.

863 Almanacco 1833, 91: Kreishauptmann Spalato Giovanni Canzio Naverschnigg, membro dell' i.r. società agronomica di Gorizia.

864 Ein Hinweis auf die Schwierigkeiten auswärtiger Beamten, sich in Dalmatien zurechtzufinden, selbst wenn sie küstenlanderfahren waren bzw. wie Naverschnigg seinem slowenischstämmigen Namen (und seiner Görzer Verbindung) nach sogar wohl selbst von dort bzw. dem slowenischen Sprachgebiet stammten. An sich hält Petter: Dalmatien, Bd. 1, 156 hinsichtlich der Eingewöhnung in Sachen der Sprache gerade als erheblichen Unterschied fest: »[...] ich kenne mehrere Krainer und Wenden, welche sich den dalmatinischen Dialekt schon in zwei Monaten ihres Hierseins aneigneten. Den Deutschen hingegen macht die Erlernung 
ben angefangen und die Geschäftsbehandlung bei diesem Kreisamte läßt nun mit allem Grunde hoffen, daß sie bald ganz entsprechend sich gestalten werde.

Der hiesige erste Kreis-Commisär [Qu 80 / 2] Martellini leistet ersprießliche Dienste; auch fehlt es dem zweiten Kreiskommisär Nachich ${ }^{865}$ nicht an Fähigkeit und Thätigkeit.

$\$ 179$ [Allgemeine Bemerkungen und Mängel ${ }^{866}$ ] Die von ${ }^{867}$ den Präturen erwähnte allgemeine Bemerkung, daß sie mehr schreibende als executive Ämter sind habe ich bei den hierländigen Kreisämtern, mit Ausnahme jenes von Ragusa, auch gemacht, hierdurch werden diese, leider! ihrer eigentlichen Sphäre, ihrer Bestimmung entrückt.

Eine Hauptursache dieses Uibelstandes liegt in der schon angedeuteten Menge ihrer Schreibgeschäfte, welche, so lange hierlandes nicht alle Administrationszweige sistemisiert sind, nicht wird bedeutend vermindert werden können, weil hier bis nun nach den Gesetzen von drei verschiedenen Regierungen und nach besonderen Statuten ${ }^{868}$, die zwar nicht sanctionirt sind, aber doch aufrecht erhalten werden, da sie für Verhältniße, die sich auf Facta aus früheren Zeiten gründen, Anwendung [Qu 80 / 3] haben, die öffentlichen Geschäfte behandelt werden müssen.

Die Kreisämter von Spalato und Zara würden nach ihrem gegenwärtigem Geschäftsstande im Küstenlande 4, Ragusa 3 Kreis Commisaere haben. Das hierländige Kreispersonale muß beständig in Sorge seyn, die vielen Geschäftsackten [sic] zu erledigen um nicht in Rückstande zu gerathen, zumal wenn irgend einer ihrer Concepts-Beamten in Commision [Dienstreise, K.C.] abwesend ist.

In anderen Provinzen giebt es unbesoldete überzählige Commisaere und Conceptspracticanten, welche eine ergiebige Aushülfe gewähren. - Eine andere Hauptursache, warum die hiesigen Kreisämter ihrer eigentlichen Bestimmung nicht vollkommen ent-

der slavischen Sprache viele Schwierigkeit, weil sie ihrem Baue nach ganz verschieden und ungemein wortreich ist."

865 Almanacco 1834, 91: 2. Kreiskommissär im Kreisamt Zara Francesco Florido Nachich, dottore in legge.

866 Dazu steht eine ausführliche, von Rossetti selbst als Gutachten bezeichnete Randanmerkung in der Gliederung, die die problematisch geringen Aufstiegsperspektiven für die in heutiger Begrifflichkeit »prekär« beschäftigten sog. Praktikanten deutlich wiedergibt (Unterstreichung im Original): »ad 179) Viele Geschäfte wenig Personal. Es mangeln Leute die den Kreisamtsdienst kennen. Es fehlen Concepts-Practicanten. Es wird bald kein Nachwuchs mehr für das Gub[ernium] u. die Kreisämter seyn[,] niemand herkommen, wenn die Concept Practikanten sitzenbleiben und Prätoren eingeschoben werden; zumal wenn diese noch dazu von der administrativen Prüfung befreit werden, die den Conc. Practicanten blutigen Schweiß kostet. Dies ist mein ehrfurchtvolles Gutachten."

867 Eigentlich gemeint ist offenkundig: die zu den Präturen erwähnte ...

868 Ein erneuter Hinweis auf teilweises Fortgelten von früheren Rechtsverhältnissen in der habsburgischen dalmatinischen Verwaltungspraxis; vgl. oben, Anm. $717 \mathrm{zu} \S 147$; sowie auch Maštrović: Razvoj sudstva, $61 \mathrm{f}$. zur schrittweisen Einführung des österreichischen Rechtssystems in den ersten Jahren nach 1813/14.

DigiOst 1 | 212 
sprechen können, liegt darin, weil außer den Kreishauptleuten Naverschnigg und Baron Schaller Niemand bei den Kreisämtern angestellt ist, welcher was ein Kreisamt seyn sollte und ist, außer[-halb von] Dalmatien zu sehen und zu lernen Gelegenheit [Qu 80 / 4] gehabt und außer Nachich und Stermich keine Dalmatiner beim Kreiskommissariat der die Studien ordentlich absolvirt [gestrichen: hätte; ergänzt: hat], auch noch keine Kreisamts-Instruktion hierlands eingeführt worden ist, die zum kreisämtlichen Wirken die Anleitung gäbe, die aber, ohne eine lebendige Schule der practischen Anschauung nichts anders als eine größere Zweckmäßigkeit und Regelmäßigkeit in der Actenbehandlung bewirken wird.

$\$ 180$ [Mittel abzuhelfen] Da eine radicale Verbesserung dieser wesentlichen Umstände nur mit der Zeit erwartet werden kann, so glaube ich mich diesfalls darauf beschränken zu sollen, allerunterthänigst zu bemerken, daß über meinen Auftrag der Entwurf zu einer Kreisamtsinstruktion bereits verfasst worden und man nur der Erledigung über die unter den [sic] 25 September 3771/5010 erstatteten Gubernial Anträge wegen Erweiterung des Wirkungskreises der Behörden entgegen sieht, um jenen Entwurf sodann hiernach modifizirt in Gubernial Berathung zu nehmen.

Mit Beziehung auf das, was ich rücksichtlich der politischen Prüfung [Qu 81/2] bei den Praeturen erwähnte, glaube ich in tiefster Ehrfurcht in Antrag bringen zu sollen, daß um so weniger bei Besetzung eines Kreis Kommissärs Postens die Dispensation von derselben statt haben dürfte.

Da übrigens die Landwirthschaft und das, hier so äußerst ${ }^{869}$ vernachlässigte Forstwesen einer besonderen Sorgfalt der Regierung bedarf und hierlands, so wie es früher in den anderen Provinzen, als die Forstverwaltung es noch erforderte, der Fall war, das Bedürfniß eigener Forstcommissäre sehr groß ist, so erlaube ich mir ehrfurchtsvollst darauf anzutragen, daß Eure Majestät den Waldinspektor Karge ${ }^{870}$, welcher sich bereits hier befindet, beim Gubernium auf immer zu belassen und annebst, sobald er seine Vorschläge an das Gubernium erstattet und dieses die weiteren Verfügungen wegen Aufrechthaltung der Forstcultur und [Qu 81 / 2] eigentlich wegen Anpflanzung und Züglung der Wälder, definitiv festgesetzt haben wird; für den Kreis Zara und Spalato überall einen, für Ragusa und Cattaro, aber mit dem Sitze in [gestrichen: Cattaro] Ragusa einen dritten Waldbereiter allergnädigst zu bewilligen [ergänzt: geruhen], weil sonst ohne diese Verfügung alle Instruktionen, welche dießfalls ergehen werden, gewiß größtentheils schon wegen der Unkunde dieses Faches bei den übrigen Beamten unausgeführt und die Wälder in der nämlichen Verwüstung bleiben würden.

869 Bleistiftunterstreichung und mit Bleistift Randbemerkung: »schon abgeschrieben«, offenbar ein eigener Bearbeitungsvermerk des Schreibers Rougier zum Stand der Reinschrift.

870 Dieser ist im Almanacco 1834 und 1835 nicht verzeichnet, aber sicher identisch mit dem von Petter: Dalmatien, Bd. 1, 133 dankend erwähnten Forstinspektor Joseph Kargl; vgl. das Zitat oben Anm. $488 \mathrm{zu} \S 97$. 
Ich besorge nicht daß Eure Majestät diesen allerunterthänigsten Vorschlag aus dem Grunde ungnädig aufnehmen werden, weil die in andren Ländern bestandenen Forstcommisaere bereits aufgehoben worden sind; denn, wenn wir mit dem Forstwesen nur zum Theile auf den [Qu 81 / 3] Grad kommen auf welchen selbes in jenen Ländern steht; so wird man die Forstcommisaere auch hier ohne weiteres wieder einziehen können; welches jedoch, nach meiner allerunterthänigsten Meinung, sicher vor 20-25 Jahren, wenn in dieser Hinsicht alles glücklich von statten gehet, nicht geschehen könnte. ${ }^{871}$

Von noch höherer Wichtigkeit erscheinen mir aber die Zutheilung eigener Wirtschaftskommisäre für eine bestimmte Zeitperiode.

Der Zustand der Landwirthschaft in Dalmatien, welchen ich bereits in aller Unterthänigkeit geschildert habe, ist auf einer so minderen Stufe, daß er eines außerordentlichen Mittels zu seiner Emporbringung absolut bedarf.

Es bestehen hier keine Musterwirthschaften und wenn sie auch vorhanden wären so könnten sie hierlands von geringem Nutzen seyn, weil sie ihre Wirksamkeit nur auf ihre nächste Umgebung äußern würden und der Morlake ohne practische [Qu 81 / 24 Belehrung und Uiberweisung ${ }^{872}$, wozu doch nur wieder eigene, dafür bestimmte, Individuen verwendet werden müßten, nach [gestrichen: seiner gewohnten] gewohnter Weise seine Wirthschaft zu bestellen fortfahren würde. ${ }^{873}$

Die Geistlichkeit, welche hierin durch die Aufstellung lebender Beispiele am meisten wirken könnte, ist im Allgemeinen genommen noch zu roh und ungelehrig um von derselben etwas Bedeutendes in dieser Beziehung zu erwerben.

Ich wäre demnach der allerunterthänigsten Ansicht, daß hierzu einige in der Wirthschaft selbst schon erfahrene und auch darin unterrichtete Dalmatiner, welche die Landessprache und die Bevölkerung wohl kennen ausgewählt und auf eine ausgezeichnete Musterwirthschaft in den deutschen Ländern auf mehrere Jahre zur gründlichen und rationellen Erlernung der Landwirthschaft abgesendet werden und wenn sie darin genügende Kenntniße und Erfahrung sich erworben haben, wenigstens den Kreisämtern von Spalato, [Qu 82 / 1] Zara und Cattaro einer derselben als ökonomischer Comissaer zugetheilt werde, weil in jenem von Ragusa die Agricultur zweckmässiger betrieben wird

871 Gleichsam ein Plädoyer für Gleichzeitigkeit des Ungleichzeitigen, bzw. für Sonderregelung für Dalmatien wegen dessen großen Problemen in den Bereichen der Forst- und der Landwirtschaft.

$872 \mathrm{Zu}$ verstehen als »Unterweisung, Anleitung «.

873 Die Passage ist nicht nur eine Ergänzung zu dem Morlakenbild Lilienbergs und dem Morlakendiskurs noch seiner Zeit, sondern auch wieder ein Hinweis auf die diagnostizierte Notwendigkeit, amtliche Herrschaft (und von dieser kommenden gesellschaftliche Anstöße) in personalisierten Formen umzusetzen.

DigiOst 1 | 214 
und alle Gründe ${ }^{874}$ den Edelleuten gehören, die ohnehin darinn [sic] unterrichtet sind und auf ihr Interesse besser sehen, ein solcher daher für Ragusa nicht nothwendig ist. ${ }^{875}$

Diesen Agriculturcommissaeren dürfte die Bestimmung ertheilt werden, bei jenen Kreisämtern alle, die Emporbringung der Landwirthschaft bezweckenden Arbeiten zu besorgen, auf dem Lande herum zu reisen, die Bauern practisch zu unterweisen und zu belehren, und wenn sie im Amte sind, sich, in so weit es der Hauptzweck gestattet und sie die Fähigkeiten dazu besitzen, auch sonst in Concept oder Kanzleysache zur Aushülfe verwenden zu lassen.

Hierdurch würde auch den politischen Kreiskommissären eine Erleichterung gewährt und selbe [die Kreiskomissäre; K. C.], desto eher im Stande seyn, ihre periodischen Bezirksbereisungen, welche für [Qu 82 / 2] Dalmatien höchst nothig und von großer Wichtigkeit sind ${ }^{876}$, ohne Furcht so leicht wie jetzt in Akten-Rückstände zu gerathen, vorzunehmen und solche nicht zu übereilen, nachdem ihnen hierbei besonders zur Pflicht gemacht werden müßte, die Amter der Präturen, der Comunen und der Territorial-Officire gründlich zu untersuchen, die Klagen der Bevöllkerung [sic] aufzunehmen, ihnen abzuhelfen, und Alles zu erheben und anzupreisen, was den Allerhöchsten Dienst und die Wohlfahrt der Landesbewohner zu befördern geeignet wäre; so wie man durch die Wirtschaftskommisäre in der Landwirthschaft wenigstens um ein halbes Seculum früher zum Ziele gelangen wird.

Die Zweckmäßigkeit eines durch practischen Unterricht nützlich einwirkenden Individuums ist auch bereits in früheren Zeiten anerkannt gewesen und es war zu diesem Zwecke ein gewisser August Krause als agrarischer Inspektor [Qu 82 / 3] bereits ernannt, da er aber bald hierauf eine andere Bestimmung erhielt, so hatten Eure Majestät mit allerhöchster Entschließung vom 24 April 1830 Z 9316/1111 zu befehlen geruht, daß es [das Landesgubernium; K.C.] von [der; K. C.] Bestimmung eines agrarischen Inspektors abzukommen habe.

Da Eure Majestät aber die Allerhöchste Gnade gehabt haben mir zu erlauben dasjenige vorzuschlagen, was ich für das Beste dieser Provinz als zweckmäßig erachte ${ }^{877}$ und ich von den agronomischen Commissaeren das Ersprießlichste zu Hebung der Land-

874 Im Sinne von Grundstücken.

875 Eine Präzision von Lilienbergs Projekt der Landwirtschaftskommissäre (vgl. Clewing: Staatlichkeit, 127 f. zur Abwürgung des Vorstoßes durch die Zentralstellen im Jahr 1835, nach dem Tod des Kaisers). Zum eventuellen Vorsprung der Landwirtschaft im alten Gebiet von Dubrovnik vgl. oben Anm. 366 zu $\$ 70$.

876 Auffällig ist das über die eigene Reise hinaus wiederkehrende Thema der in den Augen Lilienbergs - analog zum Herrschaftssystem des Monarchen - für die Verwaltungseffizienz nötigen dienstlichen Bereisungen und der damit verbundenen unmittelbaren Einwirkungsmöglichkeiten und Ortskenntnisse. Vgl. $\$ 174$, sowie auch die entsprechende Beurteilung durch Erzherzog Franz Karl (?), hier im Anhang, Seite 320.

877 Vgl. in der Einleitung, Seite 33 den hierin in der Tat weit gefassten Wortlaut des kaiserlichen Handschreibens vom 30. April 1833. 
wirthschaft, deren höchst unvortheilhafte Lage ich unter diesem Artikel treu und deutlich geschildert habe ${ }^{878}$, erwarten zu dürfen überzeugt bin, so wage ich es in tiefster Ehrfurcht zu hoffen, daß Eure Majestät diesen allerunterthänigsten Antrag nicht ungnädig aufnehmen werden ${ }^{879}$. Die Mehrauslage für diese Commissäre wird durch die bei dem, an den Obersten Kanzler erstatteten [Qu 82 / 4] Anträge über die Reduzirung der Besoldungen für Gemeindebeamte vorgeschlagene Ersparung von 8000 Gulden ohnehin reichlich ersetzt. ${ }^{880}$ Diese beiden, die Allerhöchste Bewilligung von Forst und Agriculturs-Commisaeren bezielenden, Anträge sind allerdings, wie vieles Andere, das ich mir die Freiheit nehme, hie und da allerunterthänigst vorzuschlagen, Ausnahmen von der Regel; aber ich sehe mich verpflichtet, zum Besten des Landes und Eure Majestät Allerhöchsten Dienstes in tiefster Ehrfurcht zu bekennen, daß man noch eine längere Zeit dieses Land, mit ${ }^{881}$ Ausnahme von mehreren in anderen Provinzen geltenden Grundsätzen wird regieren müssen, wenn man am Geeignetesten zum Ziele gelangen will, weil dieses Land selbst sowohl in moralischer als in phisischer Hinsicht, [gelöscht und mit Fehlzeichen am Rand versehen: der höchst unvortheilhafen [sic] Lage ich unter diesem Artikel treu und deutlich geschildert habe, ${ }^{882}$ wenn man Alles gut prüft, bis jetzt eine Ausnahme von der Regel ist. -

[Qu 83 / 1]

\section{Catastral-Direction}

$\$ 181$ Im Kreise Spalato habe ich auch von dem ämtlichen und technischen Wirken der Catastral-Direktion Einsicht genommen und mich überzeugt, daß die zwei Inspectorate, jedes mit 13 Geometers und 14 Adjuncten unter der Leitung des provisorischen Directors Panciera ${ }^{883}$, ihre Operationen zweckmäßig behandelten.

878 Dieser eingeschobene Satzteil ist eine Ergänzung in Tinte in der Schrift von Rossetti am Seitenrand. Abgesehen von »diesem Artikel « $\$ 180$ ist auch an die $\$ \$ 70 \mathrm{ff}$. zu denken.

879 Ein Beispiel für die eigenständige Selbstpositionierung Lilienbergs, der den pauschalen kaiserlichen Auftrag zu Vorschlägen hier sogar zu einer Wiederaufnahme von Vorschlägen nützt, die vom Kaiser selbst bereits einmal abgelehnt worden waren.

880 Vgl. oben, in $\$ 162$.

$881 \mathrm{Zu}$ verstehen als: unter Ausnahme von; man sollte also für Dalmatien Ausnahmen von ansonsten gesamtstaatlich verbindlich geltenden Regeln machen.

882 Diese sprachlich hier nicht korrekt angepasste Passage wurde nach der Streichung auf der Seite davor zur Landwirtschaft eingefügt. Für sich betrachtet, könnte sie auch von einem Verständnisfehler aus einem Diktat her stammen. Noch leichter wäre sie aber als Abschriftfehler zu erklären und ist insoweit ein weiteres Indiz dafür, dass die Gesamtabschrift eine Mischung aus Diktat und der Zusammenschrift von Notizen bzw. aus einer sonstigen textlich unvollständigen Vorlage war.

883 Almanacco 1834, 89: Sotto-direttore (eine Position als direttore wird nicht aufgeführt) der Direzione della misurazione catastale Giovanni Pietro Panciera, ingegnere civile, f.f. di direttore. 
Um Eurer Majestät ersichtlich zu machen, wie weit die bezüglichen Vermessungsarbeiten vorgeschritten sind, schließe ich hier in tiefster Unterthänigkeit eine Uibersichts Charte unter der Zahl 21. ${ }^{884}$ bei, aus welcher erhellet, daß die ganze Catastral-Vermessung erst anno 1839 in Cattaro und in ganz Dalmatien endet. ${ }^{885}$

\section{Forza territoriale}

$\$ 182$ Die forza territoriale ist ein von den Türken herstammendes Institut, wie es die Benennungen Serdar und Arambassa darthun, welches in den von den Türken übernommenen [Qu 83 / 2] Theilen dieser Provinz sich befand, und die einzige executive Authorität zwischen den türkischen Capitani oder Comandanten und dem Volke war, wie dieß in den angränzenden Provinzen noch ist. ${ }^{886}$

Die venezianische Republick behielt dieselbe bei, weil sie weniger, als jede andere Authorität kostete, zugleich als herkömmlicher Hebel diente, das Volk erforderlichen Falls unter Waffen zu bringen und sich desselben auch bei augenblicklicher Gefahr und feindlicher Bedrohung aushülfsweise zu bedienen. Man fand es bequem diese Anstalt auch in jenen Landestheilen auszudehnen, wo sie früher sich nicht befand, in den Seestädten aber mehrere Compagnien von Canonieri, Bombardieri, die auch zur Landmilitz gehörten, einzuführen.

Unter den nachfolgenden Regierungen war sie ebenfalls mit mancherlei Modifizierungen beibehalten und bildete unter der illirischen ein Regiment National-Garde [Qu 83 / 3]

884 Siehe Karte 14, hier im Anhang, Seite 306, bzw. Originalbeilage XXI, Reinschrift fol. 126 / Scan 254 (mit Kartenumsetzung des Standes von 1833, Ausblick auf die Arbeiten des laufenden Jahres 1834 und auf die Planung der Folgejahre bis 1839).

885 Vgl. zum Fortgang der franziszeischen Katasterarbeiten in Dalmatien Bajić-Žarko: Arhiv mapa za Istru i Dalmaciju, dort insbesondere die Einleitung, $11 \mathrm{ff}$. Zu einem 2008-2010 an den Universitäten Klagenfurt und Innsbruck von Helmut Rumpler geleiteten Pilotprojekt für die wissenschaftliche Auswertung der Katasterkarten am Beispiel Kärntens und der Bukowina siehe die Projektseite http://www.franziszeischerkataster.at/index1.html (zuletzt 9.12.2013). Die dalmatinischen Katasterkarten bearbeitet ein laufendes Projekt von Marko Rimac (Universität Split).

886 Zur Forza territoriale hat für die Zeit der österreichischen Herrschaft jüngst vor allem Tado Oršolić (Zadar) geforscht. Verwiesen sei besonders auf seine Monographie zum Themenfeld Armee, Forza territoriale und der Gendarmerie in den Jahren 1797 bis 1914; Oršolić: Vojna Dalmacija u 19. stoljeću. Dort 25-34 mit Angaben zur Entwicklung der Forza territoriale im venezianischen Dalmatien (17./18. Jahrhundert), und darin 27 auch knapper Hinweis auf das von Lilienberg angesprochene Entstehen aus zuvor osmanischen Strukturen. 
nach französischem Fuße, welches im Jahre 1814 vom Baron Tomassich ${ }^{887}$ unter provisorischer Wiedereinführung der früheren forza territoriale, aufgehoben wurde. ${ }^{888}$

Seit dieser Zeit ist Vieles für und gegen den Fortbestand und über die Organisirung derselben geschrieben und höheren Orts in Antrag gebracht, zuletzt aber im Jahre 1830 Z 98/p von meinem Vorgänger [Tomassich] ein förmlicher Plan zu ihrer definitiven Organisirung der vereinten Hofkanzlei vorgelegt worden.

Gegenwärtig besteht sie aus vier Colonnellaten:

1 Aus jenem von Zara mit einem Colonnello, 5 Serdaren und 9 Viceserdaren;

2 zu Sebenico mit einem Colonnello, 5 Serdaren und 5 Viceserdaren;

$\underline{3}$ zu Spalato mit einem Colonnello 6 Serdaren und 2 Viceserdaren;

4 und jenem zu Macarsca mit einem Colonnello 5 Serdaren und 2 Viceserdaren

Jeder Serdarie sind 24 Panduren [Qu 83 / 4] zugewiesen; übrigens werden aber noch hin und wieder zu Streifcolonnen und zu anderen besonderen Zwecken zeitweise Verstärkungen durch außerordentliche Panduren gestattet.

Der Kreis Ragusa erhielt nur einen Sopraintendenten und 3 Vice Sopraintendente, jener von Cattaro einen Sopraintendente mit vier Vicesopraintendenti, welche in ihren Verrichtungen den Serdaren und Viceserdaren gleichkommen.

Die Besoldungen und Kanzleipauschalien [sic] der territorial Officiere belaufen sich im Ganzen auf jährlich 27620 Gulden, die Arambassen bekommen nur für die Escorte von Arrestanten und Ararialgeldern festgesetzte Gebühren welche sich auf $\underset{\mathrm{m}}{9-10}\left[\begin{array}{c}9- \\ \text { - }\end{array}\right.$ $10000]$ Gulden jährlich belaufen.

Unter den Offizieren der forza terr[itoriale] fand ich mehrere, die sich durch männliche Haltung, Muth und Energie auszeichnen und es ist nicht zu läugnen daß die Panduren unter Anleitung solcher Männer für die öffentliche Sicherheit, besonders aber in Verfolgung der Verbrecher, sehr nützliche Dienste leisten könnten, weil der Morlake [Qu 84 / 1] kühn ist, den Tod gering achtet, in den unwegsam scheinenden Gegenden leichter als das Militair fortkommt und alle geheimsten Schlupfwinkel seiner Heimat kennt; daß aber die Forza terr[itoriale] in ihrem gegenwärtigen Zustande ohne Organisirung,

887 Der aus Rijeka gebürtige General Franz Xaver Tomassich / Franjo Ksaver Tomašić hatte 1813 die nach Dalmatien gegen die Franzosen vorrückenden österreichischen Truppen befehligt und war in unmittelbarem Anschluss daran von 1814 an bis 1831 Zivil- und Militärgouverneur der Provinz. Zu seiner Rolle bei der Belagerung und Eroberung von Zadar im November/Dezember 1813, die seine Bestellung zum Gouverneur einläutete, vgl. Bralić: Zadar kao administrativno i političko središte Dalmacije za francuske uprave, hier 369 und 371.

888 Das weiter oben von Lilienberg angeführte Argument - Venedig habe die Forza territoriale beibehalten, weil es die kostengünstigste Lösung war - lässt sich in der Logik seiner eigenen Darstellung also auch auf Österreich anwenden! Tatsächlich gilt die französische Phase in der Geschichte dieser Territorialmiliz, und zwar bereits für die erste Teilphase innerhalb des Königreichs Italien ab 1806, in der Forschung als der Zeitabschnitt mit der deutlich höchsten Effektivität dieser Einrichtung. Vgl. Oršolić: Teritorijalne snage (forza territoriale). Njihov preustroj i ustroj 1806.-1809., hier $344 \mathrm{f}$.

DigiOst 1 | 218 
ohne Disziplin und ohne vollkommene Dienstinstruktion, nur sehr wenig leistet, dagegen aber wegen ihrer Mängel, durch die vielen Willkührlichkeiten, die sie sich erlauben zu können bei ihrer executiven Bestimmung nur zu häufige Gelegenheit hat, ohne daß der gedrückte Landmann immer den Muth hätte, Mißbräuche der Obrigkeit anzuzeigen hin und wieder eine wahre Geißel der Bevöllkerung wird. ${ }^{889}$

Diesem, so weit es ohne eine förmliche Organisirung geschehen kann, entgegen zu wirken, habe ich mir es zur Regel gemacht, jede zu meiner Kenntniß gelangende Willkührlichkeit der Terr[itorial] Offiziere und Panduren mit aller Strenge untersuchen [Qu 84 / 2] und bestrafen zu lassen. Auch habe ich vor zwei Jahren einige provisorische Normen erlassen, um die Wirksamkeit dieser Forza territoriale einstweilen möglichst $\mathrm{zu}$ regeln und Missbräuchen thunlichst zuvorzukommen. ${ }^{890}$

[Gestrichener begonnener und inhaltlich unvollendeter neuer Absatz: Nach den von mir gemachten Beobachtungen zeichnen sich folgende Terr. Offiziere aus:]

Da ich übrigens über den Werth dieser Forza terr. und die Dringlichkeit ihrer Organisirung bei Gelegenheit der Erledigung des allerhöchsten Kabinetschreibens vom 26 Feb[ruar] $1834 \mathrm{Z} \mathrm{308/p}$ unter dem 10 April l[aufenden] J[ahre]s bereits meine allerunterthänigsten Ansichten umständlich ausgesprochen habe, so erübriget mir nur noch in tiefster Ehrfurcht kurz anzuführen, daß dieses Institut zwar ganz und gar nicht mit dem Wesen und dem Geiste der von Eurer Majestät Allerhöchster Weisheit diesem Lande verliehenen Administration übereinstimmt; daß selbes jedoch durch einen Zeitraum von 20-30 Jahren noch unentbehrlich [Q $u$ 84 / 3] bleiben werde. ${ }^{891}$

So lange nämlich das Landvolk nicht aus dem Zustande seiner Rohheit einigermaßen emporgerißen, die moralische Kraft, die in anderen Provinzen bei der administrativen Execution ungleich wirksamer ist, die Stelle der materiellen wenigstens zum größten Theile zu ersetzen vermögen [wird], so lange das Landvolk in den Gränzbezirken auch

$889 \mathrm{Zu}$ diesen deutlichen Angaben zu Willkür, Amtsmissbrauch und Korruption in der Forza territoriale während der 1830er Jahre sowie den Lilienbergschen Maßnahmen zur Bekämpfung dieser Phänomene vgl. auch Oršolić: Vojna Dalmacija, Kapitel 4.4: „Samovolja, korupcija, zlouporaba položaja, neposlušnost« (Willkür, Korruption, Amtsmissbrauch und mangelnder Gehorsam), 142-146, der sich dabei intensiv auf einige anderweitige Lilienbergsche Berichte stützt. Zu der Fortdauer von schlechter Effektivität und Willkürmöglichkeiten bis zum Ende dieser Einrichtung (an deren Stelle zu Beginn des Neoabsolutismus die unmittelbar staatliche und wesentlich straffer organisierte Gendarmerie trat) siehe Angaben für1848 in Clewing: Staatlichkeit, 81, besonders Anm. 122.

890 In Fortführung und Präzisierung von Regularien, die 1821 erlassen worden waren: Regolamento della forza territoriale, veröffentlicht in der Raccolta delle leggi ed ordinanze per la Dalmazia 1832, wie zitiert von Oršolić: Vojna Dalmacija, 145.

891 Vgl. Clewing: Staatlichkeit, $80 \mathrm{f}$. zu Aufgaben und Mängeln der Miliz als neben dem Militär einziger Verkörperung der Staatsgewalt und öffentlichen Sicherheit auf dem flachen Lande. 
zur Selbstvertheidigung der Waffen unumgänglich bedürfen, oder nicht eine ungleich größere Militairmacht hier eingeführt wird, um die Sicherheit der Personen und des Eigenthums vollkommen zu begründen, und bis die Conscription mit der Landwehreinrichtung vollkommen in Gang gebracht seyn wird, der Bestand eines vollkommen geregelten und möglichst disziplinierten Instituts dieser Art unentbehrlich seyn muß, da es seit undenklicher Zeit, außer dem - nicht immer und nicht überall [Qu 84 / 4] anwendbaren Militair der einzige Hebel, das einzige executive Mittel der Regierung gewesen ist, deßen sie zur Ausführung aller Gattungen ihrer Anordnungen sich bedient hat ${ }^{892}$

\section{Militair}

$\$ 183$ Die Mangelhaftigkeit der gegenwärtigen Forza terr[itoriale], welche wegen ihres langen provisorischen Zustandes in mehreren, den Hofstellen aus den vieljährigen bezüglichen Verhandlungen wohlbekannten ${ }^{893}$, Beziehungen ausgeartet ist und daher auch nach ihrer Organisirung noch einige Zeit bedürfen wird, um sich zu consolidiren: macht es nicht selten nothwendig, bei ernsteren Vorfällen, als: bei Streiten zwischen bewaffneten Gemeinden, bei Sicherung der Landstraßen, bei Ergreifung von Uibelthätern, wegen Contrabanden und zur Sicherung der Gränzen, sich oft der ergiebigen Mitwirkung des Militairs zu bedienen.

[Qu 85/1] Da jedoch die Besatzung für Dalmatien nur auf das höchst Nothwendige beschränkt ward, und wegen der unverhoften gewaltthätigen Besetzung von Ancona durch die Franzosen ${ }^{894}$ über 900 Mann mehr auf die Inseln detachirt [abgeordert, stationiert; K.C.] worden sind, als es für den Friedensstand ausgemessen war, welche fortan dort verbleiben müssen, so ergiebt sich der unangenehme Fall, bei den wichtigsten Umständen die politischen Behörden und die Forza terr[itoriale] mit dem regulären Militär nicht so unterstützen zu können, wie es nothwendig wäre.

892 Vgl. mit ganz ähnlicher Einschätzung und Formulierung noch Ban Josip Jelačić 1849, in seiner Funktion als Ende 1848 ernannter dalmatinischer Zivil- und Militärgouverneur, zitiert in Clewing: Staatlichkeit, 80.

893 Hier hat die Spitze gegen die von den Gubernialberichten offenbar regelmäßig wenig beeindruckte Zentralverwaltung schon eine nachgerade ironische Note.

894 Dem französischen Landungsunternehmen im päpstlichen Ancona vom 22. Februar war im Januar eine österreichische Militärintervention gegen die Unruhen im nördlichen Kirchenstaat vorausgegangen. Die französische Okkupation der Stadt dauerte bis zum 1. August 1832; die habsburgischen Truppenvorkehrungen in Dalmatien gegen eine Wiederholung etwaiger französischer Aktionen blieben aber, wie Lilienberg zu entnehmen ist, noch Jahre danach bestehen. Wie der umfassenden Studie zu Metternich und der Orientalischen Frage von Miroslav Šedivý zu entnehmen ist, hatte die französische Präsenz in der Adria die Wiener diplomatischen Versuche von 1832/33 ausgelöst, mit der Hohen Pforte einen Übergang von Klek und Sutorina an Österreich auszuhandeln (Šedivý: Metternich, the Great Powers and the Eastern Question, 684f.), und so indirekt zur Genehmigung der Lilienbergschen Bereisung Dalmatiens beigetragen (s. a. oben, Einleitung, Seite 33). 
Das Gubernium fand sich demnach veranlaßt, in einem zur Verminderung der Verbrechen und zur mehreren Sicherung der Personen und des Eigenthums erstatteten Berichte an die vereinte Hofkanzlei unter dem 28 Mai 1[aufenden] J[ahres] Z 7311/2506 unter Anderen auch die Vermehrung der hierländigen Besatzung um ein Battaillon Jäger in Antrag zu bringen und ich, von der Nothwendigkeit [Qu 85 / 2] dessen vollkommen überzeugt, kann nur Eure Majestät allerunterthänigst bitten, diesen Antrag allergnädigst zu genehmigen. Diese Vermehrung wird auch in anderen Beziehungen sehr gelegen, besonders für Ragusa und Cattaro kommen, wo Eure Majestät die Grundsteuern Allergnädigst einzuführen gedenken, und es schiene mir sehr zweckmäßig, wenn diese Vermehrung der Truppen schon geschehen wäre, ehe man von der Steuerbelegung Etwas erfahren hat ${ }^{895}$.

Rücksichtlich der Einführung der Conscription in Dalmatien habe ich bereits mit meinem früher erwähnten allerunterthänigsten Vortrage vom 10 April l[aufenden] J[ahres] Gelegenheit gehabt Eurer Majestät mein allerunterthänigstes Gutachten zu erstatten und habe mich auch bei meiner lezten Excursion vollkommen überzeugt, daß die von mir allerunterthänigst abgegebene Meinung, sowohl [Qu 85 / 3] für das Land, als für den Staat am zuträglichsten seyn wird. ${ }^{896}$

Uibrigens glaube ich nur noch in tiefster Ehrfurcht andeuten zu sollen, daß wegen Regulirung des hier noch äußerst unregelmäßigen Vorspannswesens ${ }^{897}$ unter dem 7. März 1820 Z 4207 das Gubernium seine Anträge der höheren Entscheidung unterlegt hat, welche noch gewärtiget wird, aber in der That um so dringender ist, als der arme, und in der Regel an Transportmitteln beschränkte Dalmatiner-Landmann ohnehin nur die halbe Gebühr bezieht.

895 Ein in sich faszinierender Beleg für die Schwäche der habsburgischen Staatlichkeit einerseits und für die behördliche Perzeption der Bedrohungen für die eigenen zivilen Behörden, wenn gegenüber einer nicht »disziplinierten« Bevölkerung größere staatliche Eingriffe vorgenommen wurden.

896 Eine Wehrpflicht wurde in Dalmatien erst 1853 eingeführt, in den Kreisen Dubrovnik und Kotor (wo daraufhin ein historiographisch schon mehrfach untersuchter Aufstand erfolgte; vgl. Koller: Bosnien und die Herzegowina im Spannungsfeld von «Europa` und «Außereuropa〉, 211 f.) sogar erst 1881. Das Lilienbergsche Gutachten von 1834 wurde von Oršolić nicht verwendet. Die von ihm aufgrund von Akten von 1835 und 1836 geschilderte Position des Gouverneurs galt der Einführung von Regeln für die (partielle) Konskription wie in Lombardo-Venetien (mit achtjähriger Dienstzeit der Konskribierten) und, als Anpassung an die besonderen Landesverhältnisse, der Errichtung eines »Militär-Polizei-Wach-Corps« im Lande selbst (Oršolić: Vojna Dalmacija, 120 bzw. 115). Vermutlich zielten auch die Vorschläge von 1834 auf derlei landesspezifisches Vorgehen ab. Erwähnenswert für die Beurteilung der Durchdachtheit vieler Lilienbergscher Vorschläge ist Oršolićs Einschätzung (115), das vorgeschlagene Wachkorps hätte im Realisierungsfall »den Bedürfnissen jener Provinz in Hinblick auf Verteidigung und öffentliche Ordnung vollkommen Genüge getan.«

897 Als Teil der öffentlichen Arbeitsverpflichtungen (Robot) der bäuerlichen Bevölkerung. 
Um inzwischen diese Last gerechter zu verthei[gestrichen: -digen; ergänzt: -len ${ }^{898}$ ], als es bisher geschah, Ungleichheiten, die vieler Orten Statt fanden, zu beseitigen, ein geordnetes Verfahren bei der Ausschreibung einführen [ohne "zu«, sic] [Qu 85/4] die richtige Bezahlung zu sichern und zugleich die häufigen Willkührlichkeiten und Bedrückungen zu hindern: hielt ich es für meine Pflicht, einstweilen durch das Gubernium, auf der Basis des gegenwärtigen Vorspannsistems, eine besondere Instruktion den untergeordneten Behörden zur Beobachtung vorschreiben zu laßen ${ }^{899}$.

[Qu $86 / 1]$

\section{Geistlichkeit - Seelsorge}

$\$ 184$ [Zustand derselben im Allgemeinen] Die Beschaffenheit und der Zustand der Geistlichkeit in Dalmatien verdient um so mehr Beachtung, als hierlands dieselbe unter den früheren Regierungen im höchsten Grade vernachläßigt worden ist; ferner, weil eben die Geistlichkeit der Hauptpfeiler der Volkserziehung, Sittlichkeit und Religiosität ist ${ }^{900}$; hierlands lands, aber, wo das Landvolk auf einer so niederen Stufe der Cultur stehet, mehr als wo immer sonst und in weit manigfacheren Beziehungen gerade von deren Einfluße Vieles für die Zukunft erwartet werden muß.

Der Erzbischof Novak ${ }^{901}$ ist sehr rechtlich und brav; beobachtet seine religiösen Pflichten sehr pünktlich, geht seiner Geistlichkeit mit vortrefflichem Beispiele voran; scheint mir aber zu gut und nachsichtig gegen die Mängel seiner Untergeordneten.

Im Bischof Bardini ${ }^{902}$, zu Sebenico, habe ich einen feinen artigen Mann und eifrigen Oberhirten gefunden.

898 Beispiel für Abschrift- oder Diktatfehler, mit anderer Schrift (wohl Rossetti) und anderer Tinte korrigiert.

899 Ein Beispiel für eigenmächtige Maßnahme Lilienbergs, entgegen bestehenden Regeln und Hierarchien, angesichts von (zu lange) ausständigen Vorgaben aus Wien.

900 Zur Zuweisung verwaltungsnaher Aufgaben an die katholische Geistlichkeit vgl. Clewing: Staatlichkeit, 103-105 und $110 \mathrm{f}$.

901 Almanacco 1834, 178: Ebf. von Zara, Arcivescovo e Metropolita di tutta la Dalmazia Monsignor Giuseppe Francesco Novak, president della commissione di pubblica beneficenza, e dell' i.r. commissione delle scuole elementarij. Der bereits 1821 zum Erzbischof von Zadar ernannte Böhme Joseph Nowak entsprach dabei der Vorgabe einer staatsrätlichen Bestimmung von 1818, derzufolge für dieses Erzbistum und das Bistum Dubrovnik keine Dalmatiner genommen werden sollten, sondern jemand aus den «alten Provinzen〉 mit Kenntnissen der »slavischen und italienischen Sprache«. Siehe dazu Bastgen: Die Neuerrichtung der Bistümer in Österreich nach der Säkularisation, 371, Anm. 1.

902 Bf. Filippo Domenico Bardini von Šibenik (Bf. von Šibenik seit 1830; Bf. von Hvar 18391865; auch kroatische Vornamensschreibung Filip Dominik). Für eine Namensliste der obersten Funktionsträger (Bischöfe und Domkapitulare) auf dem Stand von 1830 nach der abgeschlossenen und auch verwaltungsgeschichtlich wichtigen Neugestaltung der dalmatinischen Bistumslandschaft, siehe Ćosić: Državna uprava u Dalmaciji i crkveni preustroj 1828./1830. godine, 65). 
Bischof Miossich ${ }^{903}$ zu Spalato war einst Professor am hiesigen Seminarium und ist sehr gebildet.

[Qu 86 / 2] Jener von Cattaro Paulovich Lucich ${ }^{904}$ ist Eurer Majestät aus meinem allerunterthänigstem Vortrage vom 21 März 1833 in Folge des Allerhöchsten Kabinetschreibens vom 7 Jänner v[origen] J[ahre]s Z. 295 bekannt.

Meine Anwesenheit zu Cattaro habe ich dazu benutzt, um sowohl den Bischof, als seine Geistlichkeit, auf eine delicate Art von der Ersprießlichkeit eines, dem gegenseitigem Verhältniße von Unterordnung angemessenen, für die Zwecke unserer heiligen Religion so ersprießlichen, Betragens zu überzeugen.

Der Bischof von Ragusa ${ }^{905}$ entspricht in jeder Hinsicht seinem hohen Berufe und hält die Seelsorge in sehr guter Ordnung. - Ich darf aber nicht unterlassen, allerunterthänigst zu bemerken, daß ich die Ragusäer Geistlichkeit viel besser gebildet, als den Dalmatiner Clerus gefunden habe. ${ }^{906}$

Der Bischof Scacazo ${ }^{907}$ [sic] von Lesina ist zwar schon sehr alt und schwach und soll sich wie man mich versicherte durch einen Advocaten leiten lassen; [Qu 86/3] ich habe aber keine Gebrechen in seiner Diözese, wohl aber vollkommen bestätigt gefunden, daß

903 Bischof Paolo Clemente Miossich / Pavao (Pavo) Klement Miošić (bzw. mit dem Geburtsnamen Pavao Kačić Miošić) von Split (Bf. 1830-1837). Zuvor war er auch Gutachter für Zensurverfahren, etwa 1829/30 in demjenigen gegen die Arbeit Franz Petters, Encyclopädische Beschreybung Dalmatiens (die Frühfassung seiner beiden Bände von 1857). Dort sprach er sich gemeinsam mit einem weiteren Geistlichen mit Erfolg gegen die Veröffentlichtung aus (Pederin: Njemački putopisi, 113).

904 Almanacco 1834, 183: Bf. von Cattaro Monsignor Stefano Paulovich Lucich, preside della locale commissione di pubblica beneficienza (Stjepan Pavlović-Lučić, Bf. von Kotor 18281853).

905 Almanacco 1834, 181: Bf. Antonio Giuriceo, c.r. consigliere di governo, preside la commissione di pubblica beneficienza, e dell'opera pia. Mit Antun Giuriceo gelangte 1830 (päpstliche Bestätigung der kaiserlichen Ernennung von November 1829; Bf. von Dubrovnik bis 1842) entgegen den ursprünglichen Überlegungen des Wiener Staatsrats von 1818 doch ein geborener Dalmatiner ins Dubrovniker Bischofsamt (dazu Bastgen: Die Neuerrichtung der Bistümer in Österreich nach der Säkularisation, 371). Giuriceo stammte aus Krk, das in seiner Kindheit und Jugend noch zu Dalmatien zählte. In der Österreichischen Nationalbibliothek ist von ihm als Manuskript ein zeitgenössisch auch ins Kroatische übersetzter Hirtenbrief für den Klerus und das Kirchenvolk seiner Diözese von 1831 erhalten: Hs. Ser. n. 4318: Giuriceo, Antun: Lettera pastorale al clero e al popolo della diocesi di Ragusa, 27.3.1831. Tradotto in lingua nazionale da Anton[io] Ferd[inando] Putizza, Parocco di Canussa.

906 Ein weiteres Beispiel dafür (neben der Landwirtschaft und den weltlichen Bildungsverhältnissen), dass die Verhältnisse im Gebiet der ehemaligen Republik Ragusa von diversen Zeitgenossen für besser erachtet wurden als im ehemals venezianischen Gebiet der Provinz; allem Anschein nach mit einigem Grund.

907 Almanacco 1834, 182: Bf. von Lesina Monsignor Giovanni Scacoz, dottore in sacra teologia, commendatore dell' imperial ordine austriaco di Leopoldo, preside della locale commissione di pubblica beneficienza. (Bf. von Hvar 1822-1837; kroatische Namensschreibung Ivan 
er in der Religiosität, besonders aber in der Wohlthätigkeit gegen die Armen, von Keinem übertroffen wird.

Da ich von der Nothwendigkeit einiger Herstellungen in den bischöflichen Residenzgebäuden zu Spalato, Ragusa und Sebenico mich überzeugte, so veranlaßte ich die Beschleunigung von deren Verhandlungen durch das Gubernium. Das ganz neue anständige erzbischöfliche Gebäude von Zara ist von dem Erzbischof Novak im vorigen Jahre bezogen worden.

Ein besonderes Anliegen der Bischöfe von Zara und Spalato ist die Organisirung ihrer Capitel, die in der That auch sehr wünschenswerth ist, da hiervon sehr Vieles für die gute Ordnung in den Religions und kirchlichen Angelegenheiten abhängt. In dieser Beziehung glaube ich allerunterthänigst anführen [Qu 86 / 4] zu sollen, daß nach geschehener Zurückweisung der früheren Vorschläge für die canonicate des hiesigen erzbischöflichen Capitels am 25 Juny l[aufenden] J[ahre]s $N^{\circ} 10978$ ein neuer Antrag und für jene von Spalato [gestrichen: $\mathrm{am}^{908}$ ] im Dec[ember] v[origen] J[ahres] Z $20006 \mathrm{er}$ stattet worden ist.

$\$ 185$ [Schilderung des Clerus] Den Dalmatiner Clerus habe ich zu meinem größten Leide weit unter meiner, obgleich geringen, Erwartung gefunden; welches besonders die Landgeistlichkeit trifft. ${ }^{909}$

Rohheit, Beschränktheit, krasse Ignoranz, Vorurtheile, Aberglaube, Mangel aller Bildung, so daß sehr viele kaum lesen und schreiben können, und sich kaum durch die Kleidung von dem gemeinen Morlaken selbst unterscheiden, dem sie in der Regel im Schmutze fast gleich kommen, habe ich als Charakterzeichen an den übleren Landgeistlichen vielfältig bemerkt.

Daher kommt es, daß sie von ihren [Qu 87 / 1] Pfarrkindern wenig geachtet sind und von den Meisten um so weniger eine nützliche Einwirkung sich erwarten läßt, als ihre

Skakoc). Zu seinen ungewöhnlich regen Initiativen im Bildungsbereich der 1820er Jahre vgl. Clewing: Staatlichkeit, 113 und $124 \mathrm{f}$.

908 Das fehlende Datum hätte in die freigelassene Stelle nachgetragen werden sollen, es war dann anscheinend aber für die Verwaltung selbst nicht auffindbar, daher bloß Datierung auf »Dezember «.

909 Vgl. zum äußerst schlechten Bildungsstand der größten Teile der katholischen Geistlichkeit im Lande aufgrund innerkirchlicher Quellen (vor allem der von Kaiser Franz I. 1804 im Kernbereich des Reiches und ab den frühen 1820er Jahren auch in Dalmatien angeordneten bischöflichen Visitationsberichte an den Kaiser) Clewing: Staatlichkeit, 109-114. Bezeichnend sind auch die Angaben von Franz Graf Hohenwart in seinem amtlichen Zustandsbericht Dalmatiens von 1829 (HHStA, StK Provinzen Dalmatien 7 [alt 7/8], alt 8, fol. 294): Die Belehrung der morlakischen Bevölkerung durch die Geistlichen sei an sich die einzige Hoffnung für eine Besserung der Zustände unter den Morlaken, die Geistlichkeit sei aber selbst völlig ungebildet. Er liefert dafür auch das bezeichnende Detail, dass innerhalb der Messfeiern auf dem Lande Predigten überhaupt nur in der Fastenzeit erfolgten. 
eigene Moralität sehr oft das schlechteste Beispiel giebt und in nicht seltenen Prozeduren über deren Ausartungen Dinge vorkommen, worüber ich und das Rathsgremium erröthen müssten.

In Folge dieses üblen Beispieles habe ich an mehreren Orten mit Bedauern einen größeren Grad von Immoralität unter der Bevölkerung bemerkt, wozu auch zum Theile der Leichtsinn der, unter der vorigen Regierung hier gewesenen Franzosen den Grund gelegt hatte, und häufige Concubinate unter dem gemeinen Volke ${ }^{10}$, Abneigung gegen den Kirchenbesuch, gegen die Beichte und Comunion, Lezteres sogar unter den Gebildeteren, angetroffen.

Ich habe zwar alles Mögliche [Qu 87 / 2] angewendet, um diese Unordnungen durch den Einfluß der Bischöfe und das Einschreiten der politischen Obrigkeiten, in so weit es zuläßig ist, zu steuern ${ }^{911}$, und das Gubernium hat es nicht unterlaßen, unordentliche Geistliche mit gesetzlicher Strenge zu behandeln, auch ist hie und da rücksichtlich der Concubinate Besserung erwirket worden. Allein die Hebung dieser Uibel wird nur dann erfolgen, wenn nach und nach diese rohen und ganz ungebildeten Menschen auf eine oder die andere Art durch vollkommen Taugliche werden ersetzt werden.

Bis dahin muß die politische und geistliche Obrigkeit mit Pagliativmitteln auf das Eifrigste einwirken.

$\$ 186$ [Gründe dieser Mängel] Ein Hauptmißgriff, welcher bezüglich des Clerus in früherer Zeit begangen [Qu 87 / 3] wurde, bestand in der Leichtigkeit, mit welcher man, nach äußerst kurzem Unterrichte, [gestrichen: meistens] die geistlichen Weihen erlangen konnte.

Am auffallendsten fand dieses bei den sogenannten Glagoliten ${ }^{912}$ statt, welche die besonders für die Gebirgsbezirke zur Seelsorge bestimmten Geistlichen waren und es größtentheils noch sind.

910 Gemeint sind Konkubinate (außereheliche Lebensgemeinschaften von Mann und Frau) unter der Bevölkerung und wohl auch den Pfarrern, und deren negative Folgen für das Ansehen der Geistlichen und infolge dessen für den Kirchenbesuch durch die Bevölkerung.

$911 \mathrm{Zu}$ verstehen als »dem gegenzusteuern «, »es zu bekämpfen".

912 Das Phänomen der Glagoljica, das in seiner Bedeutung angesichts ihrer einzigartigen Stellung innerhalb der römisch-katholischen Tradition weit über den Aspekt des an sich schon bemerkenswerten eigenen Alphabets hinausgeht, ist in der kroatischen Forschung immer wieder Gegenstand von wissenschaftlichem Interesse, und auch von gewissem Belang für die nationalkulturelle Identitätsbildung von heute. Für diese Forschung und die weitgespannten kulturhistorischen Aspekte der glagolitischen Tradition sei auf einen umfangreichen Sammelband von 2004 verwiesen: Dürrigl / Mihaljević / Velčić (Hgg.): Glagoljica i hrvatski glagolizam. Obgleich am neu geformten zentralen Seminar diese Kultur weiter in der Lehre behandelt wurde, brachte die von Lilienberg angesprochene, von der Wiener Regierung 1821 verfügte Aufhebung der beiden "glagolitischen« Priesterseminare doch eine deutliche Schwächung dieser kirchensprachlichen Tradition. Zurecht weist aber Kovačić: Wandel in Struktur und Wirken der Katholischen Kirche, 443-445, darauf hin, dass die Schließung nicht nationalpolitisch motiviert war; erst Ende des 19. Jahrhundert versuchte Wien die glagoliti- 
Für diese hatte der Erzbischof Cacich von Spalato ${ }^{913}$ zu Prico $^{914}$, ganz nahe bei Almissa, ein eigenes Seminarium errichtet, dessen Localität, als ich sie besuchte, mehr einem schlechten, schmutzigen aber größeren und mehrere Zimmer enthaltenden Bauernhause glich.

Dort wurden die Kleriker des illirischen Ritus im lesen [sic] und Schreiben mit glagolitischen [Qu 87/4] Lettern und, nach einem [gestrichen: dürftigen] Traktate des gedachten Erzbischofs, lediglich über die 7 Sacramente unterrichtet ${ }^{915}$. Da sich die Zöglinge selbst verpflegen mußten und die ärmeren Bauernfamilien ihre Söhne für lange Zeit daselbst nicht belassen konnten, so eilte man sehr mit dem Unterrichte, so daß Viele, ohne frühere Bildung, schon nach mehreren Monaten Aufenthalts daselbst und höchstens nach ein Paar Jahren als Geistliche aus dieser Anstalt traten. ${ }^{916}$

Von diesen befinden sich dermalen noch 93 in der Diözese von Spalato, 2 in jener von Lesina und 2 in jener von Sebenico in der Seelsorge angestellt. Im Kreise Zara sind überdieß noch 100 Glagoliten, die zwar nicht in Prico, aber in ähnlicher Art [mit anderer Tinte wohl von Rosetti ergänzt: nach der Abhandlung des Cacic] gebildet worden waren und jenen vollkommen [Qu 88 / 1] gleich sind.

Was sich von solchen Menschen erwarten laße, gehet schon aus ihrer Bildungsgeschichte hervor; ich fand die Meisten derselben so unwissend, daß sie nicht im Stande waren, über geringe Gegenstände eine entsprechende Auskunft zu geben. Daß die Mehrzahl auch nur eine einfache Erklärung des Katechismus oder der Evangelien, eine nur halbwegs genügende Führung der Pfarr-Protocolle nicht zu leisten vermag, ist ganz natürlich. ${ }^{917}$

sche Tradition aus solchen Gründen gezielt zu beschneiden (ebd. 449). Die Gründe für die vormärzliche Neustrukturierung der Seminare lagen vielmehr im staatlichen Bestreben einer Angleichung an reichsweite Bildungsstandards - zumal am äußerst niedrigen Bildungsstand des traditionellen glagolitischen Klerus angesichts der Vielzahl und Art der Quellen, die dies belegen, auch jenseit der Lilienbergschen Angaben kein begründeter Zweifel besteht (dazu Clewing: Staatlichkeit, 183). Lilienbergs Ausführungen sind plausibel, obgleich sie mit Blick auf die Ausbildungssituation am Seminar Priko, die er selbst ja nicht mehr erlebt haben kann, auf Erzählungen Dritter basiert haben müssen..

913 Wohl Antun Kadčić (* 1686, † Split 7.10.1745), Ebf. von Split (1730-1745).

914 ON Prico / Priko, Örtlichkeit bei Omiš (also im Bereich der Poljica), von Mitte des 18. Jahrhunderts bis 1821 Sitz des glagolitischen Priesterseminars der damaligen Erzdiözese Split.

915 Die sieben Sakramente in der katholischen Kirche: Taufe; Firmung; Eucharistie; Bußsakrament; Krankensalbung; Sakrament der Weihe (auf den Ebenen von Diakon, Priester und Bischof); Ehe.

916 Ein Beleg für die ausnehmend schlechten materiellen Lebensbedingungen auf dem Lande und ihre auch institutionellen Folgen.

917 Wichtig war hier für die Verwaltung die aus deren Unbildung folgende Unzulänglichkeit der Landgeistlichen für ihre administrativen Tätigkeitsprofile; vgl. zu den aus Staatssicht essentiellen Aufgaben der Geistlichen etwa für die Grundlagen der öffentlichen Statistik Clewing: Staatlichkeit, 110 sowie zur ähnlich gearteten Kritik des Erzbischofs Nowak an dem Ausbil- 
$\$ 187$ [Die ältere Geistlichkeit der Städte] Die ältere Geistlichkeit der Städte und größeren Orte zeichnet sich zwar durch mehrere Bildung vor den Glagoliten aus, stehet aber jener in den deutschen und italienischen Provinzen Eurer Majestät in jeder Beziehung weit nach, obgleich sich einige unter ihnen, so wie auch unter den Landgeistlichen einige Ausnahmen, als sehr lobenswerth hervorthun.

[Qu 88 / 2] Im Allgemeinen aber sind auch die Stadtgeistlichen, wie ich sehr oft zu bemerken Anlaß hatte, von der wahren Würde und von dem Ideale des geistlichen Standes noch sehr weit entfernt, indem das Materielle, das Außerliche [sic] die Stelle der Wesenheit der Religion bei den Meisten vertritt.

$\$ 188$ [Geistliche, die im ehemaligen illirischen Seminar gebildet wurden] Vom Jahre 1821-1829 inclusive bestand in Zara ein sogenanntes illirisches Seminar ${ }^{918}$, wo außer den wesentlichen theologischen Wissenschaften die Elemente der Philosophie, der Phisik, Agricultur und der Pädagogik in 5 Jahren gelehrt wurden.

In diesem Institute waren 131 Priester gebildet worden, die in Dalmatien, Istrien und Triest in der Seelsorge und im Schulfache angestellt [durch Lilienberg oder Sekretär ergänzt: sind; gestrichen: wurden] und meistens dem Bedürfniße des Landvolks [Qu 88 / 3] gut entsprechen.

$\$ 189$ [Geistlichkeit aus dem jetzigen Central Seminar] Nach dessen Aufhebung hat die allerhöchste, väterliche Sorgfalt Eurer Majestä $t^{919}$ auch dieser Provinz ein, nach dem Muster des in den übrigen österreichischen Ländern bestehenden theologischen Studienplanes eingerichtetes, Central-Seminar in Zara allergnädigst zu verleihen geruhet, in welchem bisher 34 Priester ausgebildet worden sind.

Gegenwärtig hat dieses Seminar 55 Schüler der Teologie [sic], wovon 9 zur Erzdiözese, 14 zu jener von Spalato, 12 zu jener von Ragusa, 16 zur Diözese von Lesina, 2 nach

dungsstand und beruflichen Eignung der «illyrischen`(also glagolitischen) Landgeistlichkeit ebd., 111, Anm. 226.

918 Die erwähnte Ersetzung der beiden vorangegangenen glagolitischen Landseminare ab 1821 ging auf Befehl des Monarchen von 1818 zurück (vermutlich im Zuge seiner eigenen Landesbereisung). Das neue zentralisierte »illyrische« Seminar in Zadar wurde bis 1831 schrittweise in das den gesamtösterreichischen Regelungen entsprechende lateinische Priesterseminar in Zadar überführt, das 1826 gegründet worden war (vgl. Clewing: Staatlichkeit, 109). Lilienberg gibt also hier und im folgenden Paragraphen die vor seiner Amtszeit liegende Chronologie und die Jahreszahlen nicht ganz richtig wieder. Die in den nachstehenden $\$ \$ 189$ und 190 herauszulesende indirekte Kritik auch am Kaiser wegen der Aufhebung dieses in den Augen Lilienbergs erfolgreichen neuen »illyrischen « Seminars hätte durch ihn eigentlich eher relativiert werden können, weil ihm (vgl. \$204) zu diesem Zeitpunkt eine neue kaiserliche Anordnung zur Wiedererrichtung eines solchen Seminars vorlag. Zu dessen tatsächlicher Einführung scheint es aber nicht gekommen zu sein.

919 Der vorangegangene Absatz und die hier folgenden sind als ein Beispiel für die Kritik an durch Wien diktierten Abschaffungen von ortsspezifischen Lösungen zu verstehen. 
Sebenico und 2 nach Veglia ${ }^{920}$ gehören, die Letzten weil die Insel Arbe mit ihrer Geistlichkeit zur Diozese des Bischofs von Veglia zugetheilt ist.

[Qu $88 / 4]$

$\$ 190$ [Mangel genügenden Nachwuchses] So gewiß es ist, daß die Zöglinge dieser Anstalt allen anderen, nicht in dieser Art unterrichteten, Priestern Dalmatiens, auch wegen der für die jüngere Geistlichkeit seit v[origem] J[ahr] vorgeschriebenen Pfarrprüfung, in dem Grade der Bildung bei weitem übertreffen werden, eben so gewiß ist es auch, daß die ungleich längere Zeit, welche der jetzige Studien-Curs erfordert, eine verhältnißmäßig geringere und dem reellen Bedarfe nicht genügende Zahl von Geistlichen liefern werde, so, daß ich die Besorgniß nicht bergen kann, es werde nach 10 bis 15 Jahren, wenn die vielen alten Seelsorger nach und nach ausstreben, oder dienstesunfähig werden, wenigstens [Qu 89/1] die Hälfte der Curatien ohne Seelsorger bleiben müssen.

Um diesem großen Uibel zuvorzukommen wurde mit Gub:[ernial]-Berichten an die vereinte Hofkanzlei [Gestrichen: unter] No 19 May 1829 und 5 October 1830 u. 31 Dec 1832 Z 12487 [gestrichen: und] 25260 [ergänzt: und 21310] die Bestimmung von 30 Stipendien zu 100 Gulden für ärmere Gymnasial-Studenten, die sich dem geistlichen Stande widmen und von 10 Stiftplätzen im hiesigen Convicto für Cleriker in Antrag gebracht, welches ich, als das einzige und zwar dringend nothwendige Mittel zu obigem Zwecke Eurer Majestät allergnädigster Rücksicht allerunterthänigst anzuempfehlen wage ${ }^{921}$, da ohne dasselbe die Verlegenheit und der Schaden groß und unersetzbar ausfallen könnte..$^{922}$

$\$ 191$ [Zahl der Secular-Geistlichkeit] Dalmatien zählt dermalen in den fünf Diözesen mit 286664 Katholiken 380 katholische[,] 2 griechisch unirte Pfarreien, 62 Caplaneien [in Handschrift vermutlich Rossettis korrigiert aus Capalnien] zusammen 444 Curatien.

Der Stand der Secular Geistlichen belief sich auf $900^{923}$ wovon wenigstens 1/3tel als zur Seelsorge wegen Alter und anderen Gründen als nicht anwendbar zu rechnen ist.

[Qu 89 / 2] Von jenen Pfarren sind 91 dem Regularklerus zugewiesen, welcher aber dermalen, ebenfalls wegen Mangels einer genügenden Zahl tauglicher Priester nur 87 versiehet. -

920 ON/TN (Orts- und Inselname) Veglia / Krk; diese zu venezianischen Zeiten und noch unter der ersten österreichischen Herrschaft zu Dalmatien zählende Insel wurde zu Beginn der zweiten österreichischen Herrschaft zusammen mit Cres und Lošinj (als den beiden anderen hauptsächlichen »quarnerischen Inseln«) zum Küstenland bzw. Istrien geschlagen.

921 Eine höfliche, aber doch eindringliche Wendung an den Monarchen, und zwar wieder, um bei den Zentralbehörden schon lang ausstehende Entschlüsse doch herbeizuführen.

922 Vgl. auch $\$ 204$, in dem Lilienberg den Zusammenhang mit der Rekrutierung der nötigen Lehrerschaft für das auszubauende Volksschulwesen herstellt, in dem vorzugsweise die katholischen Pfarrer die Lehrerstellen übernehmen sollten.

923 Randanmerkung »Mit Bleistift«, die Zahl wurde also überprüft und später eingefügt. 
[§ 192] [Schlechter Zustand der Kirchen und Pfarrhauser] Ein Haupthinderniß in der Seelsorge ist der häufig äußerst schlechte Zustand der Kirchen und der Pfarrhäuser.

Von jenen auf dem Lande besonders habe ich die Bemerkung gemacht daß [gestrichen: viele zu einer Zeit; ergänzt: die meisten vor 2, 3, 4 Jahrhunderten] errichtet wurden [ergänzt: als; gestrichen: in] welcher die Population ein Drittheil, ein Vierttheil und in manchen Orten einen noch weit geringeren [ergänzt: hie und da nur der 8te oder 10te] Theil der jetzigen, in der Seelenzahl mit der Zeit sich vermehrten Pfarrgemeinde ausmachte und deswegen auch nur in diesem Verhältniße in der Kirche Platz findet, und Viele durch die Unmöglichkeit dem Meßsakramente beizuwohnen von dem Kirchenbesuche entwöhnt und nach und nach dagegen gleichgültig gemacht werden.

[Qu 89/3] Dermalen befinden sich noch 76 Kirchen in schlechtem und 126 in mittelmäßigem Stande, so daß sie einer oder der anderen wesentlichen Reparation bedürfen.

Noch übler sind aber die Pfarrwohnungen bestellt, wovon ich sehr viele so antraf, daß sie ohne Gefahr gar nicht für bewohnbar gehalten werden können, indem sie nicht nur der erforderlichen Localien ermangelten, sondern baufälligen, den Einflüßen der Witterung ausgesetzten, schlechten und schmutzigen Bauernhäusern gleichen.

Dermalen sind 177 Pfarrhäuser der Provinz noch in so einem [statt gestrichen: engem-] elenden Stande und 96 nur sehr mittelmäßig.

Ungeachtet aller Fürsorge des Guberniums und der beständigen Betreibungen ${ }^{924}$ an die Baudirektion und die Kreisingenieurs, in deren Folge auch wirklich manche neue Pfarrhäuser gebaut und nicht wenige wie auch Kirchen reparirt und [gestrichen: errichtet; ergänzt: erweitert] [Qu 89 / 4] worden sind, konnte leider wegen Mangels an hinlänglichen technischen Beamten zur Ausführung der dringenden Baulichkeiten aller Art, wovon ich gelegentlich der Darstellung der Baudirektion umständlicher handeln werde ${ }^{925}$, nicht so viel darin geleistet werde, als es nothwendig wäre.

Wie hierdurch der auf dem Lande in den ohnehin wegen der Lage der Ortschaften und der zerstreuten Häuser, dann wegen der Gebirge, gefährlicher Seitenwege und anderer, aus den topographischen Verhältnißen entspringenden, großen Beschwerlichkeiten so äußerst harte Stand des Curat-Clerus in einem hohen Grade verschlimmert wird, ist gar nicht zu beschreiben.

Es ist ganz natürlich, daß durch alle diese Verhältniße der im hiesigen Seminar, oder zu Wien ${ }^{926}[Q u 90 / 1]$ gebildete an eine gemächliche ${ }^{927}$ Lebensart gewohnte junge Geistliche, abgeschreckt wird, sich der Seelsorge zu widmen, zu welcher derselbe in diesem

924 Soll heißen: Die Baudirektion und die Kreisingenieure wurden in dieser Sache vom Gubernium dazu aufgefordert, aktiv zu werden.

925 Vgl. $\$ \$ 229$ und 230.

9261821 waren zur raschen Ausbildung von mehr Geistlichen mit einem Schlag 17 dalmatinische Theologiestudenten in Wien immatrikuliert worden; im ganzen Vormärz bis 1848 haben dort in der Summe wohl 34 Nachwuchspriester aus der Provinz studiert (s. Clewing: Staatlichkeit, 109).

927 In diesem Fall im Sinne von »komfortable« zu verstehen. 
Lande für dessen Mühseligkeiten eigens abgehärtet werden müßte; auch hierzu nicht ganz taugt, und daß derselbe wenn er aus Mangel an anderen Auskommen gezwungen, es dennoch thun muß, in so traurigen Verhältnißen entweder selbst wieder verwildert, oder durch Mißmuth, Krankheit und, bei der geringen Congrua von 200 Gulden, durch Mangel niedergedrückt seine Kräfte erlahmen. ${ }^{928}$

Besonders unangenehm war der erwähnte Mangel an Pfarrwohnungen in der Bucovizza einer Gegend im Kreise von Zara, wo die Wildheit und moralische Verderbenheit [sic] der Landleute das Vorhandenseyn ordentlicher Seelsorger besonders nothwendig macht, wo aber eben wegen Mangels auch nur halbwegs [Qu 90 / 2] tauglicher Wohnungen, sich Niemand entschließen wollte, das Pfarramt anzunehmen. Ich veranlaßte daher die Erbauung eines neuen Pfarrhauses, welches auch unter Mitwirkung der Gemeinde zu Stande kam, und verhielt ${ }^{929}$ den Franziskaner-Ordens-Provinzialen, einen tauglichen Seelsorger dahin zu senden.

$\mathrm{Zu}$ Risano, im Kreise Cattaro, fehlt dagegen den Katholiken nicht nur eine eigene Kirche, oder Capelle, sondern es ist sogar im Inneren der gr[iechisch] n[icht] u[nierten] Kirche in einer Nische ein katholischer Seitenaltar errichtet, wo der katholische Priester seinen Gottesdienst [gestrichen: hält; ergänzt: halten muß]. Diese wirklich höchst auffallende Unangemessenheit zu heben, verfügte ich sogleich eine Verhandlung um die Herstellung einer besonderen Capelle für die Katholiken zu bewirken. ${ }^{930}$

928 Vgl. zu den materiellen Bedrängnissen der Geistlichen (und zu den Folgen ihrer Armut) ganz ähnlich in HHStA, KFA 218 (alt 239), XCVIII, Nr. 1: Visitationsbericht des Erzbischofs von Zara, Joseph Nowak, zur Lage in der Diözese Zara (20.3.1827) (daraus längeres Zitat in Clewing: Staatlichkeit, 113f.). Dort ist ist ersichtlich, dass die Jahresdotation (Congrua) für die Pfarrer in Dalmatien bereits damals auf jährlich eben 200 Gulden provisorisch festgesetzt war. Doch wurden Realeinkünfte (Sachleistungen) der Pfarrer von Seiten der Pfarrgemeinde davon in Abzug gestellt, wodurch nur ein Teil der 200 Gulden durch den Staat auch ausgezahlt wurde. Vgl. auch hier weiter unten, $\$ 195$. Zu der verglichen mit ihrer Ausbildungszeit sehr isolierten und leicht auch demoralisierenden Lebenssituation der jungen Landgeistlichen nach ihrem erfolgten Berufseintritt siehe aber auch die plastische Beschreibung durch Petter: Dalmatien, Bd. 1, 253: »Die jungen Geistlichen, welche das herbe Loos trifft, in irgend einem Dorfe, auf einer Insel oder im Gebirge einen Seelenhirten machen zu müssen, sind übrigens sehr zu bedauern. [...] Es muss einem jungen Mann, welcher 15 bis 16 jahre auf der Schulbank gesessen und sich einen erklecklichen Vorrath von Kenntnissen gesammelt hat, äusserst schmerzlich fallen, plötzlich in eine Wildniss versetzt zu werden, und weit und breit Niemanden um sich zu haben, mit welchem er ein vernünftiges Wort sprechen kann, und der Drang nach Mittheilung ist doch ein Gefühl, das in der Natur jedes besseren Menschen begründet ist. Sieht man solche junge Geistliche nach wenigen Jahren wieder, so erkennt man sie kaum. Sie streifen unbewusst und unbemerkt die feinere Umgangssitte ab, und vergessen was sie gelernt haben, weil sie es nicht anwenden können.«

$929 \mathrm{Zu}$ verstehen als »und hielt den Provinzial dazu an«.

930 Die von ihm uneingeschränkt geteilte Grundidee vom katholischen Charakter des Staates und der daraus herrührenden administrativ-politischen Bevorzugung des Katholizismus ließ Lilienberg also auch in einem Ort, an dem die Katholiken nur eine kleine Minderheit 
[Qu 90 / 3]

$\$ 193$ [Mittel zur Hebung der Mängel] Um den vorgeschilderten allgemeinen Mängeln, wenn auch nicht vollständig, da dieß nur allmälig möglich seyn wird, doch so schnell als thunlich abzuhelfen, scheint mir vorzüglich nothwendig, daß die Regulirung der hiesigen Pfarren nach österreichischem Fuße, baldigst erfolge, deren Vorarbeiten bereits vollendet sind und worüber nur noch einige Ausweise von der Provinzial-Staatsbuchhaltung erwartet werden, um diesen wichtigen Gegenstand von der Landesstelle in Berathung ziehen zu laßen.

Hierbei wird sich eine zweckmäßige Pfar[r]-Ein und Zutheilung, vielleicht auch hie und da eine Zusammenziehung [von] mehreren kleinen Curatien erzielen und nach der bezüglichen Gestaltung und dem Umfange der Pfarrbezirke auch die Herstellung der Kirchen [Qu 90 / 4] und Pfarrhäuser sich zweckmäßiger ausführen lassen. Wegen der schon öfter bemerkten, sehr zerstreuten Lage der einzelnen Häuser ${ }^{931}$, besorge ich aber, daß die Zahl der Pfarren im Ganzen beträchtlich nicht vermindert und an den Congruen zur besseren Dotirung der anderen Seelsorger nicht viel wird erspart werden können.

$\$ 194$ [Beßere Dotirung] Die Leztere aber erscheint mir unumgänglich nothwendig, um durch eine hin und wieder einzuführende Abstufung und Erhöhung des Einkommens mehrerer größerer Pfarren, desto mehr Aufmunterung für taugliche Bewerber zu begründen und zugleich eine Aussicht zur Verbeßerung der Lage für brave, fleißige und ausgezeichnete Seelsorger zu eröffnen, da es nicht zu zweifeln ist, daß die zugleich mäBige und zu geringe Dotirung dieses Curat-Clerus [Qu 91/1] zu dessen Verfalle um so mehr mitwirkt, als dieser Umstand drückende Sorge erzeugt, welche dem Emporstreben zum Edleren [gestrichen: nicht selten] sehr entgegen wirkt und die Geistlichen zur Ergreifung von Nebenerwerben, als [im Sinne von: wie zum Beispiel: K. C.] zur Weinspeculation $^{932}$, zum Wucher und anderen Unternehmungen nicht selten veranlaßt, die mit der geistlichen Würde sich nicht wohl vereinigen lassen und wodurch die Achtung der Pfarrkinder vermindert wird.

$\$ 195$ [Befreiung von der Abhängigkeit des Clerus vom Landvolke] Da überdieß der Curat-Clerus mit seinem Einkommen an gewiße landesübliche Giebigkeiten der Pfarrkinder gewiesen ist, wonach die Seelsorger zu bestimmten Zeiten als sogenannte Pores-

darstellten, eine kirchenbauliche »Randexistenz« der katholischen Gemeinde für inakzeptabel halten. Er lehnte hier eine Lösung ab, wie sie zur gleichen Zeit in ähnlicher Gestalt in gemischtkonfessionellen deutschen Orten in Form von evangelisch-katholischen »Simultankirchen« durchaus üblich war.

931 Vgl. die Bezugnahmen auf die verbreitete Streusiedlung und deren negativen Alltags- und Verwaltungsfolgen in den $\$ \$ 129,132,191$ und 206.

932 »Spekulation« heißt hier soviel wie »Handel«. Vom Handel als Ausweg für die von zu großer Armut betroffenen Pfarrer schrieb auch Erzbischof Nowak in seinem Visitationsbericht von 1827, vgl. im entsprechenden Zitat dazu bei Clewing: Staatlichkeit, 114.

DigiOst 1 | 231 
china /: Pfarrgabe:/ von jeder Familie ein bestimmtes Maß Weines, Öhls oder anderer Produkte erhalten, und nur das, was nach Ausmittlung der Durchschnittssummen von der geringen Congrua von 200 fr. abgehet [Qu 91/2] als Ergänzung aus dem Religionsfonde ihnen angewiesen wird: so folgt hieraus daß die Existenz der Curat-Geistlichkeit von der Willfährigkeit der Landleute größten Theils abhängt, welches hierlands sehr üble Folgen hervorbringt, indem der Geistlichkeit kein freies Entwickeln ihrer vollkommenen Wirksamkeit möglich wird, da der Morlake, wenn der Seelsorger seiner Rohheit, Unsittlichkeit, Fehlern und Leidenschaften nicht nachgiebt, seinem [das heißt des Morlaken, K. C.] Willen sich nicht fügt, ihm [dem Pfarrer] nur die Poreschina, wie es nicht selten geschieht, zu verweigern braucht, um denselben in Noth zu versetzen.

Die Abhängigkeit der Pfarrer geht deshalb so weit, daß, wie ich in mehreren Orten erfuhr, die Bauern ihrem Seelenhirten vorschreiben, wann, wo und wie er den Gottesdienst zu halten habe [Qu 91 / 3] und ihm die Kirchthür verschließen, wenn er ihren Willen nicht erfüllt.

In Galla ${ }^{933}$, des Kreises Spalato, wo die größten Salz-Contrabande geschehen, erklärten Viele dem Seelsorger sogar, daß wenn er sie nicht jedesmal von der Sünde des Kontrabandes ohne Anstand losspräche, sie ihn ferner nicht mehr haben [gestrichen: und an ihm sich rächen] wollen.

Wenngleich solche und andere auffallende Unordnungen von mir gleich mündlich bei meiner Bereisung überall strenge gerügt und denjenigen Gemeinden, welche ihre christlichen Pflichten nicht gehörig erfüllen und ihren Seelsorger nicht pflichtmaßig [sic] ehren und behandeln, [gestrichen: erst] ernste Ermahnungen ertheilt wurden und auch das Gubernium möglichst darauf sieht, so ist es doch immer zu bedauern, daß solche Fälle geschehen und aus dem angegebenen Grunde sich erneuern können. ${ }^{934}$

933 ON Galla / Gala: Ansiedlung im dalmatinischen Hinterland, ca. $5 \mathrm{~km}$ im Nordosten von Sinj auf dem linken Ufer der Cetina.

934 Das behördliche Eingreifen zugunsten der Achtung der katholischen Geistlichen durch ihre Pfarrmitglieder ist ein eindrücklicher Beleg für die staatliche Privilegierung der katholischen Kirche wie auch für die josephinismustypische Verflechtung von staatlicher und katholisch-kirchlicher Sphäre. Dass dabei diese Stoßrichtung sowie die ideologisch damit einhergehende starke rechtsphilosophische Fokussierung des Staates auf das Naturrecht keineswegs mit den Vorstellungen von der Eigenständigkeit der katholischen Kirche zusammenpasste, wie sie von konservativ-katholischen Akteuren verfochten wurde, hat Waltraud Heindl mit Blick auf das Staatsverständnis der josephinischen und vormärzlichen Beamtenschaft klar gezeigt (Heindl: Gehorsame Rebellen, 2. Auflage, 131-135). Ungeachtet dessen bleibt festzuhalten, in welch hohem Ausmaß von der Verwaltung der Katholizismus als für den Staat und dessen Bürokraten verbindlich richtungsweisend angesehen wurde. Nicht nur die Bevölkerung sollte demnach mit administrativen Maßregeln zur Ehrung der Geistlichkeit erzogen werden, sondern es waren etwa auch die Kinder zum Besuch der Sonntagsschule seit 1820 ebenso amtlich verpflichtet wie seit 1824 die Beamten Dalmatiens zum Besuch der Sonntagsmesse (vgl. mit Belegangaben Clewing: Staatlichkeit, 105, Anm. 206). 
Uiberdieß dürfte es auch Erwägung [Qu 91 / 4] verdienen, daß der, im Allgemeinen genommen arme, Morlake oft in den Fall kommt, die Pfarrgabe, nicht zur bestimmten Zeit, oder nicht ganz auf einmal, zuweilen auch gar nicht, geben zu können; daß der Pfarrer dagegen wegen Mangels anderen Einkommens nicht verzich[t]en kann, demnach jährlich von dem großten [sic] Theil seiner Pfarrkinder die Gabe durch Execution mittelst der Forza terr[itoriale] [ergänzt: u. mittelst Pfändung] einbringen lassen muß, um nicht selbst zu darben; daß er folglich den Geist der christlichen Nachsicht und Milde gar nicht entwikeln, wohl aber den Schein der Grausamkeit und Härte auf sich laden und sich bei der Bevölkerung verhaßt machen muß.

Ich wäre demnach der allerunterthänigsten Ansicht ${ }^{935}$, daß es besser sein dürfte, die Pfarrgiebigkeit von Seite der Staatsverwaltung einzuheben, welche den bedrängten Familien Fristen bewilligen [Qu 92 / 1] kann, und die Geistlichen ganz aus dem Staatsschatze zu besolden.

Diese Verfügung würde außerordentlich die Achtung gegen die Pfarrer vermehren und ihren Einfluß auf das Sittliche und Religiose [sic] ihrer Pfarrkinder, sicher wirksamer machen.

Da ich übrigens bemerkte, daß hin und wieder in die Pfarrgabe auch gewiße bestimmte Geschenke für die Beicht und Comunion eingerechnet werden, so habe ich hierüber eine Verhandlung eingeleitet, um diesen Uibelstand zu heben ${ }^{936}$.

$\$ 196$ [Feier verbothener Festtage] Uibrigens habe ich noch alleruntertänigst eines Umstandes zu erwähnen, welcher auf den Wirthschaftsbetrieb der Landleute besonders nachtheilig einwirkt; dieß ist nämlich die Feier der aufgehobenen Festtage, welchen der Hang zum Müßiggange vor oder nach denselben noch andere halbe [Qu 92 / 2] Festtage beifügt, während denen, in Folge altherkömmlicher Sitte, der gemeine Landmann und an [gestrichen: vielen; ergänzt: mehreren] Orten auch der Städter, keine Arbeit unternehmen will. ${ }^{937}$

Das Gubernium und ich haben es nicht unterlaßen, dießfalls nachdrückliche Aufforderungen an die Ordinariate zu richten und den politischen Authoritäten die bezügliche Uiberwachung oft in Erinnerung zu bringen, aber ungeachtet dieser allseitigen Bemü-

935 Also eine direkte Wendung an den Kaiser, mit dem Vorschlag, die Pfarrbeiträge der (katholischen) Gläubigen durch den Staat einheben zu lassen und dann durch diesen den Geistlichen auszuzahlen. Das hätte einen Akt bedeutet von zusätzlicher »Verstaatlichung « der die katholische Kirche betreffenden Fragen.

$936 \mathrm{Zu}$ verstehen als »beheben, beseitigen (einen Mangel)«.

937 Vgl. zu derlei inoffiziellem Fortbestehen amtlich abgeschaffter Feiertage und auch zur Begründung meiner eigenen Charakterisierung solcher und anderer kirchenpolitischer Maßnahmen im österreichischen Dalmatien während des Vormärz als »spätjosephinisch«: Clewing: Staatlichkeit, 103 f. In der ländlichen lebensweltlichen Praxis wurden die abgeschafften Feiertage von der Bevölkerung wie auch von der niederen Pfarrgeistlichkeit noch Jahrzehnte später weiterhin begangen (vgl. ebd. und Petter: Dalmatien, Bd. 1, 202). 
hungen ist es, selbst nach der im November v[origen] Jahs [Jahres] erfolgten Kundmachung des Indultes Seiner Heiligkeit des Pabstes Clement XIV ${ }^{938}$ vom 22 Juny 1771, vieler Orten noch nicht gelungen, den erwähnten Gebrauch ganz abzustellen, wozu selbst die Ignoranz und die Nachgiebigkeit der älteren Seelsorger beiträgt. Es wird demnach erst allmälig mit der Zeit und nach öfteren Erneuerungen des Verbothes mit steter [Qu 92 / 3] Uiberwachung von Seite der Behörden eine vollkommene Beobachtung desselben zu erzwecken, möglich seyn.

[Am Rande vermerkt: Revisto dal Signor \{durchgestrichen: Segretario\} ${ }^{939}$ ]

\section{Regular-Clerus}

$\$ 197$ [Zustand desselben] Den Regular-Clerus [Ordensklerus; K. C.] Dalmaziens habe ich fast noch mehr unter meiner Erwartung, als den Secular-Clerus gefunden.

Die Zahl sämtlicher Klöster belauft sich auf 68, worunter 42 dem Franciscaner-Orden des Santissimo Redentore, des H[eiligen] Girolamo, del $3^{\circ}$ ordine und den Capuziner [sic; gestrichen: gehören]; 8 den Dominikanern 1 den Piäristen [sic], [gestrichen: 3 den Eremiten], 1 den Philipinern und 3 den Eremiten gehören, 13 sind Frauenklöster ${ }^{940}$.

Die gesammte Klostergeistlichkeit beträgt aber 412 Mönche und 75 [darüber ergänzt: 42] Nonnen. Da vom Regular-Clerus 87 Pfarren dermalen versehen werden, so sind viele Klöster nur kärglich mit 2-3-4 Individuen besetzt, welches die Beobachtung der Disziplin und Ornungsregel ${ }^{941}[\mathrm{sic}]$ vereitelt und wodurch die Klöster selbst und ihr Eigenthum in Verfall [Qu 92 / 4] gerathen.

Die Ordensgeistlichen habe ich, mit sehr wenigen Ausnahmen, ebenfalls sehr ignorant, um eine höhere Ausbildung wenig bekümmert, träge, schmutzig und unordentlich gefunden, fast überall war das Klosterarchiv und die Bibliothek in großer Unordnung; nur in wenigen Klöstern war es dem Einen oder dem Anderen Mönche bekannt, welche Bücher und Urkunden von einiger Bedeutung sich daselbst befinden.

Die Klostergärten und die Landwirthschaft fand ich überall in hohem Grade verwahrlost und auf den Phisiognomien einen großen Theiles der in den Klöstern lebenden Mönche das Gepräge des Müßigganges und der Trägheit ausgedrückt.

Am besten bestellt traf ich aber das Dominikanerkloster zu Sebenico, jenes der Franziskaner zu Zara, [Qu 93 / 1] eines an der Kerka, das zu Almissa und zu Ragusa.

938 Klemens XIV. (* 1705), aus bürgerlicher Familie und Franziskaner, Papst vom 18. Mai 1769 bis zu seinem Tod am 22. September 1774 .

939 Was eventuell bedeuten soll: Erst vom Sekretär Rossetti, dann zumindest bis hierher auch durch Lilienberg selbst redigiert.

940 Gestrichen ist ein grammatikalisch falsches Plural-n, »Frauenklöstern «, als ein Beispiel für seltene, aber doch gelegentlich vorkommende Grammatikfehler des Schreibers Rougier, die über den Namen hinaus für ihn einen nicht rein deutschsprachigen Familienhintergrund vermuten lassen.

941 Nicht korrigiert (in: Ordensregel) und ein klares Beispiel für einen Hörfehler Rougiers unter Diktatsituation! 
$\$ 198$ [Frauenklöster] Unter den Frauenklöstern aber zeichnet sich jenes von Zara besonders aus; die übrigen fand ich fast durchaus nicht zu meiner Zufriedenheit, indem die Kloster-Ordnung und Disziplin auch in diesen sehr Vieles zu wünschen übrig läßt und die Klosterfrauen im Allgemeinen ein unthätiges Leben führen.

Die zwei Nonnenklöster in Pago beschäftigen sich zwar mit Unterricht; allein ich traf in demselben keine zweckmäßige Eintheilung und Ordnung, weshalb ich sogleich die nöthigen Vorkehrungen veranlaßte.

$\mathrm{Zu}$ Spalato fand ich das Fenster des Parlatoriums ${ }^{942}$ zu ebener Erde, auf die Gasse hinaus gehend und ohne ein Gitter; welche Unschicklichkeit ich verbessern ließ. Bei Stagno besuchte ich zwei Klöster, welche von einer Art Nonnen bewohnt werden: die Einen vier an [Qu 93 / 2] der Zahl, sind Terziarierinen ${ }^{943}$ [,] die Anderen, sechs an der Zahl, sind Dominicanerinen. Ihre Institution beruht auf einer frommen Stiftung aus früherer Zeit.

Diese Nonnen können weder lesen noch schreiben, auch keine Arbeiten. Sie erhalten sich von den Einkünften einiger liegenden [sic] Gründe ${ }^{944}$ und von der ihnen gestatteten Einsammlung von Allmosen. Die Franziskanerinen besitzen auch 2 Häuser in der Stadt deren Zins sie beziehen. Sie thun nichts als bethen und essen. Ihr Wohnlocale ist schmutzig und elend.

Rücksichtlich derselben werde ich mit dem Bischof Giuriceo ${ }^{945}$ mich berathen, um nach und nach civilisirtere Klosterfrauen zu gewinnen, welche zum Unterrichte der weiblichen Jugend im Lesen und Schreiben, dann in nöthigen Arbeiten, besonders in der Seidenzucht [Qu 93/3] verwendet und so zu einer nützlichen Thätigkeit gebraucht werden könnten.

[\$ 199 Mittel dem Regular Clerus aufzuhelfen] Um die Beschaffenheit des Regular-Klerus zu verbessern und den bemerkten Mängeln thunlichst abzuhelfen, habe ich mich während meiner Bereisung mit den Bischöfen besprochen und sie mit meiner Absicht ganz übereinstimmend gefunden, daß der erste und wichtigste Schritt darin bestehen würde, eine Concentrirung der Geistlichen mehrerer Klöster auf ein bestimmtes Minimum zu bewirken.

942 Ein Raum des Klosters, in dem die Ordensgeistlichen der Schweigepflicht entbunden sind.

943 Wohl im Sinne von Angehörigen des »Dritten Ordens « - also Laien, die sich an den Regeln eines bestimmten und hier nicht näher definierten Ordens ausrichten (daher dann auch die einschränkende Formulierung: »eine Art Nonnen«).

944 »liegende Gründe«: zu verstehen als landwirtschaftlich genützte Grundstücke.

945 Bf. Antonio Giuriceo, in dessen Diözese Ragusa Stagno lag. Der Almanacco 1834 nennt zugleich als seine (zivil-)administrative Funktion »c.r. consigliere di governo, preside della commissione di pubblica beneficenza [gemeint wohl die des ganzen Kreises Ragusa und nicht nur der Stadt, denn auch bei anderen Bischöfen wird im gleichen Jahrgang des Almanacco diese Funktion genannt und bei einem, Scacoz aus Hvar, explizit gesagt »della locale commissione di pubblica beneficenza«, Almanacco 1834, 182], e dell'opera pia« (181). 
Nachdem die Hofkanzley-Verordnung vom 23 Mai l[aufenden] J[ahre]s $\mathrm{N}^{\circ} 4736$ welche in Folge allerhöchster Entschließung vom 17 Februar 1[aufenden] J[ahre]s erfloß, diese Maßregel unter gewissen, sehr zweckmäßigen Bedingungen empfiehlt, so zweifle ich nicht, daß die Bischöfe dießfalls einschreiten werden und sodann zur möglichsten [Qu 93 / 4] Regulirung der Klöster im Allgemeinen das Angemeßene wird verfügt werden können, wie auch wirklich schon wegen Concentrirung der Dominicaner Klöster in Trau die Verhandlung im Zuge ist.

\section{Griechische Geistlichkeit}

$\S 200$ Unter den 356000 Bewohnern Dalmatiens befinden sich 69441 Griechen $^{946}$.

Der Kreis Zara mit 126502 Einwohner[n] zählt derselben 38 191, jener von Spalato mit 149320 Einwohnern hat ihrer 6599.

Der Kreis Ragusa mit 47556 Einwohnern zählt derselben 253.

Im Kreise von Cattaro mit 33495 Einwohner[n] sind 24398 nicht unirte Griechen.

Diese haben 125 Pfarren mit $125 \mathrm{n}$ [icht] u[nierten] Geistlichen und 11 Klöster mit 58 Mönchen.

Die Rohheit und Ignoranz dieser Geistlichkeit habe ich im Ganzen noch unter dem Grade jener des weniger gebildeten Theils des katholischen Klerus gefunden, [Qu 94 / 1] dabei ist ihr Aberglaube noch ungleich größer und ihr Religionsfanatismus ist nicht selten der guten Ordnung und der Eintracht zwischen den k. k. Unterthanen beider Glaubensbekenntniße entgegen und höchst nachtheilig.

Da ich die n. u. Griechen, ihre Geistlichkeit deren Umtriebe und Mißbräuche, in meinem Berichte an die Hofkanzlei vom 14 Juny l[aufenden] J[ahre]s Z. 986/p über allerhöchsten Auftrag vom 28 Februar 1[aufenden] J[ahre]s in Folge einer Eurer Majestät von den gr[iechisch] n. u. Seelsorgern überreichten Beschwerdeschrift ${ }^{947}$ über Verfolgungen, die sie angeblich zu erleiden [gestrichen: haben; ergänzt: sollen], und mit Bericht an den Präsidenten der Polizei Hofstelle vom 18. December v[origen] J[ahre]s Z 2412/p in Folge allerhöchster Entschließung vom 14. September v[origen] Jahres ${ }^{948}$ bezüglich der Griechen im Kreise Cattaro umständlich geschildert habe, und beide Relationen ohne-

946 Innerhalb der österreichischen Verwaltung war das nicht nur in Bezug auf Dalmatien damals der gängige Begriff für »Menschen orthodoxen Glaubens« ohne jeden sprachlich-kulturellen Bezug. Die Angehörigen der (in Dalmatien trotz der aufwendigen behördlichen Förderung der Union verschwindend kleinen) Gruppe der "griechisch Unierten« figurierten konsequenterweise in diesem römisch-katholisch geprägten Sprachgebrauch nicht als derartige "Griechen«, sondern nur die Angehörigen der damals so bezeichneten »griechisch nicht unierten Kirche«, von der Lilienberg im Weiteren spricht.

947 Vgl. den Eintrag im Staatsratsprotokoll hier im Anhang, Seite 290: PPfarrvorsteher gr. n. u. in Dalmatien - gegen die augenblickliche Bedrückung ihrer Glaubensgenossen 6030«.

948 Hier war mit Bleistift am Rand vermerkt: Ausheben. Die Datierung war daraufhin in eine als Lücke belassene Stelle ebenfalls mit Bleistift eingetragen und mit Tinte nachgeschrieben worden. 
hin Eurer Majestät werden allerunterthänigst [Qu 94 / 2] überreicht werden, so wage ich es nicht, Euer Majestät mit Wiederholungen zu ermüden.

Nur soviel erlaube ich mir allerunterthänigst zu bemerken, daß die Leidenschaftlichkeit der n. u. Geistlichkeit, die möglichst baldige bestimmte Regulirung aller ihrer Verhältniße zu den Katholiken, dann ihrer Feierlichkeiten und Kirchenfunktionen zum dringenden Bedürfniße macht, weil sie sonst durch Willkührlichkeiten und Anmaßungen sich immer mehr bestreben werden, ihrem Cultus ungebührliche Ausdehnung und Ansehen zum Nachtheile der katholischen Religion zu geben.

In Folge allerhöchster Entschließung vom 16. März 1[aufenden] J[ahres] [Bleistiftanmerkung am Rande: Im 1t Departem. nachzusehen] habe ich daher nicht unterlassen sogleich die bezüglichen Anträge von dem katholischen Erzbischofe und dem früheren gr. n. u. Bischofe Rajacsich ${ }^{949}$ abzufordern und da [Qu 94 / 3] sie bereits eingelangt sind, bei dem Gubernium einer reifer [sic] Erwägung zu unterziehen, um dann einen wohlbegründeten Vorschlag der vereinten Hofkanzlei vorlegen zu können.

Die nicht herrschende Kirche sollte jedoch, nach meiner allerunterthänigsten Meinung, auf die politischen Vorzüge der herrschenden Religion ${ }^{950}$ durchaus keinen Anspruch haben und wenn ihr diese bewilligt würden, so dürfte dem Zwecke, die herrschende Religion auf alle Art zu befördern, entgegen gewirkt werden.

949 Almanacco 1834, 185: Chiesa greca non unita, Vescovo (vacante). Almanacco 1833: Monsignor Giuseppe Rajacsich (er hatte bezeichnenderweise ganz im Gegensatz zu den katholischen Bischöfen keinerlei öffentliches Amt überantwortet bekommen). Der aus der Lika gebürtige Josif Rajačić wurde zwar nach der Binnenexilierung seines die Union verfechtenden Vorgängers Benedikt Kraljević (1821) schon 1822 oder 1823 von Landeschef Tomašić der Hofkanzlei zur Ernennung vorgeschlagen, aber erst mit kaiserlicher Entschließung vom 29.12.1828 wirklich zum Bischof in Dalmatien ernannt. Im Anschluss an seine dortige Mitte 1833 beendete Dienstzeit war er zunächst Bischof von Werschetz (Vršac; bis 1842), dann Bf. von Karlowitz (Sremski Karlovci). Dort wurde er 1848 während der Revolution durch seine Wahl zum serbischen Patriarchen zu einer der wichtigsten auch politischen Gestalten der südungarischen Serben und zu einem Gründungsvater der zunächst eigenmächtig-revolutionär verfassten und dann bis 1860 in veränderter Form als österreichisches Kronland existierenden »Serbischen Wojwodschaft«. Dazu Clewing: Die doppelte Begründung der Serbischen Wojwodschaft 1848-1851. Zu Rajačić insgesamt (ohne wissenschaftlichen Apparat, aber unter Heranziehung auch von Archivalien) vgl. nunmehr: Petković: Patrijarh Josif Rajačić (1785-1861), dort 25-40 zur dalmatinischen Amtszeit Rajačićs (1828-1833). Lilienbergs Beziehung zu ihm war überaus angespannt (ebd., 28-30). Sechs Berichtsschreiben Rajačićs an den Karlowitzer Metropoliten Stevan Stratimirović über seine Visitationen in Dalmatien aus den Jahren 1829 (sic) bis 1833 wurden ediert durch Danica Petrović: Josif Rajačić - vizitacija dalmatinske eparhije 1832-1833, dort 487-495.

950 Erneut ein beredter Ausdruck für das bei der politisch-administrativen Elite herrschende Verständnis der Habsburgermonarchie als Staat mit römisch-katholischem Charakter und der in staatspolitischem Sinne »herrschenden« Stellung des Katholizismus. 
Jene hat auch ihren Standpunkt; der besteht aber bloß darin, das Recht und den Schutz gegen Beeinträchtigung anzusprechen und zu erhalten. Nach meiner Ansicht gebührt ihr keine Auszeichnung und sie wäre wie jede private Gesellschaft zu betrachten [Qu 94 / 4] und zu behandeln.

In jedem Falle wird aber stets, wie es die Erfahrung verflossener Zeiten bewährte, sehr Vieles für Eintracht, Ruhe und gute Ordnung zwischen den verschiedenen Glaubensgenoßen von den Gesinnung, der Tendenz, Mäßigung und Klugheit des mit allerhöchster Entschließung vom 5. April l[aufenden] J[ahre]s ernannten neuen gr.n.u. Oberhirten abhängen ${ }^{951}$; dann von dem Umstande, ob und welchen indirecten Einfluß insgeheim der Erzbischof Stratimirovich ${ }^{952}$ von Carlowitz auf den hiesigen gr. n. u. Bischof, der früher bei jenem angestellt war, sich zu verschaffen wissen wird, da es aus den Zeiten des Bischofes Kraglievichs ${ }^{953}$ bekannt ist, daß der gedachte gr[iechisch] nicht unirte Erzbi-

951 Im Almanacco 1834 wird der Sitz des gr. n. u. Bischofs noch als vakant geführt (185), im Almanacco 1835 dann 187 »Monsignor Panteleimone Zsivkovich, asseore alla tavola giudiziaria del comitato della Sirmia. Pantelejmon Živković war Bischof der Eparchie Dalmatien von 1834-1836.

952 Stevan Stratimirović (1757-1836), Metropolit von Karlowitz seit 1790.

953 Der von 1810 an in dem damals eingeführten Amt befindliche dalmatinische orthodoxe Bischof Benedikt Kraljević, hatte sich bereits im Mai 1818 bei einem persönlichen Treffen in Šibenik mit Kaiser Franz I. während dessen Dalmatienreise auf eine Förderung der Kirchenunion verständigt (vgl. Clewing: Staatlichkeit, 138, Anm. 312). Eben wegen dieser Ausrichtung ist er in der orthodoxen Kirchengeschichtsschreibung bis heute eine Persona non grata. Übersehen wurde in der Forschung, dass er sich durch sein forsches Vorgehen zugunsten der Union 1821 auch bei der österreichischen Regierung dauerhaft suspekt gemacht hat. HHStA, MKA 1854/1835, zu Präsidialantrag Sedlnitzkys vom 18.11.1835 über ein Gesuch Kraljevićs, der seit seinem Abgang aus Dalmatien bzw. von 1828/29 an nominell orthodoxer Erzbischof von Venedig war (vom orthodoxen Kirchenrecht her trug er diesen Titel nicht rechtmäßig). Es ging Kraljević um die Bewilligung einer Reise nach Wien, zum Glückwunsch an Kaiser Ferdinand I. wegen dessen Thronbesteigung. Kraljević, so Sedlnitzky, habe sich 1820/21 bei der Union zwar gutwillig, aber so ungeschickt verhalten, dass ihm mit a.h. Erlass Z. 863 v. 20.4.1823 der Aufenthalt im lombardisch-venetianischen Königreich unter der Bedingung genehmigt worden war, er dürfe diese beiden Königreiche ohne ausdrückliche kaiserliche Genehmigung nicht wieder verlassen. Auf Auftrag Sedlnitzkys hatte Lilienberg am 7.11.1835 eine Stellungnahme abgegeben: Zur Union selbst stimmten die betreffenden Angaben, alle Anschuldigungen wegen Kraljevićs sittlichen Lebenswandels seien aber offenbar «Gehässigkeiten der Feinde der Union`; weder in Zara noch seither in Venedig hätte Kraljevićs Verhalten irgendwelchen Anlass dazu gegeben, er habe «sich ruhig, sehr zurückgezogen, klaglos und anständig benommen> und Beweise seiner treuen Gesinnung geleistet. Seine Dalmatienkontakte seien unterdessen fast ganz erloschen. Sedlnitzky empfahl darauf die Wienreise zu bewilligen, er behalte sich aber vor, »[...] bei seiner Ankunft auf dem hiesigen Platze sein Thun und Lassen, seinen Umgang, seine Korrespondenz, so wie seine sonstigen Verbindungen einer eindringlichen aber unauffälligen Kontrolle unterziehen zu lassen. « Unter solcher Aufsicht wurde die Reise mit 12.12.1835 a. h. bewilligt. Zu Kraljević lag mir leider nicht vor: Lazarević Di Giacomo, Persida: Il primo tentativo sistematico di Unione delle Chiese 
schof der Union der Griechen mit der katholischen Kirche [Qu 95 / 1] sehr entgegen war und im Geheimen auf die Intriguen [gestrichen: und Complotte] der Griechen gegen den Bischof Kraglievich einen wesentlichen Einfluß gehabt hat. ${ }^{954}$

Uibrigens bin ich überzeugt, daß die in Folge allerhöchsten Entschließung vom 5. April 1[aufenden] J[ahre]s mit Gubernial Berichte vom 24ten May a[nno] c[orrente] Z 8586 [Bleistiftanmerkung am Rande, unterstrichen: Ausheben] in Antrag gebrachte Uibersetzung der gr. nicht unirten Residenz nach Zara von bedeutendem Nutzen seyn wird, indem der griechische Bischof hier beßer wird überwacht und alle Mißverständniße, oder Differenzen durch die in vielen Fällen weit wirksameren, mündlichen Unterredungen werden ausgeglichen werden können.

Durch die allerhöchst bewilligte gr.n.u. Clerical Schule worin im vorigen Jahre, als dem 1.en ihrer Institution, bereits 20 Jünglinge unterwiesen wurden und die einstweilen nur wirthweise in Sebenico unterbracht ist, werden brauchbarere Seelsorger gewonnen werden.

[Qu 95 / 2] Allein, auch rüksichtlich dieser Anstalt wird die Uibersetzung der griechischen Bischofs Residenz vom Nutzen seyn, weil auch jene dieser wird folgen müßen und die Behörden hierorts beßer sich werden überzeugen können, daß man mit der Ausweihung zu Priestern nicht leichtfertig sey, wie es bis itzt geschehen konnte.

Da sich übrigens einige kais[erlich] königl[iche] nicht unirte Unterthanen im vorigen Jahre erlaubt hatten, um die Weihen ohne viele Mühe zu erschleichen, mit Umgehung der polizeilichen und anderen dießfälligen Anordnungen sich ins Ausland zu begeben, so habe ich mich veranlaßt gesehen, durch Anordnung einer strengen gesetzlichen Prozedur gegen die Uibertreter und durch Veranlaßung eines Hirtenbriefes von Seite des gr. n. u. Ordinariates künftigen ähnlichen Fällen zu begegnen. ${ }^{955}$

[Qu 95 / 3] Rücksichtlich der gr. n. u. Klöster von denen ich nur jenes von Savina ${ }^{956} \mathrm{im}$ Kreise Cattaro gut bestellt und in beßerer Ordnung fand, glaube ich allerunterthänigst antragen zu sollen, daß auch wegen derselben eine ähnliche Maßregel wie die bezüglich

in Dalmazia. La figura di Benedetto Kraglievich tra storia e letteratura. In: Stefano Trinchese / Francesco Caccamo (Hgg.): Adriatico contemporaneo. Rotte e percezioni del mare comune tra Ottocento e Novecento. Milano 2008, 255-278.

954 Vgl. allgemeiner zur Geschichte und historiographischen Bewertung der beiden von der Regierung bzw. Verwaltung betriebenen Unionsversuche und hier des von Franz I. selbst vorangetriebenen Versuches unter Beiziehung von Bf. Kraljević oben in der Einleitung, 18.

955 Pederin: Dalmacija i Hrvati u vanjskoj politici bečkog dvora, 65, führt mit Aktenbelegen aus DAZd, Kt. 151 der PSN den entsprechenden Fall und die Namen der Beteiligten an. Nachdem zwei Orthodoxe aus der Boka, namens Jovo Stojanović und Marko Sofran, 1833 durch den serbischen Bischof Nićifor in dem (seit 1820 montenegrinischen) Kloster Morača als Priester geweiht worden waren, erließ Bischof Rajačić für sein Bistum die Bestimmung, dass die beiden dort nicht amtieren durften.

956 Orthodoxes Kloster Savina / Savina, auf einer Anhöhe ca. 1 km östlich (und heute im Stadtgebiet von) Herceg Novi in der Boka kotorska. 
der katholischen vorgeschlagene Concentrirung angewendet werden dürfte; worüber jedoch bis zur Ankunft des neuen nicht unirten Bischofs nichts eingeleitet werden könnte.

\section{Religionsübertritte $e^{957}$}

$\$ 201$ [Umtriebe der n.u. Griechen. Mord des unirten Pfarrers Kriska] Seit dem im Jahre 1832 erfolgten Uibertritte der gr[iechisch] nicht unirten Pfarrer Kriske ${ }^{958}$ von Kriška ${ }^{959}$ und Bussovich ${ }^{960}$ von Balke ${ }^{961}$ Bezirk Derniš im Kreise Zara haben viele Bewohner jener Umgegend sich zur katholischen Kirche bekannt, und es folgen immer noch [Qu 95 / 4] mehrere diesem löblichen Zwecke ${ }^{962}$ obgleich die nicht unirten Griechen wie es Eurer

957 Als Folge und Ausdruck der rechtlichen Privilegierung der staatstragenden katholischen Konfession bestand im vormärzlichen Österreich mit Blick auf den Katholizismus die »Freiheit« des Religionsübertritts ungeschmälert nur in der Richtung hin zu diesem. Ein Übertritt vom Katholizismus zu anderen Bekenntnissen war nur unter erheblichen behördlichen Einschränkungen möglich. Für die in Dalmatien zur Union übergetretenen Gläubigen zum Beispiel stand erst ab 1848 die individuelle rechtliche Möglichkeit offen, bei entsprechendem Wunsch zum orthodoxen Bekenntnis zurückzukehren (Petković: Patriajarh Josif Rajačić, 31) - dies im Einklang mit den Bestimmungen der sogenannten Pillersdorfschen Verfassung vom 25. April 1848, die in $₫ 17$ allen Staatsbürgern die volle Glaubens- und Gewissensfreiheit zugestanden und in $\$ 27$ die in Teilen der Monarchie bis dahin bestehenden Verschiedenheiten der bürgerlichen und politischen Rechte einzelner Konfessionen beseitigte (Gottas: Geschichte des Protestantismus in der Habsburgermonarchie, 547).

958 Petar Kriška, Anfang 1832 zur Union übergetretener orthodoxer Geistlicher des Dorfes Kriška / Kričke, der am 2. März 1834 im Zuge einer Verschwörung ehemaliger Glaubensgenossen ermordet wurde (Milutinović: Vojvodina i Dalmacija, 33).

959 ON Kriška / Kričke: Ansiedlung ca. 5 km südöstlich von Drniš.

960 Marko Bussovich / Busović, ehemals orthodoxer, dann ab Anfang 1832 (Übertritt gemeinsam mit Kriška) unierter Geistlicher der Gemeinde Balke / Baljci.

961 ON Balke [zeitgenössisch auch Baljke] / Baljci: Ansiedlung ca. $10 \mathrm{~km}$ ostsüdöstlich von Drniš.

962 Dass dieses von Lilienberg so entschieden forcierte Projekt hier in seinem Erfolg durch die Behauptung "vieler« Übertritte geschönt dargestellt wird, ergeht bereits aus der nachfolgenden Zahlenangabe durch Lilienberg selbst - auch wenn diese in der Relation einen deutlichen Zuwachs gegenüber 1833 bedeuteten. Immerhin erhielten sich die beiden kleinen Gemeinden (etwas später kam noch als dritte die von Vrlika hinzu) ab den 1830er Jahren trotz Austritten (nach 1848) und trotz Ablehnung durch die umgebenden orthodox Gebliebenen bis in den Zweiten Weltkrieg. Damals wurden sie durch gezielte Zerstörung der Kirchen und Bekämpfung der Gemeinschaften durch (serbisch-orthodoxe) Četnik-Verbände vernichtet. Siehe mit interessanten Angaben zu ihrer Entstehungs- und Zeitgeschichte sowie zum aktuellen Versuch einer teilweisen Wiederbelebung der Kirchengemeinden bzw. ihrer aufwendigen Bauten den Zeitungsartikel von Šarac, Damir: Nakon 70 godina Grkokatolici se vraćaju u Kričke. Slobodna Dalmacija 2.10.2010, http://www.slobodnadalmacija.hr/\%C5\%A0ibenik/ tabid/74/articleType/ArticleView/articleId/117151/Default.aspx. Wegen der Verknüpfung von konfessioneller und nationaler Identität, andererseits auch wegen des serbischnationalen Ideologems, wonach viele heutige Katholiken in Dalmatien »eigentlich « orthodoxer und damit serbischer Herkunft seien, und schließlich in Erinnerung an die Zwangstaufen von 
Majestät bekannt ist, nichts unterlaßen und direct und indirect auf alle mögliche Weise die Union zu vereiteln und man Grund hat, zu vermuthen, daß der an dem Pfarrer Kriska im laufenden Jahre begangene Meuchelmord in dieser Absicht durch einen gedungenen Mörder geschehen sey. -

Gegenwärtig zählt die Pfarre Kriške [ergänzt: und; gestrichen: und jene von] Balke 271 Neubekehrte ${ }^{963}$.

Die durch die allerhöchste Gnade Eurer Majestät für die zwei gr. unirte[n] Pfarren bewilligten [also staatlich finanzierten; K. C.] Kirchen welche bereits fast ganz vollendet sind und die über allerhöchste Entschließung vom 20 März l. Js. eben erfolgte Ankunft [Qu 96 / 1] des an die Stelle des ermordeten Kriske von der Kreutzer Diozese ${ }^{964}$ gesendeten würdigen Priesters Bubanovich ${ }^{965}$, laßen für die Zukunft einen noch günstigeren Erfolg der Unionsangelegenheit erwarten. [Bleistiftrandanmerkung: Vom Herrn Sec. revidirt ${ }^{966}$ ]

\section{Öffentliche Erziehungs- und Unterrichtsanstalten.}

$\$ 202$ [Höhere Bildungsanstalten] Hierlands besteht für die ganze Provinz nur eine theologische Lehranstalt nämlich vereiniget mit dem hiesigen Seminarium welches 7 Professoren und dermalen 34 Zöglinge hat. Da ich von derselben [Lehranstalt] bereits schon

sonst in ihrem Leben bedrohten Serben im faschistischen Unabhängigen Staat Kroatien wird das Thema der unierten Kirche nicht nur, aber auch zu Dalmatien bis heute je nach Glaubens- und nationalem Standpunkt völlig unterschiedlich gelesen und publizistisch emotionalisiert. Vgl. den zwölfteiligen Fortsetzungsartikel (»Feuilleton«) von Ostoja Milisavljević in der Belgrader Tageszeitung »Novosti« zwischem dem 26. August und dem 6. September 2013 (http://www.novosti.rs/dodatni_sadrzaj/feljtoni 120.html?item_id=824), sowie den ausführlichen serbischen Wikipediabeitrag »Unierte in Dalmatien«, mit weiteren aktuellen Artikelangaben auch aus der kroatischen Publizistik (http://sr.wikipedia.org/sr-ec/Унијати_у_ Далмацији (alle Webseiten 25.11.2013).

963 Bleistiftanmerkung: »Bis Ende 1833 220. Herrn G.R. [Gubernialrat] Godeassi fragen wie viele im 1.J.«Dazu notiert 51, Summe mit Tinte am Rand: $220+51=271$. Also waren es allem Anschein nach 220 Unierte in Kričke und 51 in Baljci. Giuseppe Godeassi war laut Almanacco 1834, 81, einer von vier Gubernialräten, und zwar zuständig als referente del culto. Auf diesen Posten war der aus dem Friaul gebürtige Godeassi in Nachfolge des als Bischof nach Dubrovnik berufenen Antonio Giuriceo im Herbst 1830 durch Kaiser Franz I. berufen worden. 1839 durch den Kaiser zum Bischof von Split vorgeschlagen, 1840 als solcher vom Papst bestätigt, von 1843 bis zu seinem Tod 1862 Erzbischof von Zadar. Für den Beginn seiner Karriere in Dalmatien und seine besondere Nahestellung als Kultus-Gubernialrat gegenüber den ihm vorstehenden beiden Gouverneuren siehe: Vita di Monsignore Giuseppe Godeassi, $32 \mathrm{f}$. und $33 \mathrm{f}$.; kaiserliche Benennung und päpstliche Bestätigung: 36 und 38.

964 Uniertes (griechisch-katholisches) Bistum Kreutz (Križevci), 1777 für den Bereich von Kroatien-Slawonien gegründet, mit Anfängen ab 1611.

965 Vasilije Bubanović, ab 1834 unierter Pfarrer der Gemeinde Kričke.

966 An dieser Stelle liest sich das angesichts der Zahlen- und Aktenergänzungen so, dass der Sekretär insbesondere auch für die Nachträge von offen gebliebenen Aktenverweisen und Zahlenangaben zuständig war. 
früher Erwähnung gemacht habe ${ }^{967}$, so erübrigt mir nur noch eines unangenehmen Umstandes zu erwähnen welcher darin besteht, daß ich im geheimen Polizeywege die Entdeckung gemacht habe, daß zwischen einigen dieser Zöglinge und jenen des Seminars zu Spalato eine [Anm. am Rande auf Höhe der Zahlenangaben: Buchh nachfragen? ${ }^{968}$ ] [Qu 96 / 2] geheime Correspondenz mit simpathetischer Tinte ${ }^{969}$ geführt wurde, worüber ich an beiden Anstalten Untersuchungen in den Papieren dieser jungen Leute anstellen ließ, gestrichen: woraus; ergänzt: daraus] leider, Unsittligkeiten hervorgingen. Im Seminar von Zara fanden sich aber bei einigen dieser Zöglinge Sammlungen von revolutionären Gedichten von ihnen selbst eigenhändig zusammen geschrieben.

Ich sah mich demnach veranlaßt eine formalle [sic] Disziplinarprocedur, und zugleich durch einen Kreis-Kommissär eine politische mit Vermeidung alles [sic] Aufsehens zu verfügen, welche eben in Verhandlung ist und nach deren Resultaten die angemeßenen Vorkehrungen erfolgen und die Bestrafung der Ausgearteten wird verhängt werden.

Das Convict von Zara unter der Leitung des Studien Directors Weltpriesters Appendini $^{970}$ mit 32 Schülern worunter 20 Stiftlinge ${ }^{971}$, befindet sich in jeder Beziehung in einem befriedigenden Zustande, so wie die philosophische Lehranstalt hierorts mit [Qu 96 / 3] 6 Profeßoren und 76 Schülern ${ }^{972}$ im Ganzen entsprechende Resultate liefert.

Das Seminarium und respective philosophische Lehranstalt von Spalato genoß ehemals eines ausgezeichneten Rufes. Dermalen ist aber die Disziplin daselbst etwas gesunken und es ist auch in dieser Beziehung sehr zu wünschen, daß die beim dortigen [Dom-] Capitel erledigten Canonicate bald besetzt werden, um sodann beim Seminar eine strengere und angemeßene Aussicht erzielen zu können.

Die Gymnasien in Zara, Spalato und Ragusa zusammen mit 25 Lehrern und 315 $5^{973}$ Schülern entsprechen im Ganzen genügend, jenes von Zara hat nach der Hierherkunft des neuen Gimnasial-Prefecten ${ }^{974}$, welcher ein Mann von Einsicht und Strenge ist, sich mehr zugehoben; das von Ragusa ist von den dortigen Piaristen so ziemlich bestellt. Der

967 Siehe $\$ 189$.

968 Anfrage an die guberniale Buchhaltung wegen der Zahl der Zöglinge, die vorderhand leer gelassen und dann zunächst mit Bleistift eingefügt war.

969 »sympathetische Tinte = Geheimtinte.

970 Almanacco 1834, 190: Direttore generale des Gymnasiums Zara: padre Urbano Appendini. War zugleich (187) Direktor des Lyzeums von Zara: padre U.A. delle scuole Pie, direttore generale de' ginnasj della provincia, del liceo e del convitto, assessore presso la commissione per la direzione delle scuole elementari. Appendini (zuvor lange Gymnasialprofessor in Dubrovnik) starb bald darauf, schon im Almanacco 1835 sind die beiden Zadarer Posten als vakant geführt.

971 Anm. mit Bleistift: Buchh Nachfragen, Zahlen denn auch zunächst mit Bleistift. Stiftlinge = »Interne«, Internatschüler.

972 Wieder entsprechende Anmerkung und Zahlen in Bleistift.

973 Detto, nur zur Zahl der Schüler.

974 Urbano Appendini. 
Gimnasial-Religions-Lehrer Cipico ${ }^{975}$ zu Spalato ist wegen Unsittlichkeit [Qu 96 / 4] von seinem Posten entfernt und ein geeigneter Kathechet an seiner [gestrichen: Stelle; ergänzt: statt daselbst] angestellt worden.

Der Profeßor der deutschen Sprache Petter ${ }^{976}$ an dem nämlichen Gymnasium ist zwar ein gelehrter Mann, der in einer andern Provinz gute Dienste leisten könnte; seine Schüler machen aber keine bedeutenden Fortschritte, wozu [gestrichen: auch] großentheils [gestrichen: dazu; ergänzt: der Umstand] beiträgt, daß er die italienische Sprache nicht genügend in seiner Gewalt hat, um seinen Vortrag nutzbringend, klar und leicht faßlich zu gestalten. Ubrigens [sic] wird die ihn in Folge allerhöchster Entschließung vom 18 Mayl[aufenden] J[ahre]s. Z 2829 ertheilte Erinnerung ohne Zweifel von Wirkung sein ${ }^{977}$.

$\$ 203$ [Elementarschulen] Der Elementarschul-Unterricht hat hierlands noch nicht jene Ausdehnung erlangt, welcher bei der Unkultur der Landleute vorzüglich zu wünschen gewesen wäre.

Hiervon ist hauptsächlich der Mangel an Localmitteln Schuld, wie [Qu 97 / 1] ich bereits bei Darstellung des Gemeindewesens allerunterthänigst zu bemerken Gelegenheit hatte ${ }^{978}$.

Dermalen bestehen, außer der Normal-Hauptschule ${ }^{979}$ in Zara, noch andere 6 Hauptschulen ${ }^{980}$ zu Spalato, Ragusa, Cattaro, Sebenico, Macarsca und Lesina. -

975 Almanacco 1833, 187: Professor am Gymnasium Spalato Giuseppe Cippico, sac. sec., di religione. Wird auch 1834 (191) noch so geführt. 1835 (193) heißt es zu diesem Posten: »vacante«.

976 Almanacco 1833, 187: Professor am Gymnasium Spalato Francesco Petter, di lingua tedesca, supplente di calligrafia, membro corrispondente dell r. società botanica di Ratisbona (vgl. zu Petter insbesondere in der Einleitung, Seite 31).

977 Franz Petter war auch von Kreishauptmann Nani und einigen der geistlichen Lehrkräfte am Spliter Gymnasium vorgeworfen worden, für Unterrichtserteilung in Dalmatien mangels Italienischkenntnissen und wegen Ungeduld mit den Schülern ungeeignet zu sein (Nani: »della inattitudine del Petter ad insengnare la lingua Tedesca in Dalmazia senza conoscere quant'onore la Italiana e senza essere dottato della conveniente pazienza«). Nani in Schreiben über das Gymnasium an das Landespräsidium, Spalato 15.1.1833, Nr. 30/g.p, liegt in DAZd, Tajni spisi namjesništva, sv. 2, in Nr. 19G.P., Godeassi an Nani (Konzept), wo sich Godeassi in Sachen Petter darauf berief, dass die schon angerufene a. h. Resolution abgewartet werde.

978 Vgl. oben, $\$ 171$.

979 Die Normalschule diente als Vorbildeinrichtung im Elementarschulwesen, außerdem fand dort die Ausbildung der Volksschullehrer statt.

980 Diese allesamt städtischen »Hauptschulen « unterschieden sich innerhalb des Elementarschulwesens durch ihre vier oder wenigstens drei Jahrgangsstufen von der Mehrzahl der übrigen Volksschulen, den sogenannten »Trivialschulen«, die nur zweistufig waren. Petter: Geographische Skizze, 79 schreibt allerdings leicht abweichend von je einer vierklassigen Elementarschule in den vier Kreisstädten und je einer dreiklassigen in Sebenico, Trau, Macarsca und Lesina. 
Bei der oben angegebenen Schwierigkeit mußte übrigens die Hauptsorge des Guberniums vorzüglich dahin gerichtet seyn, daß zuerst alle Präturs-Hauptorte mit Elementarschulen von 2 Klassen versehen werden; welches auch vollständig ausgeführt wurde; bis auf Slano, im Kreise von Ragusa, wo dieß aber auch nach der eben in Verhandlung stehenden Ausmittlung eines Schullokales erfolgen wird.

Außerdem sind noch einige wenige Landorte mit Schulen versehen worden. Im Ganzen fand ich die Elementar-Schulen über meine Erwartung und den Fortgang der Schüler befriedigend, so daß sich sehr gute Wirkungen erwarten laßen. Nur einige wenige erkannte ich mangelhaft besorgt ${ }^{981}$ und unterließ nicht, sogleich den Lehrern und Vorstehern nachdrückliche Ermahnungen dießfalls zu ertheilen; da aber der Schullehrer zu Curzola sich [Qu 97/2] unfähig erwies, so veranlaßte ich dessen Entfernung und habe auch dem dortigen Pfarrer, da er sehr wenig die dortige Schule besuchte, einen eingreifenden Verweis ertheilt. ${ }^{982}$

Ordentliche Mädchenschulen giebt es 4 im Lande; die in Zara bei den Klosterfrauen und jene in Spalato zeichnen sich vor denen zu Sebenico und Trau aus, obwohl auch diese genügende Fortschritte darthun. Nach dem Geschilderten hat Dalmatien im Ganzen 7 Haupt - [gestrichen: 24; ergänzt: 34] Elementar und 4 Mädchenschulen - zusammen 45 Schulen, welche unter der Oberleitung der von dem hiesigen Erzbischofe präsidirten Schulencommission stehen. ${ }^{983}$

Die Mädchenschule von Pago, die noch nicht vollkommen eingerichtet ist, habe ich in dieser Zahl nicht einbegriffen.

Seit der Bestimmung ${ }^{984}$ des früheren thätigen Schulen-Inspektors Plancich ${ }^{985}$ nach Venedig versieht deßen Stelle der Weltpriester und Lehrer der Landwirthschaft am hiesigen Seminar, Santich ${ }^{986}$, zur vollkommenen Zufriedenheit.

$981 \mathrm{Zu}$ verstehen als »eingerichtet und verwaltet«.

982 Bei dem jeweiligen katholischen Ortspfarrer lag, sofern er nicht selbst als Schullehrer fungierte, die Aufsicht über die örtliche Volksschule, wie auch die Oberaufsicht über das Volksschulwesen insgesamt zunehmend und ab 1838 in Dalmatien zur Gänze bei den jeweiligen katholischen Bistümern lag.

983 In der Summe wurde aber erst im Schuljahr 1842-43 die Zahl von 60 Volksschulen erreicht, die sich die Verwaltung schon im Organisationsreglement von 1819 vorgenommen hatte (Clewing: Staatlichkeit, 117).

984 Hier im Sinne von »Versetzung «.

985 Almanacco 1830, 194: Ispettore generale e referente bei der Commissione per la direzione delle scuole elementari della Dalmazia Giorgio Plancich, sac. sec. laureato in filosofia e sacra teologia. Figuriert als solcher noch 1832, 188, danach nicht mehr. Plancich (Plančić) hatte das Amt seit seiner Ernennung durch den Kaiser im Herbst 1819 bekleidet (siehe Meldung aus dem Intelligenzblatt der österreichischen Literatur, 18.11.1819, in Marinelli-König: Die Südslaven, 278).

986 Almanacco 1833, 189: Ispettore in capo e referente der commissione: Matteo Santich, sac. sec., provv.; Seite 184 wird er auch als Professor am Istituto teologico nel Seminario centrale archivescovile (Zara) genannt, mit dem Zusatz referente provvisorio presso la commissio- 
$\$ 204$ [Was noch im Elementarschulunterricht zu thun bleibt] In Beziehung auf den Volksunterricht ist demnach nur noch vorzüglich zu wünschen, daß die Trivialschulen [Qu 97 / 3] auch auf dem flachen Lande möglichst eingeführt werden, um durch selbe auf das Landvolk, vorzüglich in religiöser, moralischer und practischer Beziehung einzuwirken, da die zwekmaßige Umgestaltung des so äußerst rohen, aber geistvollen und empfänglichen Morlaken erst für die Zukunft und nur bei der Jugend beginnen kann.

Nach dem über die Localmittel der Communen und über den Zustand der Landgeistlichkeit von mir allerunterthänigst Geschilderten, wird jedoch erst nach Regulirung des Gemeinde-Vermögens und nach Gewinnung vieler guter Land-Seelsorger in dieser Beziehung ein vollkommen günstiger Erfolg zu erwarten seyn. Das Letztere ließe sich am Leichtesten und schnellsten erzielen wenn wieder ein illirisches Seminarium, wie das in Zara vorbestanden war, worüber ohnehin Euer Majestät allerhöchster Befehl dem Gubernium zugekommen ist und nach Einvernehmen der [Qu 97 / 4] Ordinariate die Erledigung an die vereinte Hofkanzlei vorgelegt werden wird.

Außerdem weiß ich kein anderes Mittel allerunterthänigst vorzuschlagen, als daß die Auslagen zur Errichtung und Erhaltung v[on] Trivialschulen, für jene Gemeinden, die erwiesen arm sind und selbe entweder gar nicht oder nur zum Theile zu bestreiten vermögen, inzwischen aush[gestrichen: -ü-; ergänzt: -i-]lfsweise aus der Maße des Dazio consumo bestritten; daß derley Schulen zuerst an den volkreicheren, durch Gewerbs- oder Handelsverhältniße ausgezeichneten Orten errichtet und durch taugliche Lehrer, selbst die in der Bildung schwächeren, nicht ganz tauglichen, Curaten auch im Religionsunterrichte ${ }^{987}$ unterstützt; daß, wo sich gebildetere Seelsorger befinden und es ohne Nachtheil für ihre pfarrlichen Obliegenheiten geschehen kann, der gesammte Schulunterricht wenigstens an einigen Tagen in der Woche ihnen bis zur Errichtung förmlicher Schulen gegen eine geringe Renumeration übertragen; daß die sich darin auszeichnenden Seelsorger durch Prämien belohnt werden, wie es mit Gubernial-Bericht vom 26 Februar 1[aufenden] J[ahre]s Z 2213 in Antrag gebracht ward, und daß [Qu 98 / 1] wo Klöster sich befinden, die, ohnehin müßigen Klostergeistlichen zum Schulunterricht verpflichtet würden.

$\$ 205$ [Technische Schulen] Als höchst nothwendig und ungemein nützlich für dieses Land, wo die Industrie noch so weit zurück ist erachte ich aber die Errichtung von Industrie- oder Gewerbs-Schulen.

ne per la direzione delle scuole elementari, supplente per l'agraria [am Lehrinstitut]. Santić war ab Mitte der 1840er Jahre gemeinsam mit Stjepan Ivićević auch mit der Übersetzung von Schulbüchern »in die illyrische Sprache« beschäftigt (Marinelli-König: Die Südslaven, 279, mit Meldung aus den Oesterreichischen Blättern, 25.6.1846).

987 Im Original eine sprach- und orthographiegeschichtlich interessante Schreibung, die das kommende Zusammenwachsen solcher deutscher Komposita zu einem Begriff spüren lässt: Religions unterrichte, also Getrennt-, aber Kleinschreibung! 
So wünschenswerth es seyn würde derlei Anstalten die möglichste Ausdehnung zu geben, so ist dieses in größerem Umfange theils wegen Mangels an Mitteln und an tauglichen Individuen noch unausführbar und dürfte ein frommer, aber heilsamer Wunsch für die Zukunft bleiben. Einstweilen habe ich, wie ich bei der Darstellung der industriellen Production bereits allerunterthänigst bemerkt habe, so viel als möglich abzuhelfen getrachtet. ${ }^{988}$

Rücksichtlich des nautischen Unterrichts für welchen das Gubernium unter den 20 Maj 1828 Z 83 seine Anträge erstattet hat, werden die höheren Entscheidungen gewärtiget.

[Qu $98 / 2]$

$\$ 206$ [Sonntags Unterricht] Was den Sonntagsunterricht ${ }^{989}$ betrifft, so bestehet auch hierlands die Verpflichtung der Seelsorger den Kindern den Elementarunterricht in der Religion, und der Jugend der höheren Christenlehre zu ertheilen.

Bei den älteren Seelsorgern auf dem Lande fand ich fast meistens diesen Unterricht verabsäumt; da jedoch die Ursachen hiervon in der schon früher von mir geschilderten eigenen Unfähigkeit, im hohen Alter oder in der phisischen Gebrechlichkeit der Geistlichen selbst liegt, so lässt sich eine Änderung dieses sehr unangenehmen Umstandes nur mit der Zeit, nach Gewinnung einer hinlänglichen Zahl [ergänzt: geeigneter; gestrichen: genügender] Seelsorger erwarten.

$\mathrm{Da}$ an einigen Orten aber nicht so sehr die Mangelhaftigkeit des Curaten, als die schwierige Lage der Ortschaften hieran die Schuld trägt, indem manche Pfarren 18-20 Miglien in [sic] Diameter, die Kinder 1, 2-3 Stunden Weges zur Kirche haben und Gebirge, Klüfte, Wildbäche, Flüße oder andere Wasser das Gebiet unterbrechen, zuweilen [Qu 98 /3] auch das Pfarrhaus von der Kirche sehr entfernt ist und die Häuser sehr weit zerstreut von einander liegen, wie ich schon öfters allerunterthänigst zu erwähnen Anlaß hatte; überdieß aber auch oft gar keine Straßen und Wege durch solche Gegenden geführt sind: so wird es nothwendig seyn, diesen Mängeln, so weit es geschehen kann, wenigstens zum Theile abzuhelfen.

Dieß wird einigermaßen durch die Pfarrbezirks-Regulierung gelegentlich der Sistemisirung der Pfarren geschehen können; dann dadurch, daß diejenigen Geistlichen deren Fähigkeit, Alter und phisische Constitution es zuläßt, wochentlich per turnum sich in gewiße Centralpunkte, wo sie mehrere Häuser beisammen finden, begeben und so von einem zum anderen Ort den Unterricht ertheilen, wozu diejenigen die sich in diesem Falle befinden, in den Stand gesetzt werden müßten sich ein Pferd zu halten.

988 Vgl. oben, in $\$ 118$.

989 Kirchliche Sonntagsschule. 
II Dermalige politische Eintheilung des Landes

[Qu 98 / 4]

\section{Sonstige Bildungs-Anstalten}

$\S 207$ An Bibliotheken, Naturalien-Industrie und anderen Gabinetten und Sammlungen dieser Art fehlt es beinahe gänzlich in Dalmatien.

Nur in Zara besteht eine dürftig bestellte Sammlung mehrerer phisikalischer Instrumente; und in Spalato ein Antiquitäten Musäum ${ }^{990}$.

Das Letzte befand sich, als ich es besuchte, in einem kleinen gemietheten Häuschen und enthielt Weniges von Bedeutung und in gar keiner Ordnung, meist auf der Erde herumliegende alte Steine und Geräthe; während der Antiquitäten Direktor, Doctor Lanza, der inzwischen gestorben ist, selbst eine schätzbare Privatsammlung hatte, die er selbst nach und nach zusammen gekauft zu haben, angab. ${ }^{991}$

Um dem Mangel einer Provinzial-Naturalien-Industrie-Antiquitäten- und Münzensammlung abzuhelfen, erließ ich eine Aufforderung an alle politische Authoritäten, an die Geistlichkeit und durch die ersten an die gebildeten Menschen vom Fache und Di-

990 Das heutige Archäologische Museum (Arheološki muzej) von Split wurde 1820 als eine Folge des Kaiserbesuchs vom Mai 1818 gegründet und ist damit laut der deutschen und kroatischen Webseite des Museums die älteste Museumsanstalt in Kroatien. Vgl. dort auch die Abbildung des direkt an den Diokletianspalast angrenzenden ersten Gebäudes (in Lilienbergs Diktion: des kleinen Häuschens) von 1821: http://www.mdc.hr/split-arheoloski/nj/FS-povijest.html (25.11.2013). Mit guter Einordnung in die Wissenschaftsgeschichte der Archäologie im Habsburgerreich und in die Geschichtspolitik des Hofes und der Hofstellen s. Špikić: Francesco Carrara, hier 24-26.

991 Almanacco 1833, 185: Carlo Lanza Direttore onorario del Museo di antichità Spalato; Almanacco 1834, 189: Museo di antichità in Spalato, direttore onorario il sig. Carlo Lanza, dottore in medicina. Ispettore provv. sig. Raffaele Martini. Nachtragsseite (Correzioni) dieses Almanacco meldet Lanza bereits als morto. Ein Nachruf auf ihn durch Stefano Ivacich (Stjepan Ivačić) in der Gazzetta di Zara, Nr. 22/1834, 18.4.1834, S. 88 und 23/1834, 21.4.1834, S. 91 f. Der Almanacco 1835, 192 nennt dann: Direttore onorario il sig. Giuseppe Ciobernich [181 geschrieben Ciobarnich; Kanoniker im Spliter Domkapitel], Ispettore (nicht mehr prov.) weiterhin Martini. - Zu Carlo Lanza, dem Gründungsdirektor des besagten Museums, vgl. nunmehr Špikić: Carlo Lanza. Lanza war 1818 als Münzen- und Antikensammler in seinem Privathaus, wo die Sammlung war, von Kaiser Franz I. aufgesucht (Krmpotić [Hg.]: Car Franjo I. u Hrvatskoj 1818., Bd. 1, 215 f. Eintrag unter 14.5.1818) und im Gefolge dieses kaiserlichen Eindrucks 1820 zum Direktor der neuen Einrichtung bestellt worden. Špikić weist zurecht auf die interessante Persönlichkeit Lanzas hin, er dürfte aber gemessen an den Angaben Lilienbergs die Qualitäten Lanzas als Archäologe oder doch zumindest diejenigen als Organisator sehr hoch einschätzen, wenn er 383 urteilt, Lanzas Vorgehen habe methodisch in Sachen Archäologie und Konservierung vollkommen den seinerzeitigen europäischen Erfahrungen entsprochen. Bemerkenswert ist die von Špikić (382) angegebene Summe von 3300 Gulden, die Lanza allein 1821-1826 von den Wiener Hofstellen für Grabungstätigkeiten erhalten habe, denn dieser hohe Betrag lässt wie offenbar schon für Lilienberg die Diskrepanz zwischen der Güte der öffentlichen und derjenigen der privaten Sammlung tatsächlich verdächtig erscheinen. 
lettanten zur Begründung einer derartig[en] [Qu 99 / 1] Sammlung mitzuwirken, und ich hatte die Freude in kurzer Zeit so viele und darunter so schätzbare Gegenstände von allen Seiten zu erhalten ${ }^{992}$, daß sich nicht leicht ein Unternehmen dieser Art eines gleich im Anfange so günstigen Fortganges zu erfreuen gehabt haben dürfte.

Diese Objekte habe ich insgesammt in einem Saale des Normalschulgebäudes aufstellen laßen, welches Locale aber bereits alles Eingegangene nicht mehr zu faßen vermag, so daß auf die Auffindung eines anderen geräumigeren wird vorgedacht werden müßen ${ }^{993}$.

Sobald die vorhandenen Gegenstände geordnet sind, werde ich mir erlauben Eure Majestät allerunterthänigst zu bitten damit dieses Musäum, als öffentliche Anstalt in das Leben trete, mit einer dankbar begeisternden Erinnerung auf die spätesten Nachkommen übergehe, und den Namen Franzens-Musäum führe ${ }^{994}$. Zur Erlangung dieser allerhöchsten Gnade werde ich seiner Zeit durch [Qu 99 / 2] die Studien-Hofkommißion

992 Dieser und die beiden folgenden Absätze beziehen sich auf die Anfänge des Archäologischen Museums von Zadar, das auf eine ganz persönliche Initiative Lilienbergs zurückgeht. Die Einrichtung datiert heute ihre Gründung auf 30. November 1832, als Lilienberg einen Aufruf zur Sammlung in Zadar von archäologischen Funden aus der ganzen Provinz erlassen hat. Er selbst war unter den ersten Spendern. Im Weiteren wurde der Aufbau der Sammlung intensiv medial orchestriert. In der Gazzetta di Zara erschienen gemäß meinen unvollständigen Notizen ab spätestens Herbst 1833 regelmäßig Listen der Spender und ihrer Gaben (in der GdZ 59/1834, 25.7., S. 233 etwa die 10. dieser Listen, X. specifica), die öfters in mehreren Teilen und Zeitungsnummern abgedruckt waren (z. B. Liste IX. in GdZ 54/1834, 8.7.34, S. 213 und GdZ 55/1834, 11.7., S. 217). Die Spender waren meist Beamte, daneben Grundbesitzer und Geistliche. Insbesondere unter den Beamten dürfte die rege Beteiligung als eine Art Dienstpflicht und auch als Wettstreit um die Gunst des Gouverneurs verstanden worden sein, vgl. etwa GdZ, Nr. 1/1834, 3.1.1834, S. 1: Fortsetzung von Liste VIII, mit Angaben zu Spenden der beiden Kreishauptleute von Kotor, Ivachich, und Zadar, Nachich. Insgesamt bieten die Listen eine Art »who is who" des Bürokraten-Netzwerkes im Umfeld des Guberniums.

993 Die Sammlung erweiterte sich offenbar bald auf Räumlichkeiten auch im Gymnasium der Stadt; zu einer professionellen Unterbringung kam es aber erst Jahrzehnte später ab 1877 und endgültig mit 1893 (Batović, 679).

994 Hier Einfügung am Rand mit dunkler Tinte (wohl von Lilienberg selbst), und mit gleicher Tinte wieder ausgestrichen: »und sowohl der studirenden Jugend als den Wißbegierigen möglichst nützlich werde«. Das im beabsichtigten Namen deutlich werdende Moment von Kaiserkult wurde im Weiteren in Punkto des Museums offenbar nicht umgesetzt, sei es wegen des baldigen Ablebens des Monarchen, sei es wegen der vermutlich doch noch lange mangelnden Repräsentativität der neuen Einrichtung. 
in tiefster Ehrfurcht einschreiten, $u^{995}$ sowohl der studirenden Jugend als sonst den Wißbegierigen möglichst nutzbar werde. ${ }^{996}$

\section{Polizey}

$\$ 208$ Die Local-Polizei ${ }^{997}$ fand ich fast überall in schlechtem Zustande. Der Hauptgrund deßen beruht in der noch nicht erfolgten Ausbildung des Gemeindewesens, in dem bisherigen Mangel genügender Instruktionen für alle Hauptzweige der Comunal-Geschäfte und den bereits in $\$ 170^{998}$ angeführten Umständen.

Inzwischen habe ich, so viel es möglich war, Sorge getragen, daß wenigstens die Marktordnung und Straßenreinlichkeit, in den größeren Orten besser bestellt und auch das Landvolk zu mehrerer Sauberkeit in den [ergänzt: Haus-]Höfen und in der Umgebung der Wohnungen, ermuntert und verhalten werde.

In den Kreishauptorten außer [Qu 99/3] der Provinzial-Hauptstadt, ist der Mangel von Polizei-Agenten sehr empfindlich, indem ${ }^{999}$ die Comune und das Kreisamt zur Ausübung ihrer polizeilichen Pflichten deren sehr nothwendig bedürfte. Auch hierüber wurden [gestrichen: wiederholte; ergänzt: die] Anträge von dem Gubernium an die Hofstelle unter dem 30 Jänner und 26 Juny 1833 Z. 805 und 10164 erstattet.

Da ich außer den 4 Kreis-Hauptorten fast nirgend eine nur halbwegs genügende Vorkehrung gegen Feuergefahr vorfand, und selbst in Zara die Feuerlöschrequisiten sehr mangelhaft und sonst fast nirgend vorhanden waren, so habe ich eine Verhandlung zur Verfaßung eines Entwurfes für eine neue Feuerlöschordnung veranlaßt und bereits mehrere Comunen mit den nöthigen Feuerlöschrequisiten versehen auch ein Exemplar von den aldinischen Apparaten ${ }^{1000}$ kommen laßen, um wenigstens nach und nach, soweit die äußerst beschränkten Geldmittel auslangen, diesem dringenden Bedarfe abzuhelfen.

995 Ein grammatikalisch verunglückter Satzanschluss. In der Reinschrift ist an dieser Stelle denn auch eine der äußerst seltenen Ausstreichungen vorgenommen worden, die das »um « durch ein »damit es« ersetzte (Seite 151). Das »einschreiten« ist so zu verstehen, dass Lilienberg bei späterer Gelegenheit einen förmlichen Antrag über die besagte Namensgebung an die Studienhofkommission richten wollte.

996 Auf dieser Höhe Anmerkung in Schreiberschrift mit Bleistift: bis hier vom Herren Secretaer revidirt worden.

997 Polizey/Polizei ist hier (und fast überall im Text, mit Ausnahme von $₫ 218 \mathrm{ff}$. »Geheime und höhere Polizey«) im alten, frühneuzeitlichen Sinne des deutschen Wortes zu verstehen, also in etwa als »Ordnungsamt $«$.

998 Das Thema der schlechten »Polizei«-Verhältnisse wird kurz direkt in $\$ 171$ angesprochen; in $\$ 170$ geht es dagegen um den von Lilienberg eruierten Grund für fast alle Gemeindeprobleme: die Unterfinanzierung der Gemeinden durch Verschiebung des Dazio consumo in die Staatskasse.

$999 \mathrm{Zu}$ verstehen wie »weil«.

1000 Gemäß dem einzigen inhaltlich passenden Suchergebnis in Google Books (25.11.2013), nämlich "aldinische Maschinen«, handelte es sich um eine Art hydraulische Maschine: Keeß, Stephan von: Darstellung des Fabriks- und Gewerbswesens, in seinem gegenwärti- 
$\$ 209$ [Armen- und sonstigen Wohlthätigkeitsanstalten] Die Armen- und sonstigen Wohlthätigkeitsanstalten fand [Qu 99 / 4] ich bei meiner Ankunft in dieser Provinz in einem sehr dürftigen Zustande.

Selbst in Zara, wo, doch eine Casa di Ricovero ${ }^{1001}$ besteht, war die Straßenbettelei noch sehr häufig. Ich ließ alle die älternlosen Betteljungen aufsammeln und veranlaßte dass dieselben, mit Unterstützungen betheilt, bei verschiedenen Gewerbsführern unterbracht ${ }^{1002}$; alle zu dieser Comune gehörigen Erwerbsunfähigen aber in die oberwähnte Casa di ricovero abgegeben und das Betteln auf der Straße durch die Polizei gehörig überwacht werde; wodurch dieser Unfug hierorts auch wirklich ganz aufgehört hat.

Nachdem ich auch in den andern Kreisstädten eine bedeutende Menge von Bettlern, besonders aber in Spalato so viele antraf, daß man auf den Gaßen kaum fortkommen konnte, so forderte ich die bezügliche Kreis- und die Gemeinde-Vorsteher auf, ähnliche Vorkehrungen zu treffen.

In Spalato wurde auch wirklich eine Casa di ricovero provisorisch [Qu $100 / 1]$ eingeführt ${ }^{1003}$ und es werden seither in derselben theils mittelst freywilligen Gaben, theils durch Unterstützungen aus dem Dazio consumo [gestrichen: zwischen] 20 und [ergänzt: 30; gestrichen: mehr] Individuen erhalten; wegen fernerer Dotirung dieser Anstalt ist aber von dem Gubernium unter den 30 April l[aufenden] J[ahres] Nº 6345 Bericht an die Hofkanzlei erstattet worden. ${ }^{1004}$

gen Zustande. Vorzüglich in technischer, mercantilischer und statistischer Beziehung. 2. Teil, 2. Band Wien 1824 (2. Auflage), 767.

1001 Im damaligen Amtsdeutsch ansonsten: »Armenhaus« oder »Armenverwahranstalt«. Siehe die nachstehenden Anmerkungen.

1002 Vgl. dazu auch oben, gegen Ende von $\$ 118$.

1003 Der Almanacco 1834 nennt 132f. für Dalmatien zwei Case di ricovero, d' istituzione provvisoria: Einmal das zu Zara: »Somministra a circa 300 poveri, parte alloggio e vitto, parte allogio e congrue pensioni«; Vorsitzender der Commissione estraordinaria di carità war Dr. Angelo de Benvenuti, welcher dem dalmatinischen »Ufficio fiscale cameral« als »Procuratore cameral « vorstand (85); die neun weiteren Mitglieder waren ein Vertreter des Erzbistums, einer der Stadtverwaltung, ein Arzt, einige nicht als solche ausgewiesene Grundbesitzer (Giuseppe Filippi; Pietro di Fanfogna) und weitere Bürger, sowie ein Konzeptbeamter aus der dalmatinischen Finanzverwaltung als Schriftführer. Und daneben: Curzola, dazu genannt nur der Direttore interinale Giovanni Carlo Cettineo. Der Almanacco 1835 nennt dann 131 f. zusätzlich Split, mit Angabe des Direttore Giuseppe Cindro dottore in legge und des Vice-direttore sig. Antonio Drasich, canonico onorario, sowie sechs weitere Mitglieder.

1004 Die dauerhafte Installierung dieser Institution und überhaupt der staatlichen Armenunterstützung in Dalmatien wurde bald darauf durch die Hofkanzlei unmöglich gemacht (nicht zufällig nach dem Tod des Kaisers und »Landesvaters«): Die betreffenden Entschädigungszahlungen aus dem Dazio consumo wurden ab 1835/36 gekürzt, die Einrichtung in Split ist dadurch offenbar unmittelbar untergegangen und im von Armutszuwanderung damals besonders betroffenen Zadar konnten auch die Ende 1835 zur Kostenminderung begonnenen Entlassungen von ersten Bedürftigen aus der Armenanstalt die Existenz der Einrichtung nicht auf Dauer retten. Vgl. dazu mit Aktenhinweisen Clewing: Staatlichkeit, 
Auch für Cattaro sind ähnliche Verhandlungen bei der Landesstelle im Zuge, wonach zu hoffen ist, daß dort ebenfalls etwas Ähnliches erwirkt werde, wenn gleich die wenige Großmuth die, lauth eines vorliegenden Berichts des Podestà zu Cattaro ${ }^{1005}$, der dortige katholische Bischof Pavlovich-Lucich ${ }^{1006}$ gelegentlich der dießfalligen Oblationen ${ }^{1007}$ als erster Subscribens bewiesen hat, durch das schlechte Beispiel für die Anderen die Erreichung des wohlthätigen Zweckes verzögert.

Die Opera Pia in Ragusa besitzt ein sehr bedeutendes Vermögen ${ }^{1008}$. Eine eigene LiquidirungsCommission [Qu 100 / 2] beschäftiget sich gegenwärtig mit deren Depurirung ${ }^{1009}$.

Nach dem letzten Status belaufen sich die verschiedenen im In- und Auslande angelegten Capitalien und die Grundbesitzungen [der ragusanischen Opera pia] auf 764283 Gulden mit dem Zinsenanschlage von 32206 Gulden 56 Kreuzer, wovon aber dermalen nur 20729 Gulden 1 Kreuzer einfließen. ${ }^{1010}$

Das Capital und der Zinsen Ertrag dürfte jedoch, nach völliger Ausmittlung aller Forderungen im Auslande und nach gehöriger Organisirung der Verwaltung dieser Ope-

154. Auch Petter: Dalmatien, Bd, 1, 243 hält fest (Stand von Anfang/Mitte der 1850er Jahre), es gebe im ganzen Land keine Anstalten, "wo alte gebrechliche oder sonst arbeitsunfähige Gemeindeglieder auf Kosten der Gemeinden, denen sie angehören, verpflegt werden können. Diese Unglücklichen strömen daher den Städten am Meere zu, um sich vom Strassenbettel zu nähren, weshalb man deren auch wirklich, Zara und Ragusa ausgenommen, viele sieht und darunter solche, deren Anblick eben so sehr Ekel als Mitleid eregt. Im Winter sind sie viel zahlreicher als im Sommer, weil sie in der guten Jahreszeit auf dem Lande leichter sich durchbringen und es im Winter am Meere viel wärmer ist als in den Gebirgsgegenden, wo sie aus Mangel an Schutzmitteln gegen die Kälte Gefahr liefen zu erfrieren. Bei warmem Sonnenschein im Winter kann man in Spalato auf dem Marineplatze eine Menge solcher Armen gelagert sehen, um sich zu sonnen.«(Vgl. auch $\$ 211)$.

1005 Francesco di Jacogna, siehe oben Anm. 764.

1006 Almanacco 1834, 183: Vescovo Monsignor Stefano Paulovich Lucich, preside della locale commissione di pubblica beneficenza.

1007 Oblationen: Spenden(sammlungen); vgl. italienisch oblazione: Spende.

1008 Doppelt unterstrichene Randanmerkung (Bearbeitungsvermerk): »Vermögen«. Es sollte also offenbar näher beziffert werden, was im nachstehenden Absatz dann auch durch Zahleneinfügungen geschehen ist.

1009 Depurieren, Depurierung: Anscheinend ein (österreichischer) juridischer Begriff: eine Sache gegen Forderungen Dritter lastenfrei machen, von Forderungen freistellen (vgl. auch italienisch depurazione: Klärung, Reinigung).

1010 Die große Höhe des Stiftungsvermögens ist im Vergleich mit den Jahreshaushalten der dalmatinischen Landesverwaltung erkennbar. 1847 etwa betrugen deren Gesamtausgaben etwas über 1,93 Mio. Gulden (Clewing: Staatlichkeit, 69). Auch die Kapitalerträge der Stiftung waren erheblich, wenn man sie etwa mit der jährlichen Dotation einer Bezirksarztstelle vergleicht, die 1825 bei 400 Gulden lag, oder mit der schon weiter oben angeführten Mitte der 1830er Jahre üblichen Dotierung (Congrua) einer katholischen Pfarrerstelle mit 200 Gulden (in Geld oder Naturalien) (vgl. ebd., 97, in Anm. 176, bzw. Seite 113). 
ra pia sich bedeutend erhöhen, das Armeninstitut ${ }^{1011}$ damit beßer unterstützt werden, die Bettelei, obgleich sich daselbst über 2000 arme Menschen ohne hinlängliche Nahrungs-Mittel befinden, aufhören, und die Armenhäuser ${ }^{1012}$, welche, als ich sie besuchte, bloß den Namen nach bestanden, da sie den Ärmsten blos zur Nachtszeit Obdach gewährten, in ordentlichen Stand gesetzt werden [Qu 100 / 3] können.

Uiber Antrag des Kreishauptmannes Baron Schaller ist im vorigen Jahr eine sogenannte Casa di ricovero für arme gemeine Mädchen um sie zu tauglichen und gesitteteten Dienstbothen zu erziehen, daselbst gegründet worden ${ }^{1013}$. In dieser Anstalt werden die Mädchen im Weben von Lein- und Wollenzeug, in Verfertigung von Bändern, im Wollkrämpen und Spinnen, Stricken und Nähen gründlich unterrichtet. Ich fand die Einrichtung im guten Stande und die Arbeiten befriedigend.

Außerdem bestehen noch in Trau, Macarsca ${ }^{1014}$ und Curzola Case di ricovero für arme, erwerbsunfähige Personen. Jene zu Curzola die ein eigenes Einkommen von 4000 Gulden hat, traf ich sehr rein, ordentlich gehalten und in einem geräumigen Locale miethweise unterbracht.

[Qu 100 / 4] Die zwei anderen, besonders aber die zu Macarsca laßen hinsichtlich der Reinlichkeit und guten Ordnung Manches zu wünschen übrig.

Jene zu Macarsca both als ich dort war 26 alten Individuen in 2 engen und schmutzigen Löchern lediglich einen Unterstand zur Nachtszeit, indem man sie übrigens ${ }^{1015}$ herumbetteln ließ.

Zur Verbesserung der oberwähnten Mängel ertheilte ich sogleich dem Vorsteher beider Anstalten die nöthigen Weisungen, ${ }^{1016}$ welche in Macarsca um so leichter ausgeführt werden konnten, als hiezu eine eigene Stiftung bestehet.

In den anderen Bezirks-Hauptorten bestehen zwar sogenannte Wohlthätigkeits-Commissionen; allein ich fand fast überall, daß sie es nur dem Namen nach sind, und ein höchst unbedeutendes Einkommen haben. Außer diesen Hauptorten ist aber gar keine

1011 Dieses wird im Almanacco 1834 nicht genannt, es sei denn, es ist identisch mit dem Spital Ospizio, das im Almanacco auf Seite 135 aufgeführt ist (alle Ospizj in Dalmatien - Zara, Sebenico, Spalato, Lesina, Ragusa, Cattaro - waren dem Almanacco zufolge noch provisorisch organisiert).

1012 Vgl. Anm. 1004 von eben.

1013 Diese Casa di ricovero für Mädchen wird in den Amtsalmanachen jener Jahre nicht genannt. Weiter unten spricht Lilienberg in gleichem Zusammenhang von einer "casa di lavoro« (in \$ 239). Gemein« heißt hier »aus dem gemeinen [gewöhnlichen] Volke«, bzw. auch "nichtadelig«.

1014 Jene zu Traù und Macarsca stehen nicht im Almanacco.

$1015 \mathrm{Zu}$ verstehen als: im Übrigen / ansonsten (also untertags, für ihren Lebensunterhalt).

1016 Ein weiteres Beispiel für unmittelbare Verwaltungsmaßnahmen Lilienbergs im Zuge seiner Bereisung, hier also auch in einem Bereich, der an sich nicht unmittelbar staatlich war, sondern Aktivitäten betraf, die aus wohltätigen Stiftungen finanziert wurden. 
Einrichtung dieser Art eingeführt, wovon wohl großten [sic] Theils der, im Allgemeinen genommen, geringe Grad des Wohlstandes der Bewohner die Ursache ist.

$\mathrm{Da}$ aber der Wohlthätigkeitssinn in diesem Lande allgemein ist ${ }^{1017}$, so reicht $[Q u 101 / 1]$ man den wahren Nothleidenden doch willig eine kleine Unterstützung.

$\$ 210$ [Nothstand] Was den hier nicht selten eintretenden partiellen oder allgemeinen Nothstand des Landvolkes betrift, so beruht dieser vorzüglich in dem gesunkenen $\mathrm{Zu}$ stande der Landwirthschaft und in dem Character des Morlaken welcher aus Vorurtheil und oft aus Trägheit jeder, auch wohltätigen, Neuerung entgegen ist, endlich in seiner, [gestrichen: die in wenigen Monaten den Ertrag des ganzen Jahres verzehrenden] unwirthschaftlichen Haushaltung und den vielen Gastereyen, die in wenigen Monaten den Ertrag des ganzen Jahres verzehren.

Daß bei diesen Umständen der geringste Elementarzufall den Landmann in Noth versetzen kann, ist ganz natürlich. ${ }^{1018}$

In dieser Beziehung wird nur durch die von mir zur Hebung des Landbaues und des Gewerbfleißes, dann zur Verbeßerung des National-Characters allerunterthänigst angegebenen Mittel, radikal abgeholfen werden können. ${ }^{1019}$

Inzwischen ist das Nöthige vorgekehrt, daß auch der partielle Bedarf und die Annäherung einer, auch nur theilweisen, Noth bald entdeckt, [Qu 101 / 2] und nach den von Eurer Majestät vorgezeichneten Grundsätzen durch Localmittel, und so weit diese nicht hinreichen durch öffentliche Arbeiten[,] Geld- oder Naturalien-Unterstützungen, ohne oder gegen Ersatz, bei Zeiten Hülfe geschafft werde. ${ }^{1020}$

1017 Innerhalb des Morlaken-/Dalmatinerdiskurses zeigt sich hier wieder die eine positiv konnotierte Bildseite bei Lilienberg.

1018 Peričić: Oskudica i glad, lässt dieses plausible Argument mangelnder Vorratshaltung und mangelnder Vorausplanung als (Mit-)Ursache für die schlechte Versorgungs- und Selbstversorgungslage in Dalmatien gerade nicht gelten (ebd., 2, Anm. 8, in Wendung gegen den Zeitgenossen Petter). Dies, obwohl er sonst durchaus ein ganzes Motivbündel anhand der Angaben der Zeitgenossen zur Erklärung richtig findet: schlechte Bodenqualität, Hitzeschäden, Wassermangel, Vernichtung der Wälder, kleinteilige Zerstreuung der Grundstücke und Wohnstätten (mit langen Wegen zu den einzelnen Nutzflächen), Mangel an Zuchtvieh, Abgabenlast, hoher Salzpreis und Frohndienste. Er selbst fügt als Ursache die Unordnung und mangelnde Sorge der Verwaltungsspitze für Dalmatien hinzu (2f.). Vgl. nunmehr aber Oršolić: Neke zapreke, der beide Momente - administrative Untätigkeit und mentalitätsbzw. bildungsbedingte Mängel der bäuerlichen Wirtschaftsweise - hervorhebt, wobei auch er das erstere Moment überwiegen lässt; $384 \mathrm{f}$. und 386-388.

1019 Vgl. $\$ \$ 76-82,90,92,98-100,106,112,119-120,136-137$.

1020 Lilienberg konnte sich bei seinen Maßnahmen gegen akute Notlagen (mit dem Prinzip, nach Erschöpfung lokaler Mittel auch solche auf Präturs-, Kreis- und Landesebene einzusetzen) generell auf die ausdrückliche Rückendeckung des Kaisers verlassen, der darüber hinaus anhand eines Einzelfalles auf der Insel Pago 1832 für solche Fälle auch die Hofkanzlei in die Pflicht genommen hatte (HHStA, MKA 371/1832, kaiserliche Resolution vom 16.3.1832: 
So fand ich, als ich heuer in Arbe mich befand, daß mehrere Familien wegen der außerordentlichen Dürre in Noth waren und verfügte sodann, nach gehöriger Erhebung des Bedarfs, die Anweisung einer Geldunterstützung von 200 Gulden für dieselben.

Auch hatte ich im vorigen Jahre für jene Gemeinden des Kreises Spalato und Zara, welche durch Uiberschwemmung litten, öffentliche Arbeiten zur Unterstützung der Dürftigen angeordnet und auf diese Art allen üblen Folgen [gestrichen: vorzubeugen] vorgebeugt.

Nach den Allerhöchsten wohlthätigen Absichten Eurer Majestät ist übrigens das Angemeßene zur Bildung eines Nothstandfondes vorgekehrt und es sind bei 11000 Gulden beim [Qu 101 / 3] Amortisirungsfonde angelegt, welchen die von Zeit zu Zeit einfließenden Ersätze ${ }^{1021}$ der in den Jahren 1830 und 1831 geleisteten Aushülfen werden hinzugeschlagen werden.

Den Finalbericht hierüber wird die Landesstelle ehestens zu erstatten sich beeilen.

Nebstbei beschäftigt man sich mit dem Plane, wie man die wohlthätigen Zuschüße vermehren und diese Verfügung auch, nach dem Beispiele anderer Provinzen, stabil machen könnte. Mit Bericht vom 24 December 1833 N $^{\circ}$ 21878/7137 überreichte das Gubernium an die Hofstelle auch die Gesammtübersicht aller von Eurer Majestät in den Jahren 1830 und 1831 allergnädigst bewilligten Aushülfen nebst seinen Anträgen zur Bewahrung des Landes vor ähnlichen kräftigen Unglücksfällen. ${ }^{1022}$

$\$ 211$ [Arbeits und Corrections-Anstalten] Da es in diesem Lande an Arbeits- und Corrections-Anstallten ganz fehlt, solche aber wegen des nicht wenigen müßigen Gesindels [Qu 101 / 4] besonders für Spalato und Trau nothwendig und von sehr großem Nutzen seyn würden, so glaubte ich vorerst, in der Kenntniß, daß vor wenigen Jahren eine Arbeitsanstalt in Brünn ${ }^{1023}$, mit gutem Erfolge activirt ward, die Statuten derselben verschreiben und darüber eine Verhandlung für den Fall einleiten zu sollen, als die Errichtung eines derlei Instituts die allerhöchste Genehmigung erhielte. ${ }^{1024}$

$\$ 212$ [Monte di Pieta] Rücksichtlich der allerhöchst anbefohlenen Wiedereinführung des vor mehreren Jahren, wegen übler Gebahrung aufgelösten Monte di Pieta ${ }^{1025}$, in Zara,

»Ich mache die Hofkanzley und das dalmatinische Gubernium streng dafür verantwortlich daß einer allfälligen Noth auf der Insel Pago, sowie wo immer in dem dalmatinischen GuberniumsGebieth abgeholfen und niemand ein Opfer derselben werde."

1021 Es erfolgten also Rückzahlungen von damaligen Nutznießern (ob individuellen oder von den betreffenden Gemeinden, ist hier nicht klar).

$1022 \mathrm{Zu}$ dem hier nach dem Tode des Kaisers zwischen Lilienberg und den Zentralstellen aufgekommenen offenen Konflikt vgl. Quellenanhang 1 (309-314).

1023 ON Brünn (tschechisch Brno), Guberniumssitz von Mähren.

$1024 \mathrm{Zu}$ verstehen wie: damit die Errichtung die Genehmigung erhielte.

1025 Der Monte di Pietà war eine im 14. Jahrhundert in Italien durch Franziskaner begründete Einrichtung einer Art Pfandleihanstalt, in der die ärmere Bevölkerung gegen Hinterlegung von Wertgegenständen Kleinkredite erhalten konnte. In Italien hielten sie sich ört- 
wurde die anbefohlene Verhandlung gepflogen; die Ausführung dieser Einrichtung mußte aber, wie auch ein ähnlicher Antrag des Kreishauptmannes von Ragusa für jene Stadt, wegen Mangel hinreichender Fonds verschoben werden; was in vieler Hinsicht außerordentlich zu bedauern ist. ${ }^{1026}$

$\$ 213$ [Dienstbothenwesen] Ein nicht unwichtiger Gegenstand ist überdieß auch die dringend nothwendige, Disciplinirung des Dienstbothenwesens: [Qu 102 / 1] Allgemein und gegründet ist die Klage über die Unordentlichkeit, Unsittlichkeit und Untreue der hierländigen Dienstbothen, durch welche nicht selten die Sicherheit, gute Ordnung und die Wohlanständigkeit in den Familien höchst unangenehm gestört wird. Dießfalls hat das Gubernium mit Bericht vom 10 August 1830 Z 15437 seine Anträge der vereinten Hofkanzlei vorgelegt. ${ }^{1027}$

lich bis 1862, während die Einrichtung in Dalmatien vermutlich wie hier zu sehen ca. in den 1820er Jahren ihr Ende genommen haben dürfte. Ein Banken- oder Sparkassenwesen, das seinerseits Kredite hätte vergeben können, gab es damals in Dalmatien nicht. Kredite erhielten die Bewohner des Landes nur gegen extreme Tageszinsen (von oft fünf bis zehn Prozent) oder gegen «Verkauf unter Rückkaufsrecht` beim Wucherer (vgl. Clewing: Staatlichkeit, 67).

1026 Ein bemerkenswerter Fall, in dem aus lokalem Geldmangel heraus sogar eine kaiserliche Anordnung zu einer öffentlichen Investition nicht befolgt wurde!

1027 Bei den auftretenden Problemen handelte es sich wohl nicht zuletzt um einen Ausdruck von unterschiedlichem Rechtsbewusstsein, von kultureller Differenz und von Abweichungen in der gesellschaftlichen Stellung bzw. dem geringen Sozialprestige, die Dienstboten in Dalmatien genossen, im Vergleich mit dem, was die mitteleuropäischen zugewanderten Beamten gewohnt waren. Petter: Dalmatien, schreibt dazu an zwei Stellen in Bd. 1:»Es wäre für Dalmatien zu wünschen, dass die Geistlichkeit von der Kanzel herab gegen die herrschenden Volkssünden und insbesondere gegen den Diebstahl von Seiten der Kolonen und des Dienstbotenvolkes ankämpfen möchte. Der Glaube, dass es nicht sündhaft sei, den Herrenleuten Esssachen zu stehlen, ist ziemlich allgemein unter dem Gesinde. Die Leute halten sich an den bekannten biblischen Spruch: «Was zum Munde eingeht, ist nicht Sünde, sondern was herausgeht.) Eben so gibt es nach meiner Beobachtung in Dalmatien Leute genug, welche glauben, dass man sich durch die Beicht von jeder Makel rein waschen könne.« (170 f.) »Ich habe mehrmals Morlakinnenmädchen in meinem Dienst gehabt, und sie stets williger und moralisch besser gefunden, als die Landmädchen am Meere. In Dalmatien gibt es nämlich keine anderen Dienstmägde als die aus der ärmern Volksklasse. Ein von einem sehr kleinen Gehalte lebender Beamter oder eine Bürgerfamilie behält die Tochter lieber zuhause, als dass er Dienstmädchen aus ihnen werden lässt. Man muss daher hier zu Land bei der Wahl von Dienstmägden zuerst auf ihre moralischen Qualifikationen sehen, auf Ehrlichkeit, Treue, Willigkeit; denn an Kenntnissen sind sie alle gleich, das heisst: sie sind im Kochen und andern häuslichen Verrichtungen unwissend, und die deutschen Familien sind in Bezug auf die Dienstmägde schlimm daran, weil die deutsche Hausfrau mehr von einer Magd fordert, als eine eingeborne, und sie hader erst mühsam abrichten muss. Es versteht sich von selbst, dass die Hausfrau der slavischen Sprache kundig sein muss, denn die Morlakinnen verstehen keine andere.» (189f.)

DigiOst 1 | 255 
$\$ 214$ [Concubinate und Bigamien] Das Laster des Concubinates habe ich in Dalmatien seit der Zeit der französischen Regierung besonders; und zwar auch unter dem gemeinen Volke in einer Art verbreitet gefunden, die mich wirklich erstaunen machte ${ }^{1028}$. Vieljähriges Zusammenleben verheuratheter und unverheuratheter Landleute, der - in den Landessitten gegründete Raub von Mädchen und der eigenen Bräute, selbst hie und da Austausch von Weibern sind hierlands nicht ungewöhnlich. Wie [Qu 102 / 2] sehr hievon auch die Beschaffenheit und Unsittlichkeit der Geistlichen zum Theile Schuld sey, habe ich am gehörigen Orte allerunterthänigst angedeutet. ${ }^{1029}$

Meine dießfalls getroffenen Vorkehrungen und strengen nachdrücklichen Weisungen, haben jedoch schon ihre vortheilhaften Wirkungen geäußert, indem dieses Leztere bereits sich vermindert, viele derlei wilde Ehen durch Ermahnungen in rechtmäßige verwandelt und andere, mit Dazwischenkunft der polizeilichen Maßregeln, getrennt wurden und es noch werden. ${ }^{1030}$

1028 Diese Angaben Lilienbergs (man beachte dabei den begriffsgeschichtlich interessanten Beleg für die Bezeichnung "wilde Ehe«) zu großer Verbreitung von unverheirateten Lebensgemeinschaften von Mann und Frau passen vorderhand schlecht mit der inhaltlich zu korrelierenden amtlichen Geburtenstatistik jener Zeit zusammen. Denn beim Anteil der unehelichen Geburten stand Dalmatien gemeinsam mit Oberitalien und Tirol am unteren Ende. Siehe etwa für 1837: Tafeln zur Statistik der Österreichischen Monarchie 1837. Tafel 59 Dalmatien, Tabelle Veränderung der Bevölkerung: Geburten gesamt 12521, davon unehelich 448; Tafel 60 Lombardei: Summe 103287, davon 4174; Tafel 55 Tirol: Summe 25449, davon 1228; dagegen etwa Böhmen, Tafel 56: Summe 154809, davon 21537 . Tafel 3 »Trauungen, Geburten und Sterbfälle« weist Dalmatien hinter Venedig innerhalb der westlichen Reichshälfte explizit als den Landesteil mit den relativ wenigsten unehelichen Geburten aus. Zwei eventuelle Erklärungen zur teilweisen Auflösung dieses Widerspruchs wäre zum einen die Hypothese, dass bei resultierenden Schwangerschaften "wilde Ehen" vermehrt in amtlich legitimierte umgewandelt wurden, zum anderen mögliche Mängel bei der statistischen Registrierung von unehelich Geborenen. Vgl. für ein entsprechendes Indiz hier die übernächste Anm. 1030.

$1029 \mathrm{Vgl}$. oben, in $₫ 185$.

1030 Ein gewisses Indiz für zeitweilige Wirksamkeit der Lilienbergschen Maßnahmen zur Erzeugung von Druck zur Umwandlung wilder Ehen (und zugleich für eine offenkundig mangelhafte statistische Erfassungen der Geburten, jedenfalls hinsichtlich der darin inbegriffenen, meist auffällig niedrigen und ebenso auffällig schwankenden Zahl der Totgeburten) sind die Verhältnisangaben zu den Totgeborenen jener Jahre (eheliche und uneheliche Totgeborene). Auch wenn man annimmt, dass bei nichtehelichen Schwangerschaften die Gefahr von Totgeburten damals in der Tat auch außerhalb Dalmatiens höher war als bei ehelichen (wegen durchschnittlich schlechteren Lebensumständen für die betroffenen Schwangeren und erschwerten Umständen der Geburt), legen die Zahlenverhältnisse doch nahe, dass die Anzahl der registrierten unehelichen Lebendgeburten unrealistisch gering gewesen ist: Tafeln zur Statistik 1831 (Tafel 59: Dalmatien): 291 Totgeborene, davon 16 uneheliche; Tafeln zur Statistik 1832 (Tafel 59): 16, davon 9; 1833 (Tafel 59): 89, davon 34; 
Im Kreise Cattaro ereigneten sich sogar mehrere Fälle von Bigamie unter den nicht unirten Griechen indem sie sich nach Montenero begaben, ihre Ehen dort auflösen ließen und andere schloßen.

Allein, über Verwendung an den dortigen Bischof ${ }^{1031}$, erhielt man deßen Zusicherung, daß er das dießfällige Verboth in seinem ganzen Lande erlaßen habe und das Kreisamt von Cattaro ward von der Landesstelle beauftragt, [Qu 102 / 3] die vorgekommenen Fälle dem Criminal Gerichte zur gesetzlichen Behandlung anzuzeigen.

\section{Sicherheitspolizei}

$\$ 215$ [Zahl der Verbrechen und schweren Poliz. Uibertretungen] Die Zahl der Verbrechen zur Bevölkerung gehalten ist zwar, im Vergleiche zu anderen Provinzen, unverhältnißmäßig groß, da nach den vorhandenen Verhältnißen in dem Jahre 1825: 1934, im Jahre 1826: 1667, im Jahr 1827: 1758, im Jahr 1828: 1954, im Jahre 1829: 1945, im Jahre 1830: 1574, im Jahr 1831: 1542 im Jahr 1832: 1553 und im Jahre 1833: 1688 angezeigt worden sind.

Schwere Pol[izey]-Uibertretungen wurden im J. 1826: 2641, a. 1827: 3123, im J. 1828: 3467, im J. 1829: 3442, im J. 1830: 3820, im J. 1831: 3823 im J 1832: 3937 und im J 1833: 4356 begangen. ${ }^{1032}$

1834 (Tafel 59): 48, davon 6; 1835 (Tafel 57): 81, davon 15; 1836 (Tafel 57): 76, davon 11; 1837 (Tafel 59): 71, davon 12.

1031 Petar II. Petrović Njegoš.

1032 Das Strafgesetzbuch von 1803 definierte die Gemeinsamkeit der beiden Begriffe darin, dass damit gesetzwidrige Handlungen beschrieben würden, die der Sicherheit des Gemeinwesens unmittelbar und in einem höheren Maß nachteilig waren als sonstige gesetzwidrige Handlungen. »Zum Unterschiede von andern Uebertretungen werden diese gesetzwidrigen Handlungen durch die Benennung: Verbrechen und schwere Polizeiübertretungen bezeichnet. II. Verbrechen sind gesetzwidrige Handlungen und Unterlassungen, bei welchen die Absicht eigens auf dasjenige gerichtet ist, was die Sicherheit im gemeinen Wesen verletzt, und welche die Größe der Verletzung, oder die gefährlichere Beschaffenheit der Umstände zur Kriminalbehandlung eignet. III. Absichtliche Verletzungen, welche aber nach Beschaffenheit des Gegenstandes der Person des Thäters, oder nach Beschaffenheit der unterlaufenden Umstände zu einer Kriminalbehandlunge nicht geeignet sind, werden als schwere Polizeiübertretungen behandelt. IV. Unter die schweren Polizeiübertretungen gehöret noch weiter, wenn ohne auf irgend ein Verbrechen gerichtete Absicht etwas, so durch die Gesetze, um Verbrechen vorzukommen, oder großen Nachtheil abzuwenden, zu thun verboten ist, gethan, oder etwas, was zu diesem Ende zu thun gebothen ist, unterlassen wird. V. Endlich, werden wegen des allgemeinen Einflusses der Sittlichkeit auf die Verhinderung der Verbrechen, auch Handlungen, welche die öffentliche Sittlichkeit stören, zu den schweren Polizeiübertretungen gerechnet.« Kanka (Hg.): Handbuch des österreichischen Gesetzes über schwere Polizeiübertretungen, 17-19. Delikte bei Vollrausch etwa oder bei einer anderen das Bewusstsein verhindernden Sinnesverwirrung waren »schwere Polizeiübertretungen « auch dann, wenn sie bei bewusstem Tun als Verbrechen gegolten hätten ( $46 \mathrm{f}$.). Die Unterscheidung an sich mutet durchaus modern an; vgl. etwa die Unterteilung der Strafta- 
Die Mehrzahl der Verbrechen betrifft öffentliche Gewaltthätigkeit, Mord und Todtschlag, Körperverletzungen, Brandlegungen, Diebstahl, Veruntreuungen und Raubfälle. Doch ist mir es angenehm, zu bemerken, daß die letzten 4 Jahre eine beträchtliche Verminderung im Ganzen gegen [Qu 102 / 4] die früheren 5 Jahre wahrnehmen laßen.

Die Hauptgründe einer im Allgemeinen größeren Zahl von Verbrechen bestehen: in der Rohheit, dem Rachegeiste, der Bewaffnung, vernachläßigten Erziehung des Landvolkes und in den bereits geschilderten Mängeln der Landgeistlichkeit, in der Nichtorganisirung der forza territoriale und nicht hinreichenden Militairmacht ${ }^{1033}$, um vereint mit jener, besonders die sich selbst überlassene Gebirgsgemeinden, im Zaume zu halten. Auch trägt der Umstand dazu bei, daß die Verbrecher in Bosnien und der Herzegowina nicht nur aufgenommen, sondern wohl auch von den Capidani ${ }^{1034}$ als Wachen und sogar bei dem Vesir selbst in distinguirten Posten angestellt werden: und man zieht sie anderen vor, weil man weiß, daß sie nie zurück dürfen und weil sie auch als Helden betrachtet werden. ${ }^{1035}$

Vorzüglich auffallend haben sich aber [Qu 103 / 1] besonders im Kreise Zara die Brandlegungen und die öffentlichen Gewaltthätigkeiten vermehrt, da der ersten bloß in diesem Kreise im Jahre 1833: 303 / davon 130 im Bezirke Knin allein :/ und 154 öffentliche Gewaltthatigkeiten sich ereigneten.

$\$ 216$ [Besondere Verhältniße im Kreise Cattaro] Im Kreise Cattaro werden fast alle Verbrecher der Gemeinden Maini, Pobori und Braichi, Pastrovicchio Crivoscie und Ledenizza ${ }^{1036}$, welche an den Gränzen von Montenegro und Leztere an der Türkei liegen, in hohen gebirgigen und unwegsamen Gegenden wohnen, wohin nur selten eine Authorität gelangen kann und die executive Macht, welcher, die dort in größeren Grade nothwendige phisische Gewalt mangelt, nicht zu wirken vermag - seit vielen Jahren vergeblich verfolgt. ${ }^{1037}$

Da aber dieselben die beständige Gefahr vor Augen haben, ergriffen und den Criminal Gerichten übergeben zu werden, so [Qu 103 / 2] überlaßen sie sich[,] viele derselben[,]

ten bzw. strafbaren Handlungen im deutschen Strafrecht in Verbrechen und Vergehen, in seiner älteren Fassung auch in Verbrechen, Vergehen und Übertretungen.

1033 Vgl. zur Forza territoriale und zum Wunsch Lilienbergs nach Verstärkung der Militärpräsenz oben, $₫ 182$.

1034 Vgl. oben, Anmerkung zu Beginn von $\$ 182$.

1035 Ein in sich glaubwürdiger Beleg sowohl für die Loyalitätskonzepte und -beziehungen - in denen es für die Loyalität Einfordernden günstig war, wenn die Gegenüber wenig Alternativen hatten - wie für den Heldenbegriff und Heldenkult im osmanischen Balkan und die damals noch praktisch inexistenten Prinzipien von Rechtsstaatlichkeit in der osmanischen Provinzverwaltung.

1036 ON Ledenizza / Ledenice: Ansiedlung nördlich von Risan (Kreis Cattaro).

1037 Vgl. zur Fortdauer dieser Situation im Kreis Kotor bis mindestens 1847 Clewing: Staatlichkeit, 81. 
einem herumirrenden Leben, bei welchem sie, um ihr Daseyn zu fristen, nur Verbrechen begehen. Der Kreisvorsteher von Cattaro ${ }^{1038}$ versicherte mich, daß bei 800 Menschen jenes Kreises sich in diesem Falle befinden, [gestrichen bis zum Rest dieses Absatzes und darauf auch anschließendes Absatzende aufgehoben:] und auf diese Art der menschlichen und bürgerlichen Gesellschaft entzogen werden.

Die Ausweise des Kriminal Gerichts stellen aber dar, daß gegen 603 die Verhaftung ausgesprochen worden ist, von denen jedoch nur 333 Inwohner jenes Kreises, die andern, Montenegriner und türkische Unterthanen sind.

Die Bewohner des Gemeinde-Bezirks von Braichi am Montenegro und jene von Krivoschie haben meine Anwesenheit benützt, um mich auf das Inständigste, gegen Zusicherung eines künftig ordentlichen Benehmens, zu bitten, für sie bei Eurer Majestät um die allergnädigste Zusicherung einer huldreichen Verzeihung ${ }^{1039}$ für die Vergangenheit [Qu 103 / 3] mich allerunterthänigst zu verwenden. Sehr viele Andere haben um Sicherheitsgeleit und die Gestaltung der Behandlung auf freiem Fuße mich angegangen und sich selbst zu stellen versprochen.

Was die Amnestie anbelangt, nachdem ich alle Verhältnisse gut erwogen habe, halte ich dafür, daß sie den erwünschten Erfolg nicht hervorbringen würde.

Uiber die Sicherheitsgeleite habe ich Rücksprache mit dem Appellations Gerichte gepflogen und selbe bei der Landesstelle in Berathung gezogen. ${ }^{1040}$ Dießfalls so wie über die Mittel zur Verminderung der Verbrechen sind auch bereits die Gubernial Anträge unter den 22 und 28 Maj 1[aufenden] J[ahres] No 7311 und 6499 der vereinten Hofkanzlei vorgelegt worden und es erübriget mir nur, die dießfälligen Anträge Eurer Majestät allergnädigster Beherzigung allerunterthänigst $[Q u 103 / 4]$ zu empfehlen.

Rücksichtlich der Mittel gegen die Brandlegungen gewärtige ich noch die Aeußerung des App[ellations] Gerichtes, worauf auch dieser Gegenstand in reife Erwägung vom Gubernium wird genommen werden.

In jedem Falle wird es aber zur Aufrechterhaltung der Sicherheit und zur Beseitigung der unter den Gemeinden von Pobori, Maini, Braichi, Pastrovicchio und Xuppa im Kreise Cattaro, dann zur Zügelung der Crivoschianer und Ledenzaner, welche alle dem Arme der Behörden unzugänglich und wo unter den 5 ersten Gemeinden kleine Kriege mit Waffen wegen ihre[n] Differenzen sehr häufig sind, übrigens selbe die Justiz-Pflege unter sich, auch in Criminal Fällen, durch die herkömmlichen Arbiträrgerichte, mit Umgähung der Obrigkeit abthun, - einiger außerordentlicher [Qu 104 / 1] Maßregeln für jenen Kreis unumgänglich bedürfen, welche besonders: in der zweckmäßigen Organisi-

1038 Gemeint ist der Kreiskommissär Gabriele Ivacich, vgl. oben, in $\$ 175$.

1039 Ein starker Kaiserbezug der Kotoraner Landbevölkerung, vermittelt durch Lilienberg und seine Reise, deren Rezeption hier von der Aura seiner empfundenen Nähe zum Kaiser profitierte.

1040 Hier erfolgte zunächst eine dann aufgehobene Absatzmarkierung. 
rung einer zu verstärkenden Territorial-Macht, und in Verlegung mehrerer Militair-Detachements in die Hauptorte, bestehen dürfte.

Diese halte ich auch [gestrichen: insbesondere] wegen der Excesse nothwendig, welche an den montenegriner- und an den türkischen Gränzen von dieß- und jenseitigen Bewohnern nicht selten verübt werden; und die, nach dem anarchischen Zustande jener Länder, dermalen nur mit Gewalt gehindert werden können.

Den Unfügen der Räuberbanden, welche von Bosnien und der Herzegowina aus, besonders die nördlichen Gegenden des Kreises Spalato und die Umgebungen von Sign und gegen Verlicca sehr beunruhigten, habe ich durch die dort angewendeten energischen Maßregeln, vorzüglich aber mittelst der aus Militairs und [Qu 104/2] Panduren zusammengesetzten Kreis-Colonnen größtentheils ein Ende gemacht, so daß sich Straßenräubereien jetzt seltener ereignen.

$\S 217$ [Schwere Polizei Uibertretungen] In Betreff der früher angegebenen nicht unbedeutenden Zahl von schweren Pol[izei] Uibertretungen, muß ich allerunterthänigst bemerken, daß auch die Mehrzahl derselben den Charakter der häufigeren Gattungen von Verbrechen hat, daß jedoch über 1000 davon jährlich, zu jenen Ehrenbeleidigungen gehören, die hierlands weniger, als irgend wo anders, zu bedeuten haben, indem der gemeine Dalmatiner, leicht aufgereitzt sich der Schmähworte ${ }^{1041}$ häufig bedient, ohne viel dabei zu denken und ohne daß es dem Gegner sehr empfindlich fiele; der aber doch oft aus Rachelust die Sache vor den Richter bringt ${ }^{1042}$.

Am häufigsten sind schwere [Qu 104 / 3] Pol[izei] Uibertretungen im Bezirke von Zara, wozu gewiß der Umstand sehr beiträgt, daß die hiesige Prätur ein zu geringes Personale hat, welches viele Rückstände veranlaßt, woraus wegen Langsamkeit der Prozeduren oft Straflosigkeit durch Verjährung hervorgehet, die zu neuen Uibertretungen ermuntert.

Auch in dieser Beziehung wird die Sistemisirung des Personals für jenes Amt dringend nothwendig, wovon ich unter dem Artikel Praeturen umständlichere Erwähnung zu machen mir allerunterthänigst erlaubte. ${ }^{1043}$

\section{Geheime und höhere Polizey}

$\$ 218$ [Objekte derselben] In anderen k.k. Provinzen hat man die irrige Meinung, daß Dalmatien gar keinen, oder doch sehr wenigen Stoff für die geheime und höhere Polizei liefern dürfte, da es so zu sagen von der civilisirten Welt, wo geheime Umtriebe [Qu 104 / 4] bestehen, ganz abgeschieden ist. Dieß lässt sich auch rücksichtlich des Landmannes als

1041 Das Wort »Schmähworte« hatte Rougier zunächst wohl nicht verstanden und wurde später mit anderer Feder nachgetragen.

1042 Die behördliche Auffassung von der besonderen Prozessfreudigkeit der Dalmatiner herrschte damals allgemein. Siehe auch nachstehend die Angaben zur Neigung, gegen andere mittels Verleumdungen zu prozessieren.

1043 Vgl. oben, $\$ 172$. 
gültig annehmen, welcher nicht den entferntesten Begriff davon hat und deßen Anhänglichkeit an Eure Majestät unbegränzt ist. ${ }^{1044}$

Die Städte, Präturs-Hauptorte und überhaupt die nicht zu den Bauern gehörende Menschenklaße, giebt der geheimen Polizei in zwei Beziehungen Mancherlei zu thun:

Erstlich dürfte es in allen [gestrichen: Städten ${ }^{1045}$ ] Staaten Eurer Majestät nicht so viele anonime Anzeigen geben, als in Dalmatien, wo der Rachegeist sich mit denselben Luft zu machen strebt: Neid, Mißgunst, beleidigte[r] Egoismus, und andere schändliche, durch die früheren Regirungen nicht unterdrückte, sondern vielmehr genährte Leidenschaften bedienen sich dieses [Qu 105/1] Mittels zur Vernichtung des erwähnten Opfers in einer Art, die es oft sehr schwer macht, der Wahrheit auf den Grund zu kommen.

Eine Unzahl derlei Anzeigen laufen unaufhörlich ein und, wenn auch der größte Theil nichts als Erdichtungen und Verläumdungen enthält, so geben sie doch der Polizei um so mehr zu thun, als hierlands bei den bezüglichen Erforschungen die größte Umsicht nothwendig ist, und reine Quellen der Wahrheit und Unpartheilichkeit so schwer zu finden sind.

$\$ 219$ [Geheime Secten] Die zweite Beziehung ist jene der geheimen Secten. Die im Jahr 1821 statt gehabten Criminal Prozeduren haben dargethan, daß in Dalmatien Freimaurer, Carbonari, Guelfi und greci nel silenzio ${ }^{1046}$ wirklich bestanden. Den meisten Erhellungen zufolge leben von [Qu 105 / 2] den früher [ergänzt: vorhandenen; gestrichen: bestandenen] 150, noch 61 Individuen zerstreut in der Provinz, welche der Theilnahme an einer dieser Secten beschuldigt oder verdächtig erklärt worden sind und die einer besonderen Uiberwachung nebst der Aufsicht über ihre Verhältniße und Verbindungen unumgänglich bedürfen.

Dalmatiens offene Lage auf der Meerseite, die Nähe des Päpstlichen Staates und Neapels, die beständigen Handels[-] und sonstige Verbindungen mit diesen und anderen

1044 Vgl. oben, $\$ 136$. Die auch in zahlreichen der damaligen monatlichen Stimmungsberichte des Polizeidirektors und der Kreishauptleute bzw. darauf aufbauend des Gouverneurs erwähnte »Kaisertreue« der Landbevölkerung mag zunächst wie ein bloßer Behördentopos erscheinen. Diese Art von Loyalität zeigte sich allerdings 1848 auf dem flachen Lande in einem so aktiven Maße in Aktion, dass auch davor durchaus von einer spürbaren Loyalitätsbindung auszugehen ist. Vgl. dazu näher Clewing: Staatlichkeit, 239f.

1045 Ersetzung von »Städten« durch »Staaten« in der laufenden Schreiberschrift von Rougier, vermutlich durch Hörfehler.

1046 Nenezić: Masoni enthält in Kapitel III (101-119) Angaben zu insgesamt immerhin sechs Freimaurerlogen (Zadar, Split, Kotor, Dubrovnik, Šibenik und Makarska) auf dem Gebiet der späteren Provinz Dalmatien während der Franzosenherrschaft, jedoch nichts zu den Jahren ab 1813. Zu den 1814-1824 in der Provinz tatsächlich wirksamen geheimbündlerischen Carbonari siehe Obad: O karbonarima, besonders $98 \mathrm{f}$. 
Ländern Italiens, in welchen die Giovine Italia ${ }^{1047}$ und andere gefährliche Secten mit ihren Umtrieben in jeder Art thätig sind, sich nach allen Seiten hin zu verbreiten, machen eine aller Arten, besonders aber an der Küste [gestrichen: vorzüglich; ergänzt: sehr] aufmerksame und stets rege [Qu 105 / 3] polizeiliche Aufmerksamkeit und die strengste Uiberwachung aller verdächtigen Personen, der Fremden und sorgfältige Ergründung aller zweideutigen Umstände und Ergebniße nothwendig.

Da übrigens vom Präsidenten der Polizei-Hofstelle ${ }^{1048}$ und vom Grafen Hartig ${ }^{1049}$ mir die Mittheilung zukam, daß die Secte der Giovine Italia, nach der /: jedoch höchst generischen und unbegründeten ${ }^{1050}$ :/ Aeußerung eines zu Mailand wegen Hochverraths Verhafteten; sich vielleicht auch in Dalmatien verbreitet haben dürfte; so ist dieser Verdacht nicht wenig geeignet, die [ergänzt: größte Thätigkeit; gestrichen: regste Aufmerksamkeit] der höheren Polizei in Anspruch zu rechnen. ${ }^{1051}$

$\S 220$ [Maßregeln] Ich habe mich demnach verpflichtet gehalten, dem hiesigen Polizeidirektor und den Kreishauptleuten eigene umständliche Instructionen zur gründlichsten Erforschung des obigen Umstandes und zur thätigsten Invigilirung ${ }^{1052} \mathrm{zu}$ veranlaßen; zugleich habe ich auch allen mittelbar und unmittelbar, zur polizeilichen Mitwirkung berufenen öffentlichen Organen mehrere zweckmäßige [Qu 105 / 4] besondere Belehrungen zur größten Thätigkeit ertheilt, die Paß- und die gegen Fremde nöthigen Vorsichten eingeschärft; eine strenge Controle über die Reisenden eingeführt; die genaue Haltung der Meldzettel hierlands activirt, so wie auch die Zurückweisung alles vagirenden ${ }^{1053} \mathrm{Gesin}$ dels von den Landesgränzen vorgeschrieben.

1047 Die von Giuseppe Mazzini 1831 ins Leben gerufene risogimentale Vereinigung wurde gerade nahezu zeitgleich 1833/34 in mehreren Prozessen in Savoyen zerschlagen.

1048 Josef Graf Sedlnitzky.

1049 Die Schreibung ist - offenkundig durch Lilienberg selbst - aus Hardig mit einem auffallend nachdrücklich geschriebenen »t« korrigiert, wohl, um sich nicht durch Fehlschreibung des bekannten Namens beim kaiserlichen Leser zu blamieren. Die erste falsche Schreibung Rougiers kann denn auch kaum aus einer schriftlichen Vorlage (Lilienbergs) stammen, ist aber bei einer Diktatsituation leicht zu erklären.

$1050 \mathrm{Zu}$ verstehen im Sinne von »nicht näher belegten « - denn im modernen Wortsinn für begründet hielt der Gouverneur die Darstellung ja in ausreichendem Maße, um die Geheimpolizei sich intensiv damit beschäftigen zu lassen.

1051 Die in den 1830er Jahren aufgekommene Gruppe des "Jungen Italien« scheint tatsächlich in Dalmatien eher nicht aktiv gewesen zu sein; vgl. dazu Clewing: Staatlichkeit, S. 58, Anm. 38.

1052 Überwachung.

$1053 \mathrm{Zu}$ verstehen als: herumziehenden. 
Allein alles meines aufrichtigen Bestrebens ungeachtet, kann die Polizei in diesem Lande nicht entsprechend verwaltet werden, so lange sie nicht zweckmäßiger organisirt wird. ${ }^{1054}$

Die Gemeinde-Beamten sind hierzu, wie ich bereits allerunterthänigst angedeutet habe, vollkommen untauglich und haben auch wenigen Willen sich zu verwenden. ${ }^{1055}$ Die Kreisämter sind so überhäuft mit anderen Geschäften, daß ihrem Chef und dem übrigen Personale keine oder nur wenig Zeit erübriget, wobei aber ohne ungetheilte Aufmerksamkeit wenigstens eines verständigen [Qu 106/1] und geeigneten Beamten nichts Ersprießliches geleistet werden kann.

Die Polizeidirection kann in einem, ohne die 51 [größeren; K. C.] Inseln zu rechnen, 61 deutsche Meilen langen, so wenig Comunications-Mittel besitzenden Lande, wie Dalmatien, nur im nächsten Umkreise wirken, wenn deren Chef nicht vollkommen persönliche Kenntniße der ganzen Provinz und der Bewohner besitzt, da selber wenn er die geheimen Quellen, aus welchen der selbe schöpft, nicht sehr gründlich zu prüfen und sorgfältig zu würdigen vermag, in den meisten Fällen getäuscht zu werden Gefahr lauft.

$\$ 221$ [Anträge zur zweckmäßigen Organisirung der Polizei] Diese Betrachtungen und die beständigen Klagen der Kreishauptleute von Ragusa und Spalato über den ihnen so empfindlichen Mangel an Polizei-Organen veranlaßten mich, über allerhöchsten Befehl, an den Polizei-Präsidenten ${ }^{1056}$ den Antrag unter den 22 Dezember 1832 Z 505/ Z p zur Errichtung von 2 Polizei-Commisariaten in Spalato und Ragusa zu erstatten, welche ich zum pflichtmäßigen Gedeihen aller streng-polizeilichen Zwecke für unerlässlich halten und Eure [Qu 106 / 2] Majestät um die allergnädigste Activirung derselben bitten muß.

Der Polizei-Director ${ }^{1057}$ besitzt zwar an jedem Kreis-Hauptorte einen Vertrauten; allein abgesehen davon, daß jener von Cattaro nicht in jeder Beziehung verläßlich und der zu Ragusa als Sanitaets-Deputirter ${ }^{1058}$ zu viel mit seinem eigenen Fache beschäftigt ist, zu Spalato aber gar kein zur höheren Polizei mit Erfolg verwendbares Individuum sich befindet: so stehen derlei Vertrauten diejenigen Mittel und Wege nicht zu Gebothe, welche ein ordentlich eingerichtetes Polizei-Commissariat benützen kann, das sich ausschließend damit beschäftiget.

Uiberdieß habe ich unter dem 4 October v[origen] J[ahre]s den Polizei-Präsidenten um die Erwirkung der nöthigen Weisung an die hiesige Oberpost-Verwaltung gebethen, damit die gehörige [Qu 106/3] Uiberwachung der verdächtigen Correspondenzen ord-

1054 Der Organisationsrahmen für die Polizei ist also ein weiterer Punkt in der Liste an Verwaltungskritik durch Lilienberg.

1055 Vgl. oben, $\$ 163$.

1056 Gemeint ist wieder der Vorsteher der Polizeihofstelle, Graf Sedlnitzky.

1057 Adam Stocka (in italienischen Amtsschriften: Adamo Stocka); siehe oben, Anm. 859.

1058 Sanitätsdeputierter (für maritime Sanität) und also offenbar Polizeiinformant für Ragusa war laut Almanacco 1834, 141 Giuseppe Rubrizius. Er stand (ebd., 138) zugleich dem Lazzaretto sanitario marittimo in Ragusa als Direttore itinerale vor. 
nungsmäßig activirt werden könne; was bezüglich mancher Individuen in verschiedenen Kreisen der Provinz nothwendig wäre und hinsichtlich der ausländischen Sectionen sogar vorgeschrieben ist; das aber ohne Ermächtigung von der Obersten Hofpostverwaltung und ohne angemessene Vorrichtungen gar nicht, oder nur unvollständig geschehen kann. ${ }^{1059}$

Ich sehe demnach einer höheren Veranlaßung ${ }^{1060}$ in diesem, mir dringend erscheinenden Gegenstande um so mehr entgegen, als ohne die PolizeiComisariate und die Korrespondenz-Uiberwachung die Wirksamkeit der höheren Polizei hierlands von keinem sicheren Erfolge seyn kann und diese doch, je mehr die Secten in Frankreich und in Italien wuchern täglich nothwendiger wird.

\section{Sanitaets Polizey}

$\$ 222$ [Mängel der Seesanitäts Organisirung] Bei meinen Landesbereisungen überzeugte ich mich, daß in der [Qu 106/4] Organisirung der mit 1. Jänner 1831 activirten Seesanitäts Ämter bedeutende Mängel bestehen ${ }^{1061}$.

Erstends ist sie viel zu sehr complizirt, da Local-, Districtual, und Kreissanitäts-Deputationen in Unterordnung gegen einander, in einem gewißen Abhängigkeits-Verhältniße zu den Präturen und Kreisämtern bestehen, und endlich von dem Sanitaets-Magistrate abhängen, der unter dem Gubernium steht.

Daraus folgt, daß die ämtliche Correspondenz von der Local-Sanitäts-Deputation an die Distrikts Deputation geht, von dieser zur Vidirung ${ }^{1062}$ und allfälligen Veranlaßungen zur Prätur; von der Praetur zur Kreis-Sanitaets-Deputation dann ans Kreisamt zur Vidi-

1059 Lilienberg hatte aus seiner Sicht Anlass zu entsprechender Beschwerde bei der Polizeistelle, weil ihn der Vorsteher der Amministrazione superiore delle poste in Zara, Goffredo di Giuliani, mit 14.2.1833 eine an ihn gegangene geheime Weisung des Obersten Hofpostverwalters Ritter Otto von Ottenfels vom 29. Dezember 1832 zur Ansicht weitergeleitet hatte (Abschrift in DAZd, Taijni spisi namjesništva, sv. 13, in Nr. 40 / g.p. 1833). Darin war Giuliani streng gehalten worden, auf die Wahrung der »allgemeinen Vorschrift wegen strengster Bewahrung des Brief-Geheimnisses, so wie auf den Eid, den jeder Postbeamte wegen Beobachtung dieser Vorschrift zu schwören hat [...] zu achten.« Anlass für Ottenfels gewesen waren eingelangte »Beschwerden, daß an Briefen, welche aus Dalmazien einlangen, manchmal Spuren von Verletzung der Siegel bemerkt geworden, welche die Korrespondenten auf die Vermuthung der Erofnung der Briefe bei den Postämtern bringt, wodurch das Vertrauen zur Post-Anstalt geschwächt, und deren Interesen wesentlich gefährdet wird.»

1060 Gemeint ist ein Entscheid über den weiter oben in diesem Paragraphen angesprochenen, bei Sedlnitzky bzw. in letzter Instanz wohl beim Kaiser zur Entschließung liegenden Antrag Lilienbergs über Errichtung der Polizeikommissariate.

1061 Gemäß etwa dem Almanacco 1834 bestanden die Ämter aus vier Ebenen: Magistrato sanitario marittimo in Zara, Vorsitzender Francesco Liepopilli, c.r. attuale segretario governiale, dann 2) Deputationen für maritime Sanität auf Kreisebene, auf Distriktsebene und in den Kreisen Zara, Spalato und Ragusa auch auf Ortsebene (Lokaldeputationen) an jeweils mehreren Orten, im Kreis Cattaro auf Ortsebene nur in Portorose (138-142).

1062 Einsichtnahme; Prüfung. 
rung und allfälligen polit[ischen] Verfügung; von diesem zum Sanitaets Magistrate und dann zum Gubernium. Jeder Akt läuft durch fünf Ämter zum Sanitaets Magistrate und in Seesanitätsangelegenheiten giebt es 7 Behörden oder Ämter im Lande [Qu 107 / 1] welche darüber zu sprechen haben, mit der Hofstelle in lezter Instanz bestehen aber ihrer acht. -

Dieses ist der Beförderung und Schnelligkeit, die in Sanitaets-Angelegenheiten mehr als in den meisten anderen erforderlich wird, gerade entgegen. ${ }^{1063}$

$\$ 223$ [Fehlerhafte Vertheilung und Bevollmächtigung der Seedeputationen] Die zweite wesentliche Unangemeßenheit besteht darin, daß man obige drei Gattungen mehr nach einer sistematischen, oder nach der Landeseintheilung berechneten Basis, nicht aber nach den Local Umständen und Bedürfniße einrichtete, so daß manche Orte gar keine Sanitaets-Aufsicht haben, welche deren bedürfen; und daß man den Local-Deputationen bloß die Ertheilung der libera practica ${ }^{1064}$ für Schiffe aus oester[reichischen] Häfen, den Bezirks-Deputationen für solche aus österreichischen päpstlichen und neapolitanischen, und den Kreis-Deputationen für alle Provinzen einräumte; obgleich diese nicht classenweise [Qu 107 / 2] sondern nur nach dem Bedarfe und den Local-Verhältnißen bestimmt werden dürfte, eine zu große Unterabtheilung der Vollmachten aber, sobald es sich um Schiffe mit patente libera ${ }^{1065}$ handelt, [gestrichen: unzweckmäßig; ergänzt: nicht ganz zweckgemäß $\left.{ }^{1066}\right]$ scheint.

$\$ 224$ [Mittel zur Besserung und indirekte Anträge des Guberniums] Um diesen und vielen anderen Unzukömmlichkeiten, welche aus der nicht gehörig gegründeten Eintheilung und Bestimmung der Sanitaets Aemter sich ergeben vorzubeugen, glaube ich, daß das bestehende See Sanitätssistem einer Revision unterzogen und dabei auch in Berathung genommen werde ${ }^{1067}$.

1 Ob es nicht [ergänzt: geeignter; gestrichen: zweckmäßiger] wäre, allen Sanitaets-Deputationen bezüglich der Schiffe mit patente libera gleiche Vollmacht zu ertheilen und die Unterschiede in Behandlung der Provinzen lediglich in der Instruktion für alle nach den besonderen Fällen, aufzunehmen.

1063 Wieder eine, und zwar plausible, Verwaltungskritik des obersten Landesverwalters.

1064 Offenbar die gesundheitspolizeiliche Freigabe bzw. Unbedenklichkeitserklärung.

1065 »di patente libera«: verdachtlos / unverdächtig im seuchenpolizeilichen Sinne, wenn die Schiffe aus behördlich für »seuchenunverdächtig« erklärten Häfen bzw. Ländern kamen. Vgl. die Worterläuterungen in Czoernig: Oesterreich's Neugestaltung, 221 (Treffer über Google Books).

1066 Wieder ein Beispiel für eine teilweise Rücknahme der Schärfe des »Wien« gegenüber gefürchteten Tons in der Endredaktion (so auch in der Reinschrift, Seite 163 / Scan 169) und zwar hier auch in der zweiten Texthälfte, in der ansonsten weit weniger redigiert wurde.

1067 An dieser Stelle geht der Bericht an den Kaiser fast formvollendet in die Gestalt eines Antragsschreibens über und ist insofern ein klarer Verstoß gegen den Instanzenweg. 
$\underline{2}$ Die Unterordnung der Sanitaets-Amter unter einander ganz aufzuheben, da sie ihrer Natur nach [Qu 107 / 3] Local-Anstalten sind, und selbe von den politischen Obrigkeiten, in reiner Sanitaets-Beziehung, aber zugleich vom Sanitaets-Magistrate abhängig zu erklären.

Wegen Regulirung des dermalen nur provisorischen See-Sanitaets-Magistrates sind mit Gubernial Bericht vom 9 April l[aufenden] J[ahre]s Zahl 5291 die Anträge des Guberniums, an die vereinte Hofkanzlei erstattet worden und sobald hierüber die Erledigung herabgelangt, werden auch obige zwei Fragepunkte höheren Orts zur Sprache gebracht werden ${ }^{1068}$.

$\S 225$ [Contumaz Anstalt zu Gravosa] Die Zulassung contumazierender Schiffe im Hafen von Gravosa hat für Ragusa, wie ich mich im Orte selbst überzeugte, wo ich mehrere reich befrachtete Fahrzeuge antraf, bereits vortheilhaft eingewirkt ${ }^{1069}$, da im vorigen Jahre 64 solche Schiffe dort einliefen, solche den Einwohnern an Schiffsreparationen, Facchinagen ${ }^{1070}$, Löhnungen ca. 19/m [19000] Gulden abwarfen, dem Aerar 6100 Gulden [Qu 107 / 4] Zoll und 491 Gulden Sanitaets Taxen einbrachte.

Noch größere Vortheile würden aber durch die Errichtung des von Eurer Majestät allergnädigst bewilligten Seelazarethes für Ragusa zuwachsen worüber die bezüglichen Anträge unter den $5 \mathrm{Maj}$, 18. September und 31 Dezember v[origen] J[ahre]s von dem Gubernium erstattet worden sind. Inzwischen bestehet daselbst ein provisorischer Ankerplatz für contumazirende Schiffe, welchen ich in Sanitaets Hinsicht gehörig überwacht fand ${ }^{1071}$.

$\$ 226$ [Landes Sanitätsanstalten] Die Sanitaetsanstalten zu Lande an den Gränzen der Türkei und Montenegro sind in der bekannten Art bereits regulirt und da man auch die-

1068 Hier dagegen ein gewisses Gegensteuern, in einer Art Lippenbekenntnis zum Instanzenweg, den Lilienberg aber in Wirklichkeit mit seiner ausdrücklichen Darlegung der beiden Punkte in quasi-Antragsform gegenüber dem Kaiser offenkundig umgehen wollte, um eine beschleunigte Entscheidungsfindung herbeizuführen.

1069 Im Subtext ist dies ein Unteraspekt (bzw. auch ein stützendes Argument) Lilienbergs für sein grundsätzliches Anliegen, die von Wien diktierten Kontumazvorschriften möglichst zum Handelsvorteil der Provinz aufzuweichen (siehe ähnlich in der Frage des Karawanenwesens).

1070 Von italienisch »facchinagio«: Trägerlohn (für die Schiffsträger).

1071 Der Almanacco 1835 verzeichnet (als einziges in Dalmatien) Seite 137 das Lazzaretto sanitario marittimo in Ragusa (vorläufiger Direktor wie schon 1834 Giuseppe Rubrizius), ebenso aber auch schon der Almanacco 1834, 138, der Almanacco 1833, 137 (damals noch Direttore provvisorio Giovanni Stella), ebenso 137 der Almanacco 1832 und der von 1831 (137). Im Almanacco 1830 taucht der Eintrag so nicht auf, dafür (wie in Zara, Split, und Castelnuovo) auch in Ragusa ein »Lazzaretto« (ohne nähere maritime Bestimmung), dessen Direktor (nicht provisorisch) auch schon Giovanni Stella war (147). Lilienberg hatte also offenbar den Ausbau einer bis dahin nur provisorischen Struktur vor Augen. Möglicherweise war das von ihm zu Gravosa Genannte eben jenes provisorische Seelazarett. 
se unter den Sanitäts-Magistrat zu stellen in Antrag gebracht hat, so wird [ergänzt: derfalls; gestrichen: auch] in der Hinsicht das hie und da Mangelhafte, so viel es [Qu 108/1] die äußerst coupirte Gegend zuläßt, verbeßert werden. ${ }^{1072}$

$\$ 127$ [eigentlich 227; Caravanen in Sanitäts Beziehung] Obwohl ich der türkischen Caravanen und ihrer Geleitung bis an das Meergestade bereits bei der Comerciellen Industrie im Wesentlichen allerunterhänigst erwähnt habe ${ }^{1073}$, so glaube ich doch auch in Sanitätsbeziehung auf diesen Gegenstand zurückzukommen und in tiefster Ehrfurcht bemerken zu sollen, daß diese großentheils aus mißverstandenener Furcht vor der Pestanstekung aufgehoben worden sind, obgleich man die Anstalten bei den Caravanen-Zügen so einrichten kann, daß eben diese behauptete Gefahr wegen genauerer Obsorge weit geringer wird, als bei den sorgsamsten Cordons-Anstalten. In vollster Gewißheit des Nutzens welcher dadurch dieser Provinz allmälig wieder zufließen könnte, halte ich mich demnach verpflichtet die bezüglichen vom Gubernium unter dem ${ }^{1074} 6$ Mai v. J. Z 5609 und von [Qu 108 / 2] mir unter dem 14 Mai l[aufenden] J[ahres] Z P 1080 erstatteten detaillirten Anträge wiederholt Eurer Majestät allergnädigsten Berücksichtigung, allerunterthänigst zu empfehlen.

$\$ 228$ [Spitäler] Rücksichtlich der Spitäler habe ich die Bemerkung gemacht, daß jenes von Sebenico, welches im Ganzen gut besorgt, viel zu enge ist, weshalb ich durch das Gubernium eine Verhandlung veranlaßte, die eben bei der Baudirektion in Amtshandlung sich befindet, und betrieben wird.

In jenem von Spalato habe ich einige Unordnungen, besonders aber die Luftreinigung in den Krankenzimmern vernachläßigt gefunden, in welcher Beziehung ich die gehörige Abhülfe und Fertigung der nothigen Ventillatoren sogleich verfügte. ${ }^{1075}$

Das Spital von Ragusa traf ich in erwünschtem Stande reinlich und ordentlich gehalten, nur die [Qu 108 / 3] Stelle des Abortes dünstete einen üblen Geruch aus, welches ich [gestrichen: abstellen; ergänzt: verbessern] ließ.

Im Kreise Cattaro mangeln Krankheitshäuser ganz. Die Errichtung eines solchen im Kreishauptorte ist ein höchst dringendes Bedürfniß, um so mehr, als die Transportirung der Kranken in jenes von Ragusa oft unausführbar, oft aber die Uiberfahrt zu Meere gehemmt und unbestimmt ist.

Hierzu fehlen, leider, die erforderlichen Geldmittel und müßen so lange mangeln, bis nicht den Gemeinden die [gestrichen: nothigen] nothwendigen Ertragsquellen eröff-

1072 Vgl. hier im Anhang, Seite 308, Karte 16 zu geplanten Kordonmaßnahmen im Kreis Cattaro. Der Reinschrift wurde diese Anlage nicht beigegeben.

1073 Vgl. die $\$ \$ 119$ und 124.

1074 Randanmerkung: N Aufsuchen Caravanen. Daraufhin wurden die Aktenangaben (diese und die auf der nächsten Quadrangelseite) später eingefügt.

1075 Wieder ein Beispiel für administrative Sofortmaßnahmen im Zuge der Bereisungen. 
net seyn werden, wie ich es gelegentheitlich der Schilderung des Comunalwesens allerunterthänigst bemerkte. ${ }^{1076}$

Uiberdieß besteht hierlands keine Anstalt für Irrsinnige. Derlei Unglückliche werden daher nach S. Servilio ${ }^{1077}$ zu Venedig abgesendet, und dieses scheint auch dermalen noch den Erfordernißen zu genügen.

In Ragusa besteht zwar ein besonderer Verwahrungsort für solche Kranke bis zu ihrer Absendung in die obgenannte venediger Anstalt.

Da [ergänzt: ich ${ }^{1078}$ ] jedoch jenes Locale in großer [Qu 108 / 4] Unordnung fand, so veranlaßte ich mittelst der Landesstelle die nöthige Herrichtung desselben ${ }^{1079}$.

\section{Offentliche Baulichkeiten}

$\$ 229$ [Zustand, Menge] In einem Lande, wo seit Jahrhunderten die früheren Regierungen an den Administrations Auslagen nur zu ersparen strebten ${ }^{1080}$; wo ein ausgedehntes, ausgebildetes und complicirtes ganz neues Verwaltungssistem gegenwärtig eingeführt wird: muß es auch, bis die Sistemisirung nicht vollendet ist, im Fache der öffentlichen Baulichkeiten Vieles und Ungewöhnliches zu thun geben.

In welch' elendem Zustande ich die Kirchen und Pfarrhäuser dieser Provinz fand, habe ich Eurer Majestät unter der bezüglichen Rubrik bereits allerunterthänigst geschildert ${ }^{1081}$. Die Zahl derselben, welche Zubauten oder Reparationen erfordern, ist so groß, daß eine gut organisierte Landes-Baudirektion, wenn sie auch sonst nichts Anderes zu thun hätte, fast 1 ganzes Jahr hindurch mit diesem Fache allein hinlänglich beschäftigt seyn würde.

[Gestrichen: §] Wie viele und bedeutende Wasserobjecte nicht wenige Thätigkeit, Aufmerksamkeit und Zeit den fachlichen Beamten rauben, welche nicht geringe Beschäftigung; die Straßen, wo [Qu 109 / 1] die mancherlei Verbindungen noch herzustellen und das Bestehende in gutem Stande zu erhalten ist, verursachen, gehet aus dem, was ich über die Moräste, Flüsse und Straßen in [sic] Allgemeinen allerunterthänigst bemerkte, hervor.

1076 Das wiederholte und und für die regionalen Entwicklungsperspektiven große Thema der Umwidmung des Dazio consumo taucht hier erneut auf.

1077 Die unweit südlich von Venedig gelegene Laguneninsel San Servilio wurde, so der italienische Wikipediaeintrag, ab 1715 zunächst für ein Spital und dieses dann ab 1725 als Nervenanstalt genützt; 1798 sei die Einrichtung durch die österreichische Regierung zur Nervenheilanstalt für Venetien, Dalmatien und Tirol bestimmt worden (http://it.wikipedia. org/wiki/San_Servolo - 27.11.2013).

1078 Hier und schon geraume Zeit weiter oben im Text war die Elimierung von »Ichbezügen«, die am Anfang so auffällig vorgesehen war, gar nicht mehr eingeplant worden. Vgl. für die Interpretation als Folge von Zeitnot in der Einleitung.

1079 Noch ein Beispiel für unmittelbare Maßregeln im Zuge der Bereisung, hier im Nachklang der Bereisung durch eine Weisung an die Landesbehörde.

1080 Ein Beispiel dafür, wie der Topos von den schlechten früheren Regierungen von Lilienberg verwendet wird als Anreizgabe an Wien (hier konkret den Kaiser), sich anders als jene früheren Landesherren investierend zu präsentieren.

1081 Vgl. oben, $\$ 191$. 
Uiberdieß habe ich nicht wenige Prätursamts-Localien höchst dürftig unzweckmäßig und indigent ${ }^{1082}$; nicht wenige Arreste theils sehr schlecht ungesund und unsicher, theils nicht im gesetzlichem Stande gefunden; worüber ich mittelst der Landesstelle die nöthige Abhülfe zu treffen bemüht war und noch ferner darauf zu wirken bestrebt seyn werde.

Das hiesige Criminal-Inquisitions-Haus selbst, hat noch bedeutende Mängel hinsichtlich der Rücksichten für Reinlichkeit, [gestrichen: Gesundheit] und der erforderlichen Zahl von Arresten. ${ }^{1083}$ Ein Provinzial Strafhaus fehlt ganz, wofür aber eine Verhandlung im Zuge ist.

Erhebliche Bauten in den Häfen wären auszuführen; mancherlei Brücken und Uiberfuhren zu errichten oder herzustellen.

Vielerlei detaillirte und gehörig berichtigte Administrativ- und Gränz Karten wären auszuarbeiten, worann es bis auf jene, welche ich für diesen [Qu 109 / 2] [ergänzt: allerunterthänigsten] Vortrag [ergänzt: unter meiner eigenen Anleitung] verfaßen ließ, [gestrichen: früher] fast ganz mangelte.

$\S 230$ [Landesbau Direction, beschränktes Personale, nothige Abhülfe] Die Landes-Bau-Direction, bei welcher bereits seit $1 \frac{1}{2}$ Jahren der Director mangelt ${ }^{1084}$, bestehet gegenwärtig aus dem Adjuncten, einem Zeichner und mehreren Practicanten.

Daß dieselbe mit einem so geringen Personale bei der außerordentlichen Geschäftslast nur einen geringen Theil ihrer Amtspflichten, ungeachtet des größten Fleißes der geschickten Beamten, zu erfüllen vermöge; daß daraus beträchtliche Rückstände und höchst nachtheilige Hemmungen in manchen Geschäfteszweigen entstehen müßen, ergiebt sich aus dem allerunterthänigst Dargestellten und noch mehr erhellet es aus der

1082 »notleidend, (veränderungs)bedürfitg«.

1083 Dieses Thema der Arreste und der Lebensbedingungen für die Inhaftierten interessierte, wie Lilienberg wahrscheinlich wusste (sei es vom Hörensagen oder aus eigenen Begegnungen mit dem Monarchen), den Kaiser auf dessen eigenen Reisen ganz besonders. Im Tagebuch seiner Dalmatienreise von 1818 kam der Monarch an zwei Stellen ausführlich und aufgrund eigenen Augenscheins sehr kritisch auf die betreffenden Verhältnisse in Zara zu sprechen (HHStA, FA Hofreisen, Kt. 36, S. 356-359 - gleich am Tag seiner Ankunft in Zadar, am 2.5.1818, siehe auch in kroatischer Übersetzung: Krmpotić (Hg.): Car Franjo I. u Hrvatskoj, Bd. 1, 111 f. - und dann wieder 426f. - ebd., 145); zu Ragusa hielt er ähnlich schon am ersten Tag nach der Ankunft in der Stadt kritische Bemerkungen fest über die schlechte Unterbringung der Häftlinge wie auch der Untersuchungshäftlinge, deren Untersuchungshaft überdies wie auch in Zadar in seinen Augen mit bis zu über zwei Jahren bzw. vier Jahren erheblich zu lange dauerte (HHStA., S. 856 bzw. in kroatischer Übersetzung a.a. O., 304 f.).

1084 Schon der Almanacco 1833 hatte die Stelle als "vacante« bezeichnet (88); im Almanacco 1832, 88, wird als Amtsinhaber Giorgio nobile di Frast (Georg von Frast) bezeichnet, ergänzend gab man dort den Vermerk: das ganze Personal dieser Einrichtung, mit Ausnahme des Direktors, sei nur provisorisch. Einen solchen Hinweis auf bloß provisorischen Status der Einrichtung gibt es 1833 nicht mehr. 
Betrachtung, daß in anderen Provinzen, wo doch alle Zweige der Verwaltung bereits organisirt und stabil sind und wo es nur darauf ankommt, das Bestehende zu erhalten, hie und da nachzuhelfen, selten aber etwas Neues auszuführen ${ }^{1085}$, die Landes-Bau-Direktionen mehrere Adjunkten, Ingenieure und [Qu 109/3] Zeichner haben.

Wenn gleich Dalmatien eine vergleichsweise sehr geringe Bevölkerung hat, so ist diese Provinz doch sehr ausgedehnt und schließt dermalen unendlich mehr Bauobjecte ein, als eine zehnfach stärker Bevölkerte.

Ich erlaubte mir daher Eure Majestät in tiefster Ehrfurcht zu bitten, sich allergnädist die unter dem 16. Mai v[origen] J[ahre]s Z. 3589 von der vereinten Hofkanzeley zurückzugewiesenen dießfälligen Anträge des Guberniums vorlegen zu lassen. ${ }^{1086}$

\section{Finanz}

$\$ 231$ [Finanzangelegenheiten] Die Finanzangelegenheiten dieser Provinz sind in manchen wesentlichen Beziehungen noch in einer heranreifenden Sistemisirung.

So lange alle ihre Zweige die wünschenswerthe solide Consistenz nicht erlangt haben, scheint es mir nicht an der Zeit, die Finanz-Intendenz, welche unter der Oberleitung des Landespräsidiums stehet, als unabhängig zu erklären und nach [Qu 109 / 4] der [eigentlich müsste hier im Plural stehen: den] in den anderen Provinzen Eurer Majestät bestehenden Gefälls-Verwaltungen einzurichten, da nicht alle die Assessoren dieser Behörde den Geist der oesterreichischen Verwaltung schon vollkommen gefaßt haben und der sehr einsichtsvolle und rechtliche Finanz-Intendent Celligoi ${ }^{1087}$ bis zur völligen Gestaltung aller Finanzzweige, einer energischen höheren und nahen Unterstützung bedarf.

Hierüber habe ich einen umständlichen Bericht unter dem ${ }^{1088} 26$ May J 43/p an das allg[emeine] Hofkammer Praesidium mit dem Antrage einiger Transferirungen erstattet, worauf ich die Zusicherung erhielt, daß man gelegenheitlich darauf Bedacht nehmen werde. ${ }^{1089}$

1085 Diese indirekt auf die ungewöhnlich stark erforderliche Erstellung von gänzlich Neuem (hier an Bauten) in Dalmatien verweisende Formulierung ist Ausdruck der von Lilienberg wahrgenommenen markanten Sonderstellung der administrativen Rahmenbedingungen in Dalmatien.

1086 Die direkte Hinwendung an den Kaiser dient hier dem Versuch, einen ergangenen Entscheid der vereinten Hofkanzlei zu umgehen; dieses Vorgehen wider den Instanzenzug war an sich erneut ein unverhohlener Affront gegen die Zentralbehörden.

1087 Giovanni Celigoi, k. k. Gubernialrat, Administrator der Intendenza di Finanza in Zara (Almanacco 1834, 146). Johann Celigoi (oder Celligoi) bekleidete diese Funktion bereits seit kurz nach der Dalmatienreise von Kaiser Franz I.; zuvor hatte er als Hofsekretär bei der k. k. allgemeinen Hofkammer geamtet: Wiener Zeitung Nr. 199/1818, 1.9.1818, [S.1].

1088 Randanmerkung: »? Aufsuchen." Aktennummer wurde später eingefügt.

1089 Auch dieser Bezug auf eine nichtssagende Antwort aus Wien auf einen in Lilienbergs Augen sehr dringlichen Antrag ist als eine klare Beschwerde über das Wiener Verwaltungsprozedere zu lesen. 
$\$ 232$ [Organisirung der Finanz Inspectorate] Wegen Organisierung der Finanz Inspectorate und Vereinigung derselben mit den Hafen, Sanitäts, See- und Gränzpolizei-Aufsichts Amtern wurden unter den 4 May v[origen] J[ahre]s Z. 6489/2475 die Anträge des Guberniums, dann wegen Sistemisirung der Finanzwachen, unter Vereinung des Sanitaets-Guardians- und Hafen Matrosendienstes, meine [Qu 110 / 1] Vorschläge mit Bericht vom 24 Jänner 1. Js. Z 1668/p der allg[emeinen] Hofkammer vorgelegt.

Wirklich habe ich mich auch während meiner Landesbereisung überzeugt, daß oberwähnte Vereinigung dieser mehrerer [sic] Amtsobligenheiten an vielen Orten leicht werde Statt finden können, indem die Geschäfte vieler Sanitäts- und vieler Finanzämter, und die einzeln dafür bestimmten Genüße ${ }^{1090}$ so gering sind, daß die Beamten oft nur höchst nothdürftig, an manchen Orten auch mit dem Gehalt oder Perzenten-Bezuge allein nicht leben können, wogegen die erwähnte Verschmelzung sowohl dem allerhöchsten Ärar, als den Beamten zum Nutzen gereichen wird.

Doch habe ich ebenfalls eingesehen, daß es sehr nöthig seyn wird, gleich nach der erwähnten Sistemisirung für diese Amter genaue und vollständige Amts- und Manipulations Instruktionen zu erlassen, weil die meisten unter ihnen, besonders aber die Doganalämter [Zollämter, K.C.], nicht sehr regelmäßig, nicht gleichförmig und nicht mit der wünschenswerthen Umsicht verfahren.

[Qu 110 / 2] [Ergänzt: Vorzüglich; gestrichen: Besonders] fand ich dieses bei dem Zollamte von Ragusa, wo bedeutende Amtsunordnungen statt hatten, welche zum Nachtheile des Ärars wirken; weshalb ich mich verpflichtet hielt, eine Amtsreise des Assessors Wagner ${ }^{1091} \mathrm{im}$ v[origen] Jahre zu deßen Untersuchung zu benützen; worauf ich die nothigen Weisungen zur Herstellung der Ordnung erließ.

Auch hielt ich es für entsprechend, zum Besten des allerhöchsten Ärars zu veranlaßen, daß die Cassen der Zollämter alle 10 Tage durch den politischen Orts-Vorsteher scontrirt ${ }^{1092}$ werden.

Ich habe übrigens nicht unterlaßen meine Aufmerksamkeit auf die möglichste Beförderung aller sonstigen finanziellen Zwecke zu richten.

$\$ 233$ [Postwagenfahrt] Die durch Euer Majestät unerschöpfliche Gnade activierte Postwagenfahrt $^{1093}$ von hier nach Wien hat bereits ihre manigfachen Vortheile bewährt; jene

1090 Gemeint sind die Einkommen der Beamten.

1091 Giovanni Battista [Johann Baptist] Wagner, membro corrispondente della società di agricoltura e delle arti di Lubiana, Assessor bei der Finanzintendanz in Zara (Almanacco 1834, 146).

1092 Heißt in der Regel, in Bezug auf Wechselscheine: gegeneinander aufrechnen; hier aber wohl einfach im Sinne von »Kassenstand zählen/prüfen«.

1093 Im Original unterstrichen. Die Eröffnung dieser Postwagenverbindung wurde in der GdZ Nr. 84/1833, 18.10.1833, auf der ersten Seite dieser Nummer mit amtlicher Notificazione Nr. 966 kundgemacht, zugleich die erste Fahrt von Wien in Richtung Zara für den 5. November, die erste in der umgekehrten Richtung für den 19. November 1833 festgesetzt. Wie 
nach Spalato wird das Gubernium bemüht seyn so bald als möglich in Activitaet zu setzen. Die bisherigen Erfarungen laßen [Qu 110 / 3] aus dieser Anstalt gleich im Entstehen einigen Gewinn für das Post-Gefäll hoffen.

$\$ 234$ [Salinen-Wesen] Zur Hebung des $\underline{\text { Salinen Wesens }}$ habe ich vor und nach genauer eigenen [sic] Besichtigung der Salinen von Pago und Stagno Verhandlungen eingeleitet, welche eben im Zuge sind.

Da zu Curzola sich die Einwohner bei mir beschwerdten, daß sie bei dem dortigen Salzamte schlechtes, unreines, zur Einlegung der Fische unbrauchbares Salz bekommen, so veranlaßte ich während meiner Bereisung sogleich mit Estaffette an die Finanzintendanz, die nothige Abhülfe ${ }^{1094}$.

$\$ 235$ [Contrabande] Da die Salz- und andere Contrabande zum großen Nachtheil des Ärars allgemein, besonders aber von den Inseln Curzola, Meleda in den Bocche false $e^{1095}$ bei Slano, über Jessenizze ${ }^{1096}$ und durch den Canal von Calamotta des Kreises Ragusa im Großen betrieben wurden, so veranlaßte ich daselbst häufige Streifungen durch Kriegsfahrzeuge ${ }^{1097}$ und erließ durch das Gubernium [Qu 110 / 4] eine Aufforderung an alle Ordinariate, das Landvolk durch die Geistlichkeit über die Schlechtigkeit dieses Vergehens nachdrücklich belehren und ermahnen zu lassen ${ }^{1098}$. Es wird aber auch nothwendig seyn, diese Landestrecke im Bezirk Slano mit Militair-Detachements beßer, als ich bis jetzt habe

bedeutsam die Verbindung war, auch wenn sie zunächst nur einen kleineren Teil Dalmatiens direkt an das Postwagennetz im Reich anschloss, ergeht aus der Darstellung von Petter: Geographische Skizze, 85, der für den vorherigen Zustand zwei wichtige alltagsweltliche Folgen des Fehlens beschreibt: »Postwagen (Diligencen) giebt es in Dalmatien nicht. Wer daher ein Frachtstück, z. B. einen mit Geld beschwerten Brief, aus den Erbstaaten oder anderswoher zugesandt bekommt, muß es auf seine Gefahr von dem Postamte in Fiume beziehen, wo es liegen bleibt, während dem Adressaten ein Avviso mit der Aufforderung zur Beziehung zugeschickt wird. Es versteht sich daher von selbst, daß man in Dalmatien mit der Post auch nicht reisen kann."

1094 Wieder ein Beispiel für Sofortmaßnahmen auf der Reise, hier auf ausdrückliche Beschwerden aus der Bevölkerung - und in diesem Fall durch seine schnelle Erledigung sicher eine prestigeträchtige Herrschaftsrepräsentation bei den Korčulanern.

1095 TN Bocche false (bei Slano): der buchtartige Meeresbereich zwischen Slano und Ston, mitsamt den Inseln Olipa und Jakljan.

1096 ON Jessenizze: gemeint ist wohl nicht Jesenice südöstlich von Split, sondern der Ort Jesenice am Fuße des Velebit bzw. nördlich des Novigradsko more, weil dieser Ort schon nahe an der Lika liegt, in die dalmatinisches Salz wegen der unterschiedlichen Abgabenlasten profitabel zu schmuggeln war.

1097 Ein Beispiel für den Einsatz der Marine zur Schmuggelbekämpfung.

1098 Die Verwendung der (katholischen) Pfarrer als Transmissionsriemen der Verwaltung vor allem gegenüber der ländlichen Bevölkerung war eine übliche habsburgische Verwaltungspraxis, vgl. mit Blick auf Dalmatien Clewing: Staatlichkeit, 111. 
thun können, zu besetzten und solches wird sogleich geschehen wenn Eure Majestät geruhen sollte die zur Abwendung der Verbrechen bei der vereinten Hofkanzlei angetragene Verstärkung der Besatzung um 1 Bataillon allergnädigst zu bewilligen, wodurch auch in politischer Hinsicht Ordnung und Respekt gegen die Gesetze erwirkt werden soll.

$\$ 236$ [Tabakbau - Verhandlungen] Uiber die für diese Provinz gewiß sehr nützliche Wiedereinführung des Tabakbaues hat sich das Gubernium am 5 October v[origen] J[ahre]s Z. 16376 [gestrichen: und ich unter dem [Qu 111 / 1] unter dem 3.October Z. 274 nämlichen Jahres mich] [ergänzt: unter Schilderung der Vortheile für die hiesigen Landes-Einwohner] umständlich ausgesprochen, so wie ich mit Bericht von 5. Octobers v[origen] J[ahre]s Z. 1492/p nach meiner vollkommensten Uiberzeugung, der allgemeinen Hofkammer das begründete ${ }^{1099}$ Gutachten erstattet habe, wie rathsam es sowohl in finanzieller als auch in moralischer Beziehung wegen den vielen Contrabande seyn würde, für Dalmatien das Taback-Monopol ganz aufgegeben. ${ }^{1100}$

$\S 237$ [Decima-Aufhebung: Verhandlungen] Rücksichtlich der Regulirung des Steuerwesens, [ergänzt: nämlich] der dermaligen Decima ${ }^{1101}$, wegen Unrathsamkeit der Einführung eines Steuer-Provisoriums und der wegen [mit Bleistift ersetzt durch: während] meiner Provinz-Bereisung diesfalls gemachten Bemerkungen glaube ich mich lediglich auf meinen allerunterthänigsten Vortrag vom 12 December 1833 in tiefster Ehrfurcht berufen zu sollen, wo ich die bezüglichen Verhältniße umständlich aufzuklären gestrebt habe ${ }^{1102}$.

1099 »Begründet« heißt hier wohl schlicht »mit Darlegung der Gründe«.

1100 Auch in der Reinschrift, Seite 169 / Scan 175 steht grammatikalisch falsches »aufgegeben«. Siehe zur Kritik an den Wirkungen des Anbauverbots für Dalmatien auch oben, $\$ 90$.

1101 Gemeint ist der Zehent (Zehnt) und dessen in Dalmatien im regionalen Vergleich mit den angrenzenden osmanischen Gebieten auffallend früh erfolgte (nämlich 1838 abgeschlossene) vollkommene Überführung in staatliche Verwaltungsstrukturen, als Umsetzung des staatlichen Steuermonopols; vgl. Clewing: Staatlichkeit, 101.

1102 Dieser Vortrag liegt in DAZd, Tajni spisi namjesništva, sv. 13, beigefügt zu einem Handschreiben des Kaisers an Lilienberg vom 14. Mai 1833, das gelautet hatte: "Lieber Graf Lilienberg! In Folge meiner Entschließung vom 19. März 1833 wird Ihnen im Wege der ver. Hofkanzlei, bereits die Weisung zugekommen seyn, die Grundsätze und näheren Bestimmungen in Überlegung zu nehmen, durch welche noch vor Einführung des stabilen Catasters in Dalmatien, die dermalige Besteuerung im Wege der Zehende aufgegeben werden könne.

Sie haben daher bei Ihrer bevorstehenden Landesbereisung auf diesen Gegenstand ein besonderes Augenmerk zu richten, und sich mit Berücksichtigung der öffentlichen und sonstigen Verhältnisse, die persönliche Überzeugung zu verschaffen, zu trachten, ob und in wie weit die Reluition [Ablösung/Entrichtung] der Zehende im Gelde, oder eine andere Bestimmung statt der Zehende ohne Schaden der Unterthanen in Dalmatien ausführbar sey, und Mir sodann hierüber Ihr Gutachten zu erstatten. Wien am 14 May 1833.« Lilienberg sprach sich in seinem 53-seitigen Vortrag an den Kaiser deutlich dagegen aus. Er endete 
$\$ 238$ [Domänen] Bezüglich der Staatsrealitäten-Verkäufe in Dalmatien, welche bis zur Vollendung der Catastral Operationen meistentheils Entitäten von nicht großem Belange betreffen, bemerkte [Qu 111 / 2] ich, daß die Verkäufe häufig wegen Mangel an Anbothen ${ }^{1103}$ über dem Fiskalpreis langsam vorwärts schritten; ich fand mich demnach veranlaßt, mehrere Weisungen zu erlaßen, damit den dießfälligen Versteigerungskundmachungen die größte Publizität gegeben werde und die Licitationen [Versteigerungen, K. C.] selbst mit mehr Regelmäßigkeit vor sich gehen.

$\$ 239$ [Vermögen aufgehobener Brüderschaften in Ragusa] Das Vermögen der ehemals bestandenen zahlreichen Confraternite ${ }^{1104}$ in Ragusa steht ebenfalls unter der Verwaltung des Domaniums.

Der Gewerbszunft der Pellicieri ${ }^{1105}$ daselbst wurden aber noch von der vorigen Regierung zwei Localien bis auf weitere Weisungen zum Genuße überlaßen. Da sie jedoch vor einigen Jahren darauf verzichtete um selbe zu einer Casa di lavoro für Ragusa zu widmen, wo bereits die 18 armen Mädchen provisorisch unterbracht sind und in Arbeiten unterrichtet werden, von dem ich bei Schilderung der Wohlthätigkeits Anstalten [ergänzt: allerunterthänigst] Erwähnung gemacht habe ${ }^{1106}$ so trug die Landesstelle unter [Qu 111 / 3] dem 24 April 1[aufenden] J[ahre]s No 1694 darauf an, daß die erwähnten Localien bei dieser Bestimmung belaßen werden.

$\S 240$ [Fiskalprozeße] Schließlich ${ }^{1107}$ halte ich mich verpflichtet, auch der Fiscalprocesse allerunterthänigst zu erwähnen, welche alle bei dem einzigen Tribunale in Zara als dem Sitze der Cammer Procuratur concentriert werden. Sie richten den Unterthanen in diesem sehr ausgedehnten Lande zu Grunde: Eine Angelegenheit, wobei es sich um einen Gulden handelt, kostet dann und wann der Parthei 30 bis 60 Mal so viel. Dießfalls habe ich überall die rührendsten Weheklagen vernehmen müßen. $\mathrm{Zu}$ diesem großem Uibel

mit dem Absatz: »Nur durch die Einführung des Catasters kann den hiesigen Verwirrungen in der Bewirthschaftung und Besteuerung des Bodens nach meinem a. u. Dafürhalten ein Ende gemacht; die Agriculturs-Entwicklung im Allgemeinen entfesselt; und besonders den dürftigen Bewohnern der Gebirgsgegenden, welchen von dem jährlichen Grundertrag der mindeste Theil rein übrig bleibt, ihr, sie erschöpfender Schweiß durch E. M. unbegränzten Hulden und Gnaden gelindert werden."

$1103 \mathrm{Zu}$ verstehen als »Gebote« (bei einer Versteigerung).

1104 Bruderschaften (Stiftungen).

1105 Vermutlich Kürschner, von einer (veralteten) italienischen Form, für die es auch unter Google Books nicht viele Belege gibt. Aber: Masini, Antonio di Paolo: La Bologna perlustrata. Teil 1, Bd. 2 Bologna 1823, 87: »Pellicieri detti comunemente Pelizzari«, wozu wiederum in heutigem Standarditalienisch zu vergleichen ist: pellecciaio, Kürschner; pellicceria, Kürschnerei.

1106 Vgl. oben, in $₫ 209$.

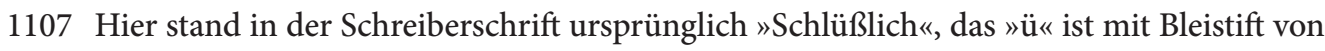
anderer Hand in $» \mathbf{i e} \ll$ korrigiert. 
gesellt sich noch der besondere Umstand, der solches um Vieles verschlimmert, daß niemand Rechtlicher etwas im Confiscations Wege kaufen will und die Effekten an die verächtlichsten Wucherer um ein Spottgeld hintangegeben werden müßen; wodurch dem Sachfälligen ein doppelter [Qu 111 / 4] Schaden zugehet.

Um diesen außerordentlichen Unfug für die arme Menschenklaße abzuwenden, hat das Gubernium rücksichtlich der Verhandlungen über Ärarial-Livelli, Canoni ${ }^{1108}$ und andere ähnliche Giebigkeiten, in so ferne es sich nicht um die Bestreitung des Rechtes handelt vorgeschlagen, im administrativen Wege abzuthun, worüber unter dem 24 Dezember $1833 \mathrm{Z} 21187$ der letzte Bericht erstattet worden ist.

Da der gegenwärtige Bestand fur Euer Majestät Unterthanenen sehr drückend und von unberechenbaren Nachteil ist, so erlaube ich mir in tiefster Ehrfurcht diesen [Vorschlag] Eurer Majestät ${ }^{1109}$ allergnädigsten Beherzigung anzuempfehlen.

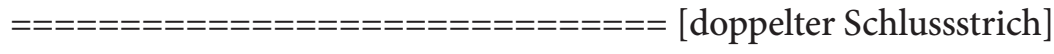

Dalmatien ist noch gegen das Allerhöchste Aerarium im Deficit und dieses betrug nach einem Durchschnitte des praelimirten Aufschlags von 1830, 1831 und 1832 die [die letzten drei Seiten des Konzepts sind nicht numeriert] Summe von jährlichen 122970 Gulden.

Nach jenem der Bilance aber des präliminierten Anschlages und den der de facto Waltung betrug das Deficit im Jahre 1833109761 Gulden. ${ }^{1110}$

Man kann aber mit gegründeter Wahrscheinlichkeit annehen, daß dieses Deficit bloß durch die Einführung der Steuer in den Kreisen Ragusa und Cattaro ${ }^{1111}$, dann durch die Organisirung der Doganalämter und der Gränzwache ganz gewiß für die Folge gedekt werden wird. ${ }^{1112}$

Wenn aber die moralische und religiose Ausbildung dieses durch Jahrhunderte vernachläßigten Volkes durch Euer Majestät unbegränzte Huld und Gnade vorgeschritten; die Rohheit und der dadurch entstandene Indifferentissmus, welcher dem sittlichen und materiellen Wohl der Menschen und des Staates so nachtheilig ist verscheucht seyn, und

1108 Livelli und Canoni waren Bezeichnungen für Gebühren gegenüber dem Staat oder Gemeinden, konkret für Dalmatien belegbar etwa als verschiedene Begriffe für Mühlzinse (Mühlgebühren); ein Canon (ein im 19. Jahrhundert noch im ganzen deutschen Sprachgebiet verbreiteter juristischer Begriff) war dabei eine alljährlich in bestimmter Höhe zu leistende Abgabe.

1109 Wieder eine direkte Wendung an den Kaiser und eine schon durch ihre Positionierung am Ende des eigentlichen Textteils betonte Kritik an den Folgen des bestehenden k. k. Verwaltungssystems (bzw. der Verwaltungsstrafen) bei ausständigen Steuer- bzw. Abgabenlasten.

1110 Entzifferung dieses Satzes gemäß der Reinschrift, Seite 171 (Scan 177).

1111 Gemeint sind die ungefähr erzielbaren Werte der damals in den beiden Kreisen noch nicht eingehobenen direkten Steuern, insbesondere des Zehents.

1112 Eigentlich müsste hier stehen »würde«, denn diese Einnahmen wurden ja weder aktuell erzielt noch konnte für die absehbare Zukunft fest mit ihnen kalkuliert werden. 
dieses Volk lernen wird, die unendlichen Urstoffe und Vortheile, die es umgeben, nach phisio[gestrichen: geographischen; ergänzt mit anderer Schrift: kratischen] und [gestrichen: materi] Mercantil-Grundsätzen zu benützen, wird auch der Boden gewiß um die Hälfte mehr als itzt tragen, ohne erst den [Seitenumbruch] Augenblick, wo die Moräste ausgetrocknet und die öden Gründe urbar gemacht sind, abzuwarten.

Um wie viel mehr wird das Land einnehmen wenn die Confection des Oehles und des Weines zweckmäßiger und diese Artikeln an alle auswärtigen Märkte mit jenen anderer Länder werden Commerz ${ }^{1113}$ halten können.

Bei Verbeßerung der Vieh- und besonders der Schafzucht, da die Veredlung dieser, wie aus dem $₫ 100$ hervorgehet hier leicht ausführbar ist, kann sich der Gewinn verdreyfachen.

Wenn aber die Seiden-Cultur, die wenigstens dem Lande 1 1/2 Million eintragen könnte, durch Euer Majestät Gnade auf den gehörigen Punkt gebracht worden seyn wird, und wenn es endlich Euer Majestät allerhöchsten Weisheit gefallen wird, dem Lande die Caravanen wieder allergnädigst zu gestatten, so kann man mit Zuversicht [gestrichen: rechnen] (Seitenumbruch) annehmen, daß dieser rohe Diamant, der durch viele Generationen blos als ein gemeiner Gneis ${ }^{1114}$ behandelt wurde, durch Euer Majestät unerreichbare Weisheit, da Allerhöchst dieselben die Gegenwart der Zukunft zu opfern und Vieles auf dieses Land väterlich zu verwenden nicht gescheut haben, zum Brillant neugestaltet und die große Schuld dem Staate in dankbarster Anerkennung unzähliger allerhöchster Wohlthaten vollkommen zurückgezahlt wird.

Von den wichtigeren militairischen Gegenständen habe ich mir nicht erlaubet weiters eine allerunterthänigste Erwähnung zu machen, weil ich in meinen dießfälligen 3 Berichten, welche Euer Majestät im vorigen Jahre durch den Hofkriegs Rath in tiefster Ehrfurcht unterlegt wurden und über deren zwei bereits die allerhöchste Resolution erfolgte, alles erschöpft worden ist; nur unterfange ich mich allerunterthaenigst beizufügen, daß die festen Punkte und andern fortificatorischen Objecte immer be[ergänzt: -dacht; gestrichen: -droht], fortan vervollkommt und daß auch die Mannszucht und militairische Ordnung, so wie der Milit[är]-Unterricht in jeder Hinsicht aufrecht erhalten werden.

[Mehrfache Schlussstriche, und daneben am Rand statt Endunterschrift eine datierte Angabe, mutmaßlich von Lilienberg selbst: Zara 16/7 18341115].

1113 Hier zu verstehen als »in Konkurrenz treten«.

1114 Ein weit verbreiteter, feldspathaltiger Naturstein. Das ihm eventuell unbekannte Wort hatte der Schreiber zunächst frei gelassen.

1115 In der Reinschrift steht hingegen (Seite 172 bzw. fol. 87v; Scan 178) neben Lilienbergs Unterschrift die Angabe »Zara am 15. July 1834 . 


\section{Anhang}

\section{Verzeichnis der in der Lilienbergschen Darstellung zitierten Akten (1815-1834)}

7.6.1815 Zentralorganisierungs-Hofdekret Z 11692/1427: Aufhebung der Steuerhoheit der Stadt- und Landgemeinden beim Dazio consumo (Aufschläge zur Konsumsteuer) und Einziehung dieser Steuer durch den Zentralstaat, der aus dieser Einnahme nur noch den Stadtgemeinden und auch diesen nur ergänzende Pauschalsummen anweist (Akt vermutlich vorhanden in: Österreichisches Staatsarchiv, Finanz- und Hofkammerarchiv, Kt. 1658 Zentralorganisierungshofkommission, Zl. 11.301/1.200 - 12.373/1.300: $1815 / 05-1815 / 06)(\$ 170)$.

7.3.1820 Gubernialantrag Z 4207: wegen Regulierung des Vorspannwesens ( $\$ 183$ ).

4.5.1821 a. h.Entschließung mit Erlass des Kommunalsystems (Gemeindeordnungen) für Dalmatien ( $\$ 170)$.

31.7.1826 Hofkanzleidekret Z 16342/4184: Zuteilung der Prätur von Arbe (nach deren Aufhebung) zu der Prätur von Pag (\$142).

20.5.1828 Anträge des Guberniums Z 83: wegen nautischen Unterrichts; Erledigung in Wien ausständig (\$205).

19.5.1829 Gubernialberichte an ver. Hofkanzlei Z 12487: Antrag zur Regelung des Stipendienwesens für Nachwuchskleriker; Erledigung in Wien ausständig (\$190).

13.7.1829 a. h. Erlass: zur Verwendung von Marichich; dessen verfügte Versetzung noch nicht erfolgt (\$177).

1830 Gubernialantrag Z 98/p: ein Plan von Lilienbergs Vorgänger Gouverneur Tomassich für die Organisierung der Forza territoriale ( $\$ 182)$.

24.4.1830 allerhöchste Entschließung Z 9316/1111: wegen Nichteinsetzung eines agrarischen Inspektors für Dalmatien ( $\$ 180$; vgl. a. Einleitung, 22, mit Datierung auf 17.4.1830).

10.8.1830 Gubernialbericht an ver. Hofkanzlei Z 15437: Anträge zum Dienstbotenwesen; Erledigung in Wien offenbar ausständig (\$213). 
5.10.1830 Gubernialbericht an ver. Hofkanzlei Z 25260: Antrag zur Regelung des Stipendienwesens für Nachwuchskleriker; Erledigung in Wien ausständig ( $\$ 190)$.

16.11.1830 a. h. Erschließung zur Errichtung der „politischen Präturen“ an den Kreishauptorten $(\$ 172)$.

21.5.1832 Gubernialverfügung Z 4192: Jagdwesen, Einführung einer Schonzeit durch Lilienberg (\$74).

14.7.1832 Monatlicher Stimmungsbericht Lilienbergs 2139/Z. 287 an ver. Hofkanzlei, darauf deren Auftrag zu Äußerung Lilienbergs über Vorschlag der Vereinigung der Kreise Dubrovnik und Kotor (\$139).

2.8.1832 Verordnung des Guberniums Z. 13701: Weinlese, amtliche Bestimmung fester Zeiträume auf Gemeindeebene ( $\$ 93$ ).

13.8.1832 Vortrag Lilienbergs an ver. Hofkanzlei Z 324: gegen Vorschlag zur Vereinigung der Kreise Dubrovnik und Kotor (\$139).

16.9.1832 Vortrag Lilienbergs an ver. Hofkanzlei Z 368/96: erneut gegen Vorschlag zur Vereinigung der Kreise Dubrovnik und Kotor (\$139).

22.12.1832 Gubernialbericht an Präs. der PHSt Z 505 / Z p: Antrag auf Errichtung von Polizeikommissariaten in Split und Dubrovnik; Genehmigung noch nicht erfolgt (\$221).

31.12.1832 Gubernialbericht an die Hofkanzlei Z 21310: Antrag auf Regelung des Stipendienwesens für Nachwuchskleriker (1834 noch unerledigt; § 190)

7.1.1833 a.h. Kabinettschreiben Z. 295: über den Bischof von Kotor Paulovich Lucich (\$184).

30.1.1833 Gubernialbericht an Polizeihofstelle Z 805: Antrag wegen Mangel von Polizeiagenten in den Kreishauptorten; offenbar unerledigt ( $\$ 208)$.

21.3.1833 Gubernialvortrag zu Bischof von Cattaro Paulovich Lucich ( $\$ 184)$.

26.3.1833 Auftrag der Hofkammer an Gubernium Z 5434/556: wegen falscher Deklaration von auswärtiger Ware (Olivenöl) als dalmatinisches Produkt zu Zollbetrug (\$124).

24.4.1833 Gubernialbericht Z 4692: Besetzungsvorschlag für Prätur Zadar (Griesz) (\$172). 
4.5.1833 Gubernialbericht an allg. Hofkammer Z 6489/2475: Antrag auf Vereinigung der Finanzwachen mit Hafen-, Seesanitäts- und Grenzpolizeiämtern; unerledigt ( $\$ 232$ ).

5.5., 18.9. und 31.12.1833 Gubernialberichte: Anträge auf Errichtung des ksl. bereits bewilligten Seelazaretts in Dubrovnik ( $\$ 225)$.

6.5.1833 Gubernialbericht Z 5609/838: Antrag auf Wiederzulassung der Karawanen; unerledigt $(\$ \$ 119,127)$.

14.5.1833: a. h. Handschreiben wegen Einführung der Grundsteuer in Dalmatien noch vor Abschluss des stabilen Katasters ( $\$ 237$, mit Abschrift des Wortlauts in Anmerkung).

16.5.1833 ver. Hofkanzlei an Lilienberg Z. 3589: Zurückweisung seiner Anträge zur Landesbaudirektion, Lilienberg bittet Kaiser um deren Berücksichtigung $(\$ 230)$.

25.5.1833 oder 1834 Gubernialbericht Z. 7311, sowie dasselbe vom 23.4.1834 an ver. Hofkanzlei (oder innerdalmatinisch an Appellationsgericht Z. 3514/2259): Antrag auf erweiterte Guberniumsvollmachten bei Personalengpässen bei den Präturen(§ 156).

26.6.1833 Gubernialberichte an Polizeihofstelle Z 10164: Antrag wegen Mangel von Polizeiagenten in den Kreishauptorten; offenbar unerledigt ( $\$ 208)$.

14.8.1833 Gubernialvortrag an Hofkammer Z 11826/4355: wegen Deklaration von auswärtiger Ware (Olivenöl) als dalmatinisches Produkt zu Zollbetrug (\$ 124).

14.9.1833 a.h. Entschließung: bezüglich der Orthodoxen im Kreis Kotor (\$ 200).

25.9.1833 Antrag der Landesstelle Z 13771/3010 [an ver. Hofkanzlei]: auf Ausweitung der autonomen Befugnisse der dalmatinischen Behörden und Ämter gegenüber den Zentralstellen, zur Verminderung von Aktenverkehr und Dienstgeschäften ( $\$ 157)$.

25.9.1833 Antrag der Landesstelle Z 6156/1351 [an ver.Hofkanzlei]: auf verminderte periodische Berichtspflicht gegenüber Wien, zur Verminderung des Aktenverkehrs ( $\$ 157)$.

25.9.[1833?] Gubernialantrag Z. 3771/5010: wegen Erweiterung des Wirkungskreises der Behörden (\$180).

1.10.1833 Gubernialbericht an den Obersten Kanzler [ver. Hofkanzlei] Z. 871/p: Einsparvorschläge Lilienbergs im Kommunalwesen aufgrund der Ergebnisse seiner Provinzbereisung und seiner dabei gemachten Beobachtungen $(\$ \$ 143,160)$.

DigiOst 1 | 279 
1.10.1833 Hofkanzleidekret: wegen Präturspersonal, Verbot des Einsatzes von Hilfspersonal (\$172).

3.10.1833 Gouverneursbericht Z. 274: Antrag auf Aufhebung des Tabakmonopols für Dalmatien (\$236).

5.10.1833 Gubernialbericht Z 16376/1833: Tabakwirtschaft, Antrag des Guberniums auf Aufhebung des Tabakmonopols (Verweis auch auf Notizzettel im Anschluss an das Konzept der Lilienbergschen Darstellung 446; mit inliegenden Abschriften: Nr. 1037/292, von Hofmann, Wien 25.2.1834 an die k. k. Finanzintendenz in Zara, Übersicht zum Anstieg des Tabakverschleißes im 1. Quartal 1834 gegenüber 1833, wobei prozentualer Anstieg in Dalmatien um 11 2/8 \% in der ganzen westlichen Reichshälfte erster Stelle lag; und 6.10.1833 Z 1492/p: Tabak). (\$ 236).

5.10. 1833 Gouverneursberichte Z. 1492/p: Antrag auf Aufhebung des Tabakmonopols für Dalmatien $(\$ 236)$.

16.11.1833 Schreiben der Hofkanzlei: doch Vollmacht an Lilienberg (entgegen Dekret vom 1.10.1833) zu allen nötigen Maßnahmen, um Bearbeitungsrückstand bei politischen Präturen zu beheben und nach einer sechsmonatigen Beobachtungszeit weitere Anträge zu stellen ( $\$ 172)$.

Dezember 1833 Z 20006: Antrag wegen Besetzung des Domkapitels von Split (\$ 184).

12.12. 1833 Vortrag von Lilienberg an den Kaiser: Antrag auf Übernahme der Zehenteinhebung durch die staatliche Steuerverwaltung für mehrere Jahre (Akt liegt in DAZd, Tajni spisi namjesništva, Kt. 13, beigefügt zu dem Handschreiben des Kaisers an Lilienberg vom 14. Mai 1833, womit der Bericht angefordert worden war). (\$237).

18. 12. 1833 Gubernialbericht an Hofkammer G Z 2297/p: wegen Schiffsbauförderung Antrag auf zollrechtliche Begünstigung für Zwischenprodukte ( $\$ 118)$.

18.12.1833 Gubernialbericht an PHSt Z 2412/p: bezüglich Orthodoxe im Kreis Kotor $(\$ 200)$.

24.12.1833 Gubernialbericht Z 21187: mit Darlegung von Strategie zur Vermeidung von existenzgefährdenden Pfändungsklagen bei Ansprüchen aus staatlichen Abgaben, die stattdessen auf dem Verwaltungsweg eingehoben werden sollten (und Lilienbergs Bitte an den Kaiser, diese Maßnahmen zu genehmigen) (\$240). 
24.12.1833 Gubernialbericht Z 22227/7910: Antrag an ver. Hofkanzlei wegen Aufhebung der Robot (\$177).

24.12.1833 Bericht an die Hofstelle [wohl Hofkanzlei, vgl. Clewing: Staatlichkeit, 153] Nr. 21878/7137: Übersicht über ksl. bewilligte Nothilfen von 1830 und 1831 sowie Anträge zu künftigen Maßregeln $(\$ 210)$.

24.12.1833 Gubernialbericht Z 21187: Bericht über Möglichkeiten zur Vermeidung von Pfändungsklagen ( $\$ 240)$.

16.1.1834 Vortrag Lilienberg an Franz I. infolge a.h. Kabinettschreibens vom 24.12.1833 Z. 1335/p: wegen Besetzung Prätur Zadar (\$ 172).

24.1.1834 Gubernialbericht Z 1668/p: Antrag auf Systemisierung der Finanzwachen unter Vereinigung des Sänitäts- und Hafendienstes; unerledigt (\$232).

5.2.1834 Guberniumsbericht an die ver. Hofkanzlei Z. 1242/433: Antrag über Anstellung eines Concelliere (Rats) und eines Schreibers in Rab (in Unterstellung gegenüber der Prätur von Pag); zurückgewiesen mit Dekret vom 17.5.1834 (\$142).

17.2.1834 a.h. Entschließung: zugunsten der Zusammenziehung des Regularklerus in weniger Klöstern mit einer gewissen Mindestgröße (\$ 199).

26.2.1834 a. h. Kabinettschreiben Z 308/p: wegen Organisierung der Forza territoriale $(\$ 182)$.

26.2.1834 Gubernialbericht Z 2213: zur provisorischen und gleichsam improvisierenden Anstellung von Geistlichen als Landschullehrer (\$204).

28.2.1834 a. h. Kabinettschreiben: über Beschwerdeschrift orthodoxer Geistlicher an den Kaiser wegen Benachteiligungen durch Gubernium; Antwort an Hofkanzlei mit 14.6.1834 (\$200).

16.3.1834 a. h. Entschließung mit Auftrag an Lilienberg: Stellungnahmen zur Neuorganisation der Orthodoxen sind beim katholischen Erzbischof Nowak und bei dem ehemaligen dalmatinischen orthodoxen Bischof Rajačić einzuholen (\$200).

20.3.1834 allerhöchste Entschließung: zur Einsetzung des unierten Pfarrers Bubanović. 
2.4.1834 Gubernialbericht Z 5067: Darlegung der Finanzbedürfnisse der Gemeinden aus dem Dazio consumo, dabei (eine hier wiederholte) Antragstellung eines Konzepts, das den bestehenden Regelungen durch Wien zuwiderlief ( $\$ 171)$.

5.4.1834 a. h. Entschließung: zur Ernennung des neuen orthodoxen Bischofs und zu dessen künftigen Sitz, Überwachungsfragen $(\$ 200)$.

9.4.1834 Gubernialbericht an ver. Hofkanzlei Z 5291: wegen Regulierung der obersten Seesanitätsebene $(\$ 224)$.

10.4.1834 Vortrag Lilienbergs an Franz I.: wegen Organisierung der Forza territoriale, und Einführung der Konskription in Dalmatien infolge Kabinettschreiben vom 26.2.1834 $(\$ \$ 182,183)$.

23.4.1834: Akt 3514/2259: Nicht näher identifizierter Akt des Guberniums wegen gewünschter erweiterter Vollmachten bei Aushilfspersonal der Präturen (verknüpft mit Nr. 7311 vom 25.5.34) (\$156).

24.4.1834 Gubernialbericht $N^{\circ}$ 1694: wegen Casa di lavoro für Mädchen in Dubrovnik (\$239).

30.4.1834 Gubernialbericht an Hofkanzlei Nr. 6345: zu Armenanstalt in Split, deren dauerhafte Finanzierung betreffend ( $\$ 209)$.

14.5.1834 Gouverneursbericht Z 1080/p: Karawanen, Antrag auf Wiederzulassung (\$127).

17.5.1834 Hohe Hofstelle [Hofkanzlei] Z 12595: Ablehnung des Antrags des Guberniums vom 5.2.1834 auf Anstellung eines Concelliere und eines Schreibers in Rab (\$142).

18.5.1834 a. h. Entschließung Z 2829: zu Franz Petter, Professor der deutschen Sprache am Gymnasium Split (\$202).

22.5.1834 Gubernialbericht an vereinte Hofkanzlei Nr. 6499: Antrag wegen Verbrechensbekämpfung (verbunden mit dem Gubernialbericht vom 28.5.34) (\$216).

23.5.1834 Hofkanzlei-Verordnung: wegen der Zusammenziehung der Regularkleriker in weniger Klöstern mit einer gewissen Mindestgröße (\$ 199).

24.5.1834 Gubernialbericht Z 8586: zu Sitz des orthodoxen Bischofs, Überwachungsfragen $(\$ 200)$. 
25.5.1834 Vortrag an vereinte Hofkanzlei Nr. 7311 (scheint nicht identisch mit Nr. 7311/2506 vom 28.5.34, denn Datierung auf 25.5. ist eindeutig lesbar im Text wie auch in Randanmerkung zur Gliederung): Bitte um kaiserliche Vollmacht zu eigenständiger behelfsweiser Aufstockung des Personals bei den Präturen in Bedarfsfällen, ohne vorherige Genehmigung in Wien ( $\$ 156)$.

26.5.[1834?] Gubernialbericht an Hofkammerpräsidium Z. 43/p: Vortrag mit Antrag über personelle Aufstockung der oberen Finanzverwaltung der Provinz (\$231).

28.5.1834 Bericht an Hofkanzlei Z 7311/2506: Vortrag über Mittel zur Verminderung der Verbrechen und zur erhöhten Sicherung von Personen und Eigentum, mit Antrag auf zusätzliches Militär zu diesen Zwecken (\$\$183, 216).

28.5.1834 Gubernialbericht an ver. Hofkanzlei Nr. 6499: Antrag wegen Verbrechensbekämpfung (\$216).

14.6.1834 Gubernialbericht an Hofkanzlei Z. 986/p: über orthodoxe Geistliche und deren Beschwerden über Benachteiligungen gegenüber dem Kaiser $(\$ 200)$.

25.6.1834 Nr. 10978: revidierter Antrag zur Besetzung des erzbischöflichen Domkapitels von Zadar (\$184).

Undatierbar (wohl 1834) Antrag des Guberniums an Hofkanzlei auf Neuzuteilung der Waldungen und Hutweiden auf Rab (\$142, Ende des Paragraphen). 
Konrad Clewing - 978-3-86688-501-1 


\section{Verzeichnis der 1834 im Staatsrat behandelten Akten zu Dalmatien}

HHStA, Staatsrat, Exhibitenindex 1834 sub voce »Dalmatien und Albanien«. Nach dem Eintrag folgen die Aktennummern. Die Akten selbst sind im Zuge des Zweiten Weltkriegs verloren gegangen. Orthographie und Abkürzungen wie im Original.

- Wegen Einführung des Wehrsystems - Konskription und Rekrutierung - dann der forza territoriale in Dalmatien: 114.80.2381

- Bazare, zwei an der Grenze Dalmatiens im türkischen Gebiete neu zu errichtende betr. 1069.2317.2780

- Karavanen-Handelszug, türkischer, durch Dalmatien - wegen dessen Wiederbelebung und wegen Wiedereröffnung des bestandenen Lazaretts zu Castelnuovo alldort. 1175.835.2790.5614.6621.6796.7720

- Regulierung der Waldkultur in Dalmatien betr. 1849.1701.4484

- Wegen Zollherabsetzung auf Dalmatiner Weine bei ihrer Einfuhr in andere Länder 1940

- Wegen des Verfahrens bei den ersten Instanzen in Dalmatien in Streitigkeiten bis zu dem Betrage von 50f. 2203.262

- Die Absendung zweier Piaristen aus Ungarn zum Grammatikalunterrichte nach Dalmatien - u. das diesfällige Schreiben des päpstl[ichen] Nuntius an den Ordensprovinziale betr. 2300.6025

- Wegen der erhöhten Preise des Viehes in Dalmatien u. Einführung der Ausgangszölle für selbes 2601

- Wegen der bei den üblichen Kirchenfesten in Dalmatien vorfallenden Streitigkeiten und Vergehen, u. den Bedrückungen der griech. Nation alldort 2710. 5750

- Wegen Zollvergünstigung für den Schiffbau auf allen Inseln in Dalmatien 2742.5800

- Land- und Wasserstraßenkarte von Dalmatien, zwei Exemplare betreffend 2787

- Dalmatiner n.u.gr. Bischof, ob demselben freigestellt werden soll, die Klöster-Archimandriten selbst zu ernennen 2911

- Wegen Einführung einer neuen Grundbesteuerung in Dalmatien 3308

- Wegen Nachsicht der den Dalmatinern in den Jahren 1815 und 1816 geleisteten Natural-Vorschüsse 3331

- $\quad$ Über die Studien der Dalmatiner in den l.v. Lehranstalten 3703

- Panteleimon Zsivkovics, neu ernannter gr.n.u. Bischof in Dalmatien - um Aushilfe zu seiner ersten Einrichtung 4012.5175.5808

- Wälder-Regulierung in Dalmatien betr. 4484.1849.1701

- Ob im laufenden Jahre ein Notstand in Dalmatien zu befürchten sei? Dann Vorkehrungen dagegen und Versorgung der Landleute mit Samenkörnern 5648.4784. 6771.6793.6884.7241.7788 
- Bauerngüter geschlossene in Dalmatien - ob selbes alldort einzuführen sei? Und wegen Beschränkung der dem Landvolke schädlich erscheinenden Verträge und Teilung des Grundeigentums 5669

- Wegen der unzureichenden Beamten bei den Präturen in Dalmatien - und Besetzung mehrerer Prätursstellen alldort 5979

- Verbrechen in Dalmatien, überhand nehmende, wegen der Mittel zu deren Verminderung 6015.6794

- Pfarrvorsteher gr.n.u. in Dalmatien - gegen die augenblickliche Bedrückung ihrer Glaubensgenossen 6030

- Straßenfrohne in Dalmatien - wegen deren Aufhebung, und Verpachtung der Erhaltung der ärarischen Straßen 6441

- Zollherabsetzung für den Eingang des rohen und alten Messings und des Glockenmetalls in Dalmatien 6578

- Wegen des Nachwuchs des gr. kath. Klerus in Dalmatien - dann wegen eines Unterhaltsbeitrags für den im gr. kath. Agramer Seminar befindlichen Jüngling Michael Vessich 7511

- Salzverschleißpreis herabzusetzender in Dalmatien betr. 7995 


\section{Verzeichnis der Originalbeilagen (in der Reinschrift und der Konzeptschrift)}

I: $\quad$ Trachten im Kreis Zara, ÖNB fol. 101r / Scan 205

II: Trachten im Kreis Spalato, ÖNB fol. 102 r / Scan 207

III: Trachten im Kreis Spalato, ÖNB fol. 103r/ Scan 209

IV: $\quad$ Trachten im Kreis Ragusa, ÖNB fol. 104r / Scan 211

V: $\quad$ Trachten im Kreis Cattaro / Kreis Ragusa, ÖNB fol. 105r / Scan 213

VI: $\quad$ Trachten im Kreis Cattaro, ÖNB fol. 106r / Scan 215

VII: Übersichts- und Straßenkarte von Dalmatien, mit: Übersicht der Distanzen und Peripherien von Dalmatien und den hiezu gehörigen Inseln, ÖNB fol. 107 / Scan 217; DAZD

VIII: Skizze der Gegend bei Imoschi, ÖNB fol. 109 / Scan 220; DAZd

IX: Skizze jenes Teils des Kreises Cattaro, in welchem die nördliche Grenze zu ersehen ist, wie sie gegenwärtig besteht und wie sie diplomatisch bestehen sollte, ÖNB fol. 110/ Scan 222; DAZd

X: Planimetria da Castel Lastua ai Confini dell'Impero Ottomano e Montenegro, nel Territorio di Pastrovichio, ÖNB fol. 111 / Scan 224; DAZd (abweichender Titel)

XI: Carta orografica della Dalmazia, ÖNB fol. 112 /Scan 226); DAZd

XII: Carta idrografica della Dalmazia, ÖNB fol. 113 / Scan 228; DAZd

XIII: Idrografia di Narenta, ÖNB fol. 114 / Scan 230; DAZd

XIV: $\quad$ Planimetria dei due Laghi temporani Rastok e Jesero, ÖNB fol. 115 / Scan 232; DAZd (in zwei Varianten)

XV a: Topografia dei Paludi d'Ostrovizza e di Morpolazzo e del Canal di Goducie fino alla sua foce nel Lago di Procliane, ÖNB fol. 116/ Scan 234; DAZd

XV b: Situationsplan der Gegend bei Knin, ÖNB fol. 117 / Scan 236); DAZd

XVI: $\quad$ Pianura dei Canali nel Circolo di Ragusa, ÖNB fol. 118 / Scan 238; DAZd

XVII: Verschiedene Muster Schafwolle, ÖNB fol. 119/ Scan 240

XVIII: Lateinische Urkunde vom Juli 1018: Tributum D. Duci Venetiarum Libras X de deta serica ab Arbensibus, ÖNB fol. 121 / Scan 244

XIX a: Reliefzeichnung aus Salona, ÖNB fol. 123 / Scan 248

XIX b: Kreis-Karte von Dalmatien, ÖNB fol. 123 / Scan 250; DAZd

XX: Übersichtskarte des vecchio, nuovo e nuovissimo Acquisto, ÖNB fol. 125 / Scan 252; DAZd

XXI: Katastralkarte, ÖNB fol. 126 / Scan 254; DAZd

Ohne Nummer: Carta indicante le tappe per le marchie militarij; DAZd

Ohne Nummer: Mappa del Cordon Sanitario del Circolo di Cattaro della piccola dimensione secondo i dissegni della Commissione Taborovich; DAZd 
Konrad Clewing - 978-3-86688-501-1 


\section{Verzeichnis der Kartenbeilagen der Edition}

Karte 1: Übersichts- und Straßenkarte von Dalmatien, mit: Übersicht der Distanzen und Peripherien von Dalmatien und den hierzu gehörigen Inseln (wie Originalanlage VII)

Karte 2: Skizze der Gegend bei Imoschi (wie Originalanlage VIII)

Karte 3: Skizze des Nordteils des Kreises Cattaro mit bestehendem und österreichischerseits angestrebtem Grenzverlauf (wie Originalanlage IX)

Karte 4: Karte des zum Teil umstrittenen Gebiets von Castel Lastua im Bereich von Pastrovichio (wie Originalanlage X)

Karte 5: Reliefkarte Dalmatiens, der Herzegowina, Montenegros und von Teilen Bosniens und Albaniens (wie Originalanlage XI)

Karte 6: Hydrographische Karte von Dalmatien (wie Originalanlage XII)

Karte 7: Hydrographische Verhältnisse im Mündungsdelta der Narenta (wie Originalanlage XIII)

Karte 8: Die zwei jahreszeitlichen Seen Rastok und Jesero (wie Originalanlage XIV)

Karte 9: Reliefkarte der Moräste von Ostrovizza und Morpolazzo und des Kanals von Goducie bis zum See von Procliane (wie Originalanlage XV a)

Karte 10: Situationsplan der Gegend bei Knin (wie Originalanlage XV b)

Karte 11: Reliefkarte der Canali im Kreis Ragusa (wie Originalanlage XVI)

Karte 12: Kreiseinteilung von Dalmatien (wie Originalanlage XIX b)

Karte 13: Übersichtskarte des vecchio, nuovo e nuovissimo Acquisto (wie Originalanlage XX)

Karte 14: Katastralkarte (wie Originalanlage XXI)

Karte 15: Militärische Marschetappen in Dalmatien (DAZd; in Reinschrift nicht vorhanden)

Karte 16: Reliefkarte des Kreises Cattaro und des dortigen Sanitärkordons (DAZd; in Reinschrift nicht vorhanden) 
Konrad Clewing - 978-3-86688-501-1 
Kartenabbildungen 


\section{Kartenabbildungen}

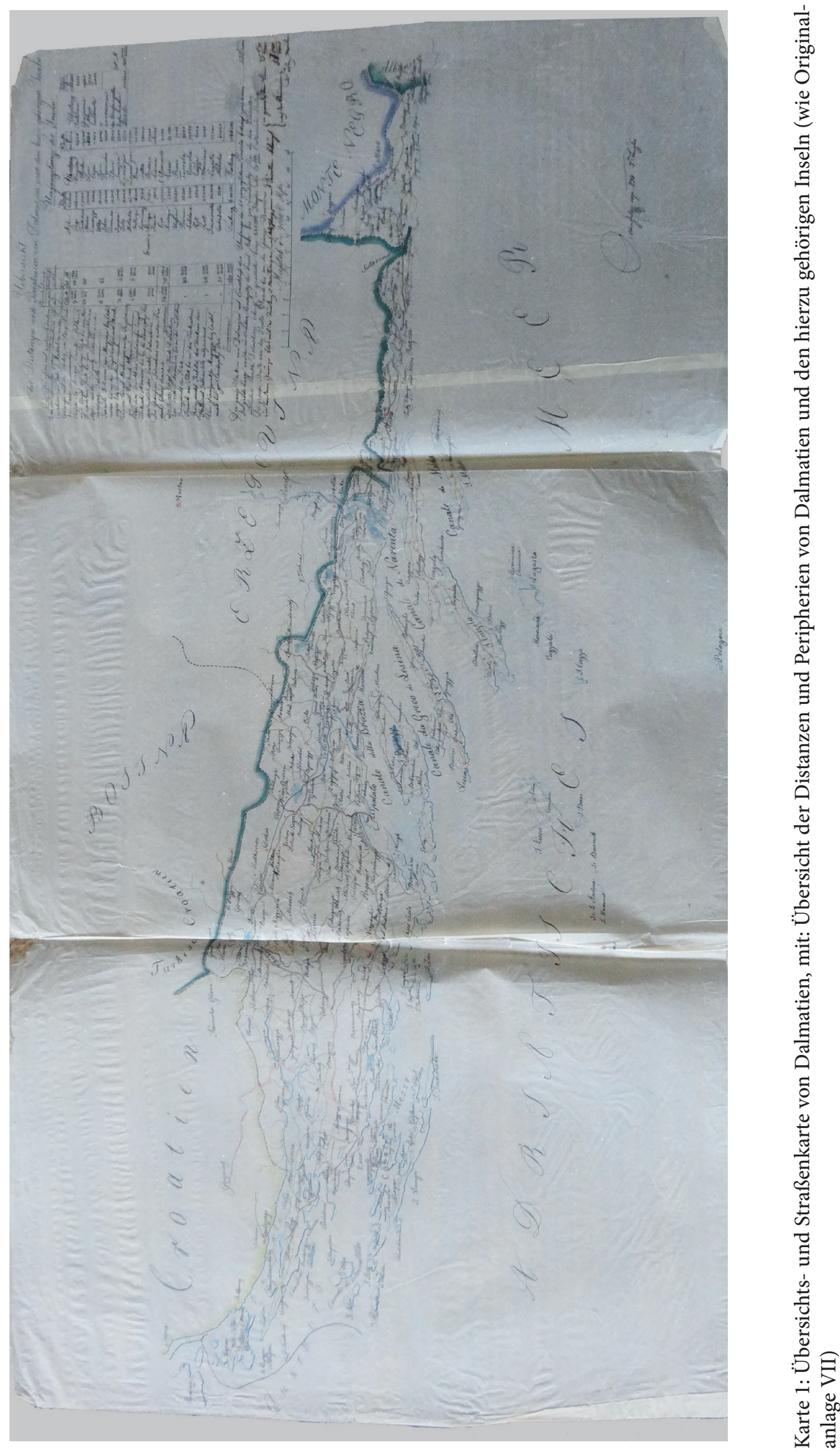

DigiOst 1 | 292 


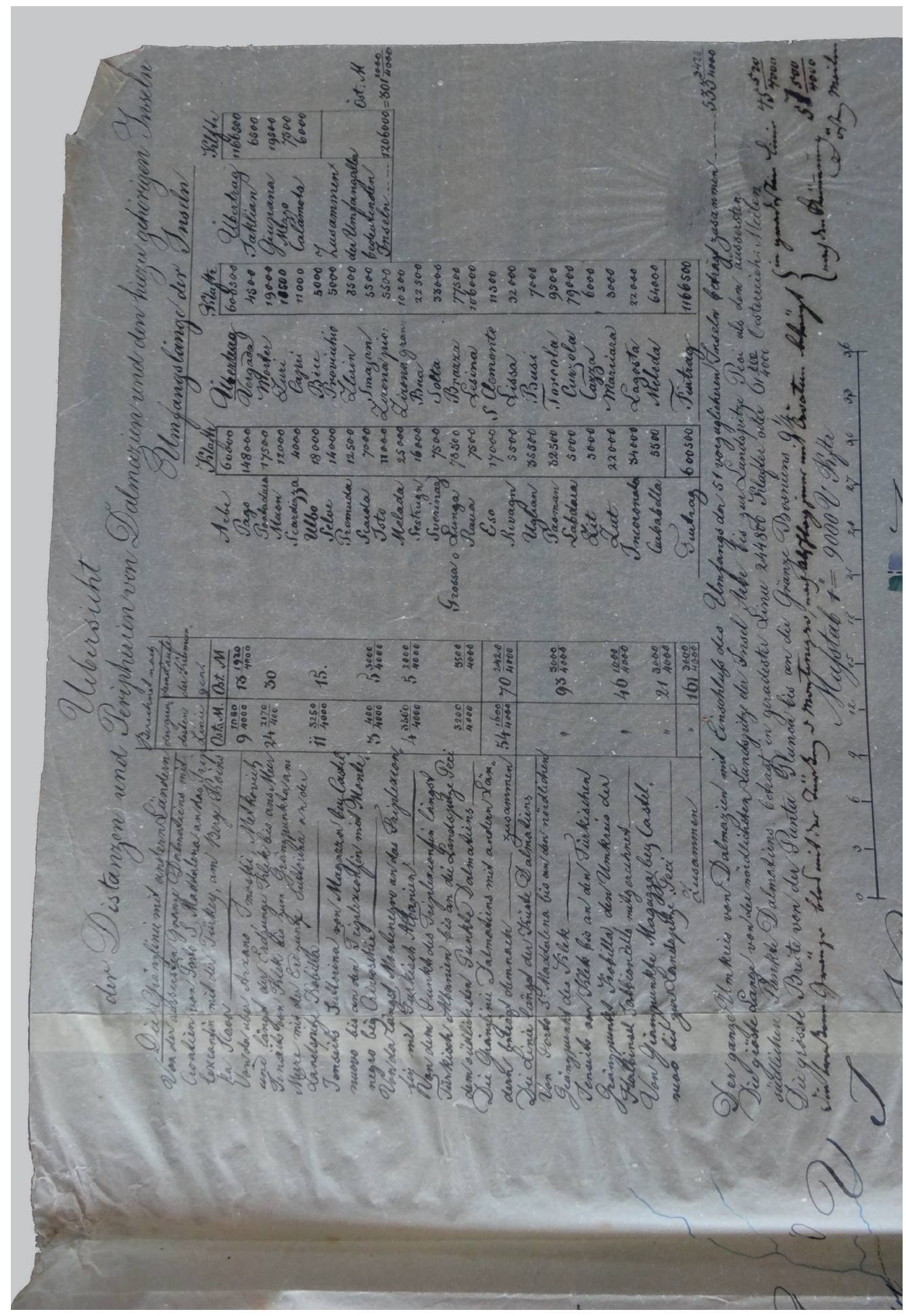

Karte 1 (Auszug): Übersicht der Distanzen und Peripherien von Dalmatien und den hierzu gehörigen Inseln (aus Originalanlage VII) 


\section{Kartenabbildungen}

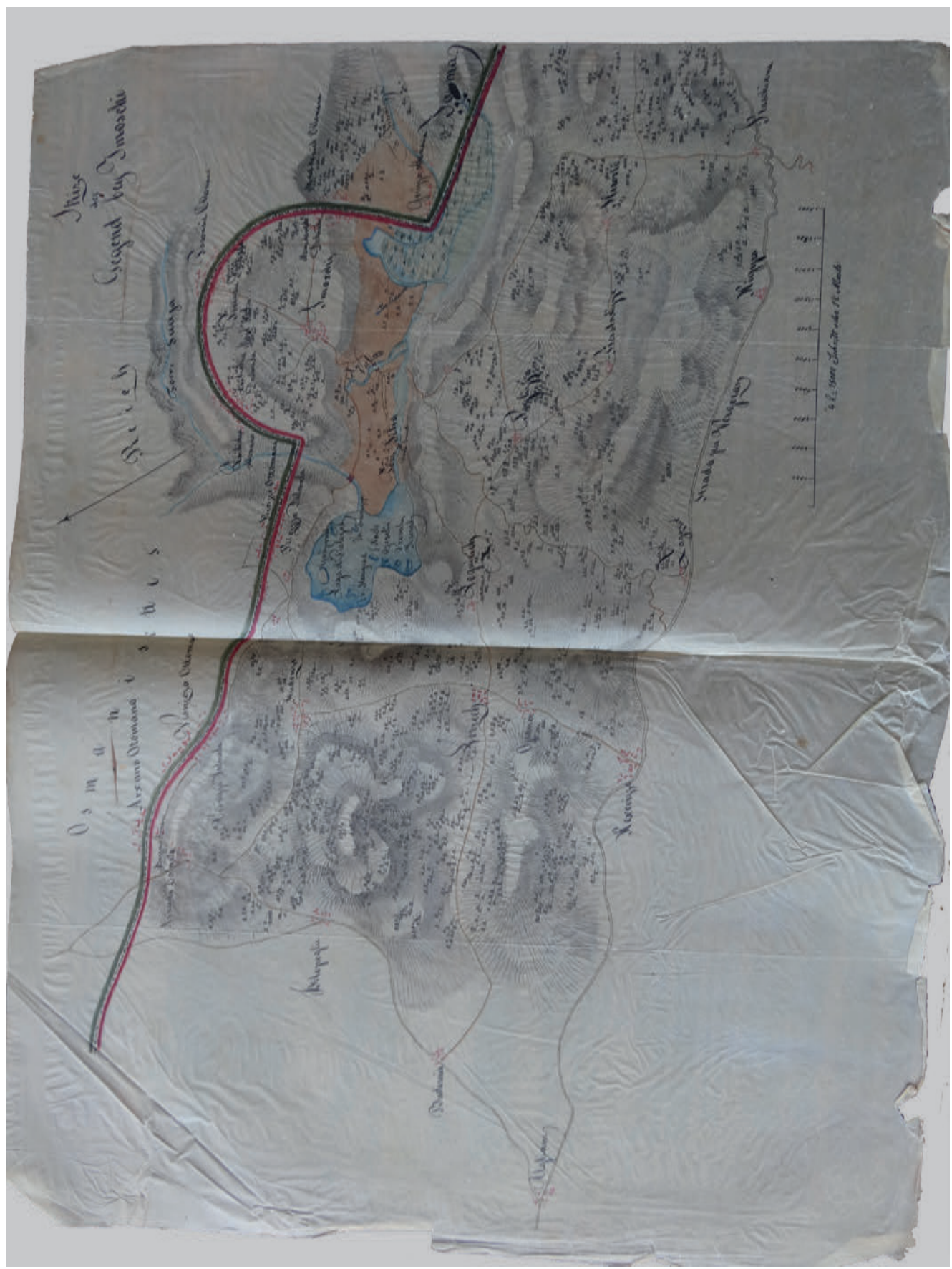

Karte 2: Skizze der Gegend bei Imoschi (wie Originalanlage VIII)

DigiOst 1 | 294 


\section{Kartenabbildungen}

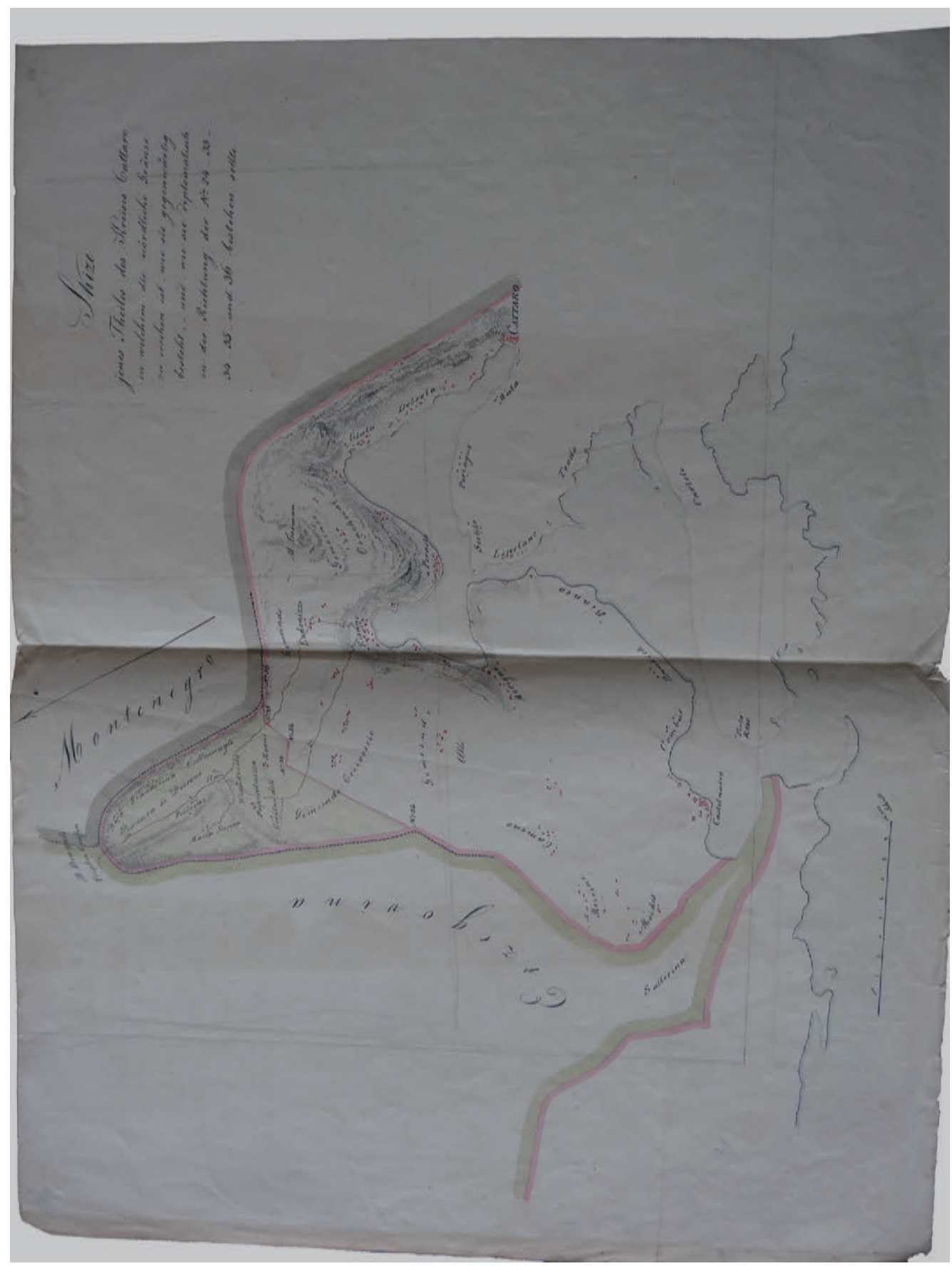

Karte 3: Skizze des Nordteils des Kreises Cattaro mit bestehendem und österreichischerseits angestrebtem Grenzverlauf (wie Originalanlage IX)

DigiOst 1 | 295 


\section{Kartenabbildungen}

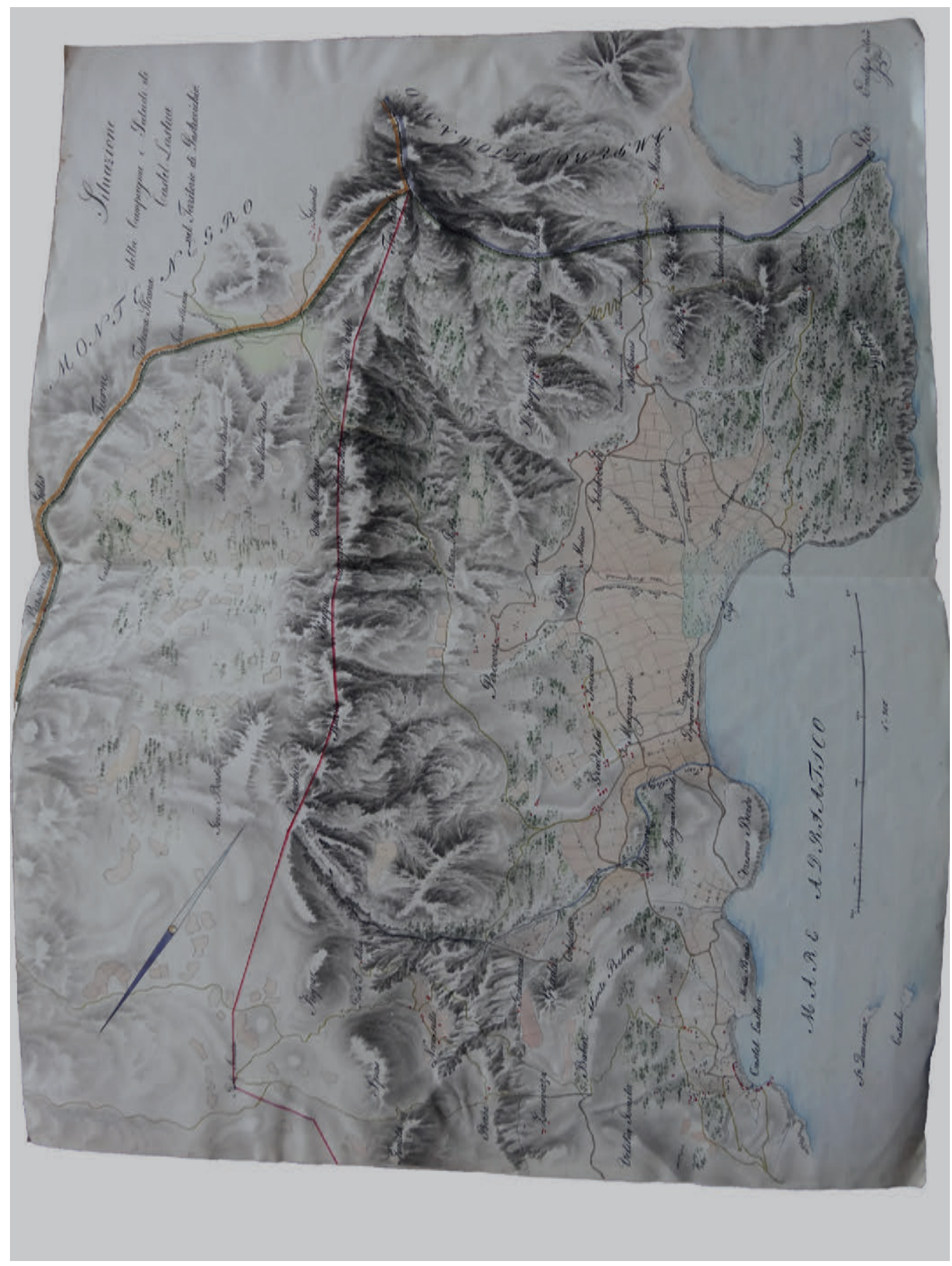

Karte 4: Karte des zum Teil umstrittenen Gebiets von Castel Lastua im Bereich von Pastrovichio (wie Originalanlage $\mathrm{X}$ )

DigiOst 1 | 296 


\section{Kartenabbildungen}

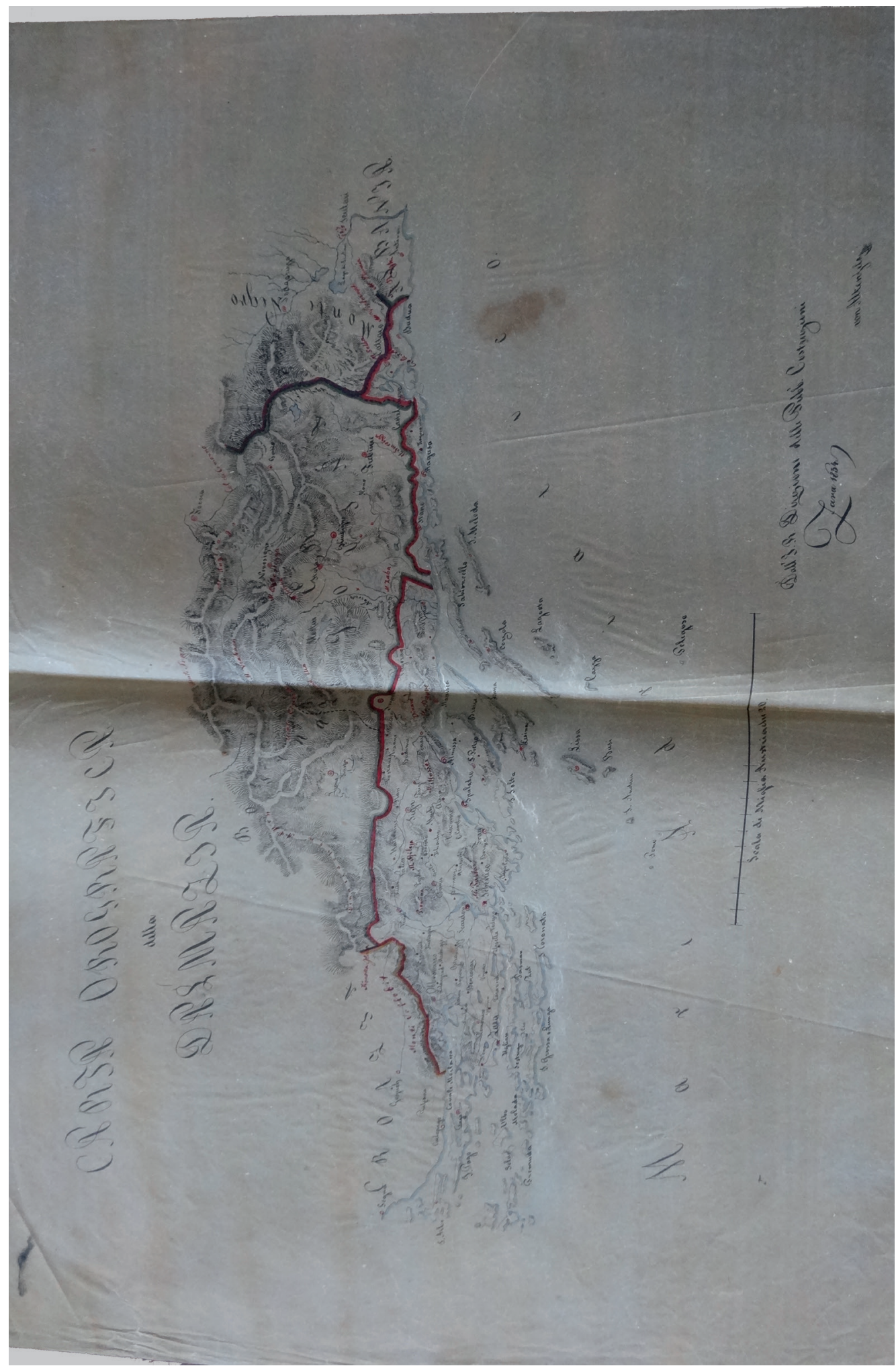

Karte 5: Reliefkarte Dalmatiens, der Herzegowina, Montenegros und von Teilen Bosniens und Albaniens (wie Originalanlage XI) 


\section{Kartenabbildungen}

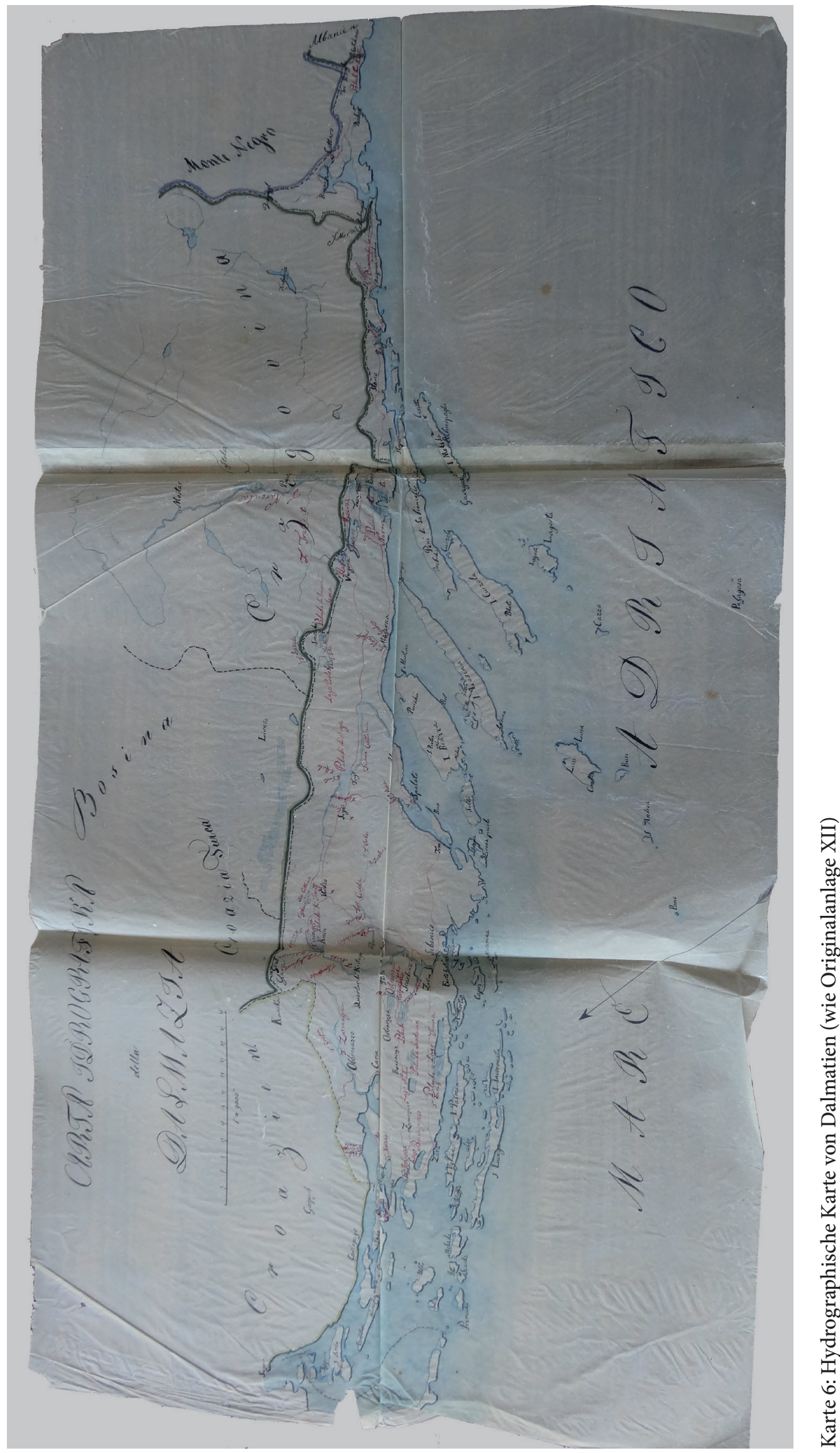

\begin{tabular}{l|l} 
DigiOst 1 & 298
\end{tabular} 


\section{Kartenabbildungen}

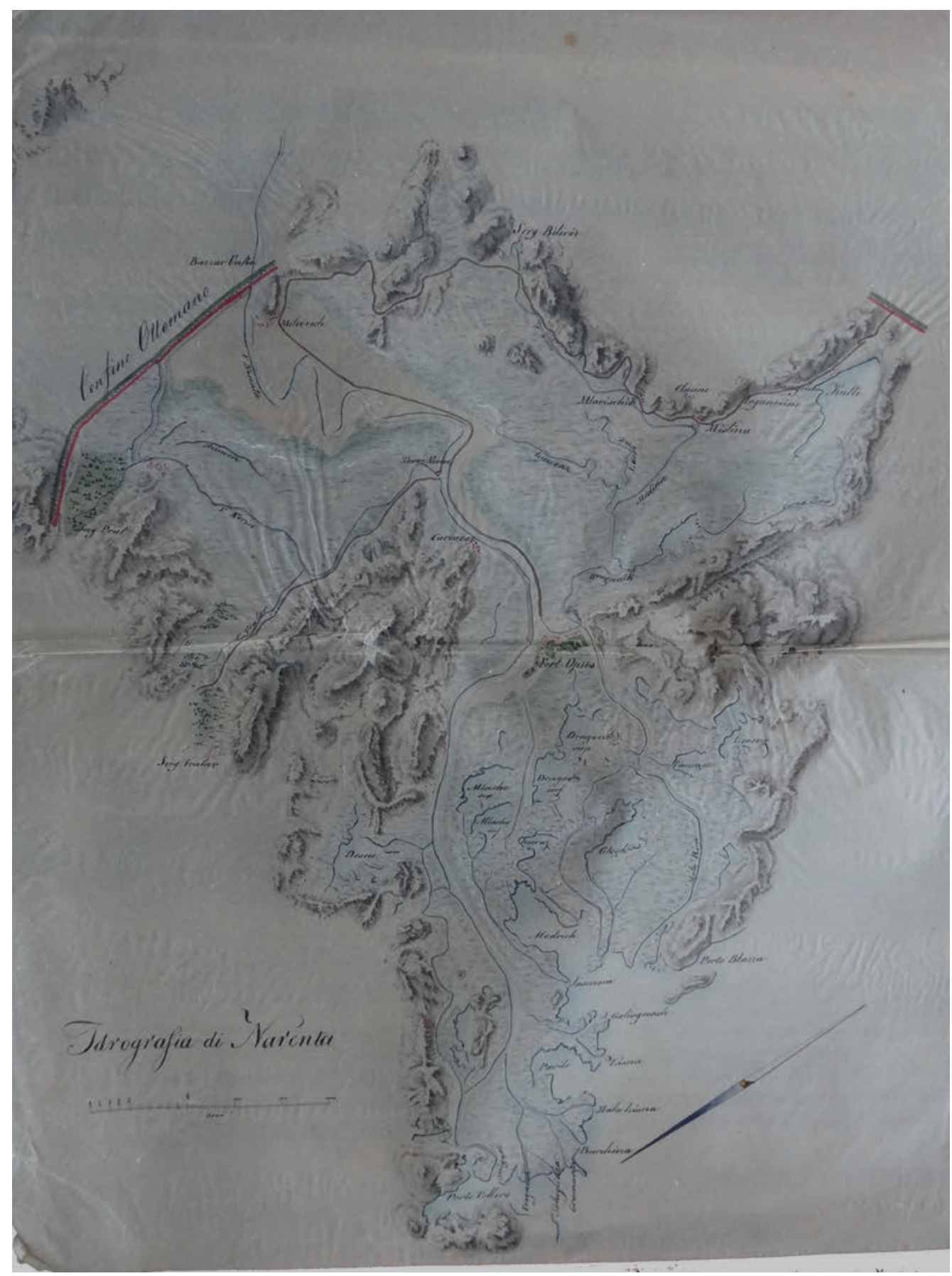

Karte 7: Hydrographische Verhältnisse im Mündungsdelta der Narenta (wie Originalanlage XIII)

\begin{tabular}{l|l} 
DigiOst 1 & 299
\end{tabular}

Konrad Clewing - 978-3-86688-501-1 


\section{Kartenabbildungen}

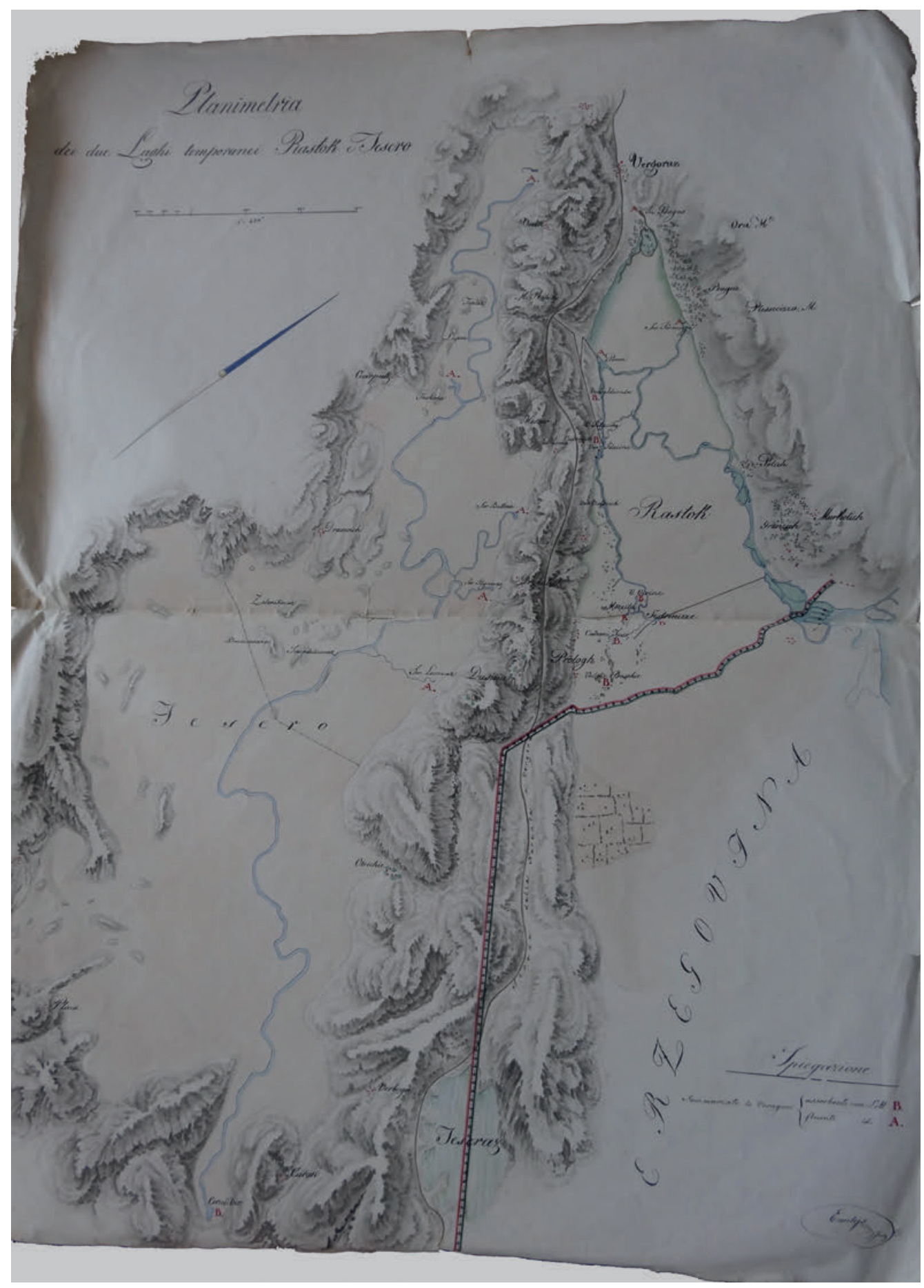

Karte 8: Die zwei jahreszeitlichen Seen Rastok und Jesero (wie Originalanlage XIV)

DigiOst 1 | 300 


\section{Kartenabbildungen}

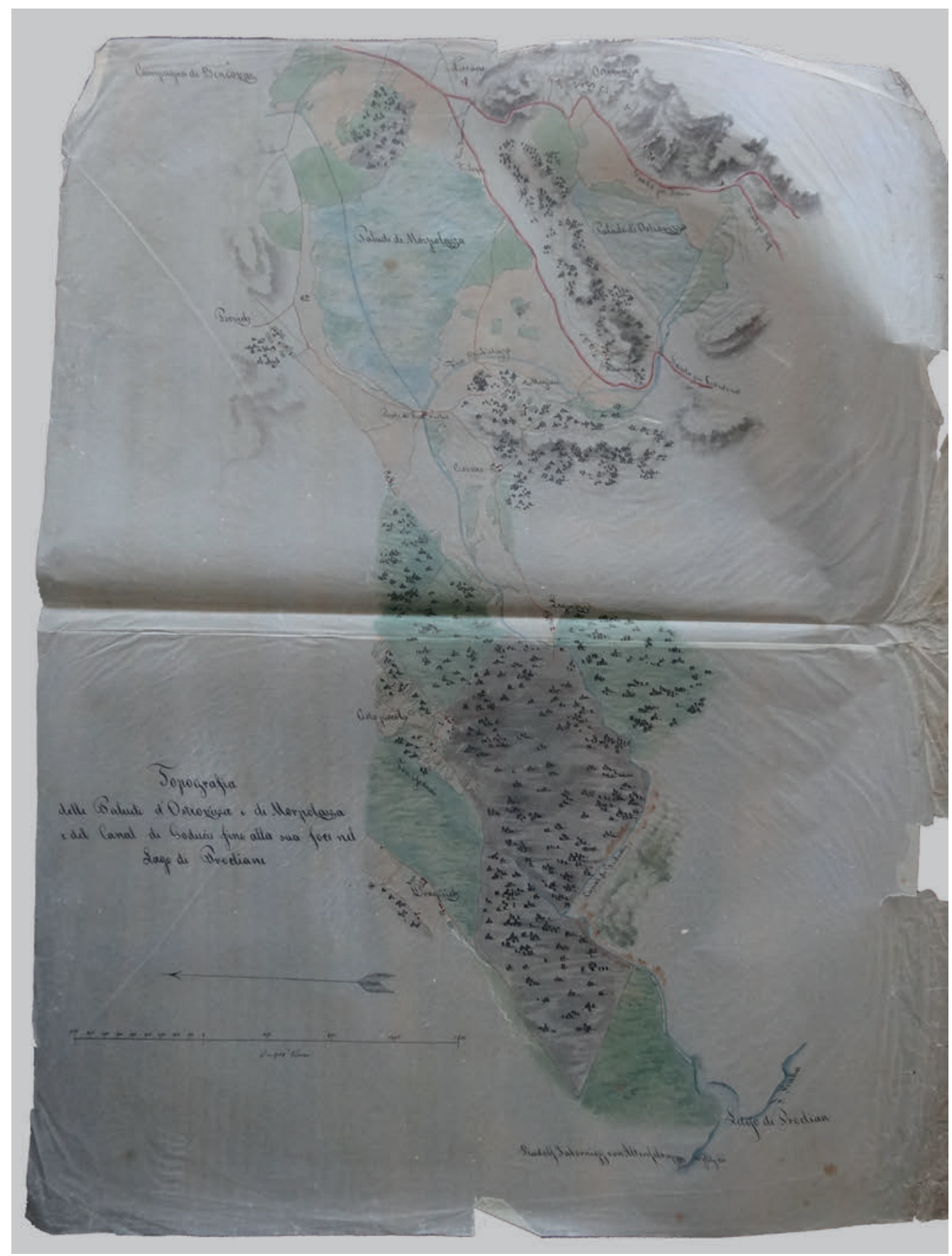

Karte 9: Reliefkarte der Moräste von Ostrovizza und Morpolazzo und des Kanals von Goducie bis zum See von Procliane (wie Originalanlage XV a) 


\section{Kartenabbildungen}

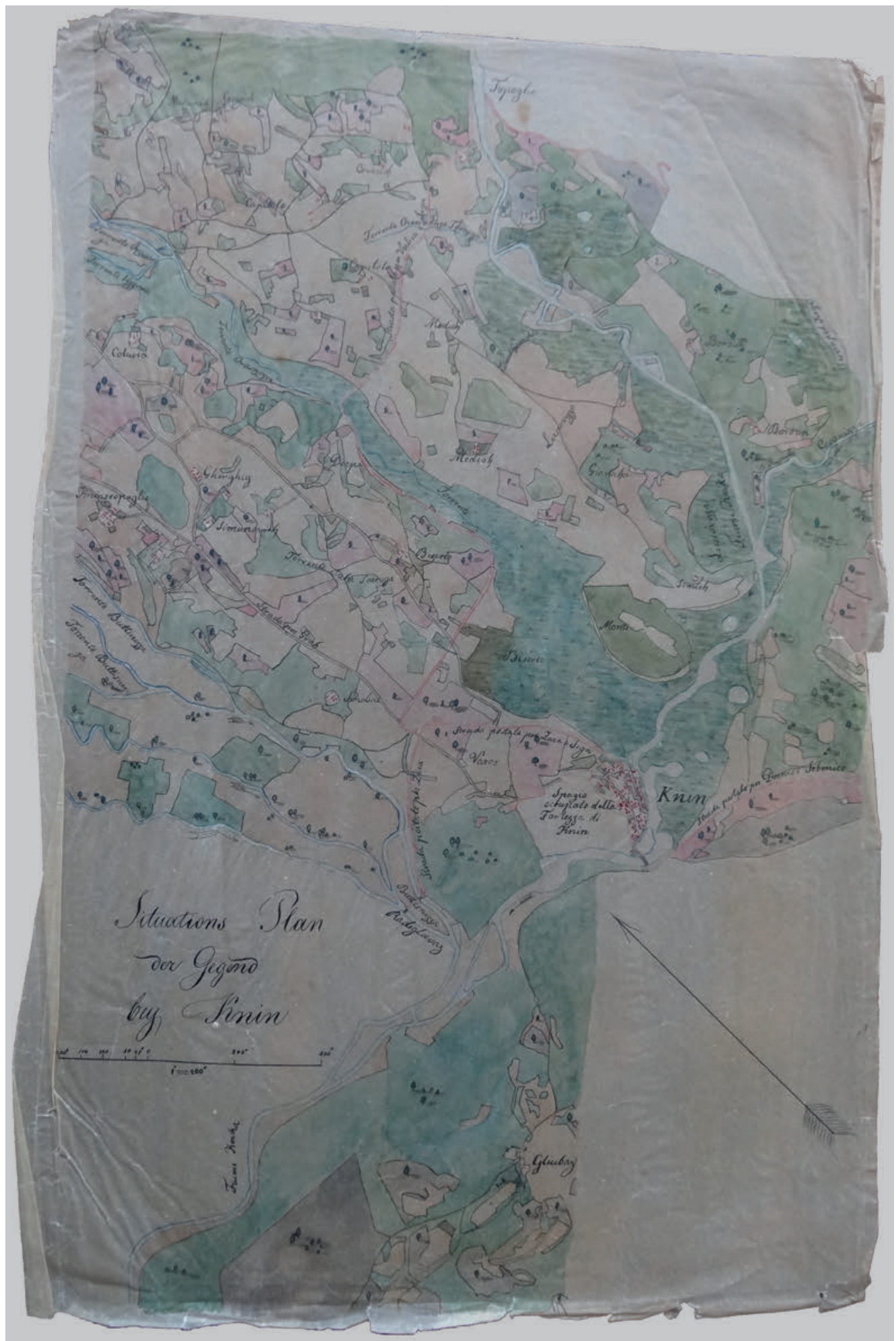

Karte 10: Situationsplan der Gegend bei Knin (wie Originalanlage XV b)

\begin{tabular}{l|l} 
DigiOst 1 & 302
\end{tabular} 


\section{Kartenabbildungen}

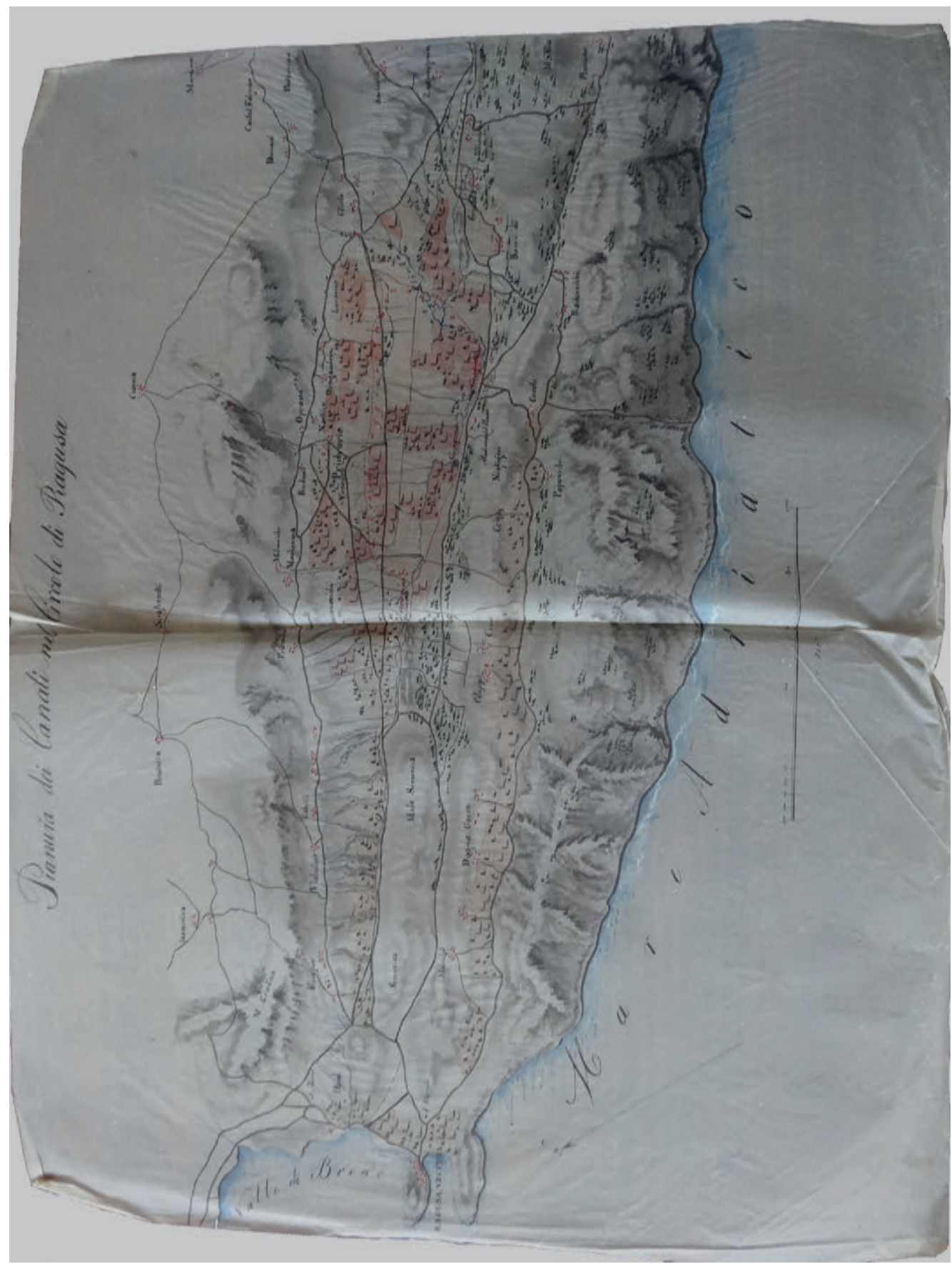

Karte 11: Reliefkarte der Canali im Kreis Ragusa (wie Originalanlage XVI)

\begin{tabular}{l|l} 
DigiOst 1 & 303
\end{tabular}

Konrad Clewing - 978-3-86688-501-1 


\section{Kartenabbildungen}

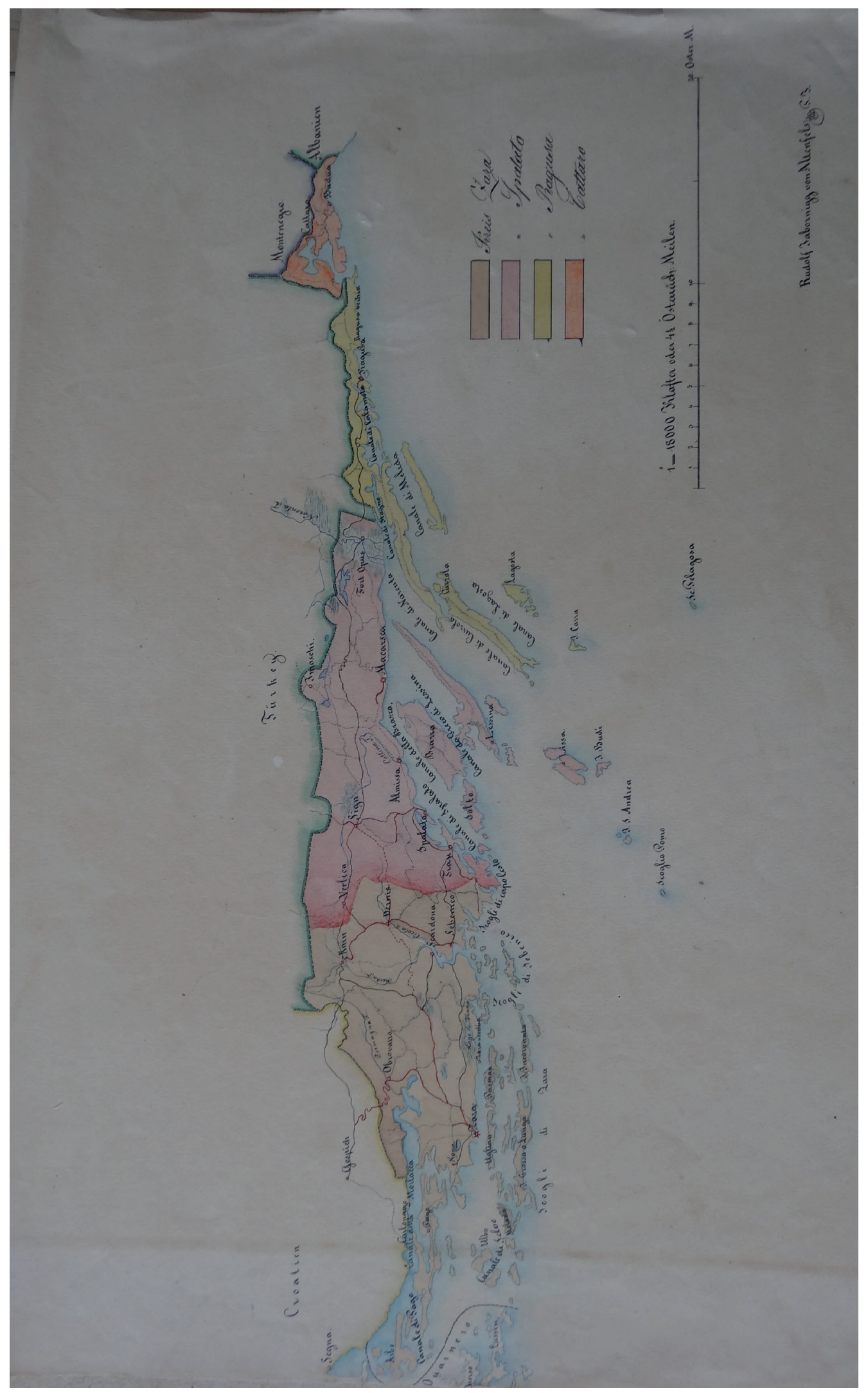

Karte 12: Kreiseinteilung von Dalmatien (wie Originalanlage XIX b)

DigiOst 1 | 304

Konrad Clewing - 978-3-86688-501-1 Downloaded from PubFactory at 01/11/2019 02:13:22AM via free access 


\section{Kartenabbildungen}

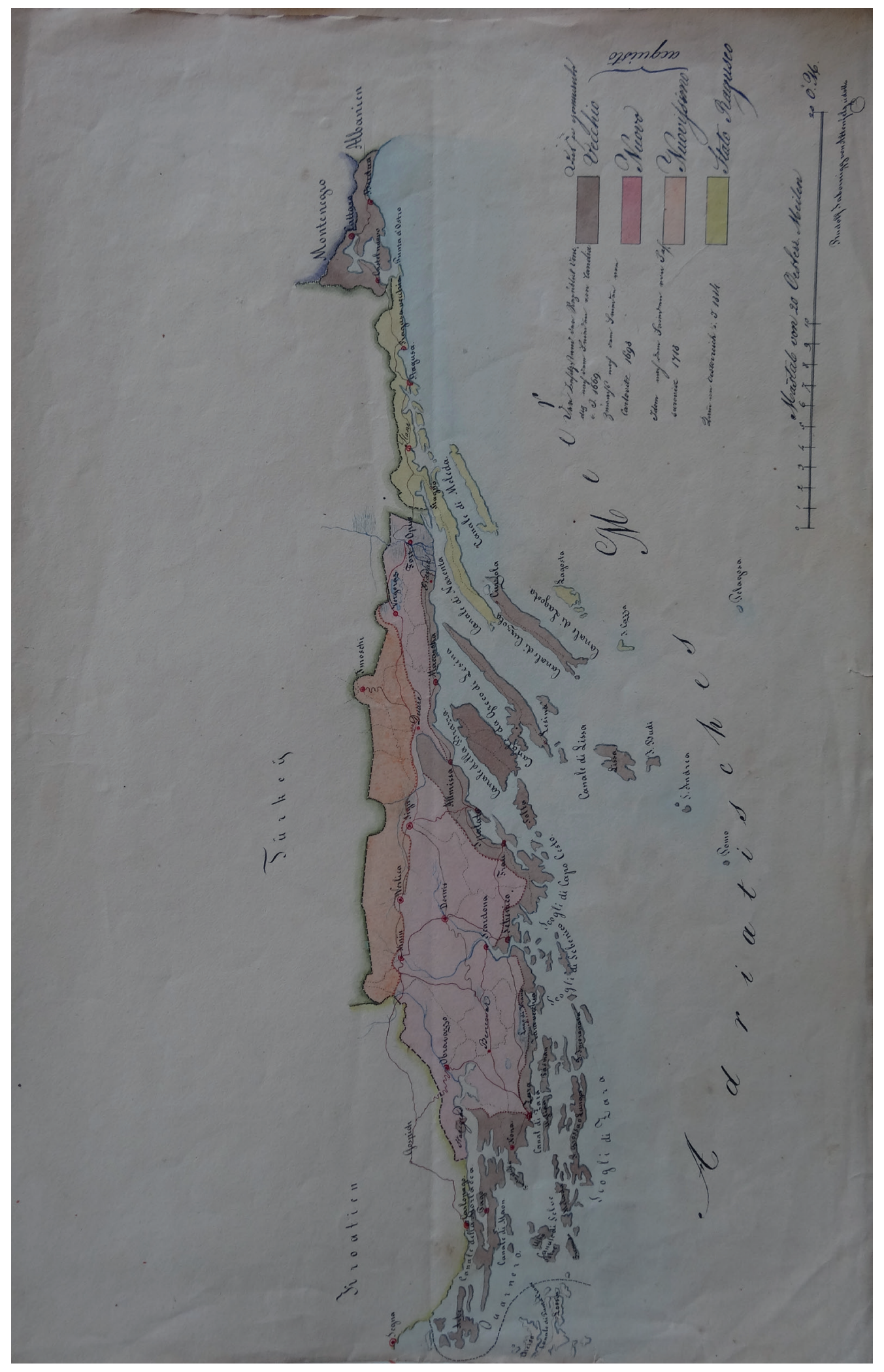

Karte 13: Übersichtskarte des vecchio, nuovo e nuovissimo Acquisto (wie Originalanlage XX)

DigiOst 1 | 305

Konrad Clewing - 978-3-86688-501-1 Downloaded from PubFactory at 01/11/2019 02:13:22AM 


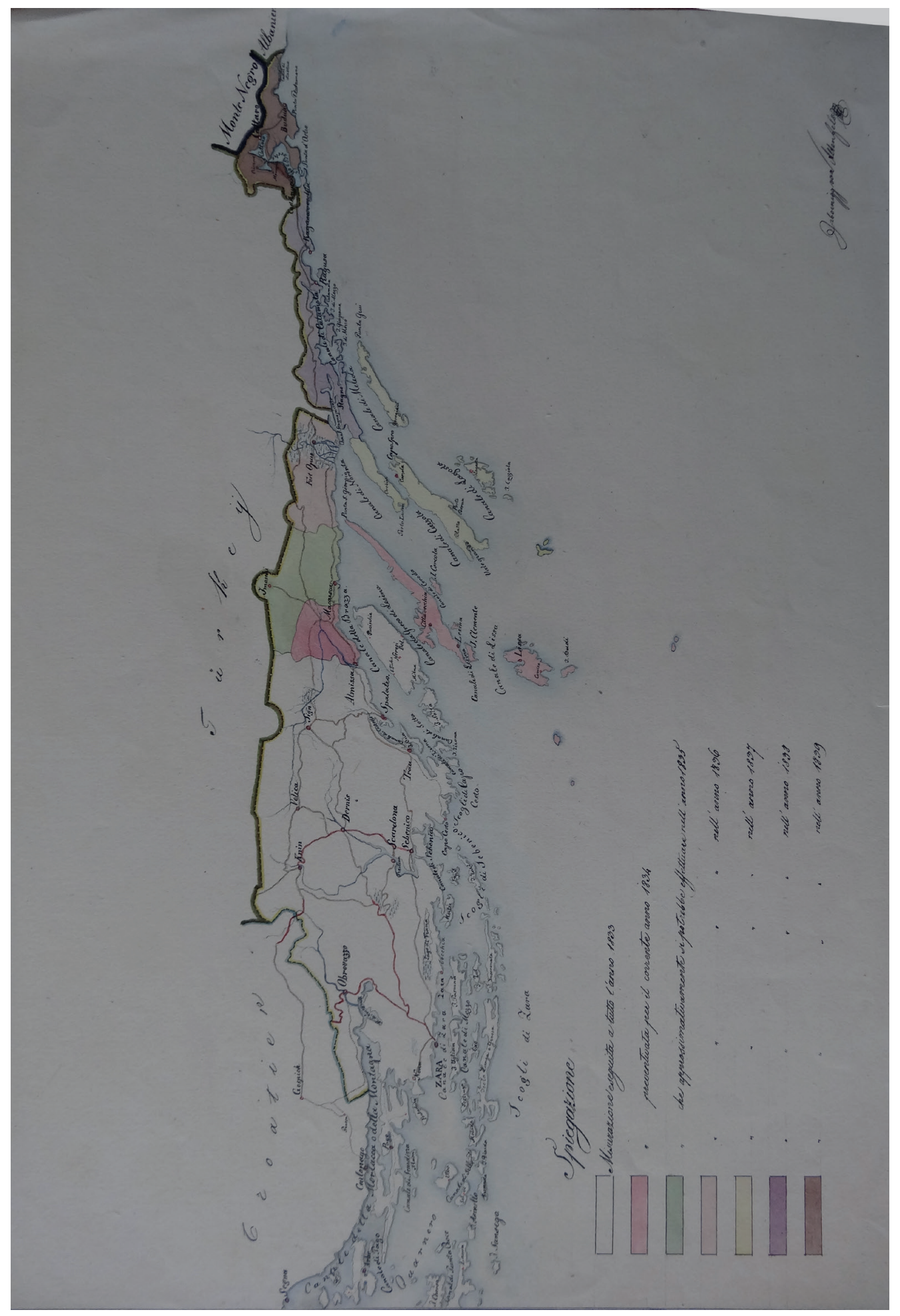

Karte 14: Katastralkarte (wie Originalanlage XXI)

DigiOst 1 | 306

Konrad Clewing - 978-3-86688-501-1 Downloaded from PubFactory at 01/11/2019 02:13:22AM via free access 


\section{Kartenabbildungen}

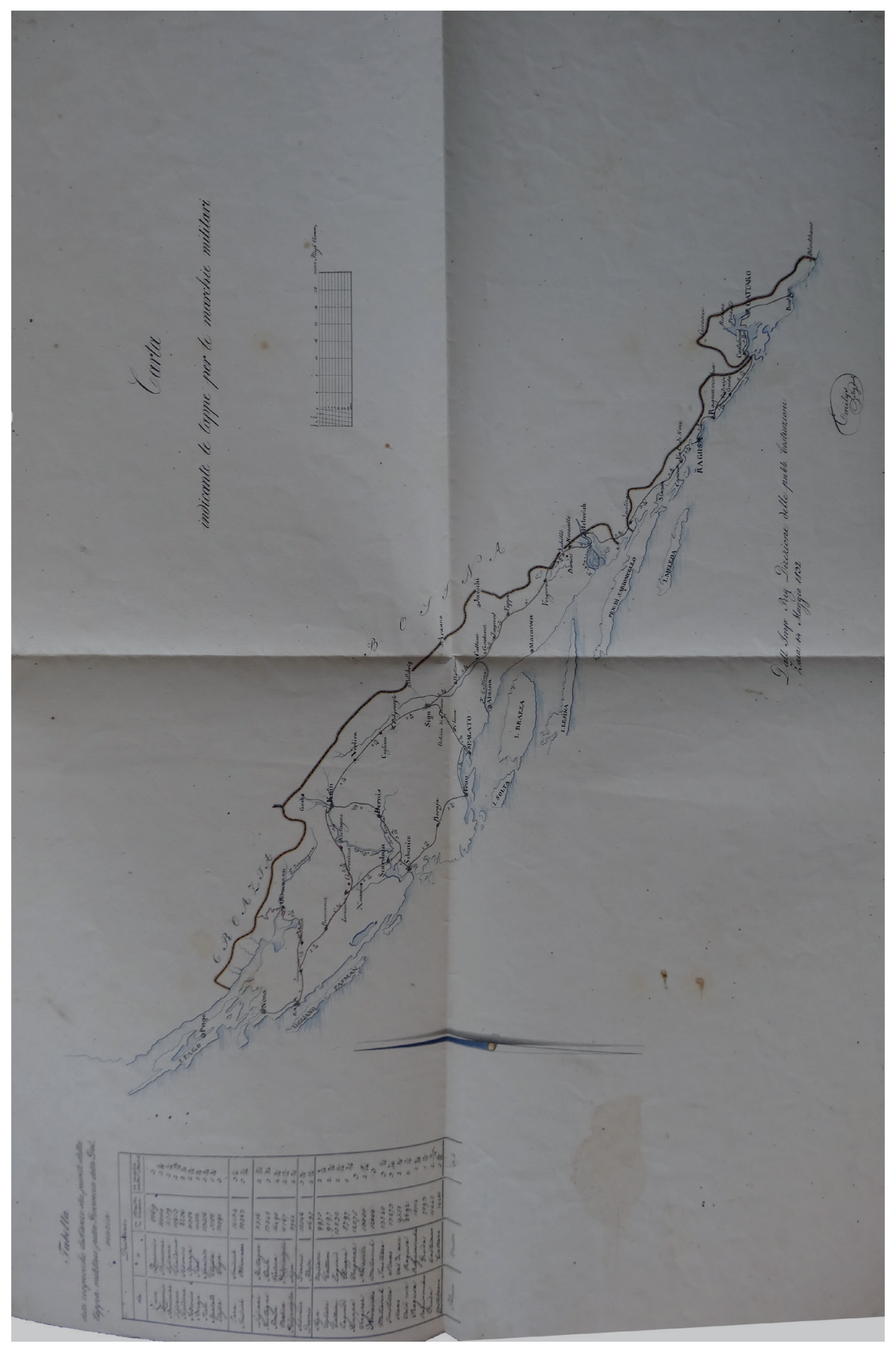

Karte 15: Militärische Marschetappen in Dalmatien (DAZd; in Reinschrift nicht vorhanden)

DigiOst 1 | 307

Konrad Clewing - 978-3-86688-501-1 Downloaded from PubFactory at 01/11/2019 02:13:22AM via free access 


\section{Kartenabbildungen}

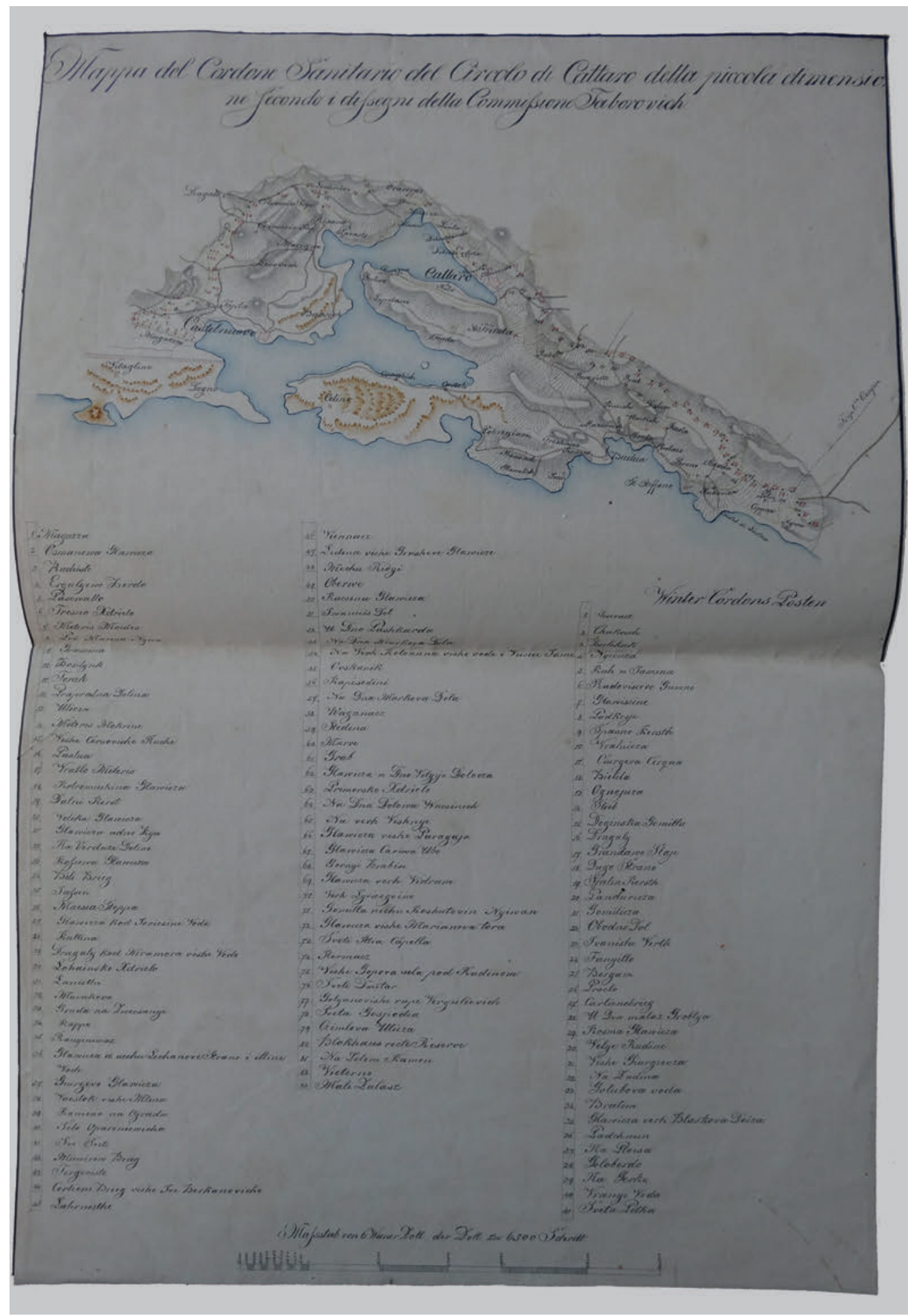

Karte 16: Reliefkarte des Kreises Cattaro und des dortigen Sanitärkordons (DAZd; in Reinschrift nicht vorhanden)

DigiOst 1 | 308 


\section{Quellenanhang 1}

Vom sehr traurigen Geschick, in Dalmatien Landeschef zu sein

oder: Nur im Zentrum kann beurteilt werden, wieviel für einzelne Provinzen der Monarchie geschehen kann. Zadar vs. Wien, 1835.

Schreiben von Gouverneur Graf Lilienberg an den k. k. wirklichen geheimen Rat, Kämmerer, Staats- und Konferenzminister Graf von Kolowrat, Zara 4.6.1835, und Antwortkonzepte des k.k. Hofsekretärs Joseph Pipitz sowie von Staats- und Konferenzminister Franz Anton Graf von Kolowrat-Liebsteinsky, letzteres mundiert und bestellt am 13.6.1835 (Haus-, Hof- und Staatsarchiv, Minister-Kolowrat-Akten, Nr. 873/1835 und ad 873/1835).

Siehe auch in der Einleitung, 27-28. - Lilienbergs Schreiben zeigt sein Amtsverständnis und auch im bürokratischen Schriftverkehr sonst selten so stark ausgedrückte persönliche Empfindungen angesichts seines engen Spielraums zur Verbesserung der Lebensverhältnisse in Dalmatien. Es wirft darüber hinaus ein Schlaglicht auf sein Verhältnis zu Kaiser Franz I. Umgekehrt werden in der von Kolowrat im Sinne des Zentralismus erheblich verschärften Antwort die Wiener zentralbürokratischen Verwaltungsprinzipien so klar wie selten herausgearbeitet. Umgekehrt wird auch der Grad der »Abstrafung « deutlich, die Lilienberg nach dem Tode von Franz I. durch die Zentralstellen für sein Verlangen nach mehr Eigenständigkeit erhalten hat. Joseph von Pipitz, der das Wiener Antwortschreiben entworfen hatte, war k.k. wirklicher Hofsekretär bei der Hofkammer (Hof- und Staatsschematismus des österreichischen Kaiserthums 1835. Teil 1 Wien 1835, 239). Warum von Pipitz in jener Funktion diese Konzeptarbeit für Konferenzminister Kolowrat vorgenommen hat, ist für mich der Zuordnung nach nicht unmittelbar nachvollziehbar. Vgl. zur Einordnung des Vorgangs in die hierarchische und konzeptionelle Neubestimmung des zentralistischen Verhältnisses der Zentralstellen zum Gubernium bzw. dem Gouverneur nach dem Tod von Kaiser Franz I. auch noch: Clewing: Staatlichkeit, 152-154.

»Hochgeborener Graf!

Ich bin untröstlich über den Inhalt der Allerhöchsten Entscheidung vom 18ten vorigen Monats Zl. 2508/712 p in Betreff der von der Landesstelle und von mir getroffenen Anstalten zur Abwendung des hier bestehenden Nothstandes; und da mir eine Rechtfertigung nicht abgefordert wurde, so darf ich mir blos die ehrfurchtsvolle Bitte erlauben;

DigiOst 1 | 309 
meine Berechnungsart bei diesem Geschäfte gütigst würdigen zu wollen, damit ich von der erhabenen Weisheit und edelsten Gesinnungen; und durch die gelegentlichste Vermittlung Eurer Excellenz die Gemüthsberuhigung, die mir dermalen mangelt und die einem Landes-Chef unentbehrlich ist, wieder erlangen könne.

Nach diesem Allerhöchsten Kabinetschreiben soll die meiner Leitung untergeordnete Landesstelle nicht mit der nöthigen Umsicht und Schonung des Staatsschatzes bei dieser Gelegenheit fürgegangen seyn, und insbesondere ist Seiner Majestät aufgefallen, daß ich keinen Anstand nahm, fortwährend so bedeutende Geldsummen ohne hohe Ermächtigung anzuweisen.

Es ist nicht zu verkennen, daß in dem verfloßenen und in dem heurigen Jahre aus Ursache der unerhörten Dürre des vorigen Jahrs die Dalmatiner theilweise in ein unermäßliches Elend gestürzt worden sind, und der öffentliche Schatz zu ihrer Rettung, da die Armuth ohnehin allgemein ist, hart angegriffen werden mußte; denn bloß das Trinkwasser für die Stadt Zara hat in dem verfloßenen Jahre 18.000 Gulden Conventionsmünze gekostet, was bei Menschengedenken nie der Fall war!

Schon aus diesem Umstande läßt sich auf die unbeschreibliche Trockenheit schließen, und es ist notorisch bekannt, daß die Oliven, der einträglichste Artikel für den Landmann, in ganz Dalmazien fehlgeschlagen haben, sowie, daß in vielen Gegenden nicht nur das Getraide gänzlich mißrathen hat, sondern auch das Gras vollkommen verdorrt, das Vieh in aller Art im Allgemeinen sehr herabgekommen, großentheils wirklich eingegangen, und der Landwirth vieler Orten bis zur Verzweiflung gebracht worden ist. Es ist ohnehin ein sehr trauriges Geschick politischer Chef in Dalmatien zu seyn; wenn aber ein wirklicher Nothstand eintritt, so ist die Verlegenheit wegen Mangel an Herschaffung und wegen Unbehülflichkeit und gänzlicher Hülflosigkeit der Comunen die Verlegenheit unbeschreiblich.

Seine Majestät der höchstselige Kaiser, wohlbekannt mit der traurigen Lage dieser Provinz, haben aus Anlaß des Nothstandes vom Jahre 1828 und 1829, unterm 30. Juli 1830 Allergnädigst zu befehlen geruhet: daß man in Fällen, wo wirklicher Nothstand eintritt, die Zeit nicht mit unnöthigen Schreibereyen verlieren, sondern dort, wo es nöthig wirt, augenblicklich Unterstützung leisten solle.

Ähnliche väterlich-wohlthätigste Allerhöchste Resolutionen vom 30ten August, und 4ten November 1830; 4ten Oktober 1831; 16ten März und 5ten May 1832 bestimmen klar und deutlich, daß alle Mittel angewendet werden sollen, damit nicht ein einziger Dalmatiner ein Opfer des Hungers werde.

In dem Präsidiale der hohen vereinigten Hofkanzley Z 1593/p vom 17ten August 1834 wird auf Allerhöchsten Befehl Seiner Majestät dem LandesPräsiddium aufgetragen: 
dort, wo die Erndte etwa ungünstig ausgefallen seyn sollte, den Bedarf hinreichend zu decken; und einem allfälligen Nothstande vorzubeugen.

Mit dem Decrete 22722/2051 vom 5ten September 1834 befahl die hohe vereinigte Hofkanzley diesem Landes-Präsidium, daß man sich rücksichtlich der zu treffenden Vorkehrungen bei diesem Nothstande nach den in früheren Jahren wiederholt gegebenen Weisungen zu benehmen habe.

Bei meiner Anwesenheit in Wien im dem verfloßenen Herbst, haben mir Seine Majestät, der höchstseelige Kaiser, mehrmals Allergnädigst zu wiederholen geruht, Ales aufzubieten, damit kein Mensch durch Hunger zu Grunde gehe, und auf meine allerunterthänigste Anzeige der dießfälligen vorläufigen Vorkehrungen, haben Allerhöchst Dieselben unterm 29ten September 1834 aus Brünn diesen Gegenstand abermals meiner besonderen Aufmerksamkeit anzubefehlen geruht.

Gleich nach meiner Rückkehr in die Provinz, langte das Hofpräsidiale der hohen vereinigten Hofkanzley 26474/2393 vom 24ten Oktober v. J. hier an, durch welches die Vorkehrungen der Landesstelle im Allgemeinen gebilligt, und einige besondere Verhaltungs-Befehle in dieser Hinsicht, zugleich aber auch die Ermächtigung dem Landes-Präsidio ausdrücklich erheilt worden ist, für das Unaufschiebbare Sub spe rati [unter Hoffnung der Genehmigung; K.C.] die nöthige Deckung zu veranlaßen.

Ich hatte demnach wirklich die Ermächtigung nöthigen Fonds anzuweisen.

Um aber diese nur wirklich für das Unaufschiebbare zu verwenden, wurden die in der That Nothleidenden durch die Capi Villa, Pfarrer und Gemeindevorsteher gewissenhaft aufgenommen und die wirklich bedrängenden Verhältnisse der Hungersnoth einer jeden Familie durch die Präturen genau erörtert, und so viel möglich berichtigt, dann durch eine besondere Commission unter dem Vorsitze des Kreisamts, und mit Beiziehung der verläßlichsten Gemeindeältesten neuerdings geprüft und beurtheilt, und überdies doppelte Domicilar-Untersuchungen [Nachprüfungen durch Hausbesuche; K.C.] durch die Kreis-Commissäre veranlaßt, diese Elaborate immer gremialiter bei der Landesstelle überprüft, und so erst das nöthige Geld mit Einverständniß dieser Landesstelle von mir angewiesen, und jedesmal allsogleich sowohl der vereinigten Hofkanzley, als auch der allgemeinen Hofkammer die Anzeige hievon erstattet; daß ich keine Antwort erhalten, ist nicht meine Schuld, wohl aber wäre es Eine die ich nicht verantworten könnte, wenn ich die Hungernden dem Todte geopfert hätte.

Auch kann man nicht scrupulöser und wirtschaftlicher zu Werke gehen, wie ich mit der Anweisung der Unterstützungsmitteln zur Abwendung des Hungertodts fürgegangen bin; es wurde per Kopf nichts mehr als eine halbe Occa Kukurutzmehl wo durchaus erwachsene Menschen waren, und für Familien, in welchen Kinder begriffen sind, 
1/3tel Occa Kukurutzmehl täglich ausgetheilt; so daß die erste Ration auf 2 4/12 Kr[euzer], und die letzte auf 2 17/12 Kreuzer dem Aerario zu stehen gekommen ist. Ich halte dafür, daß man mit weniger Speise unmöglich das Leben eines Menschen fristen kann. Ich habe dieses unterm 17ten Jänner in dem Stimmungs-Berichte in tiefster Ehrfurcht berührt, und Seine Majestät der Kaiser Ferdinand der I. haben in der Allerhöchsten Resolution vom 22ten April d.J. nichts darüber zu bemerken geruht.

Auf diese Weise habe ich, so wie die Landesstelle, keine Mühe und keine Sorge gespart, um das Land von dem schlimmen Uibel, das ihm drohte, zu bewahren, und um das Allerhöchste Aerarium zugleich nach Wissen und Gewissen nicht nur bestens zu schonen, sondern sogar Nutzen zu schaffen. Auch ward es nicht verabsäumt, die Lokalmittel immer zuerst in Anspruch zu nehmen.

Wenn man aber nur im Kreise Ragusa rücksichtlich der Subsidien das Auslangen allein in denselben finden konnte, so ist nur das Nichtzureichen der hierlands sehr beschränkten Localquellen und ihre Unverhältnißmäßigkeit zu der Größe der Noth in den andern Kreisen hieran Schuld gewesen, welche außerordentliche Mittel unerläßlich gemacht hat. -

Dadurch daß ich die Dotation für den Straßenbau für das Jahr 1835 gleich im Herbst 1834, und in dem darauf gefolgten Winter gleich durch Arbeiten verwenden, und unter das arme Volk kommen ließ, wodurch sie sich die höchst nöthigen Kleider auf den Winter, und andere kleine Bedürfnisse anschaffen konnten, und der kleine Handel und Wandel rege erhalten worden ist, habe ich gleichsam das Unglück des Mißjahrs wohlthatig verdrängt; durch die kleinern Comunal-Arbeiten und dort, wo dieses durchaus nicht möglich war, durch die Verabreichung der kargen Lebensmittel die Gegenwart den Nothleidenden erträglich gemacht, und mit wenigen Gulden Hunderten und Hunderten das Leben gerettet; mit den Vorschüßen an Saatkörnern hingegen, welche ohnehin alle, oder wenigstens mit sehr unbedeutenden Ausnahmen, zurückersetzt werden müßen, für die Zukunft gesorgt; und diese hat sich umsomehr gelohnt, als die Früchte alle sehr schön stehen, und nebst dem Ersatze des Vorgeschossenen, der Zehend, der reichlich eingehen wird, ohne die Vorschüße aber ganz ausgeblieben und der Landbau auf Jahre zu Grunde gerichtet worden wäre, wird allein das bezahlen, was vorgeschoßen worden ist.

Geruhen Euere Excellenz diese meine treue Schilderung gütigst zu würdigen und mir hochgeneigtest bekannt zu geben, ob ich es wagen darf, diese meine Rechtfertigung, da ich eine ähnliche Kränkung nach meinen 45jährigen treuen Diensten nicht zu verdienen glaube, und solche nur von einem Mißverständniße herrühren kann - in tiefster Ehrfurcht Seiner Majestät zu Füßen zu legen. 
Genehmigen Euere Excellenz auch bey dieser Gelegenheit die Ausdrücke meiner unbegränznten Verehrung und ausgezeichnetsten Hochachtung, mit welcher zu geharren die Ehre habe

Eurer Excellenz

gehorsamster Diener

Lilienberg Zara am 4ten Juny 1835.«

Antwortskonzept von Joseph Pipitz (HHStA, MKA, ad 873/1835):

»Hoch und wohlgeborener Graf!

In Ihrem schätzbaren Schreiben vom 4. Juni d. J. haben Euere Excellenz von den schmerzhaften Gefühlen gesprochen, in welche Sie der Inhalt des all.h. Cabinettschreibens Seiner kk. apost.[olischen] Majestät vom 18 Mai 1835 versetzt habe, und zugleich dem Erwähnung gemacht, wie sehnlich E. E. wünschen, Ihr und des Landesguberniums Verfahren aus Anlaß des Nothstandes, womit Dalmatien jüngsthin heimgesucht wurde, vor Seiner Majestät, Unserem allergnädigsten Kaiser, so erläutern zu können, daß jeder Zweifel über die Regelmäßigkeit und Zweckmäßigkeit des hierbei beobachteten Vorganges vollständig gehoben und entfernt würde.

Da ich als meine Uiberzeugung aussprechen darf, daß S. kk. apost.[olischen] Majestät sich zu der von E. E. berührten Maßregel keineswegs durch ein Mißtrauen in Ihre vielfach bewährte Leitungs- und Verwaltungsgabe habe bestimmen lassen, und daß vielmehr die besonders jetzt nöthige Rücksicht auf möglichste Schonung der Finanzen der vorwaltende Gesichtspunkt gewesen seyn mochte, so glaube ich zu E. E. vollen Beruhigung unbedenklich eröffnen zu sollen, daß es nach meiner Meinung E. E. unbenommen sei, Seiner kk. apost.[olischen] Majestät eine umständliche Auseinandersetzung der Gründe, und vollkommene Nachweisung der Umstände vorzulegen, welche nach Ihrer Einsicht hinreichen dürften, den aus Anlaß des Nothstandes mit den öffentlichen Geldern beobachteten Vorgang in das von Ihnen gewünschte Licht zu stellen. Uibrigens darf ich zu Ihrer vollkommenen Beruhigung die Versicherung beifügen, daß bei genauer Befolgung der von Seiner Majestät in letzter zeit gegebenen allergnädigsten Befehle, dennoch der Landesstelle und E. E. für jeden Fall, wo es die wahre Noth des Landes erfordert, sogleich die erforderlichen Hülfsmittel werden zu Gebote gestellet und in rechter Zeit die abgängigen Fonds werden zur Verfügung angewiesen werden. [Schlussfloskel]«

Wortlaut der endgültigen Antwort nach den Korrekturen durch Minister Kolowrat, wobei er ab bald nach dem Beginn des zweiten Absatzes fast den ganzen Inhalt neu im 
Sinne eines expliziten Entscheidungsvorrangs für die nunmehr de facto »kaiserlosen« Zentralstellen formulierte (ebd.):

»Hoch und wohlgeborener Graf!

In Ihrem schätzbaren Schreiben vom 4. Juni d. J. haben Euere Excellenz von den schmerzhaften Gefühlen gesprochen, in welche Sie der Inhalt des all.h. Cabinettschreibens Seiner Majestät vom 18 Mai 1835 versetzt habe, und zugleich dem Erwähnung gemacht, wie sehnlich E. E. wünschen, Ihr und des Landesguberniums Verfahren aus Anlaß des Nothstandes, womit Dalmatien jüngsthin heimgesucht wurde, vor Unserem allergnädigsten Kaiser, so erläutern zu können, daß jeder Zweifel über die Regelmäßigkeit und Zweckmäßigkeit des hierbei beobachteten Vorganges vollständig gehoben und entfernt würde. Ich bin der Uiberzeugung, daß S. Majestät sich zu der von E. E. berührten Bemerkung keineswegs durch ein Mißtrauen in Ihre bewährte Leitungs- und Verwaltungsgabe habe bestimmen lassen, sondern daß vielmehr hierbei die besonders jetzt unumgänglich nöthige Rücksicht auf möglichste Schonung der Finanzen und auch die Befolgung der diesfalls vorgeschriebenen Formen der vorwaltende Gesichtspunkt gewesen ist. Uibrigens bleibt es E. E., wenn Sie es dennoch nöthig finden sollten, gewiß ungenommen, Sr. Majestät die Gründe und Umstände näher zu entwickeln, welche Sie in Ihrer diesfälligen Handlungsweise leiteten.

E. E. können überzeugt seyn daß der Provinz Dalmatien jede [Einfügung: mögliche] in der vorgeschriebenen Form angesuchte Unterstützung mit thunlichster Beschleunigung gewährt werden wird. Es kann jedoch nur im Centrum der Staatsverwaltung mit Verläßlichkeit beurtheilt werden, wieviel für einzelne Provinzen der Monarchie geschehen kann ohne dem Allgemeinen abträglich und somit nachtheilig und unbillig zu werden. [Schlussfloskel] « 


\title{
Quellenanhang 2
}

\author{
Relation über die Präturen Dalmaziens, ihr Personale, ihren Geschäftsbetrieb, \\ Gebrechen und deren Abhilfe \\ (Erzherzog Franz Karl [?], 1844)
}

HHStA, KFA Kt. 210 (alt 226), Nr. 3 (fol. 36r bis 49r), auszugsweise Abschrift aus einem längeren Dokument. Vergleiche zur Einordnung des Schriftstücks und zu seiner Zuordnung zu Erzherzog Franz Karl in der Einleitung, 38-40.

»Die ersten Instanzen /: Präturen:/, sind mit Ausnahme der vier königl. Städte Zara, Spalato, Ragusa und Cattaro durchaus sogenannte gemischte Behörden, und verwalten die Rechtssachen, die politischen und Polizeiangelegenheiten, und sind dermal noch so wie die Stadtpräturen auch die finanziellen Untersuchungs- und Urtheilsbehörden. Zwei und zwanzig Landpräturen hat das Land.

Es sind im Kreise Zara 7, Spalato 9, Ragusa 4, Cattaro 2 \} 22

mit den Stadtpräturen 4

zusammen 26.

Sie erfüllen ihre großen auferlegten Pflichten nach den waltenden Verhältnissen noch zum Verwundern gut.

Ich berufe mich hierbei auf die in mein Reisejournal über jede der Präturen und das Personale aufgenommenen Bemerkungen.

[fol. 36v] Ungeeignet verwaltet erscheinen die Präturen der Städte und Bezirke von Zara und Cattaro.

Die Prätoren Costacchi und Wickerhauser sind zu diesem beschwerlichen Amte nach ihren Eigenschaften und nach ihrem vorgerückten Alter nicht geeignet, und ihre Pensionirung wäre von allen Umständen gebothen. Sie erfüllen oberflächlich ihre Pflichten, haben keine entsprechende Intelligenz und Bildung, noch minder aber Eifer und Thätigkeit, indem sie nicht einmal die einzelnen Gemeinden und Orte ihres Distriktes besuchen und kennen.

Wahr ist aber auch, daß ihre schwierigen Distrikte zu ausgedehnt, und voll ernster Aufgaben sind, eben darum aber auch Männer von Einsicht, Thätigkeit und Energie fordern, und nicht bloß Leute, welche beßer versorgt seyn wollen.

Ebenso ungeeignet erscheint die Landprätur Obbrovazzo durch den Prätor Urschitz verwaltet, wie in jenem Journale nach [fol. 37r] Person und Sache schon angedeutet worden ist. Obbrovazzo ist eine der schwierigsten Präturen wegen der großen Rohheit der Be-

DigiOst 1 | 315 
völkerung und der großen Zahl Vergehen und Verbrechen, wo also der Prätor in allen zu Gebothe stehenden Wegen durch Aufmerksamkeit, Einsicht und große energische Thätigkeit wirken sollte. Urschitz sollte zu einem Tribunale in angemessener untergeordneter Stellung bestimmt werden, wo er entsprechen würde, weil er sonst ein ruhiger fleißiger Mann ist.

Lissa ist ein kleiner, aber wichtiger Distrikt, und daselbst war bisher Zamboni d.b.R. Prätor. Das was ich über ihn erhob, und was mein Tagebuch darstellt, ist nur zu wahr. Er hat Ermahnungen erhalten, und wurde eben erst nach der Insel Pago übersetzt. Daselbst, fürchte ich, werden sich nach einiger Zeit seines Dortseyns dieselben Unzukömmlichkeiten herausstellen, wie sie in Lissa [fol. 37v] hervortraten, und der wird, wenn nicht pensionirt, doch wenigstens in ein Kanzleiamt bestimmt werden müssen.

Die Amtslokalitäten und die Arreste sind in dem Reisejournal genau bezeichnet worden, und ihre Erfordernisse sind dort zu ersehen.

Die Arreste von Obbrovazzo, von Imoschi, von Slano, von Curzola, von Lissa fordern schleunige Abhilfe, nicht minder die von Ragusa vecchia. Unter den Amtslokalitäten ist Imoschi so übel daran, daß Reinlichkeit und Gesundheit dabei sogar in der Frage steht. Es sind wohl wegen allem Erhebungen angeordnet, aber eigentliche Verhandlung ist nur wegen Obbrovazzo im Zuge.

Die unsicheren und ungesunden Arreste der politischen Prätur von Zara und Cattaro sind ebenfalls bereits zur Abstellung vorgeschlagen, und die Entscheidungen sind bei den Hofstellen behangend.

[fol. 38r] Der Geschäftsgang bei den Präturen ist zu formenreich, dafür langsam, und die fleißigsten und geschicktesten Beamten können nicht vollkommen entsprechen. Das Übel liegt weniger in den Individuen, als in der Sache. Es ist wahr, daß größtentheils jüngere, kurz dienende Beamte bei diesen Ämtern vorhanden sind, allein dieselben entsprechen doch mehr, als die vorhandenen älteren Prätursbeamten.

In einem Lande, wie das Gouvernement Dalmatien, bei dieser Configuration und geringen Cultur des Landes und der Leute ist es räthlich, einfache, sichere Formen auszumitteln.

Der Bauer Dalmatiens ist arm, seine Fragen um Mein und Dein sind einfach, weil es sich dabei um geringe Beträge oder Sachen handelt, er war von jeher gewohnt, in kurzer mündlicher Klage vor dem Richter Gehör und Entscheidung zu finden, nun muß er immer [fol. 38v] Prozesse führen, die ihm Stämpel [Gebühren; K.C.] und Gerichtsauslagen meistens im größeren Betrage kosten, als ihm die nach länger[er] Zeit zugesprochenen und exequirte Forderung herbeibringt, welche in Executionsfällen fast in der Regel unter den beklagten Summen steht. Das sittliche Gefühl kann dabei nicht gewin-

DigiOst 1 | 316 
nen. Auch die französische Gerichtsform war für ihn darum leichter, weil beim Friedensrichter kurz bis auf eine gewiße Summe inappellabel entschieden werden konnte. Die angeordneten Vergleichsverhandlungen bei den Präturen finden in dem größten Drange der Geschäfte nicht hinlänglichen Fortgang.

Man glaubte zu helfen und hat theilweise geholfen, indem man den Colonelli und Serdari della forza territoriale das Recht gab, über Summen bis 10 Gulden definitiv zu entscheiden.

Der Colonello und Serdaro ist aber gewöhnlich im Sitze der Prätur, und dadurch wird einerseits [fol. 39r] diese Verfügung beeinträchtigt und vereitelt, andererseits würdigt sie das Ansehn des Prätors herab, da derselbe solches Entscheidungsrecht in seinem Amte nicht hat.

Die Vizeserdare, welche in den entferntesten Gegenden mitten unter den Landleuten existiren, haben dasselbe ebenfalls nicht, obwohl sie dadurch sehr nützlich werden können, und die Partheien müßen also zu den entferntern Serdarn wandern, oder sich dem ordentlichen langen Prozeße bei den Präturen unterziehen, wodurch also gezeigt wird, daß die erwünschte schnelle Hilfe sehr erschwert ist.

Die Civilangelegenheiten muß nun meistens der Prätor selbst behandeln, weil der Landmann gewöhnlich in denselben das meiste Vertrauen hegt, und sich nur seiner Verhandlung unterwerfen will, und weil die Prätursbeamten größtentheils mit schweren Polizei-Übertretungen und Kriminalangelegenheiten auch auswärts beschäftigt [fol. 39v] sind, die ihnen auch etwas eintragen, somit der Prätor auf die Civil- und politischen Verwaltungsangelegenheiten größtentheils den nächsten unmittelbaren Einfluß nehmen muß. Auch gehört zu den Übeln, daß die Bezirksbehörden zu gering in der Zahl sind. Es entscheidet nicht immer hierüber der Stand der Bevölkerung, sondern die Distanzen, in einem wenig populirten Lande, und die erschwerten, oft zeitweise unmöglichen Communikationen. Es gibt aber auch mit Blick auf Bevölkerung zu sehr betheilte Präturen, wie Zara, Knin, Sign, Spalato, Cattaro.

Eine Bezirksbehörde kann in bedeutenden, und durch Terrain und Kommunikationsverhältnisse - durch längere unsichre Seereisen, die oft auch nicht möglich sind, bestehenden Entfernungen nichts Sicheres leisten, und am wenigsten schnell in politischer und krimineller Beziehung handeln, um so minder aber in [fol. 40r] einem Lande, wo der beschränkte Einwohner unbedingtes Vertrauen in die Obrigkeit hat, und von ihr Alles zu seinem Benehmen zu erlangen wünscht, und bedarf, und wo es noch keine Gemeindeverwaltungen im besseren Sinne gibt, welche einzuwirken vermögen.

In strafrechtlicher Hinsicht dürfte das Verfahren ebenfalls für den Einzelnen, und das Ganze eine Erwägung verdienen, und dabei die höchst bedeutenden Criminalauslagen, 
welch von Jahr zu Jahr wachsen, wie der anliegende aus der Fondsverwaltung hierorts entworfene Ausweis darstellt.

Es wird ersichtlich, daß 1819 nach den hierortigen Abschlüßen 421 Inquisiten [Untersuchungshäftlinge; K.C.] und Sträflinge waren, und daß die Auslagen 48189 Gulden betrugen.

Dagegen gab das Jahr 1843 - 695 Inquisiten und Sträflinge mit einer Auslage von 150300 Gulden. Für 1844 wurden 757 Inquisiten und Sträflinge in Anschlag gebracht, und eine Auslage praeliminirt [fol. 40v] mit 100665 Gulden, die aber nicht hinreichen wird.

Der obigen Beilage 17 gemäß, die ich zu Zara vom Gubernium erhielt, waren 1842 - 749 Inquisiten und 431 Verurtheilte, von welchen 210 in das Strafhaus kamen.

Schwere Polizeiübertretungen wurden im Ganzen 4786 denunzirt. Es waren mit Einschluß der Übertreter der Finanzgesetze 4299 Inquisiten und 2225 Verurtheilte. Laut der Vergleichstabelle - obige Beilage 19 - waren seit 1816 im Durchschnitte bis 1842 - 937 Crim.[inal-]Inquisiten - dagegen 1842 - 749 Crim.[inal-]Inquisiten und 4299 Übertretungen.

Den erlangten Detailtabellen gemäß ergibt sich laut Beilage 27, daß bei den Tribunalen zu Zara und Spalato von 1821 bis 1830 und zwar bei dem ersteren 8568, bei dem letzteren 5262 Verbrechen vorkamen.

Unter dieselben waren die zahlreichsten bei Zara: 1206, bei Spalato [fol. 41r]: 702 öffentliche Gewaltthätigkeiten - Morde und Todtschläge, bei Zara: 539 bei Spalato: 678 - Verwundungen und körperliche Verletzungen bei Zara: 1267, bei Spalato: 117 - Brandlegungen bei Zara: 2267, bei Spalato: 459 - Diebstähle, und Veruntreuungen bei Zara: 2200, bei Spalato: 1381 - Raub, bei Zara: 587, bei Spalato: 175.

Laut Beilage 28 waren mit Sanitätsübertretungen vom Jahre 1831 bis inclusive 1840 bei dem Tribunale zu Zara 8638, zu Spalato 4771, zu Ragusa 1429, zu Cattaro 1382, zusammen 16220 im Durchschnitte jährlich 1622 Verbrechen, und immer beim Kreise Zara die meisten vorgekommen.

Die öffentlichen Gewaltthätigkeiten mit 2533 und darunter Zara mit 1557, Morde und Todtschläge mit 966, Verwundungen und körperliche Verletzungen mit 1998.

Brandlegungen 2937, von welchen auf den Zarer Kreis allein 2459, auf [fol. 41v] Spalato 368 fallen.

Diebstähle und Veruntreuungen mit 5298, davon Zara 2563 und Spalato 1692.

Raub mit 679, davon Zara 312, Spalato: 247.

Die Tabelle 29 zeigt pro 1841 und 1842 in der ganzen Provinz: 3774 Verbrechen und Sanitätsübertretungen.

Speziell: 
Öffentliche Gewaltthätigkeiten 802

Morde und Todtschläge: 189

Verwundungen und körperliche Verletzungen 533

Brandlegungen 516

Diebstähle und Veruntreuungen 1263

Raubfälle 90

Werden die letzten fünf Jahre rücksichtlich dieser sechs Gattungen Verbrechen verglichen, so ergibt sich folgendes Resultat:

$\begin{array}{lrrrrr} & 1838 & 1839 & 1840 & 1841 & 1842 \\ \text { Öffentliche Gewaltthätigkeiten } & 236 & 229 & 324 & 420 & 382 \\ \text { Morde und Todtschläge } & 79 & 99 & 91 & 97 & 92 \\ \text { Verwundungen u. körp. Verletzungen } & 159 & 186 & 265 & 298 & 235 \\ \text { Brandlegungen } & 240 & 252 & 354 & 252 & 264 \\ \text { Diebstähle und Veruntreuungen } & 464 & 442 & 660 & 660 & 603 \\ \text { Raubfälle } & 51 & 59 & 71 & 52 & 48\end{array}$

[fol. 42r] Hiernach ergab sich im Ganzen keine wesentliche Beßerung in diesen Klaßen von Verbrechen. Nimmt man die Gesammtzahl der 10 Jahre bis 1840, so entfallen im Durchschnitte 1622 Verbrechen auf 1 Jahr.

1841 waren dagegen 1969

1842 waren dagegen 1805

In diesem letzten Jahr also minder gegen 1841 um 164 - dagegen aber durchaus um 2 bis 300 mehr als in dem vorausgegangenen Dezennium.

Nun ist zwar die Bevölkerung gewachsen, eine größere Demoralisirung des Volkes scheint nicht eingetreten, auch gab es keine außerordentlichen Zwischenfälle, welche eine größere Zahl Verbrechen hätten hervorrufen können; Im Ganzen, wenn auch eine geringe - ist aber doch eine Beßerung des Zustandes bemerkbar.

Woher also die ungünstige Erscheinung? Eine schwere Aufgabe.

Das Gesetz in der trefflichsten Absicht [fol. 42v] fordert auch bei den unbedeutendsten Fällen eine weitläufige zeitraubende, kostspielige Untersuchung. Die ersten Instanzen werden dadurch mit Geschäften überladen, die Arreste gefüllt, die Auslagen vermehrt, und manchen Unordnungen Raum gegeben, da die Zeugenverhöre, die Augenscheine und Reisen der Beamten zum Theile erforderlich, zum Theile, da sie eintragen, absichtlich vermehrt werden, worüber die Kontrolle schwer ist, und für jeden Fall stets zu spät kommt, um einzugreifen und zu verhüten.

Die Kriminalgerichtsbarkeit ist nach Versicherung der Mehrheit, und der häufigen Klagen gemäß, zu komplizirt und zu zweitraubend, und bedarf einer Änderung zum Bes- 
ten der guten Ordnung, zum Vortheile des Ganzen also ebenso des Einzelnen, weil die schnelle Bestrafung, wenn sie auch milde ist, größeren Eindruck macht, weil sie weniger Weitläufigkeiten [fol. 43r] fordert, daher die Behörden und Beamten nicht in größerer Zahl fordert, und die Auslagen des Staats minder in Anspruch nimmt, während sie jetzt täglich steigen, ohne Vortheile zu bringen.

Der Landmann vorzüglich im Zarer Kreise ist durch eingewurzeltes Vorurtheil und Volksmeinung bei dem Mangel alles besseren religiösen und moralischen Unterrichts noch der ersten Rohheit der Völker angehörig. Rache in die folgenden Glieder der Familien hält er für Pflicht. Streit, Rauferei, Verwundung, Todtschlag, seltener vorgesetzter Mord, sind die größeren - Brandlegung, Feld- und Viehentwendung die kleineren Rachehandlungen.

Werden solche Vergehen und Verbrechen blitzschnell gestraft, so macht es Eindruck, und hat gute Folgen. Finden lange Untersuchungen statt, so wird der Thäter ein Märtirer im Auge des Volkes, und Eindruck und Beßerung [fol. 43v] ermangelt, daher die sogenannten Malviventen [Übeltäter, K.C.] in Dalmazien.

Wenn der Priesterstand gebeßert, Unterricht vermehrt, der Einfluß der ersten Instanzen schneller und direkter gesichert, und eine wohlorganisirte exekutive Polizeimacht aufgestellt wird, so läßt sich große Besserung hoffen, aber sogleich ist, und immer wird kurze einfache Untersuchung und schnelle Abstrafung die Bedingung zur Besserung bei einem lebhaften den Eindruck der Gewalt verehrenden Volke seyn.

Auch in strafrechtlicher Hinsicht bestand früher ein einfacheres schnelles Verfahren, und die allgemeine Ansicht der Einwohner wünscht sie wieder. Für größere wichtige Verbrechen[,] hält man dafür[,] sey eine so umständliche Untersuchung wohl erforderlich, aber bei Vergehen und bei Verbrechen minderer Art sey ein einfaches schnelles Abthun des Faktums für alle und vorzüglich für die öffentliche Moral eine Wohlthat. Auch werde der Gang der Dinge [fol. 44r] noch dadurch erschwert, daß eine große Zahl Beamte bei den Präturen und Tribunalen Fremde sind, welche weder die Landessitten, noch die Sprache kennen, und sich erst allmählig die Kenntniße beilegen müßen, wodurch die Untersuchung und Beurtheilung sehr erschwert wird. Es sey allerdings richtig, daß anfangs Eingeborne mit der nöthigen Bildung zur Handhabung unserer Gesetzgebung mangelten, dieses sey aber nicht mehr der Fall, und es sollten daher mehrere Eingeborne beachtet, und Wesen und Form der Prozedur, welche für jene Regulation und Verhältniße weniger paßt, vereinfacht werden.

Würde darauf gedacht, so dürften zwar mehrere Präturen, jedoch nur der letzten Klaßen [der untersten Kategorie; K.C.], dafür aber mit der Zeit weniger Tribunale, und insbesondere ein eigenes Appellationsgericht im Lande nicht erforderlich seyn. 
Bei den Tribunalen gehen die Geschäfte wegen der unendlichen Formen [fol. 44v] in Civil- und Kriminalsachen sehr langsam und ebenso bei dem Appellationsgerichte. Durch Jahre befangen die Prozesse insbesondere Kriminalangelegenheiten bei letzteren, und die von der 1ten Instanz gefällte Urtheile werden nicht erledigt, und die Inquisiten müßen in den Kerkern sitzen. So war ein Prozeß über eine große Zahl Malviventen, die ich in den Arresten sah, vom Spalater Tribunale schon vor einem Jahre klar und bestimmt der Appellation vorgelegt worden, aber noch immer nicht erledigt, und die Inquisiten nach jahrelanger Haft brachten fußfällige Bitten, an den Präses und machen bittere Beschwerden und Klagen. Es unterliegt keinem Zweifel, daß das bestehende Civil- und Kriminalgesetz für die Einwohner Dalmatiens nicht wohl geradehin anwendbar war, und daß die Anpaßung desselben mit Opfern bedeutender Art von Seite der Unterthanen, und der [fol. 45r] Regierung durch die Zeit und Praxis erworben werden soll. Wenn man die Eigenheiten der Provinz und ihrer Bewohner genau auffaßt, so dürfte es in jeder Beziehung keinem Zweifel unterliegen, daß gleich vom Anfange an diesem Lande eine weit einfachre, wohlfeilre und den Bedürfnißen der Unterthanen weit entsprechendre, aber auch ihren eigentlichen Wünschen mehr zusagende Gerichtsverwaltung hätte verliehen werden können, wobei jedoch die ungemein verschiedene Karakter der Städter und der Landbewohner immer zu beachten gewesen wäre. Der Bauer braucht nach seiner ganzen Lage ein höchst summarisches Verfahren in allen seinen Angelegenheiten. Alle Komplikationen verwirren den einfachen Landmann. Er war seit undenklichen Zeiten gewohnt, die meisten Streitfälle aller Art schiedsrichterlich entscheiden zu laßen, oder die mündliche Entscheidung des Serdars [fol. 45v] in allen Angelegenheiten anzusprechen. Eine Reihe untereinander geordneter vieler Ämter ist ihm nicht begreiflich - ich möchte sagen, nicht einmal nothwendig, er weiß am Ende nicht, an wen er sich zu wenden hat: [Wort nicht entziffert], Prätur, Kreisamt, Tribunal, Gubernium, Appellation etc.

Des Dalmater Landmanns Partheiangelegenheiten sind durchaus zu geringfügig, daher die komplizirtere, auf höhern Kulturgrad berechneten Formen ihm nicht zuträglich werden können. Darum ist es aber nach der von mir im Lande geschöpften Überzeugung - auch noch nicht an der Zeit die Trennung der Gewalten in den ersten Instanzen vorzunehmen, ich würde fürchten, für den Fall einer solchen Sondrung mehr Schwierigkeiten und Komplikationen entstehen zu sehen, als sie jetzt schon bestehen.

Wäre anfangs eine angemeßene Zahl Bezirksinstanzen mit der Bestimmung festgesetzt worden, daß [fol. 46r] die Beamten herumreisend die Geschäfte der Einwohner des Bezirkes nach vorgeschriebenen einfachen sichernden Formen schlichten dürfen, in politischer und richterlicher Beziehung und wenn sie hierbei die Vergehen und minderen 
Verbrechen hätten bestrafen und abthun können, für wichtige Fälle die Kriminalvorerhebungen zu machen gehabt hätten, so würde die Verwaltung schneller und beßer - zum Vortheile der Einwohner in privat__ licher [muss in Vorlage geheißen haben: privatrechtlicher; der Schreiber konnte die Vorlage offenbar nicht entziffern und die unterstrichene Stelle blieb offen; K.C.], so wie zur Bildung des Volkes vorgeschritten seyn, jetzt muß das Meiste am Schreibtische im Amte geschehen, und die Schwierigkeit wird immer größer auch Personal- und Lokalkenntniß nicht so entsprechend erworben werden kann.

Ohne das Bestehende umzuwerfen, könnten aber Abhilfen dadurch geschehen, daß in den Städten Authoritäten mit einer regelmäßiger ausgeführten aber doch einfachen Geschäftsform verbleiben - auf dem Lande aber unter angemeßener [fol. 46v] Vermehrung der Präturen 3ter Klaße - die exekutiven Beamten beweglicher gemacht, und ihnen ein höchst summarisches durch einfache Formen gesichertes Verfahren in mündlicher Verhandlung vorgezeichnet werde. Wonach denn auch noch die Vereinigung der verschiedenen Amtsatribuzionen und Gewalten, in diesen Präturen durchaus zu verbleiben hätte, welches durch einfache sichernde Amtsformen noch möglicher und nützlicher gemacht würde.

Mit aller Beschleunigung dürften den Prätoren und Vizeserdaren gleiche Vollmachten wie den Colonelli und Serdaren ertheilt werden. Es wäre darauf vorzudenken, Bestimmungen zu erlaßen, vermöge welcher bis zu einer Summe von 100 Gulden unter Beobachtung einfacher sichernder Formen - die ersten Instanzen inappellabel entscheiden dürfen. Hierbei könnte für die Zukunft wohl in Erwägung kommen, ob es für dieses Land nicht von besonderem Nutzen werden könnte, eigene [fol. $47 r]$ Vergleichsgerichte zur Verminderung der moralisch politisch und ökonomisch gleich verderblichen Prozesse jeder, auch der bedeutendsten Art zu errichten.

Verfahren und Urtheil braucht große Zeit, bringt den Advokaten Vortheile, den Einwohnern kosten die Prozesse Geld, Gemüthsruhe und Sittlichkeit.

Nun liegt aber etwas Widersprechendes darin, daß der juristische Richter - einerseits Vergleiche bewirken, andererseits den Prozeß juristisch entscheiden soll, nachdem dieser Richter juristisch weiß, wem er Recht zu geben hat, und doch einen Vergleich versuchen soll. Die Vereinigung so verschiedener Pflichten in einer Person sind zu schwierig, da sie oft der eigenen Überzeugung widersprechen. Warum sollten nicht selbst im Sinne unserer Gesetze Vergleichs- und Schiedsgerichte aus angesehenen Männern des Orts und respektive des Distrikts in [fol. 47v] Dalmazien nach einfacher Weise gewählt, und aufgestellt werden, die nach einer einfach vorzuschreibenden Form vorzugehen und Vergleiche zu versuchen, und die Entscheidungen an bestimmten Tagen zu fällen 
hätten. Ich finde mich verpflichtet, diese allgemeine Idee anzudeuten, weil von Stunde zu Stunde die Streitigkeiten und Prozesse sich mehren, die Richter am Ende nicht mehr hinreichen, und der Staat mit dem Aufwande nicht mehr auslangen kann. Sind doch solche Institutionen in gebildeten Staaten für nützlich, und nothwendig erachtet, auch in verschiedenen Formen eingesetzt worden, warum sollte in solcher Versuch in einem Lande nicht gemacht werden, welches in früheren Zeiten die Mehrzahl der Parteiforderungen [der Streitparteien, K.C.] und Zwistigkeiten wirklich so verhandelt sah? Was die Tribunale betrifft, so wie sie jetzt bestehen, so will man den Leitenden derselben in Zara und Ragusa wenig entsprechende Eigenschaften zu ihrem Amte zuschreiben [fol. 48r], und dem in Cattaro die noch nicht hinlängliche Sprachkenntniß allein zur Last legen; dagegen aber die Besetzung des Tribunals zu Cattaro mit schwachen Räthen, und bei den übrigen Tribunalen in der Mehrzahl mit mittelmäßigen Individuen erkennen. Der Präses von Spalato wird sehr geachtet. Ich kenne die Individuen und Verhältnisse nicht näher, deute daher nur an, was im Ganzen mir zur Kenntniß kam.

Das Appellationsgericht sey im Ganzen gut besetzt, nur sey Appellationsrath Arneri wenig thätig, und geneigt seine Prozeße nach langem Lieben durch neue oft nicht erforderliche Rückfragen zu erledigen. Das Appellationsgericht besteht aus so wenigen Personen, daß eine zweckmäßige Berathung kaum möglich ist, und andererseits ist der Zudrang der Partheien so groß, daß die Referenten wohl manchen Kampf zu bestehen haben, und viele Zeit verlieren.

Der Appellationspräsident, welcher durch langjährige vorzügliche Dienste [fol. 48v] sich bemerkbar gemacht haben dürfte, und nun schon das 80. Lebensjahr überschritten hat, dürfte bei seinem zunehmenden Nachlaß der Kräfte, nicht mehr im Stande seyn die geistige und mechanische Leitung umfaßend zu führen.

Das Appellationsgericht kann also nicht jenen eindringlichen Einfluß auf den Geschäftsgang der untern Instanzen, der sehr heilsam und nothwendig ist, nehmen, und derselbe ist bei ihm selbst, wie man behaupten will, nicht schnell genug $\mathrm{u}$ [nd] d[er] g[leichen]. Noch nie konnten die Tribunale und Präturen von dem Obergerichte durch Absendung eines Appellationsrathes in Beziehung auf den gerichtlichen Geschäftsgang untersucht werden, weil es bei dem kleinen aus wenigen Räthen bestehenden Appellationsgerichte nicht möglich ist.

Das Appellationsgericht dürfte ohne Dienstesnachtheil, wahrscheinlich zum größeren Vortheile ganz aufgehoben werden. Es sey mir gehorsamst erlaubt, auch als Referent für das lombardisch-venetianische Königreich zu bemerken, daß im lombardisch-[fol. 49r] venetianischen Königreich die zwei Appellationsgerichte nicht zureichen, ungeachtet sie bereits zu großen Kollegien erwachsen sind, was auch seine Nachtheile hat. Würde 
nun ein drittes Appellationsgericht der Residenz in Verona angeordnete, so wäre für die lombardisch-venetianischen Angelegenheiten wohlthätig gesorgt, und dem Venediger Appellationsgerichte könnten die Dalmater Rechtsangelegenheiten zugewiesen werden, die dann einem vollständigeren Kollegium unterworfen wären; so könnte dann vielleicht auch der exponirte lomb.-venet. Senat des hochlöblichen Obersten Gerichtshofes nach Wien zurückberufen werden. Wenn die ersten Instanzen in der bemerkten Art vermehrt, und in der Geschäftsbehandlung schneller gemacht werden, würden bald, so wäre zu hoffen, die Tribunale wenigstens um eines vermindert werden können.« 


\section{Abkürzungsverzeichnis}

\begin{tabular}{|c|c|}
\hline a. h. & allerhöchst (kaiserlich) \\
\hline a. u. & alleruntertänigst \\
\hline AVA & Allgemeines Verwaltungsarchiv, Wien \\
\hline DAZd & Državni Arhiv u Zadru \\
\hline E. E. & Euere Exzellenz \\
\hline E. M. & Euerer Majestät \\
\hline f. & Gulden (Konventionsmünze) \\
\hline f. & folgende Seite \\
\hline f.f. & facente funzione (Amtsstellvertreter) \\
\hline fol. & Folio \\
\hline GdZ & Gazzetta di Zara \\
\hline gr. n. u. & griechisch nicht uniert [orthodox] \\
\hline HAZU & Hrvatska akademija znanosti i umjetnosti \\
\hline HHStA & Haus-, Hof- und Staatsarchiv, Wien \\
\hline Hs. & Handschrift \\
\hline $\mathrm{J}[]$. & Jahr \\
\hline \multirow[t]{2}{*}{ JAZU } & Jugoslavenska akademija znanosti i umjetnosti (inzwischen \\
\hline & HAZU) \\
\hline KFA & Kaiser-Franz-Akten \\
\hline kk., k.k. & königlich-kaiserlich \\
\hline Kt. & Karton \\
\hline 1. J. / l. Js. & laufendes Jahr / laufenden Jahres \\
\hline lomb.-venet. & Lombardisch-venetianisch \\
\hline MKA & Minister-Kolowrat-Akten \\
\hline MÖSTA & Mitteilungen des Österreichischen Staatsarchivs \\
\hline $\mathrm{ON}$ & Ortsname \\
\hline ÖNB, HS & Österreichische Nationalbibliothek, Handschriftenabteilung \\
\hline PHSt & Polizeihofstelle \\
\hline Präs. & Präsidium / Präsidiale \\
\hline PSN & Prezidijalni spisi Namjesništva \\
\hline $\mathrm{Qu}$ & Quadrangel (Viererbogen) \\
\hline $\mathrm{r}$ & recte \\
\hline $\mathrm{RD}$ & Rivista dalmatica \\
\hline RFFZd & Radovi Filozofskog Fakulteta u Zadru \\
\hline
\end{tabular}

DigiOst 1 | 325 
RIHP

RIJAZU

S.E.

S.M.

SOA

SOF

St. H. K.

St. K. Prov.

TN

$\mathrm{V}$

v. J. / v. Js.

ver. Hofkanzlei

$\mathrm{Z}[$.

ZR
Radovi Instituta za hrvatsku povijest

Radovi Instituta/Centra/Zavoda JAZU u Zadru

Seine Exzellenz

Seine Majestät

Südosteuropäische Arbeiten

Südost-Forschungen

Studienhofkommission

Staatskanzlei, Provinzen

Toponym

verso

voriges Jahr / vorigen Jahres

Vereinigte Hofkanzlei

Zahl (Aktennummer)

Zadarska revija (ab 1992: Zadarska smotra) 


\section{Quellen- und Literaturverzeichnis}

\section{Ungedruckte Quellen}

Allgemeines Verwaltungsarchiv, Wien:

Nachlaß 19, Familie Hohenwart. Kt. 8, 14b.

Polizeihofstelle.1814-1848.

Studienhofkommission. Kt. 445, 729, 730, 731, 863.

Arheološki muzej, Split:

Dandolo, Vincenzo: La Dalmazia ai 31 Decembre 1807. Opera in dieci parti divisa. [Ms.] Zara, 31 Dicembre 1807

ders.: La Dalmazia ai 31. Decembre 8108. Opera economico-politica. Continuazione ai due Rapporti Generali 31. Decembre 1806 e 31. Decemb[.[re] 1807. [Ms.] Zara, 31. Decembre 1808.

ders.: La Dalmazia ai 31. Decembre 1809. Opera economico-politica. Continuazione ai tre Rapporti 31 Decembre 1806, 1807, e 1808. [Ms.] Zara 31 Decembre 1809

Haus-, Hof- und Staatsarchiv, Wien:

Familienarchiv, Hofreisen. Kt. 35 (neu) -37 (neu).

Kabinettsarchiv, Vertrauliche Akten. Kt. 52.

HHStA, Kabinettskanzlei, (Bandnummer 444) Separatbilletten-Protokoll 468/1833.

Kaiser-Franz-Akten. Kt. 28, 29, 209, 210, 215, 216 (alt 232/233), 217 (alt 233/234), 218 (alt 234/235), 219, 220, 221 (alt 236/237), 222.

Minister-Kolowrat-Akten. 1831, 1832, 1835. Indizes 1827/28, 1836.

Staatenabteilung (StAbt.) Türkei III, Kt. 17: Grenzverhältnisse 1699-1859.

Staatskanzlei, Provinzen, Dalmatien.

HHStA, Staatsrat, Exhibitenindex 1834.

Državni arhiv, Zadar:

Prezidijalni spisi namjesništva 1834.

Tajni spisi namjesništva. Kt. 2, 13, 16.

Vlada/Namjesništvo za Dalmaciju, Lilienbergovi protokoli i indeksi.

Hofkammerarchiv, Wien:

Camerale. 1830, 1831. 
Kriegsarchiv, Wien:

Hofkriegsrat. 1835.

Österreichische Nationalbibliothek (Handschriften, Autografen und Nachlässe), Wien:

Cod. Ser. N. 12354: Vetter, Wenzel Graf von Lilienberg: Allerunterthänigste Relation über die in den Jahren 1832, 1833 und 1834 gemachte Dienst-Reise in Dalmatien. Zara [laut Katalog fälschlich: o. O.] 1834. Als Digitalisat zugänglich unter http:// data.onb.ac.at/rec/AL00069461.

Hs. Ser. n. 2078: Karacsay, Fedor Graf: Albanien, historisch-ethno-geographisch statistisch beschrieben. Cattaro April 1838.

Hs. Ser. n. 4318: Giuriceo, Antun: Lettera pastorale al clero e al popolo della diocesi di Ragusa, 27. 3. 1831. Tradotto in lingua nazionale da Anton[io] Ferd[inando] Putizza, Parocco di Canussa.

\section{Znanstvena knjižnica Zadar:}

Atti segreti dell'I. R. Polizia austriaca 1820-1849 (Policijska uprava - Zadar).

\section{Gedruckte Quellen}

\section{Zeitgenössische Periodika}

La Gazzetta di Zara. Zara 1832, 1833, 1834, 1835.

Österreichischer Beobachter. Wien (einzelne Nummern, 1821 ff., über Google Books)

Politische Gesetzessammlung. 1790-1848. Franz I. Bd. 61, Wien 1835.

Tafeln zur Statistik der Oesterreichischen Monarchie. 1 (1828) - 10 (1837) [Bd. 1 u. d.T. ,Versuch einer Darstellung der Oesterreichischen Monarchie in Statistischen Tafeln; Bd. 2 u.d. T. Darstellung der Oesterreichischen Monarchie in Statistischen Tafeln'].

Wiener Zeitung (Kaiserlich österreichische Wiener Zeitung). Einzelne Ausgaben diverser Jahrgänge (vorwiegend über Google Books-Suchen, teils auch über die Zeitungsdatenbank anno der ÖNB).

Zeitschrift für österreichische Rechtsgelehrsamkeit und politische Gesetzkunde. Jahrgang 1826, Bd. 3.

\section{Zeitgenössische Veröffentlichungen und publizierte Quellen}

Almanacco [provinciale] della Dalmazia per l'anno 1830. Zara 1830 (sowie die Jahrgänge 1832, 1833, 1834, 1835).

DigiOst $1 \mid 328$ 
Barth-Bartenheim, Johann Ludwig Ehrenreich Graf von: Das Ganze der österreichischen politischen Administration, mit vorzüglicher Rücksicht auf das Erzherzogthum Oesterreich unter der Enns. Bd. 1 Wien 1838.

Beidtel, Ignaz: Geschichte der österreichischen Staatsverwaltung 1740-1848. Hg. Alfons Huber. 2 Bde. Innsbruck 1896/1898.

Biasoletto, Bartolomeo: Reise Sr. Majestät des Königs Friedrich August von Sachsen durch Istrien, Dalmatien und Montenegro im Frühjahr 1838. Übers., hg. Eugen von Gutschmid. Dresden 1842.

Bottura, Pietro: Della introduzione di una specie d'ulivo in Dalmazia, delle cagioni della sua spopolazione e dei mezzi per ripararvi. Zara 1830.

[Brodmann, Giovanni de] G. d. B-n.: Memorie politico-economiche della città e territorio di Trieste, della penisola d'Istria, della Dalmazia fu veneta, di Ragusi e dell' Albania, ora congiunti al Austriaco Impero. Venezia 1821.

Carrara, Francesco: La Dalmazia descritta. Zara 1846-48.

Ćosić, Stjepan: Waidmannsdorfov izvještaj o dubrovačkom okrugu iz godine 1823. In: Anali Zavoda za povijesne znanosti HAZU u Dubrovniku 38 (2000), 201-242.

Dandolo, Vinczeno: La Dalmazia al 31 decembre 1806. Opera economico-politica. Zara 1909.

Demian, J[ohann] A[ndreas]: Statistik des Oesterreichischen Kaiserthums. Leipzig 1820.

D’Erco, Ricardo: O ribolovu na istočnom Jadranu. Historijsko-pravna, ribarstveno-politička i ekonomska građa. Hg. Branko Sambrailo. Zagreb 1973.

Emmer, Johannes: Erzherzog Franz Karl. Ein Erbauungsbüchlein für Volk und Jugend. Salzburg 1883.

Ersch, Johann Samuel / Gruber, Johann Gottfried (Hgg.): Allgemeine Encyclopädie der Wissenschaften und Künste. I. Reihe, Bd. 22 Leipzig 1832.

Grisebach, A.[ugust]: Reise durch Rumelien und nach Brussa im Jahre 1839. Bd. 1 Göttingen 1841.

Groß-Hoffinger, A.[nton] J.[ohann]: Leben, Wirken und Tod des Kaisers. Ein Charakter- und Zeitgemälde, entworfen bei Gelegenheit des Todes Franz I. am 1. März 1835. Stuttgart 1835.

[Handel, Erasmus von:] Erinnerungen des Erasmus Freiherr von Handel. Hg. Hussarek von Heinlein, Max. In: Jahrbuch der Österreichischen Leo-Gesellschaft 1930, 39-116.

Handel, Erazmo [Erasmus von]: Sjećanja. Hg. Marko Trogrlić. Zagreb 2007.

Hof- und Staatsschematismus des österreichischen Kaiserthums. Wien 1830, 1834, 1837.

DigiOst 1 | 329 
Jellachich, Joseph Baron [Jelačić, Josip]: Lebensbeschreibung des k.k. Feldzeugmeisters Vetter Grafen von Lilienberg. In: Österreichische militärische Zeitschrift. Jahrgang 1841, Zweiter Band, Heft 4, 189-203 und Heft 6, 306-321.

Kämtz, L. F.: Dalmatien. In: Ersch-Gruber I, Bd. 22 [1832], 88-94.

Kanka, Johann (Hg.): Handbuch des österreichischen Gesetzes über schwere Polizeiübertretungen, mit allen auf dieses Fach Bezug nehmenden, bis zum Ende des Jahres 1822 erschienenen Verordnungen und Erläuterungen. Bd. 1 Prag 1823.

[Karadžić, Vuk Stefanović]: Karadčić, Vuk Stef.: Crna Gora i Boka kotorska. Vorwort Ljub. Stojanović. Beograd 1922.

[Karadžić, Vuk Stefanović:] Vukova prepiska. Bd. 6 Beograd 1912.

Klingenstein, Grete / Faber, Eva / Trampus, Antonio (Hgg.): Europäische Aufklärung zwischen Wien und Triest. Die Tagebücher des Gouverneurs Karl Graf Zinzendorf, 1776-1782. 4 Bde. Wien, Köln, Weimar 2009.

Krmpotić, Ljudevit (Hg.): Car Franjo I. u Hrvatskoj 1818. 2 Bde. Hannover, Čakovec 2002.

Kupek, Jakov: Gospodarske i kulturne prilike u Dalmaciji krajem trećeg decenija XIX stoljeća. In: RIJAZU 20 (1973), 227-245.

Kuster, Thomas: Das italienische Reisetagebuch Kaiser Franz I. von Österreich aus dem Jahre 1819. Eine kritische Edition. Münster 2010.

Landes-Gesetze und Statthalterei-Verordnungen vom Jahre 1808-1895 für das Königreich Dalmatien. Zara 1896.

[Ljubić, Šime] Gliubich, Simeone: Dizionario degli uomini illustri della Dalmazia. Vienna 1856 [Ndr. Bologna 1974: Italica Gens. Repertorio di bio-bibliografica italiana, 59].

Lorentz, Fr.: Dalmatien. Geschichte. In: Ersch-Gruber I, Bd. 22 [1832], 94-103.

Malchus, C.[arl] A.[ugust] von: Handbuch der Militär-Geographie oder Erd- und Staatenkunde von Europa. Mit specieller Beziehung auf Kriegführung. Bd. 2: Staaten-Kunde. Heidelberg, Leipzig, Wien 1833.

Marinelli-König, Gertraud: Die Südslaven in den Wiener Zeitschriften und Almanachen des Vormärz (1805-1848). Versuch einer kritischen Bestandsaufnahme der Beiträge über Bosnien, Bulgarien, Dalmatien, die Herzegowina, Istrien, Krain (Kärnten, Steiermark), Kroatien, das Küstenland, die Militärgrenze, Montenegro, Serbien und Slawonien. Wien 1994.

Maštrović, Vjekoslav: Zadarska oznanjenja. Iz XVIII, XIX. i početka XX. stoljeća (Jadertina croatica). Zagreb 1979 (Zavod za povijesne znanosti Istraživačkog centra JAZU u Zadru, Djela, 6). 
Meynert, Hermann: Kaiser Franz I. von Oesterreich und sein Zeitalter. Ein Charakterbild aus der Gegenwart. Leipzig 1834.

Milović, Jevto M.: Memoar o ispravljanju granice između Dalmacije i Crne Gore od kapetana Fridriha Oreškovića iz 1838. godine, pisan po naređenju austrijskog državnog kancelara K.V.L. Meterniha. In: Milović, Jevto M.: Petar II Petrović Njegoš u svom vremenu. Titograd 1985, 346-395.

Milović, Jevto M.: Petar I Petrović Njegoš. Pisma i drugi dokumenti. Bd. 1: 17801820. Titograd 1987.

Mollinary, Anton von: Sechsundvierzig Jahre im österreichisch-ungarischen Heere 1833-1879. Bd.1 Zürich 1905.

Morović, Hrvoje: Izvještaj poglavara E. Rehe o prilikama u splitskom okrugu u godini 1822. In: Izdanje Historijskog arhiva u Splitu 8 (1974), 233-262 und 9 (1977), 165-201.

Orosz, Anton: Worte eines eifrigen und uneigennützigen Staatsdieners, die bei der Regulierung der neuen Verhältnisse des Constitutionellen Dalmatien beachtet werden mögen. Zara 1848.

Orosz de Balásfalva, Anton: Das Unhaltbare unseres Steuer-Systems, verglichen mit einer zeitgemäßen Verbesserung desselben. Praktische Ansichten. Wien 1849.

Partsch, Paul: Bericht über das Detonations Phänomen auf der Insel Meleda bei Ragusa. Nebst geographisch-statistischen und historischen Notizen über diese Insel und einer geognostischen Skizze von Dalmatien. Wien 1826.

Pederin, Ivan: Car Franjo I. o Šibeniku u svom putnom dnevniku iz 1818. godine. In: RIJAZU u Zadru 29-30 (1983), 179-206.

Pederin, Ivan: Jadranska Hrvatska u austrijskim i njemačkim putopisima. Zagreb 1991.

Pederin, Ivan: Njemački putopisi po Dalmaciji. Split 1989.

Petar [II.] Petrović Njegoš: Izabrana pisma. Beograd 1984.

Petrović, Danica: Josif Rajačić - vizitacija dalmatinske eparhije 1832-1833. godine. In: Zbornik o Srbima u Hrvatskoj 2 (1991), 485-496.

Petter, Franz: Dalmatien in seinen verschiedenen Beziehungen. 2 Bde. Gotha 1857.

Petter, Franz: Geographische Skizze von Dalmatien. In: Sommer, Johann Gottfried (Hg.): Taschenbuch zur Verbreitung geographischer Kenntnisse. Übersicht des Neuesten und Wissenswürdigsten im Gebiete der gesammten Länder- und Völkerkunde. Bd. 11, Prag 1833, 1-136 und Bd. 12, Prag 1834, 154-213.

Püchler, Benedikt von: Geschichte der Regierung Kaiser Franz I. 3 Teile, Wien 1841. [Reutz, Alexander von:] Die freien Landgemeinden von Zernagora (Montenegro), Poglizza und andere. Ein Beitrag zur Kenntniß des südlichen Slawenstammes. In: 
Berghaus, Heinrich (Hg.): Annalen der Erd-, Völker- und Staatenkunde. Bd. 6: Vom 1. April bis 30. September 1838. Berlin 1838, 224-272 (auch zuvor mit Namenzeichnung in mehreren Folgen der „Dorpater Jahrbücher für Literatur, Statistik und Kunst, besonders Russlands").

Šimunković, Ljerka (Hg.): Vincenzo (Vicko) Drago. Storico e letterato dalmata a cavallo dei secoli XVIII-XIX. Roma 2001.

Strmota, Ankica: Naputak o uredskom poslovanju predsjedničkog ureda Kraljevine Dalmacije za vrijeme »Druge austrijske uprave« (1814.-1918.). In: Arhivski vjesnik 51 (2008), 57-92.

Stulli, Bernard: Građa o gospodarstvu Dalmacije u prvoj polovici XIX. stoljeća. In: ders.: Iz povijesti Dalmacije, 535-593 [zuvor in: Izdanje Historijskog Arhiva u Splitu 10 (1980), 135-186].

Stulli, Bernard: Građa o stanju u Dalmaciji 1818. god. In: ders.: Iz povijesti Dalmacije, 449-533 [zuvor in: Zbornik Zavoda za povijesne znanosti Istraživačkog centra JAZU 13 (1983), 119-190].

Valentinelli, Giuseppe: Bibliografia della Dalmazia e del Montenero. Zagabria 1855 [erw. Ndr. Bologna 1967].

Valentinelli, Giuseppe: Supplementi al saggio bibliografico della Dalmazia e del Montenero. Zagabria 1862 [Ndr. Bologna 1975].

Vialla de Sommières, L.C. [Jacques-Louis]: Travels in Montenegro. A Topographical, Picturesque, and Statistical Account of That Hitherto Undescribed Country. London 1820.

Vita di Monsignore Giuseppe Godeassi, arcivescovo di Zara, metropolita della Dalmazia. Zara 1862.

Voigt, Bernhard Friedrich: Wenzel Vetter Graf v. Lilienberg. In: ders.: Neuer Nekrolog der Deutschen. 19. Jg. (1841), Erster Theil. Weimar 1843, 180-196.

Winiwarter, Joseph: Handbuch der Justiz- und politischen Gesetze und Verordnungen, welche sich auf das in den Deutschen Provinzen der Österreichischen Monarchie geltende allgemeine bürgerliche Gesetzbuch beziehen. 2. Auflage Wien 1835.

Wurzbach, Constantin von: Vetter, Graf von Lilienberg, Wenzel. In: ders.: Biographisches Lexikon des Kaiserthums Oesterreich. Bd. 50. Wien 1884, 239-247.

[Zavoreo, Francesco:] Memoria statistica sulla Dalmazia. Di Francesco Zavoreo, capitanio ingegnere ex-veneto e direttore provvisorio dei lavori edili e idraulici in pensione. Venezia 1821.

DigiOst 1 | 332 


\section{Sekundärliteratur}

Aličić, Ahmed S.: Pokret za autonomiju Bosne od 1831. do 1832. godine. Sarajevo 1996.

Andrijašević, Živko M. / Rastoder, Šerbo: Istorija Crne Gore. Od najstarijih vremena do 2003. Podgorica 2006.

Anselmi, Sergio: Barche e merci istriano-dalmate nella fiera-franca di Senigallia e nel porto di Ancona: prima metà del XIX secolo. In: Padoan (Hg.): Istria e Dalmazia nel periodo asburgico, 197-212.

Antoljak, Stjepan: Pregled hrvatske povijesti. 2. Auflage Split 1994.

Aretin, Karl Otmar von: Das Alte Reich, 1648-1806. Bd. 3: Das Reich und der österreichisch-preußische Dualismus (1745-1806). Stuttgart 1997.

Bajić-Žarko, Nataša: Arhiv mapa za Istru i Dalmaciju. Katastar Dalmacije 1823.-1975. Inventar. Zagreb, Split 2006.

Bakotić, Lujo: Srpski narod u Dalmaciji od pada Mletačke republike do ujedinjenja. Beo$\operatorname{grad} 1939$.

Baltzarek, Franz: Die ökonomische Bedeutung Triests, des Küstenlandes und Dalmatiens für das Habsburgerreich 1815-1848. In: Padoan (Hg.): Istria e Dalmazia nel periodo asburgico, 9-17.

Bastgen, Hubert: Die Neuerrichtung der Bistümer in Österreich nach der Säkularisation. Wien 1914.

Batović, Šime: Arheološki muzej u Zadru. In: Ravlić, Jakša (Hg.): Zadar. Geografija, etnologija, ekonomija, povijest, kultura. Zbornik. Zagreb 1964, 679-687.

Beer, Adolf: Kirchliche Angelegenheiten in Österreich (1816-1842). In: Archivalische Mitteilungen, Mitteilungen des Instituts für österreichische Geschichtsschreibung 18 (1897), 493-581.

Benna, Anna Hedwig: Organisierung und Personalstand der Polizeihofstelle (1793-1848). In: MÖSTA 6 (1953), 197-239.

Berić, Dušan: Školstvo Šibenika i njegove okolice u prošlosti (1412-1921). Split 1964.

Bersa, Josip: Dubrovačke slike i prilike (1800-1880). Zagreb 1941.

Bezić-Božanić, Nevenka: Povijest stanovništva u Visu. Split 1988.

Bezina, Petar: Pučko školstvo i franjevci Provincije presv. Otkupitelja. Doprinos poznavanju razvitka pučkog školstva u Južnoj Hrvatskoj od 1735. do 1941. godine. Split 1987 (Knjižnica zbornika 'Kačić,', Monografije, 15).

Biščević, Vedad: Bosanski namjesnici osmanskog doba (1463-1878). Sarajevo 2006. 
Bralić, Ante: Zadar kao administrativno i političko središte Dalmacije za francuske uprave. In: Trogrlić, Marko / Vrandečić, Josip (Hgg.): Dalmacija za francuske uprave (18061813). Split 2011, 351-371.

Bundy, Frank J.[ames]: The Administration of the Illyrian Provinces of the French Empire 1809-1813. [Diss. University of Kansas 1982,] Ann Arbor 1982.

Clewing, Konrad: Die doppelte Begründung der Serbischen Wojwodschaft 1848-1851. Ethnopolitik im Habsburgerreich, in: Ders. / Oliver Jens Schmitt (Hgg.): Südosteuropa. Von moderner Vielfalt und nationalstaatlicher Vereinheitlichung. Festschrift für Edgar Hösch. München 2005 (SOA, 127), 253-302.

Ders.: Staatlichkeit und nationale Identitätsbildung. Dalmatien in Vormärz und Revolution. München 2001 (SOA, 109).

Ders.: Der begrenzte Wert strategischen Wertes. Dalmatien als habsburgische Randprovinz. In: Maner, Hans-Christian (Hg.): Grenzregionen der Habsburgermonarchie im 18. und 19. Jahrhundert. Ihre Bedeutung und Funktion aus der Perspektive Wiens. Münster 2005 (Mainzer Beiträge zur Geschichte Osteuropas, 1), 217-234.

Čoralić, Lovorka: Od zapovjednika hrvatske konjice do gorljivih autonomaša - šibenska obitelj Fenzi (XVII. stoljeće - početak XX. stoljeća). In: Povijesni prilozi 41 (2011), 203-231.

Ćosić, Stjepan: Državna uprava u Dalmaciji i crkveni preustroj 1828./1829. godine. In: Croatica Christiana Periodica 34 (2010), Nr. 65, 51-66.

Ders.: Dubrovnik nakon pada republike (1808.-1848.). Dubrovnik 1999 (Zavod Povijesne znanosti HAZU u Dubrovniku. Posebna izdanja. Monografije, 17).

Ders.: Obilježja i ustroj austrijske vlasti u Dalmaciji u doba absolutizma. In: Radovi Zavoda za povijesne znanosti HAZU u Zadru 40 (1998), 349-360.

Ders. / Ljubić, Pero / Kapetanić, Niko / Vekarić, Nenad: Hrvatska granica na Kleku. Dubrovnik 1999.

Ders. / Kapetanić, Niko / Vekarić, Nenad: Prijevara ili zabluda? Problem granice na području poluotoka Kleka. Dubrovnik 2012.

Đorđević, Vladan: Crna Gora i Austrija 1814-1894. Beograd 1924.

Dürrigl, Marija-Ana / Mihaljević, Milan / Velčić, Franjo (Hgg.): Glagoljica i hrvatski glagolizam. Zbornik radova s međunarodnoga znanstvenog skupa povodom 100. obljetnice Staroslavenske akademije i 50. obljetnice Staroslavenskog instituta (Zagreb-Krk, 2.-6. listopada 2002.) Zagreb, Krk 2004.

[Ellermeyer-Životić, Olga] Elermajer-Životić, Olga: Iz nemačko-jugoslavenskih književnih veza: Hajnrih Štiglic (1801-1849) i njegov odnos prema Jugoslovenima. Beograd 
1991 (Srpska Akademija Nauka i Umetnosti, Posebna izdanza, 608, Odeljenje Jezika i književnosti, 44).

Erber, Tullio: Storia del Gimnasio Superiore di Stato in Zara. Zara 1905.

Foretić, Vinko: Prosjeci kroz prošlosti Korčule. In: Zbornik otoka Korčule. Bd. 2, Zagreb 1972, 27-71.

Garbin, Daria / de' Vidovich, Renzo: Dalmazia Nazione. Dizionario degli Uomini Illustri della componente culturale illirico-romana, latina, veneta, italiana. Trieste 2012 [http://www.dalmaziaeu.it/dalmazianazione.pdf, 22.4.2014].

Ghezzo, Michele Pietro: I Dalmati all'Università di Padova. 1801-1947. Venezia 1993 (Atti e memorie della Società Dalmata di Storia Patria, 22).

Ders.: Nobiltà dalmata e università di Padova ne XIX secolo. In: Ders. (Hg.), L'Istria e la Dalmazia nel XIX secolo. Venezia 2001 (Atti e memorie della Società Dalmata di Storia Patria, 30), 199-211 [auch http://www.dalmaziaeu.it/AlboDoro/Albodoro2-MichelePietroGhezzo.pdf, 22.4.2014].

Giormani, Virgilio: La linea vapore della Dalmazia e il colera del 1830. In: RD 53 (1982), 317-336.

Giusti, Ugo: Note demografiche sulla Dalmazia. In: RD 66 (1995), 184-208.

Goldstein, Ivo: Croatia. A History. London 1999.

Gottas, Friedrich: Die Geschichte des Protestantismus in der Habsburgermonarchie. In: Wandruszka, Adam / Urbanitsch, Peter (Hgg.): Die Habsburgermonarchie 1848-1918. Bd. 4: Die Konfessionen. Wien 1985, 489-595.

Gottsmann, Andreas: Das Bild Dalmatiens und der Dalmatiner in der österreichischen Reiseliteratur des 19. und frühen 20. Jahrhunderts. In: Österreich in Geschichte und Literatur 43 (1999), 65-83.

Hardy, Malcolm Scott: Velika Britanija i Vis. Rat na Jadranu 1805.-1815. Split 2008 (Biblioteka znanstvenih djela, 151).

Hartmann, Eleonore: Die Hofreisen Kaiser Franz I. Diss. Wien 1968.

Historia e popullit shqiptar. Bd. 2: Rilindja kombëtare. Vitet 30 të shek. XIX - 1912. Red. Kristaq Prifti. Tiranë 2002.

Imamović, Mustafa: Historija Bošnjaka. Sarajevo 2. Auflage 1998.

Ivković, Frane: Organizacija uprave u Dalmaciji za vrijeme druge austrijske vladavine 1814-1918. In: Arhivski vjesnik 34/35 (1991-1992), 31-51.

Jakir, Aleksandar: Dalmatien zwischen den Weltkriegen. Agrarische und urbane Lebenswelt und das Scheitern der jugoslawischen Integration. München 1999 (SOA, 104). Mraz, Gottfried / Mraz, Henrike (Hgg.): Kaisertum Österreich 1804-1848. Ausstellung Schallaburg, 27. April bis 27. Oktober 1996. Bad Vöslau 1996. 
Karaman, Igor: Jadranske studije. Prilozi ekonomsko-socijalnoj historiji Rijeke, Hrvatskog primorja i Dalmacije od XVIII. do XX. stoljeća. Rijeka 1992 (Biblioteka Dokumenti, 21).

Ders.: Stanovništvo i privreda Dalmacije pod austrijskom upravom (1814-1918). In: ders.: Jadranske studije, 117-140.

Ders.: Struktura dalmatinskoga građanstva u doba preporoda i njegova socijalno-ekonomska djelatnost. In: Ders.: Jadranske studije, 141-166.

Kolanović, Josip: Prilozi Bernarda Stullija o povijesti Dalmacije. In: Arhivski vjesnik 30 (1987), 41-44.

Kolić, Dubravka: Carsko-kraljevsko namjesništvo u Zadru 1814.-1918. Institucija i gradivo. Zadar 2010.

Kovačić, Slavko: Glagoljanje i glagoljaši u srednjoj Dalmaciji za vrijeme hrvatskog narodnog preporoda 1835-1848. In: ZR 36 (1987), 351-365.

Ders.: Ristrutturazione delle circoscrizioni ecclesiastiche in Dalmazia. In: Padoan (Hg.): Istria e Dalmazia nel periodo asburgico, 255-291.

Ders.: Wandel in Struktur und Wirken der Katholischen Kirche zur Zeit der österreichischen Herrschaft in Dalmatien. In: Potthoff, Wilfried / Jakir, Aleksandar / Trogrlić, Marko / Trunte, Nikolaos (Hgg.): Dalmatien als europäischer Kulturraum. Split 2010, 433-453.

Kozličić, Mithad / Bralić, Ante: Stanovništvo Kraljevine Dalmacije prema službenim izračunima i popisima 1828.-1857. godine. Zadar 2012.

Kreševljaković, Hamdija: Kapetanije u Bosni i Hercegovini. Sarajevo 1954.

Kreuter, Peter Mario: Der Vampirglaube in Südosteuropa. Studien zur Genese, Bedeutung und Funktion. Rumänien und der Balkanraum. Berlin 2001.

Kudrna, Leopold: Biographical Dictionary of all Austrian Generals during the French Revolutionary and Napoleonic Wars, 1792-1815. Unter: http://www.napoleon-series.org/research/biographies/Austria/AustrianGenerals/c_AustrianGeneralsIntro. html (9.12.13).

Lacmanović-Heydenreuter, Haira: Dalmatien in Wien. Die dalmatinischen Abgeordneten im Wiener Reichsrat 1867-1918. Hamburg 2011.

Lakuš, Jelena: Izdavačka i tiskarska djelatnost na dalmatinskom prostoru (Zadar, Split i Dubrovnik) u prvoj polovici 19. stoljeća (1815.-1850.). Split 2005.

Maixner, Rudolf: Vito Bettera-Vodopić. In: Anali Historijskog instituta JAZU u Dubrovniku 3 (1954), 407-426.

Manussi-Montesole, Alfred: Die Adrialänder. In: Hugelmann, Karl Gottfried (Hg.): Nationalitätenrecht im alten Österreich. Wien 1934, 569-684. 
Marin, Emilio: Doba francuske uprave u Dalmaciji. U svjetlu arhivske, bibliotečne i numizmatičke građe Arheološkog muzeja u Splitu. U povodu 200. obljetnice francuske revolucije. Split 1989.

Maštrović, Vjekoslav: 150 godina zadarske gimnazije. Zadar 1954.

Maštrović, Vjekoslav: Razvoj sudstva u Dalmaciji u XIX. stoljeću. Zagreb 1959 (Radovi Instituta JAZU u Zadru, Prilog 4/5).

Milutinović, Kosta: Vojvodina i Dalmacija 1760-1914. Novi Sad 1973.

Monzali, Luciano: Italiani di Dalmazia. Dal Risorgimento alla Grande Guerra. Firenze 2004.

Mraz, Gerda / Mraz, Gottfried: Österreichische Profile. Maximilian I., Wallenstein, Prinz Eugen, Maria Theresia, Kaunitz, Franz II., Erzherzog Carl, Metternich, Radetzky, Franz Joseph I. Wien 1981.

Nenezić, Zoran D.: Masoni u Jugoslaviji (1764-1980). 2. Auflage. Beograd 1987.

Novak, Grga: Povijest Splita. Bd. 4. Split 1978.

Ders.: Prošlost Dalmacije. 2 Bde. Zagreb 1944.

Obad, Stijepo: Agrarni odnosi na području bivše dubrovačke republike (1814-1850). In: RFFZd 6 (1964-67), 131-148.

Ders.: Dalmatinsko društvo u preporodna doba. In: ZR 36 (1987), 299-314.

Ders.: Dalmatinsko selo u prošlosti. Od sredine osamnaestog stoljeća do prvoga svijetskog rata. Split 1990.

Ders.: O karbonarima u Dalmaciji. In: ZR 24 (1975), 96-99.

Ders.: Trogir u narodnom preporodu. In: Mogućnosti 35 (1987), 759-771.

Ders.: Visoko školstvo u Zadru tijekom devetnaestog stoljeća. In: RFFZd 14-15 (197576), 401-423.

Oršolić, Tado: Boka kotorska u svjetlu austrijske politike tridesetih godina XIX. stoljeća. In: Čoralić, Lovorka (Hg.): Hrvatsko-crnogorsko dodiri - crnogorsko-hrvatski dodiri. Identitet povijesne i kulturne baštine crnogorskog primorja. Zbornik radova. Zagreb 2009, 415-426.

Ders.: Neke zapreke koje su utjecale na razvoj gospodarstva Dalmacije za druge austrijske uprave (do sredine XIX. stoljeća), in: Marko Trogrlić / Josip Vrandečić / Ante Bralić / Mislav Elvis Lukšić (Hgg.): Zbornik Stijepa Obada. Zadar, Split, Zagreb 2010, 377-389.

Ders.: Teritorijalne snage (forza territoriale). Njihov preustroj i ustroj 1806.-1809. In: Trogrlić / Vrandečić (Hgg.): Dalmacija za francuske uprave, 339-349.

Ders.: Vojna Dalmacija u 19. stoljeću. Vojska, teritorijalne snage, žandarmerija (1797.1914.). Zadar 2013. 
Ožanić, Stanko: Poljoprivreda Dalmacije u prošlosti. Prilozi za povijest poljoprivrede Dalmacije. Split 1955.

Padoan, Giorgio (Hg.): Istria e Dalmazia nel periodo absburgico dal 1815 al 1848. Ravenna 1993 (Atti e Inchieste di 'Quaderni Veneti', 2).

Pappafava, Vladimir: O kmetstvu osobitom obzirom na Dalmaciju. Zagreb 1886.

Ders.: Studie über den Theilbau in der Landwirtschaft, besonders in Dalmatien, sowie über die Erträge in dem Gebiete der ehemaligen Republik Ragusa. Innsbruck 1894.

Pav, Wolfgang: Niko Nardelli - Österreichs Statthalter in Dalmatien 1906-1911. Ein «politischer Beamter> im Spannungsfeld von Zentralmacht und Landesinteressen. Diss. phil. Wien 2010 (online abrufbar unter http://othes.univie.ac.at/11678/).

Pederin, Ivan: Il biografismo dell'Istria e della Dalmazia nella prima metà dell'Ottocento. In: Padoan: Istria e Dalmazia nel periodo asburgico, 75-123.

Ders.: Dalmacija i Hrvati u vanjskoj politici bečkoga dvora. Bd. 1. Zadar 2005.

Ders.: Die venezianische Wirtschaft in Dalmatien mit einem Ausblick - Die wirtschaftlichen Probleme Dalmatiens im Blickfeld österreichischer Reiseschriftsteller des XIX. Jahrhunderts. In: Studi Veneziani N. s. 18 (1989), 67-176.

Peričić, Šime: Gospodarska povijest Dalmacije od 18. do 20. stoljeća. Zadar 1998.

Ders.: Gospodarske prilike Dalmacije od 1797. do 1848. Split 1993 (Književni krug, Biblioteka znanstvenih djela, 65).

Ders.: Oskudica i glad u Dalmaciji u XIX i početkom XX stoljeća. In: RIHP 13 (1980), $1-32$.

Ders.: Pomorska trgovina Dalmacije u XIX. stoljeću. Zadar 1995.

Ders.: Prvobitna proizvodnja dubrovačkog okružja od 1815. do 1848. godine. In: Anali Zavoda za povijesne znanosti Istraživackog centra JAZU 21 (1983), 251-269.

Ders.: Razvitak gospodarstva Zadra i okolice u prošlosti. Zagreb, Zadar 1999.

Ders.: Socijalno-ekonomske prilike u Dalmaciji u XIX stoljeću. In: Godišnjak Društva istoričara Bosne i Hercegovine 16 (1965), 59-90.

Petković, Gordana: Patrijarh Josif Rajačić (1785-1861). Beograd 2009 (Biografije, 10).

Petrović, Rade: L’organizzazione amministrativa nella Dalmazia austriaca. In: Padoan (Hg.): Istria e Dalmazia nel periodo asburgico, 293-301.

Reill, Dominique Kirchner: Nationalists Who Feared the Nation: Adriatic Multi-Nationalism in Habsburg Dalmatia, Trieste, and Venice. Stanford 2012.

Rubić, Ivo: Poljica. Geografska studija. In: Poljički zbornik. Zagreb 1968, 7-31.

Rumpler, Helmut: Österreichische Geschichte 1804-1914: Eine Chance für Mitteleuropa. Bürgerliche Emanzipation und Staatszerfall in der Habsburgermonarchie. Wien 1997. 
Sandgruber, Roman: Ökonomie und Politik. Österreichische Wirtschaftsgeschichte vom Mittelalter bis zur Gegenwart. Wien 1995.

Saurer, Edith: Straße, Schmuggel, Lottospiel. Materielle Kultur und Staat in Niederösterreich, Böhmen und Lombardo-Venetien im frühen 19. Jahrhundert. Göttingen 1989 (Veröffentlichungen des Max-Planck-Instituts für Geschichte, 90).

Schmitt, Oliver Jens: Österreichs Blick auf das französische Dalmatien. In: Trogrlić / Vrandečić (Hgg.): Dalmacija za vrijeme francuske uprave, 139-147.

Scotti, Giacomo: I Pinelli di Zara da medici a imprenditori. In: La Voce del Popolo [Fiume] 2.8.2008, S. 16.

Šedivý, Miroslav: Metternich, the Great Powers and the Eastern Question. Pilsen 2013 (auch unter: http://www.metternich.zcu.cz).

Semi, Francesco / Tacconi, Vanni (Hgg.): Dalmazia. Le figure più rappresentative della civiltà dalmata. Udine 1992 (Istria e Dalmazia. Uomini e tempi, 2).

Šešo, Luka: Which woman is a witch? The stereotypic notions about witches in Croatian traditional beliefs. In: Studia ethnologica croatica 24 (2012), 195-207.

Šljivo, Galib: Izlaz Bosne i Hercegovine na Jadran: Neum - Klek i Sutorina u međunarodnim odnosima 1815.-1878. Tešanj 2001.

Soldo, Ante Josip: Prilozi proučavanju agrarno-društvenih odnosa u Gornjem Primorju od XVI do polovine XIX stoljeća. In: Makarski zbornik 1 (1970), 337-380.

Špikić, Marko: Carlo Lanza, prvi ravnatelj Arheološkog muzeja u Splitu. In: Baština 34 (2007), 373-388.

Ders.: Francesco Carrara. Polihistor, antikvar i konzervator (1812.-1854.). Split 2010 (Biblioteka Knjiga Mediterana, 59).

Ders.: Titus Novus. Emperor Francis I's iconography of power and its reception in Croatia and Dalmatia. In: IKON [Rijeka] 5 (2012), 305-319.

Stachel, Peter: Die «eigene> Fremde. Dalmatien in Reiseführern und Reiseberichten (18151918). In: Rapp, Christian / Rapp-Wimberger, Nadia (Hgg.): Österreichische Riviera. Wien entdeckt das Meer. Wien 2013, 108-117.

Stančić, Nikša: Hrvatska nationalna ideologija preporodnog pokreta u Dalmaciji. Mihovil Pavlinović i njegov krug do 1869. Zagreb 1980.

Ströll, Antun: Pučko školstvo u Dalmaciji od god. 1814 do god. 1900. Zadar 1900.

Šupuk, Ante: Stanovništvo Šibenika od početka XIX stoljeća do kraja sedamdesetih godina. In: Dalmacija 1870 Foretić, Dinko (Hg.), 87-98.

Trampus, Antonio: La censura austriaca dal Veneto alla Dalmazia della restaurazione. In: Atti e memorie della Società dalmata di storia patria 15 (N. s. 4) (1992), 117-124. 
Trogrlić, Marko / Vrandečić, Josip (Hgg.): Dalmacija za francuske uprave (1806-1813). Split 2011.

Trogrlić, Stipan: Novija literatura o agrarnim odnosima u Dalmaciji u vrijeme druge austrijske uprave. In: RIHP 13 (1980), 207-220.

Unowsky, Daniel L.: The Pomp and Politics of Patriotism: Imperial Celebrations in Habsburg Austria, 1848-1916. West Lafayette 2005.

Vince-Pallua, Jelka: Da prostite, to mi je žena! Prilog poznavanju položaja žene u drugoj polovici 18. i prvoj polovici 19. stoljeća u Dalmaciji i njezinu zaleđu. In: Studia ethnologica 2 (1990), 77-96.

Walla, Kurt: Joseph Freiherr von Weingarten. Das Leben eines vormärzlichen Beamten. Diss. Wien 1950.

Weigl, Engelhard: Wald und Klima: Ein Mythos aus dem 19. Jahrhundert. In: Humboldt im Netz. Internationale Zeitschrift für Humboldt-Studien 5 (2004), H. 9, 81-98.

Wolff, Larry: Dalmatinische und italienische Reisen. Das Paradies der mediterranen Rückständigkeit. In: Schenk, Frithjof Benjamin / Winkler, Martina (Hgg.): Der Süden. Neue Perspektiven auf eine europäische Geschichtsregion. Frankfurt, New York 2007, 207-228.

Ders.: Venice and the Slavs. The Discovery of Dalmatia in the Age of Enlightenment. Stanford 2001.

Wurzbach, Constant von: Biographisches Lexikon des Kaiserthums Oesterreich. 60 Bde., Wien 1856-1891.

Zeman, Mirna: Reise zu den »Illyriern«. Kroatienstereotype in der deutschsprachigen Reiseliteratur und Statistik (1740-1809). München 2013 (SOA, 147).

Ziegler, Walter: Franz II., 1792-1806, in: Anton Schindling / ders. (Hgg.): Die Kaiser der Neuzeit 1519-1918. Heiliges Römisches Reich, Österreich, Deutschland. München 1990, 289-306.

Ders.: Franz I. von Österreich, 1806-1835, in: ebd., 309-328. 


\section{Register}

\section{Personenregister}

In diesem Register wurde die Schreibung der Personen- und der beigefügten Ortsnamen mit wenigen Ausnahmen wie in der Quelle beibehalten. Entsprechend wird bei den Personen nur selten zusätzlich auf eine belegte heutige kroatische Schreibung verwiesen. Die Angaben zur beruflichen Stellung beziehen sich sofern nicht anders angegeben auf den Entstehungszeitraum der Quelle (außer bei aktuellen Historikerinnen und Historikern); vereinzelt werden sie aber etwa wegen Funktionswechseln präzisiert oder mit Hinweisen auf spätere Funktionen ergänzt. Die von Lilienberg zumeist verwendete Form von »di« für den italienischen Namens- oder Adelspartikel wurde innerhalb des Registers auf »de« vereinheitlicht und alphabetisch entsprechend gereiht. Für eine etwaige elektronische Suche im Quellentext empfiehlt sich in diesen Fällen die Verwendung nur des zweiten Namensteils. Auf heutige Forscherinnen und Forscher verweise ich im Register nur dann, wenn sie im Einleitungstext erwähnt werden oder wenn in einer Anmerkung Näheres zu einer zitierten Arbeit steht.

Alesani, Antonio (Podestà) 189

Alvinczy von Berberek, Josef Frhr. 19

Appendini Urbano (Pater, Generaldirektor Gymnasium, Zara, Lyzeumsdirektor, Zara) 139, 242

Aretin, Karl Otmar Frhr. von (Historiker) 26

Bajamonti, Antonio (autonomistischer Politiker, 2. H. 19. Jh.) 189

Banac, Ivo (Historiker) 62

Barbieri, Domenico (Prätor, Lesina) 204

Bardini, Filippo Domenico (kath. Bischof, Sebenico) 222

Berdar, Nicolò (Kommunalsekretär, Budua) 193-194

Bettera, Bartolommeo Prospero (Prätor, Ragusa) 201

Bettera, Luigi (Konzeptspraktikant, Kreisamt Ragusa) 201

Bettera-Vodopić, Vito Marija (regierungskritischer Autor, Ragusa) 201

Borelli, Francesco (?) (Großgrundbesitzer, Kreis Zara) 86, 108

Boscovich, Giovanni (Kaufmann aus Castelnouvo, Smyrna) 108

Brodmann, Joseph von (Giuseppe de) (Beamter und Autor, 1. österr. Herrschaft nach 1797) 147

Bubanović, Vasilje (unierter Pfarrer, Kričke) 241

Bussovich, Marko (unierter Pfarrer, 1832 v. Orthodoxie zur Union konvertiert) 240

Caboga, Oberst Bernhard Franz Maria Graf von (Militärkommissär; k.k. Kämmerer) 61

Cacich, Antonio (kath. Bischof, Spalato [18. Jh.]) 226

Canova, Antonio (Bildhauer, Venedig, 18./frühes 19. Jh.) 146

Carl, Erzherzog von Österreich (österr. Feldherr; jüngerer Bruder von Franz II./I.) 25

Carzaniga, (?) (Silbergrubenbetreiber [18. Jh.]) 146

Castell-Castell, Grafen von 17

Celigoi (Celligoi), Giovanni / Johann (k. k. Gubernialrat, Vorsteher der Finanzintendanz Zara [seit 1818]) 270 
Cernizza, Antonio (Assessor, Bürgermeisterstellvertreter, Zara) 189

Cettineo, Giovanni Carlo (vorläufiger Direktor, Casa di ricovero, Curzola) 250

Cindro, Giuseppe (Dr. iur., Direktor, Casa di ricovero, Spalato) 250

Ciobarnich (Ciobernich), Giuseppe (Direktor Antikenmuseum, Spalato) 247

Cippico, Giuseppe (Gymnasialprofessor, Spalato) 243

Cobalchini, Gormalo (Unternehmer, Spalato) 150

Čobarnić, Josip s. Ciobarnich

Columbarich, (?) (Gemeindesekretär, Risano) 195

Čoralić, Lovorka (Historikerin) 190

Coron, Antonio (Prätor, Imoschi) 81

Crillovich, Vincenzo (Podestà, Perasto) 195

Čupić, Miho (Ziegeleiunternehmer, Konavle) 149

Dall'Armi, Michele (Unternehmer, Zara) 150

Dandolo, Vincenzo (Provveditore v. Dalmatien im Kgr. Italien) 9, 19, 43, 55, 131-132, 136

Darchich, Leopoldo (Landwirt, Pago) 79, 135, 140

Davud Pascha (Vezir, Bosnien [1833-1835]) 84

Delio, Bernardo Antonio (Prätor, Pago [1831/32]) 203

de Benvenuti, Angelo (Dr. iur., Kameralprokurator beim dalmatinischen Fiskalamt, Vorsitzender Wohltätigkeitskommission, Zara) 250

de Cambi, Sebastiano (Sindaco, Much) 192

de Drago, Vincenzo (Prätor, Traù) 58, 203

de Dudan, Leonardo (provisorischer Podestà, Spalato) 189

de Fanfogna, Pietro (Grundbesitzer, Zara) 250

de Frossard, Andrea (Präsidialsekretär) 14

de Gethaldi, Biagio (Leiter Deputazione sanitaria, Kreis Zara; stellv. Landeschef 1849ff.) 190, 201

de Ghetaldi Gondola, Sigismondo (provisorischer Podestà, Ragusa) 190

de Giuliani, Goffredo (Vorsteher Oberpostdirektion, Zara) 264

de Grazio, Coroliano (Podestà, Traù) 191

de Jacogna, Francesco (Podestà, Cattaro) 190, 251

de Marmont, Auguste (französischer Marschall; Gouverneur der Illyrischen Provinzen) 94, 102

de Michieli, Simeone (Sindaco, Castel Vitturi) 193

de Natali, Carlo (Prätor, Pago [1833], Sebenico [1834]) 203

de Paitoni, Federico (Reichstagsabgeordneter 1848/49; Sohn des Giuseppe) 209

de Paitoni, Giuseppe (Gubernialrat, Kreishauptmann, Cattaro) 209

de Sanfermo, Francesco (provisorischer Prätor / Podestà, Zara) 201

De’ Vidovich, Renzo (Historiker) 191

Doimi, Stefano (provisorischer Kanzlist / Prätursadministrator, Obbrovazzo) 204

Đokić, Marija (Historikerin) 41-42

Domiacussich, Pietro (Prätor, Sebenico [1833]; Rat am Kollegialgericht erster Instanz, Ragusa [1834]) 203

Dominis, Girolamo (Podestà, Sebenico) 191

Dominis, (?), (Podestà, Arbe) 191

Dorcich, Leopoldo s. Darchich, Leopoldo

Drasich, Antonio (Vizedirektor, Casa di ricovero, Spalato; Ehrenkanoniker) 250 
Fenzi, Pietro Antonio (Podestà, Sebenico) 190-191

Ferdinand I. (Kaiser v. Österreich [1835-1848]) 16, 20, 39-40, 309-310, 312-314

Krönungsreise (Lombardo-Venetien) 40

Feruzzi, Giovanni Battista (provisorischer Kanzlist, Prätur Obbrovazzo [1831]) 204

Feruzzi, (?), (Prätorstellvertreter, Scardona) 204

Filippi, Giuseppe (Gian Giuseppe) (Grundbesitzer, Zara; Reichstagsabgeordneter 1848/49) 250

Fister, Dr. s. Pfister, Johann Christian

Fölsch, Joseph Edler von (Hofrat) 171, 185

Forlani, Casimiro (Kommunalsekretär, Derniš) 190

Fortis, Alberto (Reiseschriftsteller; Universalgelehrter [18. Jh.]) 30, 147, 165

Franz I. (Kaiser v. Österreich [1804-1835]) passim; s. a. thematische Schlagworte im Ortsund Sachregister unter »Franz I.«

Franz Joseph I. (Kaiser v. Österreich; König v. Ungarn etc. [1848-1916]) 25, 39

Franz Karl, Erzherzog v. Österreich $38-40,42,183,215,315$

Frapporti, (?) (Präsidial-Sekretär, Cattaro) 201

Frast, Georg von (Giorgio nobile di Frast) (provisorischer Direktor, Landesbaudirektion, Zara [1832]) 269

Galbiani di Vrana, (Antonio ?) (Grundbesitzer, Vrana) 86

Galzigna, Girolamo (Assesor/Podestà, Arbe) 191

Geragini, (?) (Cavagliere; Eisengrubenbesitzer, Traù) 144

Gercich, Tomaso (Sindaco, Castel Cambio) 193

Giuriceo, Antonio/ Antun (kath. Bischof, Ragusa) 223, 235, 241

Giurich, Georg (Bergbaurechteinhaber, Zara) 145

Giurich, Math. (Bergbaurechteinhaber, Zara) 145

Godeassi, Giuseppe (Gubernialrat; ab 1839/40 kath. Bf. Spalato; Ebf. Zara 1843-1862) 241, 243

Gonsa, Gerhard (Historiker, HHStA Wien) 41

Gradaščević, Husein (Kapetan von Gradačac [Bosnien]; bosn. Aufstandsführer 1831/32) 84 Griez von Ronse, Eduard (Griesz di Ronse, Edoardo) (Prätor, Split; Kreishauptmann, Cattaro [ca. 1846-1849], Ministerialkommissär Serbische Wojwodschaft [ca. 1850 - mind. 1852]; Hof- und Ministerialoffizial, Ministerium des Äußeren, Wien [1870er]) 200-201

Grisebach, August (hannoverscher Reiseschriftsteller, Botaniker) 30, 59

Hacquet, Balthasar (franz.-österr. Naturwissenschaftler) 59

Hafëz / Hafız Pascha (osmanischer Vezir, Scutari) 172

Handel, Erasmus von (ziviler Statthalter v. Dalmatien 1902-1905) 28

Hartig, Franz Graf von (österr. Staatsmann; Gouverneur der Lombardei; Publizist) 139, 262

Hartmann, Eleonore (Historikerin) 6

Heindl, Waltraud (Historikerin) 184, 200, 208, 210, 232

Hohenwart, Franz Graf (Hof- und Landesbeamter; Mäzen; Jugendvertrauter von Franz

I.) 109,224

Ipsich, Giovanni Maria (Administrator der Präturen Castel S. Pietro di Brazza und Lissa) 204

Ivacich, Gabriele (Kreiskommissär, Cattaro) 209, 248, 259

Ivacich, Stefano (= Ivačić, Stjepan) (Gymnasialprofessor, Zara) 247

Ivanović, Grafengeschlecht (Kaufmannsfamilie, Dobrota/Triest/Venedig) 155 
Ivićević, Stjepan (Philologe; Nationalaktivist, Macarsca) 245

Jelačić, Josip (k. k. Offizier /Adjutant von Lilienberg; später Feldherr; 1848 ff. Banus v. Kroatien-Slawonien, Zivil- und Militärgouverneur v. Dalmatien) 16-17, 27, 41, 220

Joseph II. (Kaiser des Heiligen Römischen Reiches [1765-1790]) 5, 25, 27, 203

Kabužić, Graf Brno (Bernard) s. Caboga

Kačić Miošić, Pavao Klement $\quad$ s. Miossich

Kadčić, Antun s. Cacic

Karacsay, Fedor Graf (geograph. Publizist; Festungskommandant, Cattaro) 108

Karadžić, Vuk Stefanović (Philologe; serbischer Nationalaktivist) 32

Kara-Mahmud Pascha (osman. Heerführer und Staatsmann) 84

Kargel, Joseph (Kargl, Joseph) (Forstinspektor) 132, 213

Kiepert, Heinrich (deutscher Geograph) 58

Klingenstein, Grete (Historikerin) 27

Klobuschitzky, Joseph von (ungarischer Geheimrat und Zivilhofkommissär) 192

Knežić, Daniel (Politologe) 41

Kolowrat-Liebsteinsky, Franz Anton Graf von (Staatsminister, Wien) 20, 28, 38-39, 309, 313-314

Kovačić, Slavko (Historiker) 225

Kraglievich (Kraljević), Benedikt (orthod. Bischof v. Dalmatien [1810-1821/28], danach orthod. Titularerzbischof v. Venedig) 237-239

Krause, August (Physiker, Agrarinspektor [1820er]) 21-22, 24, 215

Kreuter, Peter Mario (Historiker) 42

Kriška, Petar (1832 zur Union konvertierter orthod. Pfarrer) 240-241

Krussevich, (?), (Podestà, Spalato) 189

Kudrna, Leopold (Historiker) 17, 41

Kuster, Thomas (Historiker) 5, 7

Kutschera, Johann Nepomuk Frhr. von (k. k. Feldzeugmeister; Generaladjutant v. Franz I.) 19

Kutschig, Karl/ Carlo (Gubernialkonzipist; Vizesekretär des Guberniums, Zara) 200

Lanza, Carlo (Direktor, Antikenmuseum, Spalato) 247

Laurich, Andrea (Kanzlist des Giuseppe Nagy in Obrovazzo) 204

Lazzari, Bernardo (Gemeindevorsteher, Perzagno) 195

Liepopilli, Francesco (Vorsitzender, Seesanitätsmagistrat, Zara) 264

Lilienberg, Sylvine Gräfin Vetter von (verehelichte Gräfin zu Castell-Castell; Tochter v. Wenzel Vetter Gf. von Lilienberg) 17

Lilienberg, Therese Gräfin Vetter von (geb. von Daun; Gattin v. Wenzel Vetter Gf. von Lilienberg) 17

Lilienberg, Walafried Vetter Graf von (Sohn v. Wenzel Vetter Gf. von Lilienberg ) 17

Lilienberg, Wenzel Vetter Graf von (k.k. Feldzeugmeister; Gouverneur v. Dalmatien) passim; s. a. thematische Schlagworte im Orts- und Sachregister unter "Lilienberg, Wenzel «

Linné, Carl von (schwedischer Naturforscher, 18. Jh.) 163

Lucchini, Giovanni (Kreisingenieur, Spalato) 85

Lucich, Stefano Paulovich s. Paulovich-Lucich

Ludwig, Erzherzog v. Österreich 40

Mahmud Hamid Pascha (Vezir, Bosnien [1832-1833]) 84

Majláth, János (ungarischer vormärzlicher Historiker) 192 
Manfrin, Girolamo Marchese (venez. Unternehmer) 105

Manfrin, Pietro Marchese (Grundbesitzer, Eingabeschreiber) 33, 97, 105

Maria Theresia (regierende Erzherzogin v. Österreich, Königin v. Ungarn und Kroatien, faktische Kaiserin des Heiligen Römischen Reiches) 5, 25, 27

Maricich, Francesco (Kreiskommissär, Spalato) 210-211

Martellini, Michele (Kreiskommissär, Cattaro [1833]; Zara [1834]) 209, 212

Martini, Raffaele (prov. Inspektor Antikenmuseum, Spalato) 247

Matiazza, Antonio (Vize-Sindaco, Castel Vitturi) 193

Mayer von Gravenegg, Joseph Freiherr (Hofbeamter; 1806 Gubernialsekretär, Zara) 182

Mera, (?) (Advokat, Podestà, Scardona) 190

Metternich, Klemens Wenzel Lothar Fürst von (Staatskanzler, Wien) 15, 25, 28, 39

Milutinovich Millovsky von Weichselburg, Theodor Freiherr von (General) 194

Milutinović, Kosta 18

Miossich, Paolo Clemente / Pavao Klement (kath. Bischof, Spalato) 223

Mittrowsky, Anton Friedrich Graf (Oberster Kanzler der Hofkanzlei, Wien) 84, 165, 211

Morali Ali Namik Pascha (Vezir, Bosnien [1828-1831]) 83

Mraz, Gerda (Historikerin) 25

Mraz, Gottfried (Historiker) 83

Nachich (auch: Nakich), Francesco Florido (Dr. iur.; Prätor, Obbrovazzo [1833]; Kreiskommissär, Zara [1834]) 204, 212-213, 248

Nagy, Giuseppe (Prätor, Castelnuovo [1833], Obbrovazzo [1834]) 204

Nani, Girolamo (Gubernialrat; Kreishauptmann, Spalato [seit 1824]) 210, 243

Napoleon I. (Kaiser der Franzosen) 9

Naverschnigg, Johann Kanzian / Giovanni Canzio (Kreishauptmann, Zara) 211, 213

Nićifor (orthod. Bischof aus Serbien, Užice) 239

Novak (auch: Nowak), Joseph Franz/Giuseppe Francesco (Erzbischof, Zara) 222, 224, 226, 230-231

Orosz, Anton von (Zahlamtsbeamter, Zara; Publizist v. 1848/49) 13, 18-19, 28

Oršolić, Tado (Historiker) 63, 113, 217-219, 221, 253

Ortner, Michaela (Bibliothekarin, ÖNB) 36, 41

Ottenfels, Otto Ritter von (Oberster Hofpostverwalter, Wien) 264

Panciera, Giovanni Pietro (Zivilingenieur; Vizedirektor und amtierender Direktor, Katastraldirektion, Zara) 216

Pantz, Joseph Ritter von (Kommissär; Montanistiker) 147

Pappafava, Vladimir (Jurist und Rechtshistoriker; 2. H. 19. Jh.) 106

Partsch, Paul (Inspektor, Hofnaturalienkabinett, Wien) 21

Paulovich-Lucich (Pavlović-Lučić), Stefano/Stjepan (kath. Bischof, Cattaro) 17, 223, 251

Pederin, Ivan (Historiker) 7, 31

Pellegrini Danieli, Giovanni Battista de (Dr. iur.; Prätor, Sign) 205

Peričić, Šime (Historiker) 106-107, 153, 253

Petar II. Petrović Njegoš (Vladika v. Montenegro) 62, 172, 179, 257

Petter, Franz (Gymnasialprofessor, Spalato; Landeskundler) 31-32, 53, 58, 64, 68-69, 101, $145,164,176,243,253,272$

Pfister, Johann Christian von (württembergischer Historiker, 1772-1835) 192

Pinelli, Orazio (Grundbesitzer, Zara) 91, 105, 134, 149

Pini, Timoteo (Prätor, Almissa) 204

DigiOst 1 | 345 
Pipitz, Joseph (Hofsekretär, Wien) 309, 313

Plancich, Giorgio (Generalinspektor für das Elementarschulwesen [1819-1832]) 244

Plencovich, Antonio (Podestà, Derniš) 190, 205

Plencovich, Paolo (Plenković, Pavao) (Dr. iur.; Prätor, Macarsca; Reichstagsabgeordneter 1848/49) 190, 205

Potochniak, Emerico / Emmerich (Prätor, Sabbioncello) 204

Presani (auch: Pressani), Valentino (Bauadjunkt, Direktion für öffentliche Bauten, Zara) 75, $88-89,95,144,269$

Radonić, Marko (Ziegeleiunternehmer, Konavle) 149

Rajascsich, Giuseppe (Rajačić, Josif) (orthod. Bischof v. Dalmatien [1828-1833], v. Vršac [1833-1842], v. Karlowitz [Sremski Karlovci; 1842-1861; Patriarch ab 1848]) 237, 239-240

Reutz, Alexander von (vormärzlicher russländischer Jurist und Rechtshistoriker) 165

Riepl, Franz (Physiker; Professor, Polytechnisches Institut, Wien) 21

Rimac, Marko (Historiker) 41, 86, 109, 217

Rizvanbegović, Ali Pascha (Vezir, Herzegowina [seit 1832]) 57, 82, 84, 172

Roksandić, Drago (Historiker) 58

Rosetti / Rossetti, Antonio Costa (Präsidialsekretär, Gubernium, Zara) 14, 35, 93, 120, 123, 143, 147, 173, 185-186, 188, 194, 197, 199, 202, 205, 212, 216, 222, 228, 234, 241

Rothschild, Salomon Mayer (Bankier, Wien) 145

Rougier, G. (Druckereiunternehmer, Zara) 13

Rougier, (?) (Schreiber, Gubernium Zara) 12-13, 35, 49, 63, 97, 103, 120, 148, 160, 171, 213, 234, 260-262

Rubrizius, Giuseppe (vorläufiger Direktor, Seelazarett, Ragusa) 263, 266

Rumpler, Helmut (Historiker) 217

Sabalić, Josip (Brauereibesitzer, Zara) 150

Santich, Matteo (provis. Generalinspektor für das Elementarschulwesen, Zara) 244-245

Saurau, Franz Joseph Graf von (Leiter Vereinigte Hofkanzlei, Wien) 33

Scacoz, Giovanni (Skakoc, Ivan) (kath. Bischof, Lesina) 223, 235

Schaller, Ferdinand Baron von (Kreishauptmann, Ragusa) 118, 209, 213, 252

Schett, Benjamin (Historiker) 42

Sedlnitzky, Josef Graf von (Präsident, Polizeihofstelle, Wien) 193-194, 238, 262-264

Sofran, Marko (orthod. Priester mit Amtierungsverbot in Dalmatien) 239

Špikić, Marko (Kulturhistoriker) 24, 247

Stančić, Nikša (Historiker) 111

Stella, Giovanni (provis. Direktor, Seelazarett, Ragusa [1833]) 266

Stermich, Antonio (Kreiskommissär, Spalato) 211, 213

Stocka, Adamo / Adam (Polizeidirektor, Zara) 201, 209-210, 263

Stojanović, Jovo (orthod. Priester mit Amtierungsverbot in Dalmatien) 239

Stratimirović, Stevan (Metropolit/orthod. Bischof v. Karlowitz [1790-1836]) 237-238

Sulejman-beg (Kapetan, Ljubuški) 82-84

Tarboglan, Luca (Sindaco, Klis) 193

Tepperberg, Joachim (Historiker, HHStA) 41

Tomassich, Franz Freiherr von (Tomašić, Franjo) (k. k. Feldmarschallleutnant; Gouverneur v. Dalmatien [1813/15-1831]) 14, 19, 22, 33, 83, 136, 183, 185, 211, 218, 237

Tommaseo, Niccolò (dalmatin.-ital. Publizist und Vordenker des Risorgimento) 17-18 
Trogrlić, Marko (Historiker) 9, 28, 41

Tromba, Giovanni (Kreiskommissär, Ragusa) 209-210

Ulm, Francesco/Franz (Dr. iur.; Prätor, Curzola) 204

Unowsky, Daniel L. (Historiker) 6

Vezir v. Bosnien s. Morali Ali Namik Pascha

Vezir v. Herzegowina s. Rizvanbegović, Ali Pascha

Vezir v. Scutari s. Hafëz Pascha

Viviani, Domenico (italienischer Naturforscher) 123

Vlach, Johann Nepomuk Ritter von (Giovanni Nepocumeno cav. di Vlach) (Appellationsgerichtspräsident, Zara) 207

Vladica (Vladika) v. Montenegro s. Petar II. Petrović Njegoš

Vrandečić, Josip (Historiker) 9

Vuletin, Giovanni (Sindaco, Castel Nuovo) 193

Wagner, Giovanni Battista / Johann Baptist (Assessor, Finanzintendanz, Zara) 271

Wallnig, Brigitte (Historikerin) 40-41

Weingarten, Joseph Freiherr von (k. k. Landes- und Hofbeamter) 8, 18-19, 170-171

Wickerhauser, Giuseppe / Joseph (Prätor, Cattaro) 201, 315

Wolff, Larry (Historiker) 30

Wurzbach, Constantin von (Historiker, Biograph [19. Jh.]) 17, 41

Zangerolimi, Antonio (Kreissekretär, Ragusa) 210

Zavoreo, Franjo / Francesco (Zivilingenieur; Publizist, Spalato) 31

Zeman, Mirna (Historikerin, Komparatistin) 30

Ziegler, Walter (Historiker) 24-25

Zinzendorf, Karl Graf von (Gouverneur, Triest [18. Jh.]) 27

Živković, Pantelejmon (orthod. Bischof v. Dalmatien [1834-1836]) 


\section{Orts- und Sachregister}

Für dieses Register wurde hinsichtlich der Ortsnamen aus praktischen Gründen (wegen der besseren Auffindbarkeit über Suchbefehle) bei solchen Toponymen, die in den Quellen genannt werden, die im Original verwendete Namensform als Erstansetzung gewählt. Die heutige kroatische Schreibung wird jeweils in Klammern angeführt. Außerdem wird von den heutigen Formen der in den Quellen genannten Orten auf die Erstansetzung verwiesen. Wo die beiden Formen nahezu identisch sind bzw. unmittelbar aufeinander folgen würden, erfolgt kein gesonderter Verweis. Die Schreibungen bzw. Namensverwendungen der Quelle folgten wie in der damaligen österreichischen Verwaltungspraxis üblich in der Tradition der venezianischen Herrschaft der italienischen Namensform bzw. einer Schreibung der kroatischen Ortsnamen in Anlehnung an die italienische Orthographie und Phonetik. Eine der wichtigsten Auffälligkeiten ist die Verwendung des Graphems "X « für »ž«. Nur selten treten bei Lilienberg daneben Schreibungen vom Typ »Oreschitz« auf, die am Deutschen orientiert sind. Ebenso selten sind Schreibungen nach Maßgabe der am Kajkavischen orientierten, vorillyristischen Orthographie von der Art »Czerno«. Bei den Sacheinträgen gilt bei geographisch verortbaren Begriffen eine implizite Zuordnung zu Dalmatien, sofern keine andere Zuordnung angegeben ist. Ausdrücklich den Gesamtstaat bzw. »Cisleithanien« betreffende Aspekte stehen zum Beispiel hingegen unter »Habsburgermonarchie«. Explizit unter »Dalmatien « angeführt wurden vorrangig grundsätzliche Angaben Lilienbergs zur geographischen Beschreibung und zum strategischen Wert des Landes sowie Besonderheiten im gesamtstaatlichen Vergleich.

\begin{tabular}{|c|c|}
\hline $\begin{array}{l}\text { Acquisto nuovissimo } 46,111,131,136,163 \text {, } \\
173\end{array}$ & $\begin{array}{l}\text { Prätur } \quad 174-175 \\
\text { Archäologische Funde } \quad 76\end{array}$ \\
\hline Kartendarstellung 305 & Armenfürsorge $224,250-254$ \\
\hline Acquisto nuovo $111,136,163,173$ & Armenhäuser $\quad 250-253$ \\
\hline Kartendarstellung 305 & Existenzminimum $\quad 311-312$ \\
\hline Acquisto vecchio 111,173 & Mädchen 252 \\
\hline Kartendarstellung 305 & Nothilfe $\quad 310-311$ \\
\hline Agrarkommissäre s. Landwirtschaftskom- & Opere Pie $15,222-223,234,250-251$ \\
\hline missäre & Ragusa 274 \\
\hline Agrikulturfonds s. Landwirtschaftsfonds & Arxano (Aržano) 58-59, 92 \\
\hline Albanien, Reliefkarte (Nordalbanien) 297 & Ausfuhren (Exporte) s. Handel \\
\hline Albanien, venezianisches 8,61 & Außenwirtschaftspolitik 99 \\
\hline Alessandria 19 & Babodol (Bobodol) 76, 88-89 \\
\hline Almissa (Omiš) $\quad 69,76-77,102,127,176$, & Backia (Bekija) 59 \\
\hline $192,204-205,226,234$ & Bakar 67 \\
\hline Amtsgebäude & Balkan \\
\hline Zustand 316 & Heldenbegriff 258 \\
\hline Analphabetismus 193,195 & Balke (Baljci) 240-241 \\
\hline Ancona $61,159,220$ & Banja Luka 59 \\
\hline Arbeits- und Besserungsanstalten $\quad 254-255$ & Bankenwesen 254-255 \\
\hline Arbe (Rab) $46,65,70,97,104-105,130-$ & Monte di Pietà 47,254 \\
\hline $131,137,139,143,146,162,168,174-175$ & Bar 57 \\
\hline $191,196,228,254$ & Bauern \\
\hline
\end{tabular}




\begin{tabular}{|c|c|}
\hline Landwirtschaftskenntnisse $\quad 109-110$ & Rechtsempfinden 179 \\
\hline Baumschulen 91 & Religiosität 232 \\
\hline Bayerische Staatsbibliothek 37 & Sozialverhalten 275 \\
\hline Bazare s. Grenzbazare & Stellung zum Staat 317 \\
\hline Beamtenschaft $179,188-196,209,316$ & uneheliche Geburten 256 \\
\hline Ausbildung 204, 213 & Wirtschaftsmentalität 107 \\
\hline Ausbildungsbedarf 205 & Bewässerungswirtschaft 72,111 \\
\hline Beschäftigungsverhältnisse $\quad 12,210,212$ & Bihać 159 \\
\hline Dienstvorschriften 182 & Bildungsschicht 230,248 \\
\hline Diurnisten 12,210 & Bildungswesen $\quad 242-243,247-248$ \\
\hline Einheimische 184 & Bilibrigk (Bili Brig) 77, 93 \\
\hline Einkommensverhältnisse $\quad 185,251,271$ & Biocovo (Biokovo) 69,106 \\
\hline Kontinuität 201 & Biograd na Moru 66 \\
\hline Landeskenntnis 320 & Biscupie (Biskupija) 80 \\
\hline Lebensführung 209 & Bjelina 149 \\
\hline Pensionierungswesen 323 & Blato (Blato na Cetini) 77 \\
\hline soziale Stellung 248 & Blatta (Blato [Korčula]) 85 \\
\hline Sprachenkenntnisse 323 & Blutrache $\quad 164-165$ \\
\hline Sprachenpraxis 211 & Bobodol s. Babodol \\
\hline Versetzungssystem $\quad 210,213$ & Bocagnazzo (Bokanjac) 79 \\
\hline $\begin{array}{l}\text { Behördenkritik } \quad 154,180,182,196-198, \\
\quad 200,227,263-265,267,269-270,274,311\end{array}$ & $\begin{array}{l}\text { Bocche di Cattaro (Boka kotorska) } 43,51 \\
61,63,70,94,96,103,106,108,123,153\end{array}$ \\
\hline Zentralverwaltung $11-12,156,270$ & $155,163-165,168,179,223,239,257$ \\
\hline Bencovaz (Benkovac) 11, 75, 79-80, 86-87, & Grenzverlauf \\
\hline 136 & Kartendarstellung 295 \\
\hline Berliner Vertrag von $1878 \quad 63$ & interkonfessionelle Beziehungen 195 \\
\hline Bersatak 77,89 & Kartendarstellung 308 \\
\hline Bevölkerung s. a. Landbevölkerung & Sozialstruktur 193 \\
\hline Alkoholkonsum 165 & Spezifika $171-172$ \\
\hline Bewaffnung $111-112,185,220,259$ & Bocche false (Meeresbucht bei Slano) 272 \\
\hline Eheverhalten & Bodenerosion 70 \\
\hline Orthodoxe 257 & Bodenschätze $\quad 144-147$ \\
\hline Ehrbegriff 260 & Böhmen $20,23,117,152,179,256$ \\
\hline Entwicklungspotential 275 & Boka kotorska s. Bocche di Cattaro \\
\hline Ernährungsgewohnheiten 163 & Bora 100,174 \\
\hline Fleischkonsum 119 & Bosnien / Bosnien und Herzegowina 57-59, \\
\hline Herkunft 161 & $61,68,76,78,83-84,120,133-134,145$ \\
\hline Hungersnot 118 & $161,185,221,258,260$ \\
\hline interkonfessionelle Beziehungen 205 & s. a. Herzegowina; Osmanisches Reich; \\
\hline Kaisertreue $\quad 163,169$ & Türkisch-Kroatien \\
\hline Konkubinat (»wilde Ehen «) 225, & Eyalet $\quad 57-58$ \\
\hline $256-257$ & Instabilität 84 \\
\hline Konservatismus 167 & Paschalik 58 \\
\hline Lebensverhältnisse 230 & Räuberwesen 168,260 \\
\hline Orthodoxe 236 & Verwaltungsverhältnisse 258 \\
\hline physische Charakterisierung 162 & Westbosnien \\
\hline
\end{tabular}


Reliefkarte 297

Bossiglina (Bosiljina / Marina) 123

Braichi (Brajići) 63, 70, 194, 258-259

Brazza (Brač) 66, 70, 97, 103, 121, 125, 127,

155, 159, 204

Brenno (a. Breno; Župa dubrovačka) 94, 107

Brevilacqua (Punta B.; Privlaka) 142-143

Bribarich 77

Briefzensur 264

Brücke von Mostar (»Römerbrücke«) 78

Brünn (Brno) 6,15

Bua (Čiovo) 145

Bucovizza (a. Bukovizza; Bukovica) 97, 230

Budua (Budva) 57, 63, 70, 98, 103, 149, 173-174, 193-194, 202

Calamotta (a. Colomotta; Koločep) 25, 67, 272

Callerine (Karin ?) 86

Calogera (Caluggera; Ošljak) 122, 147

Canale della Morlaccha (a. Morlachenkanal; Velebitski kanal) 57, 64, 97

Canali (Konavle) 72, 107, 149, 303 Kartendarstellung 303

Canchi Buch (a. Zanchi-Buch; Skradinski buk?) 88-89

Canosa (a. Cannosa; Trsteno) 93, 107

Capo Cesto (Primošten) 65

Cartole (Krtole) 149

Castel Cambio (Kaštel Kambelovac) 174175,193

Castel Lastua (Petrovac na moru) 44, 91, 296

Castelli (Kaštela) 98, 106, 175-176, 193, 195

Castelnuovo (Herceg novi) 11, 96, 101, 103, 108, 193, 204, 266

Castel Vitturi (a. Castel Vetturio; Kaštel Lukšić) $\quad 174,176,193$

Cattaro (Kotor) 8-9, 31-32, 34, 43-44, 46$47,51,57,59,62-64,69,72,77,91,96$, $98,107-108,111,118,124,127,133-134$, $139,149,151,155,159,162-163,165$, 170-172, 186-188, 190, 193-196, 200202, 208-209, 213-214, 217-218, 221, $223,230,236,239,243,248,251-252$,
257-259, 261, 263-264, 267, 275, 315-

318,323

Cavtat s. Ragusavecchia

Cernivir 85

Cettina (Cetina) 43, 69, 71, 76-77, 89, 92, 232

Cigliane (Koljane?) 77

Čiovo s. Bua

Cisleithanien 9,20

Clissa (Klis) 44, 69, 75, 92, 103, 146, 192-193

Comacchio 140

Comicsa (Komiža) 141

Contado (vermutlich

$$
\text { Župa/Grbalj) } 196 \text { s. Xuppa }
$$

Cres 228

Crivoscie (Krivošje) 34, 61-62, 65, 131, 258

Crni vir s. Cernivir

Crno s. Czerno

Crussevo (Kruševo) 148

Curzola (Korčula) 9, 25, 44, 64, 66, 70, 85, 98, 103, 105, 107, 130-131, 138, 146, 157, $159,173,193,202,204,244,250,252,272$, 316

Czaslau (Č́áslav) 16

Czerno (Crno) 92

Dalmatien 5-13, 15, 17-19, 21, 23, 25-26, $28,30-33,35,38,40$

Sonderstellung $179,214,216,219,221$, 270

strategischer Wert 169,220

venezianisches Dalmatien 8,61

Dalmatienbild 97, 115, 162

Dalmatiner $45,97,117,126,141,152,161-$ $165,167-169,184,213-214,221-224,260$

"Nationalcharakter» 163, 253

Dazio consumo 23, 46, 104, 196-198, 245, 249-250, 268

Derniš (Drniš) 68, 71, 75, 80, 92, 97, 101, 103, 105, 119, 145-146, 149, 173-175, 190, 202-203, 205, 240

Deutsche Sprache Orthographiegeschichte $79,81-82,93$, 245

Dienstboten 252, 255 


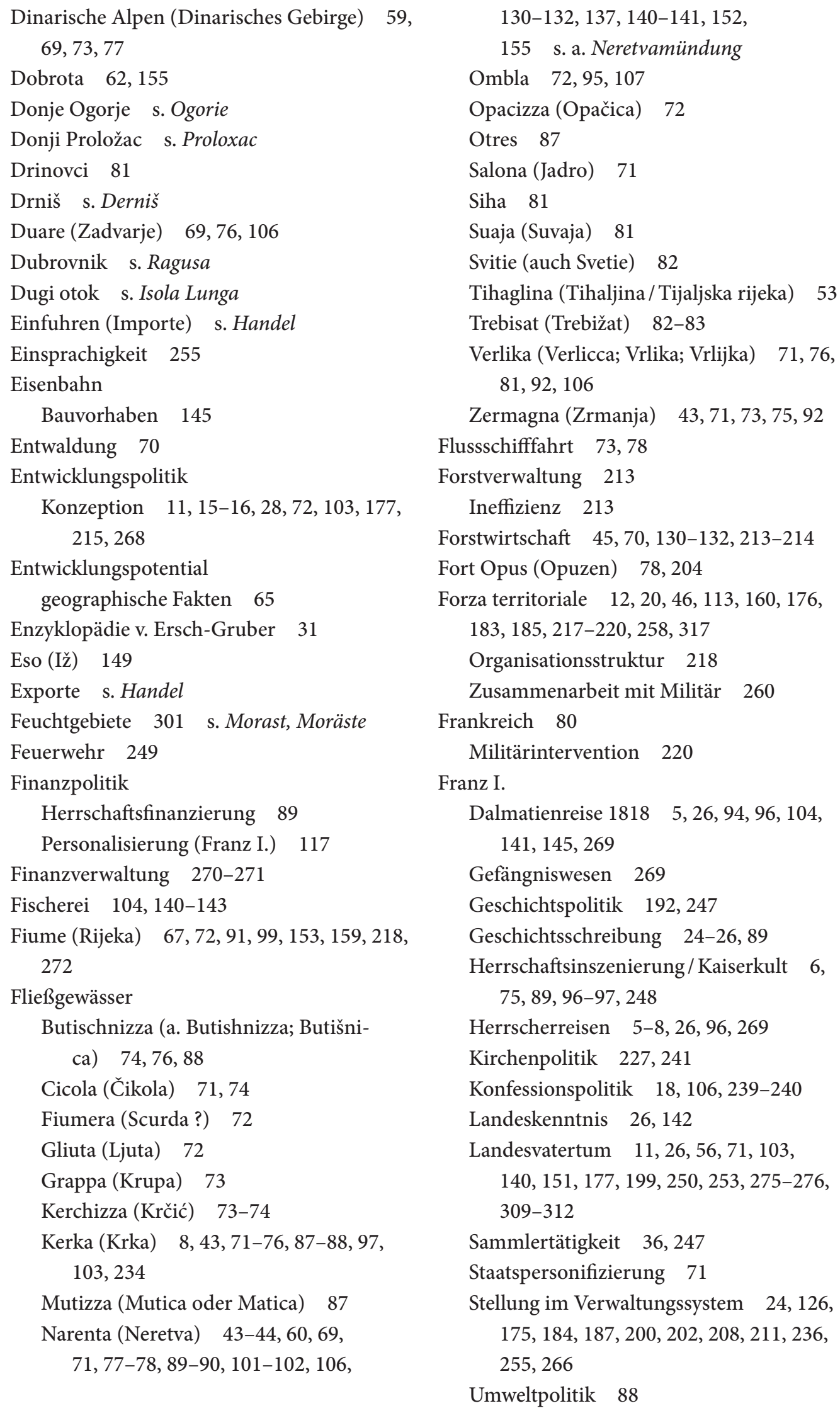




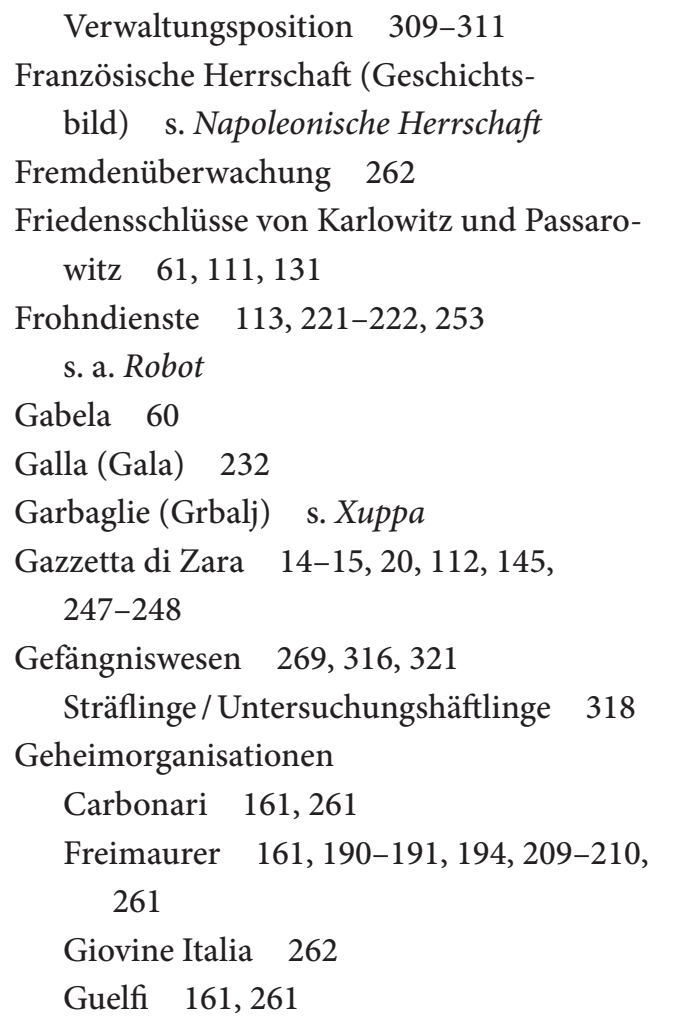

Geheimpolizei und Höhere Polizei

(Kriminalpolizei) 260-263

Geistlichkeit 47, 130,165-167, 198, 214, 222-224, 227-228, 232, 247, 255,

272 s. a. katholische Geistlichkeit; orthodoxe Geistlichkeit

Bildungsniveau 214, 234-235, 258

Bildungssystem 166-167

Religiosität 227

Gemeinden s. Kommunalverwaltung

Gesellschaft

soziale Schichten 255-256

Gewässer

Kartendarstellung 298

Gewerbeförderung 152

gewerbliche Produktion 148-151

Gewohnheitsrecht 256 s. a. krvarina; pob-

ratimstvo; vražstvo

Boka kotorska 259

Geistlichkeit 165-166

Racheprinzip 164-165

Giuppana (Šipan) 25, 67

Glagoljica 225

Glinat 76

Gliubuschi (Ljubuški / Ljubiški) 60, 82-83
Goducie (Goduće/ Guduće) 87, 301

Goliš 69

Google Books 36-37

Gornje Ogorje s. Ogorie

Gospodska špilja 76

Gouverneur s. Landesverwaltung,

Gouverneur

Grab 77, 82, 92, 102

Gradac 92, 146

Grahovo 58

Grappa 73

Gravosa (Gruž) 47, 67, 72, 94-95, 266

Grbalj (Garbaglie) s. Xuppa

Grenzabkommen Kroatien - Bosnien-Herzegowina (1999) 61

Grenzbazare 77, 92, 263, 292

Grenzgebiete

Kontrolle 59-60, 62-64, 258

Grenzstreitigkeiten

Boka kotorska

Kartendarstellung 296

Grenzverlauf 78

Grenzvermessungen (Reambulation) 58

Gromila 92

Großbritannien $\quad 15,80,173$

Gruda 149

Gruž s. Gravosa

Gubernium s. Landesverwaltung,

Gubernium

Habsburgermonarchie

administrative Unbeweglichkeit der

Zentralstellen 175

Auslandsspionage 194

Beamtenschaft

Versetzungssystem 180, 213

Behördenbescheide

Revisionsmöglichkeiten 175

Beschwerdeinstitutionen 237

Dalmatienbild 30, 49

Fideikommissbibliothek 36

Finanzlage 15

Finanzpotential 314

Gemeindefinanzen 196-198

Geschichtsbild 51-52

Herrschaft

Gewaltmechanismus 221 
Habsburgermonarchie (Fortsetzung)

Herrscherreisen 39-40 s. a. FranzI., Herrscherreisen

Hoflager 27

Hofstellen 28

interkonfessionelle Beziehungen 237

katholische Kirche

Staatskirchencharakter 230,232 233,240

Kirchenpolitik 225

Konfessionspolitik 236

Kreisämter

Funktionsweise 172

monarchisches Verwaltungssystem 23

Postgeheimnis 263-264

Pupillarwesen 202, 208

Rahmenbedingungen 177-178

Rechtswesen 25

soziale Mobilität 152

Staatskonferenz 39

Staatsrat 15,38

Vereinigte Hofkanzlei 21-22, 46, 65, $116,123,128-129,136,147,153-154$, 175, 179-182, 186, 198-200, 249, 254, $265,313-314$

Verhältnis Zentrum - Peripherie 29, $123,175,227,269,314$

Verwaltung

Beeinflussungsversuche Lilienbergs 102,104

Dalmatienkenntnis $\quad 180-181,186$

Verwaltungsebenen

Funktionsweise 182

Instanzenzug $\quad 172,175,265-266,270$

Interaktion $12,20-23,220,222,228$, 263-265

Interessenkonflikte 198, 200, 202, 250 s. a. Karawanen; Monopole

Verwaltungseffizienz 20,176-178, 181182,196

Verwaltungsgrundsätze $\quad 169-170,179$ 180,314

Augenscheinnahme 315, 321

Verwaltungskontinuität 177

Waisenkinder 202
Zensur 32 s. a. Briefzensur; vormärzliches Überwachungssystem

Zentralbehörden 311-314

Zentralismus $178,197-198,216,225$, 309-314

Häfen

Infrastruktur 67

Ragusa 266

Han $77,92-93,154$

Handel 154-161

dezentrale Struktur 159

Exportprodukte 156

Exportüberschuss 158

Importgüter $78,110,119,124,132,145$, $152,157,159$

Salz 160

Handelspolitik 99 Importaktivitäten 80 Importsubstitution 99

Sanitätsfragen 264-267

Sanitätskordon Boka kotorska

Kartendarstellung 308

Haus-, Hof- und Staatsarchiv 5, 15, 36, 41-42

Kaiser-Franz-Akten $\quad 39-40,42$

Haustypen 162-163

Heiratssitten

Mädchenraub 256

Herceg novi s. Castelnuovo

Herrschaftswechsel

Rechtssystem 212

Herzegowina $57-62,78,82,84,94,132-$

$134,171-172,221,258,260$

Paschalik 57, 82

Reliefkarte 297

Hexenverfolgung 166

Historiographie 58, 190

Historische Reiseforschung 7

Hungersnot 1834/35

Verwaltungsmaßnahmen 309-314

Hungersnöte (sonstige) 253-254

Hvar s. Lesina

Illyrische Provinzen 55 s. a. napoleonische Herrschaft

Imoschi (Imotski) 44, 59, 68, 71, 81, 93 , $100,106,123,144,174-175,316$ 


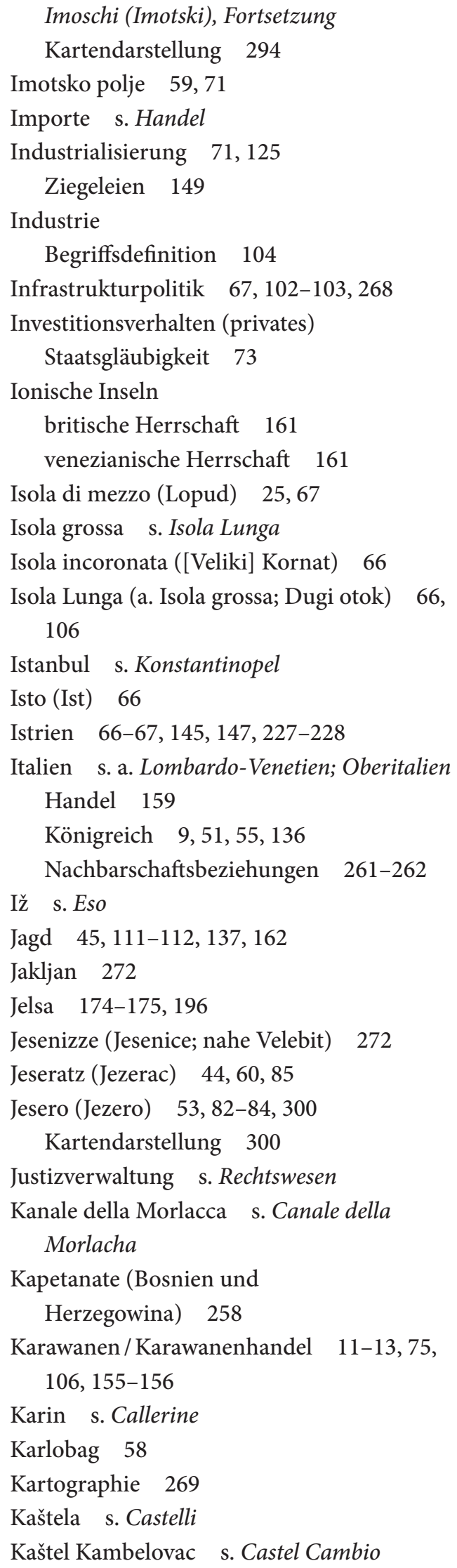

Kaštel Lukšić $\quad$ s. Castel Vitturi

Kataster 99, 114, 120, 132, 216, 274

Kartendarstellung 306

Katholische Geistlichkeit 228 s. a.

Geistlichkeit

Ausbildung 225-229

Bildungsniveau 195, 198, 224, 226-228

Domkapitel 224

Einkommensverhältnisse $\quad$ 231-233

gesellschaftliche Stellung 224

Glagoliten 226

Hierarchie 222-224

Lebensverhältnisse 229-230

Ordensgeistliche 234, 245

Verwaltungsaufgaben 222, 226

Katholische Kirche

Dominikanerorden 234

Eremitenorden 234

Franziskanerorden 230, 234

Frauenklöster 235

Infrastruktur 229-231

Kapuzinerorden 234

Klöster 62-63, 234-236, 245

Nonnen 234-235

Orden 234

Ordensgeistlichkeit 234-235

Piäristenorden 234

Priesterseminar Spalato 242

Priesterseminar Zara 241

Schulaufsicht 244

Schulpolitik 245

Schulunterricht 242, 244

Sonntagsschulen 246

Struktur 228

Verwaltungsfunktion $\quad 195,272$

Kirchenpolitik 229,231, 235

Bauförderung 268

Pfarreieinteilung 246

Spätjosephinismus 232-234

Kirchenstaat 99, 140, 220, 261

Kirchenunion s. Konfessionspolitik

Kirchliche Feiertage 233-234

Klek 33-34, 43, 56, 58, 60-61, 65, 69, 78,

$101,171,220$

Kliake (Kljake) 146

Klicsevac (Kličevac) 79 
Orts- und Sachregister

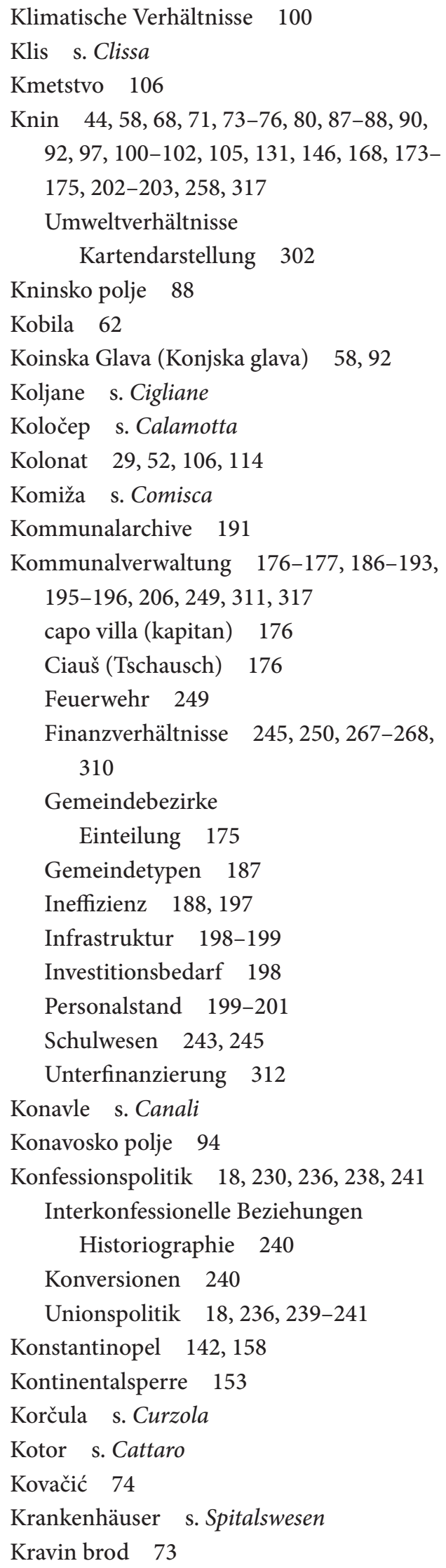

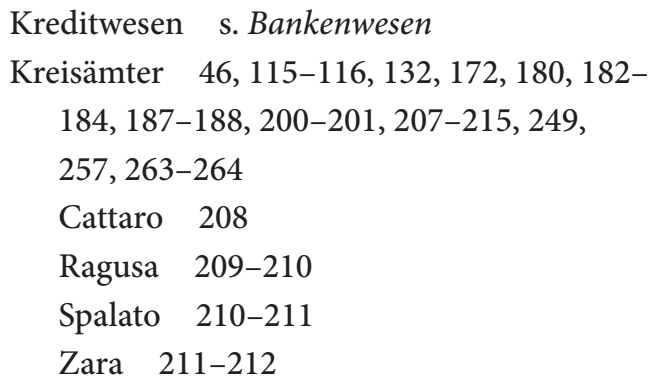

Kroatische Militärgrenze 57

Krtole s. Cartole

Krupa s. Grappa

Kruševo s. Crussevo

krvarina (Blutgeld) 165

Kula norinska s. Torre di Norino

Kulturgeschichte Geschichtsbild 76

Küstenland, österreichisches $\quad 67,100,124$, 154, 184, 206, 211-212, 228

Küstenland, ungarisches (a. Ugarsko primorje / Hrvatsko primorje) 67

Kutti (Kuti) 90

Lagosta (Lastovo) 25, 66, 70, 97, 131, 151

Laibach (Ljubljana) 6

Landbevölkerung 230

»Kaisertreue» 259, 261

Lebensbedingungen 226

Rechtsempfinden 316-317,320-321

Verhältnis zum Klerus 231-233

Wirtschaftsweise 233-234, 253

Landesbaudirektion 269

Landesbereisung $5,43,49-50,63,67,70$, $88-89,96,110,131,135-136,138-139$, $151,186,188-189,191,200,220,227,232$, $235,252,268,271-273$

Herrschaftsinszenierung 96 


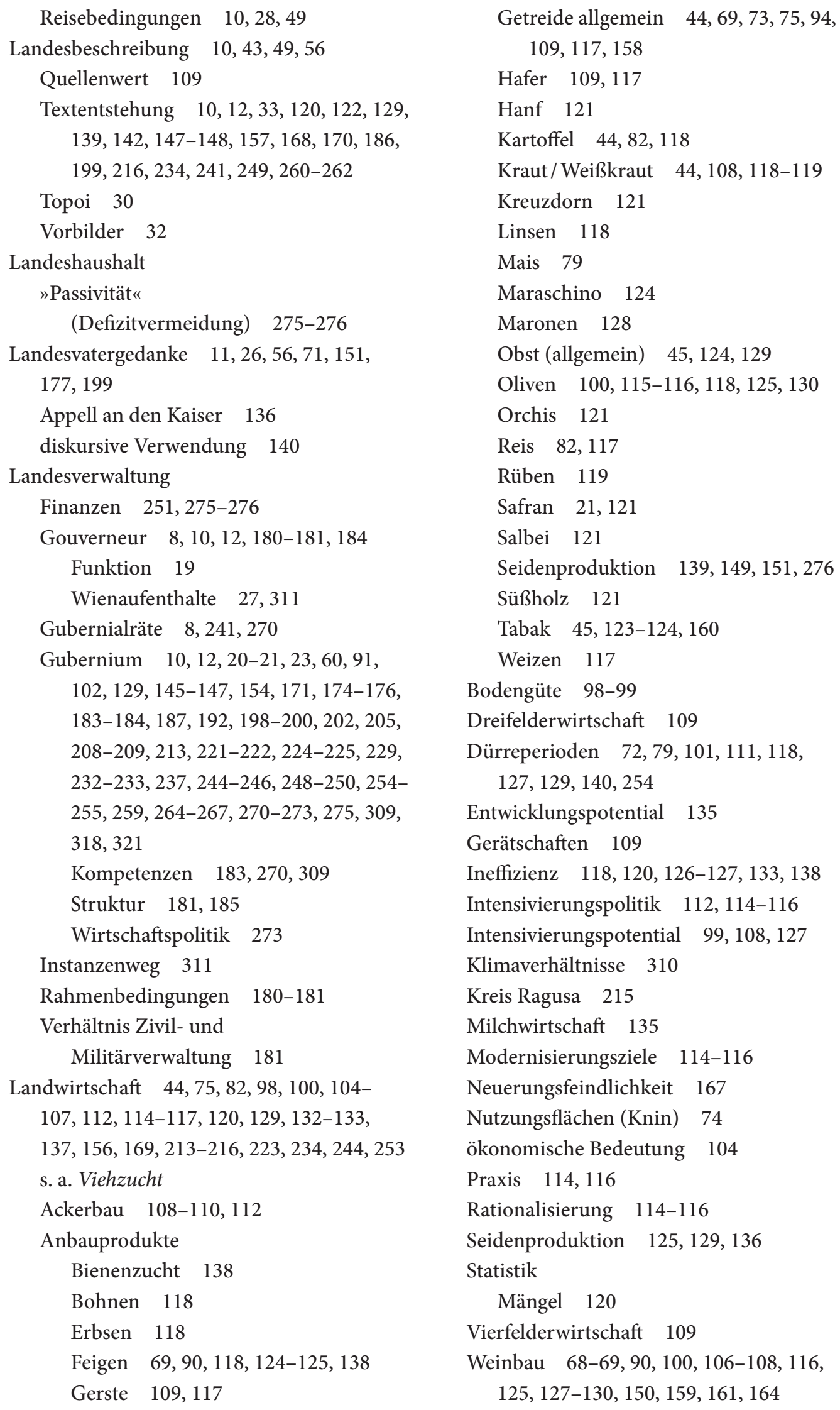

\author{
Getreide allgemein $\quad 44,69,73,75,94$, \\ $109,117,158$ \\ Hafer 109,117 \\ Hanf 121 \\ Kartoffel 44, 82, 118 \\ Kraut/Weißkraut 44, 108, 118-119 \\ Kreuzdorn 121 \\ Linsen 118 \\ Mais 79 \\ Maraschino 124 \\ Maronen 128 \\ Obst (allgemein) 45, 124, 129 \\ Oliven $100,115-116,118,125,130$ \\ Orchis 121 \\ Reis 82,117 \\ Rüben 119 \\ Safran 21, 121 \\ Salbei 121 \\ Seidenproduktion $\quad 139,149,151,276$ \\ Süßholz 121 \\ Tabak 45, 123-124, 160 \\ Weizen 117 \\ $127,129,140,254$ \\ Mängel 120 \\ $125,127-130,150,159,161,164$
}

Bodengüte 98-99

Dreifelderwirtschaft 109

Dürreperioden $72,79,101,111,118$,

Entwicklungspotential 135

Gerätschaften 109

Ineffizienz $118,120,126-127,133,138$

Intensivierungspolitik 112,114-116

Intensivierungspotential 99, 108, 127

Klimaverhältnisse 310

Kreis Ragusa 215

Milchwirtschaft 135

Modernisierungsziele 114-116

Neuerungsfeindlichkeit 167

Nutzungsflächen (Knin) 74

ökonomische Bedeutung 104

Praxis 114, 116

Rationalisierung 114-116

Seidenproduktion $125,129,136$

Statistik

Vierfelderwirtschaft 109

Weinbau $68-69,90,100,106-108,116$, 
Orts- und Sachregister

\begin{tabular}{|c|c|}
\hline Landwirtschaft (Fortsetzung) & Selbstbewusstsein $14,19,28,154,202$, \\
\hline Rebsorten 127 & $309-312$ \\
\hline Weinlese 128 & Überwachungspolitik 262-264 \\
\hline Weinproduktion 127 & Verhältnis zum Monarchen $\quad 14-16,26-$ \\
\hline Wirtschaftsweise $98,105-107$ & $27,187,207-208,227,248,263,266-$ \\
\hline Landwirtschaftsfonds $11,20,24$ & $267,270,273,275,309-312$ \\
\hline Landwirtschaftskommissäre $\quad 15,28,115-$ & Verwaltungsstellung 190 \\
\hline $116,214-216$ & Zentralbehörden $\quad 309-314$ \\
\hline 20,128 & Lissane (Lišane Ostrovičke) 87 \\
\hline Landwirtschaftspolitik 20 & Lissa (Vis) $9,25,66,70,97,103,105,121-$ \\
\hline Bedeutung 213 & $122,125,135,141,147,151,159,173,204$ \\
\hline Fördermaßnahmen 312 & 316 \\
\hline Ledenizza (Ledenice) $\quad 258-259$ & Geschichte 173 \\
\hline Lemberg (Lviv) 7 & strategische Bedeutung 173 \\
\hline Lesina (Hvar) 9, 66, 70, 97, 121-122, 125, & Livno $\quad 58-59,76-77$ \\
\hline $147,159,175-176,196,204,222-223$ & Ljubuški s. Gliubuschi \\
\hline $226-227,235,243,252$ & Ljuta s. Gliuta \\
\hline Levante $80,108,122,146,159$ & Lombardo-Venetianisches Königreich $\quad 40-$ \\
\hline Levantehandel 159 & 41,323 \\
\hline Lilienberg, Wenzel s. a. Personenregister s.v. & Lombardo-Venetien $\quad 139,187,221,238,262$ \\
\hline Lilienberg, Wenzel & Lopud s. Isola di mezzo \\
\hline Amtsbefugnisse 27,207 & Lošinj s. Lussin \\
\hline Amtsverständnis $28,38,97,180$, & Luca s. Porto Luca (Vela Luka auf Korčula) \\
\hline $309-312$ & Lucca (Luka, nahe Zadar) $\quad 59,85,167$ \\
\hline Berufslaufbahn 18,117 & Lun s. Puntalun \\
\hline Charakteristik $\quad 16-19,185$ & Lussin (Lošinj) 66, 228 \\
\hline Dalmatinerbild $\quad 168-169$ & Lussin piccolo (Mali Lošinj) 66 \\
\hline dynastische Loyalität $\quad 16,97$ & Macarsca (Makarska) $60,69,77,93,102$ \\
\hline Entwicklungsdiskurs 268 & $123,141,162,166,170,190,192,202$, \\
\hline Förderpolitik 214 & $204-205,218,243,252,261$ \\
\hline Handelspolitik 266-267 & Magazza (Magaza) 62 \\
\hline Infrastrukturpolitik 20 & Maini $\quad 194,258-259$ \\
\hline Kirchenpolitik 241 & Makarska s. Macarsca \\
\hline Landesbereisung $8-11,13,16,252$ & Mala Šuljaga s. Sugliaga \\
\hline Verwaltungsmaßnahmen $\quad 268,272$ & Malfi (Zatona, Kreis Ragusa) 93,107 \\
\hline Landesbeschreibung & Mali Lošinj s. Lussin piccolo \\
\hline Textentstehung $12-15,89,93,95,97$, & Mali Prolog 59-60 \\
\hline $100,103,120,129,139,147,199$ & Malo jezero 80 \\
\hline 262 & Maraschino Rosoglio (Typenbezeich- \\
\hline Militärgouverneur $19-20,28,173$, & nung) $124,127,151$ \\
\hline $179-180$ & Marina s. Bossiglina \\
\hline monarchische Repräsentation 259 & Marktbeziehungen \\
\hline Nachrufe 17 & Zadar 141 \\
\hline Orthodoxenbild $106-107$ & Maßeinheiten 141 \\
\hline religiöse Identität $\quad 231,237$ & Megjed 70 \\
\hline & Melada (Molat) 66 \\
\hline
\end{tabular}




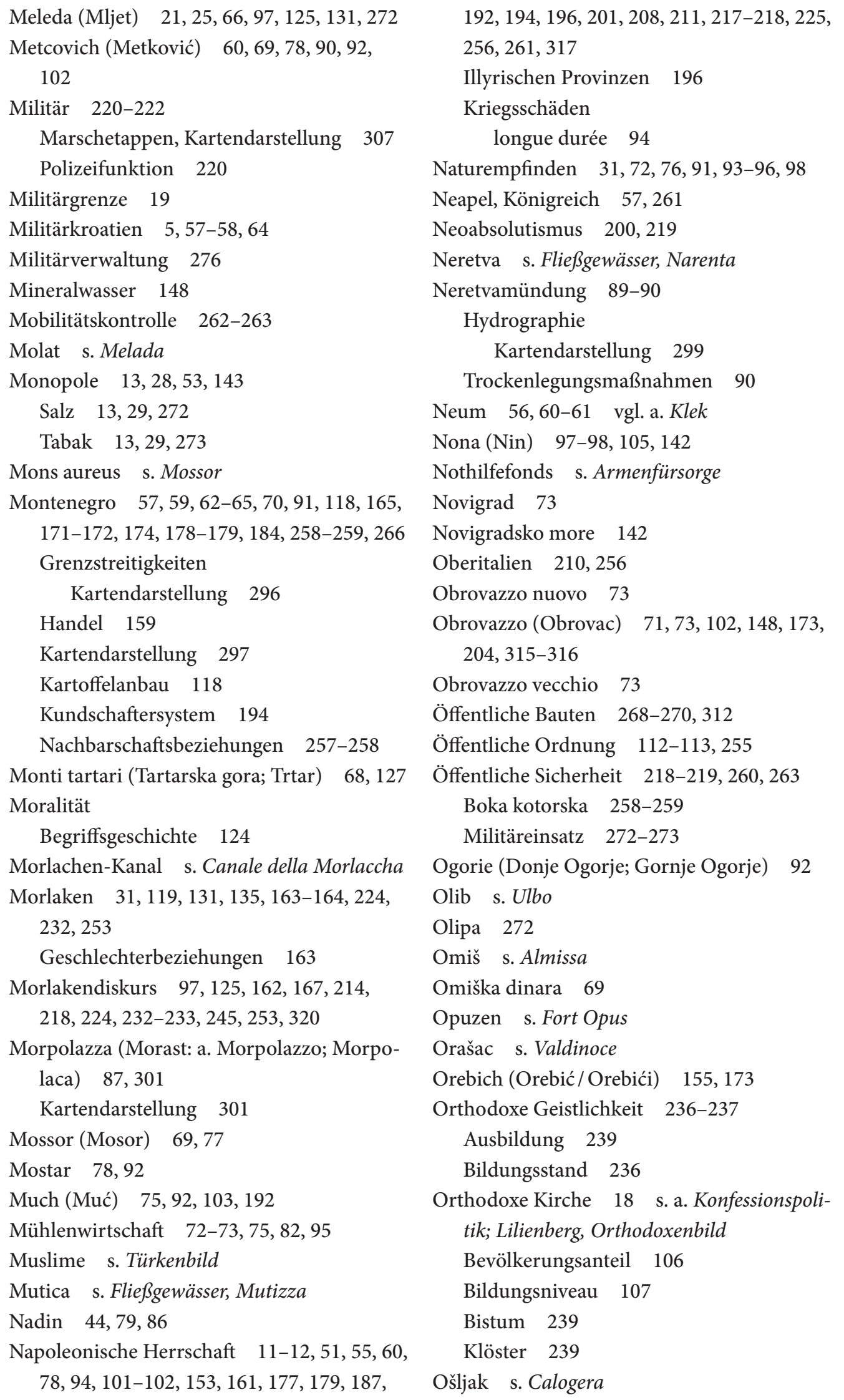




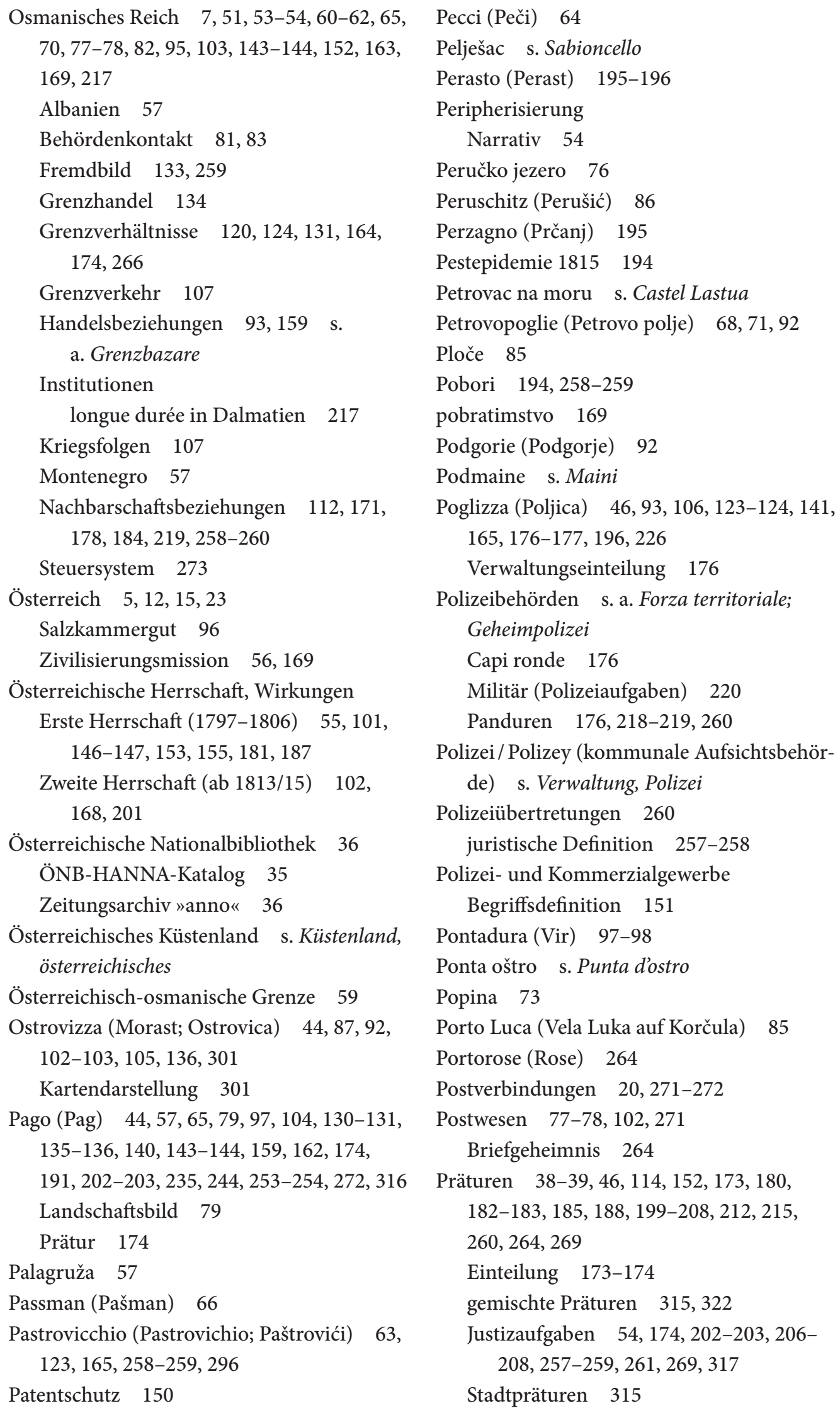


Verwaltungsaufkommen 199, 201

Verwaltungsaufsicht 193

Prčanj s. Perzagno

Preise

Salz 143-144

Premuda s. Promuda

Preßburg 7

Preußen 15

Prico (Priko) 226

Proclian (See; a. Procliane; Prokljan) 74, 301

Kartendarstellung 301

Prologk (Prolog) 59, 68, 100

Prološko blato 59, 81

Proloxac (Donji Proložac) 59, 81

Promina 68, 92, 145-146

Promuda (Premuda) 66

Provicchio (Prvić Luka) 167

Punta d'ostro (Ponta oštro) 62

Punta Dubizza (Rt Dubica) 43, 62, 64

Puntalon (a. Puntaloni; Rt Lun) 130, 174

Rab s. Arbe

Radiglievac (Radljevac) 74, 76

Ragusa (Dubrovnik) 5, 8-9, 13, 21, 31, 43, $46-47,51,56,61-62,64,66-67,72,77-$ 78, 93-94, 96, 105-107, 118, 125-128, 133-134, 139, 149-151, 153, 155, 159, $162,168,170-174,176,187-188,190$, 193-194, 200-201, 203, 209-210, 212$215,218,221-224,227,235-236,241-$ 244, 251-252, 255, 261, 263-264, 266269, 271-272, 274-275, 315, 318, 323

Kriegserfahrungen 94

Lazarett 194

Opere Pie 251-252

Republik 51

Sonderstellung 223

Ragusavecchia (a. Ragusa vecchia; Cavtat) 72, 94, 107, 148-149, 193, 316

Rastok (See) 53, 59-60, 82-84

Kartendarstellung $\quad 300$

Räuberwesen 260

Bosnien 168

Raubtiere

Fangprämien 137
Rechtsempfinden 255,261 s. a. Gewohnheitsrecht; Landbevölkerung

Rechtswesen 176, 207-208, 259-260, 268, 319-320 s. a. Präturen

Appellationsgericht $176,208,320$, 323-324

Gefängniswesen $\quad 316,321$

Gerichtswesen 322

Rechtsetzung 178

Strafrechtsverfahren 317-318, 320

Strafverfolgung (Boka katorska) 107

Verfahrensvereinfachung 322

Reisanbau (Herzegowina) 83

Reiseliteratur 30-31

Religionsgruppen Unionspolitik 106

Religiosität 225-226, 231

Rijeka s. Fiume

Risano (Risan) 34, 103, 131, 151, 195, 230, 258

Robot 113, 156, 221

Rogoznica (Rogošnica) 46, 69, 147, 176

Römisches Reich

Kulturerbe 76, 167-168

Roncislapp (Roncislapo; Roški Slap) 74

Rose s. Portorose

Rumelien 59

Russland, Zarenreich 179

Ruxich (Ružić) 103

Sabioncello (Pelješac) 64, 93, 107, 127, 155, 173, 204

Salona (Solin) 71, 93, 106, 147, 167

Salzburg 23, 39

San Giorgio (Sućuraj) 174, 176, 196

Sanitätsämter 263-265

Sanitätskordon

Boka kotorska (Kartendarstellung) 308

San Nicolò (Sv. Nikola / Tvrđava Sv.

Nikole) 74

Santa Madalena (Sveta Magdalena) 58, 64

Sant'Antonio (a. Zatton; Zaton) 74, 102

Savina 239

Scarda (Škarda) 66

Scardona (Skradin) 74-75, 88, 98, 102-103, $105,146,173,190,204$

Schifffahrt 
Orts- und Sachregister

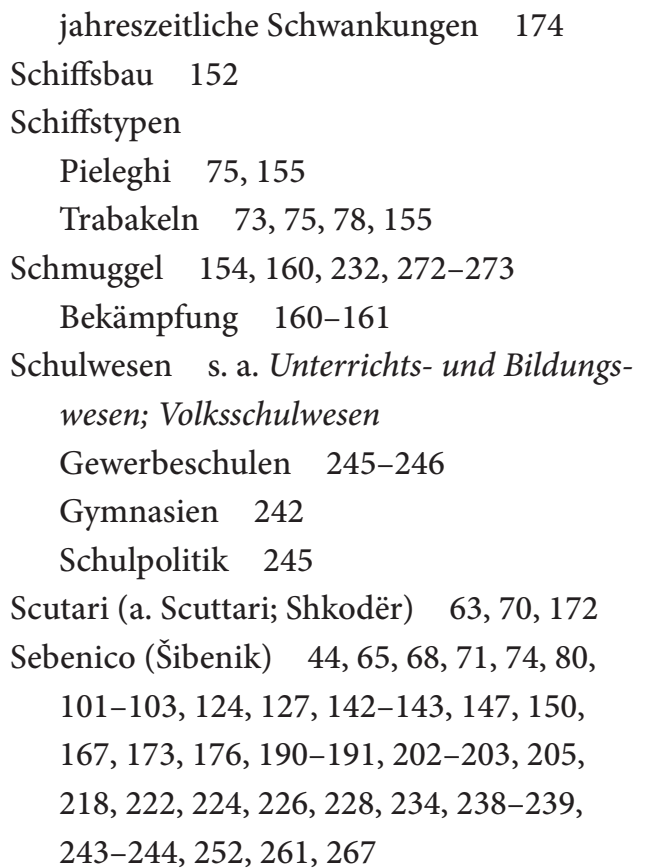

Seefahrt

Kategorien 155

Seehandel 12, 265

Seehandelsflotte 172

Seelazarette 266

Selbstverwaltung

Funktionsträger $\quad 188,191$

Verhaltensanforderungen 191

Selve (Silba) 66, 98

Sfilaja (Svilaja) $68,71,92$

Shkodër s. Scutari

Šibenik s. Sebenico

Sibut (a. Sinobat) 88

Siedlungsstrukturen 229, 246

Sign (Sinj) 44, 59, 68-69, 71, 76-78, 89-90,

$93,101,106,131,134,144,150,159,173$,

$176,192,205,232,260,317$

Silba s. Selve

Šipan s. Giuppana

Sizilien 19, 27

Škarda s. Scarda

Skradinski buk s. Canchi Buch

Sniexnizza (Snježnica) 69

Solin s. Salona

Solta (Šolta) $\quad 66,98,105,138,174-175$

Sordovan 44, 86

Soziales Kapital 261

Soziale Wohlfahrt s. Armenfürsorge
Sozialpolitik Ausbildungsförderung 152

Sozialstruktur 54

Spalato (Split) 7, 9, 13, 31-32, 41, 46, 59, 66-69, 71, 77, 85, 92-93, 98-99, 102-103, 105-106, 111, 123-125, 133-134, 141, 148-150, 159, 162, 166, 168, 170-171, $173,175-176,187,189,191-193,195-$ 196, 200-201, 203, 209-213, 216-218, 223-224, 226-227, 232, 235-236, 241$244,247,250-252,254,260-261,263-$ 264, 266-267, 272, 315, 317-318, 323

Archäologisches Museum (Arheološki muzej) 247

Spitalswesen $47,252,267-268$

Nervenheilanstalt in Venedig 268

Spizza (Spič) 63, 174

Split s. Spalato

Sremski Karlovci (Karlowitz) 237

Staatlicher Grundbesitz 274

Staatsbild

Erziehungsaufgaben 169

Staatshaushalt

Prinzipien 56

Staatsmonopole s. Monopole

Staatsschwäche 259-260,263

Stadt-Land-Beziehungen $\quad 165,321$

Stagnevich (Stanjević/ Stanjevići) 62-63

Stagno (Ston) 93-94, 143-144, 244, 272, 316

Ständesystem 54

Statistik, amtliche

Mängel 160, 256

Steinbrüche gewerbliche Produktion 146

Steinkohlen-Gewerkschaft für Istrien und Dalmatien 145-146

Steuersystem 99, 221, 273 s. a. Dazio consumo; Kataster

Zehent 161, 273

Stiftungen, wohltätige 274

Strafrechtsverfahren s. Rechtswesen

Straßenbau 20

strategische Aspekte 103

Trägerschaft 104 
Straßennetz 73-74, 77-78, 87, 101-104, 156,169 s. a. Verkehrsinfrastruktur Kartendarstellung 292-293

Subsidiarität $12,182,265,321$

Sućuraj s. San Giorgio

Sugliaga (Mala Šuljaga) 78

Sutomore 63

Suttorina (Sutorina) 33-34, 43, 56, 61-62, $64-65,72,95,101,144,171,220$

Teodo (a. Theodo; Tivat) $70,98,127$

Tirol 256, 268

Topoglie (Topolje) 74, 92

Topoljski buk 74

Torre di Norino (Kula norinska) 78

Trachten 162

Transportwesen 155-156

Traù (a. Trau; Trogir) 98, 102, 106, 111, 123, $127,131,135,144-145,176,191,193$, 202-203, 209, 236, 243-244, 252, 254

Treploghi 70

Triest $\quad 6,19,27,126,130,150,152-153,155$, 159, 201, 209, 227

Funktion als Zentralort für

Dalmatien 159

Trigl (Trilj) 69, 76-77, 106

Triplex confinium $\quad 58-59,62,92$

Trsteno s. Canosa

Trtar s. Monti tartari

Türkenbild 95

Uglian (Ugljan) 66, 122

Ulbo (Olib) 66

Umweltempfinden s. Naturempfinden

Umweltgeschichte

Überschwemmungsgebiete 75, 81-85, $88,90,95,141,254$

Umweltpolitik 75

Natureingriffe 90

Wasserwirtschaft $71,83,88$

ungarisches Litorale s. Küstenland, ungarisches

Ungarn

Staatsrecht 192

Unierte Kirche 240

Mitgliederzahlen 241

Unionspolitik s. Konfessionspolitik

Unka 60,92
Unterrichtspolitik 243

Unterrichts- und Bildungswesen 241246 s. a. Schulwesen

Urbane Bevölkerung

Sozialverhalten 261

Uspor $44,81,89$

Užice 59, 239

Valdinoce (Orašac) 93

Vampirglaube 167

Veglia (Krk) 223, 228

Vela Luka s. Porto Luka

Velbich (a. Vellebich/Vellebit; Velebit) 20, $58,68,73,100,131,144,146,272$

Velebitski kanal s. Canale della Morlaccha

Veliki Prolog 59-60

Veliko jezero 80

Venedig $6,17,19,40,43,51,53-54,105$, $111,131,139,142,146-147,152,154-$ $155,159,210,218,238,244,256,268,324$

Venezianerherrschaft $52-54,111,161,168$, $179,187,217$

Verbosca (Vrboska) 196

Verbrechen juristische Definition 257-258 Verbrechensbekämpfung 259-260

Verbrechensformen 258, 260

Verbrechenshäufigkeit 316

Verbrechensstatistik 167-168, 257-258, 318-319

Vergorac (Vrgorac) 53, 59-60, 77-78, 82, $85,92,100,123,131,145,166$

Verhältnis Zivil- und Militärverwaltung $\quad 184-186$

Verkehrsinfrastruktur $\quad 49,246,263,317$ s. a. Straßennetz

Seeweg 267

Verlicca (Vrlika) 71, 76-77, 81, 131, 134, $144,146,148,240,260$

Vernachlässigungsdiskurs 168-169

Verona 324

Verwaltung s. a. Beamtenschaft; Behördenkritik; Franz I.; Habsburgermonarchie (diverse Einträge); Kommunalverwaltung; Kreisämter; Landesgubernium; Landesverwaltung; Präturen; Rechtswesen Amtsgeheimnis 211 
Orts- und Sachregister

\begin{tabular}{|c|c|}
\hline Verwaltung (Fortsetzung) & Verwaltungsbezirke 170 \\
\hline Amtsmissbrauch 219 & Verwaltungsgliederungen \\
\hline Besoldungen und Pauschalen 218 & Mängel 176 \\
\hline Böhmen 179 & Verwaltungskritik \\
\hline Dienstanweisungen $\quad 213,219,271$ & Staatsmonopole 123 \\
\hline Dienstaufsicht 207 & Verwaltungskritik (am Monarchen) 126 \\
\hline $\begin{array}{l}\text { Dienstreisen } 8,10,13-14,50,205-206 \\
212,215,271,319,321\end{array}$ & $\begin{array}{l}\text { Verwaltungsprinzipien } \quad \text { s. a. Habsburger- } \\
\text { monarchie, Zentralismus; Subsidiarität }\end{array}$ \\
\hline Diskontinuität 187 & Augenscheinnahme $5,39,131,134,175$, \\
\hline Dörfer 195 & $186,193,204,206-207,215,319$ \\
\hline Effizienzfragen $\quad 199,202,205-207,215$, & Vido (Vid) 60 \\
\hline $219,222,253,262-265,269,316$ & Viehzucht $\quad 45,108,120,132,134,144$ \\
\hline $319-322$ & Geflügelhaltung 137 \\
\hline Gemeindehaushalte 104 & Grünfutter 120 \\
\hline geographische Faktoren 56 & Hutweiden $\quad 45,120,175$ \\
\hline Geschäftsgang $183-184,209,264-265$ & Ineffizienz 120 \\
\hline Bearbeitungsrückstände $200-202$, & Rinderhaltung 134 \\
\hline 204 & Schafhaltung $45,135-136$ \\
\hline Herrschaftsdurchsetzung 206 & Schweinehaltung 137 \\
\hline Institutionen & Weidewirtschaft 120,134 \\
\hline Kontinuitäten 218 & Wollproduktion 135 \\
\hline Interaktion mit Bevölkerung $\quad 214,219$, & Ziegenhaltung 136 \\
\hline 221 & Vir s. Pontadura \\
\hline Kartographiewesen 269 & Vis s. Lissa \\
\hline katholische Kirche & Vitaglina (Vitaljina) 107 \\
\hline Interaktion 231 & Volksfeste \\
\hline Kommunen $104,188,192$ & Feiergewohnheiten 165 \\
\hline Korruption/Amtsmissbrauch 190,193 & Volksglauben $\quad 166-167$ \\
\hline 211,219 & Volksschulwesen $\quad 169,198,228,243-245$ \\
\hline Landeskenntnisse 184 & Hauptschulen 244 \\
\hline Mähren 179 & Mädchenschule 244 \\
\hline Ordnungsfunktion 249 & Normalschulen 244 \\
\hline Personalstand $179-181,203$ & Volkssportarten 162 \\
\hline Polizei / Polizey (im Sinne von Ordnungs- & Vormärzliches Überwachungssystem 18 , \\
\hline amt, Aufsichtsinstanz) $47,113,151$ & 261-264 s. a. Habsburgermonarchie, \\
\hline $174,191,200,202,210,221,236,249-$ & Zensur \\
\hline $250,260-264$ & Öffentlichkeitskontrollen 242 \\
\hline Richtlinien $\quad 183,188$ & Spitzelsystem 263 \\
\hline Schreibertätigkeit 127 & Vottergnak 70 \\
\hline Sprachanforderungen 23 & Vrana $44,80,86$ \\
\hline Sprachenpraxis 214 & Vransko jezero 80 \\
\hline Strukturprobleme (Kreisämter) 213 & vražstvo (Blutgerichte) 165 \\
\hline Überwachungsmechanismen s. vor- & Vrboska s. Verbosca \\
\hline märzliches Überwachungssystem & Vrgorac s. Vergorac \\
\hline Unterfinanzierung 255 & Vrgorsko polje 60 \\
\hline Verwaltungskosten 207 & Vrlika s. Verlicca \\
\hline
\end{tabular}




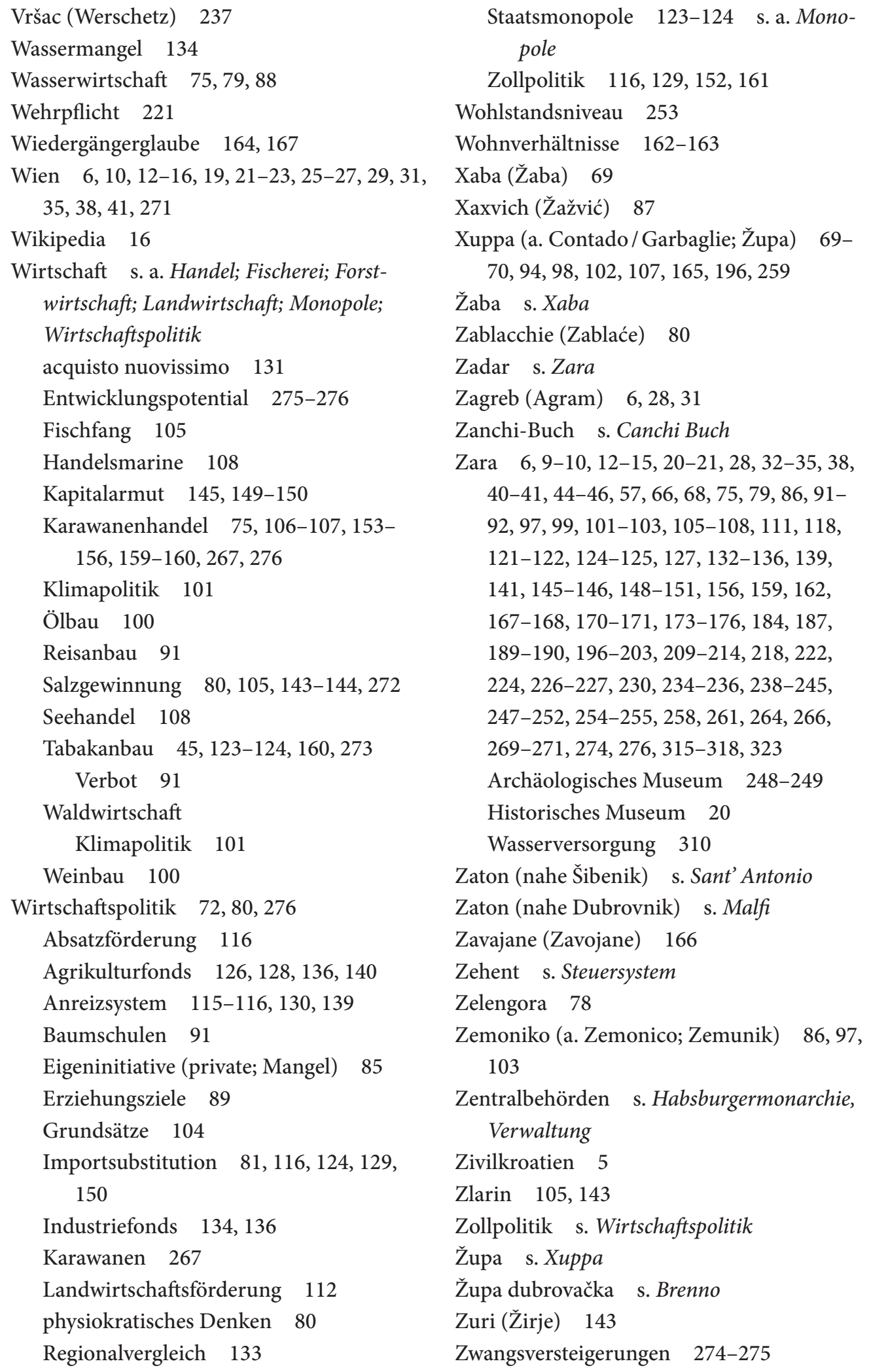


Konrad Clewing - 978-3-86688-501-1 


\section{ostdok • \\ Osteuropa-Dokumente \\ online}

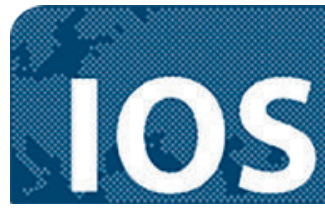

Institut für Ost- und

Südosteuropaforschung

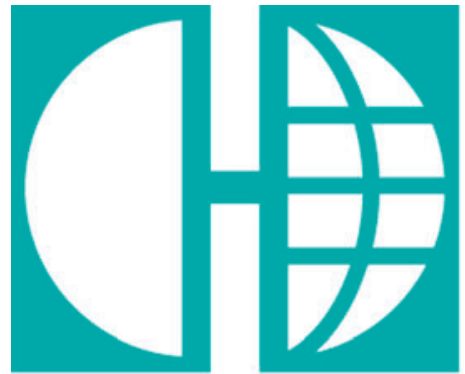

HERDER

Collegium Carolinum INSTITUT 


\section{回到}

ISBN: 978-3-86688-500-4 (print) ISBN: 978-3-86688-501-1 (eBook)

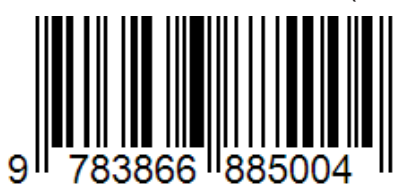

\section{Electronic Resources} digital.kubon-sagner.com/digiost

\section{BiblionMedia}

